\title{
The Russian Welfare State: Moving towards Neofamilialism?
}

\author{
By Tatyana Teplova
}

A dissertation submitted to

The School of Public Policy and Administration

Carleton University,

Ottawa, Ontario

Canada

In partial fulfillment of the requirements

for the degree of

Doctor of Philosophy

(C) Tatyana Teplova, 2006 


$\begin{array}{ll}\begin{array}{l}\text { Library and } \\ \text { Archives Canada }\end{array} & \begin{array}{l}\text { Bibliothèque et } \\ \text { Archives Canada }\end{array} \\ \begin{array}{l}\text { Published Heritage } \\ \text { Branch }\end{array} & \begin{array}{l}\text { Direction du } \\ \text { Patrimoine de l'édition }\end{array} \\ \begin{array}{l}\text { 395 Wellington Street } \\ \text { Ottawa ON K1A 0N4 }\end{array} & \begin{array}{l}\text { 395, rue Wellington } \\ \text { Ottana ON K1A ON4 } \\ \text { Canada Oa }\end{array}\end{array}$

Your file Votre référence ISBN: 978-0-494-18238-3 Ourfile Notre référence ISBN: 978-0-494-18238-3

NOTICE:

The author has granted a nonexclusive license allowing Library and Archives Canada to reproduce, publish, archive, preserve, conserve, communicate to the public by telecommunication or on the Internet, loan, distribute and sell theses worldwide, for commercial or noncommercial purposes, in microform, paper, electronic and/or any other formats.

The author retains copyright ownership and moral rights in this thesis. Neither the thesis nor substantial extracts from it may be printed or otherwise reproduced without the author's permission.
AVIS:

L'auteur a accordé une licence non exclusive permettant à la Bibliothèque et Archives Canada de reproduire, publier, archiver, sauvegarder, conserver, transmettre au public par télécommunication ou par l'Internet, prêter, distribuer et vendre des thèses partout dans le monde, à des fins commerciales ou autres, sur support microforme, papier, électronique et/ou autres formats.

L'auteur conserve la propriété du droit d'auteur et des droits moraux qui protège cette thèse. $\mathrm{Ni}$ la thèse ni des extraits substantiels de celle-ci ne doivent être imprimés ou autrement reproduits sans son autorisation.
In compliance with the Canadian

Privacy Act some supporting forms may have been removed from this thesis.

While these forms may be included in the document page count, their removal does not represent any loss of content from the thesis.
Conformément à la loi canadienne sur la protection de la vie privée, quelques formulaires secondaires ont été enlevés de cette thèse.

Bien que ces formulaires aient inclus dans la pagination, il n'y aura aucun contenu manquant. 


\section{Abstract}

This thesis explores major changes in child care/ family policies in the transformation period in Russia. With this purpose, it analyzes policymaking in the area of child care in both Soviet and post-Soviet regimes. The cases studied included child care services, maternity/parental leave provisions, as well as in-home caregiving and other family type allowances. The thesis shows that since the 1990s, Russia has undergone significant structural reforms of its social, political and economic systems, including child care. Such reforms were not limited to changes in the welfare state, but also included deep ideological changes. These changes involved a paradigm shift in the Russian welfare regime - not to neo-liberalism but rather toward a neofamilialist model of care. The thesis illustrates that the neofamilialist model was seen to fit well with new needs for a "flexible" work force, while also achieving demographic and political goals. The move towards neofamilialism reflects a set of various policy choices and the balance of power within the Russian state system, as well as the power resources of external-tostate actors. At the same time, while this shift has resulted in the greater familialisation of care, it has not, however, facilitated the "choice" to stay at home with young children, at least for most women. The very tensions within the state that favoured the adoption of a neo-familial paradigm have also limited its ability to implement it effectively. As a result, many women have to try to combine work and family life, albeit under more difficult circumstances than before. In general, this thesis aims to develop a nuanced account of social change in the region by taking into account the socialist institutional legacies and 
analyzing policy development at both national and local levels. A unifying theme of this thesis highlights the importance of institutions, ideas, historical legacies and interests.

Although the Russian case is unique, it helps us to increase our understanding of the challenges and opportunities faced by other countries in transition. 


\section{Acknowledgements}

While working on this thesis, I have benefited from consultations and communications with so many people at Carleton University and elsewhere. I wish to take this opportunity to thank them all for their valuable suggestions and support. First and foremost, I would like to thank my supervisor, Professor Piotr Dutkiewicz, for his dedication and critical feedback, guidance and constant support. His enthusiasm, commitment, and faith in my abilities made this dissertation possible. I would also like to thank my committee members. Professor Rianne Mahon provided invaluable advice, and always served as an inspiration in my research, taking an active interest in my development as a scholar and a future academic. Professor Frances Woolley was a reliable and tireless guide through the thickets of economic theory and data analysis, and I am truly grateful for her support and suggestions. I am also greatly indebted to Professor Leslie Pal for his critical advice, and generous and constructive comments, particularly at the early stages of my doctoral project. I would further like to thank my external examiners, Professors Sonya Michel and Pauline Rankin, for their insightful feedback, interest and diligence in reading my thesis. It was a great privilege to work under the guidance of these scholars, and I thank them most sincerely for the valuable knowledge I acquired during my $\mathrm{PhD}$ studies.

Special thanks to Dr. Susan Phillips, who believed in me all along the way and provided continuous support and inspiration during my studies at Carleton. I am also grateful to my fellow doctoral students, Karine Levasseur, Stephanie Paterson, and 
Robert Johnson, who not only encouraged my work from beginning to end, but also generously shared important comments and ideas. I wish to thank my unofficial thesis committee, who provided comraderie, caring, and friendly emotional support to me and my family during my work, and made me forget about work when I needed to: Paula Speevak-Sladowski, Sandra Jones, Katrina Murray, Claude Paradis, Dhurata Ikonomi, and Paul Sandage as well as Alex and Cristina Savulescu.

Professor Jane Lewis provided generous comments on some parts of the early dissertation draft as part of the New Scholars Programme, Research Committee - 19, International Sociological Association. Sincere thanks as well to Professor Ann Orloff, who kindly provided very insightful scholarly advice as well as important suggestions with regard to the dissertation topic and approach. I am also grateful to Livia Ola and Mary King for their critical comments on some parts of this thesis.

Special thanks to Canadian International Development Agency, which funded the Women in the Labour Market Reform in Russia Project on which parts of this thesis are based and again to Professor Dutkiewicz, who so kindly allowed me to use project research materials. Thank you to the faculty members of the School of Public Policy and Administration, who were always so generous with their time, support and friendly advice. I further wish to thank the Faculty of Graduate Studies, the Faculty of Public Affairs and Management, and in particular, Dean Katherine Graham, and again, the School of Public Policy and Administration, Carleton University for providing funding not only to support my studies but also to attend international conferences, including the 
International Sociological Association - Research Committee 19 Conference "Welfare State Restructuring: Processes and Social Outcomes" in Paris, France, September 2004 and International Association of Feminist Economics Conference in Oxford, UK, August, 2004, which nourished my development as a scholar. The funding support of professors Rianne Mahon, Piotr Dutkiewicz, and Leslie Pal, as well as the International Association for Feminist Economics and International Sociological Association - Research Committee 19 for attending the conferences is also gratefully acknowledged.

Finally, I am deeply grateful for the love and encouragement of my parents, who gave me the drive to pursue the challenge, made me appreciate the value of education, and expressed their unfailing support all along the way, but particularly during the final stages of my doctoral studies. I also wish to thank my in-laws for providing a loving, encouraging and supportive environment for me and my family. Most importantly, I wish to thank my husband, Alex, and my son, Michael, for their love, support, and endless patience (particularly during all those long evenings and weekends when I worked on my dissertation), and for giving me the courage and the opportunity to succeed. For what it is worth, this one is for you. 


\section{Table of Contents}

List of Tables .............................................................................................................................10

List of Figures...........................................................................................................................12

List of Appendixes......................................................................................................................13

Introduction........................................................................................................................................14

The Objective and the Argument ............................................................................

The New Russian Welfare Model.............................................................................17

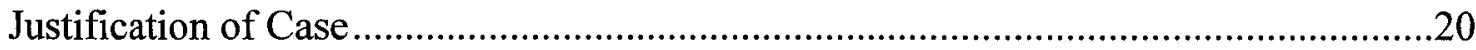

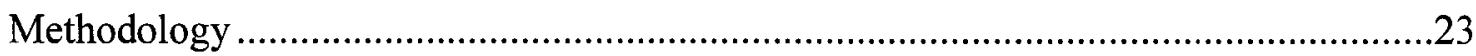

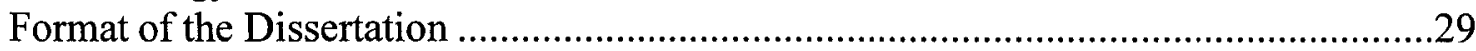

Chapter 1. Gendered Welfare State Theories, State Autonomy and the Process of Institutional Change in Child Care.................................................................................32

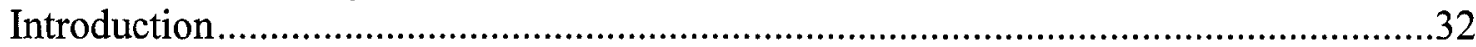

Gendering Welfare State Theories: The Role of Child Care .........................................33

Welfare State Regimes, Women's Work, Child Care and State Interests .................39

Typology of Welfare State Regimes and Child Care...................................................46

Institutional Change and Continuity in the Post-Communist Countries..........................53

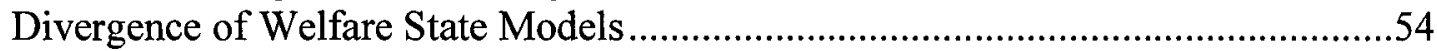

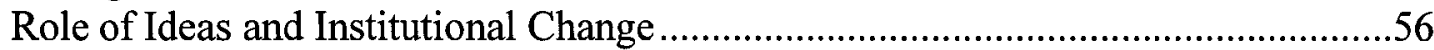

The Political Economy of the Welfare State.............................................................64

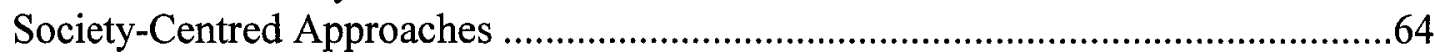

The State-Centred Approach...................................................................................67

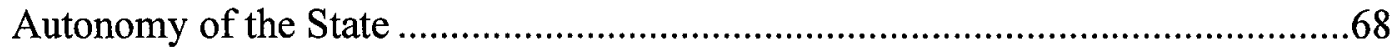

State Capacity for Policy Implementation .......................................................... 71

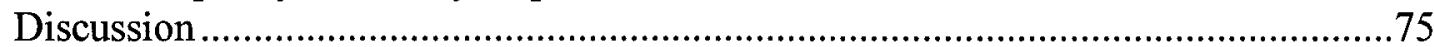

Strengths of the State-Centered Approaches ..........................................................76

Limitations of the State-Centred Approaches ........................................................81

The Need for a Synthetic Approach.......................................................................85

Conclusions........................................................................................................

Chapter 2. Soviet Welfare Regime ...................................................................................................94

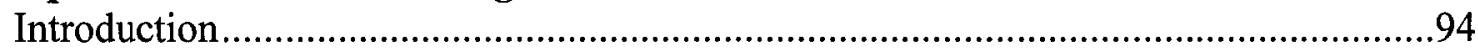

Soviet Welfare Regime: Overview ........................................................................96

Communist Ideology towards Women vs. Practice ...............................................100

Ideological Foundation of Women's Liberation...................................................100

Politics of Women's Liberation: Zhenotdel.......................................................106

Central Planning System, Decentralization and Women .........................................109

Flexible Institutions: Central Planning and Decentralization ................................110

Enterprise-based Service Delivery and Role of Trade Unions .............................112

Welfare State, Child Care Policies and Female Labour Force Participation in the

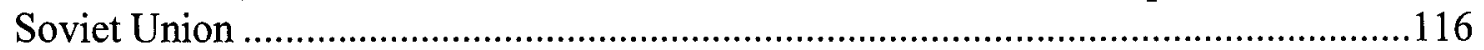

1917-1930: Post-Revolutionary Period................................................................122

Women's Liberation ..........................................................................................122

Women's Employment and Child Care ..............................................................123

Allowances for Women and Children.................................................................131

1930 - 1940: Early Stalinist Period.......................................................................134

WWII and Post-War Period ............................................................................. 140 
Child Care Policies and Female Employment in the Post-war Period..................141

Allowances for Women and Children................................................................146

Administrative Arrangements for Child Care Policies during the Post-war

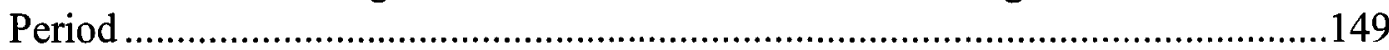

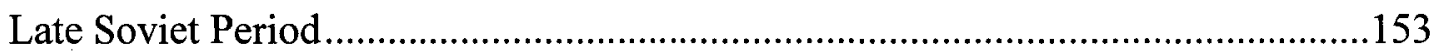

Maternity Leaves and Allowances for Mothers and Children in the Late Soviet

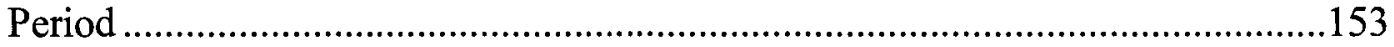

Child Care and Women's Employment in the Late Soviet Period .......................161

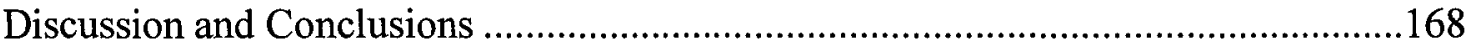

Chapter 3. Child Care Policies: "A Paradigmatic Case" of a Paradigm Shift in

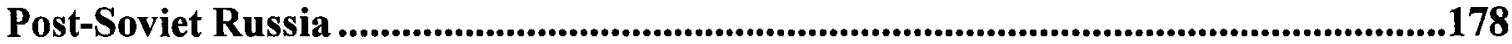

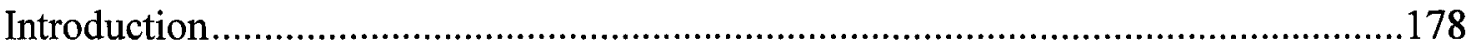

Post -Soviet Welfare Regime: Background .......................................................... 180

Economic Restructuring, Welfare State and Legacy of "Flexible" Institutions ......180

Social Policies and Unsustainability of Enterprise-based Micro-Welfare States ....187

Social Consequences: Poverty, Labour Markets and Demographics .....................191

Child Care Policies during Transformation ...........................................................195

Ideas, Role of Women and Social Attitudes .......................................................198

First Order Institutional Change: Maternity / Parental Leave ..............................210

Second Order Institutional Change: Benefits for Mothers and Children..................221

Third Order Institutional Change: Child Care Services.......................................231

Provision of Child Care: National View.........................................................233

Provision of Child Care: Local View............................................................243

Discussion and Conclusions .............................................................................253

Chapter 4. Explaining the Shift: Role of the State and Non-state Actors ................260

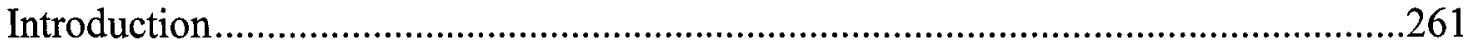

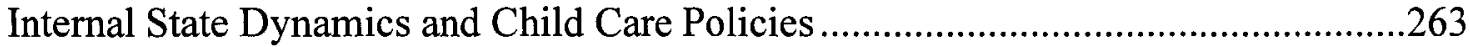

Horizontal State Dynamics: Political Regime Shifts and Soviet Legacies..............265

1991 - 1993: Neoliberal Clash with Soviet Legacies ....................................269

1993-1995: Policymaking Gridlock................................................................274

1996 - 2001: A New Turn in Russian Politics or Same Old, Same Old...?.......280

Vertical State Dynamics: Regional Independence and Legacy of Flexibility .........289

External Pressures: International Organizations, Business Interests, Trade Unions

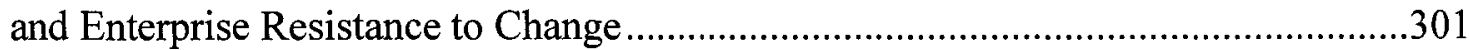

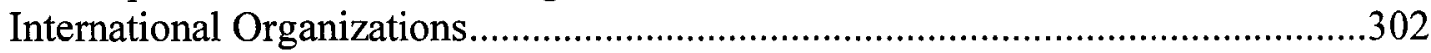

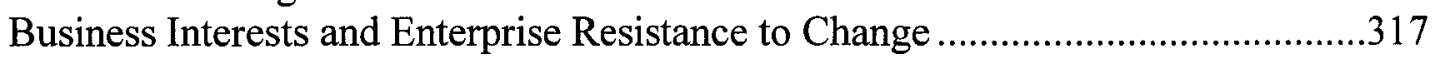

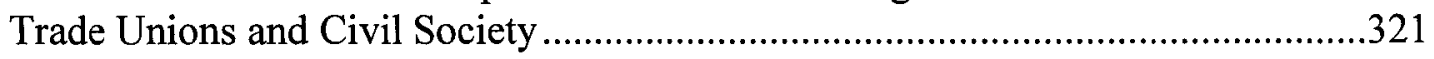

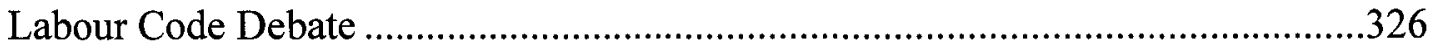

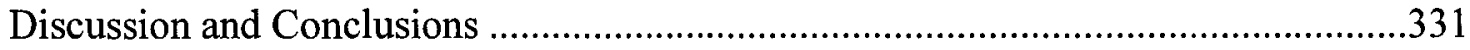

Chapter 5. Labour Market and Child Care Implications of the New Welfare

Model.........................................................................................................................336

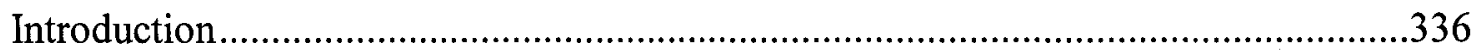

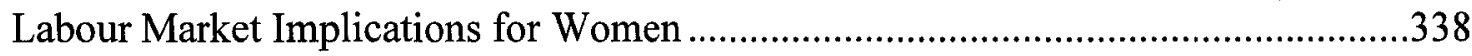

The Link between Child Care Policies and Mothers' Employment .......................338 
Unemployment and Labour Force Participation..................................................341

Current Working Status of Women/Primary Occupation ....................................351

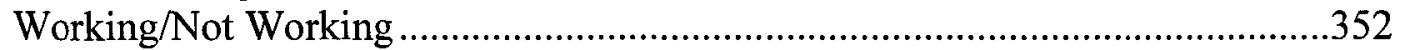

Maternity / Parental Leave...............................................................................360

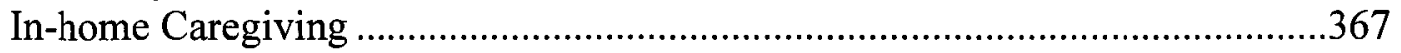

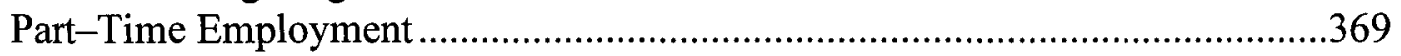

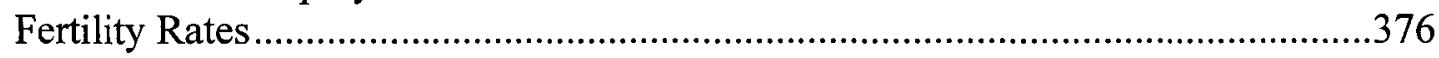

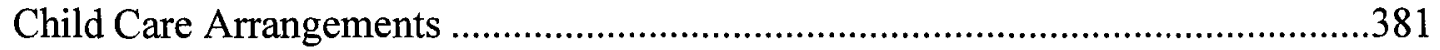

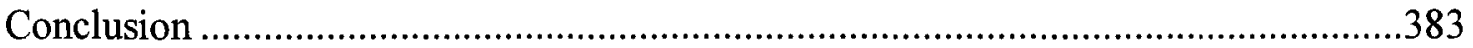

Chapter 6. Explaining the Shift: State Capacities, Soviet Legacies and

Adaptation Strategies ...........................................................................................386

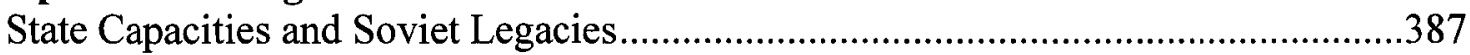

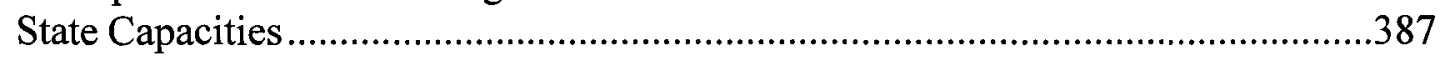

Financial and Administrative Capacities of the State ..........................................389

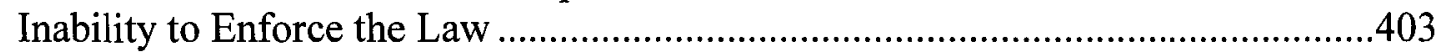

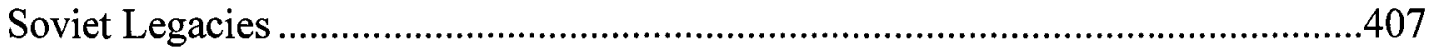

Adaptation Strategies: Labour Markets, Households, Women..................................411

Labour Market Adaptation Strategies ...............................................................412

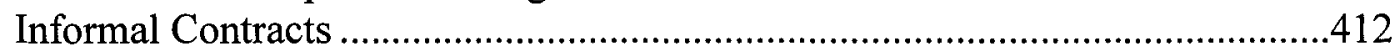

Part-time and Multiple Employment .......................................................417

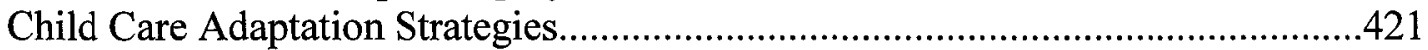

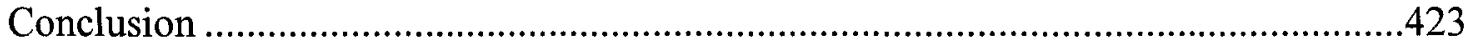

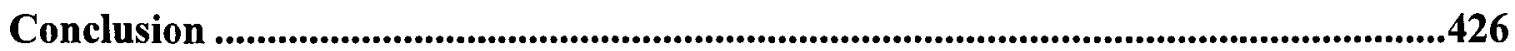

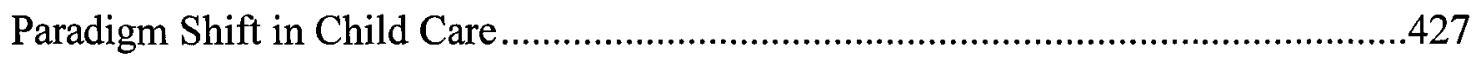

Autonomy and Capacity of the State in Russia ......................................................432

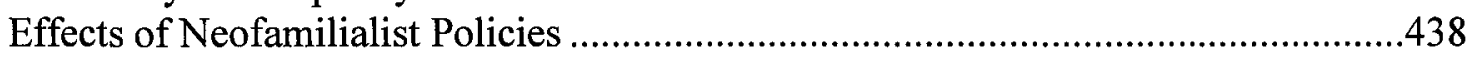

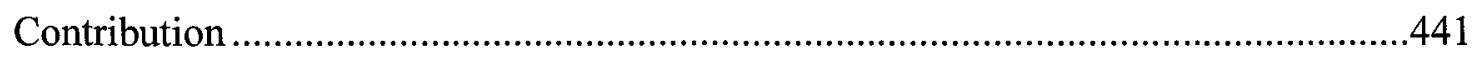

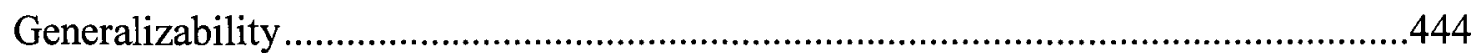

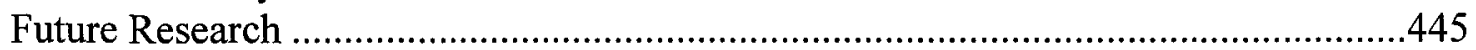

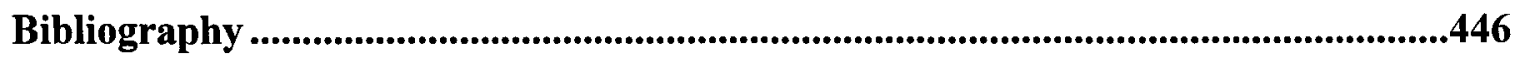

Appendixes................................................................................................................487 


\section{List of Tables}

Table 1. Institutional Changes in Child Care in Russia, 1991-2001 .............................62

Table 2. Periodic Comparison of the Child Care Policies in the Soviet Union ................118

Table 3. Percentage of the Employed Population, by Sex and Age, in the USSR in 1926 and 1959, and in the RSFRSR in 1959, per cent ...........................127

Table 4. Number of Permanent and Seasonal Nurseries, 1917-29...............................128

Table 5. Number of Places and Children in Soviet Nurseries, thousands, 1913-1964 ..130

Table 6. Fertility Rate of the USSR, 1926-66.........................................................132

Table 7. Distribution of Kindergartens, by Departmental Subordination, 1937-55 .......139

Table 8. Preschool Institutions in the Soviet Union, End of the Year, thousands ...........142

Table 9. Monthly Payments by Parents for Maintaining Children in Kindergartens,

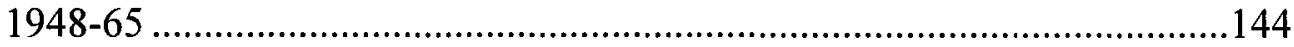

Table 10. Total Fertility Rates in the Postwar and Late Soviet Periods ..........................154

Table 11. State Expenditures, USSR (million roubles) .............................................158

Table 12. Number of Preschool Institutions, Russia, Late Soviet Period (1980-1990)...161

Table 13. Distribution of Married Women by Age, Working Status and Number of Children, 1968..............................................................................164

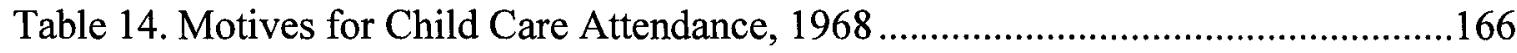

Table 15. Comparison of the Soviet Welfare Model and Social-Democratic, Conservative/Neofamilialist, and Liberal/Third Way Models of Welfare State.

Table 16. Comparison of Nancy Fraser's Universal Breadwinner Model and Soviet Model of Welfare State ...........................................................................173

Table 17. The Program of Economic Reformation Offered by IMF and World Bank....187

Table 18. Public Expenditures on Health and Education in Russia, 1991-2000 ............189

Table 19. Comparison of Late Soviet and Post-Soviet Welfare Regimes .....................212

Table 20. Allowances for Individuals with Children (2000) .......................................227

Table 21. Pre-school Institutions, Russia, 1985 - 2001 ............................................234

Table 22. Live Births/Total Fertility Rates in Russia, $(1988$ - 1991, 1994-2000) .........236

Table 23. Ownership of Child Care, 1990 - 2001, Russia ...........................................238

Table 24. Child Care Institutions in Novorossiysk and Sakha Yakutia.........................245

Table 25. Comparison of the Soviet Welfare Regime with the Post Soviet and Mahon's Types of European Welfare Regimes ........................................256

Table 26. Comparison of the Caregiver Parity Model/Neofamilialist and Post-Soviet Model of Welfare State ....................................................................2258

Table 27. Results of the Duma Election, December 1993 .........................................276

Table 28. Results of the Duma Election, December 1995 .........................................282

Table 29. Division of Responsibilities and Approach to Reforms among "Social" Ministries, Russia, 1991-2001 .............................................................285

Table 30. Current Working Status, Unemployment and Labour Force Participation Rates among Working -Age Adults (Men 18-60; Women 18-55), 1994-2001, Russia. 
Table 31. Current Working Status of Working Age Adults, 1994-2001, Russia ............354

Table 32. Current Working Status of Mothers with Children Younger than 7 Years

Old, by age, 1994-2001, Russia.............................................................358

Table 33. Employers' Reasons for Preferring to Hire Men or Women, Russia, 1999 ....362

Table 34. Which Benefits Decrease Women's Attractiveness as Employees for

Employers?

Table 35. Distribution of Mothers' Employment by Enterprise Type, 1994-2001 .........366

Table 36. Working Adults Hours of Work, by Presence of Children, 1994 - 2001,

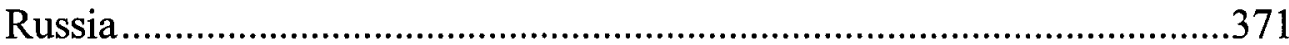

Table 37. Types of Child Care Arrangements, 1994 - 2001, Russia.............................382

Table 38. Government Social Expenditures in Russia (1987 - 1996); Roubles per year, deflated by cost of living index.

Table 39. Change in the Value of Child Allowances in Russia, 1991-1996 (Percentage of the Average Monthly Wages)

Table 40. Parental Leave Benefit in Central and Eastern Europe (Percentage of the Average Wage)

Table 41. Child Allowances Arrears by Selected Regions of Russia as of July 1, 2000 (million roubles)

Table 42. Female Labour Force Participation, 1970, 1979, 1989 .407 


\section{List of Figures}

Figure 1. Interaction of State and Non-state Actors in the Russian Welfare State ............87

Figure 2. GDP Change in Selected European Transition Countries, $1989=100 \%$.........184

Figure 3. Trends in Real GDP growth and Real Wage Growth in Russia, 1990-1998

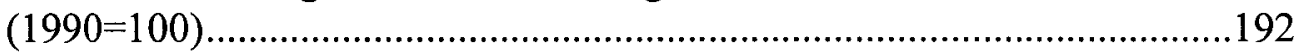

Figure 4. Duration of unemployment, by gender, 1994-2001, Russia..............................347

Figure 5. Labour Force Participation of Working-Aged Adults, by gender, 1994-

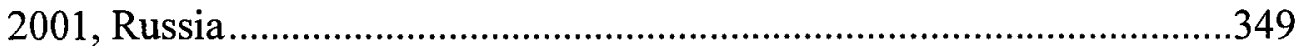

Figure 6. Poverty Status and Family Structure, RLMS 1994-1996 (percentages) ...........356

Figure 7. Rate of Women on Maternity/Parental Leave, 1994-2001, Russia ...................361

Figure 8. Rate of Women- In-home Caregivers as a Primary Occupation, 1994-

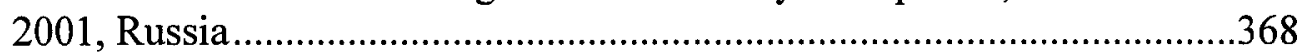

Figure 9. Total Fertility Rate in Selected CEE-CIS Countries, 1989-2003 ………..........377

Figure 10. Contraceptive Prevalence Rates in the CEE-CIS, 1990-2002 .........................379 


\section{List of Appendixes}

Appendix 1. Administration of Social Services by Ministries of Welfare, Soviet Union, 1963.

Appendix 2. System of Education in the Soviet Union, 1968

Appendix 3. Main legislation and policies with regard to the position of women in the Soviet period (1940-1988).

Appendix 4. Advice of International Organizations to Russia on Aspects of Social / Family/ Child Care Policies, 1991-2001

Appendix 5. RLMS Sample Sizes, Working Age Adults.

Appendix 6. Former Communist Party Saturation, 1999

Appendix 7. Party Membership and Participation, by Sector Type of Economic Elite

Appendix 8. Distribution of "Soviet" and New Business Elite between Sectors 


\section{Introduction}

\section{The Objective and the Argument}

This dissertation will address the shift towards neofamilialism ${ }^{1}$ in the Russian welfare regime during the transformation period. It will analyze the social and economic reforms in the former Soviet republics, using the example of the Russian Federation. The central thesis of the dissertation is as follows: The analysis of post-Soviet Russian child care ${ }^{2}$ shows that there has been a paradigm shift - not to neo-liberalism but rather toward a neofamilialist model of care. ${ }^{3}$ This reflects the balance of power within the Russian state system as well as the power resources of external-to-state actors. While this shift has resulted in the greater familialisation of care, it has not, however, facilitated the "choice" to stay at home with young children, at least for most women. The very tensions within the state that favoured the adoption of a neo-familial paradigm have also limited its ability to implement it effectively. As a result, many women have to try to combine work and family life, albeit under more difficult circumstances than before.

\footnotetext{
${ }^{1}$ Mahon (2002a). Neofamilialism can be understood as a welfare state model, developed in response to the rising female labour force participation, which draws on conservative views of gender difference. The model emphasizes choice, but mainly between a status of a temporary housewife-mother role and labour force participation and advocates solutions based on longer-term (three- to four- years) child care leave packages (Mahon, 2002). While women are encouraged to return to work, they rarely return to their former jobs and rarely on the full-time basis (Mahon 2005).

${ }^{2}$ Child care policies in this thesis refer to the policies related to the following forms of formal care provision: services, money and time-off (i.e. maternity and parental leaves).

${ }^{3}$ This work uses the term "neo-liberalism" as representing a US-type model of welfare state and child care provision. High female participation in the labour force in the US and thus the solution to the resulting need for non-parental care is largely achieved though the existence of a large pool of low-wage workerscaregivers, who are mainly female (Esping-Andersen, 1999). The role of the state in this model can be seen in workfare provisions, neo-liberal labour market regulations, tax deductions, etc. (Michel, 1999; Mahon 2005b).
} 
The thesis empirically analyzes the elements of the Soviet and post-Soviet welfare states as seen through the prism of child care arrangements in both regimes. The cases to be studied in detail are child care services, maternity/parental leaves provisions, as well as in-home caregiving and other family type allowances. The general objective is to illustrate that the emerging welfare regime in Russia possesses neofamilialist elements and represents a mixed welfare system, which evolved as a result of complex interactions of traditional policymaking in Russia, and neoliberal efforts aimed at structural adjustment. The specific objectives of this thesis are as follows: to understand the process and nature of changes in child care policies during the transformation period in Russia (1991 -2000); to assess the scope and nature of the implications of the policy paradigm shift in the area of child care for the position of women in the labour market; as well as to understand the factors influencing the process of change in Russian child care policies, along with ultimate policy effects.

This thesis will aim to develop a more nuanced account of social change in the region, and the dynamics of change within a particular social arena, in two ways. First, it develops a multiscale lens ${ }^{4}$ for the analysis of child care policies in Russia, and uses local examples ${ }^{5}$ to illustrate the complexity of welfare regime change in the context of decentralization and federalism, as affected by the unique forces of transformation. Local

\footnotetext{
${ }^{4}$ For the detailed discussion of the multi-scale approach, see Rianne Mahon, Caroline Andrew and Robert Johnson "Policy Analysis in an Era of 'Globalization': Capturing Spatial Dimensions and Scalar Strategies" in Miriam Smith and Michael Orsini (eds.) Reconfiguring Policy Analysis: Contemporary Canadian Approaches University of British Columbia Press; Peck (2002); Mahon (2003); Mahon and Johnson (2003); Mahon (2005a).

${ }^{5}$ Local examples include cases at both municipal and regional levels, unless specified otherwise.
} 
examples show how local conditions reveal the difference in the construction of child care policy and its effects.

Second, this thesis attempts to challenge the rigid approaches of mirrored opposition between "socialism" and "capitalism," by taking into account the socialist institutional legacies inherited in the transformation period. As Haney puts it,

Clearly, 1989 did not wipe the slate clean in Eastern Europe. Historical legacies continue to constrain and enable state development both within and among the countries of the region. Such legacies also condition the expectations different social groups have of the state and how they react to its metamorphosis. Only by disrupting rigid historical dichotomies and models will area specialists unearth the complex reconfigurations of state involvement in social life. ${ }^{6}$

This thesis will compare elements of the new welfare state to the Soviet welfare model, which will allow us to see institutions as "films," not as mere snapshots. This historicallysensitive and empirically-detailed way of looking at institutions allows us to understand why the public and the elite were so willing to break with the previous regime, while simultaneously generating resistance to dismantling (certain) the institutions inherited from the past. Thus the analysis conducted in this thesis suggests caution and a nuanced approach are needed when applying western theoretical models to societies undergoing a great degree of turmoil and transformation. Their situations embody different starting points, institutional legacies, as well as change adaptation and resistance strategies.

\footnotetext{
${ }^{6}$ Haney (2002): p.6
} 


\section{The New Russian Welfare Model}

Since 1990, the former Soviet republics have undergone significant structural reforms of their social, political and economic systems. The reforms were associated with the transition to the market economy, and in some cases, with accession to the European Union. Such reforms were not limited to a retrenchment of the welfare states, but also included deep ideological changes. While some of the former Soviet republics embraced neoliberalism as a way of development, and rejected everything associated with the past, others retained many elements of the Soviet welfare state. These examples suggest that the movement is not towards a neoliberal form of welfare regime (as advocated and expected by many western economists and transition specialists, and as envisioned at the beginning of the transformation by the policymakers), but towards a mix of neoliberal ideas and Soviet legacies and institutions.

Russia is a good example of a mixed regime. Despite the collapse of the Soviet Union and the installation of a set of forces determined to carry out radical neoliberal policies, there was a certain resistance from the state to pressures to adapt a neoliberal regime. The resistance was generated as a result of heated battles between inherited interests, such as the left-wing and "industrial" groups, and new players in the political arena, such as international organizations, large business and radical-liberal reformers.

This combination of neoliberal forces and inherited interests and institutions, combined with the legacy of the authoritarian state and aggravating economic conditions, resulted in a movement towards neofamilialism in the Russian welfare state, rather than 
neoliberalism or the deepening of the egalitarian norms, inherited from the Soviet period. This thesis will show that the movement towards neofamilialism involved a policy paradigm shift in the area of child care. ${ }^{7}$ Not only did the issue of care start to be framed differently, but also the underlying policy logic, which defined the nature of welfare provision, has undergone a serious change. These changes, combined with the dramatic decline in the economic wellbeing of the country, which took place at the beginning of the $1990 \mathrm{~s}$, contributed to the transformation of social reproduction and changing relationships between its main institutions - state, family and market. This transformation resulted in the family assuming most responsibilities for providing welfare to individuals, thus pointing to re-familialization of care. This was accompanied by increasing advocacy of familial values by the Russian policymakers, including opposition to female - and especially maternal - employment, which, in turn, reduced support for public child care. The paradigm shift also involved changes in child care policies, such as widespread reduction of publicly-provided child care services, without creating or facilitating the creation of viable alternatives; the extension of parental leave and an increase of in-home caregiving allowances. These changes constitute a qualitative shift in the welfare state regime: from one aiming at promoting female employment, to one aimed at the promotion of the status of temporary homemaker.

The paradigm shift came about as a result of the decade-long policy debate in Russia concerning appropriate models of social policy and the role of women, as generated by demographic, labour market and economic pressures among Russian

\footnotetext{
${ }^{7}$ Kuhn (1970): p. 275-296
} 
policymakers, as well as non-state actors. The demographic factor became especially important, since extremely high abortion rates and very low fertility rates led to a demographic crisis in Russia at the beginning of the 1990's. The country's total fertility rate, which had been around two lifetime births per woman from the late 1960s through the early 1980 s as a result of deliberate pro-natalist policies, dropped steeply from 1987 , falling to 1.4 births per woman in 1994. In 1992, the abortion rate was 98 per 1,000 women aged $15-49$, and the abortions outnumbered births by more than two to one. ${ }^{8}$ In addition, the inability of the state to sustain full employment over the transformation period, has increasingly made the idea of "bringing women back home" very popular among Russian policymakers and society in general. ${ }^{9}$

In order to explain the paradigm shift in the area of child care, and understand the nature of policymaking in Russia, this thesis will utilize a combination of both statecentered and power resource approaches. The state-centred angle views states as potentially autonomous and able to formulate and pursue goals that are not simply reflective of demands of interests of social groups, classes or society. ${ }^{10}$ Power resource theory suggests that welfare states are the outcomes of interactions between socioeconomic interest groups and political parties. By combining the two, we can appreciate the power of the internal state dynamics as well as account for the influence of external actors. This approach brings into view both horizontal relations among political parties, bureaucracy and presidency, and a vertical dimension of these dynamics, as the regions

\footnotetext{
${ }^{8}$ Hollander (1997)

${ }^{9}$ Klimenkova (1994). See also Tchekorina (2002)

${ }^{10} \mathrm{Pal}$ (1988)
} 
emerged as powerful players in the Russian political arena during the transformation period. While external actors played an important role in the policy-making process during the period of transformation, the Russian state maintained a relative policymaking autonomy in the area of child care.

\section{Justification of Case}

I am interested in exploring the dynamics of the welfare states in transition. To narrow down the scope of this work, I decided to focus on the Russian welfare state. The choice of a single case, rather than a strictly cross-country comparative case study approach, offers a number of advantages for this research and for policy analysis in general. As Pal puts it: "First, it provides a vehicle for full contextualized problem definition... Second, case studies can illuminate policy relevant questions (more as research than analysis) and so can eventually inform more practical policy analytic advice down the road." "I Yin defines "case study" as an empirical inquiry which "investigates a contemporary phenomenon within its real-life context; when the boundaries between phenomenon and context are not clearly evident; and in which multiple sources of evidence are used." ${ }^{12} \mathrm{He}$ argues that the case study method is useful for attempts to explain a contemporary set of events (when questions "how" and "why" are being asked). Questions "how" and "why" "deal with operational links that need to be traced over time, rather than mere frequencies or incidence." 13 The case study method allows us to achieve "a level of complexity and a

\footnotetext{
${ }^{11} \mathrm{Pal}(2005 \mathrm{~b}):$ p. 2

12 Yin (1989): p.18

${ }^{13}$ Ibid.
} 
density of explanation that is not usually characteristic of the other approaches"14 and "allows an investigation to retain the holistic and meaningful characteristics of real-life events." 15

A case study approach is particularly important for research on policy processes, as opposed strictly to outputs and outcomes. ${ }^{16}$ Despite the obvious importance of the latter, when the explanation of these outcomes is required, "the policy literature tends to look for proximate causes in the policy processes that produced those outcomes." ${ }^{" 17}$ Pal argues that "since policies are the product of intention, and that intention is refracted and shaped in specific processes, understanding the processes will help explain and possibly improve the policies." ${ }^{\prime 18}$ Moreover, a case study method allows us to analyze policy processes in specific institutional configurations, which are specific to a certain time and place, and assess how these institutions affected policy processes and outcomes.

The case-study approach to analyzing welfare states allows us to examine national patterns in greater detail, focusing attention on complexities of small-scale and large-scale variations. ${ }^{19}$ The case study approach is the best methodology for the study of change, since it allows for a better interpretation of the complexity of the specific cases and produces limited generalizations that are sensitive to both historical chronology and specific context. In addition, the case study method particularizes the research questions and allows us to focus on complexity and context within the national setting.

\footnotetext{
${ }^{14} \mathrm{Pal}(2005$ b): p. 5

${ }^{15}$ Yin (1989): p. 14

${ }^{16} \mathrm{Pal}(2005 \mathrm{~b})$; Yin (1989)

${ }^{17} \mathrm{Pal}(2005 \mathrm{~b}): \mathrm{p} .14$

${ }^{18} \mathrm{Pal}(1989): \mathrm{p} .15$

${ }^{19}$ Lewis (1998)
} 
Moreover, the case study approach offers the possibility of detailed descriptive and in-depth analysis. Through this method, my work attempts to obtain an understanding of the processes and forces that influence the policy-making machinery in the Russian system. Finally, it is important to note that a two-tiered periodization of Russian welfare regimes is utilized in this thesis. Historical comparison will allow the analysis of the issues of interest on both the historical and the contemporary scenes. The transformations in state policies and the institutional practices of the Russian welfare system, from 1917 to 2001 -- Soviet period (1917 - 1991) and early post-Soviet period (1991 - 2001), -provide the general timeframe for this research. Specific attention will be paid to the late Soviet period (1960-1991), since during that period all policies toward women were relatively stabilized, and the official "double ideology" ${ }^{20}$ was established. Bunce notes that that era was also characterized by "the contradictory developments of the rise of the Soviet Union as a global power and significant improvements in the Soviet quality of life, on the one hand, and on the other, the considerably less welcome trends of rising corruption and public cynicism, a breakdown in central control, and a slowdown in economic growth in general."21 The year 1991 was marked by the collapse of the Soviet Union, and associated with the beginning of "transformation," through a series of changes in the policy priorities of the state and its economic performance. The dissertation will focus on the changing nature of the Russian state, rather than examining a static picture. Wherever possible, this work highlights any observable changes within both periods.

\footnotetext{
${ }^{20}$ Khotkina (1994). Double ideology with regard to women in the Soviet period refers to the official ideology of equality provided by laws and statutes and patriarchal/protectionist ideology in the real life. ${ }^{21}$ Bunce (1999b)
} 


\section{Methodology}

In general, the research utilized both qualitative and quantitative methods of data analysis. Qualitative analysis consisted of two parts: document and literature review as well as strategic interviews at both national and regional local levels. ${ }^{22}$ Quantitative analysis, in turn, involved analysis of the data provided through the Russian Longitudinal Monitoring Survey and Survey conducted by the Centre for Labour Market Studies, Moscow. The dissertation follows an interdisciplinary approach, bridging sciences such as political economy, political science, public administration, law and economics.

Document review, for the most part, relied on national archival data, examination of Soviet and Russian key policy documents and reports, and records of parliamentary debates. Specifically, the documents reviewed included federal laws in the area of child care policies in both, presidential speeches and programmatic documents endorsed by the president, resolutions of the government of the Russian Federation, including the Ministry of Education, Ministry of Labour and Social Development, and Ministry of Health. ${ }^{23}$ Parliamentary debates and discussions were important for determining the influence that the national parliaments and individual parliamentarians exerted on the adopted policies, with respect to women in general and child care/leave provisions in

\footnotetext{
${ }^{22}$ The focus on regions and municipalities is justified by several factors helps to advance our understanding of the policymaking dynamics at the local level and appreciate the nature and the scope of changes in child care policies during the transformation period. Attention to local conditions and policymaking centres can help us understand not only the nature of the paradigm shift, but also how these shifts and occur.

${ }^{23}$ Federal policy papers, laws and administrative documents were analyzed with regard to child care, family policies and programs, as well as archival and current documents of the municipalities and state bodies responsible for education, along with enterprise statistics in the specified regions. The analysis of maternity/parental leave provisions and children allowances in both periods was based on policy documents and legislation, such as the Labour Code and Statutes regulating maternity payments and other child allowances, which existed in both periods.
} 
particular. The research also involved content analysis of, official statements made by Soviet and Russian policymakers, economists, and political analysts related to the issue. Russian-language printed and electronic media were used to provide evidence for this research work. On top of the analysis of the official documentation of the state bodies at the federal and local levels, I also analyzed the directives and policies of such international organizations as the World Bank, the International Monetary Fund, the International Labour Organization and the European Union, in order to assess the impact of these actors on the policymaking process.

Additional insight has come from studying official and unofficial documents in the local and regional governmental agencies in two Russian regions: Novorossiysk and Sakha Yakutia. The focus on regions and municipalities is justified by several factors. First, during the Soviet period, referrals to child care institutions were obtained via agencies of social protection at the municipal level, while in the post-Soviet period, those privatized enterprises which did not convert child care facilities into profit-making businesses, were required to transfer them to municipal control. Thus understanding the dynamics at the local level will help us to appreciate the nature and the scope of changes in child care policies during the transformation period. Second, attention to local conditions and policymaking centres can help us understand not only the nature of the paradigm shift, but also how these shifts occur.

Novorossiysk serves as a representative case for many Russian municipalities. Most research on Russia focuses on Moscow and St. Petersburg, cities that attracted more than $50 \%$ of all foreign direct investment. The majority (about $85 \%$ ) of the population of 
Russia lives outside of those cities however, a fact which requires a deeper look in the Russian provinces. Novorossiysk, with about 281 thousand inhabitants, is an average urban and industrial centre. About 222.6 thousand people live in the urban area and 58.4 thousand in the rural regions of Novorossiysk. The economically active population is about 149.5 thousand people, pensioners - 52 thousand people and children - 68.6 thousand people.

The city has a number of large enterprises, including the port and the cement plant (the largest producer of cement in the country during the Soviet period). The presence of such enterprises is important for the welfare state research, due to the legacy of enterprises as micro-welfare states (for example, the Port had seven kindergartens (for about 150-200 children each) as part of its social infrastructure). Novorossiysk was also characterized by a decline in production of almost 50 per cent, similar to the countrywide trend. At the same time, being the major Russian port and naval base on the Black Sea, Novorossiysk is an important transport hub of Russia. It exports grain and oil and still remains, despite the decline, a major center of the cement industry. The economic sector also makes it representative for an average Russian city: 15\% of the active population work in industry, $22 \%$ - in transport; $26 \%$ - in trade and $44 \%$ in other industries, including small business (representing $32 \%$ of the economically-active population).

Finally, Novorossiysk is situated in the Krasnodar region, known for its conservative (i.e.: Communist) stance, where a majority of the population supports the 
communist nomenklatura. ${ }^{24}$ Thus, Novorossiysk, in some sense is facing socio-political and economic isolation from federal authorities. At the same time, it has been recognized as a city of "federal importance" and therefore has a special status within the region. This, in turn, predisposed it for potential conflicts with the regional authorities. These factors can be seen as a special characteristic of the Russian realities and will serve as an important illustration of how policies are made.

The case of Sakha Yakutia is of interest because it represents the highest rates of public child care provision and attendance in Russia. These specific cases are described in chapter 3. Sakha Yakutia is a republic in the North of Russia, and serves as a unique example of an area where regional authorities intervened to have mandatory preschool education, thus influencing attendance rates in the kindergartens. Geographically, more than two-fifths of the republic lies above the Arctic Circle. Owing to its geographical location, the republic is characterized by a variety of natural conditions and resources. There are about one million citizens living in Sakha Yakutia, out of which 226.1 thousand live in the capital city of Yakutsk. The industrial sector generates almost half of the revenue of the republic, stemming primarily from mineral exploitation (the diamond, gold and tin ore mining industries).

At the local level, the documents reviewed included statutes of local authorities, local educational bodies, and various analytical materials. Several experts provided me with notes and letters pertaining to the evolution of child care policies. In total, I

\footnotetext{
${ }^{24}$ Nomenklatura system is referred to as the system of appointments to the senior posts in society by the Communist party. For more information on the nomenklatura system, see Holmes (1997).
} 
reviewed more than 400 documents, both official and unofficial, published and unpublished. These documents provided the main source of information for the empirical part of the dissertation. In addition, the thesis also relied on a review of relevant literature in the area, and key informant interviews at the local and federal levels. Finally, the Russian press (again, at the federal and local levels) was instrumental in understanding how various factors contributed to paradigm shift in social care and ultimately reflected the paradigm shift.

Key informant interviews with key Russian policymakers at both federal and local levels were intended to support and confirm the available data. The interviews, 19 in total, took place at the federal and local levels. At the federal level, the structured and semi-structured interviews were conducted with representatives of the Ministry of Education and Ministry of Labour and Social Development (in particular Committee on Women and Family Affairs). These interviews were intended to shed light on why the changes/continuities in child care policies took place. At the local level, semi-structured interviews were conducted with city officials (Novorossiysk) and region officials (Sakha Yakutia) as well as managers and representatives of trade-unions (who traditionally were responsible for provision of social services at the enterprises). The interviews were confidential and on a "not for direct attribution" basis. These interviews were supplemented by informal conversations and discussions, aimed at discovering what people thought of the current situation around child care policies. Since the interviews were not the main source of data for this research, and were intended either to confirm findings in the documents review, or obtain insight on the rationale for some 
changes/continuities in child care policies, the information from the interviews is embedded in the text, in particular in chapters 3,5 , and 6 . In addition, the interview data are supplemented with personal observations and informal conversations with women in Novorossiysk and Moscow.

Quantitative analysis involved analysis of the data provided through the Russian Longitudinal Monitoring Survey (RLMS). This household-based survey was used to measure the effects of Russian reforms on female labour force participation and child care strategies utilized by households and women. The survey contains several types of data: individual-, household- and community-level data. Overall, interviews were completed in $84.3 \%$ of the original national probability sample of $n=4718$ dwelling units. The RLMS has been conducted as a panel study. The unique contribution of this data is that we can illustrate some directions of change and raise issues for further research. The analysis conducted in it explores whether there were any changes in female labour force participation and child care arrangements during the transformation period, and whether these changes are consistent with the effects of the neofamilialist model.

In addition, a study conducted by the Centre for Labour Market Studies (CLMS) in Moscow in 1999 was also used to support the analysis. The study was conducted within the framework of Russian-Canadian Project "Women and Labour Market Reform in Russia," funded by the Canadian International Development Agency and administered by Carleton University, Ottawa. It was conducted in October 1999 in five Russian regions: Moscow, Kirov, Murmansk, Nizhny Novgorod, and Yamalo-Nenets Autonomous Area (Salekhard and Urengoi). Survey participants included heads of 
enterprises, employees and trade union representatives of the same enterprises and organizations. A total of 278 enterprises and employers were surveyed (about 50 in each of the regions and 77 in the Moscow region) with a total of 2213 employees and 131 trade union leaders. The survey provided information on the attitudes of employers towards hiring women, and allowed researchers to gain insight on the impact of neofamilialist policies in shaping these attitudes.

\section{Format of the Dissertation}

The dissertation consists of six chapters. This introductory chapter discussed the purpose, objectives, methodology and contribution of this research. Chapter 1 discusses the theoretical approaches that contribute to understanding shifts in welfare state regimes, and sets out the dissertation's analytical framework. This chapter consists of three sections. The first section concentrates on gendered theories of welfare states, with particular attention paid to the debate about child care and family policies. It discusses the uniqueness of post-communist countries and our need to take into consideration the institutional and ideological legacies constraining application of western theories in those countries. The second section elaborates upon the concepts of paradigm shift, institutional change, role of ideas and "path dependency" in the post-communist countries. Finally, the third section discusses political economy of the welfare state, as well as autonomy and capacity of the state, in order to set up a framework for understanding the policy process in Russia. 
Chapter 2 analyzes child care arrangements in the Soviet welfare state, including provision of child care services, maternity/child care leave arrangements and children allowances. The chapter also overviews ideological underpinnings, system of economic planning and decentralization of service delivery, as well as enterprise administration of benefits during the Soviet period. It also analyzes implications for female employment. A general categorization of the Soviet welfare state is provided. Chapter 3 , in turn, consists of three parts. The first part situates the post-Soviet welfare regime in the macroeconomic, ideational, and societal conditions. The second part accounts for the changes and continuities in the provision of public child care services, maternity/child care leave, as well as various children allowances in the post-Soviet period. It explores the nature of the paradigm shift in the welfare state regime, including the role of ideas. The final part assesses the new welfare model in post-Soviet Russia.

Chapter 4 explores the factors influencing the paradigm shift in the area of child care in Russia. It illustrates the process of paradigm shift during the transformation period and logic behind this process. It assesses the autonomy and the role of the Russian state in setting agenda in the area of child care policies. It consists of two main sections. The first section assesses internal state dynamics and legacy of flexible nature of political and economic institutions during the transformation period. Particular attention is paid to such internal state actors as political parties, bureaucracy and regional governments. The second section analyzes external pressures on the Russian welfare state, such as international organizations and enterprises, particularly in the context of the demographic crisis and the need to adapt to new economic and labour market conditions. 
Chapter 5 assesses the impacts of this regime shift on women and has three parts. The first part analyzes the changes in the position of women during the transformation period, compared to that of the late socialist years. The second part examines the changes in fertility rates. The third part explores the changes in the individual child care arrangements for children under seven years old. Overall, this chapter shows that the policy paradigm shift had a limited impact on female labour force participation in postSoviet Russia.

Chapter 6 examines those factors which influenced the ultimate outcomes of the family and child care policies. This chapter has two main parts. The first part focuses on the state's capacities to implement its policies, as well as Soviet legacies of flexible institutions, a culture of employment and high levels of education. The second part describes the main strategies used by labour markets, households and women to adapt to the changing economic and social conditions.

The final chapter discusses a new model of a welfare state in Russia, and makes a case for a nuanced analysis of the welfare state regimes in the post-communist space. It also outlines the contribution of this research, and offers some generalizations with regard to other post-communist countries. Last, but not least, it discusses the implications of regime shift for gender equality, and outlines opportunities for further research. 


\section{Chapter 1. Gendered Welfare State Theories, State Autonomy and the Process of Institutional Change in Child Care}

\section{Introduction}

To situate the Russian case of welfare state transformation, we need to conceptualize the nature of welfare state regimes, the nature of institutional change and continuity, and the sources of policy innovation. This chapter outlines a distinctive approach in the study of welfare state regimes in general, and the study of the Russian public policy in particular. It consists of three sections. The first reviews theories of welfare state, gender, and role of child care for female employment, arguing that child care serves as an important lens for the analysis of welfare regime transformation. It outlines the main types of welfare state regimes that will be used to analyze the Russian system, which, as will be argued in subsequent chapters, is moving towards a form of neofamilialism. This section also lays out the main challenges faced by welfare states in transition and elaborates on the need for a nuanced approach to analyzing policy changes in the countries of the region. Finally, it underscores the importance of a multi-scale lens of analysis for welfare state regimes.

The second section discusses "path dependency" thesis, the role of ideas and the notion of paradigm shift in the welfare state analysis. It stresses the need for a paradigm shift approach to the analysis of the transformation of the Russian welfare state. The third section outlines various approaches to understanding the process of public policymaking, sources of continuity and change, as well as why and how paradigm shifts 
come about. It argues the autonomy and capacity of the state, as well as state interests in the area of child care. It lays out a framework for understanding policymaking during the transformation period and discusses actors and interests influencing policymaking in Russia. Given the legacy of the authoritarian state, as well as the multiplicity of actors on the Russian political arena, there is a need for a combination of state-centred and power resources approaches, in order to fully account for the process of social change in the transformation period.

\section{Gendering Welfare State Theories: The Role of Child Care}

Understanding the transformation of the Russian welfare state requires that we understand the broader debate around welfare state regimes, and particularly the gender dimension of those regimes. Sainsbury notes that a "regime embodies values, norms, and rules, thus providing a normative or regulatory framework that shapes behaviour." 25 Welfare regimes in turn can be described as

institutionalized patterns in welfare state provision establishing systematic relations between the state and social structures of conflict, domination and accommodation. Such patterns refer to the terms and conditions under which claims may be made on the resources of the state, and reciprocally, the terms and conditions of economic, social and political obligation of the state. The elements constituting social policy regimes may be economic, legal, political and/or discursive. ${ }^{26}$

\footnotetext{
${ }^{25}$ Sainsbury (1999): p.77

${ }^{26}$ O'Connor, Shaver \& Orloff (1999)
} 
In general, most discussions of welfare regimes begin with Esping-Andersen's The Three Worlds of Welfare Capitalism. ${ }^{27}$ Esping-Andersen's original analysis of welfare regimes drew from social democratic theory and political economy, and was focused on the provision of social rights, the contribution to social stratification, and the nexus of statemarket-family relationships. He used two main concepts to construct his typology of regimes: "decommodification" - "the degree to which... people [can] make their living standards independent of pure market forces, ${ }^{28}$ describing the relationship of paid workers to labour markets -- and "stratification," to analyze class inequality. Although Esping-Andersen acknowledged the importance of taking into account "how state activities are interlocked with the market and family's role in social provision, ${ }^{, 29}$ only in his subsequent work, and in response to feminist critiques, did he add another variable for the analysis of welfare regimes, "defamilialization." Defamilialization refers to a degree to which households are freed from responsibilities to provide social welfare and diminished individual dependence on familial kinship: "Defamilialization does not imply anti-family... it refers to the degree to which households' welfare and caring responsibilities are relaxed - either via welfare state provision, or via market provision.”30 As Esping-Andersen further explains:

The concept of de-familialization parallels with the concept of de-commodification; in fact, for women de-familialization is generally a precondition for their capacity to "commodify themselves" (Orloff. 1993). Hence, de-familialization would

\footnotetext{
${ }^{27}$ Epsing-Andersen (1990)

${ }^{28}$ Ibid.: p. 3

${ }^{29}$ Ibid.: p. 21

${ }^{30}$ Esping-Andersen (1999): p. 51
} 
indicate the degree to which social policy (or perhaps markets) render women autonomous to become "commodified," or to set up independent households, in the first place. $^{31}$

This was an important concept which intersected with further work by the feminist welfare state research scholars, such as Ann Orloff, Julia O' Connor and others, whose work is described below. One of the most important features of Esping-Andersen's analysis was the attention he drew to the "division of labour" between states, markets and families in providing welfare. The state-market-family nexus helps analyzing not only how responsibilities for welfare provision are divided between states and markets, but also the contribution of families to welfare, and taking into account the social organization of caring and domestic work. ${ }^{32}$ Using these criteria, Esping-Andersen developed three types of welfare state regimes: liberal, conservative and socialdemocratic. ${ }^{33}$ Liberal regimes rely on a residual safety net and encourage dependence on the market provision of services. These regimes are open to defamilialization mainly through favouring "the market on both the demand ([service]...fees) and the supply (commercial or employer provision [of services]) side."34 Social-democratic regimes offer generous public protection from the risks generated by market or other forces. This type of regime reduces families' responsibilities for welfare by attempting to provide public services. Conservative regimes are based on a social insurance system, which is mainly available through employment. This type of regime reinforces status differences

\footnotetext{
${ }^{31}$ Ibid.

${ }^{32}$ Orloff (1993a)

${ }^{33}$ Esping-Andersen later modified his original typology and substituted the conservative regime with three others: continental Europe, Southern Europe and Japan, but for the purposes of making comparative references in this thesis I will use his original typology.

${ }^{34}$ Mahon (2002b): p.6
} 
and is most resistant to defamilialization. It is built on the principle of subsidiarity when the "state will only interfere when the family's capacity to service its members is exhausted." ${ }^{35}$ As Orloff noted, however, it "will not provide services that enable mothers...to enter the paid labor force." ${ }^{.36}$

Esping-Andersen's framework serves as a useful starting point in analyzing the distribution of responsibilities for welfare and its implications for gender relations. On its basis, other scholars have built comparative theories on gendering ${ }^{37}$ welfare state analysis. Orloff introduced the concepts of "access to paid work" and "capacity to form and maintain an autonomous household" as having the most significant impact on gender equality. ${ }^{38}$ Orloff argues that access to paid work provides independence and increases bargaining power within families. ${ }^{39}$ This point has also been emphasized by Julia O'Connor,

before decommodification becomes an issue for individuals, a crucial step is access to the labour market - that is, the potential for commodification - or, alternatively, the existence of a full range of social rights that afford economic independence without links to the labour market. Since the latter is not the case in any welfare state, labour force participation and the quality of that participation are crucial to the range and quality of social rights and to social stratification in contemporary welfare states. ${ }^{40}$

\footnotetext{
${ }^{35}$ Esping-Andersen (1990): p.27

${ }^{36}$ Orloff (1993a): p.312

${ }^{37}$ I adopt Gal and Kligman's (2002b) definition of gender which is "the socially and culturally produced ideas about male-female difference, power and inequality that structure the reproduction of these differences in the institutionalized practices of society." They argue that what it means to be a man or a woman, to be masculine or feminine varies historically.

${ }^{38}$ Orloff (1993a): p.312-19

${ }^{39}$ See also Blumstein \& Schwartz (1983); England \& Farkas (1990); Benenson (1991); Agarwal (1997)

${ }^{40}$ O'Connor et al. (1999): p.47
} 
Thus equal access to paid employment, and to the services which make this employment a viable option, has been a demand of women's movements for a long time. In marriages, the economic dependence of women "both reflects labour market realities and reinforces women's weak position in the labour market." ${ }^{, 41}$ Economic dependence is often associated with less bargaining power in the family, since it is mostly based on the contribution of spouses to family income. ${ }^{42}$ Labour supply, in turn, is sensitive to the presence of dependent children and to government policies related to caregiving. ${ }^{43}$ Thus, "the extent to which the state ensures access to paid work for different groups and the mechanisms that guarantee jobs (e.g. reliance on private employment, creation of tax incentives, legal regulation of private employers, or public jobs programs) are dimensions of all policy regimes. The key issue is ... the extent to which women can claim this right." $" 44$

The concept of capacity to form an autonomous household is also useful for assessing welfare state policies with respect to women. ${ }^{45}$ This concept is quite broad, and it hinges on whether individuals have the resources to choose to form households freely. ${ }^{46}$ The capacity to choose enhances women's power, in particular within families. This concept is more of a procedural one - it is the ability to choose that matters, not the fact of actually preferring an autonomous household. The state significantly affects this

\footnotetext{
${ }^{41}$ Hobson (1990): p. 236; Sorenson \& McLanahan (1987)

${ }^{42}$ See Blumstein \& Schwartz (1983); England \& Farkas (1986); England and Farkas (1990); Orloff (1993a).

${ }^{43}$ Gornick, Meyers \& Ross (1997)

${ }^{44}$ Orloff (1993a): p.318

${ }^{45}$ O'Connor et al. (1999)

46 Ibid.
} 
capacity via welfare provisions depending on social, political and economic targets.

Furthermore, as noted by O'Connor et al,

The dimension of capacity to form an autonomous household implies more than individual independence; it also gets at whether women and men are allowed to have, as well as to support, families, thus reflecting the character of regulations of sexuality, custody, reproduction, marriage, divorce and household composition. ${ }^{47}$

These concepts, "access to paid work" and "capacity to form an autonomous household," clearly indicate that paid work is one of the key resources in being able to form an autonomous household for women and increasing women's bargaining power within the family. Castells recognizes that "the massive incorporation of women into paid work increased women's bargaining power vis-à-vis men, and undermined the legitimacy of men's domination as providers of the family." ${ }^{48}$ Of course, as Orloff explains, "paid work exchanges one form of dependence on another - the dependence on employer... However,... [the main concern is] with the potential of paid work to provide women with some autonomy vis-à-vis marriage (or dependence on parents).,"49

Paid work is also important, as it often provides not only income but also eligibility for work-related benefits. In this way, equal access to paid work undermines a gendered differentiation of social rights, where men have predominantly claimed benefits as workers." ${ }^{, 50}$ This is particularly important in the Russian context, which inherited from the Soviet period the legacy of benefit provisions through enterprises, as will be

\footnotetext{
47 Ibid.: p.34

${ }^{48}$ Castells (1997)

${ }^{49}$ Orloff (1993a): p.318

${ }^{50}$ Sainsbury (1999): p.80
} 
elaborated in this thesis. These concepts serve as a useful foundation for incorporating gender in the analysis of the welfare states in general, and the Russian one in particular. This thesis will illustrate the degree to which a welfare state regime allows to put these concepts in practice.

\section{Welfare State Regimes, Women's Work, Child Care and State Interests}

The gendered welfare state literature suggests that access to paid work can be promoted or impeded by several factors. Availability of accessible quality child care is one of them: "[w]omen's equality in the labour market is no more than formally achieved until the matter of childcare is settled." ${ }^{\text {51 }}$ Moreover, many scholars argue that child care policies form an integral component of welfare states and can serve as a useful analytical tool for further analysis of welfare regimes. ${ }^{52}$ The changing structure of labour markets (high female labour force participation) and families (increasing divorce rates and decreasing fertility) brings child care to the forefront in the welfare state analysis.

In broad terms, the centrality of "care" to the welfare state analysis is underscored by the degree of the state involvement. It is often determined by the perception of "the proper division of responsibilities between 'the family' and 'the state," regularly based on the deeply-embedded assumptions of the role of women, as well as broader gender relations in society. At the same time, the degree of state involvement

\footnotetext{
51 Jenson \& Sineau (2001a): p.12

${ }^{52}$ Mahon (2002a,b); Jenson \& Sineau (2001b)

${ }^{53}$ Lewis (1998): p.9
} 
depends on the broader interests of the state, including economic, political, social and demographic ones. These "general" needs are reflected in the dilemma with regard to women, namely women's productive and reproductive functions. Specific interests of state include the following.

First, the state has a historically vested interest in reproduction issues: "as formulated in the European political thought... The health of a state - in many societies has been linked to the rapid reproduction of its inhabitants." ${ }^{, 54} \mathrm{Gal}$ and Kligman note that "by the eighteen century, the basis of a state's wealth and power was generally understood to lie not so much in the extent of its territory, but in the size and productivity of its population... It became a matter of significance that a large population not only increased the strength of armies, but made available increasing supplies of labour." ${ }^{, 55}$ Thus, a large population can be seen as a sign of a good, strong state. ${ }^{56}$ Moreover, it is also linked to the state's morality: "Every wise, just and mild government... will always abound in people." 57 This raises concerns about the quantity and quality of inhabitants. These concerns became particularly salient during the transformation period in Russia, when new and old elites debated over the forms the state should take.

Second, the state has an interest in reproduction, through the making and remaking of the nation and its boundaries. For many forms of nationalism, some forms of reproduction are defined as the sole legitimate, genuine, or authentic means of national

\footnotetext{
${ }^{54} \mathrm{Gal}$ and Kligman (2000): p. 19

${ }^{55}$ Ibid.:p.19

${ }^{56}$ It is also acknowledged by the author that while a large population can be seen as sign of a strong state, there is not necessarily a strong causal relationship between these two concepts.

${ }^{57}$ David Hume as cited in Gal and Kligman (2000): p.19 and in Gallagher (1987): p.83
} 
reproduction. This places the focus on motherhood and women as "vessels of the nation/race." It is women who "are blamed for demographic decline, and for being too 'selfish' to have children. Women are charged with engaging in 'birth strikes'; they are accused of siding with political systems such as communism that are considered to be unnatural or of committing treason if they do not wish their sons to die in wars... The control of women thus becomes a logical project of nationalism, [which mostly takes place] through the regulation of women's reproductive capacity. ${ }^{, 58}$

Third, debates about reproduction can be understood as coded discussions about claims to political legitimacy and credibility to rectify the wrongs of the communist past. More precisely, the issue of reproduction is used for constructing images of the morality and desirability of (new) political institutions and making claims for the "goodness" of (new) state forms. Gal and Kligman note that, throughout Eastern Europe, the morality of democracy, as opposed to the immorality of communism, was highlighted through debates about their contrasting approaches to reproductive policies. It was claimed that whereas communism went against nature in allowing women to circumvent motherhood, the post-communist state would "uphold the unchanging forces of a natural gender order.,, 59

Fourth, some states (e.g., increasingly Canada and Great Britain) are committed to providing preschool education, as an important national investment in future workers. The strategy behind this policy reasoning is that it is more important to focus on the

\footnotetext{
${ }^{58}$ Gal \& Kligman (2000b): p. 26.

${ }^{59}$ Ibid.: p.26
} 
future than on the present. As such, investment in children's education is believed to result in greater human capital accumulation and thus ensure prosperity of the nation in the long run. ${ }^{60}$ Investment in children is also seen as a way to break the cycle of poverty and maximize the potential of everyone.

Fifth, feminist analysis points out that the state commitment to promoting accessible and quality child care is one of the crucial components of genuine gender equality and equity. ${ }^{61}$ The extent to which public policies reduce the responsibility of women for child care, by shifting it to the public domain or to men, indicates the degree of woman-friendliness of the state. ${ }^{62}$ In the case of the Soviet welfare state, child care institutions were a part of the public educational system aimed at building the Soviet morale of children. Mahon ${ }^{63}$ also argues that child care can be a means to class equality and thus can constitute a state interest. Building on discourse aimed at relieving children's poverty through equal employment opportunities for parents, child care is seen as an important means for facilitating labour force participation for adults with children, and thus reducing child poverty (as part of the "active society" framework).

Finally, women's productive role also constitutes a state interest. The early Soviet period of mobilization of labour resources for undertaking the major leap in industrializing the economy, serves as an example of explicit state interests in women's productive functions. Thus, depending on the economic needs of the state, the productive

\footnotetext{
${ }^{60}$ Jenson (2005)

${ }^{61}$ See Lewis (1998); Fraser (1997); Jenson \& Sineau (2001b)

${ }^{62}$ Orloff (1993a); Daly \&Lewis (2000); Peng (2002)

${ }^{63}$ Mahon (2002b)
} 
function of women can be a powerful resource or "reserve army of paid labour," which can be drawn upon by the state, in times of need.

In light of such diverse interests of the state in regards to women, child care becomes an instrument which can shape female productive and reproductive behaviour, depending on the current state needs. Therefore, due to the unique location of child care policies on the border of public and private, social and economic, reproduction and labour force participation in general, child care policy is often designed to seek one or more of the following objectives:

- To enable higher rates of female labour force participation, which can be especially important when there are labour shortages;

- To support the transition of parents, especially those heading lone-parent families, into the labour force;

- To provide early childhood education and support good child development outcomes. In some cases, early childhood education can be used to indoctrinate children (e.g., Soviet and Chinese programs);

- To promote gender equality, by enabling women to reconcile work and family life and to foster a more egalitarian family division of labour; and

- To encourage higher fertility rates. ${ }^{64}$

Pursuit of one set of the objectives (e.g., female labour force participation), as opposed to another, will be reflected in the degree and form of the state intervention in the provision of child care. For instance,

At one extreme, care is a family obligation, and as such it is unpaid work. At the other, state responsibility can occur through provision of services and payments to carers in the home. Both forms of public involvement have the capacity to transform unpaid labour into paid

${ }^{64}$ Jenson (2003) 
work, but their implications for gender relations can be quite different. Provision of services enables women's employment and provides a potential to change the division of labour between the sexes while payments to carers in the home reinforce traditional roles. ${ }^{65}$

In other words, the degree and form of state involvement is reflected in the fundamental contradiction of whether to reinforce women's productive or reproductive function. This perennial dilemma has been handled differently in various historical moments and systems. In the post-communist nationalist discourses, for example, women are often assumed to owe a special kind of patriotic duty compared to that of men - through motherhood, which is often viewed as the primary form of female political agency. It is the opposite of the "double women's duty" during the Soviet period, which included not only reproduction but also production. ${ }^{66}$ Thus, the fluctuating nature of the policies toward women, including child care, can be seen as a reflection of shifting choices between productive and reproductive functions of women. The dilemma depends on the current social, political and economic priorities of the state, such as fertility growth or industrialization (which is a key in the Russian case, as will be shown later).

Child care policies can be therefore seen as one of the main levers for promoting women's employment or reproductive functions. It is important to note that using child care as a lever for workfare policies is not always beneficial to parents, it may involve a certain degree of coercion on the part of the state with regard to female (and, in some cases, male) workforce participation. This positions child care policy as a unique and fruitful analytical lens for developing our examination of the objectives, outcomes and

\footnotetext{
${ }^{65}$ Sainsbury (1999): p.80

${ }^{66}$ Gal \& Kligman (2000a,b)
} 
process of welfare state transformation in Russia. Moreover, child care policies in turn can foster or reflect new "ideals of care" $"$ present in society. Attention to ideals of care helps us to understand the cultural dimension of welfare states. As put by Kremer:

Ideals of care are an answer to the moral predicament of working and caring. Care ideals are an instrument to study caring states: they place caring centrally, are more accurate than the usual welfare state models, and shake hands with the broad notion of culture. They help study the moral and cultural dimension of policy and practice. What's more, care ideals can be seen as part of an adaptation process on the level of individual mothers (sometimes fathers), and are also embedded in societal structures such as schools, enterprises, social service agencies, political parties and social movements, and also in welfare state regulation. Ideals of care are country-specific. In different welfare states, different ideals of care have come into being, for different reasons and with different consequences. ${ }^{68}$

Within this framework, Kremer distinguishes five main ideals of care: full-time mother care, parental sharing, intergenerational care, surrogate mother care and professional care. These ideals reflect caring preferences and precise practices and "not only deal with the (bold) question of whether women should work or stay at home, but focus on what is seen as the appropriate care solutions when mothers are at work." ${ }^{69}$ Thus understanding not only official child care policies but also ideals of care would allow us to capture the complexity of women's response to the changing child care policies in the conditions of new economic, social and societal environment in Russia.

\footnotetext{
${ }^{67}$ Kremer (2005). A care ideal 'implies a definition of care, an idea about who gives it, and how much of what kind of care is "good enough"' (Hochschild 1995:333; see also 2003 as quoted in Kremer 2005).

${ }^{68}$ Ibid.: p.171

${ }^{69}$ Ibid: p.173
} 


\section{Typology of Welfare State Regimes and Child Care}

As discussed in the previous sections, while Esping-Andersen's typology provides a useful foundation for the analysis of welfare regimes, it falls short in terms of accounting a gender - and thus, child care - dimension of these regimes. In reviewing child care policies in Europe, Rianne Mahon ${ }^{70}$, developed a new typology of welfare state models, in order to address the wide range of possible policy goals, or to respond to the different policy challenges that exist in specific situations. She describes three models of welfare state redesign: the egalitarian, the neofamilialist, and the "third way" model. ${ }^{71}$

The egalitarian model builds on a Marshallian ${ }^{72}$ view of citizenship, and is found in welfare regimes with a clear commitment to class and gender equality. In these regimes, the state serves as the main provider of welfare. This model supports provision of care by both parents through the structure of parental leave, as well as active participation in the labour market through the provision of universally accessible and affordable non-parental care services. ${ }^{73}$ An egalitarian blueprint for child care usually includes:

- $\quad$ Paid parental leaves close to wage replacement levels (75 to 80 per cent);

- Parental leaves that include strong inducements for both parents to share the leave;

- Universally accessible, non-parental and affordable child care;

\footnotetext{
${ }^{70}$ Mahon (2002a)

${ }^{71}$ Ibid.

${ }^{72}$ Marshall (1963)

${ }^{73}$ Mahon (2002a)
} 
- Access to early childhood education services, whether or not parents are working or involved in some sort of training;

- A skilled and adequately paid work force within the child care sector; and

- A parental and community voice about child care provision and other forms of democratic control. ${ }^{74}$

This model comes close to the Universal Caregiver model developed by Nancy Fraser. To Fraser, policies which fit under the universal caregiver model serve as an illustration of a genuine commitment of the state to gender equality and equity.

The neofamilialist model draws on a traditional understanding of gender roles (male - breadwinner, female - homemaker) and provides support for those who prefer to care for their children at home, in the form of paid leave. Mahon argues that it emphasizes choice; however, "here choice is understood as women's right to choose between a temporary housewife-mother role and labour force participation, rather than the choice between different forms of non-parental care." 75 This model builds on a familialistic welfare regime, which sustains the traditional obligations of family welfare. According to Ito Peng, this kind of welfare regime tends to have the following features:

- Strong commitment to the traditional gender roles and preservation of a male breadwinner model of the household;

- $\quad$ Reliance on the family for providing welfare for its members;

- Low level of state social service provision and an underdeveloped market of care institutions;

\footnotetext{
${ }^{74}$ Ibid.: p.349

${ }^{75}$ Ibid.: p.346
} 
- Social insurance is the key mechanism of accessing welfare rights. ${ }^{76}$

The neofamilialist versions of this model include various programs which are intended to encourage mothers to withdraw from the labour market for an extended period of time. These programs may include long paid parental leaves (for more than a year), payment of caregiver allowances to compensate childbearing, childrearing and housework etc. ${ }^{77}$ This model resembles Fraser's caregiver-parity model aimed at promoting gender equality principally by supporting informal carework. ${ }^{78}$ In Fraser's terms:

The point is to enable women with significant domestic responsibilities to support themselves and their families either through carework alone or through carework plus part-time employment... The aim is not make women's lives the same as men's but, rather, to "make the difference costless. $^{79}$

Finally, the third way model, or the liberal model, as it is often referred to, draws on a "gender sameness" view, which advocates solutions enabling women to participate in the labour market. In Fraser's categories, it can be referred to as a universal breadwinner model, which largely focuses on the provision of public nonparental care. ${ }^{80}$ The main difference between this model and the egalitarian is that it also places responsibility for care on the family and encourages provision of market services through tax credits or other indirect benefits.

\footnotetext{
${ }^{76}$ Peng (2000)

${ }^{77}$ Fraser (1997)

${ }^{78}$ Mahon (2002a)

${ }^{79}$ Fraser (1997): p.55

${ }^{80} \mathrm{Ibid}$.
} 
For the purposes of this thesis, however, it is important to make an analytical distinction between policy intentions and real policy effects, or impact. Pal defines policy intentions as "subjective rationales which tie together a problem definition and goals" and policy effects as "concrete impacts which may or may not be consistent with the original policy intentions." ${ }^{, 81}$ As will be shown in the subsequent chapters, in order to achieve the desired policy objectives, certain conditions need to be present. For instance, in order for the neofamilialist policies to achieve their objectives, the welfare state needs a strong financial base. The strong financial base is needed for ensuring the sufficient financial level of allowances in order to provide enough income and incentives for women to withdraw from the labour force and provide care at homes on the full-or parttime basis (at least while children are young). This distinction will serve as one of the defining factors for the ultimate shape of the Russian welfare state.

All in all, these welfare state models have been explicitly designed to capture fundamental changes in welfare regimes. Most cases examined so far, however, include developed, OECD-member countries. At the same time, the countries in transition are affected by global trends to a similar - if not greater - degree, due to the increased economic and social vulnerability associated with restructuring and financial constraints. These welfare regime models also serve as a useful point of departure for the analysis of emerging welfare states in other countries, including Eastern Europe and Russia. The ongoing political, economic and social changes in those countries, however, require a more nuanced approach to understanding the ways of consolidating new socio-political

\footnotetext{
${ }^{81}$ Pal (1986): p. 101.
} 
systems. One needs to account for the complexity of interactions between old traditional norms and institutions with new policies, which are often adopted with the expectation that the old policies (or, more precisely their old substance) will be preserved. ${ }^{82}$

There is a considerable variation among the countries of the former socialist bloc and their welfare regimes. Dutkiewicz and Plekhanov argue that countries undergoing the process of transformation en masse adopted "liberal-democratic" norms which have been compatible with their inherited systems. ${ }^{83}$ This resulted in "a range of varieties of the emerging synthesis between the old and the new - from those cases where the new norms, being more compatible with traditions, have gained systemic significance, to the cases where they have existed as primarily a cover for the intractable old norms, found to be largely incompatible with the challenge of liberalism." ${ }^{\prime 84}$ Thus the approach utilized in the dissertation attempts to account for a complex mix and interactions of continuities and change, old and new norms and institutions in the transformational welfare states. It utilizes a lens that would accommodate "considerable continuity through and in spite of historic break points, as well as dramatic institutional reconfiguration beneath the surface of apparent stability or adaptive self-reproduction as a result of an accumulation over longer periods of time of subtle incremental change." 85

In general, welfare regimes in these countries have inherited institutions which to a varying degree combine elements of conservative and social-democratic models (in

\footnotetext{
${ }^{82}$ Dutkiewicz \& Plekhanov (2002): pp. 113-145.

83 Ibid.

${ }^{84}$ Ibid (2004): p.114

${ }^{85}$ Streeck \& Thelen (2005): p. 12.
} 
Esping-Andersen's categories). "Conservative" elements include child care and other service provisions through employment, while social-democratic ones include public provision of child care, universal access to child care (through mandatory and thus nearly full employment) and paid parental leaves. Mahon noted that the welfare models of the former Soviet bloc come closest to the French or Belgian models. ${ }^{86}$ The Soviet welfare model, as will be elaborated in chapter 2 , was based on the contract between the state and the family (in the absence of the markets). The so-called "Soviet gender contract" allowed women to combine employment and motherhood. As a result of the pressures for economic restructuring and introduction of markets (commodity, financial, and labour markets), most post-Soviet welfare regimes underwent a transformation of social reproduction with changing relationships between the state, the family and the market. The state's inability to continue being a main welfare provider, due to the financial constraints and undeveloped market institutions, has led to the increase of the family's role in welfare provisions in general, and child care in particular. The family became a main buffer to absorb social tensions and served as a reservoir of unpaid labour. ${ }^{87}$

As illustrated in the subsequent chapters, these pressures, combined with the demographic crisis and labour market changes, compelled Russian policymakers to develop policies aiming at bringing women back to homes, i.e. neofamilialism. The goals of these policies fall into traditional neofamilialist framework:

- Provide women with the "choice" to stay at home;

- Increase the country's fertility;

\footnotetext{
${ }^{86}$ Mahon (2002b)

${ }^{87}$ Gurgenko (2002): p. 195.
} 
- Reduce labour market tensions.

As will be further elaborated in chapter 5, the Russian welfare state however has fallen short in achieving these goals to the full extent, due to limited financial, administrative and law enforcement capacities, as well as the unique (formal and informal) change adaptation approaches utilized by women, households and labour markets.

Full understanding of the reasons of why the Russian policymaking framework acquired a neofamilialist character, as well as the reasons for its limited powers to achieve its objectives, requires a layered/multi-scale approach to the welfare state analysis. To appreciate the nature of changes in child care policies, as well as the role of ideas, interests and institutions, it is necessary to go beyond the national state level, "to probe developments in the intra-national scalar arrangements governing these policy areas. ${ }^{\prime 88}$ In the Russian context, this requires looking at the relationship between international bodies and the central government, the central government and the regions, between the regions and municipalities, as well as municipalities and enterprises which often serve as micro welfare states. In addition, as the Russian case will illustrate, the multiscale lens of analysis helps to reveal not only formal, but also informal arrangements and relationships between the central and the regional areas.

In general, the need for a multiscale approach is emerging in response to the increasing prominence of international organizations in the national areas, as well as greater tendency for the decentralization of not only policy implementation and

\footnotetext{
${ }^{88}$ Mahon (2005b)
} 
adaptation but also policy development and regulation. ${ }^{89}$ The multiscale approach can help us appreciate the deeply politicized and highly dynamic nature of the relationships between the actors at different levels. It is closely connected with the changes and continuities in the process of welfare state transformation, including child care policies and politics. Peck points out that scale and scale relations matter "in ways that are politically mediated and institutionally specific. ${ }^{900}$ For instance, the unique combination of the legislative and institutional legacies and changes in Russia permitted the regional governments to ignore interscalar arrangements, thus giving rise to a different shape in some social policies, including provision of child care.

This thesis will aim to reflect the ways in which, as noted by Mahon, "the supraand the sub-national are implicated in the restructuring/redesign of welfare regimes, without losing sight of the national. In this way too, it becomes possible to see how national path dependencies may be (partially or radically) disrupted, as alternative models of social citizenship are introduced from "below" as well as from "above.","91

\section{Institutional Change and Continuity in the Post- Communist Countries}

This section will develop a framework for analyzing the unique response of the Russian welfare state to global challenges. It will situate the importance of institutional legacies

\footnotetext{
${ }^{89}$ Peck (2002)

90 Ibid.

${ }^{91}$ Mahon (2003)
} 
and continuities in welfare state redesign, as well as the role of interests and ideas. It will also develop a foundation for the analysis of why and how paradigm shifts come about.

\section{Divergence of Welfare State Models}

Despite the "irresistible" pressures facing all postwar welfare regimes, the patterns of response within national arenas have diverged considerably. The responses varied even among the countries which fall into any single one of Esping-Andersen's categories. ${ }^{92}$ Despite a similar set of external challenges, institutional differences continue to exist between and within the countries, including post-communist counties. The variety of different interactions between internal and external actors, old and new norms and institutions, produced diverse systems across the former Soviet bloc, despite the enduring strengths of the Soviet system. The process and extent to which these countries adopted new liberal-democratic institutions depended on a number of institutional constraints.

In light of these differences, contemporary scholarship on "varieties of capitalism" has produced an influential body of work on path dependency, stressing the role of culture, pre-existing patterns of behavior, norms, and institutions in shaping and constraining state choices in the process of institutional design. ${ }^{93}$ A broader path dependency argument can be divided in two streams. The first stream views path dependency as emphasizing contingent institutional choice and deterministic institutional

\footnotetext{
92 Mahon (2002a,b)

${ }^{93}$ See Hall \& Soskice (2001); Amable \& Barre \& Boyer (1997); Casper (1999)
} 
reproduction. It implies a strong distinction between periodic episodes, in which institutions are originally formed, and long periods of institutional continuity. ${ }^{94}$

The second stream is milder, using a concept of path dependency to support a broad view that legacies of the past always weigh on choices and changes in the present, and limit the range of possibilities for institutional innovation. ${ }^{95}$ This is often seen as a counter statement to the view that new institutions can build on a more or less "clean slate." 96 The approach suggests that old institutions and norms continue to have their effect on the course of reforms, and that the actors, in many instances, continue to be influenced by their reflections on past experiences. ${ }^{97}$ This is an important point to remember, particularly when analyzing transformation in post-socialist countries.

Most transition specialists tend to adhere to a model which breaks the history of the region into two periods of "state socialism" and "welfare capitalism." Haney notes that, as guided by this static periodization, transitologists oppose the welfare systems before and after 1985 because they are thought to be so qualitatively different. ${ }^{98}$ The institutional designs of these countries, however, present a much greater continuity with the Soviet past than was expected, or immediately apparent. ${ }^{99}$ Gal and Kligman note that "sometimes hidden and subtle continuities are as powerful as dramatic ruptures. Social actors all over the region have been reaching into presocialist past, claming historical

\footnotetext{
${ }^{94}$ See Krasner (1988); Mahoney (2000); Pempel (1998)

95 See Sewell (1996)

${ }^{96}$ See Stark (1995); Stiglitz (1999).

${ }^{97}$ Crouch \& Keune (2005): p. 3

${ }^{98}$ Haney (2002): p. 5

${ }^{99}$ Luong (2002): p. 2
} 
models, inspiration, and justification of current political policies and gender arrangements. Nostalgia for earlier historical periods - different ones for different historical constituencies - is a pervasive aspect of making the post-socialist future."100 This thesis will build on the second approach to path dependency, in attempting to account for some nuances in the development of the socialist institutions in different periods, as well as for the institutional legacies in the midst of radical changes the transformation period.

\section{Role of Ideas and Institutional Change}

The path-dependency argument is, clearly, an important one. Institutions matter, and they affect "the nature and intensity of the challenges faced, the values and ideas held by social actors, and the strength of diverse interests." ${ }^{.101}$ Yet, it is also clear that institutions are not immutable. There were significant shifts and changes in the political, social and economic regimes of the countries of the former Soviet Union, and that the actors did not simply continue in their familiar paths. Policies are being redesigned; rules and ideas governing and shaping welfare states are changing. Small changes in eligibility rules, details of services, or the forms of delivery may lead to the dramatic restructuring of welfare systems and have "different consequences for fostering equality and entrenching inequalities that matter." ${ }^{102}$ Thus, there is a need for an approach that allows us to account for a complex mix of continuities and change in the post-communist welfare

\footnotetext{
${ }^{100} \mathrm{Gal} \&$ Kligman (2002b): p. 4

${ }^{101}$ Mahon (2002b):p.11

${ }^{102}$ Jenson \& Sineau (2001a): p.5
} 
states. We need a lens that would accommodate "considerable continuity through and in spite of historic break points, as well as dramatic institutional reconfiguration beneath the surface of apparent stability or adaptive self-reproduction as a result of an accumulation over longer periods of time of subtle incremental change." 103 There is a need for a public policy approach that acknowledges paradigm shifts in order to account for more than incremental change, similar to one elaborated upon by Thomas Kuhn, Andrew Janos and Peter Hall. ${ }^{104}$ The paradigm shift approach allows for the possibility that the rise of new paradigms does not destroy the validity of the old ones, or that it implies the discovery of a whole range of new categories. ${ }^{105}$ Janos argues that "the new paradigm only provides a new way of looking at old categories."106

Hall defines the policy paradigm as an interpretive framework to understand the role of ideas in the policy process. A policy paradigm defines "the broad goals behind policy, the related problems or puzzles that policy-makers have to solve to get there, and,... the kind of instruments that can be used to attain these goals." ${ }^{107}$ Hall argues that ideas are central to the policymaking process, since "policymakers employ a customary terminology and frame of reference, [which] specify the kind of techniques are to be used in any particular policy area, but equally important, it also specifies what kind of problems are to be addressed..." ${ }^{108}$ Similarly, in the area of child care,

\footnotetext{
${ }^{103}$ Streek \& Thelen (2005): p.12

${ }^{104}$ Kuhn (1970); Janos (1986); Hall (1993)

${ }^{105}$ Janos (1986): p.149

106 Ibid.

${ }^{107}$ Hall (1993): p.59

108 Ibid.
} 
[p]olicy-makers, like policy advocates, share certain assumptions about the role of women, about relations between women and men, about the role of the family, and so on. The assumptions generate a set of representations of working mothers. Their labour force participation, for example, may be described as good or bad. Their participation in the paid labour force may be described as necessary or not, comparable to that of men or different, a right or a choice. ${ }^{109}$

Such ideas about gender differences ultimately shape configurations of state policies. ${ }^{110}$ Socially constructed ideas of masculinity and femininity and their embeddedness in other social categories have an effect on how policies are shaped. These ideas often interact and influence other social constructions such as "the nation, the family, the public good."111 The policies, which promote different behaviours of men and women, circumscribe the range of all possible relations between genders. One needs to consider how ideas about gender relations form, and are formed by the public policies.

This thesis will explore in greater detail these representations and respective frames during both the Soviet and post-Soviet periods, and will show that there has been a shift with regard to the role of women in society, and obligations of the state with regard to provision of care. This thesis will also show that there was a change in the framing of care. The subsequent chapters will show how policymakers and other social actors struggle over women's representations when making family and child care policies.

\footnotetext{
${ }^{109}$ Jenson and Sineau (2001a): p. 16

${ }^{110} \mathrm{Gal}$ and Kligman (2000b)

111 Ibid.: p.4
} 
How do paradigm shifts come about? According to Hall, the process of paradigm shift can be characterized by three levels of changes in policymaking. ${ }^{112}$ The first two levels of changes represent "cases of normal policymaking, namely of a process that adjusts policy without challenging the overall terms of a given policy paradigm..." while the third order change represents "a very different process, marked by the radical changes in the overarching terms of policy discourse..."113 In terms of policy development, the first two levels of change can be seen as continuities, while the third one marks a radical change or discontinuity. ${ }^{114}$ As Hall notes,

[t] he process of first order change is likely to display the features of incrementalism, satisficing, and routinized decision making that we normally associate with the policy process. Second order change and the development of new policy instruments may move one step beyond in the direction of strategic action. But third order change is more problematic; the literature provides far less guidance for modeling this sort of process... The movement from one paradigm to another that characterizes third order change is likely to involve the accumulation of anomalies, experimentation with new forms of policy, and policy failures that precipitate a shift in the locus of authority over policy and initiate a wider contest between competing paradigms. This contest may well spill beyond the boundaries of the state itself into the broader political arena. It will end only when the supporters of a new paradigm secure positions of authority over policymaking and are able to rearrange the organization and standard operating procedures of the policy process so as to institutionalize the new paradigm. ${ }^{15}$

At the same time, the first two orders of change, while incremental, may also generate transformative change. In other words, incremental changes may have transformative

\footnotetext{
${ }^{112}$ Hall (1993)

${ }^{113}$ Hall (1986): p.279 as quoted in Peng (2003): p.5

${ }^{114}$ Peng (2003): p.5

${ }^{115}$ Hall (1993): p.280
} 
potential. ${ }^{116}$ Transformation may result from changes in actual consequences of institutionalized behaviour, possibly "changing meanings and functions attached to otherwise stable institutions," as well as different purposes "pursued by means of a given institutional arrangement." 117 This shows that there is also a potential for "dramatic institutional reconfiguration beneath the surface of apparent stability or adaptive self-reproduction as a result of an accumulation over longer periods of time of subtle incremental change."

In order to capture gradual but nevertheless transformative institutional change, Thelen and Streek developed the following typology, which would prove useful in our analysis of the changes in child care policies in Russia:

- Displacement. This type of institutional change assumes that new models emerge and diffuse and thus call into question existing, previously taken-for-granted organizational forms and practices. Such change may occur through the rediscovery or activation of alternative institutional forms.

- Layering. Institutional change through layering occurs when total dismantling of old institutional systems comes at very high political or social costs due to the lock-in effects and additional vested interests in maintaining the old system. In this case, change can occur not so much through a frontal attack on traditional institutions, but through differential growth of new institutions.

\footnotetext{
${ }^{116}$ Streeck and Thelen (2005): p.12

${ }^{117}$ Ditto: p. 25
} 
- Drift. This type of institutional change occurs when institutions are not actively maintained, and are not re-set and re-focused in response to changes in the political and economic environment in which they are embedded. The change through drift, while potentially fundamental, may be masked by stability on the surface.

- Conversion. This mode of change occurs when institutions are redirected to new goals, functions or purposes and not so much amended or allowed to decay. Such redirection can be a response of policymakers to changing external conditions, who use the existing institutional resources for achieving new ends. The elements of stability and lock-in are also present here but the main strategy utilized by the actors is that existing institutions are adapted to serve new goals or fit the interests of new actors. One of the sources of such change is compromise through political negotiation, when parties agree on policy goals or means but for different reasons. Another possible source of change through conversion is institutional "transplantation" from one country to another and adaptation to the new environment through the gradual process of interpretation by local actors.

- Exhaustion. This mode of change occurs when behaviors invoked or allowed under existing rules operate to undermine these. For instance, due to various political reasons, policymakers may adopt new policies or create institutions which are not always compatible and sometimes contradictory to the existing ones. This may not cause immediate acute contradictions in the system but with 
time, they may become intolerable (e.g., paying parental/maternity leave through employers). ${ }^{118}$

This typology combined with the Hall's framework for analyzing the process of change offers important insights for looking at the institutional transformation in the area of child care in Russia. Thus while the process of paradigm shift in Russia will be analyzed in detail in chapter 3 , it is useful to note here that the process of change in the area of child care involved a three-level framework: from the subtle changescontinuities with the potential of transformative change, such as extension of parental leave and in-home caregiving allowance, to a more dramatic rupture, such as drastic decline in provision of public child care (Table 1). This thesis will utilize Hall's approach to paradigm shift and will attempt to answer the following questions: How and why did child care policies change during the transformation period? Who were the main actors in bringing about the process of paradigm shift? And what were the implications of this shift to women's position in the labour market and fertility growth?

Table 1. Institutional Changes in Child Care in Russia, 1991-2001

\begin{tabular}{|c|c|c|c|c|c|c|}
\hline $\begin{array}{l}\text { Order of } \\
\text { changes }\end{array}$ & $\begin{array}{c}\text { Types of } \\
\text { institutional } \\
\text { change }\end{array}$ & Displacement & Layering & Drift & Conversion & Exhaustion \\
\hline $\begin{array}{l}1^{\text {st }} \text { order } \\
\text { change }\end{array}$ & $\begin{array}{l}\text { Extension of } \\
\text { parental and } \\
\text { maternity } \\
\text { leaves }\end{array}$ & & $\mathrm{X}$ & & $X$ & \\
\hline $\begin{array}{l}2^{\text {nd }} \text { order } \\
\text { change }\end{array}$ & $\begin{array}{l}\text { Introduction } \\
\text { of in-home } \\
\text { caregiving } \\
\text { allowances }\end{array}$ & & $X$ & & $\mathrm{X}$ & \\
\hline $3^{\text {rd }}$ order & Decline of & & & $\mathrm{X}$ & & \\
\hline
\end{tabular}

${ }^{118}$ Thelen and Streeck (2005) 


\begin{tabular}{|l|l|l|l|l|l|l|}
\hline $\begin{array}{c}\text { Order of } \\
\text { changes }\end{array}$ & $\begin{array}{c}\text { Types of } \\
\text { institutional } \\
\text { change }\end{array}$ & Displacement & Layering & Drift & Conversion & Exhaustion \\
\hline change & $\begin{array}{l}\text { child care } \\
\text { facilities }\end{array}$ & & & & & \\
\hline
\end{tabular}

Source: Compiled by the author

The nature of institutional changes in child care, as illustrated in Table 1 and will be discussed later, varied. For the purposes of this chapter, it is worth highlighting though that changes in provisions of parental and maternity leaves involved institutional change through a combination of conversion (through a compromise among political parties with regard to the role of women in society) and layering (e.g., adding new elements on top of the old ones); introduction of in-home caregiving allowance similarly can be seen as a change through both layering (i.e., adding this allowance on top of other elements) and conversion (as it represented a compromise among political parties with regard to the role of women in society); finally dismantling of the inherited system of child care institutions involved both radical change (i.e., emphasis on reducing social expenditures and thus decline in facilities) and some incremental changes in form of drift (i.e., child care institutions in many cases did not meet growing care standards and were allowed to decay). What is most important however is the cumulative impact of these mostly incremental and gradual changes, as it marked a shift in the trajectory of the welfare state guided by the idea of "bringing mothers back to homes." This idea was premised on highly ambiguous agreements with various parties advocating for it (for divergent reasons), and led to a broader change of the policy logic which defined the nature of social provision and role of the state vis-à-vis family. Thus, the cumulative impact of 
these changes led to the transformation in the nature of the welfare state in Russia, from the mix of conservative-egalitarian (Soviet) model towards neofamilialism. This model, while in principle accepting that women would work, placed policy incentives for mothers of young children to withdraw from the labour market and become caregivers (full- or part-time), thus providing for refamilialization of care.

\section{The Political Economy of the Welfare State}

Understanding the process of and factors influencing a paradigm shift in the area of child care requires the understanding of the institutional arrangements, the complex external and internal social forces, and the actors who influenced these developments in the national arenas. The welfare state theories can be placed within a larger framework of analysis of state-society relations. Contemporary scholarship distinguishes several approaches to understanding the relationship between state and society, and their influence on general policy discourses. In general terms, they can be classified as societycentred and state-centred approaches.

\section{Society-Centred Approaches}

The society-centred framework includes both neo-Marxist and pluralist theories which attempt to understand the state and policy process in terms of class struggle or conflicts of interest groups and ideology. ${ }^{119}$ Each of these theoretical schools provides a wide

\footnotetext{
${ }^{119}$ See Louis Althusser, Ralph Miliband, and Nicos Poulantzas followed by Perry Anderson, James O'Connor, Ian Gough, E.P. Thompson, Erik Olin Wright, Claus Offe and Adam Prezworski
} 
range of literature, which examines the interactions between societal groups and the state. The main argument of the society-centred approaches can be summarized as follows: "public policy is understood primarily as a response to the expectations, demands and pressures of those who control the largest proportion of especially effective resources." ${ }^{.120}$ The state is seen as a "mirror reflecting particularistic societal interests"121 and as an actor, which does not have "independent interests, separate agendas and self-sufficient routines." $" 122$

In studying welfare states, the larger society-centred framework includes the power resource as well as logic of industrialism schools. The power resource theory, which underlies Esping-Andersen's approach, is one of the most influential theories for explaining the variations in welfare state models in the developed capitalist societies. Welfare states are seen as outcomes of conflicts between class-related, socio-economic interest groups, and that in these distributive conflicts, partisan politics is likely to matter. 123 The main argument of the power resource approach is that social policy development is heavily influenced by the ruling parties. The presence of strong left-wing parties (e.g., Socialist, Labour and Social Democratic), the powerful labour unions and a significant working-class presence in the decision-making apparatus are more likely to

\footnotetext{
${ }^{120}$ Nordlinger (1981): p. 3

${ }^{121}$ Krasner (1978): XI

${ }^{122} \mathrm{Pal}(1988)$ : p. 94

${ }^{123}$ Korpi \& Palme (2003): p. 425
} 
instigate the development of a generous welfare system than those with strong rightwing parties. 124

While the power resources approach could potentially offer some explanations for social policy development in Eastern Europe and Russia, the impact of ruling parties on social policy reform is relatively under-researched. Although studies examining the impact of right-left ideological conflict in six East-Central European countries and their influence on welfare state suggest that right-wing or centre parliaments were more likely to implement more drastic measures in reducing social expenditures, this relationship was not supported with respect to the adjustment made to maternity and family benefits. ${ }^{125}$ Aidukaite notes that this means that other factors may influence the development of social policy in those countries, including global pressures, affordability of the welfare state, or demographic factors. ${ }^{126}$

Another approach to understanding welfare states, the Logic of Industrialism, is associated with the work of Wilensky. ${ }^{127} \mathrm{He}$ argued that social security growth is accompanied by economic growth and its demographic outcomes, which are also hastened by the interplay of the political elite's perceptions, welfare bureaucracies and great pressures. Thus the aggravation of the economy in post-Soviet Russia, accompanied by the dramatic decline in GDP, the financial crises and high inflation rates during the first years of independence, affected the fiscal basis of the welfare state

\footnotetext{
${ }^{124}$ See Esping-Andersen (1990); Hicks et al. (1995); Huber and Stephens (1996); Quadagno (1987); Korpi (1989); Korpi (1983); Smelser (1994)

${ }^{125}$ Lipsmeyer (2000)

${ }^{126}$ Aidukaite (2004)

${ }^{127}$ O'Connor \& Prym (1988); Aidukaite (2004)
} 
and altered its policies. At the same time, however, while economic conditions are certainly very important for the ability of the welfare state to withstand global pressures, they do not allow us to fully account for the direction of the changes perceived in the welfare state model. This approach also fails to fully explain the differences between welfare state regimes in the developed countries, since differences in economic growth are much less pronounced than the differences in social policies.

\section{The State-Centred Approach}

The state-centred approach to understanding welfare state development suggests that one should look inside the state for explanations of policies. The state bureaucracy and political elites are central actors in the policy formation process, and they make a significant impact on the development and introduction of welfare programs. ${ }^{128}$ Nordlinger states that in "determining public policy 'the preferences of the state are at least as important as those of civil society."'129 Indeed, numerous studies have demonstrated the importance of studying state contributions to economic and social transformation. For instance, Skocpol showed how the bureaucracy and political elite significantly influenced the development of social provisions for soldiers and mothers in the United States (as well as women's organizations). ${ }^{130}$ She argued that social policies have not simply been direct responses to the emerging demands that social classes have placed upon governments. Instead, governmental institutions, electoral rules, political

\footnotetext{
${ }^{128}$ See Pal (1988): p.96; Carroll (1999); Palme (1990); Quadagno (1987); Smelser (1994)

${ }^{129}$ Nordlinger (1981): p. 1

${ }^{130}$ Skocpol (1992)
} 
parties, and prior public policies have, all of them, affected the abilities of politicallyinvolved actors to devise and change social policies. She further noted that "politicians and administrators must be taken seriously. ${ }^{131}$ Not merely agents of other social interests, they are actors in their own right, enabled and constrained by the political organizations within which they operate. Political officials can therefore make independent contributions to the development of a nation's social policies." Pal, in his study of government funding of interest or "advocacy" organizations in Canada, revealed that government funding was not neutral but "was driven by "interests of the state," in particular by a national unity agenda." 132 Smith, in turn, demonstrates that the relationships of policy networks and the state depend not on the resources of the group, but on the way in which state policy is made. $^{133}$

\section{Autonomy of the State}

The state-centered approach views the state as being able to formulate and pursue goals that are not merely simple reflections of demands or interests of social groups, classes or society. ${ }^{134}$ This approach views states as potentially autonomous and as "configurations of organization and action that influence the meanings and methods of politics for all groups and classes in society." "135 Skocpol argues that

Because states are authoritative and resourceful organizations collectors of revenue, centres of cultural authority, and hoarders of

\footnotetext{
${ }^{131}$ Ibid.: p. 42

${ }^{132} \mathrm{Pal}(1993)$

${ }^{133}$ Smith (1993)

${ }^{134}$ Skocpol (1985): p. 9

${ }^{135}$ Ibid.: p. 28
} 
means of coercion - they are sites of autonomous action, not reducible to demands or preferences of any social group. Both appointed and elected officials have ideas and organizational and career interests of their own, and they devise and work for policies that will further those ideas and interests, or at least not harm them. Of course, elected or appointed officials are sensitive in many ways to social preferences, and they normally want to promote the health of the economy. Yet politicians and officials are also engaged in international and domestic (including intrastate) struggles by using the capacities of the organizations within which they are situated. ${ }^{136}$

This description of the state implies relative state autonomy, which is defined by Leftwich as the ability of the state "to achieve relative independence (or insulation) from the demanding clamour of special interests (whether class, regional or sectoral)" and "to override these interests in putative national interest." ${ }^{137}$ Insulation, in its turn, should be understood as the ability of the state "to formulate and implement policies in keeping with politically formulated national goals with minimum of lobbying for special favours from... interest groups." ${ }^{\text {138 }}$ Smith notes that "the notion of state autonomy maintains that the state/state actors have interests of their own and, in certain circumstances, the ability to transform these interests into policy."139

Skocpol makes an important analytical distinction between the ability of the state to set independent goals and its capacity to achieve them. For Skocpol, state autonomy assumes its ability to generate goals independently, not just reflect the demands and interests of social groups. Having done that, "one may then explore the 'capacities' of

\footnotetext{
${ }^{136}$ Skocpol (1992): p. 22

${ }^{137}$ Leftwich (1995): p. 408

${ }^{138}$ World Bank (1993): p. 167

${ }^{139}$ Smith (1993): p. 49
} 
states to implement official goals, especially over the actual or potential opposition of powerful social groups or in the face of recalcitrant socioeconomic circumstances." $" 140$ Skocpol emphasizes the distinctive sources of goals of state elites, regardless of the relationship of these elites with non-state actors. The design of policies correlates with policy content, which "must be tracked back always to an amalgam of intentions, perhaps not always fully conscious, but intentions nonetheless." ${ }^{141}$ The potential for state officials to formulate their own goals (and thus, policies) is based in the "distinctive positions and functions of the states."142 Orloff argues:

There may be overlap at times between the interests and policy preferences of elected or appointed state officials and those of the dominant economic class, yet it is critical to understand their different sources. States carry out specific functions, two of which are particularly important for the formation of distinctive interests on the part of state elites and for stimulating their pursuit of policies separate from those of important social groups (Skocpol 1985:9; Mann 1988:13-14). These are maintaining internal order, and... the position of the state within the international state system. The basis of state power resides in state elites' control of the administrative and coercive institutions which carry out these tasks and in their ability to take advantage of "balancing possibilities" or "maneuvering space" (Mann 1988:15). The latter refers to the ways that state elites may be able to play off different social groups against each other to create their own power... ${ }^{143}$

In broad terms, state actions can be seen as actions of individuals within particular state agencies and departments. The interests of these institutions and individuals vary, and sometimes are outright conflicting. Weir and Skocpol emphasize that both elected

\footnotetext{
${ }^{140}$ Skocpol (1985): p. 9

${ }^{141} \mathrm{Pal}(1988):$ p. 173

${ }^{142}$ Orloff (1993a): p. 85

${ }^{143}$ Ibid.: p. 15
} 
politicians and officials, "have organizational interests of their own." ${ }^{144}$ Consequently, state policy often can be derived from conflicts within the state - between different agencies and departments. ${ }^{145}$ Smith notes that, although the specific interests are related to the department and policy concerned, one can highlight the broad parameters of the interests of state actors. For instance, while politicians have interests in their re-election and ideological goals, bureaucrats have interests in their careers and increasing their power vis-a-vis politicians and other departments. Bureaucrats are motivated to develop policies which might increase their power, make life easier or solve problems, and are concerned with what they see as the long-term interests of the department. ${ }^{146}$

\section{State Capacity for Policy Implementation}

While the autonomy of the state to formulate independent policy is an important concept for understanding how policies are made, one should not overlook the importance of exploring "the 'capacities' of states to implement official goals, especially over the actual or potential opposition of powerful social groups or in the face of recalcitrant socioeconomic conditions." 147 Skocpol argues that even when it seems that the autonomous power of the state is limited by various non-state interests, the ability of the elites to generate independent policy goals and interests is not limited, although the capacity to achieve them may be. ${ }^{148}$ Ultimately, the ability of the state to pursue any of these interests, and implement policies related to reproduction, or any other policy areas,

\footnotetext{
${ }^{144}$ Smith (1993): p. 49

${ }^{145}$ Ibid.

${ }^{146}$ Ibid.

${ }^{147}$ Skocpol (1985): p. 9

${ }^{148}$ Ibid.
} 
significantly influences policy outcomes. Therefore, one cannot ignore state abilities for action - "the extent to which it can intervene in society, to achieve its policy goals without the support of societal actors." ${ }^{149}$ Weir and Skocpol highlight while the politicians and career bureaucrats are engaged in struggles among themselves, "they must pursue these struggles, along with any initiative they take in relation to the economy or the mobilization of social support, by using - or taking into account -the coercive fiscal, judicial, and administrative capacities of the state structures within which they are located." ${ }^{150}$ Mann further describes the capacities of the state to implement political decisions as "infrastructural power," which depends not only on the sovereignty of the state and its control of the territory, but also on financial and administrative resources, which can vary across levels of government and areas of state activities. ${ }^{151}$ The sources and amounts of available financial resources, and the degree of flexibility in their collection and spending, are also important for analyzing the state's capacities to attain certain goals. ${ }^{152}$ Skocpol concludes that the autonomy of the state can vary over time and across systems. ${ }^{153}$ She also notes the unevenness across policy areas and across departments within the state itself, when, under the weak state system, some agencies or departments or areas may be "strong" or autonomous in particular situations. State capacities to implement policies are an integral component of welfare regimes. The degree to which the state can implement the policies influences the actual policy

\footnotetext{
${ }^{149}$ Smith (1993): p.52

${ }^{150}$ Weir \& Skocpol (1985): p. 118

${ }^{151}$ Mann (1988): p.7; Orloff (1993b): p.86; see also Skocpol (1985): p.17; Evans \& Rueschemeyer \& Skocpol (1985)

${ }^{152}$ Orloff (1993b)

${ }^{153}$ Skocpol (1985): p.14
} 
outcomes. Now, whether the policy was able to achieve its objectives (i.e. to obtain desired results/outcomes) depends on implementation. Pal suggests that policy implementation depends on organization, personnel and resources (in other words, on the capability of the state to intervene in society through its administrative machinery). ${ }^{154}$ In order to do so - and do so effectively, - it requires coercive, administrative (organization and personnel) and financial resources. If the state is well resourced, it has the potential to achieve its originally-stated goals. ${ }^{155}$

There is an increasing amount of literature arguing that the post-socialist state in Russia has limited capacities to implement its policies. ${ }^{156}$ Indeed, as subsequent chapters will demonstrate, the Russian state, despite the intent to establish a maternalist ${ }^{157}$ regime, has a limited capacity to do so, which undermines the original policy objectives. The literature identifies a range of factors undermining the state capacity in Russia, including oligarchy, personalism, corruption, underdevelopment of civil society, weak economy, and ambiguity in the citizenship boundaries of the Russian state, which can be classified in three broad categories: financial, administrative and law enforcement capacities.

First, the financial well-being of the state is based on its ability to claim taxes and control the economy through financial and monetary levers. During the

\footnotetext{
${ }^{154} \mathrm{Pal}(2005 \mathrm{a})$

155 Smith (1993)

${ }^{156}$ See Sperling (2000); Illarionov (1999); Malleret et al (1999); Robinson (1999); Sapir (1999); Hanson (1999); Bova (1999); Ma (2000); Peregrudov et al (1999); Roberts and Sherlock (1999); Robinson (2002); Smith (1999); Beissinger and Young (2002)

${ }^{157}$ While there is no agreement among scholars of what constitutes a "maternalist regime," (see, for example, Skocpol \&Ritter (1991); Skocpol (1992); Gordon (1977; 1993; 1994), this thesis will utilize Theda Skocpol's (1992) approach to using the term "maternalist" to characterize social policies that benefited some women as mothers, particularly in their role as domestic caregivers.
} 
transformation, the Russian state has had a rather limited ability to collect taxes, because of either fraud, or generally low income/profits of the population and enterprises. ${ }^{158}$ This, combined with high inflation rates, has seriously undermined the financial situation of the state, and made it more dependent on external borrowing.

Second, institutional rigidities, obsolete institutions inherited from the Soviet regime and incompatible or insufficient in the new conditions, as well as empowerment of regional elites, have limited the ability of the Russian bureaucracy to effectively carry out administrative tasks, control their subordinates and "penetrate civil society and implement logistically political decisions throughout the realm."159 The main problem is that although the state institutions were more or less in place during the last decade of the past century, they seemed to be presiding over a growing political and economic vacuum. The federal structure of the Russian state, regional elitism, and differences in budgetary provisions generated significant variations in the way social policies are administered locally, despite a unified legislative framework. Thus, in assessing the capacity of the state to implement its policies, a special attention should be paid to local institutional practices and policies.

The executive apparatus is only one part of a much larger political system required for effective policy implementation. There is also a need for strong coercive institutions enforcing order and the principle of the rule of law (defined as "the dominance of formal institutions: universal rules and norms serve as significant

\footnotetext{
${ }^{158}$ A more detailed description of the economic and social situation in Russia at the beginning of transformation period is provided in chapter 3 .

${ }^{159}$ Way (2003): p. 7-8
} 
constraints on major actors and their strategies within the given polity.") ${ }^{160} \mathrm{~A}$ wellequipped, compliant and trained security force, and other state agencies such as the tax administration and regional governments, also represent important elements of the state capacity. ${ }^{161}$ The corruption of the court system, police and other enforcement structures, resulted in the undermining of the authority of law and an emergence of local elite coalitions. Gel'man notes that the non-existence of the rule of law means a dominance of informal institutions, based on particularistic rules and norms, like clientelism and corruption. $^{162}$

Although the topic of the state capacity in Russia touches on a number of very difficult practical and theoretical issues, and is not an immediate focus of this thesis, it is important to take it into account. A limited capacity of the state to implement the maternalist policies (e.g. financial constraints resulting in some of state policies becoming simply ineffective in achieving their objectives, as well as the state's inability to control local implementation of federal acts), led to the emergence of a unique form of welfare regime in Russia. The next subsections will lay out the strengths and limitations of the state-centered approaches and will highlight a need for a synthesized approach.

\section{Discussion}

Both society- and state-centred approaches have a number of merits for the analysis of the developments in the Russian welfare regime. There is a vast society-centred literature

\footnotetext{
${ }^{160}$ Gel'man (2000): p. 2

${ }^{161}$ Ibid.

${ }^{162}$ Ibid.
} 
arguing that the state in post-Soviet Russia was captured by business oligarchs and regional elites, and that it was acting mostly in response to the demands of these and external international lending organizations. ${ }^{163}$ This brings forward an argument of the Russian state being "weak" and the need to look in greater detail at social forces affecting the autonomy of the Russian state. Even President Yeltsin, in his 1997 state of the nation address to parliament, publicly expressed concern that the state was too often at the service of a narrow set of private interests and, as a consequence, post-communist transformation was stymied. ${ }^{164}$ At the same time, focusing solely on these factors would underestimate important internal state dynamics and dismiss the state-building vision of state actors. While the evidence of the social actors' strong influence does call for the need to bring them into the spectrum of analysis, the state in Russia continues to play an important role in the making of social policy.

\section{Strengths of the State-Centered Approaches}

There is a limited number of studies which note the importance of bureaucracy in the former socialist bloc. Aidukaite, in studying the emergence of welfare states in three Baltic countries (Latvia, Estonia and Lithuania), stresses the importance of bureaucrats' and the political elite's views on shaping social policy. ${ }^{165}$ Other studies briefly point out that, in some transitional countries, the ministries of welfare and finance have been fully responsible for social security reform. ${ }^{166}$ Haney, in her study of the Hungarian welfare

\footnotetext{
${ }^{163}$ See Mao (1998); Volkov (1998); Robinson (2004); Gel'man (2000).

${ }^{164}$ Robinson (2004): p. 1

${ }^{165}$ Aidukaite (2004)

${ }^{166}$ See Muller (2001); Rys (2001)
} 
state, noted that the state, through its policies and practices, not only created provisions to redistribute benefits, but also constructed "architectures of need." ${ }^{167}$ Crouch and Keune, in their analysis of institutional change in one of Hungary's municipalities, also argued for placing members of elites at the centre of the analysis, thus highlighting their importance to the policymaking process and ability to creatively mobilize resources and adopt external elements in a selective mode. ${ }^{168}$

Similarly to these studies, the state-centred approach points to a couple of essential characteristics of policymaking in Russia, as well. First, according to the Russian Constitution, the Russian president sets priorities for the country's domestic and foreign policy. Political decisions taken by the head of the country in order to achieve certain goals however, do not come with a guarantee for their implementation and support by bureaucracy and politicians. Given the dual executive and semi-presidential political system of Russia, the arrangements within this system lead to the creation of additional lines of conflict atypical of parliamentary systems. In such semi-presidential systems, a popularly elected executive (the president, in the Russian case) is pitted against a popularly elected parliament. ${ }^{169}$ Such a system creates potential for conflicts between the president and the cabinet of federal ministers. The multiplicity of independent and powerful actors within the Russian executive branch may hinder the development of a coherent long-term policy. This is why, besides the analysis of bureaucratic politics and role of politicians, it is necessary to explore the efforts of the

\footnotetext{
${ }^{167}$ Haney (2002)

${ }^{168}$ Crouch and Keune (2005): p.3

${ }^{169}$ Huskey (1999)
} 
president to create an enabling environment for the realization of his policy vision via his ability to push his agenda through.

Second, the Russian state bureaucracy traditionally has significant policy-making capacities, and often serves as the main source of policies. Unlike in classic parliamentary systems, the Russian Parliament does not have the authority over organizational matters of the executive branch. ${ }^{170}$ This points to the significant insulation of the state bureaucracy and executive from the parliament.

Third, various governmental departments (e.g. Ministry of Labour and Social Development, Finance Ministry, Ministry of Education) have different interests in various policy areas. For instance, in the area of child care, some of the departments may be more concerned with the labour markets, while others may have interest in the development of education, or relieving child poverty. As Jenson notes:

If the centre of decision-making authority were to shift from social service and family bureaucracies to those responsible for employment, for example, we would expect to observe changes in the policy packages proposed. More emphasis might be placed on solving the dilemmas of workers and employers (e.g. job creation and reducing unemployment) than on the problems of poor families or single parent families. Alternatively, if ministries of finance become involved in policy networks, one might expect cost cutting to become an important goal and tax systems the mode of delivery. ${ }^{171}$

\footnotetext{
${ }^{170}$ Constitution of the RF (1993); Huskey (1999). In the Russian system, a number of prescribed powers "put the president in a superior position vis-à-vis the legislature. The president has broad authority to issue decrees and directives that have the force of law without legislative review, although the constitution notes that they must not contravene that document or other laws." According to the Constitution, the prime minister is normally appointed by the president, with the consent of the State Duma. In consultation with the prime minister, the president appoints cabinet members, including the deputy prime ministers. Source: Constitution of the Russian Federation 1993; Wikipedia.

${ }^{171}$ Jenson and Sineau (2001a): p.15
} 
The similar dynamic can be observed in the Russian political arena, as will be illustrated in chapter 4 in detail. Fourth, the federal structure of the Russian state draws attention to the regional power institutions such as regional and local governments. As will be discussed in chapters 4 and 6, it is important to pay attention to both national and regional levels of the state, as the regional state elites are "in the position to influence institutional design and to shape the political and economic reform agenda." ${ }^{172}$ In many cases, as illustrated in chapter 4 , they comprised the main actors involved in discussing and adopting new social systems and policies. The historical legacy of decentralized institutions has also contributed to the heightened power of the regions in the post-Soviet period. As Valerie Bunce noted,

in the early years of socialism socialist institutions produced strong regimes, weak societies and robust economic growth. They served the interests of the communist party in general and its leadership in particular. However, as these regimes matured, a quite opposing set of outcomes began to materialize. These regimes depended for their very survival on maximizing growth and safeguarding the economic and political monopoly of the [communist] party, yet their institutional structure began gradually but surely to undermine growth and deregulate the party's monopoly. ${ }^{173}$

This institutional structure of decentralization became even more powerful after the 1992 privatization, which concentrated most power in the hands of local elites.

Fifth, while political parties have been rather fragmented in Russia after the fall of the socialist regime, and the differences among political parties are not so pronounced as in the West, they also represent relatively important actors influencing the development of

\footnotetext{
${ }^{172}$ Luong (2002): p.23

${ }^{173}$ Bunce (1999b): p.20
} 
child care policies in Russia. During the transformation period, Russia saw several parties in power: Russia's Choice (1993), Our Home is Russia (1995), Fatherland - All Russia (1999) and Unity (1999). These parties in power were electoral blocs, organized by state actors to participate in parliamentary elections and forge national organizations for presidential elections. They do so by relying mostly on state resources for building a party bureaucracy. ${ }^{174}$ Although several studies identified a weak relationship between the ruling party and social policy outcomes in Eastern Europe, political parties (including those in the opposition) take an active part in shaping policies, through their contributions to policy debates in the State Duma in Russia. For instance, the Communist party of the Russian Federation (CPRF) pushes for the preservation of social infrastructure inherited from the Soviet period, including public child care institutions, while the nationalist party of Russia, the Liberal-Democratic party, advocates for prolonging parental leave, so that women could stay at home for a more extended period of time. Therefore, the strength of the party, in terms of its popularity with the electorate and the nature of its allies, influences policymaking in general and the area of child care in particular. ${ }^{175}$

Politicians in the post-Soviet region are in a bind, balancing public support for maintaining welfare provisions developed in the socialist era (fearing large-scale dissatisfaction if payments are cut) and the need to ensure economic growth. Among elites, the decisions about the proper course of action are subject to political negotiation

\footnotetext{
${ }^{174}$ Smyth (2002)

${ }^{175}$ Jenson and Sineau (2001b)
} 
and manipulation. ${ }^{176}$ The state-centred approach assumes that the elites' perceptions of power shifts during the transformation period will affect both the degree of institutional change and its direction. ${ }^{177}$ Elites who are concerned with preserving or even augmenting their power either promote or resist institutional innovation. For example, those who believe that the balance of power shifts in their favour as a result of change, will seek to design new institutions, and those who believe that their power would decline would attempt to retain older institutions. As Luong puts it "what motivates elites to adopt political reform is their desire to acquire or retain as much power as possible given their perceptions of how present changing circumstances are affecting their previous ability to influence the distribution of goods and/or benefits." 178

\section{Limitations of the State-Centred Approaches}

Though the state-centric approach offers many insights in understanding of policymaking processes in Russia, it also faces a couple of problems. First, much of the analytical power inherent in this approach still remains at the level of theorizing. It overlooks the important social processes which influence state behaviour and decisionmaking. In reality, the division between the state and society is too blurred for such a clear distinction, particularly in Russia. Policies and state interests do not come from a void, and are not developed in a vacuum, but within the context of society, during daily interactions and contacts with society. ${ }^{179}$ The perceptions of politicians and interests of

\footnotetext{
${ }^{176}$ Gal \& Kligman (2000b)

${ }^{177}$ Luong (2002)

${ }^{178}$ Ibid.: p.3

${ }^{179}$ Smith (1993)
} 
state bureaucrats are influenced by their everyday social interactions. Second, despite the fact that the state-centred approach can explain much of the development of social policies in general, and child care in particular, it cannot account for a number of disjunctures in these policies. Strong fluctuations in policies during the first decade of transformation do not seem to be caused by long-term planning, but rather are better understood as an attempt to balance often conflicting internal and external pressures. Third, even within the state there are ideological battles which may produce mixed policies, serving as compromises (e.g. between liberal and communist parties). In general, although the state-centred approach offers a useful lens for assessing policy development in Russia, it is not able to account for all of the factors influencing the making and implementing of policy, including international and other social powerful forces.

Several caveats are in order, when one attempts to analyze the post-Soviet states. Most of the scholarship on the state assumes that the modern state already exists as a relatively fixed and consolidated entity. Consequently, these works focus on the outcomes of the states as consolidated structures and established entities. ${ }^{180}$ Many theories assume that there is a relatively "identifiable set of actors and/or institutions that exert legitimate authority over a given territory."181 This, however, is not always the case in the post-communist space: the states are not stable or consolidated, the process of state formation is ongoing and, as such, presents many contradictions in policy analysis. It

\footnotetext{
180 Tilly (1975); Eisenstadt \& Rokkan (1973)

181 Ibid.
} 
would be useful to pay attention to the processes of policymaking during the state formation, as opposed to measuring specific outcomes.

Second, while this thesis argues that the state is an important policymaking player, this approach poses several difficulties in the post-Soviet environment. Seeing the state as a unitary and intentioned agent able to coherently formulate goals, act on its policy preferences and resist other (societal) actors is quite problematic in Russia, due to the ongoing state formation and blurry boundaries between "state" and "society." As noted by Anna Grzymala-Busse and Jones Luong "No one single agent has uniform influence or authority across all state sectors, and state action is neither centralized nor coherent. The emerging states in the post-communist world, therefore, are best characterized as having multiple centers of authority-building, each with different sectoral capabilities and degrees of influence." 182 This is partly due to the fact that the nomenklatura kept most positions in Russia, thus making it difficult to distinguish between the state or non-state agents. According to Anna Grzymala-Busse and Jones Luong:

On one hand, an integral part of the communist state-building project was to develop a ruling apparatus that was clearly separate from and superior to society in order to establish and maintain a legal-rational order. On the other hand, communist leaders armed with the vision of creating a heroic-Leninist state purposefully blurred the distinction between state and society in both their rhetoric and policy efforts. ${ }^{183}$

\footnotetext{
${ }^{182}$ Grzymala-Busse \& Jones Luong (2002): p.531

${ }^{183}$ Ibid.: p.534
} 
Finally, while most scholars see the state as a set of formal practices (the official, writtendown rules, contract enforcement, extraction and redistribution, and the designated organizations that serve and enforce these rules), which help to implement policies, ${ }^{184}$ it is important in the Russian case to analyze informal mechanisms, such as personal agreements and networks, informal contracts, shared understanding etc. Grzymala-Busse and Luong argue that the change in the post-communist world is

characterized not by the development of formal institutions alone but by the recombinance of the formal and the informal. The postcommunist state...inherited an intricate and robust set of informal structures and practices utilized by political elites, factory managers, and ordinary citizens alike, which have survived the collapse of communism. ${ }^{185} \ldots[\mathrm{T}]$ he post-communist experience illustrates that both formal and informal legacies act as important constraints on state formation because they constitute the primary resources available to elites competing for authority. The rapidity of postcommunist state-building, moreover, serves to reinforce the effect of these legacies. The fact that the postcommunist state is being hastily rebuilt in years, not built anew over centuries, makes this statebuilding project more akin to bricolage than to building up the state brick by institutional brick. Competition between well-placed elites is thus all the more constrained by the availability and configuration of formal institutions and informal practices. ${ }^{186}$

These considerations with regard to the state in Russia require us to look at other factors, which influence state and regime building.

\footnotetext{
${ }^{184}$ See Kohli (1986); North \& Weingast (1979); Stepan (1978). An important exception is Khoury \& Kostiner (1990).

${ }^{185}$ Stark and Bruszt (1998), in Postsocialist Pathways, developed the notion of "recombinant property" as neither wholly private nor state-owned.

${ }^{186}$ Grzymala-Busse \& Luong (2002): p.535
} 


\section{The Need for a Synthetic Approach}

When taking into account the strengths and limitations of both approaches to analyzing the process of paradigm shift in child care policies in Russia, this thesis will advise a more synthetic approach to how the state and society interact in the process of policy development and implementation. This approach would combine both state-centred and power resource theories. Skocpol called such a combined approach "polity-centred" and noted that it "views the polity as the primary locus of action, yet understands political activities, whether carried on by politicians or by social groups, as conditioned by the institutional configurations of governments and political party systems." ${ }^{187}$ This thesis will assess the autonomy of the Russian state through an analysis of its ability to control the policy-making process in this area, or, in other words, its ability to set independent policy goals and generate independent interests within given economic, political and social constraints. ${ }^{188}$ I will argue that despite the growing number and influence of various interests, the executive branch of the government (president and bureaucracy), along with the politicians, still plays a significant role in policymaking.

In order to assess the autonomy of the Russian state, I will assume that "the state" is comprised of Russian political leaders and bureaucrats, which represent the interests of the state as opposed to the non-state groups. I will also assess the activities of the external actors to the state, such as international organizations as well as business elite, trade unions and civil society. These actors are illustrated in Figure 1. The inclusion of political

\footnotetext{
${ }^{187}$ Skocpol (1992): p.41

${ }^{188}$ Skocpol (1985)
} 
leaders (of ruling and opposition parties) as part of the state, as well as accounting for the influence of external interests, brings a power resource perspective into the analysis. This combined approach will allow us to illustrate how internal state dynamics (between president, governmental departments and political parties, as well as among those groups themselves) paired with the need for balancing the demands of external actors to a degree compatible with the state vision, have instigated the emergence of a new model of welfare state in Russia.

The uniqueness of the Russian situation should be noted, however. While for the purposes of this thesis business groups and trade unions in the transformation period will be treated as external-to-the-state actors, it will be shown that in fact many of these institutions have a history of acting as quasi-state institutions. This legacy and inherited state/political/economic networks conditioned their behaviour and role in the post-Soviet period. 
Figure 1. Interaction of State and Non-state Actors in the Russian Welfare State

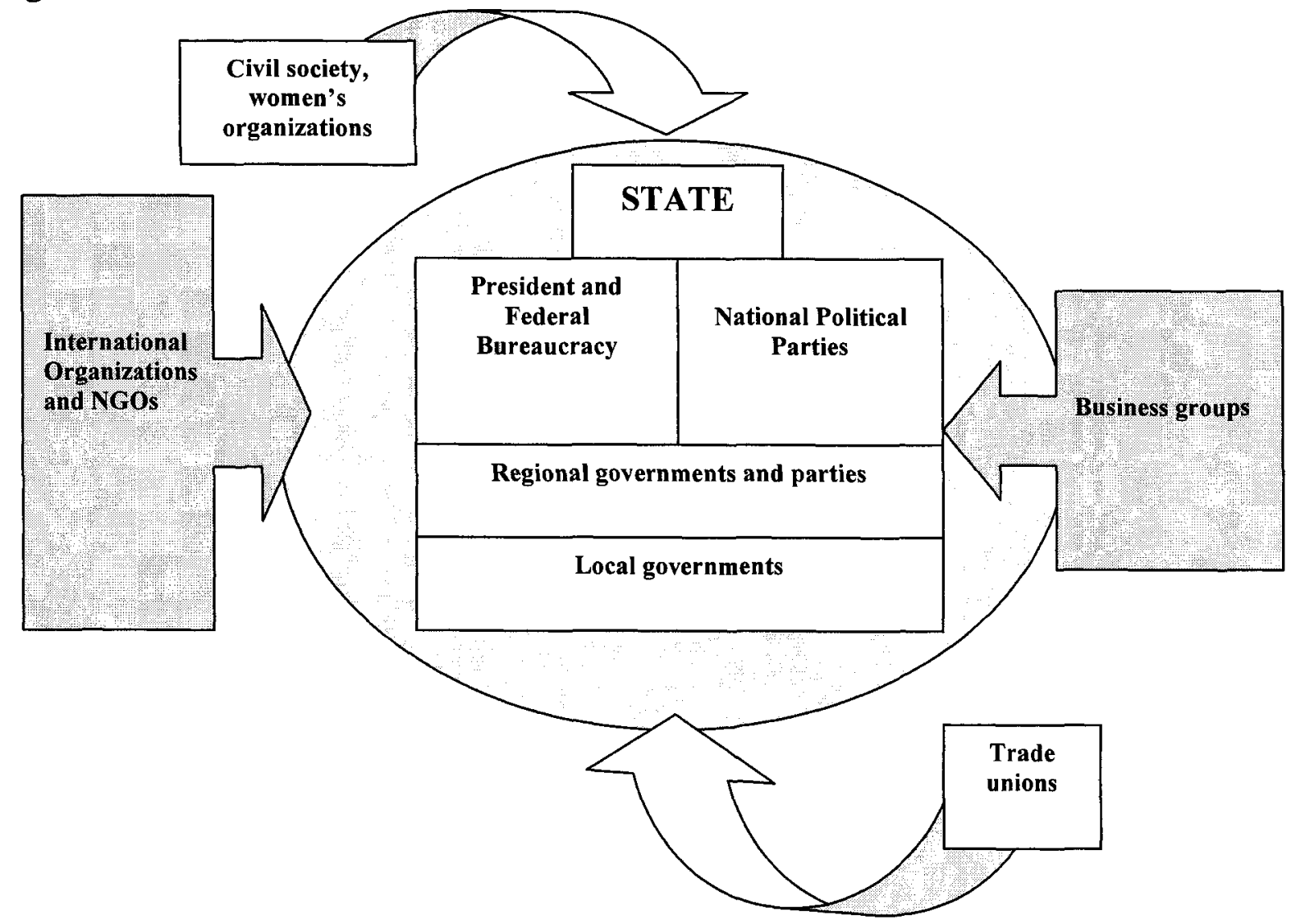

In broad terms, external groups can be divided between global and domestic.

Global actors include the World Bank, the International Monetary Fund (IMF), the International Labour Organization (ILO), the European Union, United Nations agencies and others. These global forces affect the development of the welfare state in the Eastern European countries and Russia. At the same time, there are various quite different opinions on the direction and degree of such impact. Thus Palier observes that, "the analyses of the impact of globalization and European integration vary between those who acknowledge significant impact of these processes on welfare state to those who deny 
any influence (or even existence) to these economic trends on welfare states." ${ }^{189}$ In addition, globalization and European integration sometimes push social policy in a different direction. The World Bank and the IMF influence policy in residualist and privatizing directions. The main recommendations of these organizations, with respect to child care, include a movement towards market provision of child care services, and a significant reduction of the duration of maternity/parental leaves and allowances, in order to achieve labour force flexibility. The opposite pressure to develop a social market strategy came from the European Union and International Labour Organization. These actors rather advocate the preservation of the inherited social welfare system, with some restructuring. The economic vulnerability and desire of Eastern European countries to join Euro-Atlantic organizations has made their political elite keener to accept and balance often conflicting advice from global organizations. Such conflicting advice produces mixed policy outcomes. Thus, although various studies provide strong evidence that Eastern European countries are rather susceptible to the influence of globalization largely due to their economic vulnerability, other studies suggest that these globalizing or "neoliberal" policies have been adopted mostly to the degree compatible with the existing institutional structure and independent goals of the state. ${ }^{190}$ The counterbalance of these actors seems to be quite important for the policymaking process in Russia, and their interaction with the Russian state needs to be examined more closely, in order to assess the degree of their influence on the development of the child care policies.

\footnotetext{
${ }^{189}$ Palier (2003): p.148

${ }^{190}$ Dutkiewicz \& Plekhanov (2002)
} 
Domestic interests, in turn, include economic elites, trade unions and civil society. These groups have a fluctuating influence on the state. The first group is the new and old business elite and managers of the former Soviet enterprises. As a result of the legacy of fusion of economic and political, after the collapse of the Soviet Union, a significant share of political and bureaucratic positions by the large former state-owned enterprise managers and directors. I would consider this group however as being able to challenge the state's capacity to implement its goals, and it will be important to consider its influence on the policymaking process, particularly in the area of social policies, since the main burden of welfare provision (in our case, child care provision, in the form of child care services and payments of maternity/child care leaves) was placed on enterprises. As will be shown in chapter 4, the 1992 privatization process in Russia allowed the concentration of most of the state's assets in the hands of enterprise directors and managers, thus transforming them in powerful interest groups. It will be shown how enterprise managers influenced the development of both social and child care policies through coalition-building throughout the 1990 s, first via the so-called Civic Union and then coalitions with the parties of power. One of the main reasons for such empowerment is the legacy of the merged state-economy networks, when the managers of large enterprises were appointed by the party through the so-called "nomenklatura system." This had important implications, not only for the autonomy, but also for defining the boundaries of the Russian state during the transformation process.

The role of trade unions has significantly declined in the transformational period, when compared to the Soviet regime. Kapelushnikov argues that although approximately 
two thirds of the Russian workers are still members of the trade-unions, even in the postSoviet period, in practice their role in the Russian labour market (and thus lobbying capacities) is quite weak. ${ }^{191}$ The high level of unionization can be explained rather by inertia. ${ }^{192}$ Nonetheless, the trade-unions did play a prominent role in the development of the new Labour Code at the end of the decade and were instrumental in protecting some of the provisions from the previous labour regulations during the transformation period. This had an important effect on the ultimate shape of the Russian welfare state, which will be accounted for in detail, in chapter 4 .

The role of civil society in influencing public policy processes, although growing, is still insignificant. A number of studies indicated that civil society is "weak" in the postcommunist countries. For instance, the role of civil society was insignificant in promoting social rights in Hungary and its weakness was among several major reasons for the retrenchment of benefits and services for mothers in the Baltic countries. ${ }^{193}$ As part of civil society, many scholars have noted the importance of mobilization of women's groups and other social movements for the analysis of welfare states; in the Russian case, however, these movements do not yet have a strong influence over the policy process, as the civil consciousness of the Russian society is quite low. The civil society and women's movement might gain strength in the future; at the present time, however, its impact in the social area is hardly noticeable in Russia.

\footnotetext{
${ }^{191}$ Kapelushnikov (2001):p.96

192 Ibid.

${ }^{193}$ See Ferge (2001); Aidukaite (2004); Paluckiene (2000)
} 
This section outlined the need for a combined approach, in order to understand how the paradigm shift in child care came around, and what factors influenced the emergence of the unique mix of Russian welfare regime. The next chapters, particularly chapters 5 and 6 , will examine in greater detail how political institutions, state and nonstate interests, along with the legacies from the previous policies, have influenced the agenda of debates over policymaking in the area of child care. They will explore the questions of how and why the changing state capacities affected the ultimate effects of child care policies. They will also assess the adaptation strategies and informal mechanisms utilized by the various players. The combined approach will help to account for the multiplicity of actors and factors shaping the post-Soviet Russian welfare regime, in order to develop a more comprehensive picture of social changes in general, and in Russia and other transition countries in particular.

\section{Conclusions}

This chapter provided the theoretical foundation for a further analysis of the transformation of the Russian welfare state, particularly with regard to gender, the role of child care and female employment. It argued that child care serves as an important lens for the analysis of the welfare states, and can offer useful insights in explaining the policymaking dilemma of balancing the productive and reproductive functions of women.

In addition, this chapter provided a framework for assessing changing ideas and their role in influencing child care policies. It argued that the paradigm shift approach is 
best suited to explaining the changes experienced by the Russian welfare state in the area of child care. At the same time, it stresses the importance of historical institutions and interests in defining the ultimate shape of the welfare regime. It showed that there is a need to account for interests, institutions and ideas, in order to understand how and why a mixed model of the Russian welfare state is emerging. This chapter underscored the importance of interests and institutions (such as political parties, structure of the policymaking process, federal structure of the Russian state and Soviet policy legacies) in shaping the policymaking process at the federal, regional and local levels.

Finally, this chapter outlined the main approaches to understanding the process of public policymaking, sources of continuity and change, as well as why and how paradigm shifts come about. It argued that it is necessary to combine state-centred and power resources theories in order to fully account for the process of change in the Russian welfare state. For instance, in line with Jenson and Sineau's argument, this chapter indicated that that the design of child care would respond to a different combination of objectives and models, depending on the balance of political forces and the ways in which the legacy of existing policy influences policy debates. ${ }^{194}$ Intragovernmental power balance, shifting political configurations and changing economic conditions determine the emerging child care policies, and the instrumentalization of reproductive arguments shapes the policies and practices of reproduction supported by the state and

\footnotetext{
${ }^{194}$ Jenson \& Sineau (2001b)
} 
experienced by men and women. ${ }^{195}$ These power and ideological struggles take place in response to falling birth rates, unemployment and regulation of labour markets.

The next chapter will analyze the welfare regime developments in the Soviet period, with particular attention to the ways of solving the so-called "woman question." Understanding the institutional legacies of the Soviet period will help us better understand the emerging model of the welfare state in Russia in the post-Soviet period.

${ }^{195}$ Gal \& Kligman (2000b): p.34 


\section{Chapter 2. Soviet Welfare Regime}

\section{Introduction}

In order to grasp the scope and nature of some of the changes and continuities brought about by the process of transformation in child care policies, it is important to take a look at the specific elements of the Soviet welfare state. This chapter argues that, despite the broad goal of the Soviet family/child care policy to ensure full employment for women, the manner in which it was framed varied during various periods of the Soviet history (1917 - 1991), depending on what was needed more: children or workforce. ${ }^{196}$ These frames covered a range of goals: from gender equality and building communism, to the need for a "Soviet family" and "healthy and educated citizens," and subsequently generated changes in the policies and instruments used by the state.

This chapter shows that the Soviet system had a sufficient degree of elasticity to quickly adapt to the changing needs of the state, a flexibility that was achieved through the specific institutional configuration of the Soviet welfare state. This institutional configuration can be characterized by a number of factors, including fusion of politics and economics, the widespread penetration of the party, central planning but decentralization of service delivery (e.g., through enterprises). We will see how this social system adapted to the changing priorities of the state, using the example of child care in four periods: post-revolution (1917-1930); early Stalinist period (1930 - 1940), WWII and post-war period (1941 - 1960), and late Soviet period (early 1960s - 1991).

\footnotetext{
${ }^{196}$ Policies in the area of childcare are traditionally called "family policies" in Russia and are used interchangeably in this thesis.
} 
What remained constant throughout the Soviet history was the commitment to the full female labour force participation and a perception of children as public goods. This was primarily achieved through the provision of services through enterprise-level "welfare states," allowing women to combine employment and motherhood.

This chapter advances a two-fold sub-hypothesis:

- The institutional configuration of the Soviet welfare state, including central planning and decentralization, produced the flexibility required to respond to the changing needs of the state with respect to women;

- Through different policy frames, the Soviet state reinforced either women's productive or reproductive functions, depending on its socio-economic needs, while remaining committed to full female employment and a perception of children as public goods.

These sub-hypotheses advance the main thesis hypothesis by situating changes in child care policies during the transformation period within the broader historicinstitutional framework. The chapter begins with the general characteristics of the Soviet welfare state: its ideological underpinnings, system of economic planning and decentralization of service delivery, as well as enterprise administration of benefits. Next, I will analyze child care policies in the Soviet Union using Bettio and Plantenga classification: ${ }^{197}$ child care services (including places in both nurseries and kindergartens) as well as money and time off (maternity/parental leave and working time, as well as

\footnotetext{
${ }^{197}$ Bettio and Plantenga (2004): p.90
} 
allowances for in-home caregiving and other family allowances). I also look at the policy implications for female employment. The chapter will conclude with the analysis of the general trends of the Soviet welfare state, which will serve as a foundation for comparisons with the model of welfare emergent in the early post-communist period. ${ }^{198}$

\section{Soviet Welfare Regime: Overview}

Before proceeding with the analysis of the gendered provision of the Soviet welfare state, it is important to highlight the key features of the Soviet system, which will have an important influence on the transformation of the Russian welfare state in the $1990 \mathrm{~s}$. The first feature of the Soviet system was the ideological mission of its ruling elite, which was future-oriented, anti-capitalist and committed to rapid economic mobilization. This led to a number of consequences, including extreme models of import substitution by "creating fully autarkic economies, starving the agricultural and the consumer sectors, speeding the rate of urbanization, generating unusually high rates of savings, and targeting investment toward both education and heavy industry."199

A second defining feature of socialism was the construction of a conjoined economic and political monopoly, which rested in the hands of the Communist Party. This monopoly originated in the replacement of private ownership, markets, and the bourgeoisie, as well as a competition in politics and economics, by transformative

\footnotetext{
198 The analysis in this chapter is based on both primary and secondary sources. The primary sources included the legislative and policy acts of the Soviet period (archival research). The secondary sources included newspapers and literature review.

${ }^{199}$ Bunce (1999b):p.21
} 
ideology, central planning, and state ownership of the means of production. ${ }^{200}$ Thus, in Bunce's terms, there was a "mono-organizational" order with the Communist party having enormous economic and political resources at its disposal, which led to the fusion between politics and economics. ${ }^{201}$ This had important implications for the system, in developing "investment" and "power" hunger among the Soviet elite respectively in both the economy and polity. ${ }^{202}$

The third feature of socialism could be referred to as the fusion of the party and the state. Despite the fact that it had its own institutions, the state was highly dependent on the Party. As pointed out by Bunce, the party-state relationship was a sum of

a complex array of dyadic linkages between appointed positions that extended from the very bottom of the system (for instance, within enterprises, schools, hospitals, local governments, and neighborhood associations) to its apex. These appointed positions were located within the party or within the state bureaucracies, and the linkages - which were the mechanisms for distributing political power and economic resources tied party positions to each other or to positions within the state. The end result was that the party-state produced in effect a single extraordinarily detailed tapestry that covered the entire system ${ }^{203}$

Because party positions were interwoven in the texture of the state, the state relied on the party for personnel (through the system of appointment of party-approved candidates), in the design of the state institutions, as well as for resources and leadership. Bunce notes that the state was never free to make independent decision-making, being neither separate nor equal to the party. This led to the next feature of socialism - what is called

\footnotetext{
${ }^{200}$ Ibid.: p.22

201 Ibid.

${ }^{202}$ Ibid.: p. 22

${ }^{203}$ Ibid.: p.23
} 
"extraordinary institutional penetration of the party-state." Penetration of the party-state, besides the economic and political monopoly enjoyed by the party, sheer size, density, and sectoral as well as geographical coverage of the party-state, implies the institutional capacity of socialist systems to orchestrate developments within their environs, which reflected a tendency towards excess in everything, be it urbanization or literacy rates. ${ }^{204}$

The elastic nature of the socialist institutions can also be seen as one of the defining features of socialism. Such elasticity or flexibility of the socialist institutions (both political and economic, given the fusion of the two) was produced by the combination of political and economic monopoly of the party, realized through central planning and total party control of the political environment, combined with a decentralized mode of delivery and atomized party structure and nomenklatura system. ${ }^{205}$ Such institutional arrangements, in the end, provided a certain elasticity in the political environment, "wherein existing political alignments are disturbed, political access widens, the policy agenda is reordered, and the costs of mobilization decline alongside the benefits of standing passive on the sidelines."206 This political elasticity, under the conditions of federalism, resulted in a greater empowerment of the local political and economic units, which later served as one of the impediments for successful exercise of power by the central government during the transformation process.

\footnotetext{
${ }^{204}$ Ibid.: p.24

${ }^{205}$ According to Holmes (1997:136), "nomenklatura system basically meant that the communist party was involved in the appointment of people to all the most senior posts in society - not merely within the party itself, but also in the state administration, the police, the military, the judiciary, education, the economy (including managers of enterprises), women's organizations, trade unions, etc."

${ }^{206}$ Bunce (1999b): p. 18
} 
Decentralized service provision, organized on a hierarchical basis, can be seen as the sixth and final feature of socialism, which is relevant to the discussion in this thesis. Most often services were provided through economic units - such as enterprises, farms and stores. These often served as micro welfare states, providing a wide range of services, from child care to access to health resorts. ${ }^{207}$ For those units which were a part of the so-called budgetary sphere (public sector), the services were provided through the local divisions and branches of the respective "social" ministries: Ministry of Health, Education, and Social welfare. ${ }^{208}$ As shown in the subsequent chapters, such decentralized service provision generated a number of interests protecting it, which contributed to the complex nature of transformation in the post-Soviet period, and the ultimate shape of the Russian welfare regime at the end of the 1990s. This was also intensified by the federal structure of the Soviet system. The federal structure of the Soviet Union, and the vast territory of Russia, with its increasingly powerful regions as a result of decentralization of service provision and authorities in general, generated a pattern typical for centre -periphery dynamics, with the central party-state apparatus facing republican or regional/local apparatus that "fanned out" from the federal centre. ${ }^{209}$ Thus, decentralization of authorities and federal structure provided regions with an opportunity to capture and hoard the resources leaked from the center over time, thus shifting the resource power from the center to the regions.

\footnotetext{
${ }^{207}$ It is important to note that not all enterprises were equal in their capacity to provide services. Large, industrial enterprises had a more developed infrastructure than small factories and stores.

208 The names of the ministries varied depending on the historical period

${ }^{209}$ Bunce (1999b)
} 
These features not only defined the nature of child care and other service provisions in the Soviet Union but also, as will be demonstrated later, became critical factors in determining the speed and nature of the transformation of the post-Soviet welfare regime. Before proceeding with the analysis of child care policies in the Soviet period, however, it is important to examine the ideological doctrine of the Soviet state with regard to women and children, as well as understand the institutional configuration of the Soviet welfare state, in order to situate the developments in child care policies and their impact on women. These will be considered in the next sections.

\section{Communist Ideology towards Women vs. Practice}

\section{Ideological Foundation of Women's Liberation}

Overall, the Soviet period was characterized by a change that resulted from revolution, industrialization, urbanization and civil and Patriotic (WWII) wars. The ideology underlying women's liberation in the first years of the Soviet period was based on the belief that capitalism had created a contradiction between the demands for work and the needs of the family, which was felt most painfully by women. Under capitalism, as more women were entering the labour force, the conflict between the demands of production and reproduction resulted in high infant mortality, broken homes and neglected children, as chronic health problems also became more apparent. ${ }^{210}$ Bolsheviks saw socialism as

\footnotetext{
${ }^{210}$ Goldman (1993)
} 
the only way of resolving this contradiction. They based this postulate on several interrelated assumptions, listed below. ${ }^{211}$

The first assumption was that household labor should largely be removed from the home to the public sphere. For instance, it was envisioned that such tasks as child care, laundry and cooking would be performed in public, universally accessible facilities. One of the Soviet theorists, Preobrazhenskii noted that "[o]ur task does not consist of striving for justice in the division of labor between the sexes, [but] is to free men and women from petty household labor." 212

Second, Bolsheviks argued that women's liberation could take place only if they entered the world of wage labor. Socialism was seen as providing women with a chance to be equally educated and paid, and able to pursue their own individual goals and development. The meaning of a separate wage in women's lives was equated with economic independence and access to a wider public world. This ideological discourse also presented wage labor as a way for women to contribute to the building of socialism, thus constituting work as a social and personal "need" and necessity for women. ${ }^{213}$ During the development of Soviet history, however, work became regarded as the single and sufficient, rather than just one necessary precondition, of women's emancipation, even though the communist theory had outlined the socialisation of

\footnotetext{
${ }^{211}$ As will be shown in this chapter, this ideological framework prevailed only in the first years of the Soviet history. In subsequent periods, ideology was changing, depending on the political, economic and social situation in the country.

${ }^{212}$ Preobrazhenskii (1920): p.19.

${ }^{213}$ Haney (2002)
} 
domestic labour as well as women's inclusion in the production process as other prerequisites of female liberation. ${ }^{214}$

Third, little importance was attached to the bonds between parents and their children. It was assumed that most care for children could be delegated to paid, public employees. As observed by Kirschenbaum, "It was an article of faith among socialists that the family was useless, often harmful, and in any case disappearing; guided by superstition and limited by poverty, it oppressed both women and children."215 Over time, free union was to gradually replace marriage, reducing pressures of economic dependency and need. It was also envisioned that parents would care for their children with the help of the state, and that the family would gradually wither away, having lost all its previous social functions. ${ }^{216}$ Furthermore,

The rearing of children by society was hailed by all not only because it saved time and released the mother for outside work, but because it could be more scientific, more rational, more organized than rearing within the individual family. Some carried the argument even further and contended that in a society organized around a collective work system it was more appropriate to accustom a child from the earliest years to life in the collective rather than to train him in the individualistic small family. Kollontai's early formulation is characteristic: "The contemporary family, as a specific social collective, has no productive functions and to leave all care for posterity in this private collective cannot be justified by any positive considerations . . . Logically speaking, it would seem that care for the new generation should lie with that economic unit, with that social collective, that needs it for its further existence. $^{, 217}$

\footnotetext{
${ }^{214}$ See Einhorn (1993): p.20.

${ }^{215}$ Kirschenbaum (2001): p. 29-30.

${ }^{216}$ For a detailed description of this period, see Goldman (1993); Lenin (1970); Engels (1972); Lenin (1934); Kollontai (1921)

${ }^{217}$ Geiger (1968): p.47
} 
What precisely would replace family, however, remained open to the debate among Bolsheviks. For instance, as Lisa Kirschenbaum notes in her account of the development of child care policies in the early Soviet period, Bolsheviks and educators from the Commissariat of Enlightenment, the Preschool Department, and kindergartens proposed multiple visions of the future of family and children. For instance, kindergartens were seen as "both a catalyst of cultural transformation and as a precocious, fully functional outpost of emerging socialist society."218 Similarly, different assessments of the family's proximity and role of parental and maternal rights to children generated a variety of answers of when public child-rearing would replace parents entirely. ${ }^{219}$

Finally, while ideologically promoting freedom of individuals, communists enlarged the role of the state immensely, by aiming to eliminate intermediary bodies like the family. The abolition of the family, rather than the gender conflict within it, held the key to women's emancipation. The socialization of household labor was assumed eventually to eliminate women's dependence on men and promote a new freedom in relations between the sexes. ${ }^{220}$

Despite the common ideological framework, the position of the new state with respect to the "woman question" was neither unambiguous nor unanimous. One group of Bolsheviks considered the female population as passive and conservative, and capable under certain conditions to become an obstacle in the way of revolutionary changes. Women, who were less literate and subject to a greater influence of church, were

\footnotetext{
${ }^{218}$ Kirschenbaum (2005): p.50

${ }^{219}$ Ibid.

${ }^{220}$ Goldman (1993): p.6
} 
perceived as a potential conservative force, and they were "supposed" to participate in the revolution only by supporting their husbands. ${ }^{221}$ Others, however, - mostly female leaders of the communist party (first of all, Alexandra Kollontai) - had a different view on the role of women in the new society and the resolution of the "woman question." Kollontai saw a revolutionary potential in women and believed the changes in their lives (withering away of the family, participation in the labour force, socialization of domestic life) were a necessary condition for a communist revolution. She believed that marriage becomes a personal and secondary matter, while motherhood had ceased being a private matter, becoming a matter of state importance and significance, and a woman's main duty:

Working society should place a pregnant woman in the most favourable conditions, however, a woman herself should follow all rules of hygiene during her pregnancy, keeping in mind that while pregnant, she belongs not only to herself, she is serving the society by producing a new unit of labour. Another main socialist duty of a woman is breastfeeding. Only having breastfed her baby, a woman has a right to say that she has fulfilled a duty toward her child and society. ${ }^{222}$

In this light, motherhood was seen as solely the biological function of giving birth to a child and breastfeeding, while the function of socialization is transferred from parents to the state. ${ }^{223}$ In order to support this vision, Kollontai developed the initial concept for what became known as "the" Soviet gender contract - direct contract of the state with a

\footnotetext{
${ }^{221}$ As statistics indicate, women in the pre-revolutionary Russia were much less literate than men: "under the census of 1897, the last general census before the World War, 37.9 per cent of the male population above seven years were literate and 12.5 per cent of the female population. During the next fifteen years literacy made no great strides among the population. The general census of December, 1926, however, revealed that... for the first time in Russian history the majority of the population could read and write. The percentages of literacy were 65.4 for males and 36.7 for females (above the age of seven years)." Soviet Union Information Bureau (1929)

${ }^{222}$ Kollontai (1922): p.173

${ }^{223}$ Gurgenko (2002): p.80 - translation by the author
} 
woman bypassing the family, where a woman was seen as a privileged partner of the state in building a new society. Social guarantees and benefits were provided to a Soviet woman through her obligatory participation in both social reproduction and economic production. Maternity was seen as a main duty for women, but it was the role of the state to provide all possible aid for women to perform this function. In her book "Women's Labour in Economic Development" published in 1923, Kollontai writes about the new roles of a woman and the state: "[m]otherhood is looked at from a new angle: the Soviet government regards it as a social obligation. With this principle in mind, the Soviet government outlines a number of reforms tending to lift the burden of motherhood from woman's shoulders and to place it on the state."224 This was supported by Krupskaya who saw matters in a similar light:

How can one help the mother, suffering under the weight of childbirth, child-rearing and education? The answer is clear-the government needs to undertake not only to look after the woman during her pregnancy and during and after childbirth; but it must also establish tens of thousands of creches, kindergartens, children's colonies, children's communities, where children would receive care and food, where they would live, develop and learn under conditions ten times better than those which could be created by a caring mother single-handed. 25

These beliefs about the role of women as both mothers and workers, children as public goods, and the role of the state as having an obligation to lift the "burden" of child rearing from women's shoulders, served as a foundation for child care and family policies throughout the Soviet period (even though major fluctuations took place with regard to women). The next subsection will describe the efforts to bring these ideas to life through the Zhenotdel, as woman's section of the Communist party.

\footnotetext{
${ }^{224}$ Quoted in Schlesinger (1949): pp.48-53.

${ }^{225}$ Krupskaya (1938): pp. 192-3 as quoted in Heitlinger (1979)
} 


\section{Politics of Women's Liberation: Zhenotdel}

Women's situation in the country, after the revolution, was far from ideal, with many neither educated nor politically active. It was one of the main challenges of the new regime to reach and mobilise the women masses to support the new regime. As one of the steps to mobilization of women, in November 1918, Kollontai, together with her supporters, organized the First Congress of Peasant and Working Women. The main items on the agenda included: "the question of women workers in Soviet Russia, the relationship between the family and the Bolshevik government, the social security of women, the international proletarian revolution and the woman worker, the organisational question, the struggle against prostitution, the struggle against child labour, and the housing question." ${ }^{, 26}$ As a result of resolutions passed at the Congress, "the Central Committee of the Bolshevik Party established in September 1919 a women's section, known as Zhenotdel.,227 The purpose of Zhenotdel was twofold: to train women to enter the Party and government, and transform the domestic sphere through socialization. Transformation of daily life was not simply limited to the establishment of one more laundry or day-care center. It had a far more reaching goal - a structural transformation of the family, women's roles, and society itself. ${ }^{228}$ The principles of Zhenotdel, as described by Inessa Armand, ${ }^{229}$ who was appointed as its director, among others included:

1. "Zhenotdel should increasingly and urgently draw women workers and peasants into all Soviet institutions-executive committees of Soviets or sections of Soviets, the party, professional and technical schools, etc. It was emphasized that women

\footnotetext{
${ }^{226}$ Artiuchina (1959): p.31 as quoted in Heitlinger (1979): p.56.

${ }^{227}$ Heitlinger (1979): p.57.

${ }^{228}$ Goldman (2002)

${ }^{229}$ The report prepared for the First International Conference of Women Communists, July 1920 by Inessa Armand
} 
should be drawn into such work in order to liberate them from domestic and family servitude...

2. Through the delegates' meetings, the party should exercise influence on the women masses. In villages, delegates' meetings should help to differentiate bourgeois elements from proletarian ones.

3. Elected delegates should enlist the services of Soviet departments not only for the inspection and control of nurseries, orphanages, public dining rooms, hospitals and other institutions, but also for the delegates' meetings themselves...

4. The Communist Party should lead propaganda campaigns to enlighten the masses on questions of prejudice in attitudes towards women, and of their roles in the family and in social production." 230

In practice, however, Zhenotdel functions were not that different from the modern women's centres. They included:

organizing campaigns, exhibitions, meetings, consciousness-raising, etc. Its various bodies catered for the nucleus of active party women who, as representatives of the women's sections on various party committees at all levels of the hierarchy, had a permanent place in the party apparatus. At the same time, through the delegates' meetings, the Bolshevik feminists reached the mass of women previously outside politics. The delegates' meetings were set up in factories, villages or workers' settlements in the towns. $^{231}$

At the same time, there was a division within the Party over the mandate of Zhenotdel.

Some wanted it to serve the Party's general goals and train Party members, while others saw its role mainly in promoting women's interests and issues. Some of the male party members "regarded agitation and propaganda work among women as of secondary importance." These attitudes stemmed from both the "fundamental Bolshevik distrust of all specialised mediating networks standing between the population and the party-state, unless those networks were totally subject to central surveillance, manipulation and control," and as well as male prejudice. ${ }^{232}$ As a result, Zhenotdel was often seen as having a potential to "distort the overall Bolshevik thrust, dilute women's revolutionary

\footnotetext{
${ }^{230}$ Heitlinger (1979): p.58

${ }^{231}$ Ibid.: p.59

${ }^{232}$ Ibid.: p.59
} 
concern, and sidetrack them into narrow feminist pursuits. ${ }^{, 233}$ Male prejudice, in turn, resulted in the weak co-operation between Zhenotdel and other party committees, as well as state institutions.

In the 1920s, the Zhenotdel began to move from focusing on issues specific to women to concentrating on training women to enter Soviet institutions. The socialization of the domestic sphere ceased to be an end in itself, and became necessary only "to achieve other aims."234 The New Economic Policy of 1921, however, and the subsequent cutbacks in social spending, as well as the ruin of industry, the mass unemployment of women, the deep poverty of the countryside, and the orphaning of hundreds of thousands of children through a civil war (1917-1922) and famine, posed serious obstacles to the Zhenotdel's activities. Moreover, male Party members at every level of the Party hierarchy - but especially at the local level - were loath to devote scarce resources to the organization's programs and goals, which also prevented Zhenotdel from realizing its aims. $^{235}$

Ideological aims were hence only patchily translated into practical measures. Although, from the outset, the leadership of the Communist party had placed the "Woman Question' on the political agenda, distinct policy phases were identifiable throughout the history of the Soviet Union. These phases are elaborated upon in the subsequent sections of this chapter. What this period teaches us is that despite the communist ideology,

\footnotetext{
${ }^{233}$ Ibid.: p. 59, also see Mandel (1975)

${ }^{234}$ Goldman (2002): p.41; Hayden (1973)

${ }^{235}$ Ibid.: p. 41
} 
patriarchal institutions remained strong, affecting lives of women in a variety of important ways.

\section{Central Planning System, Decentralization and Women}

Most scholars denied the existence of a welfare apparatus in the early years of socialism, reducing the regime's policy apparatus to the economic organization of state socialism. ${ }^{236}$ The gendered implications of centralized planning, decentralized delivery and enterprise assistance schemes developed under the socialist regime are rarely addressed. ${ }^{237}$ Haney notes that these gaps have led feminists to view "Stalinist emancipation" as focused primarily on women's position in the labor force, and to argue that, since the regime never rethought gender oppression in the home, it failed to undermine the source of gender subordination. ${ }^{238}$

This thesis, however, is enlightened by Lynne Haney's analysis of welfare apparatus in the communist states, which states that "although much of the regime's welfare apparatus was rooted in its economic structure, a complex system of policies and agencies did operate with the explicit goal of securing the population's well-being."239 Her approach is consonant with Zsuzsa Ferge, who characterized the regime as "societal"

\footnotetext{
${ }^{236}$ See Robert Deacon (1983); Kornai (1996). The important exception includes the analysis of the welfare apparatus with regard to children in the early years of the Soviet state by Lisa Kirschenbaum (2001). ${ }^{237}$ The literature in the area of early communist welfare is still relatively limited, although some ground breaking work has been done by such feminist scholars as Lynne Haney (2001), Susan Gal and Gail Kligman (2002). Analysis done by Lynne Haney, although based on the Hungarian case is applicable to most of the countries of the so-called "Soviet bloc."

${ }^{238}$ Haney (2002):p.27

${ }^{239}$ Ibid.:p.27
} 
in nature and investing in altering the "profile of society." 240 Ferge saw the provisions of early socialism as seeking to restructure nothing less than "basic human and social relations." 241 Thus, although rarely recognized as a form of redistribution, many of the key re/distributive mechanisms of state socialism were rooted in the unique combination of centralized economic planning and decentralized service delivery (as explained below), often without a separate apparatus for administering social policies. These provisions were diffused throughout different economic and social terrains, and administered in most cases through the system of state enterprises, which often operated as autonomous welfare provision units in themselves. The next subsections will elaborate on the nature of socialist institutions and mechanisms of enterprise service delivery.

\section{Flexible Institutions: Central Planning and Decentralization}

The Soviet welfare state responded to the changing needs of the country, and was able to quickly mobilize women in their productive and reproductive functions. The ability in this system to adapt to changing priorities and respond to the external signals may seem counter intuitive, because the Soviet state machine is often depicted as rather rigid. Yet, its very flexibility was due to the lack of

the kinds of constraints that, in more pluralist political settings, moderate and correct the course of public policy - for instance, the ever present possibility of enterprise arid electoral failures, and the considerable pressures on elites within capitalist economies, whether situated within a

\footnotetext{
${ }^{240}$ Ferge, Z. (1979): p. 13

${ }^{241}$ Ibid.: p.20-22
} 
democratic or a dictatorial political context, to juggle their own political needs with the demands of capital and labor. ${ }^{242}$

There were two main mechanisms through which this flexibility was achieved: central planning and decentralization. "The plan" was the means through which the government engaged in broader social engineering and reshaping of general social relations. ${ }^{243}$ The process of central planning involved both defining population needs and developing mechanisms to satisfying them and can be seen as an important characteristic of the Soviet welfare regime.

The second mechanism included the geographical, economic, political and administrative decentralization of powers, including service delivery. This led to creation of power centers with their "own political leadership and representational bodies,"244 or atomization of the party. These local centers "shared power with the center in decision making and implementation, while functioning at the same time as a key level within the state's administrative chain of command." 245 Such decentralization was a result of the sheer size of the party-state, which simply could not control all of its units. This, in turn, "made monitoring difficult, while the fusion of economic and political resources and the absence of competition made rent-seeking behavior quite tempting. The problem, in short, was one of principals controlling a vast array of potentially independent and resource-rich agents."246

\footnotetext{
${ }^{242}$ Bunce (1999b): p.24

${ }^{243}$ See Kligman (1998)

${ }^{244}$ Bunce (1999b): p.46

${ }^{245}$ Ibid.: p.46

${ }^{246}$ Ibid.:p. 24
} 
Solutions to this principal-agent problem ranged from job insecurity, the party's appointment monopoly, planning, ideological incentives and rapid economic growth, to the atomization of the party-state itself. The first set of measures, developing a cadre system of party and state officials, drawn from the regions and locales, created competition and interdependency among the elites at different levels, as they depended on Moscow for their promotion. This, combined with the initial measures of ensuring bureaucratic compliance, such as terror and job insecurity, had allowed the party-state to achieve domination across the country, at least during the early stages of the Soviet reign. In addition, the atomization of the party-state, "when each unit within the system, including individuals and enterprises reproduced the overall structure of the system,"247 provided the party-state with the ability to have control over itself at different geographical and administrative levels.

Such an institutional configuration -- widespread penetration of the party-state, nomenklatura-based appointments and fusion of the economy and the state - allowed the fast adaptation of the system to the changing political and economic priorities of the state, including those in regard to women. Next, we will describe the specific mechanism of decentralization in the Soviet-system, enterprise service delivery and role of trade unions.

\section{Enterprise-based Service Delivery and Role of Trade Unions}

One of the main characteristics of the Soviet state was the tendency to reproduce itself at different geographical and organizational levels. In the area of welfare provision, the

\footnotetext{
${ }^{247}$ Ibid.
} 
federal system was reproduced at the level of enterprises (both administrative and production levels). Each enterprise was considered a micro-welfare state in itself, and had its own system of child care facilities (kindergartens ${ }^{248}$ and nurseries ${ }^{249}$ ), transportation, schools, food provision, pioneer camps and rest houses. Maternity leaves and other benefits were also paid through enterprises. Thus, the Soviet model of the welfare regime was designed in a highly decentralized form, in order to allow enterprises to control welfare provision, including child care facilities, as well as other provisions facilitating women's employment.

Such decentralization of social service delivery resulted from a central planning, which was considered as a more rational form of economic and social regulation. ${ }^{250}$ As part of the planning system, state-owned (i.e.: "all") enterprises were required to submit yearly "social plans" to the Ministry of Labor. This requirement was designed to lessen the variation among enterprises in their benefits available to workers. The plans included the mechanisms used by the enterprises to improve working conditions and employees' "everyday lives." The enterprises had to report on a number of areas, including working conditions for employees, their health and general welfare programs, including provisions for employee meals, transportation, child care, and housing. Enterprises also had to take

\footnotetext{
${ }^{248}$ The kindergartens form the first level in the Soviet educational system and admit children from 3 to 6 years old

${ }^{249}$ Nurseries in the Soviet Union were regarded as school educational establishments and "served as day nurseries for infants from two months and children up age 3" (Dodge 1966:76). Dodge (1966:76) further explains: "Some nurseries operate on a permanent, year-round basis and are housed in substantial buildings, but many more function on seasonal basis and are designed primarily to take care of the young children of farm women during the peak agricultural season. These temporary nurseries often have little or no plant or equipment and are located in the fields where the women work, in order to make it possible for mothers to nurse their babies during the working day."

${ }^{250}$ Derluguyan (2001)
} 
into account employees' social and family conditions and reflect these in their respective welfare programs. $^{251}$

This system of enterprise-level plan-related benefits constituted a large part of the policy regime of the period. In constructing these policies, the state not only attempted to satisfy the population's needs but also interpreted them in order to meet its goals. The framing of the programs and policies depended on the socio-economic situation in the country, and was linked to the larger demands of industrialization and production. For example, full-employment policies positioned work as a basic need and the wage structure made work a practical need for families. ${ }^{252}$ This characteristic of the Soviet welfare state was formed at the early stages of socialism, and is also crucial for understanding the developments of child care policies during the transformation.

This system gave rise to the power of trade unions and their increased control over the administration of social benefits. ${ }^{253}$ Trade unions had become central players in this system, as they were incorporated formally into centralized planning at the national level. ${ }^{254}$ Essentially, during the Soviet period trade unions assumed many state functions.

\footnotetext{
${ }^{251}$ Haney (2002) pp.:30-41

${ }^{252}$ Ibid.: p.39

${ }^{253}$ Mandel (2001):p. 172 also notes that another reason why trade unions were an important instrument in the hands of the party-state is that workers under the Soviet system could mobilize spontaneously and on a large scale with the main reasons for potentially such mobilization being: "the state as unique employer, centralized economic management, the relatively homogeneous character of the working class, its concentration in giant enterprises, and, above all, the regime's fragile legitimacy."

254 In 1917, after the revolution, the trade unions started administering social insurance for unemployment and sickness... In 1933, the USSR people's commissariat of labour was merged with All-Union Central Council of Trade Unions. The merge involved a transfer of all resources of social insurance, sanatoria, pioneer camps, rest homes and others institutions, as well as of labour inspection functions, including issues of health and safety. The unions assumed overall management and control of social insurance funds. The administration of funds was undertaken by the branch, the territorial inter-union trade union bodies, while the assignment of benefits was done through enterprise trade union committees. In 1977, in addition
} 
They were monitoring the application of the Labour Code, negotiated labour standards and "took part in administering social benefits such as sick leave, pregnancy and maternity leave, pensions, health care, vacation subsidies, child care, leisure activities." 255 Yet, David Mandel noted

Soviet trade unions were undemocratic and notoriously subservient to management and political authorities. After Stalin's death, they were cut a somewhat longer leash, but the bias in favour of meeting production targets, hence in favour of management, remained very strong. Basic decisions affecting wages, social benefits, and labour rights were made by central party-state authorities, unions playing at most a consultative role. The national union apparatus had little political clout within the bureaucracy, its meetings followed closely on those of the party Central Committee so that they could take the appropriate decisions. The union bureaucracy was widely known as a 'graveyard' for 'non-perspective' party and state cadres. ${ }^{256}$

This subservience of trade unions to the Soviet state could be due to the widespread penetration of the party-state, where union leaders on most levels were appointed and removed by the party. Furthermore, due to the fact that "management" was not a class of owners, but a "group of administrators organized in a hierarchy of power and privilege, each one under the thumb of his or her superiors," workers saw themselves as lower rungs for those above. ${ }^{257}$ As a result, the role of trade unions was perceived to be more of monitoring and administration of social redistribution.

to labour inspection, trade unions were given the right to control observance of labour legislation. For more information on the history of the Russian trade-unions, see Kozina (2005)

${ }^{255}$ Ibid: p. 172

${ }^{256}$ Ibid.: p. 173

${ }^{257}$ Ibid.: p. 173. Mandel further explained that "While workers were indeed powerless, they did enjoy important social rights, notably job security, a guaranteed job, and a 'social wage' that included free health care and education at all levels, pensions, subsidized housing, communal services, leisure and cultural activities, public transport, basic foodstuffs, etc. In 1984, this was equal to two-thirds of the money wage and gave workers a solid level of economic security. Official propaganda aside, there was a material basis for workers to view this state as a protective father, albeit an authoritarian and corrupt one. The father-state also defended them against a hostile capitalist world." 
In addition, as we will see, the ties between trade unions and managers also conditioned the activities of trade unions in the post-communist period, when they became powerful allies of managers in a number of post-Soviet reforms, including the reform of social service provision at the enterprises, and their privatization. Overall, these institutional arrangements, tied with a strong ideological foundation and widespread penetration of the party-state (in the form of the atomized communist units, government bureaucrats, trade unions and managers) allowed the system to adjust quickly to the needs of the state and respond to changing priorities with regards to women by changing available child care provisions. The next section examines the instruments utilized by the state in stimulating productive and reproductive functions, and analyzes their impact on female labour force participation and childrearing throughout the Soviet period.

\section{Welfare State, Child Care Policies and Female Labour Force Participation in the Soviet Union}

This section explores the development and changes in child care policies and their implications in female employment in four periods: post-revolution (1917 - 1930), early Stalinist period (1930 - 1940); WWII and post-war period (1941 - 1960), late Soviet

period (early 1960s - 1991). It examines institutional and organizational changes in child care policies, as well as the creation of different frames for female employment and the role of women. It will argue that the changes took place in response to the shifting needs of the state during well-defined periods of time. Specific attention will be paid to provision of child care services (including places in both nurseries and kindergartens), and maternity/parental leave, as well as other benefits to mothers and children. Table 2 
highlights the key periods in the needs of the state, and subsequent changes in the instruments and framing/ideas in the area of child care. It also shows the changes in the respective policies throughout the Soviet period, which will be elaborated upon in this section. 
Table 2. Periodic Comparison of the Child Care Policies in the Soviet Union

\begin{tabular}{|c|c|c|c|c|}
\hline & $\begin{array}{l}\text { Post-revolutionary } \\
\text { period (1917-1930) }\end{array}$ & $\begin{array}{c}\text { Early Stalinist period } \\
(1930-1940)\end{array}$ & $\begin{array}{c}\text { WWII and post war period } \\
(1941-1960)\end{array}$ & $\begin{array}{l}\text { Late Soviet period } \\
\text { (1961-1991 [1989]) }\end{array}$ \\
\hline $\begin{array}{l}\text { Socio- } \\
\text { economic } \\
\text { situation }\end{array}$ & $\begin{array}{l}\text { - Need to mobilize the } \\
\text { labour and develop } \\
\text { Soviet citizenship } \\
\text { values }\end{array}$ & $\begin{array}{l}\text { - Drastic drop in fertility rates } \\
\text { - Limited resources to invest } \\
\text { in child care } \\
\text { - Increase in child neglect }\end{array}$ & $\begin{array}{l}\text { - Production for the war needs } \\
\text { - Post-war collapse } \\
\text { - Catastrophic demographic } \\
\text { consequences of the war }\end{array}$ & $\begin{array}{l}\text { Low birth rates } \\
\text { - Family instability and } \\
\text { unsupervised children } \\
\text { - Extensive economic } \\
\text { development }\end{array}$ \\
\hline $\begin{array}{l}\text { Main state } \\
\text { needs }\end{array}$ & - Production & - Reproduction & $\begin{array}{l}\text { - During the war and } \\
\text { immediate post-war periods } \\
\text { - Production } \\
\text { - Late post-war period - } \\
\text { reproduction } \\
\end{array}$ & - Reproduction (production) \\
\hline Ideas & $\begin{array}{l}\text { Women's liberation } \\
\text { from capitalist } \\
\text { oppression through } \\
\text { waged work } \\
\text { - Transforming ideology } \\
\text { of the citizens of the } \\
\text { new communist state } \\
\text { through paid } \\
\text { employment }\end{array}$ & $\begin{array}{l}\text { Importance of nuclear } \\
\text { family for raising children }\end{array}$ & $\begin{array}{l}\text { - A concept of "working } \\
\text { mother"- gender contract of } \\
\text { the state directly with the } \\
\text { mother } \\
\text { - Restoration of the country } \\
\text { from the ruins is a duty of } \\
\text { every Soviet woman } \\
\text { - Creation of happy homes is } \\
\text { the main duty of women }\end{array}$ & - "Rational female employment" \\
\hline $\begin{array}{l}\text { Instruments to } \\
\text { stimulate } \\
\text { production }\end{array}$ & $\begin{array}{l}\text { - Communist ideology } \\
\text { - Abolition of family } \\
\text { wage } \\
\text { - Quotas for industrial } \\
\text { retraining } \\
\text { - Investment in child care }\end{array}$ & $\begin{array}{l}\text { - Abolition of family wage } \\
\text { - Quotas for industrial } \\
\text { retraining }\end{array}$ & $\begin{array}{l}\text { - Labour duty } \\
\text { - Direct support for a working } \\
\text { mother } \\
\text { - Child care }\end{array}$ & $\begin{array}{l}\text { - Labour duty } \\
\text { - Investment in child care }\end{array}$ \\
\hline $\begin{array}{l}\text { Instruments to } \\
\text { stimulate } \\
\text { reproduction }\end{array}$ & $\begin{array}{l}\text { - Paid maternity leaves } \\
\text { (12-16 weeks) } \\
\text { - Unpaid child care leave } \\
\text { (time -off) up to child's } \\
1^{\text {st }} \text { birthday } \\
\text { - Birth grants (average }\end{array}$ & $\begin{array}{l}\text { - Paid maternity leaves } 16 \\
\text { weeks (1936) } \\
\text { - Maternity leave } 9 \text { weeks } \\
\text { (1938) } \\
\text { - Unpaid child care leave up } \\
\text { to child's } 1^{\text {st }} \text { birthday } \\
\end{array}$ & $\begin{array}{l}\text { - Paid maternity leaves } \\
\text { - Unpaid child care leave up } \\
\text { to child's } 1^{\text {st }} \text { birthday } \\
\text { - Access to benefits depends } \\
\text { on the number of children } \\
\text { irrespective of income and }\end{array}$ & $\begin{array}{l}\text { - Lumpsum birth grants for the } \\
\text { first child (in } 1990 \text { equal to three } \\
\text { times the minimum wage) } \\
\text { - Interest-free credits to families } \\
\text { for the birth of the first child } \\
\text { - Maternity and child care leaves }\end{array}$ \\
\hline
\end{tabular}




\begin{tabular}{|c|c|c|c|c|}
\hline & $\begin{array}{l}\text { Post-revolutionary } \\
\text { period (1917-1930) }\end{array}$ & $\begin{array}{l}\text { Early Stalinist period } \\
\quad(1930-1940)\end{array}$ & $\begin{array}{l}\text { WWII and post war period } \\
(1941-1960)\end{array}$ & $\begin{array}{l}\text { Late Soviet period } \\
(1961-1991[1989])\end{array}$ \\
\hline & $\begin{array}{l}\text { monthly salary) } \\
\text { - Universal child benefits } \\
\text { for } 9 \text { month after birth } \\
\text { of a child } \\
\text { - Banning night and } \\
\text { overtime work for } \\
\text { pregnant and nursing } \\
\text { women; } \\
\text { - Banning sending } \\
\text { pregnant women (over } \\
\text { five months) to business } \\
\text { trips without their } \\
\text { consent; } \\
\text { - paid nursing breaks (at } \\
\text { least } 0.5 \text { hour at least } \\
\text { every } 3.5 \text { hours }\end{array}$ & $\begin{array}{l}\text { - Birth grants (average } \\
\text { monthly salary) } \\
\text { - Universal child benefits for } \\
9 \text { month after birth of a child } \\
\text { - Banning night and overtime } \\
\text { work for pregnant and } \\
\text { nursing women; } \\
\text { - Banning sending pregnant } \\
\text { women (over five months) } \\
\text { to business trips without } \\
\text { their consent; } \\
\text { - paid nursing breaks (at least } \\
\text { 0.5 hour at least every } 3.5 \\
\text { hours }\end{array}$ & $\begin{array}{l}\text { marital status } \\
\text { - Monthly child allowances } \\
\text { with the 3rd child } \\
\text { - Child allowances paid as a } \\
\text { recognition of children as } \\
\text { public good (paid } \\
\text { irrespective of mother's } \\
\text { employment status) } \\
\text { - Monthly state grants for } \\
\text { single mothers paid up to the } \\
\text { child's sixteenth birthday (if } \\
\text { the child continued to study, } \\
\text { the grant was paid up to the } \\
\text { eighteenth birthday). } \\
\text { - Taxes on single people and } \\
\text { small families } \\
\text { - Others (recognitions of } \\
\text { motherhood (medal, } \\
\text { additional benefits)) }\end{array}$ & $\begin{array}{l}\text { - Right of mothers to stay at home } \\
\text { until child reaches } 14 \text { years of } \\
\text { age (unpaid leave or part -time } \\
\text { work) } \\
\text { - Family allowance for under- } \\
\text { provisioned families: paid to } \\
\text { families with a per capita income } \\
\text { under the unofficial poverty line. } \\
\text { - Monthly child allowances with } \\
1^{\text {st }} \text { child (since } 1981 \text { ) }\end{array}$ \\
\hline \multicolumn{5}{|c|}{ Child Care Services } \\
\hline Development & Growth & Stagnation & Growth & Growth \\
\hline Rationale & $\begin{array}{l}\text { - Access to employment } \\
\text { - Forming qualities of a } \\
\text { Soviet citizen in } \\
\text { children }\end{array}$ & $\begin{array}{l}\text { - Access to employment } \\
\text { - Forming qualities of a } \\
\text { Soviet citizen in children }\end{array}$ & $\begin{array}{l}\text { Emphasis on proper health } \\
\text { care (including physical } \\
\text { training, nutrition and } \\
\text { hygiene) }\end{array}$ & $\begin{array}{l}\text { Emphasis on pre-school education } \\
\text { (to increase efficiency and } \\
\text { effectiveness of school education, } \\
\text { in order to train better workers) }\end{array}$ \\
\hline Distribution & \multicolumn{4}{|l|}{ Planning system } \\
\hline Administration & \multicolumn{4}{|c|}{$\begin{array}{l}\text { - Enterprise-based } \\
\text { - Jurisdiction of department of Public Education (local offices) for kindergartens }\end{array}$} \\
\hline
\end{tabular}




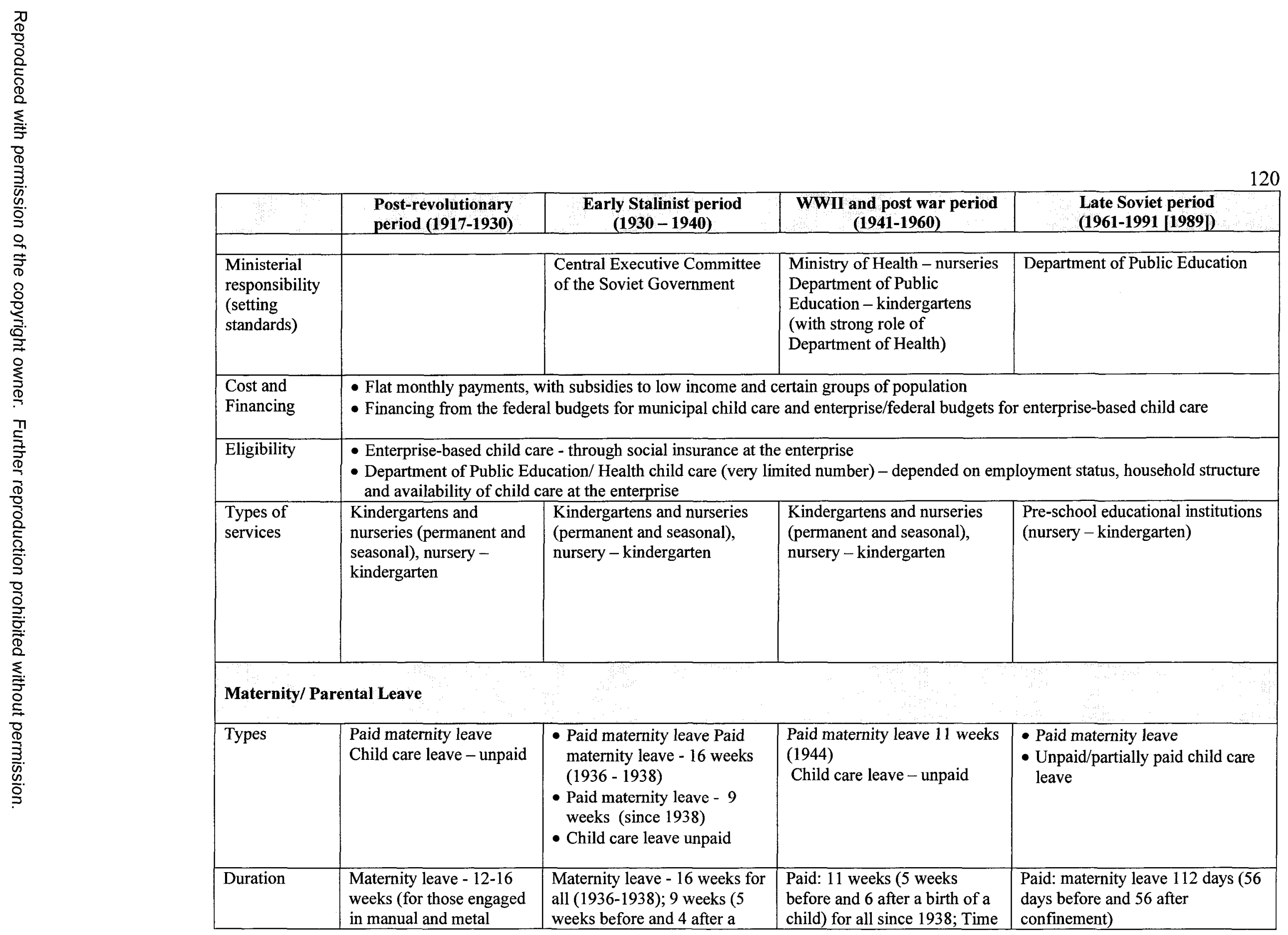




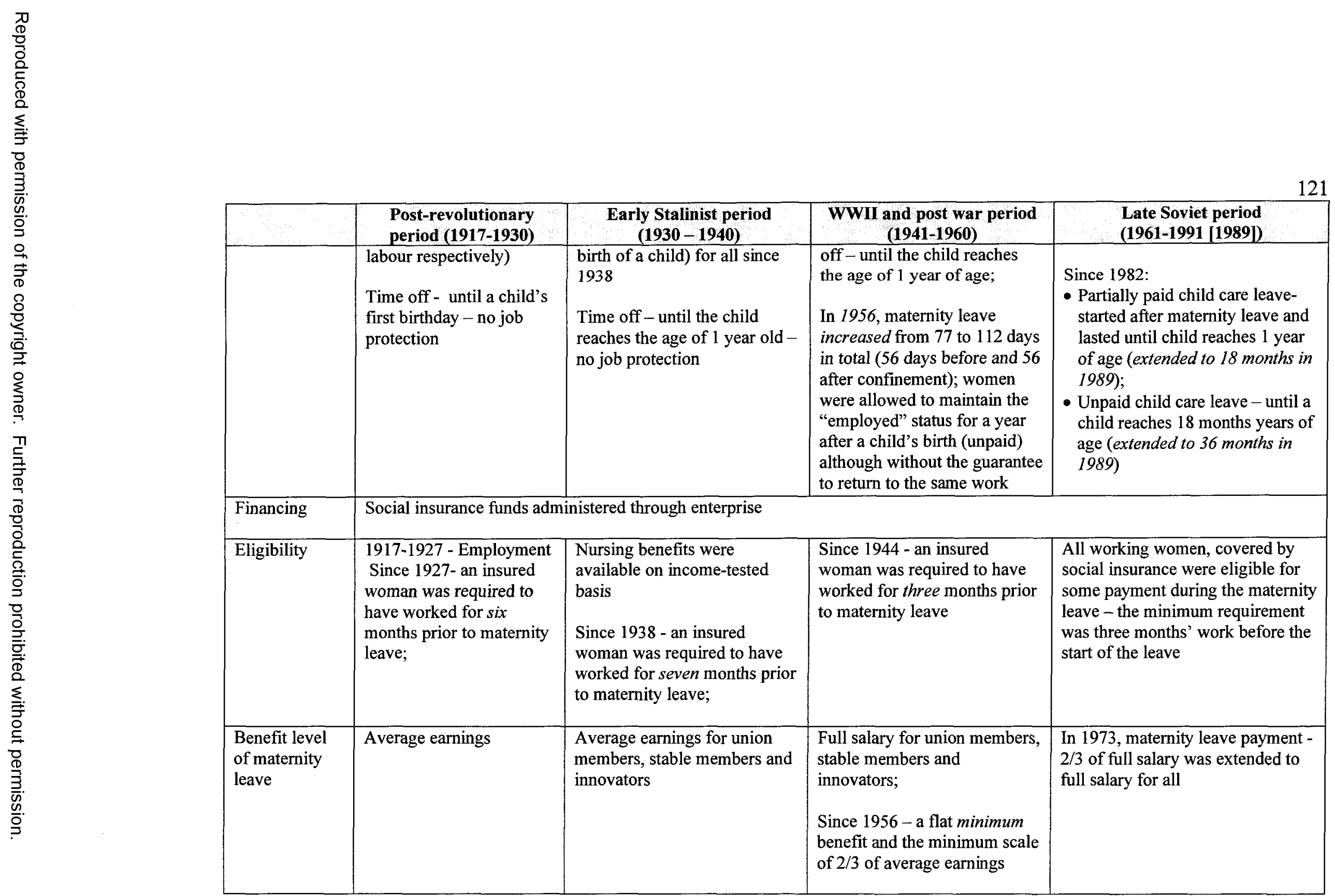

Source: Compiled by the author 


\section{7-1930: Post-Revolutionary Period}

\section{Women's Liberation}

Although the Soviet model of social reproduction and the state's position concerning the character and function of the family have undergone substantial changes along the road "all the way from efforts to hasten the "withering away" of the "bourgeois" family (until the mid-1930's) to attempts to strengthen the family's social role,"258 - the foundations of the family policy were built in the first years of the Soviet state. As noted by Madison, "Soviet policymakers never planned to abolish marriage and the family as such. Rather, their attack immediately after the Revolution was directed against the formal institution of marriage and against the family as an economic and legal unit as these were to be found in the traditional father-dominated Russian family. ${ }^{, 259}$ A Marriage and Divorce Decree which officially released women from patriarchal dependence on the family was adopted in December 1917. The Decree gave women freedom of migration, employment and choice of family. It recognized rights of children and legalized abortions. A complete Code on Marriage, the Family, and Guardianship was ratified by the Central Executive Committee of the Soviet (VTsIK) a year later, in October 1918.

The new Code abolished all patriarchal norms and established new norms based on formal/legal gender equality doctrine. The main ideas were drawn from the Marxist vision of family relations in its emphasis on freedom, independence, and equality of both

\footnotetext{
${ }^{64}$ Madison (1968): p.35

${ }^{65}$ Ibid.
} 
spouses. First, the law set new guidelines for marriage and gave legal status to civil marriage only. Second, the law established divorce at the request of either spouse. ${ }^{260}$ Applicants only had to demonstrate that their marriage had "decayed." Third, the Code set new property relations for couples, by giving women joint ownership rights to property obtained during marriage. These new legal provisions established a new model of a socialist family and served as a foundation for further policymaking in areas of both family and labour force participation. The Code was considered not as communist, but as transitional legislation, since it still preserved marriage registration, alimony, child support, and other provisions related to the continuing if temporary need for the family unit. $^{261}$

\section{Women's Employment and Child Care}

In this early Soviet period, the idea of a welfare state was to support mobilization of labour to achieve ambitious industrial targets and compete with the West. Thus, the "resolution of a woman question" was guided not only by the communist ideology of emancipation but also the necessity of economic modernization. A woman was predominantly seen as a productive unit and an important economic resource, and she had to be included in the production process. In the conditions of the collapse after the World War I, Revolution and Civil War, the Soviet state needed additional labour resources, and female labour force was cheap and disciplined. ${ }^{262}$ This stipulated the need

\footnotetext{
${ }^{260}$ The Marriage Laws of Soviet Russia: The Complete Text of the First Code of the RSFSR (1921) translation by the author

${ }^{261}$ Goldman (1993)

${ }^{262}$ Gurgenko (2002) - translation by the author
} 
of placing the full-employment provisions at the heart of the Soviet societal policy regime. As Ferge put it, "All those who were of working age should avail themselves of the right to work. The state guarantees the opportunity to work and the stability of employment." ${ }^{, 263}$ Lynne Haney continued that "[w]ork was thus constituted as a basic social need; it was both a right and an obligation....able-bodied men not gainfully employed were deemed 'publicly dangerous work avoiders'."264

The state used several instruments to stimulate the entrance of women in the labour force. The first was communist ideology, which became both a rationale and an instrument. As noted by Dodge:

The main weapons in this struggle have been propaganda, agitation, education, and law. The propaganda efforts have been conducted largely by the Women's Affairs Sections of the party, which have stressed the importance of education and have furthered its development. Similar work has been carried on by the Komsomol, the trade unions, and the local governments, all of which concern themselves in varying degrees with women's affairs... The Soviet Union has succeeded in creating an atmosphere in which a woman feels apologetic if she does not work... Bearing children and caring for a home are not considered a sufficient contribution to society. ${ }^{265}$

Indeed, as will be shown throughout the chapter, the Soviet state was successful in using communist ideology in framing of the importance of paid work as a right, need and a duty of every Soviet woman and mobilizing women to enter the labour force.

The second type of instruments included various forms of economic incentives and necessities, including the abolition of the family wage. As a result of the depression in

\footnotetext{
${ }^{263}$ Ferge (2001): pp. 88-89

${ }^{264}$ Haney (2002):p.32

${ }^{265}$ Dodge (1966):p.54
} 
wages, the supply of cheap labor needed for industrialization quickly increased. The industrialization process in turn was accompanied by massive urbanization, which also supplied cheap peasant labour to the cities. ${ }^{266}$ In addition, family laws played a role in inducing women to join the labour force. Thus, the new family laws, in which divorces could be easily obtained (only a post-card notification was needed) had a similar effect on women's need to being employed. As Dodge notes, “[w]hile women may have gained much from the new ease in dissolving an unhappy relationship, many faced the necessity of self-support and, possibly, of furnishing whole or partial support for minor children. Even if a married woman did not need or wish to work, it was good insurance for her to have a working skill in reserve or to acquire one."267

Third, quotas for industrial retraining programs were also used to stimulate women's work. Under the quota's system, women were to constitute 30 to 50 per cent of newly trained workers and apprentices. ${ }^{268}$ As a result of these measures, the Soviet state was able to achieve relatively high female labour force participation in a short period of time (Table 3). By the year 1922, 25 per cent of the labour force was represented by women (1,560 thousand). ${ }^{269}$ By the year 1926 , female labour force participation rate constituted $52 \%$ for women of all ages, while for some categories of women the participation rate went as high as 93 per cent (in case of women 20-24 years old). These

${ }^{266}$ As a result of collectivisation and industrialization, from the early 1920 s onwards the proportion, the USSR experienced steady growth of urban population: from 14 per cent in 1920 to 74 per cent in 1991 (with the most rapid expansion in the 1930s (from 18 per cent in 1926 to 33 per cent in 1941). Source: Afontsev et al. (2005)

${ }^{267}$ Dodge (1966): p.55

${ }^{268}$ Sacks (1976): p.71. Sacks further notes that in the mid 1930s, however, the minimum quotas for females in vocational schools, training classes and certain professions became unnecessary as the demand for female labour was no longer had to be bolstered.

${ }^{269}$ Heitlinger (1979): p. 97 
figures attest to the enormous capacity of the Soviet state to mobilize labour resources in a short period of time.

Table 3. Percentage of the Employed Population, by Sex and Age, in the USSR in 1926 and 1959, and in the RSFRSR in 1959, per cent

\begin{tabular}{|c|c|c|c|c|c|c|c|}
\hline & \multicolumn{3}{|c|}{ Males } & \multicolumn{4}{c|}{ Females } \\
\hline & $1926 \mathbf{b}$ & $\mathbf{1 9 5 9 b}$ & $\mathbf{1 9 5 9 c}$ & $\mathbf{1 9 2 6 b}$ & $\mathbf{1 9 5 9 b}$ & $\mathbf{1 9 5 9 c}$ & $\mathbf{1 9 7 0 b}$ \\
\hline $10-14$ & 58 & - & - & 53 & - & - & $7 \mathrm{~d}$ \\
\hline $15-19$ & 88 & 63 & 64 & 80 & 63 & 62 & $21 \mathrm{e}$ \\
\hline $20-24$ & 98 & 88 & 89 & 93 & 81 & 83 & 88 \\
\hline $25-29$ & 99 & 94 & 94 & 75 & 80 & 81 & 88 \\
\hline $30-34$ & 99 & 95 & 95 & 75 & 78 & 79 & 86 \\
\hline $35-39$ & 99 & 97 & 96 & 77 & 77 & 78 & 86 \\
\hline $40-44$ & 99 & 94 & 94 & 77 & 76 & 76 & 83 \\
\hline $45-49$ & 99 & 92 & 91 & 77 & 75 & 73 & 83 \\
\hline $50-54$ & 98 & 90 & 86 & 72 & 69 & 68 & 75 \\
\hline $55-59$ & 97 & 82 & 78 & 68 & 55 & 47 & 53 \\
\hline $60-64$ & 92 & 79 & 67 & 55 & 48 & 39 & 37 \\
\hline $65-69$ & 84 & 54 & 45 & 47 & 35 & 30 & 37 \\
\hline All ages & 64 & 56 & 56 & 52 & 49 & 43 & n.a. \\
\hline
\end{tabular}
a) n.a.: data not available
b) USSR
c) RSFRS
d) Age group 14-15
e) Age group 16-19

Source: Dodge 1966, pp. 35, 37, 262; Lapidus 1975, p.1982

To facilitate women's employment, the state had to invest in the development of services to reduce domestic responsibilities, including caring for children: "Initially, 
only permanent nurseries were established, and until 1921 all were confined to the Russian republic ... In 1929, at the beginning of the Five-Year Plans, the Russian republic had approximately 75 per cent of the permanent and 70 per cent of all seasonal nurseries, and the latter outnumbered the permanent nurseries almost seven to one."270 Permanent nurseries referred to nurseries which operated on a "permanent, year-round basis and are housed in substantial buildings," while seasonal nurseries functioned on "a seasonal basis and are designed primarily to take care of the young children of farm women during the peak agricultural season."271 The dynamics of growth of nurseries in that period is illustrated in Table 4 and the number of children in nurseries can be seen in Table 5.

Table 4. Number of Permanent and Seasonal Nurseries, 1917-29.

\begin{tabular}{|r|r|r|r|r|}
\hline \multirow{2}{*}{ Year } & \multicolumn{2}{|c|}{ U.S.S.R. } & \multicolumn{2}{|c|}{ R.S.F.S.R. } \\
\cline { 2 - 5 } & \multicolumn{1}{|c|}{ Permanent } & \multicolumn{1}{|c|}{ Seasonal } & \multicolumn{1}{c|}{ Permanent } & Seasonal \\
\hline 1917 & 14 & - & 14 & - \\
\hline 1918 & 78 & - & 78 & - \\
\hline 1919 & 126 & - & 126 & - \\
\hline 1920 & 565 & - & 565 & - \\
\hline 1921 & 769 & 46 & 668 & 125 \\
\hline 1922 & 967 & 248 & 914 & 209 \\
\hline 1923 & 535 & 475 & 447 & 524 \\
\hline 1924 & 615 & 956 & 503 & 1853 \\
\hline 1925 & 708 & 2647 & 536 & 2924 \\
\hline 1926 & 824 & 3985 & 610 & \\
\hline
\end{tabular}

${ }^{270}$ Dodge (1966): p. 76-7;

${ }^{271}$ Ibid: p. 76 


\begin{tabular}{|r|r|r|r|r|}
\hline 1927 & 944 & 5662 & 669 & 4254 \\
\hline 1928 & 1172 & 6947 & 880 & 5099 \\
\hline 1929 & 1367 & 9021 & 1044 & 6380 \\
\hline
\end{tabular}

Source: Dodge, N.T. (1966). Women in the Soviet Economy. Their Role in Economic, Scientific, and Technical Development. Baltimore. The Johns Hopkins Press.

By the late 1920s, however, it became clear that the Soviet state's actual record of resolving the tension between mothers and workers had been a mixed one. The massive entrance of women into the labour force in the late 1920 s led to a drop in the birthrate and decrease of family size. Child care became even more of a pressing necessity and, thanks to the efforts of the state planners and party leaders, expanded rapidly. The number of nurseries (both permanent and seasonal) increased twenty-fold between 1928 and 1934 from 257 to more than five thousand, and kindergartens multiplied by a factor of 12 , going from 2.1 thousand in 1928 to 25.7 thousand in 1935 , serving about 1.2 million children. ${ }^{272}$ Child care facilities were hastily organized in factories, kolkhozes (collective farms), sovkhozes (state agrarian enterprise), cooperatives and homes.

Despite this, the number of child care facilities was far from adequate. By comparing the number of children of nursery age ${ }^{273}$ with the number of places available (Table 5), we can see that less than 5 per cent of the children could be accommodated in permanent nurseries in the urban centres. Seasonal nurseries however, could accommodate additional 28 per cent of the children younger than 3 years of age. ${ }^{274}$

\footnotetext{
${ }^{272}$ Zhenshchina v SSSR (1936): 124, 127 - translation by the author

${ }^{273}$ According to some estimates, in 1939 there were about 15 million of children aged from 0 to 38 months in the country (as quoted in Dodge, 1995)

${ }^{274}$ Dodge (1966): p.77
} 
Table 5. Number of Places and Children in Soviet Nurseries, thousands, 1913-1964

\begin{tabular}{|c|c|c|c|c|c|c|c|}
\hline \multirow{2}{*}{ Year } & \multirow{2}{*}{\multicolumn{2}{|c|}{$\begin{array}{c}\text { Number of } \\
\text { Permanent and } \\
\text { Seasonal Nurseries }\end{array}$}} & \multicolumn{3}{|c|}{$\begin{array}{c}\text { No. of Places in Permanent } \\
\text { Nurseries }\end{array}$} & \multirow{2}{*}{$\begin{array}{c}\text { No. of } \\
\text { Children } \\
\text { in } \\
\text { Seasonal } \\
\text { Nurseries }\end{array}$} & \multirow{2}{*}{$\begin{array}{c}\text { No. of } \\
\text { Children in } \\
\text { Permanent } \\
\text { and } \\
\text { Seasonal } \\
\text { Nurseries } \\
\end{array}$} \\
\hline & & & Total & Urban & Rural & & \\
\hline 1913 & & & 0.6 & 0.6 & n.a. & 10.6 & 11.2 \\
\hline 1917 & 14 & & 2.2 & n.a. & n.a. & n.a. & \\
\hline 1918 & 78 & & n.a. & n.a. & n.a. & n.a. & 25.2 \\
\hline 1928 & 1172 & 6947 & 62.0 & 54.7 & 7.3 & 197.8 & 259.8 \\
\hline 1929 & 1367 & 9021 & 64.6 & 56.0 & 8.6 & 179.8 & 257.0 \\
\hline 1930 & & & 107.4 & 71.6 & 35.8 & 750.0 & 854.4 \\
\hline 1931 & & & 299.9 & 171.5 & 128.4 & $2,271.0$ & $2,571.7$ \\
\hline 1932 & & & 600.9 & 258.4 & 342.5 & $3,920.3$ & $4,868.6$ \\
\hline 1933 & & & n.a. & n.a. & n.a. & n.a. & $4,529.3$ \\
\hline 1936 & & & n.a. & n.a. & n.a. & n.a. & $4,744.6$ \\
\hline 1937 & & & 718.2 & 378.1 & 370.1 & n.a. & n.a. \\
\hline 1940 & & & 824.1 & 523.8 & 300.3 & $4,049.1$ & $4,873.2$ \\
\hline 1950 & & & 735.5 & 470.1 & 265.0 & $1,813.1$ & $2,548.6$ \\
\hline 1955 & & & 851.0 & 567.6 & 283.4 & $2,334.0$ & $3,185.0$ \\
\hline 1956 & & & 904.3 & 604.0 & 300.3 & $2,386.8$ & $3,291.1$ \\
\hline 1957 & & & $1,046.0$ & n.a. & n.a. & $1,750.0$ & $2,896.0$ \\
\hline 1958 & & & $1,135.0$ & n.a. & n.a. & n.a. & n.a. \\
\hline 1959 & & & $1,271.0$ & n.a. & n.a. & $(1,500.0)^{*}$ & $(2,771.0)$ \\
\hline 1960 & & & $1,402.2$ & n.a. & n.a. & n.a. & n.a. \\
\hline 1961 & & & $1,574.2$ & n.a. & n.a. & n.a. & n.a. \\
\hline
\end{tabular}




\begin{tabular}{|c|c|c|c|c|c|c|c|}
\hline Year & \multicolumn{2}{|c|}{$\begin{array}{c}\text { Number of } \\
\text { Permanent and } \\
\text { Seasonal Nurseries }\end{array}$} & \multicolumn{3}{|c|}{ No. of Places in Permanent } & $\begin{array}{c}\text { No. of } \\
\text { Children } \\
\text { in } \\
\text { Neasonal } \\
\text { Nurseries }\end{array}$ & $\begin{array}{c}\text { No. of } \\
\text { Children in } \\
\text { Permanent } \\
\text { and } \\
\text { Seasonal } \\
\text { Nurseries }\end{array}$ \\
\cline { 2 - 8 } & Permanent & Seasonal & Total & Urban & Rural & & \\
\hline 1962 & & & $1,754.0$ & n.a. & n.a. & n.a. & n.a. \\
\hline 1963 & & & $2,050.8$ & n.a. & n.a. & n.a. & n.a. \\
\hline 1964 & & & $2,253.2$ & n.a. & n.a. & n.a. & n.a. \\
\hline
\end{tabular}

Source: Dodge, N.T. (1966). Women in the Soviet Economy. Their Role in Economic, Scientific, and Technical Development. Baltimore. The Johns Hopkins Press.

*Figures in parentheses are estimates.

Public child care was seen as a solution to more than the women's access to labour force. It also had to do with the need to transform the psychology of the citizenry, and its commitment to early childhood education. The early Soviet period was characterized by the search for an educational ideology that would advance the new social order. It became a hot debate issue at conferences, in seminars, and through newsletters. A number of universities across the country, including Moscow State University, established departments of Early Childhood Education. There were also a number of experimental preschools which served as research, demonstration, and teaching centers. Preschool institutions were supposed to foster collectivism and the willingness to put aside one's own interests in favor of socially useful work; it was expected that children thus schooled would be prepared to contribute to society and would accord equal respect to manual and intellectual work. ${ }^{275}$

\footnotetext{
${ }^{275}$ Ispa (1994): p.9
} 


\section{Allowances for Women and Children}

Declining fertility, particularly in the urban centres (Table 6) compelled policymakers to introduce relatively generous maternity allowances. Depending on the type of labour (intellectual or physical) they were engaged in, expectant mothers were granted a total of 12 to 16 paid weeks of maternity leave respectively (60 to 80 paid days), 6-8 weeks before and 6-8 weeks after the birth of a child, irrespective of their length of employment. ${ }^{276}$ Payment of maternity leave allowances was done through social insurance funds in the amount of full wages. ${ }^{277}$ The postnatal leave period was extended to 10 weeks for women who had multiple or abnormal births. Mothers were entitled to unpaid leave up to the child's first birthday, without a break in their employment record and with the guarantee of returning to their original job.

Table 6. Fertility Rate of the USSR, 1926-66

\begin{tabular}{|r|r|r|r|r|r|}
\hline \multicolumn{1}{|c|}{ Year } & $\begin{array}{c}\text { Total } \\
\text { Fertility } \\
\text { Rate }\end{array}$ & Year & $\begin{array}{c}\text { Total } \\
\text { Fertility } \\
\text { Rate }\end{array}$ & Year & $\begin{array}{c}\text { Total } \\
\text { Fertility } \\
\text { Rate }\end{array}$ \\
\hline 1926 & $5,566.0$ & 1940 & $3,752.1$ & 1954 & $2,974.4$ \\
\hline 1927 & $5,418.3$ & 1941 & $3,742.6$ & 1955 & $2,909.1$ \\
\hline 1928 & $5,318.1$ & 1942 & $2,933.1$ & 1956 & $2,859.2$ \\
\hline 1929 & $4,985.8$ & 1943 & $2,366.2$ & 1957 & $2,903.9$ \\
\hline
\end{tabular}

\footnotetext{
${ }^{276}$ For those mothers engaged in non-manual (intellectual) labour, leave lasted up to 12 weeks; for those engaged in physical labour, leave lasted up to 16 weeks. Decree on social security (1918); Labour Code of RSFSR (1922): article 132, 181 - translation by the author

${ }^{277}$ Decree on Social Security (1918); Labour Code (1922); Decree on Social Insurance (1931) - translation by the author
} 


\begin{tabular}{|r|r|r|r|r|r|}
\hline Year & $\begin{array}{c}\text { Total } \\
\text { Fertility } \\
\text { Rate }\end{array}$ & Year & $\begin{array}{c}\text { Total } \\
\text { Fertility } \\
\text { Rate }\end{array}$ & Year & $\begin{array}{c}\text { Total } \\
\text { Fertility } \\
\text { Rate }\end{array}$ \\
\hline 1930 & $4,826.1$ & 1944 & $1,942.0$ & 1958 & $2,899.3$ \\
\hline 1931 & $4,255.0$ & 1945 & $1,762.1$ & 1959 & $2,903.8$ \\
\hline 1932 & $3,573.6$ & 1946 & $2,868.3$ & 1960 & $2,940.0$ \\
\hline 1933 & $3,621.6$ & 1947 & $3,232.9$ & 1961 & $2,879.6$ \\
\hline 1934 & $2,904.9$ & 1948 & $3,079.4$ & 1962 & $2,755.0$ \\
\hline 1935 & $3,263.3$ & 1949 & $3,007.5$ & 1963 & $2,688.1$ \\
\hline 1936 & $3,652.7$ & 1950 & $2,851.1$ & 1964 & $2,564.4$ \\
\hline 1937 & $4,308.6$ & 1951 & $2,914.7$ & 1965 & $2,487.7$ \\
\hline 1938 & $4,351.3$ & 1952 & $2,898.8$ & 1966 & $2,452.4$ \\
\hline 1939 & $3,964.4$ & 1953 & $2,762.9$ & & \\
\hline
\end{tabular}

Source: Sacks (1988) : p. 39

In addition to leave allowance, there was also a birth grant (fixed lump sum) equal to an average monthly wage in the region, which was doubled at the birth of the second and third child. ${ }^{278}$ Mothers also received child allowances for the first 9 months after birth of a child on the universal basis. Other employment benefits in the early Soviet period for mothers, as stipulated in the first Labour Code of the socialist Russia, included banning night and overtime work for pregnant and nursing women (article 131) and sending pregnant women (over five months) to business trips without their consent (article 133); and the introduction of paid nursing breaks (at least 0.5 hour at least every

${ }^{278}$ See Labour Code of RSFSR (1922) - translation by the author 
3.5 hours) (article 134). These employment benefits for women were a part of the decree of the proletariat state, established in 1917 , along with the 8-hour working day.

The early Soviet period is characterized by creating a new area of the state regulation - female employment, due to massive involvement of women in the mass production. In the early post-revolutionary period, the role of the state was predominantly focused on a maximum involvement of women in public production, and was developing in several directions: legislating equality between men and women in the labour market, the use of administrative methods (mostly quota system) in order to achieve equality in the fastest way; direct regulation of female employment through directive planning, mostly by utilizing administrative methods and economic coercion for labour. This required effective child care policies. Therefore, this early Soviet period established foundations for further handling of productive and reproductive behaviour of women through ideological and administrative measures.

\section{0 - 1940: Early Stalinist Period}

During the 1930s, women were caught up in the turmoil of Stalin's era, alongside men. Millions of former peasants were migrating to cities to form a new proletariat class. Shortages of food, housing and other goods led to the cutbacks in programs designed to ease the double burden of women's labour. A new Soviet woman was needed, who would "have equal rights with men in all spheres of economic, state, cultural, social and political 
life"279 but would also have to be a loving wife and mother. This led to the emergence of two ideologies with regard to the status of women in society: "an ideology of equality which existed in laws and statutes, and a patriarchal ideology which operated in real life." ${ }^{280}$ This means that formally, the state provided women with equal rights and freedoms, same educational and professional opportunities. At the same time, even in laws (mainly social policies) women were defined as naturally having a dual role, both productive and reproductive. In the real life, there remained a practical domination of men in most political, socio-economic spheres. Despite joining the labour force, women continued to be treated mainly as important producers of children and housekeepers. This led to what can be called a misbalance of legal situation (de jure) and real life (de facto) and thus a double ideology and double burden of women - at work and at home.

This patriarchal ideology was based on the belief in essential sex differences as a result of the different male and female roles in reproduction (e.g., women's maternal function), held by the Soviet policymakers. We could identify fundamental purposes behind promoting the image of this new Soviet woman. Her unpaid household labour freed resources for industrialization. But more importantly, the Soviet leaders started to see women's position in society being linked to political arrangements and objectives. Women were enjoined to tend to their families, and the party leaders started to teach that the nuclear family was one of the main foundations of the Soviet society. ${ }^{281}$

\footnotetext{
${ }^{279}$ Constitution of the USSR (1938): p.104 - translation by the author

${ }^{280}$ Khotkina (1994): p.87

${ }^{281}$ Clements et al (1991)
} 
During that period, divorce became harder to get and criminal penalties for men who refused to pay alimony or child support introduced. Liberal abortion laws, which were enacted after the Socialist Revolution in order to control birth rates and allow women to stay in the labour force, were abolished in $1936{ }^{282}$ Officials stressed the temporary nature of the earlier legalization and announced that every woman could now realize her right to be a mother. Wendy Goldman observed that "officials lectured women loudly about their selfish failure to appreciate the larger needs of the state."283 Nikolai Krylenko, the people's commissar of justice, admonished, "A basic mistake is made in every case by those women who consider 'freedom of abortion' as one of their civil rights." Another official carefully explained that maternity was not more than a biological function, it was also a matter of state and social importance. ${ }^{284}$ The measures against abortion included negative (imprisonment for a minimum of two years for those performed the operation, high fines for women received abortions) and positive ones (stipends for new mothers, large bonuses for women with many children, and longer maternity leaves for white-collar women). The number of maternity clinics, child care institutions, and milk kitchens was also increased.

Thus, the 1930s marked a drastic re-orientation of the state policy toward family as a main unit of social reproduction (while still supporting female employment). The official ideology of equality and real-life policies were getting further and further apart. A new Constitution was adopted in 1936, officially announcing equality of men and women

\footnotetext{
282 Ibid.

${ }^{283}$ Goldman (1993): p.285

${ }^{284}$ Ibid.
} 
in the USSR. The same year saw the introduction of new measures on "strengthening the family" and increasing fertility rates, which included, among others, increasing benefits for families with many children. In 1941, the Presidium of the Supreme Council of the USSR released the order "Concerning the tax for never-married, lone and childless citizens of the USSR," along with other laws.

At the same time, the state continued to play an active role in providing for its children, which was much greater than in most western countries. The number of child care facilities slowly continued to grow. In 1931, through a Decree on Social Insurance, the state obliged social insurance authorities to "speed up the process of development of preventive, medical and everyday services for the population, including rest houses, sanatoriums, nurseries, kindergartens, pioneer camps, public dining rooms laundries....etc. ${ }^{9285}$ Access to these facilities was tied to labour force participation, which in practice became an obligation. Social insurance funds were formed through the paid contributions of employers as a per cent of the total amount of payroll at the enterprise/organization. ${ }^{286}$ In general, social insurance payments covered pregnancy leave, payments during nursing, and other compensation payments (e.g., declined earnings as a result of time spent in breast feeding).

The same decree reorganized the system of social insurance. Each enterprise had to form a social insurance unit, which would be responsible for everything associated with accruing social insurance funds and paying all allowances and pensions at the given

\footnotetext{
${ }^{285}$ Decree on Social Insurance (1931) - article 12 - translation by the author

${ }^{286}$ Labour Code of RSFSR (1922) - translation by the author
} 
enterprise. In case of savings in the social insurance funds, $50 \%$ of these savings should have been used for building additional objects of social infrastructure (e.g. kindergartens) on top of the budget already allocated for these purposes. Thus, the bigger the enterprise (e.g. metallurgical plants, ports, etc), the more developed its social infrastructure. These enterprise-based social insurance units were supervised by All-USSR industry-specific social insurance funds (metallurgy, engineering, coal-mining, chemical, railway and water transport industries), which had the same rights and budgets as territorial and republican SI funds for earmarked social insurance funds. Territorial/republican and industry-specific SI funds were regulated and supervised by the USSR Central Directorate of Social Insurance.

In practice, this led to the emergence of two types of child care facilities: enterprisebased and local (municipal). Municipal nurseries were a maintained by the Department of Health, and kindergartens by the Department of Education (local offices). Enterprisebased child care facilities were maintained by appropriate ministries, depending on the type of enterprise. The distribution of kindergartens by departmental subordination is shown in Table 7. Eligibility for enterprise-based child care depended on employment at the specified enterprise, while eligibility for local child care was based on several criteria, including the mother's employment status, household structure, the number of children already in child care, and the existence of extended family networks and availability of enterprise child care. In addition, municipalities often exercised a so-called "patronage" over municipal child care by enterprises or organizations (in return for additional child care places as benefits to their workers). These institutional arrangements provided the 
flexibility required to respond to the changing needs of the state, while maintaining a general commitment to female employment. 
Table 7. Distribution of Kindergartens, by Departmental Subordination, 1937-55

\begin{tabular}{|c|c|c|c|c|c|c|c|c|}
\hline \multirow{2}{*}{ Year } & \multicolumn{2}{|c|}{ Total } & \multicolumn{2}{|c|}{$\begin{array}{c}\text { Departments of Public } \\
\text { Education }\end{array}$} & \multicolumn{2}{|c|}{$\begin{array}{c}\text { Other Departments and } \\
\text { Organizations }\end{array}$} & \multicolumn{2}{|c|}{ Collective Farms } \\
\hline & Kindergartens & Enrolment & Kindergartens & Enrolment & Kindergartens & Enrolment & Kindergartens & Enrolment \\
\hline 1937 & 24,535 & $1,045,289$ & 7,220 & 335,541 & 12,570 & 573,762 & 4,745 & 135,986 \\
\hline 1940 & 23,999 & $1,171,507$ & 8,762 & 451,381 & 12,883 & 649,240 & 2,354 & 70,886 \\
\hline 1945 & 28,436 & $1,471,036$ & 9,926 & 531,335 & 17,404 & 910,018 & 1,106 & 29,683 \\
\hline 1946 & 27,662 & $1,283,230$ & 10,165 & 491,598 & 16,680 & 769,791 & 817 & 21,841 \\
\hline 1947 & 27,246 & $1,253,621$ & 10,197 & 486,207 & 16,358 & 749,514 & 691 & 17,900 \\
\hline 1948 & 26,143 & $1,054,657$ & 10,017 & 414,077 & 15,695 & 630,846 & 431 & 9,734 \\
\hline 1949 & 25,499 & $1,088,561$ & 9,787 & 418,920 & 15,240 & 659,790 & 472 & 9,851 \\
\hline 1950 & 25,624 & $1,168,779$ & 9,928 & 445,945 & 15,275 & 711,396 & 421 & 11,438 \\
\hline 1951 & 26,337 & $1,256,948$ & 10,130 & 482,482 & 15,747 & 759,798 & 460 & 14,668 \\
\hline 1952 & 27,140 & $1,352,550$ & 10,300 & 510,232 & 16,337 & 826,844 & 503 & 15,474 \\
\hline 1953 & 28,258 & $1,438,307$ & 10,611 & 535,348 & 17,140 & 887,188 & 507 & 15,771 \\
\hline 1954 & 29,896 & $1,577,398$ & 10,929 & 574,700 & 18,369 & 983,421 & 598 & 19,277 \\
\hline 1955 & 31,596 & $1,730,941$ & 11,244 & 609,216 & 19,510 & $1,091,343$ & 842 & 30,382 \\
\hline
\end{tabular}

Source: Dodge, N.T. (1966). Women in the Soviet Economy. Their Role in Economic, Scientific, and Technical Development. Baltimore. The Johns Hopkins Press. 
Thus, in the pre-WWII period - 1930s, the role of the state was characterized by further strengthening of its administrative levers of influencing labour force participation, centralization of employment policies, use of non-economic methods of coercion to work (criminalization of idleness etc.), combined with the administrative regulation (even criminalization) of reproductive behaviour. ${ }^{287}$ Such a relatively quick reorientation of the family policies toward new goals, and the continued growth of female employment, illustrates the flexibility of the system to adapt to external signals, which later became one of the main impediments to structural transformation, during the transformation period.

\section{WWII and Post-War Period}

WWII reinforced the importance of women's productive functions, as they were encouraged to take the place of men in industry and agriculture. As Dodge notes, "[w]ith the outbreak of the war and the mobilization of a large portion of the able-bodied male population, women were absolutely essential to the war effort." 288 Women's mobilization was supported by the respective changes in legislation, such as suspension of all restrictions on overtime (except for pregnant women from the sixth months of pregnancy) as well as other provisions regarding pregnant women and mothers. After the war, the catastrophic demographic crisis, when "war eliminated about 26 - 27 million people, excluding unborn children, and markedly deformed the demographic composition and

\footnotetext{
${ }^{287}$ Mezentzeva (1993): p.8 - translation by the author

${ }^{288}$ Dodge (1966): p. 67
} 
gender balance in the USSR,"289 had a double effect. On one hand, women were "required" to stay in the labour force, particularly in those positions which could not be reclaimed back by men (although in the case of more prestigious positions, women were asked to step aside, so that men could have a decent employment). The state denounced married women who were not in the labour force as "idle dependents," with a number of social restrictions following from it. On the other hand, the tremendous loss of population intensified the importance of the reproductive function. This instigated a strong state interest to make it possible for women to be simultaneously engaged in productive and reproductive labour. The state found a non-trivial solution: instead of supporting and strengthening a traditional family, it offered material, moral and organizational support to mothers with one restriction - they had to be working mothers. The resulting policies, as described later in this section, simultaneously aimed at stimulating motherhood and employment, with the direct control and paternalist guardianship of the state.

\section{Child Care Policies and Female Employment in the Post-war Period}

The post-war gender contract gave rise to policies promoting female employment, as well as pronatalist policies. The ideological framework which governed these policies in the immediate post-war period was very powerful - it was the patriotic duty of every Soviet woman to participate in the mass production, in order to restore the country from the ruins after WWII, and have more children, in order to restore the workforce and security forces to protect the country from further invasions. Once again, the production function

${ }^{289}$ Afontsev et al. (2005) 
of a woman was seen as important for restoring the country and occupying the industrial positions for which there were not enough men. This was also reflected in the state policies: attention was paid not only to building and improving maternity houses, but also increasing the number of public nurseries and kindergartens. The 1949 Resolution stipulated: "With the purpose of further expansion in the network of child care facilities and maternity houses and improving their operation, the Council of Ministries of the USSR resolves to:

a) increase the number of child care places in existing facilities up to 849 thousand, and the number of children in child care facilities up to 1,270 thousand, distributed to the respective ministries and industries. places.

b) Build additional nurseries with 22,912 places, and kindergartens for 35,815

c) Starting with 1950 , every large residential complex should be build with a kindergarten and a nursery ( $5 \%$ of the total square footage of construction)

d) The construction of every new industrial enterprise with 500 and more of employed women should include a kindergarten ( 15 places per 100 women employed) ....

e) Build new maternity houses in every city for at least 2,000 places"290

Table 8. Preschool Institutions in the Soviet Union, End of the Year, thousands

\begin{tabular}{|c|c|c|c|c|c|c|}
\hline Year & 1940 & 1960 & 1970 & 1975 & 1980 & 1985 \\
\hline $\begin{array}{l}\text { Preschool institutions, } \\
\text { total, including }\end{array}$ & 46,0 & 70,6 & 102,7 & 115,2 & 127,7 & 140,1 \\
\hline - nurseries & 22,0 & 27,0 & 19.6 & 15,8 & 12,1 & 9,6 \\
\hline - kindergartens & 24,0 & 37,4 & 35,4 & 34,1 & 32,0 & 29,4 \\
\hline $\begin{array}{ll}\text { - } & \text { nurseries- } \\
& \text { kindergartens }\end{array}$ & -- & 6,2 & 47,7 & 65,3 & 83,6 & 101,1 \\
\hline $\begin{array}{l}\text { Number of children in } \\
\text { the kindergartens }\end{array}$ & 1953 & 4428 & 9281 & 11523 & 14337 & 16140 \\
\hline - in nurseries & 781 & 1313 & 1181 & 1053 & 873 & 685 \\
\hline - in kindergartens & 1172 & 2756 & 2791 & 2591 & 2387 & I 980 \\
\hline $\begin{array}{l}\text { - in nurseries- } \\
\text { kindergartens }\end{array}$ & - & 359 & 5309 & 7879 & 11077 & 13475 \\
\hline
\end{tabular}

Source: Mashika, (1986): p.248

${ }^{290}$ The Council of Ministries of the USSR Resolution (1949) - translation by the author 
Table 8 shows the dynamic of growth in child care facilities (from 46 thousand in 1940 to more 70 thousand facilities in 1960), and reflects the increasing number of children attending kindergartens and nurseries. Once again, however, the Soviet state had but mixed capacities to achieve its goals and fulfill its plans. The growing participation of women in the labour force required a greater quantity and quality of services, including child care, than the state was able to provide. Even five year plans could not respond to the growing demand in child care to the full degree. Thus, despite the 1944 Decree of the Presidium of the Supreme Council, the number of places in child care centres, "in 1946 was lower than planned by 310 thousand children, in 1947 - by 222 thousand and in 1948 by 187 thousand children."291 The plan concerning the number of places in nurseries was also unfulfilled in 1946 by 137 thousand, in 1947 - by 74 thousand and in 1948 - by 47 thousand (in total 258 in three years).

Furthermore, government funding for building and expanding child care facilities was only used at $86 \%$ during that period (compared to the planned $100 \%$ ), which again points to the limited capacity of the state to fulfill its ambitious plans. According to the Five-Year Plan, in 1947, some additional 31,340 places in nurseries and 44,650 places in kindergartens were expected to be built. In fact, the state was only able to provide additional 4,075 and 6,375 places respectively, which represents a little bit more than $13 \%$ of the planned child care places. A similar situation was observed in 1948 - instead of the planned 28,178 additional nursery spots and 63,485 kindergarten spots, the state was able to add only 6,203 and 9,910 spots respectively. In 1949, more than 18 thousand

\footnotetext{
${ }^{291}$ Ibid. - translation by the author
} 
children lacked a space in child care centres, particularly in large cities. ${ }^{292}$ In $1959,7.4$ million preschool-age children received child care in both permanent and seasonal facilities (about 23 per cent of the 33.4 million child care of the appropriate age). 1966 saw an increase by $177 \%$ per cent.

Parents were required to pay child care fees (for both nursery and kindergartens), which were "determined on the basis of family income, number of children in the family, length of stay, and whether the facility urban or rural."293 Overall, these fees did not exceed $20 \%$ of child care costs and there were a number of categories of people who received a $50 \%$ discount for child care fees. These included widows of military personnel (whose death was service-connected), unmarried mothers with earnings less than 60 roubles, and the mothers of four children. No payment was required for orphaned children, who lived with their guardians (Table 9). ${ }^{294}$

Table 9. Monthly Payments by Parents for Maintaining Children in Kindergartens, 1948-65

\begin{tabular}{|l|r|r|r|}
\hline \multirow{2}{*}{ Parents' Total Monthly Earnings } & \multicolumn{3}{|c|}{ Monthly payments } \\
\cline { 2 - 4 } & \multicolumn{3}{|c|}{ Time of Child's Stay } \\
\cline { 2 - 4 } & $\mathbf{9 - 1 0 h r}$ & $\mathbf{1 2 - 1 4} \mathbf{~ h r}$. & $\mathbf{2 4} \mathbf{~ h r}$. \\
\hline Cities and workers' villages & & & 6.00 \\
\hline Up to 40 & 4.00 & 5.00 & 8.30 \\
\hline $40-60$ & 5.50 & 6.90 & 10.50 \\
\hline $60-80$ & 7.00 & $\mathbf{8 . 8 0}$ & 12.80 \\
\hline $80-120$ & 8.50 & 10.60 & 15.00 \\
\hline Over 120 & 10.00 & 12.55 & \\
\hline Rural Localities & & & 4.50 \\
\hline Up to 40 & 3.00 & 3.80 & 6.80 \\
\hline $40-60$ & 4.50 & 5.60 & 9.00 \\
\hline $60-80$ & 6.0 & 7.50 & \\
\hline
\end{tabular}

\footnotetext{
${ }^{292}$ Ibid. - translation by the author

${ }^{293}$ Madison (1968): p. 152

294 Ibid.: p. 153
} 


\begin{tabular}{|l|r|r|r|}
\hline $80-120$ & 7.50 & 9.40 & 11.30 \\
\hline Over 120 & 9.00 & 11.30 & 13.50 \\
\hline
\end{tabular}

Source: Dodge (1966)

This period was also marked by the wide recognition and acceptance that group care has a strong developmental effect (both physical and psychological). With this in mind, the staff of nurseries included pediatricians, teachers and nursemaids (two per five children). ${ }^{295}$ Madison observed that "close contact with the children's families is maintained by home visits and by inviting parents to the facility, the main object being to teach parents correct methods of upbringing. $" 296$ In 1956, both nursery and kindergarten services began to be provided within the same institution - "nursery-kindergarten" - in order to simplify logistics for mothers of children of different ages and avoid a disruptive environment for child development under seven years of age, which may occur as a result of changing child care providers. There were several types of child care arrangements available to parents through these institutions: "one is for a period of nine hours-equal to the mother's working hours plus time for shopping; one is for a longer period, for children whose mothers live some distance from the facility; and one is an all-day service, for mothers whose jobs require them to travel or to work at night, and who can take the child home only on Sundays and holidays."297

After 1955, however, the dual nature of the Soviet family policy became more pronounced. The family orientation was reflected in the respective social/family policies. For instance, professional social services were nearly absent to spouses as people, while services for parents were abundant. Madison further notes that there was a recognition

\footnotetext{
295 Ibid.: p. 152

${ }^{296}$ Ibid. p. 153

${ }^{297}$ Ibid. p. 152
} 
that "t hough the attainment of communism calls for the eventual transfer of family functions to society, the placement of all children in a state-manipulated upbringing environment is impossible, and considered by many undesirable, in the foreseeable future. The family...will remain influential in personality formation, and it is crucial therefore that it be a good family."298

\section{Allowances for Women and Children}

Other measures which reflected the pro-natalist character of the state policies included state benefits, based on the number of children, irrespective of parental income level and marital status. The 1944 Decree of the Presidium of the Supreme Council ${ }^{299}$ established monthly family allowances for families with many children, from the third child onwards (with the lump sum payment on the birth of every child). This grant was paid from the time of the additional child's second birthday, up to its fifth birthday. It is important to note that the amount of the lumpsum birth grant for the fourth child was equal to an average worker's salary for a month, while the birth grant for the 9th child was four times larger. In addition, the Decree established additional privileges and benefits for lone mothers. For instance, monthly state grants for lone mothers were paid up to the child's sixteenth birthday (and if the child continued to study, the grant was paid up to the eighteenth birthday).

The level of monthly allowances/grants however, was low. For instance, the allowances for the fourth child amounted to four rubles, and allowances for the eleventh

\footnotetext{
${ }^{298}$ Madison (1968): p. 148

${ }^{299}$ Decree of the Presidium of the Supreme Council (1944) - translation by the author
} 
and subsequent children rose up to 15 rubles. According to Madison, “the fourth child's allowances during the entire five years will come to only two months of average wages, and the eleventh child's to about seven months of such wages."300 This means that in families with four children, the yearly payment of family allowances will represent only 4.4 per cent of the average wage. This amount rises substantially for the families with more than four living children.

The amount of child allowances did not change for several decades. According to Madison, some of the reasons for such stability in family allowances were:

Various explanations have been offered for the failure to increase allowance amounts since 1947, to provide allowances for the first two children of married mothers, and to continue payments for eligible children beyond the age of five. One is the previously noted fact that although individual amounts are modest, in the aggregate allowances constitute a large sum (in 1963, mothers received 452.3 million roubles in fourteen republics); another is that mothers receiving allowances are entitled to many privileges that add substantially to their well-beingfor example, they have first priority in placing their children in preschool facilities, and pay nothing or very little for such care; a third is that the overall standard of living has improved. On the other hand, with regard to mothers of illegitimate children, Soviet society is concerned with the loose morals that it is felt unmarried motherhood represents, and many question the desirability of helping the unmarried mother even to the extent that she is being helped now-though they would deny wishing to punish the children for the misdeeds of their parents. ${ }^{301}$

What was important, however, was the intent of the monthly allowances: they were paid not so much to allow women to stay at home (payment of the allowances was universal and regardless of whether a woman was working or not), but as a recognition of children

\footnotetext{
${ }^{300}$ Madison (1968): p. 209

${ }^{301}$ Ibid.: pp.208-209
} 
as a "public good." Through these allowances, the state committed to a child as a citizen, irrespective of parents' social, economic or family status.

In this period, the law banning abortions was also repealed, since it proved to be an ineffective measure to control the demographic situation in the country. In addition, the 1944 Family Code stipulated state support for children up to the age of 12 , by providing options for mothers to rear their children in institutions, either temporarily or permanently. The Code also released fathers from responsibilities toward children born outside of marriage, and offered necessary financial state support to mothers - thus presumably freeing men to sire more children. ${ }^{302}$ In addition, the 1944 Decree established a tax on lone people and people with small families (e.g., a couple without children or only with one child). The tax was paid by both men (from 20 to 50 years old) and women (from 20 to 45 years old), in the amount of $6 \%$ of their total income. By 1957, when the pressure to have babies had abated a little, the tax was abolished for people with one child, as well as for lone women without children.

Encouraging fertility growth also took place through the introduction of the socalled "Medal of Motherhood," to be awarded to women with five to six children and the order of the "Glory of Motherhood" for mothers who raised seven to nine children. Additionally, the women who brought up ten children were awarded the order of the "Mother Heroine" with the title of Heroic Mothers. Maternity leave duration and the level of maternity allowances stayed relatively constant during that period. Such pro-natalist

\footnotetext{
${ }^{302}$ McKinney (2004): p.41.
} 
policies were also consistent with the ideological views that women's main destination was the creation of "happy and pretty homes."

\section{Administrative Arrangements for Child Care Policies during the Post-war Period}

The general administrative arrangements for the provision of social services, including child care, evolved in the 1930's. The main state organs responsible for welfare provision included the Ministries of Welfare, Education, and Health, and the All-Union Central Committee of Trade Unions. The division of responsibilities among these ministries appeared as follows:

If the primary need of a person seeking help is health care, he is referred to the Ministry of Health; if the best way to solve his difficulties is through training and upbringing, he is sent to the Ministry of Education; if he requires custodial care or long-term economic assistance, he turns to the Ministry of Social Welfare; if he is a member of the labor force and his need is for assistance - economic and social—arising out of temporary illness, or for rest and recreation, he applies to the trade union at his employing establishment. However, of the four organs, only the Republic Ministries of Social Welfare devote their entire activity to social services; for the other three, the welfare function is only an auxiliary one. ${ }^{303}$

These ministries were responsible for providing services to children and mothers. The Ministry of Social Welfare, however, struggled to find an appropriate area for welfare activity. In the area of family policies, the ministry was responsible for grants and allowances for unmarried mothers. This ministry had a "weak" status, which was reflected in the fact that it did not have all-Soviet Union representation, operating only at the republican (Russia's) level. Other so-called social ministries, such as Health and

${ }^{303}$ Madison (1968): p.79 
Education, operated at two levels, — the Country-wide (USSR) and the respective republics. ${ }^{304}$ The absence of a national Ministry of Social Welfare points to the fact that welfare function was not considered as important as education, labour or health, thus placing social welfare ministries at a disadvantage and "assigning" it less power than other "more socially important" ministries.

These social ministries also had a fairly decentralized structure. For instance, the (republican) Ministry of Social Welfare had control over the regional and local unit through policy-making and supervisory powers. For instance, in addition to the common monitoring and inspecting function, the ministry had control over regional and local budgets. There was, however, a great degree of decentralization and flexibility in its structure, which significantly increased the role of republic and local authorities (see Appendix 1). ${ }^{305}$

In the late 1960s, the division of responsibilities among the social ministries for the provision of selected services to preschool children and mothers appeared as follows:

\footnotetext{
${ }^{304}$ Ibid.

${ }^{305}$ Ibid.: p.88; The Appendix 1 shows "the lines of authority connecting a republic ministry with the government organs to which it is responsible as well as with those subordinate to it. It will be noted that the Republic Minister of Social Welfare takes his directives from and is accountable to both the Republic's Soviet of Ministers and the Bureau of Pensions, which is an all-Union organ. Social welfare departments below the republic level are similarly related to two governmental bodies: the next higher division in the social welfare system itself and the governmental unit at its level of competence, that is, the regional, district, or city Soviet. This is because welfare activities are financed by funds from the national and republic budgets as well as local budgets.... Institutions are financed out of republic budgets, and public assistance out of district budgets... Day-to-day administration of programs is the responsibility of the district departments of social welfare, and that substantial powers of review and control are exercised by a variety of local groups... These committees prepare the necessary documents and make recommendations concerning eligibility, which are then reviewed by the local welfare department. The next higher links in the chain of command are the district, regional, and republic committees. These are made up of representatives of collective farms, Soviets, departments, Ministries of Social Welfare, and state fiscal units... Regional committees assist with complicated cases, republic committees determine policy." Source: Madison (1968): p.86
} 
- Ministry of Social Welfare. The services related to children and mothers, provided by this ministry, included finding suitable work for mothers, improving their living conditions, placing small children in nurseries and kindergartens and assisting neglected or abused children. As Madison noted, however, "most local offices do not furnish any of these services, claiming that mothers who have social problems can get the necessary help at their places of employment or in their social organizations."306

- Ministry of Health. This organisation was responsible for the provision of medical and socio-legal services in women's and children's clinics and other establishments. Earlier on, the Ministry was also responsible for nurseries, a responsibility which was later transferred to the Ministry of Education.

- Ministry of Education. Since 1961, both nurseries and kindergartens became a responsibility of the Ministry of Education. The ministry was responsible for setting the standards and monitoring of quality childcare (see Appendix 2 for the System of Education in the Soviet Union).

Due to a division of responsibilities for enterprise-based child care among various ministries, it would not be correct to view the state as a unity. Some departments had lesser capacities to implement plans than others. Thus, the Resolution of May $1949,{ }^{307}$ pointed to the "unsatisfactory performance of some of the ministries, in particular the Ministry of Metallurgy, Ministries of Oil, Lumber and Timber industries of USSR, to

\footnotetext{
306 Ibid: p. 149

${ }^{307}$ Government of USSR (1949) - translation by the author
} 
fulfill plans with respect to child care." The noted level of plan fulfillment was from 6 to $25 \%$. Moreover, the responsibility for child care was divided between several ministries: Councils of ministries were responsible for determining the needs for child care and establishing local facilities, the Ministry of Health was in charge of establishing standards and requirements for child care facilities, while industrial ministries were responsible for setting up enterprise-based child care facilities. The Resolution of October 1956 ordered the Ministries of Health and the Councils of Ministries of the Soviet republics to transfer child care facilities to industrial enterprises, as their sole responsibility. ${ }^{308}$

The standards for those facilities, however, were unified and established by the Ministry of Health. For example, the state plan established norms of nutrition in kindergartens and nurseries, necessary equipment, inventory for each of the facilities, and staffing. This reflected the increased focus on raising healthy children, due to the enhanced need for workforce in that period. The need for child care services was framed in terms of ensuring that children receive due health care in child care facilities (which parents could not provide). Child care facilities were to have certified healthcare (including nutrition, physical training) providers and undergo monthly sanitations, inspections and attestations. This division of responsibilities among the social welfare ministries, as well as changes in the responsibility for the centres for child care institutions (from Health to Education) resulted in often disjoint and contradictory policymaking, and affected the process of transformation in the post-Soviet welfare state, as will be shown in chapter 4 .

\footnotetext{
${ }^{308}$ Government of USSR (1956) - translation by the author
} 
Overall, this section illustrated that the postwar period, in Soviet history, was marked by the creation of what was later became known as a "Soviet gender contract," under the conditions of which the state provided support directly to the working mother. This period was characterized by the use of ideological, as well as administrative (including wage structure and pension legislation), and even coercive (including duty to labour) mechanisms of stimulating both production and reproduction on the part of women.

\section{Late Soviet Period}

\section{Maternity Leaves and Allowances for Mothers and Children in the Late Soviet Period}

In the late Soviet period, the state encountered again many of the problems of the $1940 \mathrm{~s}$ (low birth rates) and the 1920 s (family instability and unsupervised children). ${ }^{309}$ In the 1970 s and 1980s, the negative consequences of urbanization and migration became more apparent. The country's fertility rate started to decline (Table 10). Here is how Geiger explained this phenomenon in 1968 :

Behind the over-all trend stand two important factors: first, the huge population losses and the break-up or separation of families suffered during the man killing crises and frenetic mobility of the Soviet era; and second, the countless individual decisions to restrict births made by the husbands and wives of intact families. Circumstance, an involuntary factor, and voluntary birth restriction have worked together, and it is hard to separate the relative influence of each. Clearly, though, the small family of one or two children has become a

\footnotetext{
${ }^{309}$ Harwin (1996): pp.38-40.
} 
strongly entrenched cultural ideal in the Soviet urban environment and is well on its way to acceptance in the villages as well. ${ }^{310}$

This situation clearly required a package of measures making the conditions surrounding motherhood more appealing and easing the reconciliation between family and work responsibilities. The state introduced a concept of "rational female employment," which intended to achieve a balance between economic and demographic societal goals. ${ }^{311}$ Thus if earlier, the family policy was primarily oriented toward providing economic and moral support to families (promoting families with many children through measures introduced in 1936 and 1944, and economic support of low-income families starting in 1974), new measures introduced in 1981-1983 contained a principally new approach to family support. The new measures included lump sum birth grants for the first child (earlier, such grants were paid only after the birth of the third child), partially paid child care leave up to 1 year; and interest-free credits to families who had their first child. Mothers were considered as requiring special treatment, when compared not only to men, but also to childless women.

Table 10. Total Fertility Rates in the Postwar and Late Soviet Periods

\begin{tabular}{|c|c|c|c|}
\hline Years & All & Urban population & Rural population \\
\hline $1958-1959$ & 2.626 & 2.068 & 3.379 \\
\hline $1961-1962$ & 2.417 & 1.935 & 3.195 \\
\hline $1963-1964$ & 2.227 & 1.782 & 3.026 \\
\hline $1965-1966$ & 2.125 & 1.728 & 2.974 \\
\hline $1967-1968$ & 1.998 & 1.677 & 2.746 \\
\hline
\end{tabular}

${ }^{310}$ Geiger (1968): pp.87-88

${ }^{311}$ Mezentzeva (1994) 


\begin{tabular}{|c|c|c|c|}
\hline Years & All & Urban population & Rural population \\
\hline $1969-1970$ & 1.972 & 1.733 & 2.535 \\
\hline $1971-1972$ & 2.053 & 1.825 & 2.656 \\
\hline $1973-1974$ & 2.000 & 1.770 & 2.704 \\
\hline $1975-1976$ & 1.969 & 1.734 & 2.779 \\
\hline $1977-1978$ & 1.938 & 1.717 & 2.734 \\
\hline $1979-1980$ & 1.888 & 1.698 & 2.504 \\
\hline $1981-1982$ & 1.951 & 1.739 & 2.758 \\
\hline $1983-1984$ & 2.083 & 1.850 & 2.988 \\
\hline $1985-1986$ & 2.111 & 1.874 & 3.003 \\
\hline $1986-1987$ & 2.194 & 1.947 & 3.162 \\
\hline 1988 & 2.130 & 1.896 & 3.057 \\
\hline 1989 & 2.007 & 1.826 & 2.630 \\
\hline 1990 & 1.887 & 1.701 & 2.526 \\
\hline
\end{tabular}

Source: Women of Russia. Statistical collection. Goskomstat of Russia. Moscow, 1995

Although the main emphasis during that period was on reproduction, the policies were mostly focused ideologically on "increasing effectiveness and efficiency of social production and reproduction" and were formulated as such. Early childhood development can serve as an illustration of the Soviet approach to "economic efficiency."

Policymakers argued that there was a direct correlation between a number of days a woman spent in the labour force and her child's attendance of child care, thus illustrating high efficiency and effectiveness of child care system. ${ }^{312}$ Another example of quest for high efficiency included the statement from the official document with regard to "need

${ }^{312}$ See Lutzenko (2002); Gurgenko (2002) 
for reduction of the disease rate among children through improved medical care in child care facilities. Improved health of children would reduce losses in female productive labour and thus serve as an important reservoir of increased effectiveness. Therefore, it is important to focus on sanitation activities in child care facilities, and provide moral and material bonuses to care providers for high quality medical care." ${ }^{313}$

This attention to the "effectiveness" of social reproduction could be seen a response to industrialization and extensive economic development. As Gurgenko notes, the nature of this period was a maximum involvement of women as manpower, on one hand, and the state use of the female function of biological reproduction for renewing labour resources, on the other. As such, the woman, as a mother and an employee, became an object of economic and demographic state policies, which evolved into a) the development of "protectionist concept" of female labour, ensuring full employment and b) the social protection of motherhood and childhood. This model of development of the Soviet welfare state, however, had an extensive character, and created serious contradictions in the area of social reproduction. It required universal mobilization of female labour and simultaneously created a demand for the future labour resources in order to maintain high level of economic development. ${ }^{314}$

As part of the late Soviet model of welfare regime, the state continued its attempts to reduce the private costs of raising children, through increased maternity leave provisions. The original Labour Code (1971) established maternity leave allowances at

\footnotetext{
${ }^{313}$ Ibid - translation and modification by the author

314 Ibid.
} 
the level of two thirds of full salary, which was extended in $1973^{315}$ to full salary. A paid child care leave until child reached the age of 1 year and unpaid child care leave until a child reached 18 months of age were introduced in $1982 .{ }^{316}$ Paid child care leave was a new and a different form of caring for a child, as opposed to maternity leave, which had mostly been associated with the biological functions of giving birth. Additionally, women had a right to take unpaid child care leave, for 6 months from the child's first birthday, up to the age of eighteen months. In 1989, paid child care leave was extended to cover children up to the age of eighteen months, followed by unpaid child care leave up to the age of three. ${ }^{317}$ The law provided the right for mothers to stay at home until the child's fourteen years of age, with the right to return to their previous employment. This could be seen as a beginning of radical changed in child care policies associated with the period of transformation. $^{318}$

This period was also characterized by the increase in other benefits, such as the birth grant and the lone mother's benefit (see Table 2). The size of monthly family allowances was not increased, however, except for the attempt to target families with especially low per capita income, by introducing small monthly allowances for every child under the age of eight in such families. ${ }^{319}$ Furthermore, to address family instability, unsupervised children and the like, the leaders attempted to increase parents' sense of personal responsibility. In 1968 , for the first time since 1944 , women started to be able to

\footnotetext{
${ }^{315}$ Supreme Council of USSR (1973)

${ }^{316}$ Supreme Council of USSR (1982)

${ }^{317}$ Council of Ministers USSR (1989)

${ }^{318}$ While technically, the collapse of the Soviet Union took place in 1991, the transformation of economic, political and social systems began in 1985 with Gorbachev reforms.

${ }^{319}$ Lapidus (1978): p.305; Harwin (1996): p.40
} 
file paternity suits. Although the state apparently wanted fathers to assume greater financial responsibility, mothers received the bulk of attention from Soviet analysts, who attributed social problems primarily to women's failure to perform adequately as mothers. To resolve this matter, the state invested much more in the care for children outside home (e.g., kindergartens), than cash payments to mothers directly through child-related allowances. As Table 11 shows, in 1980, the former figure in Russia was 7.3 billion roubles, the latter only $2.6^{320}$

Table 11. State Expenditures, USSR (million roubles)

\begin{tabular}{|c|l|l|l|l|l|}
\hline & 1940 & 1960 & 1970 & 1980 & 1985 \\
\hline $\begin{array}{l}\text { Maternity and child care } \\
\text { allowances up to 1 year old, } \\
\text { allowances for families with } \\
\text { many children, allowances for } \\
\text { lone mothers and allowances for } \\
\text { children from poor families }\end{array}$ & 179 & 1005 & 1301 & 2,624 & 4938 \\
\hline $\begin{array}{c}\text { Per cent of the state budget } \\
\text { revenue* }\end{array}$ & 1.0 & 1.4 & 0.84 & 0.9 & 1.3 \\
\hline $\begin{array}{l}\text { Expenditures on kindergartens, } \\
\text { nurseries, kindergartens- } \\
\text { nurseries and pioneer camps }\end{array}$ & 432 & 1725 & 4298 & 7,261 & 8825 \\
\hline $\begin{array}{c}\text { Per cent of the state budget } \\
\text { revenue* }\end{array}$ & 2.4 & 2.35 & 2.8 & 2.46 & 2.3 \\
\hline
\end{tabular}

Source: Mashika (1989): p.244

*Note: Figures on the state budget revenue available from the Slavic Research Centre "Soviet Economic Statistical Series," Hokkaido University

${ }^{320}$ Central Statistical Service USSR (1985): pp.84-5 as quoted in Mashika (1989): p.244 
Finally, the labour legislation also preserved and even increased protective provisions. ${ }^{321}$ These included:

- Restriction on overtime work and business trips for women with children

- Prohibition of overtime work and business trips for pregnant women and women with children younger than three years old (this norm extended the period of prohibition from 2 to 3 years old).

- Mandatory transfer of pregnant women to an easier job (until such job is found, a woman should be released from work, with preservation of her average salary) and others.

In addition, as a result of the debate around the role of women, in the late 1960s, the Labour Code of the late Soviet era introduced a concept of "part-time work." The article 49 stipulated: "On request of a pregnant woman, a woman with a child younger than 14 years old (or a disabled child) or any other employee caring for a disabled relative, the employer has to provide an opportunity to work part-time [without any limitations]... Part-time work allows for the same duration of the annual leave and maintains all the benefits and privileges." In practice, this meant that women could take an unpaid leave to care for a child up to 14 years old, without any break in the employment record (a way to secure pensions and means for other benefits). At the same time, in the late Soviet period, only $1 \%$ of the employed population utilized this opportunity (mainly women with small children, pensioners or invalids). It can be explained by the general rigidity of

\footnotetext{
${ }^{321}$ Labour Code USSR (1971)
} 
labour market regulations in the Soviet period, low level of wages (forcing women to work), high human capital resources of women, and the general condemnation of "idleness." 322

There is however a caveat to this provision. Given the mandatory obligation for full-time work, the opportunity to work part-time was provided only to mothers with children under 14 (or disabled) who were legally registered at enterprises full-time prior to the request to become part-timers (in the employment and enterprise records, for pension and other purposes, it was still shown as full-time work). Thus if a father or a childless woman/man wanted to work part-time, legally s/he could not (unless there are extraordinary circumstances). As such, this form of a part-time work can be seen as a specific protectionist/pronatalist policy (in contrast to the part-time employment introduced during the transformation period - see chapters 3,5 and 6 ).

These measures appeared to have some positive effects, according to the socialdemographic research conducted by the Central Statistical Unit of the USSR. Thus, in 1983 , up to $92 \%$ of the women who gave birth used child care leave (up to 1 year). A year after the introduction of these measures, the share of women who gave birth to a second child increased by 12 per cent, to a third child - 14 per cent, and to a fourth child -10 per cent. ${ }^{323}$

\footnotetext{
${ }^{322}$ Posadskaya and Zakharova (1990)
}

${ }^{323}$ Mashika (1989): p.76 


\section{Child Care and Women's Employment in the Late Soviet Period}

The provision of public child care continued to steadily grow in the late Soviet period.

This growth is illustrated in Table 12. What is worth noting is that the growth of child care provision took place at a much lower rate in the rural settlements, as compared to urban areas. Osborn notes that all-day or 24-hour care was available for virtually every urban child. The child care fees covered from 10 to about 70 per cent of the total cost for each child. ${ }^{324}$ Subsidies and discounts were available to parents from certain categories of population, including families with many children and lone-parent households.

Table 12. Number of Preschool Institutions, Russia, Late Soviet Period (1980-1990)

\begin{tabular}{|c|c|c|c|}
\hline Categories & 1980 & 1985 & 1990 \\
\hline \multicolumn{4}{|l|}{ Total } \\
\hline Number of preschool institutions, thousand & 74.5 & 87.8 & 87.9 \\
\hline $\begin{array}{l}\text { Number of children in preschool institutions, } \\
\text { thousand }\end{array}$ & 8,149 & 9,180 & 9,009 \\
\hline $\begin{array}{l}\text { Percentage of children in child care ( } 0-6 \text { years of } \\
\text { age) }\end{array}$ & 64.9 & 68.3 & 66.4 \\
\hline $\begin{array}{l}\text { Number of children in child care per } 100 \text { child care } \\
\text { spots }\end{array}$ & 109 & 106 & 108 \\
\hline \multicolumn{4}{|l|}{ Urban settlements } \\
\hline Number of preschool institutions, thousand & 43.2 & 45.9 & 47.3 \\
\hline $\begin{array}{l}\text { Number of children in preschool institutions, } \\
\text { thousand }\end{array}$ & 6,446 & 7,118 & 6,860 \\
\hline $\begin{array}{l}\text { Percentage of children in child care (of all children } \\
\text { of the respective age group) }\end{array}$ & 73.8 & 74.6 & 70.5 \\
\hline Number of children in child care per 100 child care & 113 & 111 & 113 \\
\hline
\end{tabular}

${ }^{324}$ Osborn (1970): p.59 


\begin{tabular}{|c|c|c|c|}
\hline Categories & 1980 & 1985 & 1990 \\
\hline \multicolumn{4}{|l|}{ spots } \\
\hline \multicolumn{4}{|l|}{ Rural settlements } \\
\hline Number of preschool institutions, thousand & 31.3 & 35.9 & 40.6 \\
\hline $\begin{array}{l}\text { Number of children in preschool institutions, } \\
\text { thousand }\end{array}$ & 1,703 & 2,062 & 2,149 \\
\hline $\begin{array}{l}\text { Percentage of children in child care (of all children } \\
\text { of the respective age group) }\end{array}$ & 44.6 & 52.9 & 56.1 \\
\hline $\begin{array}{l}\text { Number of children in child care per } 100 \text { child care } \\
\text { spots }\end{array}$ & 97 & 93 & 94 \\
\hline
\end{tabular}

Source: Women of Russia. Statistical collection. Gokomstat of Russia. Moscow, 1995

The late Soviet period was also characterized by the shifting focus of child care policies. While public child care was still a "hot" button, it was framed in terms of the need of bringing up healthy and well-educated citizens of the Soviet state. This trend began in the 1960s with the adoption of the 1959 resolution, which, unified kindergartens and nurseries into a single "preschool educational institution" and transferred it to the Ministry of Education at the respective levels (except industrial enterprise preschool institutions). ${ }^{325}$ The 1973 federal law "On Education" established that preschool education is part of the unified educational system of the country. ${ }^{326}$ Article 25 of the law stipulated that the main objectives of preschool educational institutions, working in close collaboration with the family, are the comprehensive and harmonic development of children, protecting and strengthening their health, ensuring physical and esthetical development... preparation for school education. As Heitlinger noted,

${ }^{325}$ Central Committee CPSU, Council of Ministers of USSR (1959)

${ }^{326}$ USSR Federal Law. (1973) [Zakon SSSR ob Utvergdenii Osnov Zakonodatel'stva Souza SSR i Souznih Respublik o Narodnom Obrazovanii]; For other legislative acts with regard to the role of women in the Soviet period, see Appendix 3. 
The kindergarten and the nursery are thought of as collectives, and the children are taught to consider themselves as part of the collective... Following the guidelines of Makarenko, a prominent Soviet educationalist in the $1930 \mathrm{~s}$, the young child is taught a few basic rules of socialist morality: politeness, unselfishness, tidiness, working for others and self-discipline. ${ }^{327}$

The development of child care in the period of so-called stagnation ${ }^{328}$ was supported by both social motives and economic necessities. The same resolution also obliged the party and youth communist organization to "increase awareness among parents about the importance of education and health of children of the preschool age," increase quality, quantity and dissemination coverage of materials on these issues. The government, women's, and other journals, devoted to health, education, employment and family issues (е.g., “Дошкольное воспитание” [Preschool Education], “Семья и школа” [Family and School], “Крестьянка" [Peasant-woman], "Работница" [Worker-woman] and “Здоровье" [Health]) were ordered by the state to systematically publish materials related to preschool health and education. Moreover, the state-controlled media attempted to create a new "norm": the three-child family. Nevertheless, women were in most cases portrayed as workers, but with equal orientation towards both family and work.

Kharchev and Golod's 1968 "Professional Female Employment and Family" study examined the status of women in the society and aimed to assess the relationship between female employment and family life. ${ }^{329}$ Some of the results of the study are shown below. For example, Table 13 shows the distribution of married women by age,

\footnotetext{
${ }^{327}$ Heitlinger (1979): p.116.

${ }^{328}$ The stagnation period refers to a period of economic and social crisis in the history of the Soviet Union that tentatively began in the mid-1970s. The period was characterized by the sharp reduction of economic growth and was marked by the increasing role of foreign trade and imports.

${ }^{329}$ Kharchev \& Golod (1968)
} 
working status and number of children. This Table illustrates that the level of use of maternity/child care leaves in that period is very high.

Table 13. Distribution of Married Women by Age, Working Status and Number of Children, 1968

\begin{tabular}{|c|c|c|c|c|c|c|c|c|}
\hline \multirow[t]{2}{*}{ Age } & \multirow[t]{2}{*}{$\begin{array}{l}\text { Number of } \\
\text { women, } \mathrm{n}\end{array}$} & \multicolumn{6}{|c|}{ Including with children (\%) } & \multirow{2}{*}{$\begin{array}{c}\text { Average } \\
\text { number } \\
\text { of } \\
\text { children } \\
\text { at home }\end{array}$} \\
\hline & & 0 & 1 & 2 & 3 & 4 & $\begin{array}{l}5- \\
\text { more }\end{array}$ & \\
\hline \multicolumn{9}{|l|}{ Working } \\
\hline $\begin{array}{l}\text { younger } \\
\text { than } 20\end{array}$ & 18 & 50 & 33.3 & 16.7 & & & & 0.67 \\
\hline $20-29$ & 1121 & 18.8 & 46.7 & 27.5 & 5.9 & 0.7 & 0.4 & 1.24 \\
\hline $30-39$ & 1921 & 8.9 & 20.1 & 37.2 & 21.5 & 8.0 & 4.3. & 2.12 \\
\hline $40-49$ & 1107 & 7.6 & 16.5 & 35.1 . & 25.0 & 9.3 & 6.5 & 2.31 \\
\hline $\begin{array}{l}50 \text { and } \\
\text { older }\end{array}$ & 681 & 13.6 & 18.7 & 33.2 & 18.1 & 9.2 & 7.2 & 2.12 \\
\hline Total & 4848 & 11.7 & 25.3 & 33.8 & 18.2 & 6.7 & 4.3 & 1.96 \\
\hline \multicolumn{9}{|c|}{ Not working* } \\
\hline $\begin{array}{l}\text { younger } \\
\text { than } 20\end{array}$ & 13 & & 53.8 & 38.5 & 7.7 & & & 1.69 \\
\hline $20-29$ & 721 & 2.8 & 36.2 & 39.3 & 15.8 & 4.4 & 1.5 & 1.88 \\
\hline $30-39$ & 1212 & 4.6 & 16.3 & 37.3 & 23.4 & 11.7 & 6.7 & 2.41 \\
\hline $40-49$ & 552 & 9.4 & 17.2 & 26.5 & 20.7 & 12.3 & 13.9 & 2.51 \\
\hline Total & 3102 & 6.9 & 22.8 & 33.7 & 19.6 & 9.6 & 7.4 & 2.24 \\
\hline
\end{tabular}

${ }^{*}$ women on maternity/child care leave

Source: 1. Prokopets (1968), "A Married Woman in Family and at Work" in Fertility and the Affecting Factors. p.63. 
Thus child care remained women's responsibility throughout the Soviet period. Children were looked after either by their mothers and grandmothers or by female teachers, nurseries, doctors, up-bringers in the kindergartens and nurseries. This reflected the prevalent ideology in the society that child care was a woman's business (irrespective of her labour force status). As Mandel observed in 1975, this was what the majority of women in the Soviet Union wanted:

The right to enter any profession, yes. The right to have the number of children you personally wish, yes. The right to make decisions jointly with your husband, or not to have a husband, or to get rid of him, yes. Most divorces are now initiated by women in the USSR. But if you have a child, or more than one, rearing is yours, the woman's task. So the relationship is 'equal' in your eyes if the husband does everything but participate in child-rearing and say, major cooking. ${ }^{330}$

The perception that care was a woman's task was also reflected in the "ideal preferences" for child care. Many women believed that it would be better for a child to be cared for at home. ${ }^{331}$ Public provision of child care services, however, was the most common and "acceptable" way to combine both employment and motherhood, thus pointing to the professional care ideal. As seen in the Leningrad sample, out of 308 families with children, children from 259 families attended public child care institutions (nurseries and kindergartens). In total, according to this study, $83.7 \%$ of all children attended child care.

In order fully to assess public child care, it is important to pay attention to the quality of care, framed in terms of better education (Table 14). Despite the relatively small ratio of the second factor - recognition of priority of public education over private - there was a steady tendency for growth in understanding of importance of child care in

\footnotetext{
${ }^{330}$ Mandel (1975): pp. 227-8

${ }^{331}$ This finding was derived on the basis of informal conversations with older women in Russia.
} 
public education. This motive lay in a direct relationship with the level of education of a woman: $35.3 \%$ of women with college education reported this motive, while only $18.9 \%$ of women with high school did the same. According to these women, this motive did not reject the importance and necessity of family education, but indicated growing recognition of the importance of professional public education for child development. This was also corroborated during informal conversations with women in Russia:

Yes, my daughter attended public child care. That way I knew that she would get the preschool education she needed and would be ready to go to school. Schools relied on kindergartens to teach children how to read, do basic math and acquire other essential knowledge and skills... Those children who did not go to kindergartens often found themselves far behind other children... In addition, my daughter was exposed to other children and adults, learned socialization skills, learned how to share with others and respect... I believe that this helped her to be prepared for future life in society... (Natalia, 48 years old)

This shows that while it was acknowledged that care is a woman's task, there was a recognition of importance of professional care provided by educators and teachers. Importance of preparation for the future life and learning of basic socialization skills was also noted.

Table 14. Motives for Child Care Attendance, 1968

\begin{tabular}{|l|l|l|}
\hline Motives & Absolute & $\%$ \\
\hline $\begin{array}{l}\text { No one else to look after a } \\
\text { child }\end{array}$ & 410 & 74.0 \\
\hline Public education is better & 108 & 19.5 \\
\hline Better financially & 36 & 6.5 \\
\hline
\end{tabular}

Source: Kharchev and Golod (1968) 
In general, by the end of the Soviet period, the steady growth in child care, as well as availability of a package of measures allowing to combine employment and motherhood, allowed female employment (according to the 1979 Census) to reach its maximum: about $92 \%$ of able-bodied women worked or studied, with $84 \%$ out them working. The proportion of women in the labour force of the USSR was relatively stable - about $51 \%$. Only $8 \%$ of the able-bodied women of working age did not work. As a rule, this category included women on maternity or child-care leave (thus still officially being a part of the labour force). Moreover, at the end of the Soviet period, the educational level of women was even higher than that of men. At the same time, this period formed a highly segregated labour market, characterized by a number of highly feminized areas and industries. It is also characterized by a shift, from the focus on equality in the labour market, to the provision of measures of social protection.

Consequently, the beginning of the 1980 s was marked by the practical exhaustion of the late Soviet welfare regime. Female employment was at a nearly maximum level, and the continuous decline in birth rates came to be considered a serious socio-economic problem. The inability of the state to relieve the double burden of Soviet women implied their reduced efficiency in the labour market, limited career growth and labour market segregation (concentration of women in less paid and "supporting" positions, which led to the feminization of certain industries). Some analysts pointed out that such a welfare state model already became inadequate to meeting the demands of post-industrial society in the1970s and 1980s. ${ }^{332}$ The strategy of increasing economic effectiveness in the area of

${ }^{332}$ Gurgenko (2002) 
social reproduction had not been realized, partly due to the inability of the state to reduce women's responsibilities in the domestic sphere. The greater task of intensive development of the economy was also not realized. The Soviet version of Fordism ${ }^{333}$ proved to be unable to ensure intensive modes of economic development, due to a number of factors, including absence of any incentives for labour discipline - from market and credit systems, to the threat of unemployment. This is why the extensive economic development, occurring due to inertia, assumed a full-scaled use of female labour.

\section{Discussion and Conclusions}

This chapter illustrated that, at different historical points throughout the Soviet period, the state policies were guided by different economic and societal demographic goals: in the early years it was female emancipation through the inclusion in the workforce, later it was the promotion of traditional families to increase fertility; from the $1970 \mathrm{~s}-$ it was maximum involvement of women in the labour market and an increase in fertility. As highlighted throughout the chapter, the two underlying assumptions remained constant: women as workers and children as public goods. When concentrating on the next stage, policy makers did not abandon their commitment to maintain a high level of women's employment, or invest resources in raising healthy and educated citizens (builders of the future communism). These two assumptions served as policy continuity, while accompanied by respective changes in emphasis or framing, depending on the socioeconomic environment and needs of the state.

\footnotetext{
${ }^{333}$ Fordism can be defined as the system of mass production and consumption, which prevailed in western developed countries during the 1940s-1960s.
} 
What was also evident was that the emphasis on public child care provision (through kindergartens and nurseries) had been strong throughout the Soviet history (Table 2). As indicated, the importance of child care services was framed differently, depending on specific state needs (allowing access to female employment at the earlier stage of female mobilization; providing necessary healthcare services [and ideological atmosphere] for children, in order to raise healthy citizens during the times of war and disease; and providing necessary preschool education in order to increase the efficiency of school education, and thus quality of the future workers, during the times of the extensive economic development of the late Soviet period).

As highlighted throughout the chapter, the responsiveness of the system to external signals, and its ability to effectively reframe the role of women and child care, was achieved through the party-state monopoly and its widespread penetration. This interconnectedness and interdependence between the state, the party and the economy provided the state with far reaching abilities to influence women's responses. What was also important was that, over time, this institutional system seemed to have led to a different set of consequences, where the flexible nature of the socialist institutional framework "functioned to deregulate the party's monopoly and to undermine economic growth. ${ }^{, 334}$ Combined with the political and economic monopoly of the party and presence of the regions' own economic and political institutions, including their own Communist parties, such decentralization resulted in practical sharing of all decisionmaking powers and creation of "an elaborate array of regionally based and regionally

\footnotetext{
${ }^{334}$ Bunce (1999b): p.26
} 
controlled social and cultural institutions. ${ }^{335}$ The redistribution of political and economic resources from the centre to the regions provided a regional and local locus for development. ${ }^{336}$ The policy of "stability of cadres," introduced by Brezhnev in the late Soviet period, further undermined the ability of the party-state to maintain control over the country. ${ }^{337}$

This process was accompanied by the increasing power of elites, due to a gradually reduced capacity of "the upper reaches of the party to control what happened elsewhere within the apparatus." ${ }^{338}$ Such "elite sensitivity" and decentralization of power had an important impact on the process of transformation of the post Soviet welfare state, generating powerful vested interests and blurring the boundary between the state and society. This conditioned which elements were to be transformed and which were to stay.

Although it is not a direct focus of this thesis, it is possible to classify the Soviet system in Esping-Andersen's terms as a large-scale decommodification through subsidies (particularly for food and housing), limited stratification and high degree of defamilialization. Moreover, welfare provision through enterprises created close relationships and interdependencies between labour markets, industrial relations and social policies. This indicates that the Soviet welfare regime contained elements of both

\footnotetext{
${ }^{335}$ Ibid.: p.46

${ }^{336}$ Ibid.: p.47; Derlugian (2001)

${ }^{337}$ Bunce (1999b) notes that "Brezhnev consolidated his power in effect by giving it away - to everyone through depolitization and reduced control of the center over the economy, to the public through the social compact, and to elites through security of tenure. For the [regional] party elites, this meant a decline in mobility opportunities and in access to economic resources (Bahry, 1987). This also allowed the republics to build their region-based institutional infrastructure, which was only facilitated by the institutional density at the regional level and by the fusion of politics and economics." Holmes (1997):p. 105 noted that "many cadres felt so secure in their jobs that they were prepared to block their superiors' policies if it suited them."

${ }^{338}$ Ibid.
} 
social-democratic and conservative regimes, according to Esping-Andersen and Mahon's terms (Table 15), while also containing its unique features. ${ }^{339}$ This is particularly interesting, as the Soviet welfare state was seen by many western and Soviet scholars as antisystemic, in a sense that it was supposed to be a different structure of welfare provisions than that of the West's since it was in a different economic, political and ideological environment (non-market and non-capital society).

Table 15. Comparison of the Soviet Welfare Model and Social-Democratic, Conservative/Neofamilialist, and Liberal/Third Way Models of Welfare State

\begin{tabular}{|l|l|l|l|}
\hline \multicolumn{1}{|c|}{ Soviet } & \multicolumn{1}{c|}{$\begin{array}{c}\text { Social- } \\
\text { democratic }\end{array}$} & $\begin{array}{c}\text { Conservative/ } \\
\text { Neofamilialist }\end{array}$ & $\begin{array}{c}\text { Liberal Third } \\
\text { way }\end{array}$ \\
\hline Public provision & + & -- & -- \\
\hline Universal & + & -- & -- \\
\hline Economic planning & -- & -- & -- \\
\hline Enterprise-based & -- & $+--{ }^{340}$ & -- \\
\hline $\begin{array}{l}\text { Low incentives for in- } \\
\text { home caregiving }\end{array}$ & + & -- & + \\
\hline Communist ideology-based & -- & -- & -- \\
\hline
\end{tabular}

Source: developed by the author

\footnotetext{
${ }^{339}$ See Esping-Andersen (1990); Mahon (2002)

${ }^{340}$ Enterprise-based provision is seen as an element of a conservative model of welfare regimes, it is recognized that in the conservative model benefits are mostly tied to male employment (mediated through the father, i.e., paternalist system), while in the Soviet system benefits are mediated through the mother (i.e., maternalist system)
} 
The main elements of the social-democratic regimes, with respect to child care, included universal state provision of public child care services, while conservative elements include the provision of these services via enterprises, or only through employment. In order to understand how universal provision could be tied to employment (which seems a bit contradictory), it is necessary to understand the Soviet system of welfare provision and, most importantly, its two main elements: state ownership of enterprises and mandatory employment. In the Soviet era, all enterprises were owned by the state, and the provision of welfare services and payments through enterprises was seen as another level of the state distributional system. Mandatory employment, in turn, could explain how welfare provision based on employment can become universal. What the Soviet state did not develop, as opposed to the social-democratic model, is the mechanisms for involving men in caring/domestic responsibilities. The absence of this element became crucial during the 1990s, and partly determined the direction of transformation of the welfare state in Russia.

Thus the Soviet welfare system, in many aspects, resembles Fraser's Universal Breadwinner model. ${ }^{341}$ The crucial elements of this model include:

- enabling women to support themselves and their families through their own wage-earning, so that the breadwinning role is universalized;

${ }^{341}$ Fraser (1997) 
- $\quad$ creating a set of employment-enabling services, such as day care and elder care, aimed at freeing women from unpaid responsibilities, so they could take full-time employment on terms comparable to men;

- $\quad$ linking most of the benefits to employment; and

- $\quad$ shifting the bulk of care from the family to the state. ${ }^{342}$

The comparison of this model with the Soviet welfare state is documented in Table 16. As apparent from the Table, the Soviet model deviates in a number of ways from this ideal model, including the state's inability to completely shift the bulk of care from family to the state, which resulted in a double burden for Soviet women - having to work full-time and assuming household responsibilities while not working. At the same, it provided a solid foundation for the comparison with the model emerging in the postSoviet period. The most important indicator in this model is that the bulk of care is provided by the state, and policies are designed to support women's full-time employment.

Table 16. Comparison of Nancy Fraser's Universal Breadwinner Model and Soviet Model of Welfare State

\begin{tabular}{|l|l|}
\hline Universal Breadwinner Model $^{\mathbf{3 4 3}}$ & Soviet model \\
\hline Female wage-earning & ++ \\
\hline Employment-enabling services & ++ \\
\hline Linking most of the benefits to employment & ++ \\
\hline Shifting the bulk of care from the family to the state & + \\
\hline
\end{tabular}

${ }^{342}$ Ibid.: p.:52

${ }^{343}$ Ibid. 


\begin{tabular}{|l|l|}
\hline Access to social insurance & + \\
\hline Low labour market segregation & -- \\
\hline
\end{tabular}

++ Model is strong in achieving the objective

+ Model is relatively strong in achieving the objective

-- Model is weak in achieving the objective

In Nancy Fraser's analysis, the achievement of full gender equity, under the

Universal breadwinner model, would depend on whether men can be induced to do their fair share of household work. If no mechanism exists to ensure that men fully participate in sharing domestic obligations, women's chances for equal leisure time would be very low, and women would end up having to work a "double shift." This model devalued unpaid work as petty and valorized the paid work. Since, traditionally, the paid work is seen as men's sphere, the model simply tries to help women fit in.

The Soviet model produced similar consequences. Despite all the achievements of the Soviet state with regard to mobilization women, the welfare state lacked a mechanism of inducing shared responsibility for domestic work between both man and woman, due to its initial focus on socialization of domestic sphere. As a result, the 'woman question' failed to address the 'gender question,' such as gendered division of labour at home, thus achieving only partial emancipation / liberation of women. As noted by Alsop with regard to Eastern Germany, but can be applied to the Soviet case as both welfare states were guided by similar socialist ideological frameworks and principles with regard to role of women,

It was a one-sided approach to gender equality... Paradoxically, the legislation that sought to liberate women actually perpetuated their inequality. Women were generally the sole targets of family and 
domestic legislation, thereby cementing women's links to housework and childcare. The measures introduced by the state aimed to ease the reconciliation of work and motherhood rather than work and parenthood, thereby maintaining and reinforcing the sexual division of labour. If there was a 'Mummy policy,' there was no accompanying 'Daddy policy.' 344

In addition, the Soviet ideology and respective policies did not deal with the full complexity of gender inequalities, including the multidimensional character of women's oppression, such as the sexual division of labour, domestic violence and rape. Instead, the state equated women's employment with equality, which was seen as "as something that can be given to women without affecting the position of men."345 Crucially,

the high level of female employment had not been achieved as the result of a long political struggle on the part of women but instead at the will of a political dictatorship. If the regime were to fail women's hold on employment may also falter. The high levels of female (and male) employment were the direct result of the state socialist political and economic system. Women's place within the labour market was awarded to them by a particular political system within a particular economic order. $^{346}$

In conclusion, we can say that these rights to employment and education were "granted" in return to political loyalty and active support for a new state. ${ }^{347}$ Thus, "providing women with the political, economic and social rights was not an end but a means of the new state... This is why the woman question and appropriate gender policy was determined not so much by the official ideology and necessity of labour mobilization but by the principles of distribution of power within the Soviet system and hidden

\footnotetext{
${ }^{344}$ Alsop (2000)

${ }^{345}$ Scott as cited in Einhorn (1993): p.32.

346 Alsop (2000)

${ }^{347}$ Gurgenko (2002): p.81 - translation by the author
} 
mechanisms of its functioning." 348 What was also unique to the Soviet model was the biologization of gender roles, and first of all, that of the motherhood, despite the official ideology of equality. For example, a Soviet pro-natalist "educator," Mashika, insists on a special societal role of motherhood: "Female labour around caring and upbringing of children is characterized by being more important than male labour. This is due to the fact that this is female destiny to give birth, breastfeed and bring up a child. She has special motherly feelings." 349 That explains why the state abstained from supporting "shared" domestic and parental responsibilities between spouses, despite official egalitarianism. "Equality," as such, was reduced to the expansion of restrictions on female labour in hazardous conditions, and the expansion of benefits and privileges related to motherhood.

This chapter has shown that the historical development of the welfare state in general, and child care policies in particular, is more complex than some other studies have tended to suggest. The periodic examination of ideas, policy instruments and policy frames governing child care policies, has aimed to illustrate the balancing by the Soviet state of the productive and reproductive functions of women, depending on socioeconomic needs, through various policy frames. A detailed account of developments around child care services, along with maternity/parental leave provision and children allowances in the Soviet period, helps us understand the nature of the changes/continuity brought about by the post-Soviet transformation. The main policy/ideological continuities were the commitment to full female employment and perception of children as public goods. Thus this historical analysis aimed to advance a nuanced account of family/child

\footnotetext{
${ }^{348}$ Ibid.: p.81-82 - translation by the author

${ }^{349}$ Mashika (1986) - translation by the author
} 
care policies in different periods of the Soviet history and increase our understanding of the challenges and opportunities faced by the countries undergoing the transformation of their political, economic and ideological regime. 


\section{Chapter 3. Child Care Policies: "A Paradigmatic Case" of a Paradigm Shift in Post-Soviet Russia}

\section{Introduction}

This chapter shows that post-Soviet child care policies reflect a paradigm shift in the ideas and policy discourse governing the development of the post-Soviet welfare state. The chapter will argue that the state's inability to sustain full employment during the transformation period, and the dramatic decline in the birth rate, made the idea of "bringing women back home" popular among Russian policymakers, and society in general. ${ }^{350}$ It was envisioned that easing women out of the workforce would prevent social disintegration and growing unemployment. This led to the increasing advocacy of family values, and changes in the ideological discourse surrounding female employment. 351 This change in the discourse with regard to women contributed to the transformation of social reproduction and change of relationships between its main institutions - state, family and market - which led to the emergence of a mixed welfare model in Russia.

This chapter consists of three main sections. The first section describes the macroeconomic, societal and ideational conditions in Russia, in order to situate the postSoviet welfare state. The next section focuses on the nature of the changes in child care / family policies in Russia. It shows how the framing of care has changed, and how this was reflected in child care policies. Finally, the last segment will analyze the new welfare

\footnotetext{
${ }^{350}$ Klimenkova (1994); Tchekorina (2002) - translation by the author

351 Khotkina (1994)
} 
model, and argue that it represents a blend of neofamilialist, Soviet and neoliberal elements of welfare regimes.

This chapter advances two interrelated sub-hypotheses:

- The transformation period was marked by a policy paradigm shift in social care, moving it from the public to the private domain;

- As a result of the paradigm shift, child care policies reflect a set of changes and continuities, and contributed to the emergence of the mixed welfare model, which combined neofamilialist (conservative) elements blended with neoliberal ideas and Soviet legacies. ${ }^{352}$

These hypotheses advance the main thesis by increasing our understanding of both the nature of the paradigm shift and the emerging model of the welfare state. The chapter demonstrates that the uniqueness of the shift was in that it did not simply follow the neoliberal trajectory of development, as pressured for (by international organizations

\footnotetext{
352 The methodology employed in this section combines quantitative and qualitative approaches. Quantitative methods included data analysis for the institutional analysis of childcare provision in Russia in the post-Soviet period using the Russian Longitudinal Monitoring Survey. The qualitative methods, among others, included official document review at both federal and local levels. The documents reviewed included federal laws in the area of child care policies, resolutions of the government of the Russian Federation, including Ministry of Education, Ministry of Labour and Social Development, and Ministry of Health. At the local level, the documents reviewed included statutes of local authorities, local educational bodies, and various analytical materials. In addition, the Chapter also relied on a review of relevant literature in the area and key information interviews at the local and federal levels. At the local level, semistructured interviews were conducted with city officials (in Novorossiysk) and region officials (in Sakha Yakutia), as well as managers and representatives of trade-unions (who traditionally were responsible for provision of social services at the enterprises). These interviews were supplemented by informal conversations and discussions, aimed at discovering what people thought of the current situation around child care policies. Finally, the Russian press (at the federal and local levels) was instrumental in understanding how various factors contributed to paradigm shift in social care and ultimately reflected the paradigm shift.
} 
and a range of internal interests) at the beginning of the transformation. Neither had it moved towards a deepening of the egalitarian elements, which could have been expected by historical institutionalists and "hard" path dependency advocates. Rather, as we will see, the shift took a "third" road, which combined both neoliberal ideas and historical legacies, by moving to a conservative adjustment of women in the labour force, i.e. towards neofamilialism.

\section{Post -Soviet Welfare Regime: Background}

\section{Economic Restructuring, Welfare State and Legacy of "Flexible" Institutions}

The 1980 s were characterized by a stagnant economy and close-to-zero social mobility, accompanied by "ensuing disillusionment, pervasive hypocrisy and individualistic opportunism." 353 This had an "immensely damaging effect on the Soviet citizenry: although largely unseen and unmeasurable by common social indicators, the decline in work ethic and civic morality of the Brezhnev era was to become a major structural antecedent of the post-communist morass. ${ }^{354}$ Furthermore, due to the institutional structure of the Soviet system, which could be characterized as monopoly (of the party-state over the economy and politics) and deregulation of politics (through decentralization of authorities and thus local empowerment), the capacity of the Soviet

\footnotetext{
${ }^{353}$ Derluguian (2001): p. 16

${ }^{354}$ Ibid.: p. 16
} 
regime to extract compliance declined over time. ${ }^{355}$ This was a result of the reduced ability of the state to oversee the activities of enterprise directors (who acted as state agents, given the state ownership of enterprises), the increased number of transactions to be monitored (prices, quotas), weakening of the watchdog organizations (such as State Security Committee (KGB) and Communist Party), as well as absence of economic incentives. ${ }^{356}$ Consequently, " $[\mathrm{t}]$ hese regimes had fewer and fewer mechanisms, aside from socioeconomic transfers, for either forcing or encouraging the compliance of ministries, enterprises, local party secretaries, and even publics." ${ }^{357}$ This, in turn, created "a vicious circle: less legitimacy, less institutional capacity to govern, fewer resources." 358

In 1985, in order to "cure" the situation, Gorbachev introduced a set of reforms aimed at deregulating the Soviet institutions in the economy and, later, in the polity (liberalization of the media, open political debate, high turnover of party and state officials) and society. He envisioned developing an efficient economy within a "socialist" system, but "overestimated his own power and underestimated how far redistribution had already gone as a result of the very institutions of Soviet socialism.",359 The results, as we know, have been mixed. The transformation process required not only the introduction of markets (commodity, financial and labour ones) in Russia, but also

\footnotetext{
355 Bunce (1999b)

${ }^{356}$ McFoul (1999)

${ }^{357}$ Bunce (1999b): p.56

${ }^{358}$ Derluguian (2001):p. 19

${ }^{359}$ Bunce (1999b)
} 
structural changes in the political and social systems. Gorbachev's centrist political orientation was not seen as strong enough to carry out more profound liberal reforms.

The Party's declining capacity to control its lower levels, and its inability to keep its promises of ever-expanding resources to the elites and public, resulted in growing . discontent among elites at different levels of the party system across the country, which became one of the most prominent reasons for the collapse of the Soviet Union ${ }^{360}$ :

The Soviet Union was not brought down from without - the West stood watching in amazement. Nor was it undermined either from above or below. Rather it imploded from the middle, fragmenting along the institutional lines of different bureaucratic turfs. The collapse occurred when mid-ranking bosses felt threatened by Gorbachev's flakiness as head of the system, and pressured by newly assertive subordinates beneath them. ${ }^{361}$

The bringing down of the regime was led by the former leaders of the Young Communist League, joined by the governors of national republics and Russian provinces, senior bureaucrats of economic ministries and other middle-level managers. ${ }^{362}$ After the collapse of the Soviet Union, the power struggle over policy and resources between the elites at different levels (most of which were formed in the Soviet period, as part of the so-called nomenklatura system) continued and had unusually powerful consequences throughout the period of transformation. These trends will be detailed in chapter 4 . For the purposes of this chapter, it is worth mentioning that one of the examples of the importance of old Soviet ties and legacies includes the relationship between the centre and the regions. When competing for presidency, in 1990, Yeltsin promised Russian

\footnotetext{
360 Ibid.

${ }^{361}$ Derluguian (2001): p.21

${ }^{362}$ Ibid.
} 
regions as much sovereignty "as they could digest." 363 This, combined with the legacy of flexible institutions (decentralization of authority) of the past, resulted in constant "battles" between the federal government and the regions over the division of powers, including financial jurisdiction. Popov and Dutkiewicz note that "many of [the regions] directly blackmailed the federal government, threatening to withhold money from the federal treasury."364

Gorbachev's successors, who were much more reform-oriented, saw that in order to move from the planning-based system to the market economy, Russia had to meet two fundamental and interdependent goals - macroeconomic stabilization and economic restructuring. The former entailed implementing a careful calibration of fiscal and monetary policies, and the latter required establishing commercial, legal, and institutional entities-(banks, private property, and commercial legal codes) that permit the economy to operate efficiently. ${ }^{365}$ The "need" to achieve those goals, combined with the negative attitude towards the old system, resulted in a blind stimulation of markets through the diminishment of planning and decentralized democratic regulation, with reduced control from the centre. ${ }^{366}$ What these policies failed to take into account was the need for an infrastructure, including economic and legal institutions, for the effective functioning of the markets and a well-being of all spheres of society, polity, and economy; these goals were initially absent in a society faced with the remnants of the state planning system.

\footnotetext{
${ }^{363}$ Dutkiewicz and Popov (2006): p.6

${ }^{364}$ Ibid:p.6

${ }^{365}$ Buckley (1992): pp. 4-5; See for details US County studies (2003-2005)

${ }^{366}$ Shkaratan et al (2003):p.111
} 
Figure 2. GDP Change in Selected European Transition Countries, $1989=100 \%$

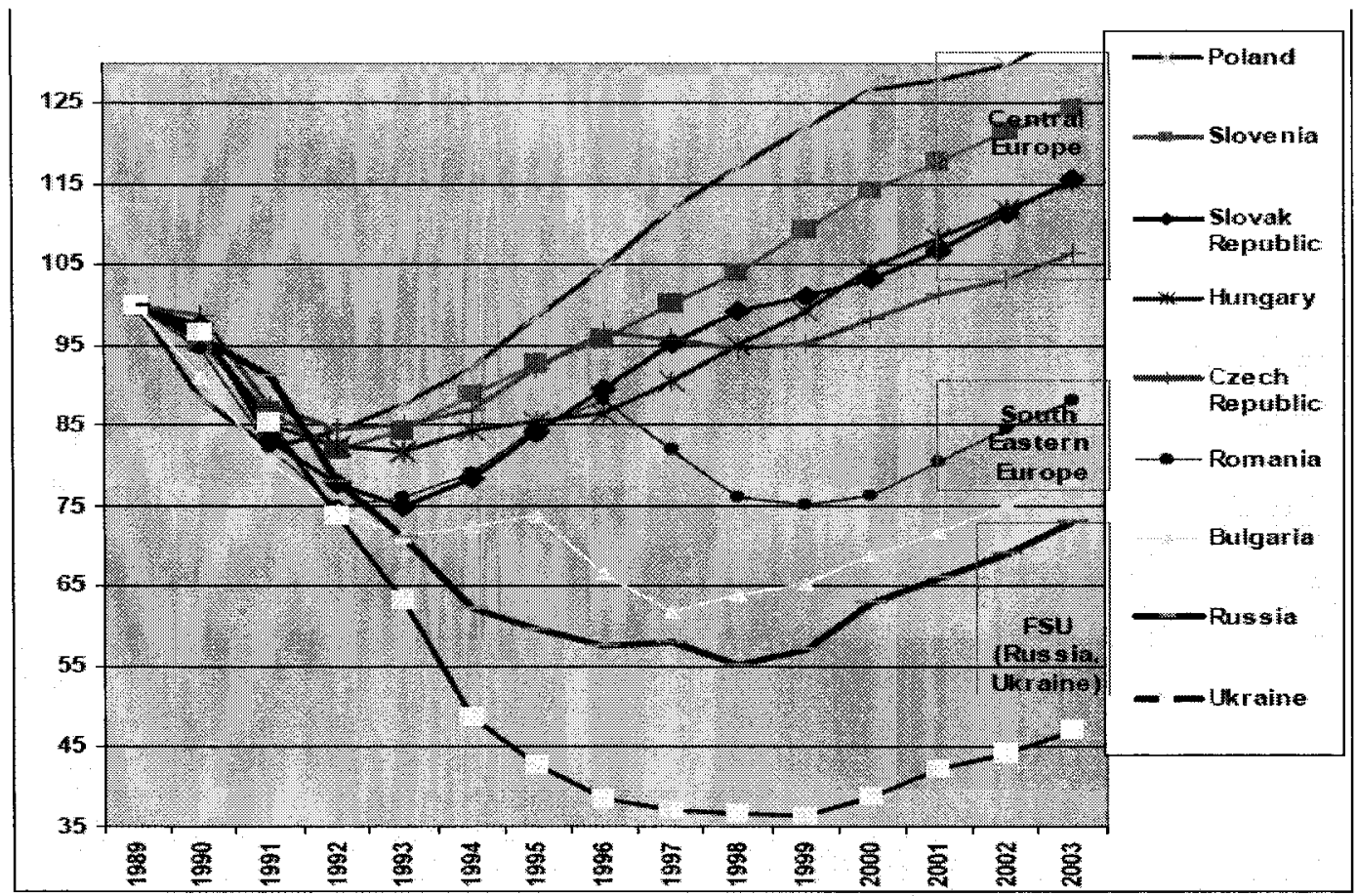

Source: Popov (2005): p. 4

This led to gaps between the imagined process of transition and the reality of the process of transformation, as well as gaps between legislation and reality, as the existing institutions of the command economy partially collapsed and an alternative was in the making. ${ }^{367}$ Thus, during the $1990 \mathrm{~s}$, the Russian production dropped by more than $50 \%$. Popov and Dutkiewicz argue that

the scale of the decline in production in Central European countries is roughly comparable to the losses of the Great Depression of the 30 's - an approximate $30 \%$ drop in 1929-32... The drop in output in the countries of the former USSR is described in economics textbooks as the biggest manmade economic crisis in the history of mankind, that is, a crisis produced by the efforts of the policy makers. ${ }^{368}$

\footnotetext{
${ }^{367}$ Nosyk (2004).

${ }^{368}$ Dutkiewicz and Popov (2006): p.3; See for details: Popov (2000): pp. 1-57.
} 
The collapse of output during the transformation required careful restructuring of most former Soviet industries, including heavy industries, financial systems and distribution mechanisms (in the absence of plans).

The privatization of state assets was conducted with hopes of recovery from the recession. At the same time, the Russian privatization program has been highly controversial, not only due to the blatant corruption found in some cases, but the privatization scheme itself. The Russian scheme provided massive advantages to enterprise managers and other employees in acquiring shares in the firms in which they worked. This scheme was mainly adopted as a result of the strong resistance to other privatization schemes proposed by so-called "socialist conservatives," who represented mainly enterprise managers. Managers of the former Soviet enterprises represent nearly the most powerful group of interests inherited from the Soviet period and, as will be shown in chapter 4 , resisted many changes proposed by the new reforms:

No Soviet institutional arrangement was more consequential to diluting, challenging, and transforming neoliberal ideas about social policy than the Soviet enterprise... Long before Anatoly Chubais or Yegor Gaidar had ever begun to pen their proposals for privatization, Soviet enterprise directors had seized de facto many of the rights associated with ownership (McFoul 1995). When the Chubais/Gaidar privatization program threatened to "take back" these property rights from the factory directors, the directors mobilized to protect their ownership claims. $^{369}$

This led to a further empowerment of enterprise managers and bureaucratic units, who already enjoyed significant powers as a result of Brezhnev's "stability of cadres" policy

\footnotetext{
${ }^{369}$ McFoul (1999): p.213
} 
in the late Soviet period. It produced the fusion of the local bureaucratic and enterprise manager networks, and creation of local power centres.

The feeling of "ownership" was a characteristic not only of enterprise managers, but also of employees. For example, while employees could sell their enterprise shares quickly, the rate of sale of shares to the general public outside of their enterprise was minimal. John Earle mentions several reasons for this reluctance to sell shares, including "employees' desire to retain control of their companies and their lives (an aspect often ignored), the tradition of solidarity among Russian workers, the central place occupied by the enterprise and the employment relationship in society, and the fact that little would be gained from selling, considering the poor functioning of Russia's capital markets." 370 Thus, the continued ownership of the companies by the employees and managers of the former state enterprises, and their resistance to significant changes in the ownership structures, brought about other implications, such as the resistance to re-shape the enterprises' social infrastructure, even in the conditions of pressing market necessities. As will be shown in chapter 4 , these trends have significantly contributed to the emerging shape of the Russian welfare mix during the transformation period.

The transformation not only brought market liberalization, but also the virtual collapse of various functions of the state. Again, the spending on "ordinary government" (excluding spending on defence, investment and subsidies, and debt servicing) decreased three-fold and more in real terms, ${ }^{371}$ so that purely government functions - from

\footnotetext{
${ }^{370}$ Earle (1999)

${ }^{371}$ Dutkiewicz and Popov (2006)
} 
collecting custom duties to law enforcement - were, to all intents and purposes, transferred to the private sector or were de facto "privatized." ${ }^{, 72}$ The next section will show how these trends were reflected in social policies.

\section{Social Policies and Unsustainability of Enterprise-based Micro- Welfare States}

Traditionally, in both Soviet and post-Soviet periods, social policies were considered to be part of the economic strategy of the country. This was also reflected in the transformation discourse, when the reforms mostly focused on the economic side, while the development of a social sphere was not even mentioned among the goals of the reforms. This discourse was mainly influenced by the International Monetary Fund and World Bank, which recommended concentrating all initial reform efforts on getting the economic side "right."

Table 17. The Program of Economic Reformation Offered by IMF and World Bank

\begin{tabular}{|l|c|c|c|c|c|c|c|c|c|c|}
\hline \multirow{2}{*}{ Systemic Transformations } & \multicolumn{9}{|c|}{ Years } \\
\cline { 2 - 11 } & $\mathbf{1}$ & $\mathbf{2}$ & $\mathbf{3}$ & $\mathbf{4}$ & $\mathbf{5}$ & $\mathbf{6}$ & $\mathbf{7}$ & $\mathbf{8}$ & $\mathbf{9}$ & $\mathbf{1 0}$ \\
\hline Microstabilisation & $*$ & & $*$ & $*$ & $*$ & $*$ & $*$ & $*$ & $*$ & $*$ \\
\hline Liberalization of Prices & $* *$ & $* *$ & $*$ & $*$ & $*$ & $*$ & $*$ & $*$ & $*$ & $*$ \\
\hline Liberalization of Trade & $* *$ & $*$ & $*$ & $*$ & $*$ & $*$ & - & - & - & - \\
\hline Liberalization of Distribution & - & $* *$ & $* *$ & $* *$ & $*$ & $*$ & $*$ & - & - & - \\
\hline Liberalization of Labour Market & $*$ & $*$ & $* *$ & $* *$ & $* *$ & $* *$ & - & - & - & - \\
\hline $\begin{array}{l}\text { Liberalization of Independence of } \\
\text { Banking System }\end{array}$ & $*$ & $*$ & $*$ & $*$ & $* *$ & $* *$ & - & - & - & - \\
\hline $\begin{array}{l}\text { Liberalization of the Other Financial } \\
\text { Markets }\end{array}$ & $*$ & $*$ & $*$ & $* *$ & $* *$ & $* *$ & $*$ & $* *$ & $*$ & $* *$ \\
\hline $\begin{array}{l}\text { Partial Privatization and } \\
\text { Development of Private Sector }\end{array}$ & $* *$ & $* *$ & $* *$ & $* *$ & - & - & - & - & - & - \\
\hline
\end{tabular}

${ }^{372}$ Dutkiewicz et al (2000) 


\begin{tabular}{|l|c|c|c|c|c|c|c|c|c|c|}
\hline \multirow{2}{*}{ Systemic Transformations } & \multicolumn{9}{|c|}{ Years } \\
\cline { 2 - 11 } & $\mathbf{1}$ & $\mathbf{2}$ & $\mathbf{3}$ & $\mathbf{4}$ & $\mathbf{5}$ & $\mathbf{6}$ & $\mathbf{7}$ & $\mathbf{8}$ & $\mathbf{9}$ & $\mathbf{1 0}$ \\
\hline $\begin{array}{l}\text { Revision of Rules for Foreign } \\
\text { Investments }\end{array}$ & $* *$ & $* *$ & - & - & - & - & - & - & - & - \\
\hline Total Privatization & - & $* *$ & $* *$ & $* *$ & - & - & - & - & - & - \\
\hline Structural Changes and Privatization & $*$ & $*$ & $* *$ & $* *$ & $* *$ & $* *$ & $*$ & $* *$ & $*$ & $* *$ \\
\hline $\begin{array}{l}\text { Changing of State Status in } \\
\text { Legislation Sphere }\end{array}$ & $* *$ & $* *$ & $* *$ & $* *$ & $* *$ & $* *$ & $*$ & $*$ & $*$ & - \\
\hline $\begin{array}{l}\text { Institutional Reform of the State } \\
\text { Social Protection of Unemployment }\end{array}$ & $* *$ & $* *$ & $* *$ & $* *$ & $* *$ & $* *$ & $*$ & $* *$ & $*$ & $* *$ \\
\hline Other Reforms of Social Sphere & - & - & - & $* *$ & $* *$ & $* *$ & $*$ & $*$ & - & - \\
\hline
\end{tabular}

Stage of intensive implementation

** Preparation Stage

- $\quad$ Pre-Reform, After-Reform Stage

Source: Gleb \& Greich (1995): p. 24

Table 17 shows the stages of reform recommended by the international financial organizations. These recommendations will be discussed in greater detail in chapter 4 . It is important to note that these recommendations implied that the social policy should be guided by almost one single factor - the need to prevent acute social crises. ${ }^{373}$ The state made several attempts to increase the generosity of financial aid and increase the proportion of social expenditures in the GDP, but high inflation rates ${ }^{374}$ and the increasing number of people who required assistance made these increases negligible in terms of generosity of aid. Table 18 shows the increasing rates of expenditure on health and education. When the ratio of social expenditures in a continuously declining GDP reached about $50 \%$ in 1995 , the policymakers were "compelled" to search for ways of reducing social expenditures and increasing effectiveness of social assistance. These included attempts to implement an income-tested approach to social assistance, and

\footnotetext{
${ }^{373}$ Shkaratan et al. (2003)

${ }^{374}$ Inflation rates in Russia in 1992 constituted $2,520 \%$; in $1994-224 \%$.
} 
transfer of responsibility for the social sphere from the federal centre to the regions and municipalities.

Table 18. Public Expenditures on Health and Education in Russia, 1991-2000

\begin{tabular}{|c|c|c|c|c|c|c|c|c|c|c|}
\hline & 1991 & 1992 & 1993 & 1994 & 1995 & 1996 & 1997 & 1998 & 1999 & 2000 \\
\hline \multicolumn{11}{|l|}{ Health } \\
\hline \multicolumn{11}{|l|}{ In \% of GDP } \\
\hline Total & 2.9 & 2.6 & 3.7 & 4.0 & 3.5 & 3.6 & 4.2 & 3.6 & 3.3 & \\
\hline $\begin{array}{l}\text { Consolidated } \\
\text { budget }^{375}\end{array}$ & 2.9 & 2.6 & 3.3 & 3.1 & 2.6 & 2.6 & 3.1 & 2.5 & 2.3 & \\
\hline $\begin{array}{l}\text { Compulsory } \\
\text { Medical } \\
\text { Insurance Fund }\end{array}$ & $\mathrm{n} / \mathrm{a}$ & $\mathrm{n} / \mathrm{a}$ & 0.4 & 0.9 & 0.9 & 1.0 & 1.1 & 1.1 & 1.0 & \\
\hline \multicolumn{11}{|l|}{$\begin{array}{l}\text { Index } 1991= \\
100\end{array}$} \\
\hline $\begin{array}{l}\text { Total (real } \\
\text { roubles } \\
\text { expenditure) }\end{array}$ & 100 & 76.6 & 99.4 & 93.3 & 73.6 & 75.3 & 92.2 & 78.2 & 75.5 & \\
\hline \multicolumn{11}{|l|}{ Education } \\
\hline \multicolumn{11}{|l|}{ In \% of GDP } \\
\hline Total & & 3.58 & 4.03 & 4.36 & 3.4 & 3.49 & 3.48 & 3.34 & 3.47 & 3.58 \\
\hline General & & 2.37 & 3.27 & 3.49 & 2.88 & 3.01 & 2.89 & 2.93 & 2.95 & 2.95 \\
\hline Professional & & 1.21 & 0.76 & 0.87 & 0.52 & 0.48 & 0.59 & 0.41 & 0.52 & 0.63 \\
\hline \multicolumn{11}{|l|}{$\begin{array}{l}\text { Index } 1992= \\
100\end{array}$} \\
\hline $\begin{array}{l}\text { Total (real } \\
\text { roubles } \\
\text { expenditure) }\end{array}$ & & 100 & 102 & 96 & 68 & 69 & 72 & 69 & 75 & \\
\hline General & & 100 & 126 & 117 & 87 & 90 & 91 & 91 & 97 & \\
\hline Professional & & 100 & 57 & 57 & 31 & 36 & 36 & 25 & 33 & \\
\hline
\end{tabular}

a) data on health. Source: Goskomstat, various publications. For consolidated budget expenditures 1992-94, see World Bank, Fiscal Management in the Russian Federation, 1996.

b) data on education. Source MOE (2001a).

Under the new macroeconomic pressures, the Soviet system of enterprises as micro-welfare states became unstable. However seen, during the Soviet period social

\footnotetext{
${ }^{375}$ Includes public expenditure on sport.
} 
services were often provided through enterprises. This non-monetary social wage constituted a significant portion of the operational expenses of an enterprise, and was a key element in stimulating labour market behaviour in Russia, even during the transformation. The services included regular paid vacations, paid sick leaves, payment for sanatoria or children's camps, and (increasingly rare) child care, as part of the benefits package. In the 1980 s, this was about $25 \%$ of the total monthly salary, and in the 1990 s the ratio went up to as high as 50\% (for those enterprises which provided it), partially due to a relative decline in the nominal monetary value of salaries. ${ }^{376}$ According to Rose, in 1992, more than $50 \%$ of the urban population received assistance through enterprises in the form of either health services, places in child care facilities or other incentives. ${ }^{377}$

Work, therefore, represented more than financial income, and this is why employment was so important for the well-being of the population. This is partly the reason why the reaction of the Russian labour market to the transformation shock differed from that of any other transition countries. Despite the drastic decline in the industrial output, the level of open unemployment remained relatively low (below $10 \%$ in the middle of the 1990s). Even though it became possible to obtain social benefit-type services in the market, the low wages and general pauperization of the population meant that employees valued the old benefits, particularly as these encompassed all the employees of an enterprise. Moreover, social provision by the large enterprises was one of the main reasons why employees tolerated unpaid leaves and wage arrears: a major

\footnotetext{
${ }^{376}$ Shkaratan at el. (2003): p.77

${ }^{377}$ Rose (1999): p. 10 as cited in Shkaratan et al. (2003)
} 
portion of their income was not monetary, but came in the form of goods and services provided through the enterprise. ${ }^{378}$

Nevertheless, a serious loss of income as well as financial autonomy dramatically undermined the ability of the former state-owned enterprises to function as micro-welfare states. Macroeconomic stabilization policies, based on restrictive monetary and fiscal measures and accompanied by tax-based income policies, suppressed real wages and incomes, and reduced enterprise profits. Direct subsidies to enterprises were significantly reduced, and indirect subsidies - in the form of special prices for production inputs - were gradually removed. In many cases, these enterprises had been reducing their provision of social services, through the transfer of some facilities to municipalities, in order to reduce production costs. There was certain resistance, however, to transferring all social infrastructures, due to the need to retain control of the enterprise assets and to maintain additional labour incentives. These factors will be analyzed in greater detail in chapters 4 and 6.

\section{Social Consequences: Poverty, Labour Markets and Demographics}

Such neglect on the social side of the reforms produced an unprecedented tension in the social sector, which was particularly salient in 1992 (period of shock therapy) and 1998 (financial crisis). In 1992, the consumer spending capacity decreased by more than two thirds. The liberalization of prices, open import of consumer goods and increasing

\footnotetext{
${ }^{378}$ Teplova and Woolley (2005)
} 
reliance by the government on "printing money" to raise revenue resulted in hyperinflation, which depreciated wages, pensions, and welfare payments. ${ }^{379}$ The social consequences of the transformation also shaped the response of women to state child care policies:

A catastrophic triple fall of wages. The fall in real wages was associated with adjustments in the labour market. In the Russian conditions, these adjustments meant that there was little release of labour and low unemployment, compared to the scale of output decline. This in turn led to the significant decline in labour productivity and earnings. The depreciation of wages was also a result of price liberalization in 1992, and had not yet been recovered by early 1999 . For instance, in 1998, the level of real wages was only half of its 1990 level. Moreover, the real extent of decline was even higher as a result of constant delays in wage payments. ${ }^{380}$

Figure 3. Trends in Real GDP and Real Wage in Russia, 1990-1998 (1990=100)

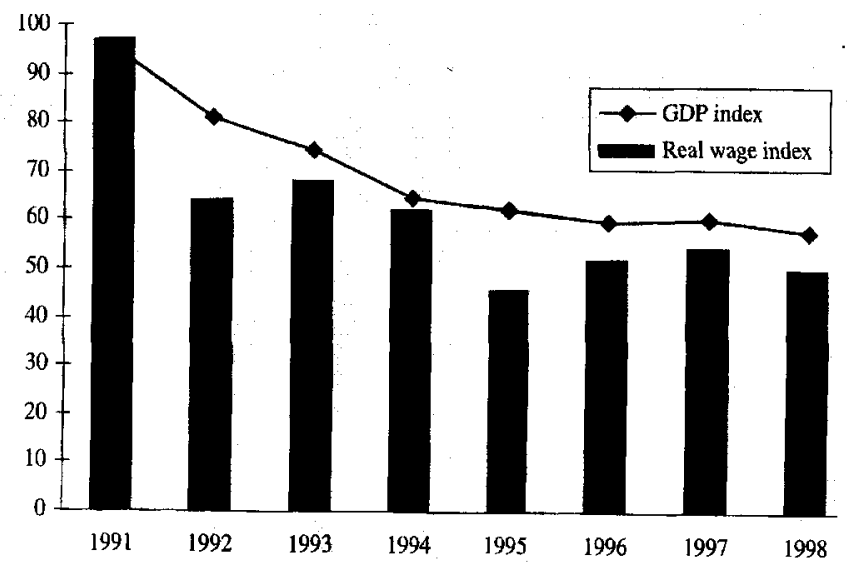

Source: EBRD (1999) as cited in Motivans and Klugman (2001): p 15

\footnotetext{
${ }^{379}$ The discussion in this section is based on the Report "Social Protection in Russia under the Crisis," released by the University of Calgary Gorbachev Foundation

${ }^{380}$ Motivans and Klugman (2001); Standing (1997)
} 
Since wages remain the basic source of income for the majority of the population (about $70 \%),{ }^{381}$ this created a new category of poor people - "the working poor." This category mostly includes families with two working parents and a small number of children (1-2). This is part of another negative trend in Russia: the unprecedented growth of poverty, indigence and social exclusion. In 1992, more than $70 \%$ of the population found themselves below the poverty line. ${ }^{382}$ An overwhelming majority $(72 \%)$ of households with unemployed members live in absolute poverty. ${ }^{383}$ The feminization of poverty is another characteristic of this transformation period, and is due to:

- incomplete families (one parent with children); in $97 \%$ of cases, the lone parent is a mother;

- lower wages (and thus, pensions) of women, compared to those of men; ${ }^{384}$ and

- a proportion of women-pensioners much higher than that of men, due to higher life expectancy.

Labour markets have also undergone a number of changes. First, reduced labour demand resulted in a decline in the economically active population (EAP) from 74.9 to

\footnotetext{
${ }^{381}$ In 1998-2000, ISESP RAS conducted the surveys of households in Taganrog: "Taganrog - IV" [5,6]

${ }^{382}$ There is a debate around different methods of calculation of poverty line which produce slightly different numbers of poor population in Russia (but very significant numbers of poor people in all cases!). While this debate is out of the scope of the present work, a comprehensive overview can be found in Kalugina E., Montmarquette, and C. Sofer "An Analysis of Poverty Persistence in Russia: 1994-2001," Available at: http://www.univlille3.fr/jma2004/papiers/KaluginaJMA04.pdf\#search='absolute\%20poverty\%20russia'

${ }^{383}$ Absolute poverty here is defined as a line constructed as an estimate of households' minimum consumption needs. Absolute poverty line in Russia tends to be updated for price changes only. ${ }^{384}$ See Katz (2002)
} 
70.2 million people. ${ }^{385}$ Second, the manifestation of important changes in the sectoral structure of the labour markets. Multiple and informal employment had become widespread. ${ }^{386}$ According to the All-Russia Centre for Public Opinion Research ${ }^{387}$ (VCIOM) survey, between $11 \%$ and $17 \%$ of the total working population were involved in multiple employments. Informal employment has also undergone unprecedented growth. The Goskomstat of the Russian Federation shows that the shadow sector of the economy is equivalent to $25-27 \%$ of the official GDP figure, while, according to the Ministry of Internal Affairs, it reaches as high as $60 \%$.

Superimposed on these economic and political realities was a demographic crisis: extremely high abortion and mortality rates, and very low fertility rates. The country's total fertility rate, which (as a result of deliberate pro-natalist policies) was around two lifetime births per woman from the late 1960s through the early 1980s, dropped steeply after 1987 , falling to 1.4 births per woman in $1994{ }^{388}$ The most recent United Nations Human Development Report data puts the Russian birthrate at 1.1 during the 2000 to 2005 period. $^{389}$ In 2000 , there were 70 per cent more abortions than live births. ${ }^{390}$ At the same time, male life expectancy plummeted from 62.2 years in 1984 to 57.6 years in $1994,{ }^{391}$ although it seems to have recovered slightly (to 60.7 years) in $2002 .{ }^{392}$ These

\footnotetext{
${ }^{385}$ At the same time, as noted earlier, the unemployment rate was not as high as was predicted by the western economists prior to the beginning of transformation due to the adaptation without restructuring of the Russian labour market. For more on this, see Kapelushnikov (2002).

${ }^{386}$ This is particularly important, due to the restrictions in the labour code for this type of employment, present in the Soviet period and to some extent in the 1990s.

${ }_{387}$ Monitoring of public opinion VCIOM 1997-1998.

${ }^{388}$ Goskomstat of Russia (2002)

${ }^{389}$ UNDP (2005)

${ }^{390}$ Grogan and Horrocks (2005)

${ }^{391}$ Goskomstat of Russia (2002)
} 
demographic and macroeconomic factors are continually present in the background, conditioning Russian policy and legislation. These pressures conditioned the transformation of the Russian welfare state. The next section will analyze how these changes affected child care policies and the ideas about the role of women in the society, by utilizing Hall's three-order framework of paradigm shift.

\section{Child Care Policies during Transformation}

This section shows that child care policies in the Russian case have undergone a paradigm shift, which mainly reflect changing ideas with regard to women and the responsibility of the state to provide social care. Wilson notes that "a paradigm shift involves a process that leads to the discrediting of the dominant paradigm and the ascension of an alternative or opposition paradigm." ${ }^{393}$ In order to assess the nature of the phenomenon, this section utilizes Hall's three-level analysis of changes in the ideas governing child care policies and shaping the image of women in the Russian society. It shows that the idea of child care as being primarily a state obligation shifted to one which assumed the family to be the main provider of child care. The case of child care illustrates the changing priorities of the state, from supporting women's participation in the labour force (achieved in part through a public provision of care for children) to shifting most of caring work to families and calling on women to follow their natural destinies - "stay home."

\footnotetext{
${ }^{392}$ UNDP (2005)

${ }^{393}$ Wilson (2000): p.263
} 
The paradigm shift involved policy changes, both significant and incremental, and is best analyzed using three main variables of policymaking: "the overarching goals that guide policy in a particular field, the techniques or policy instruments used to attain those goals, and the precise settings of these instruments. ${ }^{\text {394 }}$ In Hall's terms, the paradigm shift involves the change of all three variables, including overarching policy goals, which should be distinguished from the changes in the levels of benefit provision. Changes in instrument settings, made in the light of new experiences, knowledge and needs, with the same goals and instruments, are seen as a first order change in policy. The changes in policy instruments and their settings, while the overarching goals remain the same, reflect a second order change. The first two-order changes have an incremental character, and often can be seen as policy continuities. While, changes of the first and second order often referred to as rarely leading to a paradigm shift, they may have an eventually transformative potential. ${ }^{395}$ As noted by Palier, "[t]hese changes, while gradual, are nonetheless highly significant because, although they take a form rarely analyzed within the literature on welfare state developments,... their cumulative impact over time implies a major shift in social policy orientation." 396 Finally, "simultaneous changes in all three components of policy: the instrument settings, the instruments themselves, and the hierarchy of goals behind policy" represent the third order change. ${ }^{397}$ In the area of child care, the overarching goals may include a stimulation of female labour force participation or/and childbirths, the chosen instruments might be public child care services or in-home

\footnotetext{
${ }^{394}$ Hall (1993): p. 278

${ }^{395}$ Streeck and Thelen (2005)

${ }^{396}$ Palier (2005): p. 128

${ }^{397}$ Hall (1993): p.278
} 
caregiving allowances, and the settings would refer (among others) to the level of provision and eligibility criteria. The third order changes, combined with the cumulative effect of changes of the first and second order, may often result in or reflect in shift a paradigm governing policy domains and generate transformative change.

In the Russian case, the first and second order changes in child care policies can in fact be seen more as continuities of the Soviet increasingly pro-natalist policies of the late 1970-'80s. These include the extension of parental leave (i.e., change in the settings) and introduction of in-home caregiving allowances as part of the traditionally numerous benefits for women (change in the instrument, and thus the setting) and are depicted in Table 19. At the same time, these changes/continuities, as will be described below, shifted the nature of the welfare state in Russia, thus bringing about regime transformation. The widespread decline of publicly provided child care services, without facilitating the creation of viable alternatives (in the absence of market provided care), in turn, can be seen as a third order change in a paradigm shift in the area of social care. This change epitomized a reorientation in the overarching policy goals: from stimulating female employment to promoting the "homemaker" status; the change in instruments (very limited provision of child care services either through state, enterprises or market) leading to that in settings (very restricted access to child care). When combined, these developments constitute a qualitative shift in the welfare state regime in post-Soviet Russia. 
These aspects are different from the changes in framing of the issue of care and role of families, which took place during the Soviet period, as the state remained committed to female employment throughout that period and maintained the "gender contract" with working mothers. In the conditions of the post-Soviet environment, the state "broke" its commitment to working mothers, by assigning them to homes (and without a proper financial base, as will be shown later). Building on this theoretical foundation, the next subsections will analyze in greater depth the kinds of changes and continuities in child care and family policies, manifested during the transformation period in Russia.

\section{Ideas, Role of Women and Social Attitudes}

In order to understand the process of paradigm shift, it is important to acknowledge the importance of ideas in the policymaking process. There is an extensive literature on the role of ideas in policy. For instance, Anderson notes that "the deliberation of public policy takes place within a realm of discourse ... policies are made within some system of ideas and standards which is comprehensible and plausible to the actors involved."398 Hall further elaborates that "policymakers customarily work within a framework of ideas and standards that specifies not only the goals of policy and the kind of instruments that can be used to attain them, but also the very nature of the problems they are meant to be addressing. ${ }^{399} \mathrm{He}$ refers to this framework as a policy paradigm. A policy paradigm

\footnotetext{
${ }^{398}$ Anderson (1978): p. 23 as quoted in Hall (1993): p.279

${ }^{399}$ Hall (1993): p.279
} 
"shapes the way problems are defined, the types of solutions offered, and the kinds of policies proposed."400

As such, in the Soviet period, the existing policy paradigm revolved around promoting both employment and motherhood (with the specific emphasis on one or another function of women at a specific point of time). Child care was seen mainly as a public responsibility, and aimed at supporting women's employment (even when the policy emphasis was on reproduction). While ideals of care fluctuated throughout the Soviet history, depending on the needs of the state, from family to public professional care, professional care was seen as an important vehicle to balance both employment and motherhood. In addition, professional group care was seen to provide a number of other benefits, such as early childhood development, socialization skills, preschool education, professional healthcare (each kindergarten or nursery had a medical worker), proper nutrition, among others.

In the post-Soviet period, however, the focus turned to promoting the maternal function of women, emphasizing the "choice" to care for children at home, with a simultaneous "disapproval of employment." ${ }^{401}$ Most previous notions of gender (read "women's") equality and Soviet achievements in this area appeared to have lost their legitimacy. Instead, various ideas concerning the "natural" aspects of gender relations started to dominate the official ideology, which mainly acquired a conservative and

\footnotetext{
${ }^{400}$ Wilson (2000); Other theorists referred to similar phenomena as "labeling."

${ }^{401}$ Gurgenko (2002)
} 
nationalist character. This ideology has also been echoed by renewed religious beliefs in Russia. As Wendy Slater puts it:

These ideologies are often imbued with the traditions of Russian Orthodox Christianity, and draw heavily on the portrayal in Russian literature of women as the embodiment of moral perfection and the spirit of the nation. Reacting against Soviet proclamations of sexual equality, they insist that female emancipation had a harmful effect on women's 'natural femininity', and was responsible for social problems such as marital breakdown, and health problems which complicated women's reproductive role. $^{402}$

Such opposition to female, particularly maternal, employment, in the social ideological discourse, constitutes a qualitative difference between the Soviet and early post-Soviet welfare regimes. What is also radically different is that the Soviet state offered a number of social guarantees to women in return for fulfilling "reproductive obligations," while the post-Soviet state had only a maternal ideology at its disposal (with low generosity of maternity provisions in real terms). The main characteristics of this neofamilialism included the absolutization of family as the highest social value and form of relationship (as opposed to other "deviant," "non-family" forms of social relationships); negative attitudes toward the practice and results of Soviet family and gender policies (i.e., combining motherhood and employment, particularly at early stages of child development); positioning reproduction as the primary female function, as well as the promotion of natural division of gender roles within a family. ${ }^{403}$

This process was also accompanied by changes in the ideals of care. The transformation period saw the emergence of new images of a good care, of who should

\footnotetext{
${ }^{402}$ Slater (1995): p.78

${ }^{403}$ Gurgenko (2002)- translation by the author
} 
provide it and "how much and of what kind of care is good enough." 404 Thus, images of full-time mother care started to appear as ideal. But as will be shown later, in many cases, women could not afford to be full-time carers for a long time. This led to the emergence of other care ideals, such as intergenerational care and care by a surrogate mother, which acquired popularity as "the second best" and "the third best" choices. The examples of statements made during informal conversations with mothers of young children include:

Since I cannot afford staying at home, I am counting on my mother to look after my son... We are lucky that she lives nearby and that we do not have to worry about making other care arrangements... With her, I can be confident that my son would get the high quality care... (Olga, Mother of a 4-year-old)

If I can't stay home, then of course our grandma is much better than a kindergarten or some kind of nanny... if the circumstances would be as such that neither me, nor our grandma be able to take care of my child, than I will try to find a place in the kindergarten for him as I cannot afford a nanny... But before taking him to the kindergarten, I will find out everything possible about the quality of care there... If I do not like it,... I will stay at home no matter what, at least until he reaches 5 years old...

Why do not I like kindergartens? Well, let me explain... I have a nephew who is attending a kindergarten... every month he catches some sort of a disease there... in the kindergarten, the care providers shrug their shoulders, explaining that there are not enough nurses to make sure that all children are dressed warmly... (Natalia, Mother of a 3-year-old)

I would vote for the "grandma - babushka (Russian)" if I could choose who could care for my child for me. There are several reasons for that. First of all, no one would argue against the fact that babushka (my mother or mother in law), has a good experience in care provision. She brought us up very well, so why not entrust her bringing up of her grandson...

${ }^{404}$ Kremer (2002): p.116 
Second, babushka has time. I have to work all day and of course, my child does not receive attention and care he needs and deserves. Thus babushka can compensate for such lack of attention.

Third is comfort for everyone. Normally, grandchildren for babushka are not a burden but a joy. An it is convenient for parents to get some help from someone they are comfortable with... Of course it would be better, if I could be with my child all the time, but since this is not feasible, this is the best workable solution for everyone... (Elena, Mother of a 2.5-yearold)

Of course, it would be nice to have a nanny to look after my daughter... This way I would know that my daughter receives the quality of care she deserves... But since we cannot afford a nanny [market prices for nanny's services are very high - normally starting with $\$ 100$ USD per month with the average salary around \$200 US in 1999-author's insertion] and babushka lives in another city, we had to find a spot in the kindergarten... (Natasha, Mother of a 4-year-old)

Importantly, while most of these women were exposed to publicly provided group child care while being children themselves in the Soviet period, most of them did not cite any negative experience with it either own or on the part of their parents. This leads us to believe that perhaps changing care ideals, as evident from the quotes cited above, mainly reflect dissatisfaction with dramatically deteriorating quality of public child care services in the early transformation period (when public kindergartens were short of basic equipment and qualified personnel to take care of children as a result of financial constraints and extremely low wages, in addition to the low enforcement of hygiene and educational standards), inability to afford private child care as well as massive flow of information from a variety of sources, ideologically directed against public child care and maternal employment prevailing in the early transformation period. Such changes in the care ideals further reinforced specific institutional configurations with regard to child care, and were further reflected in the declining number of public child care institutions. In case 
of a surrogate mother, however, even though it was seen as "acceptable," widespread poverty and underdeveloped market regulations prevented any viable emergence of this type of care. Specific factors affecting the outcomes of the neofamilialist state will be discussed in detail in chapter 6.

The mere presence of ideas is not, however, sufficient for leading to changes in policies. In order for the paradigm shift to take place, certain conditions must be present, which would make one set of ideas more attractive than another. In the Russian case, these conditions included worrisome demographic and labour markets pressures (such as forecasted massive lay-offs), and neoliberal urgings to reduce state social expenditures and enterprise social assets, including child care. These pressures made the ideas about the "changing role of women" popular among Russian policymakers. Furthermore, as will be discussed in chapters 5 and 6 , factors such as tightening municipal budgets and privatization and thus quickly and significantly deteriorating quality of publicly provided care, combined with the rejection of everything associated with the communist past (including women's emancipation, even though partial), ${ }^{405}$ made the ground for acceptance of these new ideas even more fertile, on the part of the policy makers and society at large.

As such, public leaders heatedly debated questions of "proper" gender roles, birthrates, contraception, and child care. Increasingly, families became an important "social partner" in tackling the demographic crisis and the problems of neglected

\footnotetext{
${ }^{405}$ While the issue of women's emancipation during the Soviet period is discussed throughout this chapter, for the purposes of this argument I will assume that the Soviet state made significant advancements in the area of emancipation of women.
} 
children. The assumption that a mother was a "working mother," prevalent in the Soviet period, seemed to be abandoned by policy makers. For example, former Soviet leader Mikhail Gorbachev made headlines in 1987 when he said perestroika offered Soviet women what they really wanted: the chance to stay at home with their children. ${ }^{406}$ Another example includes the vice governor of the Tyumen region stating, in 2001 that "the main purpose of the family policies in Russia should be creation of a favorable atmosphere for families, in which spouses would want to have as many children as possible... This is why it is most important to finally enact a federal law on state support of families with many children, which would expand rights and benefits for such families. ${ }^{407}$ This opinion was echoed by a number of academics, who advocated for increasingly pronatalist solutions, such as expanding support not only to families with many children, but also families with just one child. ${ }^{408}$ For example, in 2001, Russian academic, Alexander Sinelnikov argued that

society has to develop a critical attitude toward single people and help them to create a family, have children... We need to form a favourable climate around those women who preferred a "career" of a housewife and a mother of several children as opposed to the professional one. It is a role of the state to give them an option to stay in that role for as long as possible, even until the pension age through providing social guarantees... There is at least as much usefulness from the work of a mother of three who stays at home as from a woman who works somewhere in the office. The positive public opinion toward housewives should be formed through mass media, educational institutions and public organizations. This should become a priority of the social policy. ${ }^{409}$

\footnotetext{
${ }^{406}$ UNICEF (1999)

${ }^{407}$ Artyukhov (2001) - translation by the author

${ }^{408}$ For example, Elizarov (2001); Popova (2001); Darmodekhin (1998)

${ }^{409}$ Sinelnikov (2001): pp. 65-6 - translated by the author
} 
Sociologists and journalists began to debate "a right for choice" for women, pitted between family and career (with the hypothetical image in mind that successful economic reforms would allow families to live on the husband's income, thus allowing women to make a choice between paid and unpaid work). Women's double burden, combining their productive role within families and their paid labour, became a popular topic for the TV shows and newspapers. The debate, however, did not revolve around how to share/reduce domestic responsibilities between men and women, but around allowing women to make the "right" choice and devote themselves to families (something that Soviet women were deprived of). As a means for allowing this choice, the family had to be able to live on one income, thus pointing to the Jane Lewis' notion of a male breadwinner regime. ${ }^{410}$ This need for a family wage served as an additional reason for economic reforms, under the noble task of easing women's burden. In addition, some of the media took the position of justifying gender role distinctions in the workplace. For example, in 1993, the magazine “Семья" [Family] justified female unemployment as a means of strengthening families, as under those circumstance women are expected to have more time to provide quality care to their husbands and children.

Furthermore, women were depicted as finally having a chance of fulfilling their natural destiny of devoting themselves to children and family. Even central newspapers (such as “Аргументы и Факты" [Arguments and Facts] buttressed the notion that women are a subordinate sex. For example, in 1996, “Аргументы и Факты” [Arguments and Facts] published an article describing all the misfortunes and mistakes that could

${ }^{410}$ Jane Lewis (1992) 
occur if a woman would become a president. Konstantin Borovoy (a leading businessman and politician) mentioned in the weekly magazine "Ogonyek" that he wrote a little poem about women in politics, "Частушка“[Chastooshka]: "I will never cast a ballot/ For a Russian woman/ I would rather pull this woman/ Into my bed." ${ }^{411}$ Political leaders such as Ivan Rybkin and Gennady Seleznev have made numerous negative comments about women in politics. In addition, during elections, one could find a range of posters and statements in political platforms, advocating liberating women from the double burden, by assigning them back to home.

Changing ideas (alongside other legacies of rigid Soviet labour protection) were also reflected in the employers' preferences to hire men. In a 1999 survey, the Centre for Labour Market Studies in Moscow interviewed 278 managers, finding that 88 per cent of employers preferred to hire men (although when asked about specific positions, for example "receptionist," more employers had a preference for women). Of that 88 per cent, 23.4 cited higher productivity and 11.4 per cent fewer associated costs as the reason for their preference. ${ }^{412}$

Moreover, as a reflection / or a cause of changing "ideals of care," the depiction of group care also started to change. Issues such as high levels of contagion among infants, and neglect by caregivers, who had to divide their attention among 15 small children, started to be widely discussed in the press (as opposed to the discussion of improvement of child's welfare, enhancing of their development, importance of their

\footnotetext{
${ }^{411}$ As quoted in Glad \& Shiraev (1999)

412 Teplova \& Woolley (2005)
} 
socialization and preparation for school and society). Accordingly, the media picked up a full-time mother care ideal as the best way to bring up children. For instance, some of the media statements include:

When mama is always close, a child is healthier, calmer and more balanced, than when cared for by grand mothers, nannies or professional carers. There is no substitute for a full-time mother's care!

A full-time mother - carer can ensure the best intellectual, spiritual and physical development of a child. Of course, working mothers cannot give as much to their children as those who devote all their time to child care. $^{413}$

Other forms of individual care, such as intergenerational care or surrogate mother, as mentioned earlier, were mostly discussed in the context of when mothers were not in the position to "choose" to stay at home and become full-time carers.

Paradigm shifts often lead to/or reflect changes in social attitudes. ${ }^{414}$ A study conducted by Zdravomyslova reveals that women themselves increasingly expressed traditional views on gender roles, and reaffirmed that their manifest destiny was to look after their homes and families $(55 \%) .{ }^{415}$ This is significant given the legacy of nearly fulltime employment inherited from the Soviet period. The desire to be able to stay at home was also revealed during informal conversations with women in Russia:

I have been dreaming of becoming a housewife for all my life... I believe that those women who stay at home have a big potential for selffulfillment through discovering an art of homemaking... My life simply did not work out this way... (Natalia, 38 years old)

\footnotetext{
${ }^{413}$ See Семья (Family Magazine): 1999, 2000.

${ }^{414}$ Janos (1986)

${ }^{415}$ Zdravomyslova (2003) - translation by the author
} 
Gender roles gained widespread acceptance among women: in Zdravomyslova's study, $58 \%$ of women noted that a husband should be a breadwinner in the family ( $66 \%$ of men agreed with this statement as well) and a wife's main destiny is to be a good wife and mother (supported by $53 \%$ of women and $69 \%$ of men). Both men and women mentioned the "natural" side of this kind of gender relations:

A wife, who stays at home, is in charge of the house, family, its wellbeing... I believe that there is nothing more important for a woman than her family... We, men, we should simply be in the business of "winning bread..." (Evgeniy, 33 years-old) ${ }^{416}$

My wife is a homemaker. Of course, this is her decision, but I support it. I believe it is more natural for women to care for their children at home... (Dmitriy, 47-years-old)

Every genuine woman is a homemaker by nature. If she is not a good homemaker, she cannot be a good friend, a good wife, or a good mother. Keeping her nest clean and neat is an essential duty of every true woman. Irrespective of what she is - an artist, a composer or a minister, she should be a good homemaker. This is a foundation of everything else. (Sergey, 39-years-old)

I believe that it is natural for women to stay at home: they are born to be mothers and wives... If a woman works, she loses a part of her femininity and it is unfortunate that in the course of the history of our country, women did not have a chance to fulfill their feminine side to the full extent... (Olga, 22 eyars-old)

What was notable during these conversations is that the higher the economic well-being of the family (where the husband earns more than the wife), the greater the orientation toward a traditional family. Even among those women who are still working, the majority

${ }^{416}$ Conversations by the author 
mentioned that they only worked because of economic need. These women indicated that if they had a choice of staying at home, they would. At the same time, many women are not resigned themselves solely to the roles of homemakers. For instance during the interview for the national radio show, Arina Sharapova, a famous journalist, mentioned:

Of course, women have to work. I cannot imagine my life without work... When at work, women have a greater chance of being satisfied with her life, even if they do not necessarily have to go to work for economic reasons...

Other statements included:

No, a woman should not stay at home... She needs to find a good, interesting, and highly-paid job to be able to respect herself and earn respect of others...

These statements reflect the legacy of high rates of employment and education inherited from the Soviet period and the assumption that a working woman - is the woman respected in the society. Nevertheless, the emerging trend of expressing greater preferences to stay at home is apparent. There is a big step, however, from these changing attitudes to actual changes in the social structure, such as female labour force participation. We cannot argue that these attitude changes led directly to changes in behaviour. In the Russian case, factors such as the legacy of nearly maximum female employment, widespread poverty and low level of allowances (which will be analyzed in the subsequent chapters), significantly shape the actual choices made by women. The next sections will show us how and whether the changes in ideas were reflected in child care policies. 


\section{First Order Institutional Change: Maternity / Parental Leave}

The first order change in paradigm shift represents an incremental change, and can be seen as a case of normal policymaking, and even policy continuity from the previous period. These incremental adjustments, often built on previous policies and developed within existing frameworks, occur on a routine basis, as a result of adjusting to different budget provisions and government priorities. These changes represent much less of a rupture than a continuity. At the same time, even though new measures/changes may be introduced at the margin, "as if their purpose were only to fix or complement the system,... they [may - insertion by the author] develop to become very important, causing a shift in the whole welfare state trajectory." ${ }^{417}$ The post-Soviet welfare state is characterized by a number of such potentially transformative incremental changes / policy continuities, which were inherited from the Soviet period and protected by groups of vested interests. These changes and continuities, as we will see, played an important role in shaping the form and nature of the shift, and the resulting policy mix.

Thus changes in the maternity / parental (child care) leave provision can serve as a first order institutional change through a combination of layering and conversion types of changes. These changes can be seen in the progressive expansion of legal entitlements to maternity and parental (child care) leave throughout the transformation period, in terms of both the number of people eligible for benefits and the length of benefit entitlement. Thus, Russia inherited two Soviet-era types of leave: maternity and child

\footnotetext{
${ }^{417}$ Palier (2005): p. 131; for discussion on the transformative nature of incremental changes, see Thelen and Streeck (2005).
} 
care. Maternity leave was traditionally paid at full salary-level by the employer, through enterprise-based social insurance funds. The transformation introduced a number of changes: in 1993, maternity leave was extended to women who were laid off during pregnancy (in these cases, paid from municipal/regional social insurance funds); in 1995, it was extended to full-time students; and in 1997 it was extended to 156 days for multiple births (see Table 19). At present, maternity leave normally lasts 140 days (70 days before and 70 days after the delivery) and still is linked to employment (except for the self-employed, farmers, and students). ${ }^{418}$

While the method and amount of payments have also slightly changed, maternity leave payments remain reasonably generous. Mothers with at least one year of employment receive 100 per cent of their regular salary during their maternity leave, with a maximum total monthly payment of 85 times the minimum monthly wage (set at 450 roubles, or about US\$14 per month in 2002). Another change is that, if the leave benefits previously had a fixed amount, they now depend on the minimum wage, which is regularly adjusted, depending on the country inflation rates. ${ }^{419}$

\footnotetext{
${ }^{418}$ Gusov (2003). This paragraph is extensively based on the jointly (50/50) written paper with Frances Woolley

${ }^{419}$ Resolution of the Supreme Council of the USSR (1991) - translation by the author
} 
Table 19. Comparison of Late Soviet and Post-Soviet Welfare Regimes

\begin{tabular}{|c|c|c|}
\hline & $\begin{array}{l}\text { Late Soviet period } \\
1961-1991(1989)\end{array}$ & $\begin{array}{l}\text { Post-Soviet period } \\
1991(1989)-2001\end{array}$ \\
\hline $\begin{array}{l}\text { Socio-economic } \\
\text { situation }\end{array}$ & $\begin{array}{l}\text { - Low birth rates } \\
\text { - Family instability and unsupervised children } \\
\text { - Extensive economic development }\end{array}$ & $\begin{array}{l}\text { - Introduction of flexible labor markets } \\
\text { - Demographic crisis } \\
\text { - Economic reforms with adverse social consequences, widespread } \\
\text { poverty of the population }\end{array}$ \\
\hline $\begin{array}{l}\text { Main state } \\
\text { needs }\end{array}$ & - Reproduction (production) & - Reproduction \\
\hline Ideas & - "Rational female employment" & $\begin{array}{l}\text { - Providing a "choice" for women to stay at home } \\
\text { - Opposition to female employment } \\
\text { - Children are a family responsibility }\end{array}$ \\
\hline $\begin{array}{l}\text { Instruments to } \\
\text { stimulate } \\
\text { production }\end{array}$ & $\begin{array}{l}\text { - Labour duty } \\
\text { - Investment in child care }\end{array}$ & $\begin{array}{l}\text { - Creation of employment service, introduction of flexible labour } \\
\text { markets }\end{array}$ \\
\hline $\begin{array}{l}\text { Instruments to } \\
\text { stimulate } \\
\text { reproduction }\end{array}$ & $\begin{array}{l}\text { - Lumpsum birth grants for the first child (in } 1990 \text { equal to three } \\
\text { times the minimum wage) } \\
\text { - Interest-free credits to families for the birth of the first child } \\
\text { - Maternity and child care leaves } \\
\text { - Right of mothers to stay at home until child reaches } 14 \text { years of } \\
\text { age (unpaid leave or part -time work) } \\
\text { - Family allowance for under-provisioned families: paid to } \\
\text { families with a per capita income under the unofficial poverty } \\
\text { line } \\
\text { - Monthly child allowances with } 1 \text { st child (since 1981) }\end{array}$ & $\begin{array}{l}\text { - Maternity and long parental leaves } \\
\text { - Monthly child benefits with the birth of every child (universal since } \\
1994 \text { to 1998; income-based since 1998) } \\
\text { - Others (recognitions of motherhood (medal, additional benefits)) } \\
\text { - Lumpsum birth grants starting with the first child } \\
\text { - Allowance for registering with an obstetrician during the first } 12 \\
\text { weeks of pregnancy }\end{array}$ \\
\hline \multicolumn{3}{|l|}{$\begin{array}{l}\text { Child care } \\
\text { Services }\end{array}$} \\
\hline Development & - Growth & - Strong reduction \\
\hline Rationale & $\begin{array}{l}\text { - Emphasis on pre-school education (to increase efficiency and } \\
\text { effectiveness of school education, in order to train better } \\
\text { workers) }\end{array}$ & - Emphasis on family-based care \\
\hline Distribution & - Planning system & - Municipalities \\
\hline Administration & $\begin{array}{l}\text { - Enterprise-based } \\
\text { - Jurisdiction of department of Public Education (local offices) }\end{array}$ & $\begin{array}{l}\text { - Enterprise-based } \\
\text { - Municipalities and local divisions of Ministry of Education }\end{array}$ \\
\hline
\end{tabular}




\begin{tabular}{|c|c|c|}
\hline (3) & $\begin{array}{l}\text { Late Soviet period } \\
1961-1991(1989)\end{array}$ & $\begin{array}{l}\text { Post-Soviet period } \\
1991(1989)-2001\end{array}$ \\
\hline $\begin{array}{l}\text { Ministerial } \\
\text { responsibility } \\
\text { (setting } \\
\text { standards) } \\
\end{array}$ & - Department of Public Education & - Ministry of Education/municipalities \\
\hline $\begin{array}{l}\text { Cost and } \\
\text { Financing }\end{array}$ & $\begin{array}{l}\text { - Flat monthly payments, with subsidies to low income and } \\
\text { certain groups of population } \\
\text { - Financing from the federal budgets for municipal child care } \\
\text { and enterprise/federal budgets for enterprise-based child care }\end{array}$ & $\begin{array}{l}\text { - Flat monthly payments - ratio of total child care costs }(20 \%) \text { for } \\
\text { municipal child care } \\
\text { - Entrance fees } \\
\text { - Flat monthly payments for some enterprise-based child care } \\
\text { - Financing from municipal and enterprise budgets for respective types } \\
\text { of child care }\end{array}$ \\
\hline Eligibility & $\begin{array}{l}\text { - Enterprise-based child care - through social insurance at the } \\
\text { enterprise } \\
\text { - Department of Public Education/ Health child care (very } \\
\text { limited number) - depended on employment status, household } \\
\text { structure and availability of child care at the enterprise }\end{array}$ & $\begin{array}{l}\text { - Enterprise-based child care - through employment at the enterprise } \\
\text { - Employment; waived/reduced eligibility requirements for lone } \\
\text { parents and other "vulnerable" groups of population }\end{array}$ \\
\hline $\begin{array}{l}\text { Types of } \\
\text { services }\end{array}$ & Pre-school educational institutions (nursery - kindergarten) & - School-kindergarten, pre-school educational institutions and others \\
\hline \multicolumn{3}{|l|}{$\begin{array}{l}\text { Maternity/ } \\
\text { Parental Leave }\end{array}$} \\
\hline Types & $\begin{array}{l}\text { - Paid maternity leave } \\
\text { - Unpaid/partially child care leave }\end{array}$ & $\begin{array}{l}\text { - Paid maternity leave } \\
\text { - Unpaid/partially child care leave }\end{array}$ \\
\hline Duration & $\begin{array}{l}\text { Paid: maternity leave } 112 \text { days ( } 56 \text { days before and } 56 \text { after } \\
\text { confinement) } \\
\text { Since 1982: } \\
\text { - Partially paid child care leave- started after maternity leave and } \\
\text { lasted until child reaches } 1 \text { year of age (extended to } 18 \text { months } \\
\text { in 1989); } \\
\text { - Unpaid child care leave - until a child reaches } 18 \text { months years } \\
\text { of age (extended to } 36 \text { months in 1989) }\end{array}$ & $\begin{array}{l}\text { - Statutory maternity leave - } 10 \text { weeks before and } 8 \text { weeks after } \\
\text { confinement (or longer for multiple births) - until } 1993 \text {. } \\
\text { - Post-partum maternity leave was extended to } 10 \text { weeks (16 weeks for } \\
\text { multiple births or births with complications) in } 1993 \text {. } \\
\text { Child care/ parental leave - since 1989: } \\
\text { - Partially paid child care leave accompanied by in-home caregiving } \\
\text { allowance - started after maternity leave and lasted until child } \\
\text { reaches } 18 \text { months of age; } \\
\text { - Partially paid (practically unpaid in real terms) child care leave - } \\
\text { starts after "paid with in-home caregiving allowance" portion of the } \\
\text { leave ends and lasts until a child reaches } 36 \text { months of age } \\
\end{array}$ \\
\hline
\end{tabular}




\begin{tabular}{|c|c|c|}
\hline & $\begin{array}{l}\text { Late Soviet period } \\
1961-1991(1989)\end{array}$ & $\begin{array}{l}\text { Post-Soviet period } \\
1991(1989)-2001\end{array}$ \\
\hline & & (accompanied by a "compensation allowance" paid by employer), \\
\hline Eligibility & $\begin{array}{l}\text { - All working women, covered by social insurance were eligible } \\
\text { for some payment during the maternity leave - the minimum } \\
\text { requirement was three months' work before the start of the } \\
\text { leave }\end{array}$ & $\begin{array}{l}\text { - Access to leave benefits depend on the access to social insurance but } \\
\text { also provided to students, those who were fired while pregnant } \\
\text { - In } 1993 \text {, maternity leave was extended to women who are laid off } \\
\text { during pregnancy } \\
\text { - In } 1995 \text {, it was extended to full-time students } \\
\text { - In } 1997 \text { it was extended to } 156 \text { days for multiple births }\end{array}$ \\
\hline Benefit level: & $\begin{array}{l}\text { - In } 1973 \text {, maternity leave payment - } 2 / 3 \text { of full salary was } \\
\text { extended to full salary for all }\end{array}$ & $\begin{array}{l}\text { - } 100 \text { per cent of their average earnings during maternity leave } \\
\text { - Partially paid are compensated through } \\
\text { - In-home caregiving allowance (about } \$ 17 \mathrm{USD} \text { ) during parental leave } \\
\text { - Compensation payment from employer payroll funds (about } \\
\$ 1.7 \mathrm{USD} \text { ) during both maternity and parental leaves until a reaches } \\
36 \text { months of age }\end{array}$ \\
\hline
\end{tabular}

Source: Complied by the author 
Thus maternity leaves (about 20 weeks with almost full salary and job protection) are relatively generous in Russia. But it is mainly the changes in child care leave that contributed to Russia's becoming a neofamilialist regime. Child care leave normally starts after a woman's maternity leave entitlement has ended. As discussed, in the late Soviet period (1982 -1989), paid child care leave lasted until the child reached 12 months old and unpaid child care leave was available to mothers until the child reached 18 months old. In 1989 (with the main law coming into force in 1991), the early transformation period/ last years of the Soviet period, paid child care leave was extended until the child reached the age of 18 months and unpaid leave was extended up to 36 months of age of a child. What is also important here is that those who do not have employment experience will have access to leave (50\% of the benefits). Women have an opportunity to work part-time or from home while taking leave, or to take leave in segments (with breaks) with the right to return to the same position.

The experience of other countries ${ }^{420}$ shows (e.g., Finland and France) that such long leaves serve as a foundation for neofamilialist regimes, particularly when accompanied by a move away from institutionalized child care, "as a right of social citizenship, pertinent to achieving both equality of the sexes and equal opportunities for children." ${ }^{, 21}$ Similarly to these countries, access to long leaves and in-home caregiving allowance even working part-time favours the growth of labour market flexibility and expansion of "low-wage, low-skill work for women." 422 Indeed as we will see in chapter

\footnotetext{
${ }^{420}$ See Michel \& Mahon (2002); Jenson and Sineau (2001b)

${ }^{421}$ Mahon (2002a): p. 350

${ }^{422}$ Ibid.: p. 352
} 
5, there has been a substantial growth in part-time employment in Russia at the beginning of the 1990s. In addition, long leave schemes have other implications for women, including potentially declining earnings:

First,... [a] small portion of this decline will result from the reductions in average experience levels. Second, extended work absences may impose substantial nonwage costs on firms. As the leave entitlement lengthens, it is likely to become much harder to schedule replacement workers... The costs may be sizable even when workers do not use all of the allowed leave, since employers face considerable uncertainty regarding the timing and ultimate likelihood of the individual's return to the job. Third, extremely lengthy leave guarantees introduce the possibility that women having multiple children in a short period of time may be away from their jobs for several years consecutively, or with just brief spells of intervening employment, causing substantial depreciation of human capital. This becomes even more likely when paid leave is supplemented by rights to unpaid but job-protected time off work. ${ }^{423}$

In addition, as we will see below, long leave schemes may also lead to discrimination against women in the labour market, as employers may be unwilling to hire women due to the aforementioned reasons.

At the same time, despite the predominantly neofamilialist nature of the changes in the leave schemes, the year of 1992 saw the extension of eligibility for child care leave to fathers and other family members, which essentially transformed child care leave to "parental" leave (at least on the paper), when both parents were allowed to take time off to care for their children. ${ }^{424}$ While the wording in the policy still addresses mothers as main-leave takers, if fathers (or other family members) wish to take any parts of this

\footnotetext{
${ }^{423}$ Ruhm (1998): p.316

424 Zakon RF \# 3543-1 (September 25, 1992) "Concerning Amendments to the Code of Labour Legislation." - translation by the author
} 
leave, they may do so (with the written permission of the mother). The main condition for taking the leave is the access to social insurance.

Thus, while it appears that Russia picked up on the "right" solution being pushed in the Western Europe and OECD countries by extending child care leave to fathers and other family members, it has been done in a shallow way. Similarly to other countries, ${ }^{425}$ these long leaves are taken almost exclusively by mothers and appear to have even further reinforced a perception of women as main care providers. Our data indicate that nearly 100 per cent of leaves are taken by women. The reasons of why men take leave so rarely vary from cultural norms to differences in earnings capacity. ${ }^{426}$ Furthermore, as noted by Barbara Bergman, "[t]he social pressure resulting from even gender-neutral parental leave will put social pressure on mothers, but not fathers, to do so. Anything that increases the social pressure for having children cared for full time by their own mothers is a step back toward rigid gender roles, with each gender limited to sex appropriate activities." ${ }^{427}$ Thus while long child care leaves may serve well the current "ideals of care" in contemporary Russia and indicate a move toward refamilialization of care, they pose a longer term challenge to the goal of achieving gender and class equality.

In general, parental leave is substantially less generous than maternity leave. While on parental leave, a parent is entitled to 50 roubles (about US\$1.7) per month in so-called "compensation payments," paid by the employer from the payroll funds, until

\footnotetext{
${ }^{425}$ Even in Sweden, which has the strongest incentives for men to take some leave, only 7 to 10 per cent of men took some part of leave in 1988. Sources: OECD (1995); Leira, A. (2002).

${ }^{426}$ Ruhm (1998): p. 292

${ }^{427}$ Bergman (2000): p.81
} 
the child is three years old. The 1994 Resolution No. 1206 of the Government of the

Russian Federation, establishing the order to and sources of these allowances, states:

Monthly "compensation" allowances are paid in the amount of $50 \%$ of the minimum wage (starting with 2001, the Order No. 136 of the President established a fixed amount of such allowances of 50 roubles) to women (or other official guardians) on childcare /parental leave until child reaches 3 years of age. The same rules are applied in case if woman/legal guardian was laid off as a result of liquidation of an enterprise. Application is made at the enterprise (or a local social insurance body in case of an applicant is laid off)... Monthly allowances are paid from the payroll funds of the enterprises and organizations, irrespective of its ownership status and legal form. ${ }^{428}$

This "compensation" allowance is a direct cost to the enterprise, and paid from the general pool of money. While negligible in real terms, the cumulative effect of these payments again may affect the employer's willingness to hire women (see chapter 5). In addition to this, a monthly in-home caregiving allowance, with a payment of 500 roubles (about US\$17) from the social insurance funds, is available to parents every month, until the child reaches 18 month of age. ${ }^{429}$ It is also often referred to as a parental leave benefit. A parent is entitled to this allowance while on leave, or working part-time. This allowance will be discussed in greater detail in the next section. ${ }^{430}$

In 2001 , the responsibility for paying maternity allowances and in-home caregiving allowances to those on parental leave was transferred to the regional social funds; until that time, these sums were paid for by employers, out of employer-

\footnotetext{
${ }^{428}$ Government of the Russian Federation (1994) - translation by the author

${ }^{429}$ This allowance is often referred to as a parental leave benefit but for the purposes of this thesis it will be referred to as in-home caregiving allowance.

${ }^{430}$ Some sections of this chapter are extensively based on the paper written jointly (50/50) with Frances Woolley.
} 
administered social funds. After this transfer, employers have been required to pay a new "single social tax," or "unified social tax." In 2004, this amounted to 35.6 per cent of an employee's earnings up to 100,000 roubles (around US\$3,500), 20 per cent of earnings between 100,000 and 300,000 roubles (around US\$10,500), and lower amounts on higher earnings. In other words, if an enterprise paid an employee 50,000 roubles per year (around US\$1,750), it would pay an additional 17,800 roubles (around US\$600) into the social insurance fund. ${ }^{431}$ Both before and after the change, however, parental leave payments (in-home caregiving allowances) were much less generous than maternity leave payments, with a fixed replacement rate typically around 25 per cent of the minimum monthly wage in the country. ${ }^{432}$

While the effects of these changes on women's position in the labour market will be analyzed in greater detail in the next chapters, it is important to note that they often constitute a disincentive to hire women. New private sector employers resisted both the Soviet-style enterprise-level provision of benefits and the new social insurance funds. Employers often associate costs with extended paid leaves, which in turn impedes female employment. Despite the fact that the social insurance fund has been paying the maternity and in-home caregiving (during parental leave) allowances, the costs of leave are associated with women (i.e., mostly with replacement workers - hiring and letting them go at the end of a permanent employee's leave, as well as "compensation" payments until a child reaches 36 months of age). From an employer's point of view, however, the dislocations involved may not be trivial, as Michael Malloy puts it "There have been

\footnotetext{
${ }^{431}$ KPMG (2004)

${ }^{432}$ This section is extensively based on the paper written jointly (50/50) with Frances Woolley (2005)
} 
cases when employees thought to be long gone have suddenly reappeared after almost three years of absence; and under Russian law, they have every right to expect their positions back." ${ }^{, 433}$

As such, the extension of maternity and parental leave schemes, even though gradual and incremental, can be considered as a change in the setting of an instrument (i.e., leave), and can be seen as a first order paradigm shift change in child care. In terms of the nature of the change, one could see it as layering of new institutional elements on top and through reference to the previous ones. Furthermore, such attachment of new elements to existing leave institutions is gradually changing their status and structure. Thus, while the official policy goals remained practically unchanged, the impact of such an extension went beyond a mere change in the instrument - it involved change in the meaning attached to the leave and the purposes it served. If earlier (during the Soviet period), leaves were used to stimulate female entrance to the labour force and help them balance caring for an infant and employment, the new leave scheme aims to facilitate the status of a temporary homemaker for an extended period of time and release tension from the labour market. Therefore, despite the seemingly incremental nature of the leave extension, it marks an institutional change through a combination of layering and conversion (when old and modified institutions serve new goals) and serves as an important step towards the neofamilialist regime with the strong potential to influence the social structure (e.g., female employment, at least during early years of motherhood). The next sections will illustrate the second and third order changes.

${ }^{433}$ Malloy (2003): p.1 


\section{Second Order Institutional Change: Benefits for Mothers and Children}

In broad terms, benefits and allowances for mothers and children represent a unique mix of changes and continuities from the Soviet period. At the same time, the changes in the system of benefits for children and mothers, in particular the introduction of in-home caregiving allowance, can be characterized as the second-order change in the paradigm shift of child care policies, which involved changes in both instruments and settings. The in-home caregiving allowance was introduced in 1991 to encourage women to stay at home and care for their young children. ${ }^{434}$ Currently the in-home caregiving allowance, ending when the child reaches 18 months of age, starts right after the end of the maternity leave together with the parental leave. As with eligibility to parental leave, it is also possible to receive the allowance by working either from home and/or part-time. This benefit is paid to the working mothers (fathers, or other official guardians) if they have access to social insurance funds; or to students and women fired as a result of the liquidation of an enterprise during the maternity or parental leave. There are other cases when this allowance can be paid (e.g. women serving in the Army etc). The size of the allowance was equal to $100 \%$ of a minimum monthly wage, irrespective of the number of children and employment experience. In 1994, this amount was further increased up to 500 roubles, which represents about $150 \%$ of a minimum monthly wage. ${ }^{435}$

The new Russian child care model resembles the Finnish one, when parents are entitled to a child care leave accompanied by a home care allowance, after their

\footnotetext{
${ }^{434}$ Supreme Council of the RSFSR (1990) - translation by the author

${ }^{435}$ Government of the Russian Federation (1994) - translation by the author
} 
entitlements to maternity, paternity and parental leaves end. Similarly to Finland and other countries with analogous provisions (e.g., France), it is mostly women who are being affected by in-home caregiving allowance. ${ }^{436}$ While this allowance has low monetary value in real terms and as a result produced mixed effects (as will be shown in chapter 5), a number of women interviewed admitted that they would have not withdrawn from the labour force if such an allowance did not exist. Furthermore, the fact that the inhome caregiving allowance is available to families even with one child and that parents could combine access to the allowance and part-time work has a strong potential to propel women out of the labour force for an extended period of time.

Part-time employment is by no means neutral in its effects on gender equality. As noted by Jenson:

Promoted in the name of 'choice' for those who are consumers of services and social 'solidarity' with those at risk of being excluded from mainstream society, these programs rarely deploy a discourse of equal social citizenship. They seek less to generate social equality across classes or gender equality between women and men than to limit state spending on public services and to reduce the social costs of long-term unemployment and non-employment. A job, any job, is the watchdog. There is little concern about whether the job will ghettoize certain people in low-paid precarious employment with few prospects for the future. $^{437}$

This shows how the state is shaping its policies towards women's employment by moving away from the traditional professional child care center toward supporting some forms of family care. Furthermore, a number of feminist scholars see in-home caregiving allowances as "undermining publicly subsidized childcare and implicitly encouraging a

\footnotetext{
${ }^{436}$ Morgan (2002).

${ }^{437}$ Jenson and Sineau (2001a): pp. 36-7
} 
gendered division of labour within the household." ${ }^{438}$ For instance, Barbara Bergman

argues that:

A child care policy that sends large stipends to parents caring for their own children at home, or that provides years of paid parental leave, may engender social disapproval toward the woman who keeps working through her child's early years. If she can receive substantial monetary benefits by staying home, the excuse that she "has to work" will no longer be accepted as valid. It becomes obvious that if she does stay at work she is doing it for her own gratification, something the more socially conservative part of the population still considers off-limits for women. The provision of significantly large benefits to mothers caring for their own children thus puts social pressure on all mothers to stay home. It threatens the advances women have made in achieving parity with men in status through their willingness to work continuously, whether or not they have young children. In the current state of the culture, if children are cared for at home, in almost all cases it will be the mother who stays home and does it. ${ }^{439}$

Thus, along with the long child care leaves, in-home caregiving allowances have a strong potential to affect long-terms gender relations. In addition, while the in-home caregiving allowances do not constitute a direct disincentive to hire women, as they are paid from the regional social insurance funds, their effects can be detrimental for gender equality in the labour market, in the long run:

The child home care allowances deal with the pressure for defamilialisation by making the choice of "temporary homemaker" status attractive, at least for some. Though the language is often gender neutral, the underlying philosophy is clearly one of gender difference... The effect is to reinforce gender inequality in the labour market. The allowances reinforce employers' views that women will be absent for sustained periods and this affects recruitment choices and wages, not to mention the career development prospects of those whose "human capital" has been

\footnotetext{
${ }^{438}$ Brennan (2003)

${ }^{439}$ Bergman (2000): p.82
} 
devalued by relatively long spells of absence from the labour market. ${ }^{440}$

What is also important is that these allowances do not affect all women equally. As quoted in Mahon, the OECD revealed that "Mothers with lower levels of education, who have worked in less skilled occupations are most likely to take these low-paid leaves, which may further marginalize them from the labour market. In some cases, children are not allowed to attend public early childhood education and care during the leave period which raises equity concerns." 441

Thus three-year long parental leave combined with in-home caregiving allowance may have a strong effect on a woman's decision to withdraw from the labour force. This in turn can have a major impact upon “women's skill retention, confidence, and employability. There are likely to be effects upon lifetime earnings, economic independence, and retirement income. ${ }^{, 442}$ Overall, the introduction of in-home caregiving allowance can be seen as a second order institutional change. The nature of the change, similarly to extension of child care leave, can be seen as a combination of layering (adding of new norms on top of the existing ones) and conversion (changing the meaning of benefits to mothers from facilitating both employment and motherhood to promoting homemaking). This institutional change, though minor has a transformative character with regard to the nature of welfare regime in Russia. The cumulative impact of such

\footnotetext{
${ }^{440}$ Mahon (2002a): pp. 351-2

${ }^{441}$ OECD (2001): p.33 as quoted in Mahon (2002a): p. 352

${ }^{442}$ Brennan (2003)
} 
seemingly incremental changes, which facilitated a new policy goal - bringing mothers home - contributed to the paradigm shift in child care in Russia.

Other benefits for women and children have also undergone a number of changes (Table 20). In general, these changes can be classified as simultaneous devaluation, rationalization, shift from universal to residual (strengthening of the targeting of benefits to the poor) and benefits expansion. ${ }^{443}$ The first and the main characteristic of the prolific number of both types of benefits - (those inherited from the Soviet period and the new ones) - is their substantial decline in real value, and widespread arrears in their payment. Most benefits became negligible in real terms and thus almost meaningless. While these trends will be detailed in chapter 6 , it is worth highlighting here that these tendencies emerged as a result of galloping inflation rates, as well as neoliberal pressures coming from international financial organizations, such as the World Bank and the International Monetary Fund. These organizations focused mostly on the poverty reduction side of the benefit provision. As a result, the focus on poverty and the arguable need to direct resources to the people who need them the most, according to the World Bank and IMF recommendations, has become the official rhetoric of the government.

The second and third characteristics of benefit provision during the transformation period include attempts on the part of international financial organizations and the new executive branch to rationalize the system of child benefits, inherited from the late Soviet period, as well as increase targeting of benefits towards the poor. As will be shown in chapter 4 , these efforts had very limited success, due to the resistance of the left-wing and

${ }^{443}$ Klugman \& McAuley (2001). 
socialist conservative groups. For instance, the first change in child benefits, in 1994, actually expanded them: child benefits were changed from "income- tested" to "universally provided." These benefits started to be differentiated by two age categories (younger than 6 years old - 70\% of the minimum monthly wage; 6-16 years old $60 \%) .{ }^{444}$ Extra benefits became available to lone mothers, families with many children and others. In 1996, the neoliberal forces were successful in introducing a further set of reforms with regard to child benefit simplification (the age differentiation was removed). In July 1998, the benefits were changed again, from universally provided to needs-based testing, which makes it "limited to families with children, whose average per capita income does not exceed twice the minimum subsistence level." ${ }^{, 45}$ Another rationalization effort can be seen in the changes of administration of benefits. Thus in 1998, there was a shift from the enterprise-based administration of monthly child benefits to regional departments of social protection. If the previous financing of these benefits came from the federal budget, under the new system these benefits were financed from local municipal budgets (which led to high strain and pressure on those budgets). Overall these changes were a result of heated debates among policymakers, as well as recommendations (read: “pressures”) from international financial organizations. These will be illustrated in detail in chapter 4.

\footnotetext{
${ }^{444}$ Elisarov et al (1997)

${ }^{445}$ Klugman and Motivans (2001): p. 143, Government of the Russian Federation $(1995,1998)$
} 
Table 20. Allowances for Individuals with Children (2000)

\begin{tabular}{|c|c|c|c|c|c|}
\hline $\begin{array}{l}\text { Type of } \\
\text { allowance }\end{array}$ & $\begin{array}{c}\text { Size of } \\
\text { allowance }\end{array}$ & $\begin{array}{l}\text { Duration/ } \\
\text { frequency }\end{array}$ & $\begin{array}{c}\text { Source of } \\
\text { financing/ } \\
\text { administration* }\end{array}$ & $\begin{array}{c}\text { Basis/ } \\
\text { Rationale }\end{array}$ & Eligibility \\
\hline $\begin{array}{l}\text { Maternity } \\
\text { allowance }\end{array}$ & $\begin{array}{l}100 \% \text { of } \\
\text { actual wage. }\end{array}$ & $\begin{array}{l}70 \text { days } \\
\text { prior and } 70 \\
\text { days after } \\
\text { giving birth/ } \\
\text { monthly }\end{array}$ & $\begin{array}{l}\text { Contributory. } \\
\text { Federally mandated. } \\
\text { funded by a tax paid } \\
\text { to the Social } \\
\text { Insurance Fund (SIF). } \\
\text { Administered by } \\
\text { enterprises. }\end{array}$ & $\begin{array}{l}\text { Giving birth/ } \\
\text { stimulation } \\
\text { of fertility }\end{array}$ & $\begin{array}{l}\text { Mothers (or legal } \\
\text { guardians) with } \\
\text { access to social } \\
\text { insurance funds, } \\
\text { laid off while } \\
\text { being pregnant in } \\
\text { case of } \\
\text { liquidation of an } \\
\text { enterprise, or } \\
\text { students or } \\
\text { serving in the } \\
\text { Army }\end{array}$ \\
\hline Birth grant & $\begin{array}{l}15 \text { minimum } \\
\text { monthly } \\
\text { wages }\end{array}$ & $\begin{array}{l}\text { One-time } \\
\text { cash } \\
\text { payment }\end{array}$ & $\begin{array}{l}\text { Non-contributory. } \\
\text { Federally mandated. } \\
\text { Funded by SIF for } \\
\text { the employed and } \\
\text { local governments for } \\
\text { the unemployed. } \\
\text { Administered by } \\
\text { enterprises and local } \\
\text { social protection } \\
\text { administration. }\end{array}$ & $\begin{array}{l}\text { Giving birth/ } \\
\text { stimulation } \\
\text { of fertility }\end{array}$ & $\begin{array}{l}\text { All women, who } \\
\text { have just given } \\
\text { birth }\end{array}$ \\
\hline $\begin{array}{l}\text { Allowance } \\
\text { to mothers } \\
\text { who } \\
\text { registered } \\
\text { for prenatal } \\
\text { care during } \\
\text { the first } 12 \\
\text { weeks of } \\
\text { pregnancy }\end{array}$ & $\begin{array}{l}1 \text { minimum } \\
\text { monthly } \\
\text { wage }\end{array}$ & $\begin{array}{l}\text { One-time } \\
\text { cash } \\
\text { payment; }\end{array}$ & $\begin{array}{l}\text { Non-contributory. } \\
\text { Federally mandated. } \\
\text { Funded by SIF for } \\
\text { the employed and } \\
\text { local governments for } \\
\text { the unemployed. } \\
\text { Administered by } \\
\text { enterprises and local } \\
\text { social protection } \\
\text { administration. }\end{array}$ & $\begin{array}{l}\text { Registration } \\
\text { with an } \\
\text { obstetrician/ } \\
\text { ensuring } \\
\text { healthy } \\
\text { pregnancy } \\
\text { and thus } \\
\text { children }\end{array}$ & $\begin{array}{l}\text { All women who } \\
\text { registered with } \\
\text { an obstetrician } \\
\text { during the first } \\
12 \text { weeks of their } \\
\text { pregnancy }\end{array}$ \\
\hline $\begin{array}{l}\text { Child } \\
\text { benefit }\end{array}$ & $\begin{array}{l}70 \% \text { of a } \\
\text { minimum } \\
\text { monthly } \\
\text { wage }\end{array}$ & $\begin{array}{l}\text { From birth } \\
\text { until a child } \\
\text { reaches } 16 \\
\text { years old / } \\
\text { monthly }\end{array}$ & $\begin{array}{l}\text { Social insurance } \\
\text { fund; Non- } \\
\text { contributory. } \\
\text { Federally mandated. }\end{array}$ & $\begin{array}{l}\text { Income-test/ } \\
\text { poverty } \\
\text { reduction/ } \\
\text { fertility } \\
\text { stimulation }\end{array}$ & $\begin{array}{l}\text { Children from } \\
\text { low income } \\
\text { households } \\
\text { (universal - } \\
\text { 1994-1998; } \\
\text { income tested } \\
\text { since 1998: per } \\
\text { capita household } \\
\text { income below } \\
\text { regional } \\
\text { subsistence } \\
\text { minimum); paid } \\
\text { to one of the } \\
\text { parents for each } \\
\text { child under } 16\end{array}$ \\
\hline
\end{tabular}




\begin{tabular}{|l|l|l|l|l|l|}
\hline $\begin{array}{c}\text { Type of } \\
\text { allowance }\end{array}$ & $\begin{array}{c}\text { Size of } \\
\text { allowance }\end{array}$ & $\begin{array}{l}\text { Duration/ } \\
\text { frequency }\end{array}$ & $\begin{array}{c}\text { Source of } \\
\text { financing/ } \\
\text { administration* }\end{array}$ & $\begin{array}{c}\text { Basis/ } \\
\text { Rationale }\end{array}$ & Eligibility \\
\hline $\begin{array}{l}\text { In-home } \\
\text { caregiving } \\
\text { allowance } \\
\text { until a child } \\
\text { reaches 1.5 } \\
\text { years of age }\end{array}$ & $\begin{array}{l}\text { monthly } \\
\text { wages }\end{array}$ & $\begin{array}{l}\text { Monthly } \\
\text { cash benefits } \\
\text { after the } \\
\text { maternity } \\
\text { leave end } \\
\text { and until a } \\
\text { child } \\
\text { reaches six } \\
\text { months of } \\
\text { age }\end{array}$ & $\begin{array}{l}\text { Fon-contributory. } \\
\text { Funded by SIF for } \\
\text { the employed and } \\
\text { local governments for } \\
\text { the unemployed. } \\
\text { Administered by } \\
\text { enterprises and local } \\
\text { social protection } \\
\text { administration. }\end{array}$ & $\begin{array}{l}\text { Stimulation } \\
\text { of provision } \\
\text { of child care } \\
\text { at home, } \\
\text { poverty } \\
\text { reduction }\end{array}$ & $\begin{array}{l}\text { Employed } \\
\text { mothers with } \\
\text { access to social } \\
\text { insurance funds } \\
\text { or laid off while } \\
\text { being pregnant in } \\
\text { case of } \\
\text { liquidation of an } \\
\text { enterprise }\end{array}$ \\
\hline $\begin{array}{l}\text { Child care } \\
\text { compensati } \\
\text { on" } \\
\text { allowances } \\
\text { until a child } \\
\text { reaches } 3 \\
\text { years old }\end{array}$ & $\begin{array}{l}\text { minimum } \\
\text { monthly } \\
\text { wage }\end{array}$ & $\begin{array}{l}\text { After } \\
\text { maternity } \\
\text { leave ends } \\
\text { and until a } \\
\text { child } \\
\text { reaches } 3 \\
\text { years of age }\end{array}$ & $\begin{array}{l}\text { Payroll funds } \\
\text { (employer) }\end{array}$ & $\begin{array}{l}\text { Poverty } \\
\text { reduction, } \\
\text { stimulation } \\
\text { of provision } \\
\text { of child care } \\
\text { at home }\end{array}$ & $\begin{array}{l}\text { Employed } \\
\text { mother (or legal } \\
\text { guardian) or laid } \\
\text { off while being } \\
\text { pregnant, in case } \\
\text { of an liquidation } \\
\text { of enterprise }\end{array}$ \\
\hline
\end{tabular}

* This column was informed by the Report No. 24450-RU. Russian Federation. Child Welfare Outcomes During the 1990s: The Case of Russia. Volume 1: Executive Summary, p-p 23-24 (World Bank: Human Development Sector Unit Europe and Central Asia Region, November, 2002)

Finally, the expansion of other allowances, which aim not only to increase the birthrate, but also prevent/ alleviate poverty, such as a lump-sum payment of 4,500 roubles (representing about $\$ 230 \mathrm{CDN}$, while the poverty line is 2000 roubles or $\$ 100$ $\mathrm{CDN}$ per month) at the birth of a child represent a fourth change in the system of benefit provision during the transformation period. Additionally, a concern with infant mortality and the deteriorating health of mothers and children, provided the context for the introduction of an additional allowance for registering in prenatal care during the early stages of pregnancy (during the first 12 weeks). ${ }^{446}$ These are depicted in the Table 20 ,

${ }^{446}$ President of the RF (1993) Order \#405 - translation by the author 
and can be considered as another example of second-order change in child care

policies. $^{447}$

In addition to the various cash benefits, there are a number of other programs

which aim to increase fertility rates and promote healthy motherhood and childhood.

Thus, in 1995, the Government released a National Plan for Improving the Status of

Children in the Russian Federation until 2000, which included a number of programs

such as Family Planning, Safe Motherhood and others. For instance, the Safe

Motherhood program (demanded by the Ministry of Health) was created in order "to

develop new measures of supporting families, and measures aimed at increasing

awareness of the population on the issues of healthy motherhood and maternity." From

the Program:

Protection of motherhood is one of the priority goals of our state, because the transition to the market economy has negatively influenced a number of aspects of motherhood, family and childhood. ... The program requires the development of additional measures of the state's support of families, motherhood and

\footnotetext{
${ }^{447}$ An additional concern, which drew attention to the importance of the family as a natural place for bringing up children, was the rise in numbers of neglected children, which almost reached the same level as in the 1920s. As cited in the 2005 Russia's NGOs Alternative Report, the number of neglected children in Russia in 2001 was close to 1.5 million. The state, which was increasingly investing in establishments rendering social assistance to families and children, rehabilitation centers for families and children, and children shelters, was looking for new paradigms in working with families. Valentina Matvienko, Deputy Prime-Minister in 2000, stated during the government question period in Duma that the government created a new system of providing services to families and children living in difficult conditions. The number of social assistance centres working with such families increased from 107 in 1993 to 2240 in 2000 . These priorities were reflected in the program of social reforms for 1996-2000, which highlighted guarantees for free healthcare and education, the transformation of child benefits from universal to targeted, and additional guarantees for children in difficult life situations (children orphans, disabled children and others). The measures also sought a reduction of social orphanages, expansion of new forms of family upbringing for children, the creation of an effective preventive system of children's neglect. The President approved the main directions of these social policies in the Russian Federation until 2000, whereas the family was to be supported as a natural place for bringing up children.
} 
childhood, by adding new benefits, privileges and guarantees

aimed at improving conditions of motherhood... 448

The specific measures included:

- $\quad$ The increase of the lump-sum payment to women who registered for prenatal care during the first 12 weeks of pregnancy;

- Introduction of family planning education in high schools and others;

- $\quad$ The increase of required frequency of medical check-ups for pregnant women;

- Development of educational programs, and preparation of informational packages for a wide distribution, concerning the foundations of healthy motherhood and importance of families

- Recommendations to the regional authorities to:

o Provide free medication to pregnant women;

- Reimburse transportation expenses associated with travelling to the medical centres/hospitals (related to pregnancy);

- Provide women who have just given birth with their complete sets of medical tests upon release from the hospitals; and

- Create family planning centres. ${ }^{449}$

Overall, the new child care measures described in this subsection can be classified as second-order changes through institutional layering. Similarly to the French case, as described by Palier, "[t]heir development has often led to a change in their meaning within the system. They are first introduced to 'complete' or repair the existing system, but then gradually become the base for a new type or logic of social protection within that system. The interplay between the new policy and the existing system has meant, progressively, a change in the overall trajectory of the system." 450 The post-Soviet period

\footnotetext{
${ }^{448}$ Exert and translation by the author

449 Ibid

${ }^{450}$ Palier (2005): p. 138
} 
was thus marked by the shift in child care policy aimed at supporting female employment and raising educated citizens to the demographic/ child health domain. A strong family policy, however, may not be the same as a strong gender equality policy. It may be directed towards increased fertility, support of families and traditional gender roles, as well as refamilialization of care (as it is in the Russian case). Thus, the cumulative impact of gradual changes in parental leave schemes, in-home caregiving allowances, and a range of benefits aimed to stimulate birthrates combined with the changes in care ideals effected much more profound changes in the trajectory of the Russian welfare state and social structures, leading to refamilialization of care. And even if the monetary level of provision of the new in-home caregiving allowances is low, the accompanying reduction in the number of child care institutions reinforced the trends of family provision of care. It is clear that in the absence of child care services, facing societal pressures in terms of what is seen as "acceptable" care and having policy incentives (i.e., long leave and allowances), one of the parents (in most cases a woman) is compelled to stay at home or look for other "acceptable" solutions (e.g., intergenerational care). Such focus on return to traditional roles, combined with the state's withdrawal from its previous commitment to full female employment threatens both gender and class equality by affecting not only family income and the woman's career but also gender relations at large.

\section{Third Order Institutional Change: Child Care Services}

Child care serves as a paradigmatic case of the institutional change, and through the lens of child care policy we can see how the institutional constraints on women's labor market 
choices have changed in the transformation period. Child care services epitomize the differences between Soviet and post-Soviet regimes, and serve as a third-order change in Hall's framework, which is required for the paradigm change to be complete, or to make a new paradigm. It represents a departure from the underlying logic of the previous paradigm that existed in the Soviet period - full female employment and massive investment in child care. The new logic reflected the need to provide women with "choice," and allow them to stay at home to care for children (without providing sufficient viable public or market options to make a real choice, thus pushing the responsibility for care provision to families). Therefore, not only did the policy prescriptions of the new advocates for women's "choice" differ from the Soviet massive investments in child care, aimed to facilitate women's employment, but they were also based on a different conception of the role of women and families in the society. This coincided with the new liberal ideology of individualism, which came in the package of market reform. It placed a much greater responsibility on the individuals and their families for their personal welfare, including care provision. The changes in child care provision represent not just a mere change in the instrument (or lack of thereof) - child care services, but a replacement of one set of goals (i.e., female employment) with another ("choice" to be good wives and mothers without "having" to perform paid work). Institutional changes or changes in the policy instruments include significant declines in the number of child care facilities and number of children per facility, as well as changes in the actual type and ownership of these facilities. The nuanced analysis of such decline reveals a certain degree of the "drifting" process of institutional change, when child care institutions were allowed to decay without active maintenance and adaptation to changing 
economic situation and care ideals (i.e. expectations with regard to the quality of care). Finally, the changes in the settings included changes in the financing of child care services, as well as the eligibility criteria for "qualifying" for child care services.

The next subsections analyze the changes in child care provision at both national and local levels. These will highlight the importance of the local dimension of child care provision, which is particularly salient due to the legacy of decentralization of welfare provision, inherited from the Soviet system, as well as the further empowerment of the locales and regions, obtained during Yeltsin's presidency. This was partly a result of the privatization schemes (which allowed elites to obtain control of most of the former state assets) along with the division of powers and greater independence promised by Yeltsin to the regions, in return for their loyalty, as well as the offloading of responsibilities for welfare provision to the regional/ local levels. The analysis of changes in both national (country-wide) and local child care services will allow us to obtain a deeper understanding of how and why these changes take place.

\section{Provision of Child Care: National View}

As illustrated in the previous chapter, the provision of child care services in the Soviet period was mainly public (via state enterprises and municipalities) and characterized by universal affordability and access to those services. The Soviet state was also able to achieve high levels of child care provision (Table 21). The transformation period saw a 
sharp decline in both the number of pre-school institutions and the number of children enrolled in them. ${ }^{451}$

Table 21. Pre-school Institutions, Russia, 1985 - 2001

\begin{tabular}{|c|c|c|c|c|c|c|c|c|c|c|}
\hline 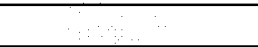 & 1985 & 1989 & 1990 & 1992 & 1994 & 1997 & 1999 & 2000 & 2001 & 2002 \\
\hline $\begin{array}{l}\text { Total number of } \\
\text { pre-school } \\
\text { institutions (both } \\
\text { kindergartens } \\
\text { and nurseries, } \\
\text { thousands) }\end{array}$ & 87.8 & & 87.9 & 82.0 & 72.4 & 60.3 & 53.3 & 51.3 & 50.0 & 48.9 \\
\hline $\begin{array}{l}\text { Total number of } \\
\text { children enrolled } \\
\text { in pre-school } \\
\text { institutions (both } \\
\text { kindergartens } \\
\text { and nurseries, } \\
\text { thousands) }\end{array}$ & 9,180 & & 9,009 & 7,236 & 6,118 & 4,706 & 4,225 & $\begin{array}{l}4,26 \\
3\end{array}$ & $\begin{array}{l}4,24 \\
6\end{array}$ & $\begin{array}{l}4,26 \\
7\end{array}$ \\
\hline $\begin{array}{l}\text { Including urban } \\
\text { areas }\end{array}$ & $\begin{array}{l}7,118 \\
(74.6 \\
\% \text { of } \\
\text { all } \\
\text { childr } \\
\text { en })^{*}\end{array}$ & & & 5,569 & 4,723 & 3721 & 3378 & $\begin{array}{l}3,40 \\
9\end{array}$ & 3384 & $\begin{array}{l}339 \\
8\end{array}$ \\
\hline $\begin{array}{l}\text { Including rural } \\
\text { areas }\end{array}$ & & & & 1,667 & 1,395 & 985 & 847 & 855 & 862 & 869 \\
\hline $\begin{array}{l}\text { Total number of } \\
\text { children enrolled } \\
\text { in nurseries } \\
\text { (thousands) }^{\text {b }}\end{array}$ & & 2,514 & 1,968 & 1,178 & 936 & & & & & \\
\hline $\begin{array}{l}\% \text { of children in } \\
\text { kindergartens }\end{array}$ & & & & & $\underset{c}{35.59}$ & & & $\begin{array}{l}39.4 \\
0 \\
(200 \\
1)\end{array}$ & & \\
\hline $\begin{array}{l}\% \text { of children in } \\
\text { nursery }\end{array}$ & & 26 & 21 & 14 & 14 & & & $\mathrm{n} / \mathrm{a}$ & & \\
\hline $\begin{array}{l}\text { Waiting Lists } \\
\text { (both } \\
\text { kindergartens } \\
\text { and nurseries, } \\
\text { thousands) }\end{array}$ & & & & & & 240.2 & 192.9 & $\begin{array}{l}238 \\
2\end{array}$ & $\begin{array}{l}302 . \\
7\end{array}$ & $\begin{array}{l}404 . \\
9\end{array}$ \\
\hline
\end{tabular}

a) Number of institutions based on The Demographic Yearbook of Russia. 2002: Statistical Handbook/Goskomstat of Russia. - Moscow, 2002

b) Savelyev A. "Higher Education: Status and Problems of Development," Moscow, 2001, p. 40 (Source is in Russian: Высшее образование: состояние и проблемы развития. М.: НИИ ВО, 2001,с. 40).

${ }^{451}$ Teplova \& Woolley (2005) 
c) The percentage of children in the kindergartens was calculated by the author using the Russian Longitudinal Monitoring Survey (based on the answers of mothers about care for their children)

* Source: Women of Russia. Statistical collection. Gokomstat of Russia. Moscow, 1995

These figures, documenting the decline in the number of children in pre-schools and nurseries, are well-known. There are just a few points to be emphasized here. First, the number of child care institutions fell at a much greater rate in the rural areas, compared to urban areas - a reduction of 2,000 child care institutions per year, versus 1,000 per annum. Second, in urban areas, the percentage of children in child care facilities collapsed during the initial part of the transformation period - for example, the percentage of children attending nurseries declined from 26 per cent in 1989 to 14 per cent in 1992. The percentage of children in kindergartens is also very low compared to the Soviet period - some estimates put the percentage of children in pre-school during the Soviet period as high as 74 per cent (in urban areas). This trend is often explained by the limited financing and declining demand, due to declining number of children, long maternity leaves (up to 3 years), and home care allowances. ${ }^{452}$ During the late 1990 s, the percentage of children enrolled in pre-school stabilized - or even increased - despite the steep decline in the number of child care institutions and number of enrolled children. A sharp decline in fertility at the beginning of the 1990 s meant there were fewer children of pre-school age in the country, which in turn resulted in a relatively greater number of child care places per child (Table 22). ${ }^{453}$

\footnotetext{
${ }^{452}$ Local interview participants

${ }^{453}$ This paragraph is extensively based on the paper jointly written (50/50) with Frances Woolley
} 
Table 22. Live Births/Total Fertility Rates in Russia, (1988 - 1991, 1994-2000)

\begin{tabular}{|c|c|c|}
\hline Year & Live Births & Total Fertility Rate \\
\hline \multicolumn{3}{|c|}{ Children to be in the age of 3-6 years old in 1994} \\
\hline 1988 & $2,348,494$ & 2.130 \\
\hline 1989 & $2,160,559$ & 2.007 \\
\hline 1990 & $1,988,858$ & 1.887 \\
\hline 1991 & $1,794,626$ & 1.732 \\
\hline \multicolumn{3}{|c|}{ Children to be in the age of 3-6 years old in 2000} \\
\hline 1994 & $1,408,159$ & 1.400 \\
\hline 1995 & $1,363,806$ & 1.344 \\
\hline 1996 & $1,304,638$ & 1.281 \\
\hline 1997 & $1,259,943$ & 1.230 \\
\hline 2000 & & 1.25 \\
\hline 2003 & & 1.33 \\
\hline 2005 & & 1.27 \\
\hline
\end{tabular}

Source: Calculated by the author using the Russian Longitudinal Monitoring Survey

During the transformation period, child care services also saw changes in the institutional structure. According to the Law on Transfer of Social Assets, social assets, belonging to the former-state enterprise had to be transferred to municipalities. This process was to take place concurrently with the privatization of state enterprises (starting in 1992). The aim of this process was to relieve enterprises from economically unreasonable activities such as maintenance of social infrastructure and allow to concentrate on investments and production sides. The assumption was that municipal governments would be in the position to manage such "objects of the social 
infrastructure" in a more effective and efficient way. Another assumption was that the federal government would be transferring additional resources to municipalities to assist in maintaining and operating the facilities. The process of municipalization, however, took place at a different pace across Russian cities and villages. As we will see in the subsequent chapters, some enterprises resisted offloading their social assets to municipalities and in some cases, municipalities refused to assume responsibility for the additional assets due to the lack of capacity (financial and administrative). As it turns out, such transfer was not supported by the adequate reallocation of funds to municipalities. ${ }^{454}$

Table 23 provides a snapshot of the institutional changes in the nature of child care provided in Russia. Using the Russian Longitudinal Monitoring Survey data, which questioned mothers about their children's care facilities, data were assembled concerning the ownership of child care facilities. This analysis has some inherent limitations however. The main privatization of state enterprises and thus privatization or transfer to municipalities of their assets took place in 1992, while the data available cover only the later transformation period, from 1994-2001, where one could observe a relative stability in ownership and number of child care facilities. As will be shown in the local casestudies, in the early transformation period the enterprise child care facilities usually were either privatized and sold for other use, simply closed down or transferred to municipalities.

It is important to note here that even though the enterprises were privatized, the social infrastructure should not have been. According to the law, all the social

\footnotetext{
${ }^{454}$ TACIS $(1998 \mathrm{a}, \mathrm{b})$
} 
infrastructure facilities at the enterprises, such as sanatoria, child care, rest houses, and pioneer camps, remained a state property, and the enterprises could not dispose of these facilities in any other ways but to transfer them to municipalities (or maintain them at the enterprise). ${ }^{455}$ While it is not evident from the available data at the national level (but will become clearer in the local case-studies), as a result of the enterprise privatization and municipalization of social assets, the number of municipal child care facilities increased three-to-fivefold across the country (while the overall number of facilities have declined). As noted in the TACIS report on child care in Russia, "there is a series of CCI [child care institutions - inserted by the author] in possession of federal agencies (the Communication Lines Ministry, the Education Ministry, the Russian Academy of Sciences), which are funded from the federal budget... A number of agencies, such as Gazprom, do not intend municipalization of their CCI." ${ }^{456}$ Thus, institutional changes in child care provision (reduction in the number of public child care facilities and change in ownership), can serve as a foundation for the third-order change.

Table 23. Ownership of Child Care, 1990 - 2001, Russia

\begin{tabular}{|l|c|c|}
\hline & $\mathbf{1 9 9 4}^{\mathbf{a}}$ & $\mathbf{2 0 0 1}$ \\
\hline Government $^{457}$ & $\mathbf{\%}$ & $\mathbf{\%}$ \\
\hline Official department or enterprise & 80.7 & 91.40 \\
\hline Private owner & 18.5 & 8.02 \\
\hline Someone else & 0.3 & 0.57 \\
\hline
\end{tabular}

a) Ownership figures calculated by the author using Russian Longitudinal Monitoring Survey individual data. For 1994, $\mathrm{n}=373$, for $2001 \mathrm{n}=349$.

In addition to the deliberate privatization and sale of child care facilities, a

number of the facilities were allowed to simply decay and were closed by the sanitary

\footnotetext{
${ }^{455}$ Government of the RF (1992) - translation by the author

${ }^{456}$ TACIS (1998b): p. 3

${ }^{457}$ Government includes governments at all levels (federal, regional and municipal)
} 
inspectors due to their unfitness for child care purposes. ${ }^{458}$ Elements of decay included poor quality of care (low standards according to the emerging care ideals in the country), poor quality of physical plants as well as of hygiene and health side of services provided. In general terms, maintenance and adaptation to the political and economic environment in which they are embedded, a number of child care facilities eroded through what Thelen and Streeck termed drift. Such institutional change, however, does not just happen. As highlighted by Thelen and Streeck: "Like change by layering, change by drift can also be promoted by political cultivation." 459 In case of Russian child care, political cultivation involved policymaking through deliberate nondecisions when the emerging gaps in quality of child care services started to emerge. While the reasons for such nondecisions will be analyzed in the next chapter, it is worth mentioning here that the downloading responsibility for financing of child care facilities from the federal/formerstate-enterprises budgets to municipalities (which had very poor financing), the low importance attached to child care in the conditions of changing attitudes with regard to the role of women in the 1990s, and emergence of other priorities can help explain this trend. Thus despite the fact that there were no major regulations or policies dismantling child care services, the decline (very significant one) happened nevertheless - through "failure actively to maintain an institution, that is to say,... to actively allowing it to decay. ${ }^{, 460}$ These trends are most visible at the local level and elaborated upon below.

\footnotetext{
${ }^{458}$ As described by interview participants - translation by the author

${ }^{459}$ Streeck and Thelen (2005): p.25

460 Ibid.
} 
By 1994, however, the situation became relatively stabilized. The majority of remaining child care facilities (both nurseries and kindergartens) were "owned" by the government, as a result of the transfers from enterprises (some enterprises remained involved even after transferring them to municipalities, in order to provide child care spots to their employees). Nevertheless, a number of child care centers - almost 20 per cent - still belonged directly to the enterprises, as shown in the second row of Table 23. Although the new private enterprises have also provided some social services, the child care centres are more typically found in large industrial privatized enterprises.

The trend of transferring child care enterprises to municipalities is not problemfree, however. In general, the social assets that have been transferred to the ownership of municipalities, incurred considerable adverse implications. Across the country, "the municipalities have generally been reluctant or unable to cover the financial cost of taking over these activities; during the past five years, the hand-over of social assets to municipalities was not supported by an adequate reallocation of funds." ${ }^{461}$ Further, as detailed through the Novorossiysk and Sakha Yakutia case studies in this chapter, some of the "solutions" used by municipalities included the tendency to use child care facilities for purposes other than designated (e.g., a soccer club) or sell them for commercial purposes (not child care). I will argue in chapter 4 that this was a result of low financial capacities of municipal authorities, their resistance to federal regulations and overall low importance attached to child care.

${ }^{461}$ TACIS (1998b): p. 19 
As we saw from Table 23, the institutional change in child care, however, did not go through the full spectrum of possible options. Despite the ostensible government commitment to private enterprise and initiative in other sectors of economy, there has been no indication of the emergence of a viable, privately-owned, child care sector (including surrogate mothers). Even in 2001, less than one per cent of child care facilities were privately owned. Although Table 23 does not distinguish between public and private enterprises (the "official department or enterprise" could be private), it is safe to assume that most of the centers listed under this category are in public or privatized enterprises, which have inherited the facilities from the Soviet past and often are either receiving state donations for maintaining their facilities, in the process of transferring them to municipalities, or keeping them as a labour incentive.

Finally, there were a number of other changes in child care provision, which can be seen, in Hall's terms, as changes in the settings. The first change is the introduction of a municipal tax on the enterprise social infrastructure, which is paid by the enterprises. The more developed the infrastructure provided by employers (including child care facilities, canteens, camps for children etc), the higher the tax on it. It can go as high as $1.5 \%$ of the total income of an enterprise. The specific rates are established directly by municipalities. The enterprise can deduct all expenses associated with maintaining the infrastructure, however this is seen as a toll, particularly by the enterprises which are struggling to make their ends meet in the new economy. The second change is the financing of child care services. Since 1993, municipal kindergartens have been financed from the municipal budgets (as opposed to the federal ones in the Soviet period). In 
general, the local document review revealed that the municipal financing covers less than 70 per cent of the child care cost per child (mainly the wage-related items: wages, payroll taxes and associated social contributions). Municipal financing is normally insufficient to cover costs of major repairs, as well as to finance the training and professional development activities and materials (these are financed only at one-third). The lack of financing resulted in deterioration of the capital base of child care institutions: more than a half of these institutions require major repairs. To offset some child care costs, parents pay a fee for care, calculated at $20 \%$ of the cost of child care services per child (with some exceptions in the case of families with three children, children with disabilities and others). ${ }^{462}$ The requirement to pay is not a new phenomena, but the move from the flat rate fee charged in the Soviet period to the ratio from the total cost, in the conditions of high inflation and widespread poverty, made even publicly provided child care services increasingly expensive for the majority of the population. Finally, the federal government introduced an accreditation system (every preschool institution has to undergo accreditation every five years) and established inspections to check the quality of child care services and compliance by local authorities and other owners of child care facilities. These measures were introduced by the federal government to prevent a widespread (and hardly legal) privatization of child care facilities by both enterprises and municipalities, and ensure a certain quality of the remaining child care services.

\footnotetext{
${ }^{462}$ Council of Ministers of the Government of the RF (1993) Resolution "On financing of objects of social infrastructure, which were transferred to municipalities"; Supreme Council of the RF. The Resolution \# 112 "On Payments for attending municipal/enterprise-based child care facilities and financial support of the system of these facilities."
} 
Thus, a combination of these institutional and organizational changes in child care can be seen as representing a third-order change in Hall's framework and serves as an adjustment to the growing internal and external pressures, as well as a response to the declining perceived importance of child care services. While some of the elements of change in child care provision have a relatively gradual character and there are undoubtedly some, while insufficient, attempts on the part of the federal government to preserve the system, the overall trend of reducing provision of public child care represents a significant departure from the previous paradigm, where child care was seen as a crucial element for enabling female employment, even in times when reproduction was the key concern of the state. The new paradigm saw public child care provision as mainly inefficient remains of the past and implied that care should be provided by mothers at home thus breaking the link between public accessible child care and women's work. Thus child care services epitomize the ideological changes with regard to the role of women and nature of welfare state in Russia during the decade of the 1990s. The next subsection will highlight the local trends in changes in child care service and will show that part of the process of change took place though institutional drift, without specific political maneuvering.

\section{Provision of Child Care: Local View}

This section examines changes in child care services at the subnational levels. Given the legacy of the decentralization of the Soviet welfare provision, the regional and local lens of analysis (or subnational scales in Mahon's terms), remained important during the transformation. As Mahon points out, "[t]his left scope for the development of forms of 
social reproduction that differed from the logic embedded at the national scale."

Furthermore, the multiscale lens of analysis is important, as it can provide insight on the nature of changes at the local level. To quote again Mahon:

Exposed to forces of change, including changes in relations of social reproduction, such spaces can become veritable laboratories of experimentation, as urban denizens struggle to fill the gaps in existing arrangements revealed in their encounters with the novel. In the process, new rights claims arising out of these urban experiences may lead to the emergence of forms of urban citizenship at odds with national welfare regimes. ${ }^{464}$

It is precisely the nature of the changes that will be explored in this section. The analysis will focus on two locales: municipal (the city of Novorossiysk, which represents the common trends across the country with regard to provision of child care services) and regional (the republic of Sakha Yakutia, which demonstrates a unique case of maintaining its full commitment to provision of public child care). These local examples will help us understand why and how the policy paradigm shift in child care took place (as detailed in chapter 4). We will explore the nature of the changes in child care service provision in both locales, and provide a micro-level analysis of macro-institutional changes, a lens that is rarely used.

Table 24 presents the main institutional changes in child care provision in both Sakha Yakutia and Novorossiysk. There are a number of factors to be emphasized here. First, these changes indicate that there has been a decline in the number of child care facilities in both locations. The total number of child care facilities in Novorossiysk declined from 85 in 1992 to 58 in 1998, thus marking almost 30 per cent decline in the

\footnotetext{
${ }^{463}$ Mahon (2005a): p. 346

${ }^{464}$ Ibid.
} 
number of facilities. In Sakha Yakutia, the main decline took place in urban settlements:

from 431 in 1992 to 274 in 1998 , thus also constituting a change of more than 30 per

cent. Overall, these cases show that the trend of decline is within the limits of an all-

Russia trend.

Table 24. Child Care Institutions in Novorossiysk and Sakha Yakutia

\begin{tabular}{|c|c|c|c|c|c|c|}
\hline & \multicolumn{3}{|c|}{ Novorossiysk } & \multicolumn{3}{|c|}{ Sakha Yakutia } \\
\hline & Municipal & $\begin{array}{c}\text { Enterprise- } \\
\text { based }\end{array}$ & Total & Urban & Rural & Total \\
\hline \multicolumn{7}{|c|}{ Preschool institutions } \\
\hline 1992 & $\begin{array}{c}19 \\
(22.3 \%)\end{array}$ & 66 & 85 & 431 & 585 & 1016 \\
\hline 1998 & 37 & 21 & 58 & 274 & 508 & 782 \\
\hline 2001 & 39 & 17 & 56 & & & \\
\hline 2002 & 41 & 14 & 55 & & & \\
\hline \multicolumn{7}{|c|}{ Number of children in the preschool institutions, thousands } \\
\hline 1995 & & & & & & 64.1 \\
\hline 2001 & 5.561 & 1.153 & 6.714 & & & $51.6^{*}$ \\
\hline \multicolumn{7}{|c|}{$\begin{array}{l}\text { Percentage of all children (from } 1 \text { to } 7 \text { years old) in preschool institutions - total } \\
\text { number of children from } 1 \text { to } 7 \text { in Novorossiysk is } 14,992\end{array}$} \\
\hline 1995 & & & & & & $61.5 \%$ \\
\hline 2001 & $37 \%$ & $7.7 \%$ & $44.7 \%$ & & & $69.8 \%$ \\
\hline
\end{tabular}

*data for 1999

Source: 1) Novorossiysk municipal documents

2) Republic Sakha-Yakutia in years of sovereignty (1990-2000). Yakutia, 2000, p.62.; Russian Statistical yearbook. 2000. Moscow.p. 182

3) Most v Buduchee. Yakutsk. (2000):p. 10; O Pologenii Detei v Rossiiskoi Federacii (2000): p.95, Social'no-economicheskoe pologenie v Rossii (1999): p.205. [Bridge to the Future. Yakutsk. (2000); p.: 10; Report "Position of Children in the Russian Federation." (2000) p.:95; Report "Socio-economic Situation in Russia. (1999), p.: 205"]

Second, the table also illustrates the changes in the ownership, in the Novorossiysk case. Thus, for the period of 1992-2002, the majority of Novorossiysk enterprises transferred their child care facilities ( 52 in total) to the municipality. For example, one of the richest enterprises in the city, Novorossiysk Marine Trade Port (NMTP), the largest oil port in Russia, reduced its number of child care facilities from 7 
to 4 , and even the remaining facilities are planned to be transferred to the city. When they were asked, during the interviews, why the enterprises closed and transferred their child care facilities, enterprise representatives mentioned the declining number of children in the 1990 s and the fact that the facilities became very expensive to maintain. ${ }^{465}$ Other reasons named included high taxes on all objects of social infrastructure:

It is unprofitable for our enterprise to maintain these facilities, due to the large extra tax load associated with them. If they were previously financed from the central ministries, now financing has to come out of our profit.

Under the old system, the enterprise had a childcare inspector, a position which is still maintained, but soon will be abolished. Now we are planning to transfer the facilities, since the new enterprise policy under the current economic conditions is to pay higher salaries, and workers would be able to afford any child care they need/want. ${ }^{466}$

Nevertheless, one interview participant admitted that the change had to be gradual in order to be "understood" by the employees:

Of course we could have sold the facilities earlier, but we decided to maintain some of them, as the workers would not have understood us.

The City, in turn, did not demonstrate the required commitment, and neither had the capacity to maintain the "inherited" child care facilities. ${ }^{467}$ Local document reviews further revealed that the municipal facilities (both inherited from the Soviet period and transferred from the enterprises) were used in the following way:

- 41 institutions continue providing child care services; but

\footnotetext{
${ }^{465}$ The interviews were conducted by the author in the Summer 2004.

${ }^{466}$ Interview by the author

${ }^{467}$ The low capacity of the city, in the conditions of the tight budgets, was mentioned during the interview with the city official.
} 
- 21 institutions were used for other purposes, including private schools, the Armenian Society, the soccer club, military base, court infrastructure, the children's shelter, IT company, a private educational institution, a barber shop, etc;

- 5 institutions were closed due to poor sanitary conditions; and

- 4 institutions were sold (for exhibition halls and business centers).

Thus, out of 71 institutions, which might have been providing child care services under municipal auspices, more than $40 \%$ are used for other purposes or closed. The major transfer of facilities took place between 1992 and 1998. The same is true for the major changes in the use of facilities. As seen from the Table 24, after 1998, one could observe a relative stability in the number of child care institutions. Meanwhile, the municipal waiting list for the child care places is increasing: in 1998, the general waiting list was about 1,100 children, with a preferential number hovering at 300 ; in 2001 , the list consisted of 2,444 children; in $2003-2,800$ children. This is significant, as the total number of children in the city (up to the age of 16 ) is about $68,000 .{ }^{468}$ In response to the citizens' requests to return child care facilities, which were earlier re-profiled, or build new ones in order to accommodate the rising need in child care, the municipal head stated that neither funds nor appropriate land spots were available to build new child care institutions. Interestingly, despite the noted limited financing and infrastructure/land capacity, the city saw the emergence of municipally funded soccer clubs, aqua-parks and other institutions, which apparently were seen as more important at the time.

This situation is not unique to Novorossiysk. As stated in the Moscow Branch of the Department of Education, "despite the Presidential Decree banning privatization of

\footnotetext{
${ }^{468}$ Novorossiysk City Administration (2006) - translation by the author
} 
the objects of social infrastructure, including child care institutions, new political, bureaucratic and business entrepreneurs managed to somehow get them sold / privatized and used for commercial purposes. Thus in the last fifteen years, Moscow saw closing of 640 former enterprise-based child care institutions out of 1007."469 It is worth mentioning here that some of the Moscow kindergartens can be worth millions of dollars as real estate property, particularly those situated in the downtown areas of Moscow. It is also notable that Moscow municipal budget per capita is one of the largest in Russia thus making potential complaints on financial difficulties by municipal authorities a bit doubtful.

In another Russian city, Tomsk, ${ }^{470}$ the waiting line to receive a spot in a child care institution consists of more than 12 thousand children. The city also saw closing of more than 400 child care institutions: out of 647 child cares inherited from the Soviet period, only 216 remained. ${ }^{471}$ In order to solve the emerging problem with child care, the local city administration decided to compensate for the insufficient supply of public child care services by the additional payments to all mothers to stay home until a child reaches three years old (this payment would be offered in addition to federally provided in-home caregiving allowance paid until a child reaches 18 months of age and only to employed mothers). The rationale provided for this solution is that it is much more cost effective to pay mothers to stay with children at home than maintain child care facilities. It is proposed to make these payments income-tested. The suggested payment amount is from

\footnotetext{
${ }^{469}$ Moscow branch, Department of Education - public statement - translation by the author

${ }^{470}$ Population of Tomsk (a city in Siberia) is estimated to be around 500 thousand inhabitants.

${ }^{471}$ State radio "Tomsk" (2005) - translated by the author
} 
four to six thousand roubles ( $\$ 150$ - $\$ 200$ USD) monthly, which is much greater than the federal in-home caregiving allowances (\$17 USD per month) and "compensation" payments, provided by employers until a child reaches 3 years old ( $\$ 1.7$ USD per month). ${ }^{472}$ According to Nagovitsin, the member of the Tomsk Regional Duma, "paying mothers to stay at home would allow to quickly resolve the issue of child care, particularly for children under three. We believe that a child until reaching three years old should be brought up at home. And for those who are in need of assistance, we would provide public financing so that a mother could afford to stay at home with her child."473

These statements and proposed policies serve as an illustration of the prevalence of the "full-time mother" ideal of care not only among federal, but also local policymakers. Such policies illustrate not only the lack of commitment on the part of local authorities to maintain child care facilities but also a shift in the paradigm governing care provision, thus downloading the responsibility for child care provision from the state to "mothers." We can see that local provisions significantly affect the ultimate shape of child care policies. These examples show that some of the child care facilities were allowed to "decay" or were disposed for undesignated purposes without introduction of major changes in official policies. This $d r i f t$ form of institutional change partly resulted from the "natural" trends, with changing images of women's role in the society and appropriate ideals of care (particularly in light of other policy incentives available to women to care for children themselves at home, i.e., in-home caregiving allowance). The next chapter will account in detail for the main reasons of why municipalities chose not

\footnotetext{
472 Tomsk TV-show "Час-Пик" (2005) - translated by the author

${ }^{473}$ State Radio "Tomsk" (2005) - translated by the author
} 
to maintain all child care facilities with particular attention to the gaps in rules and capacity of federal and local actors that resulted in decaying of public child care provision.

While there are no data on the child care ownership structure for Sakha Yakutia, the document reviews and interviews revealed that the there is a commitment on the part of authorities to provide public child care. Thus, the 1997 order of the regional minister of education of Sakha Yakutia introduced mandatory kindergarten attendance by all children older than 5 years. The rationale for this was to improve the children's preparedness for school years. As a result, the percentage of 5 year olds enrolled in kindergartens was $69.7 \%$ in $1997-1998 ; 83.8 \%$ in $1998-1999$; and $89.7 \%$ in $1999-2000$. The number of enterprise-based child care institutions, however, is declining: both "poor" and "rich" enterprises close child care facilities. ${ }^{474}$

The third factor that needs to be highlighted with regard to the local care provision is that regions and municipalities mirrored federal changes in the cost structure of child care. For example, in Novorossiysk, by the order of the Mayor, starting in 1997, parents pay for preschool education - about $20 \%$ of total child care costs. In 2000 , the amount of payment was 120 roubles per month; in 2003 it increased up to 321 roubles (\$11 USD). There is, however, a system of state income-based subsidies for certain categories of the population, including families with many children (50\% discount), lone parents, poor families and others.

\footnotetext{
${ }^{474}$ This degree of poverty or wealth of enterprises refers to a number of factors, including the difference in the ability to adjust to the new economy, the sector they represent (e.g., oil versus light industry), private sector versus public sector (education, health and other so-called "budgetary" spheres)
} 
In addition to the regular payments, in order to meet market needs and generate some revenue, the city introduced another type of payment - an entrance lump sum payment (about $\$ 320$ US). This payment was optional, and allowed parents to obtain a child care place without having to wait for several years. Enterprises, in turn, introduced monthly payments equal to 800 roubles (about \$26 US - a sum which is 2.5 times higher than the municipal one), irrespective of income level and employment experience, with the purpose of offsetting some of the costs. There is no entrance payment for enterprisebased child care. Additionally, in some cases, the enterprises remained involved after transferring the facilities to municipalities, by providing funding and securing a number of spots for their employees. In these cases, enterprises often cover all or some of the entrance payments to the municipal kindergartens. Private kindergartens (there are two in the city) charge parents about 4,500 roubles (about $\$ 150$ USD), with the entrance payment of $\$ 500$ USD. These fees cover special preschool programs and a range of additional services (English, French, ballroom dancing).

Fourth, the municipality determines the eligibility criteria and processes of obtaining a municipal child care spot. All the children, prior to being assigned to a municipal preschool institution, have to register with the municipal education body. There is a unified waiting list for the city. Child care places are centrally administered and distributed (at the municipal level). In order to obtain a place, parents are required to prove their employment. Lone parents, student mothers, large families, families with twins and other categories, have a right to child care without being placed on the waiting list (if there is a place; if no place is currently available, representatives of the 
aforementioned groups of population are being placed in the "priority" waiting list).

Employees of child care institutions also have the right to obtain a child care spot without a waiting period (which is also a way to attract them to the low-paying jobs in child care institutions). The places are provided with the condition of staying there for at least three years (and the threat of losing the place if they leave). The main criterion for enterprisebased child care included employment of one of the parents at the enterprise.

Finally, all child care institutions, including private and enterprise-based ones, must undergo state accreditation. Most of the enterprise-based child care facilities do not have an accreditation, as they still being considered part of an enterprise. These cases show that the child care policies, while in most part shaped by national policies, are affected by the local institutions and regulations, as well as the level of importance attached to them by the local officials.

Thus, this section demonstrated that the nature of the changes in welfare regimes and in child care in particular - is determined to a large extent by the local settings and conditions. This is particularly true in the cases that involved decentralization of the service provision functions, as seen in the Russian (and Soviet) case. While obviously decentralization of service delivery is ultimately a result of centralized decision-making, the significant empowerment of regional and local elites vis-à-vis the federal state allowed a much greater room for maneuvering with regard to social and other policies at the local level, than provided for by official federal regulations. For instance, some of the national regulations on child care services (i.e., banning privatization) were indeed ignored at the local level. As Mahon has noted "Newly voiced needs may, in turn, give 
rise to local programs that sometimes anticipate national developments but may also break with them." ${ }^{475}$ In the Russian case, the developments at the local levels, together with the national level changes in the ideas and policies concerning child care and the role of women, show the specific nature of the third-order change in the policy paradigm shift in child care, and will help us understand how the change takes place, accounting for the complexities and nuances of the transformation, as well as the federal structure of the Russian state. Chapter 4 will further examine the role of local governments and enterprises in bringing this change about, while chapter 6 will assess other factors, such as shrinking budgets and the state's inability to enforce the law, at both federal and local levels.

\section{Discussion and Conclusions}

Overall, this chapter has illustrated that the demographic crisis, and the need to release tension in the Russian labour market significantly contributed to the creation of a broader political agenda among Russian policymakers, aimed at "returning women to homes."476 This changing ideological discourse, combined with the absence of real results of the market reforms, resulted in a combination of changes and continuities in child care policies and marked a significant shift in the paradigm governing the provision of social care in the post-Soviet Russia. The shift is significant, because it involved a rethinking of policy logic, from the Soviet gender contract (where every mother was supposed to be a working mother) to one adhering and even reinforcing the male breadwinner / female

\footnotetext{
${ }^{475}$ Mahon (2005a): p.354

${ }^{476}$ Gurgenko (2002): p 101 - translation by the author
} 
homemaker arrangement and familial welfare obligations. Specifically, the new welfare logic involved two sets of ideational changes: first, a shift in the idea that care for children is mostly a state responsibility. The declining interest and ability of the state to maintain this responsibility shifted the bulk of it to the families, particularly under the conditions of underdeveloped market institutions. Second, the shift involved the notion that a woman's place is at home, which was expressed in the increasing advocacy of familial values, including opposition to female, and especially maternal employment, and served as a convergence point for Russian policymakers and various political leaders. In general terms, the shift involved the redefinition of the role of the state vis-à-vis family, and led to refamilialization of care.

In broad terms, the three-order institutional changes in child care policy in Russia, during the first decade of transformation, represented a combination of neoliberal adjustments to the new economy (privatization of state enterprises and subsequent reduction of the number of child care facilities) and policies inherited from the Soviet period (i.e., extension of child care leave). These were subsequently adapted to the new conditions and extended in order to serve new economic and social goals (i.e., release of labour market pressure and resolving of a demographic crisis). The overall cumulative effect of the institutional changes, which may seem to have an incremental nature led to the transformation in the nature of the Russian welfare regime, from the one seeing women as simultaneously mothers and workers, to the one promoting a status of a temporary homemaker and aiming to "bring mothers back home" under the notion of "free choice" to stay home. A full understanding of how this shift came about (and the 
role of ideas) requires attention to both state and non-state actors. The detailed account of the debate among policymakers and non-state actors on the nature of these changes will be provided in chapter 4 .

Table 25 illustrates how the post-Soviet welfare state encompasses elements of different welfare models, developed by Esping-Anderson and advanced by Mahon in gender terms, to accommodate for the labour market changes. It also provides a comparison with the Soviet model. Table 25 highlights once again that Russia neither embarked on the purely neoliberal way, nor moved towards a social-democratic ideal, in its welfare state development. While neoliberal reformers managed to shift child benefit provision from universally provided to a means-tested basis of provision, and reduce provision of public child care services, overall they were only partially successful in their attempts to reduce commitment to provision of social benefits and restructure enterprises to eliminate social infrastructure. There are a variety of possible explanations for this phenomenon. The first is that the development of a fully-fledged neoliberal model required developed market institutions, which include not only private child care facilities, but also legal and institutional frameworks allowing for these facilities to emerge and to be sustained. The neoliberal model would require strong law enforcement institutions, where women can protect their rights, a stable purchasing power, enabling parents to buy child care services on the market, and stable market institutions for private child care to evolve. Given the institutional constraints, and the low wages and high costs of private daycare, the market was not able to provide a sufficient, amount of high quality/low price trusted child care institutions. Moreover, the values of state paternalism, high inertia in social policies, the 
fear of failure and unstable balance of "power - elites - masses," particularly given the lack of trust in the reforms, made the neoliberal model quite unpopular with the Russian masses. This can be seen as the so-called "policy feedback" $" 777$ of the Soviet social policies and economic system, which suggests that policies have important effects on organized interests, political elites as well as citizens generally.

Table 25. Comparison of the Soviet Welfare Regime with the Post Soviet and Mahon's Types of European Welfare Regimes

\begin{tabular}{|c|c|c|c|c|}
\hline Soviet & Post Soviet & $\begin{array}{c}\text { Social- } \\
\text { democratic }\end{array}$ & $\begin{array}{l}\text { Conservative/ } \\
\text { Neofamilialist }\end{array}$ & $\begin{array}{l}\text { Third } \\
\text { way }\end{array}$ \\
\hline Public provision & + Limited & + & -- & -- \\
\hline Universal & -- targeted & + & - & -- \\
\hline $\begin{array}{l}\text { Economic } \\
\text { planning }\end{array}$ & -- & -- & -- & -- \\
\hline Enterprise-based & $\begin{array}{c}-+ \\
\text { very limited (from } \\
\text { the enterprise } \\
\text { profits) }\end{array}$ & -- & +-- & -- \\
\hline $\begin{array}{l}\text { Low incentives } \\
\text { for in-home } \\
\text { caregiving }\end{array}$ & $\begin{array}{c}-+ \\
\text { (legislative } \\
\text { framework } \\
\text { provides high } \\
\text { incentives but low } \\
\text { generosity of } \\
\text { benefits in fact } \\
\text { obviates them) }\end{array}$ & + & -- & + \\
\hline $\begin{array}{l}\text { Communist } \\
\text { ideology-based }\end{array}$ & + & -- & -- & -- \\
\hline
\end{tabular}

Source: developed by the author

In addition, the elements of policy feedback produced by the Soviet welfare policies included the fact that, the social-democratic model seems to be the one most close to the mass consciousness, due to its principles of social equality and equity, and

${ }^{477}$ Pierson 1993; Skocpol 1992 
collective values even in the midst of the neoliberal changes. ${ }^{478}$ Some elements of the post-Soviet welfare state, including resistance to restructuring of child and other benefits, can be attributed to the legacy of Soviet and (arguably) social-democratic regimes. Once again, the mechanisms of transmitting Soviet legacies included inherited policy norms, and rules, which were earlier imposed on recipients and which were proved hard to change, as they conveyed certain rights and privileges (as well as duties and obligations) to a range of policy constituencies. It is likely that Soviet policies in many cases contributed to shapes of subjective experiences of citizens and interest groups, and gave them a sense of there role and place within the system. ${ }^{479}$

At the same time, in order to be successful, the political basis of the socialdemocratic model requires strong parties with social-democratic values, while its sustainability needs a well-functioning market economy, with developed institutions of tax collection and law enforcement. Furthermore, Nordic social-democratic models are normally associated with adherence to gender equality, which in the Russian context, as discussed, often invokes a negative connotation with the Soviet past. ${ }^{480}$ Thus, the option of moving towards a social-democratic regime was also not perceived as viable by the

\footnotetext{
${ }^{478}$ Gurgenko (2002) - translation by the author

${ }^{479}$ See Landy 1993; Mead 1986, 7; Schneider and Ingram 1993, 1997

${ }^{480}$ As discussed elsewhere in this thesis and succinctly summarized by Vlasta Jalu iX (1994), the reasons for anti-feminist views, which are mainly associated with the socialist pas mainly include:

- the social experience, rejecting feminism as a bourgeois, capitalist phenomenon

- lack of tradition of an independent women's movement lasting several decades

- socialism had proclaimed the nonexistence of a separate women's issue and thus made it extra-political

- the equality and emancipation of women were already a part of the very legitimacy of the socialist system (also partly drawn up in the form of a law)

- the "emancipation" that came from the top (ie laws) which supported the equality of women were not a result of a long-lasting struggle or of claims from the people

- a certain role in all this was played only by an elite of women belonging to the ruling party, the socalled "state feminists". This elite has been, irrespective of its own intentions, unpopular and stigmatised."
} 
Russian policymakers, due to a number of constraints, including external neoliberal pressures, financial constraints, shadow economy, labour market pressures, demographic crisis and others.

The post-Soviet model, in general terms, resembles Fraser's caregiver parity model, albeit with many limitations and deviations from the theoretical model. The Fraser caregiver parity model aims to support informal carework and allow women to "support themselves and their families through carework alone or through carework and part-time employment." 481 The model seeks to elevate childbearing, childrearing, and informal domestic labour to parity with formal paid labour. ${ }^{482}$ The comparison of the post-Soviet welfare state with Fraser's Caregiver parity/neofamilialist model is documented in Table 26.

Table 26. Comparison of the Caregiver Parity Model/Neofamilialist and Post-Soviet Model of Welfare State

\begin{tabular}{|l|l|}
\hline Caregiver Parity Model & $\begin{array}{l}\text { Post-Soviet } \\
\text { model }\end{array}$ \\
\hline $\begin{array}{l}\text { Enabling women with significant domestic responsibilities to support } \\
\text { themselves and their families, either through carework alone or } \\
\text { through carework plus part-time employment }\end{array}$ & + \\
\hline $\begin{array}{l}\text { Compensating for childbearing, child rearing, and informal domestic } \\
\text { labor }\end{array}$ & + \\
\hline Providing sufficiently generous allowances & -- \\
\hline $\begin{array}{l}\text { Providing flexibility at the workplace, in order to facilitate the } \\
\text { possibility of combining supported carework with part-time } \\
\text { employment }\end{array}$ & ++ \\
\hline $\begin{array}{l}\text { Developing generous programs of mandated pregnancy and family } \\
\text { leaves }\end{array}$ & ++ \\
\hline Keeping the bulk of carework in the household & ++ \\
\hline Supporting carework provided at home with public funds & + \\
\hline
\end{tabular}

\footnotetext{
${ }^{481}$ Fraser (1997): p.55

482 Ibid
} 
++ Model is strong in achieving the objective

+ Model is relatively strong in achieving the objective

-- Model is weak in achieving the objective

Source: developed by the author

As Table 26 illustrates, the post-Soviet model (at the policy level) is very similar to the caregiver parity/neofamilialist model, via such elements as generous maternity and parental leaves, compensation for childbearing and childrearing, through the in-home caregiving allowance, provisions in the Labour Code allowing for various arrangements of part-time or in-home employment for women with young children, and the encouragement of part-time employment (if not staying at home!) provided through inhome caregiving allowance and provisions in the Labour code. There are a number of important deviations from the neofamilialist case, though, which include an insufficient level of in-home caregiving allowance. Under the conditions of widespread poverty, this became a crucial factor for determining the outcomes of this model. As McKinney notes: "A shrinking state budget - due both to declining production and to failure to collect taxes - limited the state's ability to make payments." 483 Moreover, "inflation, which outstripped government measures to adjust the size of payments, quickly reduced the purchasing power of state allowances to virtually nothing." 484 This was further worsened by the widespread arrears in payments of benefits and allowances (see chapter 6 ).

As chapter 5 will show, these constraints coupled with other characteristics, such as the legacy of full employment and Russian cultural heritage, have seriously undermined the ability of neofamilialist policies to achieve their objectives, (i.e. to pull

\footnotetext{
${ }^{483}$ McKinney (2004): p.46

${ }^{484}$ Ibid.: p.46
} 
women out of the labour force and increase birth rates across the country). The next chapter will analyze the main reasons for paradigm shift in the area of child care, while chapters 5 and 6 will provide evidence that, however strong the pro-family ideology may be, women's actions are shaped and constrained by economic realities. 


\section{Chapter 4. Explaining the Shift: Role of the State and Non-state Actors}

\section{Introduction}

Chapter 3 discussed the emergence of the mixed Russian welfare state, arguing that it was a result of a paradigm shift in the area of child care policy and the interplay of new ideas, historical legacies and changing economy and society. The main focus of this chapter will be on how and why such a significant policy paradigm shift happened and such a unique welfare blend emerged. This chapter will answer the question: how did the idea of allowing women a choice between motherhood and employment become such a powerful framework for policy shift? I argue that we need to look at :1) the political regime shifts and legacy of flexible political and economic institutions, through horizontal and vertical state dynamics and 2) external pressures, in the context of the demographic crisis and the need to adapt to new economic and labour market conditions. In order to better account for and understand the developments on the political arena, I will look at the broader political economy of the welfare state in Russia, with specific attention to child care policies.

This chapter will illustrate how internal state dynamics, paired with the balancing of the external actors' demands, to a degree compatible with the state vision, instigated the emergence of a new mixed model of welfare state in Russia. It also presents a case for relative state autonomy in the area of social/child care policies, by showing that, in the Russian case, it is the state which was the main actor in formulating goals and 
policies. 485 While the influence of non-state actors is undeniable, this chapter will show that the state (as a whole) was susceptible to these pressures mostly to the degree in which they were compatible with its internal goals.

This chapter advances four interrelated sub-hypotheses:

- While the paradigm shift in child care was a result of interaction of both state and non-state actors, the Russian state maintained a relative autonomy during this process;

- Internal units of the state (vertical and horizontal) often operate at crosspurposes;

- The legacy of decentralization of power and flexible institutions in the Soviet period has contributed to the regional and enterprise resistance to change;

\footnotetext{
${ }^{485}$ The methodology employed in this chapter included: Archival research: transcriptions of Duma hearings, central and local newspapers, Duma documents, presidential statements, government press releases and publications (East View). Other documents reviewed included:

- Electoral platforms for the Duma elections 1995, 1999 (KPRF, liberals, LDPR, Yabloko)

- Electoral platforms for the presidential elections 1996, 2000 In addition to the archival research, interviews with federal and local officials and enterprise managers were also conducted. The leading institutions reviewed include: the International Monetary Fund, the World Bank, the US Programs, EU (European Bank for Reconstruction and Development), European Union's technical Assistance to the Commonwealth of Independent State program (TACIS). Key documents (only public ones) reviewed include:

- $\quad$ IMF public statements

- IMF staff papers and Program review documents, the Russian Government letters of intent and memoranda of economic polices

- World Bank Country Assistance Strategies, Assistance Strategy evaluations, Official statements and other publications (from 1991 to 2002)

- EBRD Country strategies and transition reports

- State department annual reports and USAID annual country strategies; and TACIS indicative and action programs for Russia
} 
- The state has adopted the recommendations of non-state actors mainly to a degree compatible with the institutional legacies and interests which emerged to protect them.

These sub-hypotheses serve the main thesis hypotheses, by illustrating that the state remained the main actor in the social policy arena during the first decade of the transformation period (1991-2001) and stayed relatively autonomous during the process of policy paradigm shift in child care. At the same time, this chapter shows that non-state actors also played an important role in bringing the paradigm shift about, thus justifying the use of a combined state-centred and power-resource approach to understanding the policymaking process in Russia.

\section{Internal State Dynamics and Child Care Policies}

This section examines the role of the state in the policy paradigm shift. It aims to develop an empirical analysis of the concept of the relative autonomy of the state, and shows that the state was guided by its own internal logic, and formulated its own role and interests. The autonomy of the state, as elaborated in chapter 1, refers to its ability to formulate goals independently from non-state actors, such as social groups, classes or society. Therefore, it is precisely the generation of independent interests, goal formulation, and problem definition processes within the state, that this section is going to focus on. It illustrates "the specific attributes of the relative autonomy: the state understanding of its own interests; the inner dynamics of state organization; the casting of policy and political 
problems in terms of those interests and dynamics."486 The actual ability of the state to pursue these goals and implement policies, will in turn be assessed in the next chapter.

This section shows not only the state's ability to formulate independent goals, but also how the substantive content of the state actions comes from the "way in which administrative and political mechanisms contain their own logic, dynamics, and cognitive horizons." 487 It will demonstrate that the policies were devised in response "to a complex combination of internal and external problems, which $[\ldots]$ cannot be reduced to controlling labour or accumulating capital." 488 The first part of this section will assess the horizontal dynamics within the state, while the second will focus on the vertical ones, the interaction between the federal centre and the regions and cities.

A few caveats are in order, however. First, the current Russian state inherited the full infrastructure of the Soviet regime, which was characterized by the fusion of partystate with economy and politics. While having undergone a major transformation in the 1990s, the legacy of former "state - nomenklatura networks" of political appointments at enterprises, courts, trade unions and other units of the economic, judicial, and social systems still persists; this makes the boundary between "state" and "society" appear relatively blurry. The main difference from the capitalist state is that those networks used to be a part of the "state" itself, while western capture theories often portray the state as an extension of economic interests. This makes an important analytical distinction, since in the Russian case the state actors actually led the process of redistribution of social

\footnotetext{
${ }^{486}$ Pal (1986): p. 76

${ }^{487}$ Ibid.: p.77

488 Ibid: p. 77
} 
assets during the transformation. Appendixes 6, 7, 8, illustrate how the former Communist party members and other ex-nomenklatura appointees are present in the current financial, economic and social units, as well as ruling elites of the Russian government. This also is why a mixed approach of the state-centered and power resources theory should be used, in order to understand the nature of policymaking in Russia.

\section{Horizontal State Dynamics: Political Regime Shifts and Soviet Legacies}

The transformation was characterized not only by changes in the economy, but also through political shifts, which in turn had many implications for the Russian economic and social reforms. These shifts gave rise to a variety of political parties, including democratic-reformist parties (e.g. Yabloko, Russia's Choice); centrist parties (Our Home is Russia, which was a "party of power" with Chernomyrdyn's government in 19951998; Unity, Fatherland-All Russia), and the rightist parties (e.g., Liberal Democratic Party of Russia, with its extreme nationalist programs). ${ }^{489}$ Additionally, the transformation created a number of leftist parties, including the revamped Communist Party of the Russian Federation (CPRF). As opposed to other parties which emerged only during the transformation, the CPRF (and the Agrarian party) has the longest organizational continuity, and inherited a significant electorate, large membership and a broad network of local organizations. ${ }^{490}$

\footnotetext{
${ }^{489}$ For more detailed description of the Russian political system, see Barry (2002)

${ }^{489}$ Cichock (1999): p. 27

${ }^{490}$ Ibid.: p. 27 explains "The Communist party was divided into several ideological streams within the communist idea: modernized anti-bureaucratic Marxism (Duma chairman Gennady Seleznev), nationalism (or, as sometimes called "statist-patriotic communism" (Leader of the CPRF Gennady Zyuganov) going to
} 
While the general party discourses differed significantly, they seemed to agree on the "but" solution to the woman question (although for different reasons and through different means): women should have the right to stay at home. For instance, Liberals, who vehemently embraced neoliberal norms and culture and rejected everything associated with the Communist past, emphasized individual rights and a choice for women to go "back to the home." ${ }^{491}$ The main aim was to restore women's natural rights to be good wives and mothers, rights of which they were deprived of during the Soviet period. We analyzed these arguments in the chapter 3. As Gal and Kligman argue

a contrast about morality of democracy as against of immorality of communism was often highlighted through debates about their contrasting approaches to reproductive policies... as many insisted, communism went against nature in allowing women to circumvent motherhood, postcommunist state $\ldots$ promised to uphold the unchanging forces of a natural gender order. ${ }^{492}$

Moreover, the women's role was seen as providing support for "male autonomy in an expanded private sphere. ${ }^{, 493}$ Goven argues that participation of women in the public sphere was seen as a threat to emerging democratic development.

The rightist political force (very popular during the 1990s), represented by the Russian nationalist opposition (Liberal Democratic Party of Russia - LDPR), saw women's reproductive function as a key to the future development of the nation and used falling birth rates as a weapon to attack "emancipated women." The low population density in a number of Russian regions, as well as the potential decline in the military

the extreme of national chauvinism (Victor Ilyushkin, former Duma Speaker). What united all of them was the commitment to conservative communism and attachment to the symbols and institutions associated with national greatness."

${ }^{491}$ Khotkina (1994)

${ }^{492}$ Kligman (2000): p.29

${ }^{493}$ Goven (2000): p.288 
forces stemming from the decline in birth rates, generated vehement statements about women's natural role. The LDPR program states that the party is "for a woman to fulfill the great mission from nature, God - to reproduce the human race. This is why the LDPR is advocating the Russian idea, which serves as a basis for the ideological party platform. ${ }^{\text {494 }}$ The leader of the LDPR, Vladimir Zhirinovsky, even put forward a bill to the Duma, proposing to allow polygamy, release of men of obligations for child support etc, in order to increase a birth rate in the country. ${ }^{495}$

The Communist Party, in turn, condemned the overall reform program as a national disaster and betrayal, and advocated maximum protection of women and support of the family, through the preservation of the social protection of the Soviet period. The CPRF 1995 Duma elections Program committed to free education and care, through a preservation of the universalistic and paternalistic elements of the Soviet welfare state. In addition, the communists stressed the need for a strong nation with a large army, which grew as a special form of nationalism. This form of nationalism placed the main emphasis on the country's need for children. The party's platform stated that women should be able to have children, and be confident in their future. ${ }^{496}$ This demographic concern, combined with the lack of energy for modernization, made the Communist party join the calls for more choices to women and increased importance of family for children.

\footnotetext{
${ }^{494}$ LDPR program (2000) - translation by the author

${ }^{495}$ The Bill "On Fatherhood" was put forward to the Duma in 2000. Other proposed measures include a 10 year ban on abortions, reduction of marriage age to 15 years old (from 18), or a 10 year ban on women leaving the country (for women up to 42 years of age).

496 CPRF Duma Elections platform (1995)- translation by the author
} 
Thus, despite the diverging rationales, nearly most parties seemed to have arrived to the conclusion that reproduction is a woman's main duty, right, and destiny, and openly called women to return to the home, thus contributing to the paradigm shift in the area of child care. ${ }^{497}$ As discussed in chapter 3 and will be elaborated further in this chapter, the main unifying reasons for such an agreement included the proximity of a demographic crisis and need to release pressure in the shrinking labour market. While disagreeing on specific discourses of demographic policies (adopting either a reactive approach, and reducing the drastic fall of child birth and ensuring health of mothers and children, or a proactive approach, through stimulating fertility by all possible means), the parties were united by a joint vision: the nation's survival and future prosperity depend on overcoming the demographic crisis and increasing fertility rates (the divergence remained mostly around available resources, means to ends, gender roles and relations). ${ }^{498}$

Such an ambiguous agreement involved redirection and extension/modification of existing institutions (e.g., child care leave) in combination with the relatively new elements (e.g., in-home caregiving allowance) and decay of others (e.g., child care services) to serve new purposes and goals, i.e., bringing women back to homes. This involved "the redirection of institutional resources, [that] occur[ed] through political contestation over what functions and purposes an existing institution may serve. Political contestation driving change ... is made possible by the gaps that exist by design or

\footnotetext{
${ }^{497}$ Khotkina (1994)

${ }^{498}$ Gurgenko (2002): p.125 - translation by the author
} 
emerge over time between institutionalized rules and their local enactment.",499

Nonetheless, the divergent reasons and means envisioned by each player resulted in a conflict in the political arena, among political parties and between the legislature and executive branches. This partly explains why the old policies and systems of the benefits were not restructured at that time, but in fact enjoyed significant continuation. These dynamics were reflected in the contradictory nature of the Russian welfare state, best followed through the analysis of three periods: 1991-1993, 1994-1995, and 1996-2001. Each period accounts in detail for the policymaking process in the broad social policy discourse, and child care policies in particular. The analysis highlights that the state is not a monolith, and shows the importance of internal state dynamics for bringing about a paradigm shift, and shaping the welfare regime. This analysis also presents the case for the relative state autonomy and illustrates the importance of institutional legacies and vested interests.

\section{1 - 1993: Neoliberal Clash with Soviet Legacies}

The collapse of the Soviet Union in 1991, and the need to restructure the economy, engendered a heated debate among different players proposing reform programs. Among the most influential were the liberal ideas (informed and promoted by the "Washington Consensus" ${ }^{, 500}$ ), which subsequently had an important impact on the early discourse of

\footnotetext{
${ }^{499}$ Streeck and Thelen (2005): p. 26

${ }^{500}$ As defined in the Wikipedia, "The Washington Consensus is a set of policies promulgated by many neoliberal economists as a formula for promoting economic growth [in the developing and transition countries] by introducing various market-oriented economic reforms which are designed to make the target economy more like that of First World countries such as the United States. It was first presented in 1989 by John Williamson, an economist from the Institute for International Economics, an international economic think tank based in Washington, D.C. It is so-called because it attempts to summarize the commonly-shared
} 
the post-Soviet welfare state. Yegor Gaidar, chosen by Yeltsin to guide the transition, developed a plan offering a radical quick change in the economy, namely immediate liberalization of prices and trade (with government's control of money supply and spending), followed by privatization. ${ }^{501}$ The main "social policy," considered by Gaidar, was the control of inflation through resistance to wage indexation or savings compensation. He argued that "social policy, first of all, is the budget [GDP], real money you give to people," 502 and firmly believed that the best social policy for Russia is economic growth. $^{503}$

Liberal reformers hoped that the socialist welfare state and historical institutions associated with it would fade away, after the economic reforms. This strategy fell short, however, considering the institutions inherited from the Soviet period and the interests which empowered them. As will be shown in this section, these vested interests and institutions reacted by selectively opposing the reforms, in order to preserve the inherited welfare state. In general, the transformation period saw the formation of two main types of vested interests: industrial enterprise managers (who often cannot be separated from the state, since they were appointed through the nomenklatura system) and members of the former Communist party. ${ }^{504}$ While the communists faced a lack of confidence immediately after the collapse (since people held the party responsible for the economic

\footnotetext{
themes among policy advice by Washington-based institutions at the time, such as the International Monetary Fund, World Bank, and U.S. Treasury Department.

${ }^{501}$ McFoul, M. (1999): p. 211

${ }^{502}$ Gaidar (1995) - translated by the author

${ }^{503}$ For more detailed discussion of the Gaidar's social policy visions (or lack of thereof), see Ringold (1999)

${ }^{504}$ Not all the members of the former Communist party opposed the reforms. As shown in the appendixes $4,5,6$, the process was quite the opposite. A majority of the former party elite found themselves either in the parties of reformers or among ruling elites, in the financial, banking and industrial sectors.
} 
and social crises ${ }^{505}$ ) and made their come back later, in the middle of the 1990s, the enterprise managers emerged as powerful political forces at the very beginning of transformation. As discussed in chapters 2 and 3, enterprise managers maintained their historical de-facto control in managing state assets (including social infrastructure such as kindergartens) due to the state's limited ability to oversee them. They morphed into powerful interest groups during the market reforms, and some of them also felt they had a responsibility for the welfare of their employees. Therefore, in response to the changes proposed by the neoliberal reformers, such as open privatization of all state assets, including the enterprises and their social infrastructure, which implied that shares would be available to the public at large, ${ }^{506}$ these groups formed an inter-party political bloc “Civic Union." The "Civic Union" was mainly a partnership with trade unions, who, as will be explained later in this section, were also interested in maintaining the existing structure of former state enterprises (while changing the form of ownership). As such, the Civic Union started its activities by opposing the proposed neoliberal privatization plan, in which the majority of shares of state enterprises should have gone to the larger public. Predictably, the Civic Union was unhappy with this provision, and developed a different privatization plan, which gave enterprise managers significant control over enterprise assets. Eventually, the Union was successful in winning a majority of votes for its plan in the Duma. Furthermore, it also managed to gain a widespread support among the declining sectors of economy, thus becoming a strong political force. This compelled

\footnotetext{
${ }^{505}$ Zaslavskaya (1992), as quoted in Aidukaite (2004)

${ }^{506}$ For more on Gaidar's privatization plan, see McFoul (1999). In a nutshell, this plan offered $25 \%$ of shares to the workers of an enterprise (non-voting, at no price), $5 \%$ of shares at a full price to the management of the enterprises and the rest was to be publicly sold, again at a full price.
} 
Yeltsin to secure the support of the Civic Union, in order "to maintain social harmony and political power," and make significant compromises in the course of reforms.

The resulting power shift, combined with institutional ambiguity, "undermined neoliberal ideas about reforms and social policy," 507 and can explain an ad hoc character of the social and child care policy, which was characterised by a counterbalance of periodic radical liberal reform efforts and resistance from socialist conservatives. The ability of the Civic Union and other actors to influence policy debates on the economic and social development of the country and resist changes in the social infrastructure of the enterprises, thus affecting child care, at the beginning of the transformation period, could be explained by the ambiguous balance of power between legislature and executive branches (since the new Constitution was adopted only in 1993), and increasing power of the legislature in the policymaking process, which maximized the power of such antiliberal political groups like Civic Union, who dominated the legislature. This was buttressed by another factor: Russia had not yet held any elections since the collapse of the Soviet Union, which made unclear the real balance of power in society. ${ }^{508}$ Yeltsin's insecurity in power and the course of reform had further implications for the success of reforms and development of the social policy in Russia. The tacit agreement with the Civic Union represented a compromise at that stage, which saw the regime cautiously proceeding with economic reforms, while maintaining significant features of the Soviet social policy. ${ }^{509}$

\footnotetext{
${ }^{507}$ Gaidar (1997): p.217 - translated by the author

${ }^{508}$ McFoul (1999): p.217

${ }^{509}$ See Obosrevatel (2005) - translation by the author
} 
In the area of child care, this compromise resulted in a mix of continuities and changes. The opposition advocated the preservation of the largely universalistic benefits, egalitarian standards and benefit levels inherited from socialism. Moreover, in order to cope with inflation, the parliament insisted on increased benefits, allowances and other "compensations" for the entitled groups, including women with children, despite the pressures to the contrary. These demands were supported by the Ministry of Health, which, in the conditions of drastically declining living standards, deteriorating maternal health and falling birth rates, had lobbied for an additional lump sum benefit for women who registered for prenatal care in the early stage of pregnancy, in order to avoid later complications. ${ }^{510}$ Moreover, the same law extended maternity leave from 56 days prior to giving birth and 56 days afterwards, to 70 days in both cases, in the case of a normal pregnancy, and to 86 days, in case of complicated births. This was built on the system of benefits developed by Gorbachev's government of the very late Soviet period, including introduction of in-home caregiving allowance and a possibility to work part-time until a child reaches the age of 14 years. ${ }^{511}$ The rationale behind this system is best expressed by Mikhail Gorbachev, who declared that "women are more important as producers of good people than as producers of fabric or whatever. I am going to propose a system of economic benefits throughout childhood, for each child born, so that it becomes economically possible for women to devote more of themselves to their families. The

\footnotetext{
${ }^{510}$ Federal Law on Additional Measures on Protecting Motherhood and Childhood (April 1992) translation by the author

${ }^{511}$ Supreme Council of the RSFSR (April 10, 1990) - translation by the author
} 
dropping birthrate and the rising divorce rate show that family life is in trouble and needs more protection." 512

Facing the need to restructure labour markets and fearing high unemployment and social discontent, it was convenient to blame the deteriorating national health and declining birth rates on the legacy of female employment, and to call women to return to their natural destinies, their homes. ${ }^{513}$ For the same reasons, the government chose not to notice high rates of hidden unemployment (employees were registered at the enterprises and could use social facilities, but were on unpaid leave for indeterminate periods of time), so that people would not claim unemployment insurance from the shrinking state budget. Providing women with the option of a 3-year parental leave (which was/partially is paid by employer) was a convenient solution to avoid social discontent and increases in social spending, as well as increasing the number of babies in the country. Therefore, during this early transformation period, the majority of parties agreed that paying women to stay home to care for children (instead of enterprise restructuring and expensive maintenance of daycares), would be the solution which could satisfy all the parties.

\section{3-1995: Policymaking Gridlock}

The broad disagreements between the legislative and executive branches led to civil conflict in $1993,{ }^{514}$ which altered the balance of power among various interests in the

\footnotetext{
${ }^{512}$ Quoted in Ispa (1994); Press (1989): p. 18

${ }^{513}$ Other tactics employed by the enterprises included unpaid undetermined leaves, wage arrears etc, so that the volunteer return to homes was seen as the "best" solution. For discussion of such policies in other countries, see Corrin (1990)

${ }^{514}$ In September 1993, President Boris Yeltsin suspended parliament and called for new elections as a result of the differences with Duma deputies. Deputies barricaded themselves inside the parliament
} 
Russian political arena. A new 1993 Constitution significantly widened the presidential powers, allowing almost absolute control over policymaking process. Ministries were responsible for implementing the domestic programs, while the president assumed responsibility for political initiatives. ${ }^{515}$ The Constitution also allowed almost inordinate powers to the executive branch, which provided for a significant insulation of the executive branch from Parliament. The new government offered a set of reforms, summarized below:

1. Eliminate all universal entitlements (including child benefits) and replace them with a system of means-tested benefits, targeted on the poor, and sufficient to alleviate poverty;

2. Restrict eligibility, cut payments, and eliminate Soviet-era privileges from all benefit programs;

3. Replace state-funding and provision of benefits with private insurance and market-based provision for all but the poor;

4. Privatize most social assets and services (including enterprise-based and municipal childcare facilities) and move toward full cost recovery for all subsidized services and social goods. ${ }^{516}$ Subsidies to enterprises for maintaining childcare facilities are to be cut and transferred directly to individuals on a meanstested basis.

This reform agenda was blocked by the legislature, in which the balance of power, after the 1993 Duma elections, was not in favour of government. As Table 27 shows, altogether the pro-reform parties comprised only $34 \%$, facing the $43 \%$ of anti-reformist blocs, including Communists and ultranationalist Liberal Democratic Party. ${ }^{517}$ The new

building. In October 1993, Yeltsin ordered the army to attack parliament. After a bloody battle, parliament was recaptured. Source: BBC News. Timeline Russia: Chronology of Events. Available at:

http://news.bbc.co.uk/1/hi/world/europe/1113655.stm

${ }^{515}$ Ibid.

${ }^{516}$ Policy statements of the government, Cook (2002); 1993 Yeltsin's Political Program; Council of Ministers' package of social reforms

${ }^{517}$ Smyth (2002): p. 555-578. 
legislature was divided on principles, the parties' positions on key institutional and policy variables, and the role of the state in the economy and social sphere. The rise of the Communists' popularity during this period can be explained by the growing nostalgia for communist stability and a certain fatigue from constant reforms and poverty. The communists were not able to legislate any additional protection mechanisms, or develop a clear vision of social policy or social security programs. Their standpoint concerning welfare policy was relatively vague, but they did appeal to the voters requiring more protection, including women.

Table 27. Results of the Duma Election, December 1993

\begin{tabular}{|c|c|c|c|c|c|c|}
\hline \multirow{2}{*}{ Party } & \multicolumn{3}{|c|}{ PR Party List } & \multirow{2}{*}{$\begin{array}{l}\text { District } \\
\text { Voting }\end{array}$} & \multicolumn{2}{|c|}{ Total Seats } \\
\hline & $\begin{array}{c}\% \\
\text { votes }\end{array}$ & seats & $\begin{array}{c}\% \\
\text { seats }\end{array}$ & & $\mathbf{N}$ & $\%$ \\
\hline 1. Russia's Choice & 16.0 & 40 & 18.0 & 30 & 70 & 15.6 \\
\hline 2. LDPR & 22.9 & 59 & 26.2 & 5 & 64 & 14.2 \\
\hline 3. CPRF & 12.4 & 32 & 14.2 & 16 & 48 & 10.7 \\
\hline 4. Agrarian & 7.9 & 21 & 9.3 & 12 & 33 & 7.3 \\
\hline 5. Yabloko & 7.9 & 20 & 8.9 & 3 & 23 & 5.1 \\
\hline 6. Women of Russia & 8.1 & 21 & 9.3 & 2 & 23 & 5.1 \\
\hline 7. PRES & 6.8 & 18 & 8.0 & 1 & 19 & 4.0 \\
\hline 8. Dem. Party of Russia & 5.5 & 14 & 62 & 1 & 15 & 3.3 \\
\hline 9-12. Four Parties below 5\% & & 0 & & 8 & 8 & 1.7 \\
\hline 13. Cedar & 0.8 & 0 & & 0 & 0 & 0.0 \\
\hline Independents & & & & 141 & 141 & 31.3 \\
\hline Total & & 225 & & 220 & 445 & \\
\hline
\end{tabular}

Source: Adapted from White, Rose and McAllister 1997, 123 
Notes:

a) Party abbreviation: CPRF - Communist Party of the Russian Federation; LDPR - Liberal Democratic Party of Russia

b) Parties 9-13 received a combined total of 8.73 per cent of the vote. The reminder of the party votes, 7.5 per cent, was made up of invalid or ballots cast "against all" parties.

The power of opposition groups was heightened by the Duma's internal structure, which incorporated both strong party and committee powers, distributed according to party representation and therefore reflecting the balance of power within the party system. Thus, despite the increased power of the executive branch, the need for the President to build legislative support for the executive reform agenda, under conditions of executive-legislative conflict, resulted in a significant policymaking gridlock. ${ }^{518}$ The gridlock showed the lack of a middle ground in the Russian social policy discourse, and was characterized by a series of standoffs between radical liberal reformers and socialist conservatives. "Both sides revealed an apparent preference to do nothing and let the welfare system suffer the consequences, rather than accept the proposals of the other side. In part, this reflects deep divisions in Russian society and the polarization of its political leaders," as well as ineffectiveness of the political institutions in Yeltsin's Russia. ${ }^{519}$

For example, the gridlock prevented the neoliberal reform package from coming through in full scale, including means-testing for all types of social assistance and privatization of state assets, including educational institutions. The heated debates in the State Duma, as well as those between the Duma and the President, consequently led to a number of resignations (for instance, that of the Minister of Social Protection). ${ }^{520}$ Only in 1995, did the Duma pass the law on benefits to the families with children, which

\footnotetext{
518 Smyth (2002): p.558

${ }^{519}$ Cook et al (1999)

${ }^{520}$ Shkaratan et al. (2003) - translation by the author
} 
established means-tested child-benefits. This came into effect in 1997, with full implementation only in 1999. It involved confrontations around family policies, on whether child benefits should aim at providing an equal opportunity for all children or provide assistance only to those in need. At the same time, the law maintained in-home child care allowance as universal (thanks to the different aims of allowances: child benefits - for poverty relief, and the in-home caregiving allowance - enabling women to care for their children at home). The law also established that the in-home caregiving allowance was to be paid from the social insurance funds, while the "compensation for caring for children until they reach 3 years of age" continued to be paid by the employer. Prior to the law, in 1994, the President issued a decree "on increasing generosity of the compensation payments" to women on parental leave, until a child reaches 3 years of age.

Despite the neoliberal orientation of the government of the day, the Ministry of Education officially expressed numerous concerns with respect to the declining number of child care institutions, since child care was still seen as part of the state educational system, and the Ministry was responsible for the oversight of child care facilities across the country. Moreover, there were several attempts, at the federal level, to preserve a system of public education and "ensure state guarantees for free education, including preschool education." These measures can be divided in two categories: measures around municipal child care, and measures around enterprise-based child care. With respect to the municipal child care first, in 1992, at the start of the widespread privatization, the Government issued resolution \# 312 "On urgent measures concerning the economic and social protection of the system of education," which banned the sale, 
elimination or change of use of buildings and facilities belonging to the educational system, without a special permission from the Ministry of Education. Later on, given the increasing tendency of the regions to use the state child care facilities for other purposes, the 1993 Committee on State Assets (letter 6/1389) clarified that educational facilities, including child care, which were created as a result of budgetary transfers, were federal state property and could not be privatized. This Letter declared all the resolutions of local authorities on the liquidation, change of profile, or sale of these facilities, as nil and requiring reversal. Furthermore, according to the main provisions of the State Program of Privatization of State and Municipal Enterprises in the Russian Federation, approved by the President's Order \#1535, any privatization of state and municipal educational establishments and their social infrastructure was banned after 1994. To strengthen these earlier announced measures, the 1995 Federal law "On preserving the Status of state and Municipal educational institutions and moratorium on their privatization" placed a three year moratorium on the privatization of kindergartens (or until the adoption of another Federal Law).

The other set of measures was related to enterprise based child care. The status of the enterprise-based child care facilities, during the process of privatization, was determined as follows: according to the joint instruction of Supreme Council and Government of the RF \# 59 dated by March 1993, enterprise-based child care facilities could not be privatized. Further, the 1993 order of the Committee on State Assets \#135 "On division of property rights on the objects of social a, cultural, and utilities infrastructure of the privatized enterprises," allowed that child care facilities, in case of 
the privatization of an enterprise, can be transferred to municipalities and become a municipal property (in case of mutual agreement of parties). A tender could be announced for selling an enterprise-based kindergarten, but with two conditions: it had to be conducted under the supervision of a local committee on State assets, and it had to be used as a kindergarten only. What is important here is that facilities which used to be municipal were recognized as federal property and thus could not be disposed of, but the facilities transferred from enterprises became municipal property without any restrictions on their use (according to the Constitution). This turned out to be a significant factor in maintaining and disposing the facilities, which will be elaborated upon in the next section.

\section{6 - 2001: A New Turn in Russian Politics or Same Old, Same Old...?}

The changes which took place in the government after the 1996 presidential elections seemed to involve a new turn in Russian politics. It led to further strengthening of the socalled bureaucratic market and implementation of the neoliberal elements in social policies. The new "group of young reformers" in the government had placed a moratorium on all the laws which it did not have the financial capacity to implement. This was related mostly to the social sphere. In the area of social payments, the government issued a "golden rule": "All laws should be supported financially" - for those funded from the state budget, off-budget funds or local budgets. The federal government denounced the practice of making empty promises, and placed a moratorium on any new laws establishing new social benefits. The move away from the ideology of paternalism 
and protection in social assistance was also reflected in the name change of the Ministry of Labour and Social Protection to the Ministry of Labour and Social Development. The new Minister, Mikhail Dmitriev, favoured a radical version of the reform. The new priorities of the government included the reduction of the number and generosity of benefits (including maternity benefits) and a move from universal to means-tested provision in all areas of social assistance (e.g., the Program of Social reforms in the Russian Federation for 1996-2000); the need for developing a privatization scheme for the state social objects (including child care), and need for a new active labour market policy and mitigation of consequences of releasing labour excess from the former state owned enterprises. ${ }^{521}$

Nonetheless, the implementation of the neoliberal intentions of the government was again impeded by the Duma's resistance to change. After the 1995 elections (Table 28), the new power balance inside the Duma, with the Communists and other anti-reform parties having a majority of seats, re-opened the conflict with the neoliberal President/executive branch. The Government's reforms package was rejected by the Duma in the first reading, except for the child benefit system (on which the agreement was reached before). The left saw the package as anti-people, while the Yabloko (centrist) party was sceptical of the savings estimates. Only the pro-government part "Our Home - Russia" and LDPR supported the package. In the end, after long debates, the package was rejected by the majority votes. ${ }^{522}$

\footnotetext{
${ }^{521}$ Rossiiskaia gazeta. 02-24-98 (RGA-No.036). - translation by the author

${ }^{522}$ The State Duma hearing 1997 \# 111 (253), For more details on the social policy package debates, see $\operatorname{Cook}(2002)$
} 
Table 28. Results of the Duma Election, December 1995

\begin{tabular}{|l|c|c|c|c|c|c|}
\hline \multirow{2}{*}{ Party } & \multicolumn{3}{|c|}{ PR Party List } & \multirow{2}{*}{ District } & \multicolumn{2}{c|}{ Total Seats } \\
\cline { 2 - 7 } & $\begin{array}{c}\text { \% } \\
\text { votes }\end{array}$ & seats & \% seats & Voting & N & $\%$ \\
\hline 1. CPRF. & 22.0 & 99 & 44.0 & 58 & 157 & 35.0 \\
\hline 2. LDPR & 11.2 & 50 & 22.2 & 1 & 51 & 11.3 \\
\hline 3. Our Home Russia's Choice & 10.1 & 45 & 20.0 & 10 & 55 & 12.2 \\
\hline 4. Yabloko & 6.9 & 31 & 13.8 & 14 & 45 & 10.0 \\
\hline 5-22. Other A (see below) & & 0 & & 64 & 64 & 14.2 \\
\hline 22-43. Other B (see below) & & 0 & & 0 & 0 & 0.00 \\
\hline Independents & & 0 & & 78 & 78 & 17.3 \\
\hline Total & & 225 & & 225 & 450 & \\
\hline
\end{tabular}

Source: Adapted from White, Rose and McAllister 1997, 224-25

Notes:

a) Party abbreviation: CPRF - Communist Party of the Russian Federation; LDPR - Liberal Democratic Party of Russia

b) Parties 5-22, "Other-A": Eighteen parties that failed to reach 5\% threshold but managed to win lonemember seats. The number of such seats ranged from 20 for the Agrarians to one each for ten different parties, and the total number of seat for all 18 was 64 . These parties received a combined total of 36.6 per cent of the party vote.

c) Parties 23-43, "Other-B": Twenty-one parties that contested the election but failed to win either PR seats or district seats. These parties received a combined total of 8.2 per cent of the party vote.

The remainder of the party vote, 4.7 per cent, was made up of invalid or ballots cast "against all" parties.

Having encountered another stage of Duma's resistance, the President made numerous critical statements, calling on the Duma to cooperate in "making order in the benefits system" by "getting down to business and stopping irresponsible debates." ${ }^{523}$ In his 1998 address to the nation, the President said that "the State Duma should reconsider its decision [to block a package of liberal social assistance laws]. In order for the social policy to be effective and efficient, we need to help only those in need. Those politicians who would like to keep universal benefits, in practice deprive of support the poorest

${ }^{523}$ See Rossiiskaia gazeta 10-04-1997 (RGA-No.193). - translation by the author 
segments of the population... This is a time to move from words about targeting social assistance to business. It is the task of the government to develop concrete mechanisms of restructuring the social assistance system in order for the resources to go to those in real need. ${ }^{252}$ In response, the President blocked most attempts by the Duma to raise minimum wages and pensions (he only signed the two of these acts: first during the presidential race in 1996 and second, as part of a tacit deal to gain Duma approval of the 1997 budget). In addition, Yeltsin also vetoed Communist-sponsored legislation to increase child benefits for lone parents, and to raise and index the wages of budget-sector workers in education and health care. ${ }^{525}$

At the same time, the government was increasingly concerned with the demographic, maternal and children's health crisis, as well as education. Accordingly, it put forward a number of initiatives. First, the program of social reforms for 1996-2000, proposed by the government to the Duma and President, argued the need to create favorable conditions for families to fulfill their economic, reproductive and upbringing functions; ensure safe motherhood and childhood through a system of state social guarantees for families with children; the development of new technologies of family support and creating conditions for safe reproductive behaviour of mothers. ${ }^{526}$

Second, the 1996 Order of the President "On main directions of the state family policies" provided further development of the system of child benefits and home care allowances, increased the proportion of expenses for these allowances in the GDP up to

\footnotetext{
${ }^{524}$ See Rossiiskaia gazeta 02-24-1998 (RGA-No.036). - translation by the author

${ }^{525}$ Cook \& Orenstein (1999)

${ }^{526}$ Government of the RF. (1996). Program of Social Reforms in the Russian Federation for 1996 - 2000. translation by the author
} 
$2.2 \%$, increased allowances for lone mothers, increased control around child support payments, and the expansion of a natural support system (through goods and foodstuffs), depending on the socio-economic condition of the region, and others. Many provisions of this Order, however, have not been implemented in practice yet, and there have been no resolutions of the Government further developing the provisions of this Order.

Third, in 1999, given the widespread practice of municipalities and enterprises of using former child care facilities for other purposes, the federal government introduced so-called control inspections. ${ }^{527}$ The specific goals of such inspections included "realization of principles of the state educational policies; ensuring that the state educational standards and minimal social standards are followed etc." The main objects of control included activities of local authorities and their bylaws (to ensure that they were in accordance with the federal legislations and frameworks).

Fourth, in 2000, the Ministry of Education put forward the Federal program of development of education, which among other objectives aimed at:

- Preservation and development of the different types of preschool institutions and their maintenance in accordance with the needs of the population;

- Development of state standards and templates of preschool educational programs; and

- Facilitation of family education and upbringing for children of the preschool age, those not attending preschool institutions and others. ${ }^{528}$

These programs, however, had a limited effect, due to the disjointed, uncoordinated and inconsistent decision-making by the government, which is a result of

\footnotetext{
${ }^{527}$ Ministry of Education. (October 1999). Order \# 473; Ministry of Education. (1999). Federal Template of Bylaws on controlling inspections in the Subject of the Russian Federation.

${ }^{528}$ Ministry of Education .(April 10, 2000) "Development of Federal Program of Education" \#51 -Ф3
} 
the functional fragmentation of the child care policymaking system, within three

ministries: Ministry of Health, Ministry of Education, and Ministry of Labour and Social Development, responsible for various segments of child welfare (Table 29). Thus, the Ministry of Health is logically responsible for policymaking in the area of health and demographics - its prominence in the child care policies has grown significantly due to the shift in priorities to health issues. The Ministry sets up the demographic goals and, in light of declining maternal and children's health, is responsible for the introduction of benefits for prenatal care registering, and others. These benefits are intended to stimulate mothers' healthy behaviour. The Ministry is one of the main drivers for the pro-natalist approaches to reproduction (and care) ${ }^{529}$ and has influenced the introduction of the "Safe Motherhood" program, which as discussed earlier, places its main emphasis on the family as the main unit for caring for children, along with maternal and children's health.

Table 29. Division of Responsibilities and Approach to Reforms among "Social" Ministries, Russia, 1991-2001

\begin{tabular}{|l|l|l|l|}
\hline & Ministry of Health & \multicolumn{1}{|c|}{$\begin{array}{l}\text { Ministry of } \\
\text { Education }\end{array}$} & $\begin{array}{l}\text { Ministry of Labor } \\
\text { and Social } \\
\text { Development }\end{array}$ \\
\hline $\begin{array}{l}\text { Area of } \\
\text { responsibility }\end{array}$ & $\begin{array}{l}\text { Demographic goals, } \\
\text { benefits for registering } \\
\text { for prenatal care, other } \\
\text { health programs }\end{array}$ & $\begin{array}{l}\text { Preschool education } \\
\text { (provided through the } \\
\text { system of child care } \\
\text { facilities/preschool } \\
\text { institutions), state } \\
\text { educational standards } \\
\text { for preschool } \\
\text { education }\end{array}$ & $\begin{array}{l}\text { Social benefits and } \\
\text { allowances, } \\
\text { including child } \\
\text { benefits and in- } \\
\text { home caregiving } \\
\text { allowances }\end{array}$ \\
\hline Approach & $\begin{array}{l}\text { Pro-natalist approaches } \\
\text { to reproduction and thus }\end{array}$ & $\begin{array}{l}\text { Concerns with the } \\
\text { decline in the }\end{array}$ & $\begin{array}{l}\text { Liberal approach to } \\
\text { reforms }\end{array}$ \\
\hline
\end{tabular}




\begin{tabular}{|l|l|l|l|}
\hline & care & $\begin{array}{l}\text { educational levels of } \\
\text { children }\end{array}$ & \\
\hline
\end{tabular}

Source: Developed by the author, based on the literature review.

The Ministry of Education is responsible for the educational system, including preschool education, which is provided through child care facilities/preschool institutions. The Ministry lobbied for the establishing of state standards for preschool education, reflected in the President's address to the Federal Assembly. ${ }^{530}$ In 1997, it introduced changes to the federal law on education, requiring all kindergartens to undergo attestation and accreditation. Notably, the efforts around the preservation of the system of preschool education are related to concerns with the decline in the educational levels of children, rather than allowing women to balance employment and motherhood. While the Ministries of Health and Education retained residual commitment to the old system, the Ministry of Labour and Social Development advocated an increasingly neoliberal approach to reforms. This Ministry was responsible for the social benefits and allowances, including child benefits and in-home caregiving allowances. Some key information interviews shed some light on the reasons for this liberal orientation, which included "arrears on child benefits, which are around 10 billion roubles - we need to alleviate this pressure on the system. Restructuring and transforming the system, introduction of means-testing is the only way out."

Together with the President and Prime Minister's office, the Ministry of Labour initiated a number of liberal reforms. These were subsequently blocked by the Duma, in part or in a whole. The most obvious example was the 1997 liberal social policy package,

\footnotetext{
${ }^{530}$ Rossiiskaia gazeta (1998) - translation by the author
} 
which targeted preschool education. The package was proposed by Mikhail Dmitriev, Minister of Labour. The purpose of the reform was to increase commercially-operated schools and preschools, and change the financial structure of education from its budgetary form to joint financing. ${ }^{531}$ This resulted in a bureaucratic conflict with the Ministry of Education (as these proposals meant budgetary cuts for the Ministry) and another wave of Duma's resistance, which believed that the reforms were too radical, and would contribute to the dismantling of the system.

These fluctuations in the political power of pro- or anti-reform parties and units of bureaucracy, significantly affected the ultimate results in policy. With such ups and downs, the political process in Russia explains why reforms have been so slow, and why a number of neoliberal initiatives have been blocked. The leftist parties played an important role in "defending the ideas of social cohesion and social rights against a liberal-individualist discourse that attacked the welfare state and other forms of state intervention in the economy." ${ }^{532}$ As such, the policymaking gridlock, when the left parties could not override presidential vetoes on most of their policy initiatives and vice versa, had important implications for the ultimate shape of the welfare state in Russia by the end of the 1990s, and exacerbated systemic distortions inherited from the past. It is apparent that, broadly speaking, the Russian social and child care policy was guided by three main factors: first, inertia and legacies from the previous periods (expressed institutionally in political parties and bureaucratic structures, as well as in political discourse); second, a demographic crisis and third, new and brutal economic

\footnotetext{
531 Dmitriev (1998) - translation by the author

${ }^{532}$ Cook et al (1999): p.241
} 
conditions. ${ }^{533}$ Although Korpi has stressed the influence of the parties in power on the welfare state regime, in the Russian case it was a coalition of parties in Duma, which resulted in reforms being implemented in patches, and led to the emergence of a mixed welfare state.

Furthermore, reproduction has been a state priority and interest, even though the reasons differed for each of the players. These included either state-building purposes, through reviving national identities (LDPR and often CPRF), or building political legitimacy and credibility, through rectifying the wrongs of the past (democratic parties). Thus development or non-development of child care policies took place through political compromise. But in the case of the government as whole, the attention to reproduction, despite other pressing needs, was a response to the demographic crisis. The crisis conditions in the area of reproduction and subsequent need to act, takes us away from the simple dichotomy of weak-strong state, and shows that weak states can exercise relative autonomy in, using Skocpol's terms, specific policy areas in times of crisis. ${ }^{534}$ Thus, child care policies are not a simple reflection of power struggle, but also the legacy of "statehood" or bureaucratic "weltanschauung," historical legacies of "responsibility before nation," combined with the planning, experience and expertise available to the state actors. ${ }^{535}$ In consequence, state interests in reproduction and the releasing tension from the labour market had a determining effect on the paradigm shift in the area of care, and thus the shape of the welfare state in Russia.

\footnotetext{
${ }^{533}$ Shkaratan et al. (2003): p.8 - translation by the author

${ }^{534}$ Skocpol (1992)

${ }^{535}$ Scott (1998); Pal (1986)
} 


\section{Vertical State Dynamics: Regional Independence and Legacy of Flexibility}

An additional aspect of internal state dynamics is reflected in the relations between federal and regional authorities. The analysis of the vertical dynamics of the state, once again, will highlight that the state is not a unitary actor and that internal units of the state in many cases operate at cross purposes. This section also stresses the importance of the Soviet legacy of decentralization of power, and fusion between the politics and economics.

The 1990s were characterized by exacerbated challenges to the central state authority in the Russian regions. The new 1993 Constitution stipulated a new division of powers between the federal centre, the regions and local governments, providing the regions and local governments with even greater policymaking capacities, compared to the Soviet period. This led to a clash of views between central and regional authorities concerning the appropriate distribution of power between levels of government. These conflicting perspectives were reflected in "the 'war of laws' when regions passed laws that directly contradicted federal law, and [exercised] chronic non-compliance to existing

federal laws. ${ }^{, 536}$ In cases of symbolic importance to the federal government (e.g. constitutional matters), the president forced the compliance with the federal legislation, but in most cases, such direct interventions did not prove feasible. The cases of noncompliance included declaring regional ownership for all federal property located in a particular region, or disregarding bans on the privatization of federal assets, including child

${ }^{536}$ Stoner-Weiss (2003): p.2 
care. The federal government, notably the Ministry of Education, which constantly resisted the widespread privatization of state educational assets, made several attempts to preserve the educational institutions by placing a moratorium on their privatization or offering to transfer them to municipalities. The widespread trend across the country however, illustrated the significant (over 30\%) decline in the number of child care facilities. This trend was also noted by the Ministry of Education, which later in the decade decided to introduce the inspection function, invoking the following reasons:

- Absence of a mechanism controlling fulfillment of the state orders;

- Absence of effective interaction and coordination of structural divisions of the education administration bodies, during licensing, attestation and inspection of educational facilities;

- Violations and failures to observe the law at the local and regional level by the local authorities, education administration bodies and regional authorities in the area of education due to:

- Absence of structural divisions in most local education administration bodies, engaged in inspection and control

- Insufficient number of experts, engaged in inspection and control and lowlevel of their qualifications

- Unsatisfactory analysis of materials, obtained during the inspection and control, formal and episodic character of conducted inspections

- Substitution of analyzing the real situation with the analysis of the activity reports of the local authorities

- Low level of executive discipline among the specialists of education, administration bodies and local authorities ${ }^{537}$

While the first point refers to state capacity, and will be discussed in the next chapter, the second and third points deal directly with state autonomy - the internal state conflict around policy - and decision-making. The absence of interaction between levels of

\footnotetext{
${ }^{537}$ Ministry of Education of Russia (October 5, 1999) Order \# 473 - translation by the author
} 
authority and disregard for federal legal acts are also reflected in the interviews in

Novorossiysk and Sakha Yakutia. The interview participants, both local bureaucrats and enterprise managers,${ }^{538}$ noted that despite opposed federal regulations the main reasons for decline in the number of child care facilities were:

- Privatization and sale of child care facilities by enterprises;

- Closings ordered by the sanitary-epidemic bodies, due to poor sanitary conditions;

- Use of child care facilities for other purposes by municipalities (change of profile); and

- Sale of child care facilities by municipalities.

When asked what were the reasons for selling or changing the profile of the institutions, the interview participants named the following factors:

- Drop in the number of children and lower demand for child care in the $1990 \mathrm{~s} ;{ }^{539}$

- Decreased demand for child care, due to increased costs of attending child care facilities;

- Unsustainability of facilities (growth of utility costs, transport expenses, food and equipment expense);

- Tight financial constraints of municipalities to maintain all facilities, under the conditions of rising costs on utilities, equipment, etc;

- A number of other needs and activities, which required facilities;

- It was not a priority to have public child care, as mothers should stay at home;

- Opportunity to look after children at home until they reach 3 years of age, without loss of "employment record;"

\footnotetext{
${ }^{538}$ It is important to note that the discussion never took a negative connotation. The reasons named for the decline were considered as facts of life, and the decisions that "had to be made"... No guilt or concern were expressed during the interviews.

${ }_{539}$ According to the Russian legislation, child care facilities have to have on staff at the very least a nurse, an educator, a nutritionist/cook; a number of developmental activities have to be a part of the daily routine (dancing, music lessons etc) which require specialists in this area to be on staff at least part -time. The facilities have to meet mandatory sanitary and hygiene standards; and they resemble schools in terms of their size and scope.
} 
- In-home child care allowances (allowing parents to get paid if they care for children at home);

- The system of preschool education is outdated (large facilities, no on demand care, high costs to maintain, no flexibility); and

- Low wages and lack of qualified personnel. ${ }^{540}$

In particular, the municipal authorities mentioned the inability to provide adequate

financing for all the facilities. As noted by an interview participant:

We suddenly became responsible for all these child care facilities, as well as former enterprise housing and other assets... Our budget, however, has not been adequately increased and we simply do not have the capacity to maintain these facilities... ${ }^{541}$

Other studies also showed that one of the main challenges faced by municipalities in dealing with social assets included budgetary problems. Thus the TACIS municipal survey, indicated that "current budgetary constraints seemed to be a very serious obstacle to welfare reforms. Rating the state of the city's budget in their sector, $53,4 \%$ answered that there were Very Serious Budget Problems (highest in Rybinsk/ Yaroslav 73,3\%) while 43,1\% answered that there were Serious Problems (highest in Astrakhan $66,7 \%) .{ }^{.542}$ Thus as the municipal stock of assets significantly expanded, local budget revenues shrank and subsidies from the federal budget were made sporadically and with delays. Municipal officials in Novorossiysk confirmed that they allocated only a small and insufficient share of budget resources for child care facilities as they had other more pressing issues to deal with (e.g., sewage systems, housing). This resulted in the situation when municipal authorities refused responsibility for maintaining of such social assets, including child care.

\footnotetext{
${ }^{540}$ These factors are listed in no particular order.

${ }^{541}$ Interview by the author, Novorossiysk

${ }^{542}$ TACIS (1998b); p. 19
} 
As a result of the influence of these factors at the local level, child care services were allowed to degrade, be under-maintained and, in some cases, completely broken down. As discussed in chapter 3, this form of institutional change can be referred to as drift and reflects not only specific decisions with regard to child care institutions (e.g., sale or privatization) but also cases of non-decisions and lack of actions (decay of sanitary and hygienic conditions, outdated facilities etc). In cases of "decisions," however, local documents reveal that every decision with regard to the status of preschool institutions was approved by the head of the city administration (Mayor), including the transfer of a kindergarten to the city, the degree of involvement of an enterprise, future use, and others. The municipal decrees dealt with every single case of municiplization, disposing or re-profiling of child care facilities. Thus a review of the Mayor's decrees revealed that some of the facilities, which were received by the city, were further "transferred to the city soccer club, due to its high importance to the city." The interviewees were subsequently asked if there were any legal documents/guidelines specifying under which circumstances a child care facility could change its profile. Most of the respondents answered "no," and some admitted that they did not know.

This apparent non-compliance on the part of the municipal authorities with the federal acts raises the question of why the regions felt so empowered to disregard the federal legislative framework. Several explanations come to mind. The first is that the legacy of decentralization of authority, flexible institutions and the fusion between the state and economy (more precisely, the corporate elite) had an important effect on the vertical dynamics within the state. The relative independence of regional elites during the 
Soviet period meant that social and other policies in the regions often contradicted, or at least were not in sync with, the federal priorities. Historically, the increased elite power was due to the "stability of cadres" introduced in the late Socialist period and the redistribution of power through economic resources, given the fusion between economics and politics. As Bunce argues, "[t]he slowdown in political mobility created both an insulated if not self-satisfied and corrupt elite at the center and an elite in the periphery that was increasingly entrenched and highly resentful of declining opportunities to move onward and upward."

New and old interests, including regional and local politicians and bureaucrats, as well as economic interests (managers of former state-owned enterprises, formerly "part of the state" and newly-emerged companies), became empowered in different ways, objecting to federal involvement in their affairs. Boris Fedorov, former Minister of Finance, cautioned in July 1994 that "[t]he danger now is that . . local powers communists and other interest groups - will fight to the last battle to stop privatisation. There are signs of that in the Parliament, regions, and in the government." corroborated Fedorov's concern and maintained that "the dilemma now is between bureaucratic 'nomenklatura' (state) capitalism or democratic (civic, open) capitalism. The potential of bureaucratic elites to derail the reforms is especially strong in the regions, where they retain absolute power." ${ }^{, 545}$ For example, the way in which Russian privatization was conducted resulted not only in creation of private ownership, but also

\footnotetext{
${ }^{543}$ Bunce (1999)

${ }^{544}$ Fedorov (1994): p. 2 - translation by the author

${ }^{545}$ Gaidar (1994): p. 10 - translation by the author
} 
super rich private interests, which became often interwoven with those of state officials.

Kathryn Stoner-Weiss observes that

Regional governments in Russia tended to pass legislation that contradicted the federal constitution predominantly in ways that affected economic conditions in their regions thereby undermining the central state's ability to even minimally regulate their activities...

Regional violations of federal housing and privatization policies were designed to ensure that regional interests controlled valuable regional real estate assets... The interdependence and collusion between regional enterprises and governments stems back to the Soviet era, but was further extended through the 1992 privatization program that institutionalized the de facto ownership that many managers had established over their factories in the late 1980's.... The 1992 privatization program enabled insiders to maintain effective control over their enterprises. This, in turn, initiated a property rights regime that has proven ... difficult to change... ${ }^{546}$

The second explanation for the regional non-compliance and independence in "policymaking," including child care, comes from a close look at the Russian Constitution. Part 1 of Article 130 explicitly states that "Local self-government in the Russian Federation shall ensure independent solution by the population of local issues, the ownership, use and disposal of municipal property," thereby granting the right to municipalities to dispose at will of any municipal property, including child care facilities. At face value, the federal government's policies, including the ban and moratoriums on privatization and change of profile of child care institutions, contradicted the main law of the country. Furthermore, the quality of the federal regulations in the area of child care is rather low, with numerous careless and contradictory statements.

Such an obvious contradiction among the federal legislation acts, coupled with the decentralization of responsibility for the "social sphere," including education and welfare

${ }^{546}$ Stoner-Weiss (2003): p.19 
payments to the regional/local budgets (which essentially can serve as a third explanation) led to an exacerbated "independence" and an internal vertical conflict between the state units. The question of fiscal federalism addressed the regions' contributions to the federal budget and redistribution of resources, both sectorally and regionally. ${ }^{547}$ This gave rise to the additional discontent, as the centre was seen as demanding too much from impoverished localities, while not providing them with a fair share of revenue in light of increasing expenses. Given the fact that the areas of social development and education lie within the joint jurisdiction of the federal centre and the government, such decentralization generated an additional wave of discontent, since the regional governments do not see themselves as being "responsible" under the Constitution for those areas.

Another set of relevant factors, which contributed to the regional/local noncompliance with federal laws, is related to the capacity of the state, and will be discussed in the next chapter. Here however, it can be noted that they include the increasingly nonmonetary nature of inter-budgetary relations and the low financial, administrative and institutional capacity of the majority of the regions to maintain the facilities, or, in some cases, pay the benefits. At the same time, while undoubtedly financial and administrative difficulties were prominent across the country, the case of Sakha Yakutia showed that if there is a commitment to public child care provision, the results can be quite positive. We also learned that Moscow saw a strong decline in the number of child care institutions, while its municipal budget per capita is one of the largest in the country. This raises an

\footnotetext{
${ }^{547}$ Smith (1995).
} 
interesting question of why most local/regional governments did not value child care. Perhaps this was a reflection of the tension between the interests of the federal/national government and the local/regional ones. Naturally, the national government had more of an interest in raising birth rates and producing educated citizens than local governments did, thus reflecting the vision of state building and silent instance of "politics of reproduction." In contrast, for the local government, objects of local importance (e.g., a soccer club) and interests (e.g., maintenance of quasi state-economic networks and development of small/medium businesses, such as barber shops, which pay taxes directly to the local budget) through disposing of child care facilities (in some cases worth millions of dollars) may have greater short-term importance, particularly in the conditions of increased fiscal imbalance. For instance, as noted by the interview participant in the Novorossiysk city administration:

During the municipalization process, enterprises mainly transferred kindergartens to the city (of all enterprise social assets)... There were many of them, they were very expensive to maintain, particularly with the low number of the preschool-aged children in the country (beginning - middle of the 1990s)... and women finally could stay at home to take care of their children... so the "need" for those facilities naturally declined... the facilities became simply the remains of the past... It was more "reasonable" to allow private companies to occupy former child care institutions - they were in business of developing local economy and paid taxes to the local budget... also they took care of the capital assets of those facilities which otherwise would have decayed due to the lack of financing for their repairs... ${ }^{548}$

This highlights once again both the complexity of the issues surrounding child care institutions in Russia as well as relatively low importance attached to provision of public child care.

${ }^{548}$ Interview by the author 
So what does this tell us? First, looking at the state as consisting of multiple actors, reveals the important dynamics of internal interaction, both vertically and horizontally: even if one level or branch of the government is willing to intervene, these efforts can be blocked or compromised by others within the state. As Pal put it "state actors play their games according to the rules which in part are defined by jurisdictional conventions and bargaining. There was no single actor, no single autonomous state to enforce a coherent strategy." ${ }^{, 549}$ Further exploration of both horizontal and vertical dynamics within the Russian state shows that the state is not a single and coherent actor. It illustrates "frequent acrimony, dissent and division" $" 550$ not only between the orders of government (federal, regional and local), but also horizontally, among bureaucratic departments, political parties and presidential administration. ${ }^{551}$ It also shows that the state, as an actor, did not have a "coherent and self-conscious strategy," but was engaged in heated debates over a range of child care related policy issues. As such, the internal conflicts and dynamics within the state generated much of the changes in child care policies in Russia.

Second, while being a part of the "state," the regional and municipal governments exercised significant autonomy from the federal level of government, which had further implications for respecting federal regulations and laws. Such insulation was often a result of "high" bargaining power obtained by the regions, as a result of Soviet economic

\footnotetext{
${ }^{549}$ Pal (1986): p.192

${ }^{550}$ Ibid.: p. 74

${ }^{551}$ For the purposes of this thesis, as mentioned earlier, I assume that the state consists of bureaucratic departments (executive branch), presidential apparatus (executive branch), and political parties (legislative branch of the state) as well as courts (judicial branch) at all levels (federal, regional and local).
} 
and social policy - aptly called by Bunce "monopoly and decentralization." 552 The case of child care illustrates that the closing, transferring or decaying of child care facilities was mostly done on the initiative or lack of thereof of the state actors at the local level. At the same time, municipalities applied such logic mostly to child care facilities, and only in rare cases to other objects of social infrastructure. ${ }^{553}$ Perhaps, this could be seen as a sign of a relatively low importance attached to public child care, which in turn could be a reflection of diverging interests of the state at the local and federal levels (e.g., the benefits of higher birth rate / better educated population may go to all of Russia, not just local community).

Finally, the state has always been the main agent of change in Russia. Plekhanov notes that if people do protest, they protest against the actions of the state. ${ }^{554}$ The Russian transformation and approach to resolving demographic issues were deeply traditional: "a top-down, elite-driven overhaul of social relations with society's role being that of mostly passive objects... and the bearer of the huge costs of change. The reformers had a program, and a personality of Boris Yeltsin symbolized a determination to implement it quickly, at all costs, overcoming resistance by all means available. It has been aptly termed 'Market Bolshevism.", 555 The change, however, did not have a unitary direction. Multiple actors, who were involved in the policy formation, had access to the nascent state structures and influenced the policymaking process. Grzymala-Busse and Jones

\footnotetext{
${ }^{552}$ As discussed, decentralized nature of institutions and blurry boundaries between the state and economy (which in many cases was maintained after the collapse of the planning economy) allowed regions to feel empowered up to the degree of disregarding some of the federal requirements. Source: Bunce (1999) ${ }^{553}$ As will be illustrated below, enterprises in turn were also reluctant to transfer other objects of social infrastructure to municipalities

${ }_{554}^{554}$ Plekhanov (2003): p.19

${ }^{555}$ Ibid.
} 
Loung note that "the emerging states... are best characterized as having multiple centres of authority building, each with different sectoral capabilities and degrees of influence." 556

Overall, despite a multiplicity of state actors, this section shows the importance of the state-centered theory in advancing our understanding of how social change is made. It showed the ability of the Russian state at all levels to generate independent interests with regard to women, which, as will be shown, in many cases were contrary to the ones suggested by external actors. This section illustrated that the demographic crisis, labour market and other pressures were important in shaping the internal state interests in "returning" women back to homes. Moreover, the ideational shifts with regard to the role of women (and thus, child care) can be seen as an important compromise within the state, both horizontally and vertically, in the area of social policies. Such ability of the Russian state to generate independent interests and formulate goals (e.g., increase in the number of childbirths in the country) points to its relative autonomy from external-to-state or quasi-state actors, such as international organizations, businesses, civil society and tradeunions. This is not to say that non-state actors did not have any influence. As will be shown in the next section, external political, social and economic forces constrained and affected the state's autonomy and capacity to act. But, as pointed out in this and following sections, the state had remained an important and relatively autonomous actor in policymaking, thanks to the legacy of "seeing like a state," particularly in times of crisis (e.g., demographic crisis). The capacity of the state to pursue its goals is, however,

\footnotetext{
${ }^{556}$ Grzymala-Busse and Jones Loung (2002): p.533
} 
a different matter. As was illustrated in the previous chapter, the results of the Russian child care policy mix have indeed been mixed. The main reasons for such outcomes, including state (in)capacity to implement its policies (financial, administrative and law enforcement) are analyzed in the next chapter.

\section{External Pressures: International Organizations, Business Interests, Trade Unions and Enterprise Resistance to Change}

This section analyzes the influence of external and quasi-external actors on the policymaking process in the area of social and child care policies. These actors include international organizations, businesses and former state enterprises, as well as trade unions and civil society. The analysis presented here indicates these actors had an important, though limited, influence on the state dynamics in the area of social and child care policies. This section specifically shows that the advice of international organizations was mainly implemented to the extent compatible with the inherited institutional structures and internal interests of the state. The analysis also indicates that former state enterprises contributed to the unique shape of the Russian welfare regime, by resisting changes to their social infrastructure. The role and contribution of trade unions are also addressed. In broad terms, this section underscores the importance of utilizing the power-resource approach in the analysis of the policymaking in Russia (in addition to the state-centred one), by bringing forward the important external dynamics which ultimately influenced the change in the welfare regime. 


\section{International Organizations}

After the collapse of a Communist superpower like Russia, international agencies saw the potential in involvement in the countries in transition, particularly in the social sphere, mainly in order to avoid and prevent social upheavals and discontent with the course of reforms, which may threaten emerging but vulnerable democracies. ${ }^{557}$ At the same time, these organizations were not able to reach the full potential of the development assistance and direct Russia towards a certain path (e.g. "pure" neoliberalism). As elaborated below, the main reasons for their limited impact included both the resistance on the part of the vested historical interests and institutions as well as disagreements among the international organizations, lack of coordination and different policy orientations existing within some of the organizations themselves.

While Russia saw most of international organizations' involvement in its development, the most prominent presence was that of the International Monetary Fund, the World Bank, the International Labour Organization, the European Union (Technical Aid to the Commonwealth of Independent States) and United Nations agencies (UNDP and UNICEF). While the rationale for intervention in Russia in the area of social policies was similar among these organizations, there was no agreement on the nature of social policies to be supported. This involved debates "between those who in effect argued that nothing short of a major social redistributive effort... would stabilize the new market economies, and those who favoured traditional structural adjustment loans on commercial

\footnotetext{
${ }^{557}$ Mros (1993) as quoted in Deacon (1997)
} 
terms aimed at enabling the new economies to grow their way out of impoverishment.",558 Strategies, means and areas of intervention also became a matter of disagreement between the international organizations. For instance, the needs assessment studies conducted in parallel by the IMF, the World Bank, OECD and ILO after the collapse of the Soviet Union reached different conclusions with regard to required changes in the area of social policies. The conclusion reached by the World Bank and IMF studies stressed the importance of the social safety net: "if the state can actually ensure minimum standards of living for the entire population, it will have achieved a major objective of any social security system. ${ }^{, 559}$ The social safety net however was seen as requiring major restructuring, along with economy and macroeconomic stabilization, based on the principles of the so-called "Washington consensus." on removing the welfare function from the enterprises, targeting and reducing types of social assistance. The ILO in turn emphasized the areas of its interest, including strengthening social dialogue, tripartism and assistance with social protection provisions, and supported more of a European level of social provision. ${ }^{561}$ During the first decade of transformation, the specific ILO objectives, among others, included:

- Promote and realize standards and fundamental principles and rights at work;

- Create greater opportunities for women and men to secure decent employment and income;

- Enhance the coverage and effectiveness of social protection for all; and

\footnotetext{
${ }^{558}$ Deacon (1997): p.94

${ }^{559}$ OECD (1991): p.191-2 as quoted in Deacon (1997): p. 93

${ }^{560}$ This term is first introduced by the economist John Williamson in 1990 to describe main principles of economic policy toward developing countries. Later it became associated more generally with the view that economic development is best served by free markets, private property and individual incentives.

${ }^{561}$ ILO (1991)
} 
- Strengthen tripartism and social dialogue. ${ }^{562}$

Thus, even at the outset of the transformation period, one could observe disagreements and a lack of a common vision in the approaches to reforms in Russia among international players, which became more salient in the subsequent years.

The intended strategies and means of assistance in the area of social and child care policies mostly reflected the individual missions of international organizations, which prevented collaboration from the beginning (Appendix 4). For example, the IMF saw its role in Russia in providing loans and advice to the Russian government to help bring inflation under control, stabilize its economy, and address structural issues, such as bank and industrial restructuring, tax policies, and trade policies. As of August 2000, the IMF has disbursed more than $\$ 20$ billion dollars in loans for Russia. While in general refraining from specific social policy recommendations, the IMF economic stabilization agreements prescribed the Russian government to reduce its budget deficits primarily through reduction in public expenditures, which naturally would have embraced child care programs. The position of the IMF with regard to the social sphere included:

(a) that stabilization programmes are liable to have appreciable effects on the distribution of income but that these are apt to be rather complex;

(b) that groups of the poor can indeed be among the losers, with the urban working class particularly at risk;

(c) that governments adopting Fund programmes are none-the-less free to adopt measures to protect vulnerable groups, although there may be hard negotiations with the Fund over measures which are liable to create large claims on public revenues. ${ }^{563}$

\footnotetext{
${ }^{562}$ LO (2001)

${ }^{563}$ Killick and Malik (1991): p.16 as quoted in Deacon (1997): p. 131
} 
In addition, the Fund provided hidden policy recommendations to the Russian government through the loans. For instance, the Fund started to explicate its social policy advice (mainly on creating the social safety net) through negotiations of compensatory mechanisms and the statements of Michel Camdessus, Managing Director of the International Monetary Fund. Thus in 1994, Mr. Camdessus noted at the Second Annual Francisco Fernández Ordóñez Address that recommended policy strategy along with the liberalization and stabilization of the economy, should include "last but not least, social safety nets that are cost-effective and well targeted at the poor and most vulnerable." ${ }^{, 564}$ In 1996 he noted that "[i]ndeed, this is a danger we must try to guard against—in the first instance, by ensuring that there is an adequate social safety net in place and that the fiscal program produces sufficient budgetary resources to support it. Beyond this, we must encourage the Government to do all that it can to ensure that the benefits of reform emerge - and become evident to the Russian people-as soon as possible." 565 This shows that IMF has moved towards acknowledging that there is a need for a fairly substantial safety net and that financial stabilization should be accompanied not only by the required stabilization but also poverty reduction strategies. At the same time, given the focus on poverty reduction and economic stabilization, the IMF social policy advice was generally oriented towards strict targeting of benefits to the most needy.

The goal of the World Bank in turn was to specifically promote economic reform, alleviate poverty, and develop and strengthen institutions. The amount of assistance, up until 2000, was about $\$ 12.1$ billion dollars (combined adjustment and investment

\footnotetext{
${ }^{564}$ IMF (1994)

565 IMF (1996)
} 
loans). ${ }^{566}$ Overall, the World Bank had the most comprehensive social policy reform package of recommendations. The Bank launched social protection lending programs (the Employment Service and Social Protection (ESSP) loan and the Social Protection Adjustment Loan (SPAL)), in order to battle poverty resulting from the "economic performance ([and thus] high inflation, decline of GDP, consumption, real wages, and household incomes)...; expected unemployment; and inefficiency of social

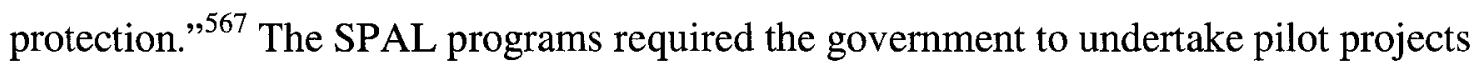
to test better targeting of social assistance. ${ }^{568}$

Through these programs, the Bank has put pressure on the Russian Government to introduce a social safety net for the most vulnerable segments of the population, simultaneously stating that "economic growth and expanding employment are the primary guarantees of social protection., ${ }^{569}$ The Bank also emphasized the creation of a private sector for social services (including child care) or development of a contracting system, where public authorities could contract out service delivery to private or nonprofit organizations. ${ }^{570}$ With respect to enterprises as "micro-welfare states," the World Bank recommended restructuring and releasing them from welfare functions, including kindergartens, as inefficient. The 1993 World Bank report argued that

retaining child care as an enterprise responsibility without subsidy will therefore quickly become a deterrent to female employment. Gradual elimination of child-care at the place of work must therefore be accompanied by stimulating quality private child-care services by

\footnotetext{
${ }^{566}$ World Bank (2000) as quoted in US General Accounting Office report (2000)

${ }^{567}$ The World Bank No 27970 (2002f).

568 The World Bank No 11168 (1992).

${ }^{569}$ World Bank No 11748-RU. (1994c).

${ }^{570}$ World Bank No 24450-RU. (2002h)
} 
private enterprise and, especially in the short and medium term, by national and local governments. Subsidies for private child-care in the form of grants or tax-credits are a necessary complement to reform; such subsidies can be directed to the provider of child-care or to parents needing child-care. ${ }^{571}$

The same report was concerned with the protection of women's labour. It recommended careful examination of the implications of

additional concessions, of a shortened work week and prohibition of dismissal of women with small children proposed in the Family Law of $1992 .$. If the cost of the shortened work week is borne by the government, then this regulation could facilitate women's employment; if it is to be shouldered by the employer, it would create obstacles to female employment.' The prohibition against dismissal is a two-edged sword - on the one hand it protects women and children, but on the other, it severely discourages recruitment of women; for, once hired, a woman cannot be fired. It would thus have the effect of freezing labor mobility for a substantial portion of the labor force at a time when increased mobility is critical. ${ }^{572}$

Furthermore, by the mid 1990s, being concerned with the limited restructuring taking place in the Russian economy, due "to the significant inertia on the part of enterprises... [except kindergartens] ${ }^{573}$ and continuing widespread subsidization," ${ }^{574}$ the World Bank issued another set of recommendations, focusing on the social infrastructure at the enterprises and streamlining the system of maternity/parental benefits. The 1996 report stated that "the government should develop and execute a privatization plan for corresponding assets based on the general principles of the overall Russian privatization program." 575 The World Bank was concerned that

\footnotetext{
${ }^{571}$ World Bank No 12305 (1993f). Italic added by the author

572 Ibid.

${ }^{573}$ Added by the author

${ }^{574}$ World Bank No 117 48-RU. (1994c)

${ }^{575}$ The World Bank No 1635 (1996c)
} 
financing allowances through several different agencies (including the enterprise) and without a clear accounting of costs was viable in a centrally planned economy in which social costs were spread out among different entities. In profit-oriented enterprises, however, management may have incentives to hire persons for whom concessions do not apply. Employers may see all women as potential caretakers of children, the sick, and the elderly, in view of the current division of labor in the household. Women may also be offered lower salaries for the same work to compensate for perceived increases in the cost of female labor (although this is a dubious distinction--the social insurance deduction is levied on all employees). ${ }^{576}$

This shows that Bank's recommendations in Russia in general focused on poverty reduction, removing "obsolete" protection laws and institutional structures, such as enterprise service delivery inherited form the Soviet period, and moving toward a more liberal / third way model of the welfare provision. Interestingly, with respect to child benefits, in contrast to what one might have expected (given the generally neoliberal orientation of Bank's advice provided to Russia at the beginning of transformation), the 1994 report advised against making them income-tested. While supporting the move to means-tested provision in most other social insurance benefits, in 1992, the World Bank specialists maintained that "family allowances are inherently well-targeted, since the presence of children, particularly three or more, sharply increases the likelihood that a household will be in poverty." ${ }^{, 577}$ At the same time, the Bank stressed the importance of reviewing and adjusting the system of assigning both administration and responsibility for some elements of family policy to the enterprise, through leaves and allowances to mothers of small children. It recommended the establishment of "a high-level body at the ministerial level for the implementation and coordination of family policy and the

\footnotetext{
${ }^{576}$ The World Bank No 11748-RU. (1994c)

${ }^{577}$ World Bank No 11748-RU. (1994c)
} 
provision of services of social support." that targeted cash benefits should include child benefits. ${ }^{579}$

This points to some contradictions and fluctuations in the recommendations of the Bank's experts. This was also highlighted by Deacon, who reviewed the Bank's policy recommendations with regard to social policies across countries in transition and noted the internal divisions within the Bank on the definition of the "best" policy ${ }^{580}$ For instance, the question of whether family allowances should be income tested or universal became a subject of strong disagreement among Bank's experts. As Deacon noted that, "[t]he argument against means testing rests for some Bank personnel on the grounds of the continuing narrow range of income differentials, the absence of administrative infrastructure, and the close association of children with family poverty." The examples of variations of policy advice include:

- The universal coverage (1994); income test (2002) (Russia);

- Differentiating by number of children; means test (Hungary);

- Reduction of the universal coverage; need based transfer to low income families (Bulgaria); and

- Pending income testing and poverty levels differentiated by region benefits to vulnerable groups only; reduction of general subsidy (Ukraine). ${ }^{581}$

\footnotetext{
${ }^{578}$ Ibid.

${ }^{579}$ World Bank No 24450-RU(2002h)

${ }^{580}$ Deacon (1997) explains that such difference in policy orientation of some of the World Bank experts was a result of the influence of European tradition on traditionally neoliberal orientation of this organization. For a more detailed description of the divisions within international organizations and there reasons, see Deacon (1997)

${ }^{581}$ Information on advice to Hungary, Bulgaria and Ukraine is based on the table developed by Bob Deacon (1997): p. 135
} 
Presumably, such variation in policy advice is a reflection not only of different political, economic and social realities in these countries but also "differences in the inclinations of report authors and consultants." ${ }^{582}$ This, as we will see, combined with the lack of agreements and coordination of the strategies of provision of international assistance contributed to the overall limited impact of these programs in Russia.

Other international agencies and programs, such as the International Labour Organization, the European Union TACIS Program and United Nations Development Program had a less comprehensive set of recommendations, but nevertheless had an important influence on the Russian state, with respect to the broader course of social development, including child care policies. The presence of the EU agencies in Russia became more prominent, as Russia started to gear its foreign policy to relations with the EU. European organizations, in turn, pushed the Russian welfare state to maintain a "European" level of provision and spending. For example, the EU TACIS Programs focused on enterprise restructuring, and "[r]eform of the social security, pension and health systems in line with market principles, with the aim of helping Russia to tackle the issue of inequalities and improve the quality of basic public social and health services, covering the modernisation of municipal services." ${ }^{583}$ Specifically, TACIS recommendations in the area of child care included:

- Development of the basic standard for the services provided by child care institutions, including the minimum level of services to be provided by different types of child care institutions in terms of both their composition (types of services) and quantity (number of hours for training, health-improving, etc. by each type of services);

\footnotetext{
${ }^{582}$ Deacon (1997): p.134-5

${ }^{583}$ TACIS (2001); TACIS (1999); TACIS (1998a)
} 
- Development of a system of differentiated rates of payment for the child care services by families, depending on the family income level (with the payment ceiling of 20 percent of the costs of the services);

- Encouraging conclusion of agreements with enterprises on coverage of a part of expenditures on keeping children in municipal child care institutions;

- Development of a procedure for involvement and utilization of donations from legal entities and natural persons providing for peculiarities in operation of child care facilities. ${ }^{584}$

As we saw in chapter 3, some of these recommendations (e.g., agreements with enterprises to cover costs of children in child care institutions, municipalization of child care facilities) were in the process of being implemented in some of the Russian municipalities (even though not without challenges). Recommendations of some other international players in fact contradicted to those made by the World Bank and IMF, which in turn contributed to the counterbalance of different interests and ideas in the area of the Russian social and child care policies. For example, the International Labour Organization underplayed the Bank's prognosis of financial crisis and advocated high levels of social protection. The ILO pressed the Russian government to maintain the protection for mothers and increase maternity provisions. Convention No. 183, "Convention concerning the revision of the Maternity Protection Convention, 1952," was adopted by the General Conference of the International Labour Organization on June 15, 2000. The Convention called for widening the coverage (all employed women, instead of different categories of employed women), and strengthening protection (14 weeks of maternity leave instead of 12 weeks). ${ }^{585}$ Although Russia has not ratified the convention yet, Russian policymakers made public statements on the importance of adhering to ILO

\footnotetext{
584 TACIS (1998b): pp. 5-6

${ }^{585}$ ILO (2004a)
} 
principles in maternity and other social provisions. ${ }^{586}$ In addition, the 1995/1996 ILO "World Employment" report criticized the pace suggested by the IMF and World Bank, at which trade liberalization, privatization and enterprise restructuring took place, by arguing that "there are strong arguments against adopting this approach." The report noted the intolerable social costs associated with transition and suggested adopting a gradual approach inasmuch as "there exist policy instruments which make it feasible to temporarily slow down the process of restructuring while still ensuring that change occurs in the right direction." 587

The United Nations agencies, UNDP and UNICEF, also constantly highlighted negative effects of the transition, in particular on women and children. For instance, the 1995 UNDP Russia Human Development Report "Status of Women," painted a "disturbing picture" of the state of human development in Russia. ${ }^{588}$ The Report stressed that the transition "created a steep increase in the mortality level and a dramatic decrease in life expectancy, resulting in a decreasing population." The Report recognized that "Reforming and restructuring the economic and social sectors in an equitable and efficient manner, and in a way that is more conducive to genuine human development, remains a big challenge for Russia. The problems associated with the nature of the transition, as well as those inherited from the Soviet era, are complicated by the absence of a clear and comprehensive strategy." As such, one of the main recommendations of the report included the development of a comprehensive strategy for the Russian

\footnotetext{
${ }^{586}$ See for example statements by Valentina Matvienko, former Deputy Prime Minister, in address to the ILO roundtable "The Social Dimension of Globalizations" on February 2002

${ }^{587}$ ILO (1995)

${ }^{588}$ UNDP (1995b)
} 
development, which would promote not only economic growth but also address the social side of the transformation process.

The UNICEF 1999 Report "Women in Transition" focused more on the impact of obsolete institutions inherited from the Soviet past and directed its recommendations mainly to restructuring strategies. Thus in the area of child care, UNICEF recommendations included:

Two areas that obviously need development are the status of new private-sector employers in promoting family-friendly workplace policies and programmes and the explicit public policies that encourage the growth of registered home-based childcare services. The one-sizefits-all approach of communism needs to be replaced with a flexible widespread network of childcare options that responds to the diversity emerging in the work and family lives of women and men.

The development of private child care services, however, as was shown in chapter 3 , is still in the embryonic stage in Russia. This could be explained by a number of factors, including the low income of the population, lack of market incentives (e.g., there was no credit for child care expenses; undeveloped or overpriced insurance schemes), as well as instability of business regulations (some observers noted that regulations, tax rates and other requirements were changing nearly every month).

Thus, it is apparent that the "international community has spoken with a variety of voices on welfare state reform, constituting a running battle between different perspectives, and carried on through different ground-level welfare consultants who advocate different welfare state models. ${ }^{, 589}$ Lack of cooperation and agreement among and often within the international organizations themselves, as pointed out in a number of

${ }^{589}$ Cook et al (1999): p. 239 
studies (e.g., Bruno 1998; WB technical assistance evaluation reports), undermined the ability of these programs to achieve their full potential. Thus despite such numerous programs and investment of billions of dollars, the results of these organizations' assistance programs in Russia have been mixed. For instance, as noted in one of the World Bank evaluation reports in Russia, it has not been easy for the World Bank to integrate its advice into Russian policymaking. According to the Bank,

the "Statement about the RF Government Policy in the Social Protection Sphere" of 1997 envisaged the implementation of measures aimed to systematize social benefits and allowances, with eligibility limited to the poorest families. The Labor Ministry of the Russian Federation published guidelines for the regions on the application of eligibility principles to the payment of social benefits, but, due to the Duma's opposition, they were not implemented (the 1999 federal law "On Public Social Assistance," which was intended as a systemic legislation, fell short of expectations). ${ }^{590}$

This shows that the degree to which the policies recommended by the international organizations were implemented, depended on their compatibility with institutional constraints and national goals (e.g., transformation of enterprises as micro welfare states). Duma's opposition, described in the previous subsections, combined with the contradictory advice given by the international organizations contributed in patchy implementation of policy recommendations. Another reason for the limited impact of international assistance included the fact that at the project level, Russians accepted international aid and co-operation programs as given and

are weaving them into the complex system of patronage, social relations and survival strategies which are taking shape in post-socialist Russian reality. Many of the glass barriers and obstacles which international projects come up against, but fail to foresee and understand, arise from the

${ }^{590}$ The World Bank No 27970 (2002f) 
fact that, as sources of income but also as loci of power, development projects and international co-operation have been engulfed in the realm of local social, economic and political relations and therefore follow a logic which is Russian more than Western... In the field of aid and development this attitude [feeling of monopoly on the definition of social reality] is being substantially challenged by the dual strategies of Russians who have learnt to play along the lines of international organizations but also use what is on offer in an entirely different logic. ${ }^{591}$

Such attitudes of "gaming the system" prevented a number of programs from achieving their objectives of restructuring and democratization. This was particularly a result of the fact that while those Russians involved in the international projects have "fulfilled" their obligations towards those projects, failure to obtain a buy in from key stakeholders (e.g., local governments), and adapt the projects to the local institutional realities of Russia contributed to low institutionalization of project activities and objectives and thus their low success rate.

A similar situation, but with a much greater magnitude, could be observed at the governmental/national level. For instance, the economic advisor to the Russian government, Jeffrey Sachs, from Harvard University, admitted that "The two packages announced for Russia, \$24 billion announced in May 1992 and \$28 billion announced in July 1993, were never properly elaborated or delivered." ${ }^{\text {592 }}$ Sachs later reflected that "Russian governments, since the start of reforms, have failed to deliver on their promises of stabilization. Rather than sticking to clear and transparent rules of actions, backed by the west, these governments have relied on an unending series of improvisations and

\footnotetext{
${ }^{591}$ Bruno (1998): p. 171

592 Sachs (1995): p. 55
} 
often deceptions of the public, with little Western support and heavy dose of bad IMF advice., 593

Overall, the study conducted by the US GAO office summarized that the main reasons for the limited results of the reform-oriented projects included: lack of domestic political consensus behind reform, and the emergence of powerful vested interests; sometimes poorly designed and implemented programs; and the sheer scale and complexities of the challenges. ${ }^{594}$ We can add here that the conflicting and contradictory advice on the part of international players, existence of divergent policy orientations within some of the international organizations, failure to understand institutional context and obtain support of local stakeholders have also negatively affected the outcomes of international assistance to Russia, particularly in the area of social and family policies.

Thus as we saw in the previous chapters, Russian social and child care policies show that these neoliberal financial institutions (IMF and WB) did not fully "capture" the discourse of policy formulation: child care and maternity leaves were extended, new benefits introduced and old ones were hardly streamlined; enterprises were very slow in terms of the restructuring of their social assets; and private (child care) service provision remained in the embryonic state throughout the first decade of the transformation period. At the same time, the influence of international organizations cannot be discounted. The influence of liberally-oriented international players can be seen to some extent in the low level of allowances even though numerous, reduction of state social expenditures, decline in the number of public child care facilities, and changes in eligibility criteria for child
${ }^{593}$ Ibid.
${ }^{594}$ Kura (2001) 
benefits (from income-tested to universal and back to income-tested). The impact of more socially-oriented players, in turn, can be noted, among others, in attempts to preserve the social protection system, including long paid leaves, attempts to transfer child care institutions to municipalities, thus demonstrating some commitment even at the national policy level to public provision of child care and preservation of labour standards, particularly for women. Hence, the advice of international players can be seen to be implemented in patches and mainly to the extent of its compatibility with the state needs (as complex the array of state actors and thus vision of state needs as they were in Russia) and its institutional frameworks. This shows that "[w]hile [international organizations added by the author] undoubtedly exert some pressure toward policy reform, they must contend with the discursive legacy of ... [domestic] politics that shapes both the interpretation of policy and the course of political bargaining." ${ }^{595}$ Thus the new ideas (e.g., neoliberal) were mainly successful to the degree of their compatibility with the inherited ones, including state commitment to provision of care and paid leave, which resulted in a synthesis between the old and the new, which did not merely coexist, but blended in a unique way.

\section{Business Interests and Enterprise Resistance to Change}

Other interests, which are often considered to be external, and may influence the developments in the Russian welfare state, include those of businesses. The "externality" of businesses, in the Russian case, is a contested concept. There is a well-developed body of literature on the issue of the concentration of national resources in the hands of a

\footnotetext{
${ }^{595}$ Goven (2000): p.303
} 
narrow circle of elite in Russia, which was a result of the Soviet legacy of fusion between economy and the state. For example, Shkaratan argues that the modern Russian state is neither socialist nor capitalist, but a direct continuation of the social structure that existed in the Soviet Union. ${ }^{596}$ That system was based on the "power - property" relations, and social differentiation had non-class character, and was determined by the ranks in the power hierarchy. ${ }^{597}$ Shakaratan notes that a "merger" of power and property obtained a new "private ownership" shell, but in practice remained unchanged. Due to the fact that the economy was a part of the "state system" during the reforms, a dual process took place, whose separate elements represent a historical blend and are hard to distinguish. On the one hand, former state-owned enterprise managers were a part of the state industrial horizontal and vertical networks, in a sort of "directors' club" during the Soviet times. These networks were formed by, and were a part of, a ministry responsible for certain sectors of the economy. During the transformation, these managers, while still being a part of the state networks, managed to retain a significant portion of the enterprise assets. At the same time, through the same networks, the nomenklatura has also obtained significant part of the state property and transformed itself into large quasi-bourgeoisie (for a snapshot of distribution of former communist party officials across the sector, see Appendixes 6, 7, 8).

At the macro-level, the speedy privatization practically "gave for free" to the ruling nomenklatura (those close to the presidential circle) significant public property, which was topped by a more deliberate attempt to create a "political business class"

\footnotetext{
${ }^{596}$ Shkaratan et al. (2003)

597 Ibid.
} 
through providing loan shares in major Russian companies for prices at least 20 times under the market level to the so-called "oligarchs to be." businessmen in Russia, noted that a fair share of the Russian oligarchs were appointed, rather than becoming oligarchs as a result of competitive business. ${ }^{599}$ These are the oligarchs (as opposed to the newly-emerged businesses) who are often seen as opposing the real market reforms with transparent rules.

The resistance to change, manifested by the former state owned enterprise managers, is also observed at the micro-level. Numerous studies have pointed out that enterprise restructuring in Russia has been very slow. For example, the European Union experts, when assessing the impact of enterprise restructuring policies, note that "while technical assistance has exposed thousands of enterprises of all sizes to modern management techniques, actual restructuring has been slow, there has been little investment in companies receiving advice" ${ }^{, 600}$ Some of the factors affecting such mixed results included the legacy of the former State owned enterprise enjoying relative isolation, in both geographical and managerial terms, which turned them into social, economic and political units into themselves. ${ }^{601}$ Subsequent privatization further increased the operational and financial autonomy of managers and regional and local authorities. The way in which privatization was conducted (by the higher echelons managers and directors, with some workers' shares) resulted in the blurred ownership of SOEs and multiple claimants, with overlapping and conflicting control rights. In order to

\footnotetext{
${ }^{598}$ For more on the process of privatization, see Shkaratan et al. (2003): p.56

${ }^{599}$ See Delovaya Gazeta "Vzglyad" (2005) [Business newspaper "Outlook"] - translation by the author

${ }^{600}$ European Union (2001)

${ }^{601}$ Bruno (1998): p.176
} 
keep effective control of the enterprise, managers relied on workers' shares and votes.

Unable to pay high salaries, due to the decay of the industrial production, the management often had to guarantee the protection from the onslaught of economic reforms, using the social infrastructure at hand. ${ }^{602}$ This was also the reason for the limited effect/adaptation of the recommendations made by the international organizations, encouraging wide private ownership. Various tactics employed by the enterprises, in many cases, even prevented employees from selling their shares to outsiders. $^{603}$

Thus, most social reforms, which were a part of the neoliberal package, remained unimplemented in whole or in part. As a result, the enterprise continued to serve as the main provider of social welfare of that period, adding uniqueness to the shape of the Russian welfare state:

This [political] situation impeded structural reform at the enterprise. In fact given the tax system, the low cost of labour, and the extreme dependence of these workers on the enterprise, factory directors had real incentives to maintain Soviet-era employment levels and higher (Commander, Dhar, and Yemtsov 1996; Layard and Richter 1995). Threatening social chaos if workers had to be fired, enterprise directors also could blackmail the state to transfer subsidies to cover their wage bill, housing costs, retirement benefits, etc. In nonproductive enterprises, state transfers for wage bills serve effectively as unemployment compensation from the state. ${ }^{604}$

The enterprises' resistance to change is important for several reasons. First, it illustrates an important continuity from the Soviet period, and the fact that, despite relative state autonomy from the external actors, the welfare state generated vested interests reluctant

${ }^{602}$ Ibid.: p. 177

${ }^{603}$ Stoner-Weiss (2003)

${ }^{604}$ McFoul (1999): p.221 
to change the existing structures. This, once again points to the importance of the synthetic approach (both state- and society-centred) to the analysis of policymaking and welfare state development in the post-Soviet Russia. Second, the retained control of social infrastructure by former state-owned enterprises (and thus, the provision of services through enterprises) can be seen as a unique, but important element of the Russian welfare state. Finally, the de facto control by enterprise managers of enterprisebased former state infrastructure gave them a power to "choose" which facilities to retain and which to municipalize, sell, privatize or close. This power, in the conditions of changing ideological framework with regard to women and thus child care, resulted in child care facilities being the first to go. The next chapter will describe the strategies used by enterprises, which allowed them to retain a number of functions of welfare states, while abolishing others, and to adapt to new quasi- market conditions without restructuring.

\section{Trade Unions and Civil Society}

As discussed in chapter 2, trade unions were mainly subservient to the needs of managers and political authorities in the Soviet Union, due to the political nature of their leaders' appointments. After the regime change, despite the expectations of most economists, trade unions did not collapse. Neither did they "become independent, despite the radical decentralization of power within their organizations after 1990. There were some exceptions, mainly where there had been spontaneous rank-and-file mobilizations, but 
these were rare." ${ }^{, 65}$ Trade unions managed to survive the first decade of transformation by adopting a strategy of "social partnership." The approach, in Mandel's terms, implied "a strategy based on subordination of union strategy to the aims of management at the enterprise and political levels." ${ }^{606}$ This was based on the premise that workers and management/state have an overall shared interest in the survival of their enterprise in the new economic conditions. This placed the union in a familiar situation, where, as in the Soviet times, unions mainly played on the management / state side, but using the appropriate market terminology. ${ }^{607}$

Kozina notes that this strategy was adopted as a result of the weakened position of the trade unions. She mentions that, while the beginning of the 1990s was characterized by clear confrontation between trade unions and the government, when trade unions attempted to oppose liberal reforms, the leadership of Federation of Independent TradeUnions of Russia (FNPR) drew their lessons from the armed events of 1993 "when Parliament was bombarded by tanks and the trade union was subjected to repression." 608

She further notes that

Of course, the trade unions faced a difficult choice. On the one hand, in order to preserve their status they had more actively to defend the interests of their members. On the other hand, having taken this road, they risked becoming useless to the state. For the still cumbersome territorial-branch apparatus of the trade unions to function freely, more as a large distributive resource than a real defender of the interests of workers, a sharp reorientation was extremely undesirable. On the other hand, it had to take into account the fact that the apex of the Federation was a group of holding companies which own hundreds of properties,

\footnotetext{
${ }^{605}$ Mandel (2001):p.174

${ }^{606}$ Ibid.: p. 179

${ }^{607}$ Ibid.: p. 180

${ }^{608}$ Kozina (2005)
} 
which makes FNPR one of the largest owners in the country. The threat of nationalisation of this property or simply its privatisation through free sale was an important lever of pressure on FNPR from the government. The contradiction between the traditional role of the trade union as part of the state and local administrative apparatus and its role as defender of the rights and interests of its members was not resolved in favour of the latter. The traditional trade unions chose the course of 'constructive interaction' with the authorities, gradually constructing their familiar niche as an official semi-governmental organisation. ${ }^{609}$

Hence, the establishment of "social partnership," as an agreement between the trade unions and the state apparatus, allowed the trade unions to maintain their status of quasistate organization. Mandel argues that “"[p]artnership” is attractive to union leaders because it is a less risky, and certainly less onerous, strategy from the vantage point of their own personal interests."

Under the 1993 Russian Constitution, trade unions lost their right of legislative initiative, ${ }^{611}$ so they had to cooperate with other parties, in order to be visible in the legislative arena. In the 1993 elections, FNPR became a major supporter of the Civic Union, and participated in the campaigns for privatization schemes, allowing enterprise managers to retain control over enterprises. In the 1999 Duma elections, FNPR actively supported the "centrist" party Fatherland-All Russia. With the support of this party, unions made a major come back at the end of the 1990s, during the Labour Code debate (as shown in the next section).

In terms of the institutional structure, the Federation of Independent Trade Unions of Russia (FNPR) became the successor of the All-Union Central Council of Trade

\footnotetext{
${ }^{609}$ Ibid.: p. 23

${ }^{610}$ Mandel (2001):p.182

${ }^{611}$ Kozina (2005)
} 
Unions (VTsSPS). The transformation also saw the creation of new trade unions who disagreed with the traditional functions of the FNPR, and became their competitors. These new trade unions placed demands on the FNPR, as it was the inheritor of the property of the former Soviet trade unions. Over time, this opposition smoothed out, and the new trade unions became less visible on the political arena (having much less access to power than traditional trade unions). ${ }^{612}$ Overall, though trade unions have been drastically reduced in membership and split into competing organizations, they have remained among the most institutionalized organizations, which had strong connections with the past. ${ }^{613}$ Kapellushnikov argues that high level of unionization can be explained more by inertia than activism, and trade unions became rather passive. ${ }^{614}$

Despite a strong institutional base and a variety of strategies employed by the trade unions to remain visible and effective in the new conditions, including social partnership, the role of the trade-unions has significantly decreased in the transformational period, and their capacity to challenge the autonomy of the state is relatively low. At the same time, there were some actions where the role of trade unions was rather prominent, demonstrating their ability to significantly affect policymaking in certain cases. The first was the combined action with the Civic Union, at the beginning of the transformation, to oppose the liberal privatization plan, a joint venture which proved to be relatively successful in accomplishing its immediate goals. Other cases included the introduction of mandatory gender-based analysis in the general agreements between trade unions and employers, as well as effective lobbying against the neoliberal Labour Code

\footnotetext{
${ }^{612}$ Ibid.

${ }^{613}$ Cook p.:240

${ }^{614}$ Kapellushnikov (2001)
} 
proposed by the government (in partnership with the centrist party Fatherland- All Russia - see the case study below). This, once again, highlights the importance of utilizing a combined approach to understanding policymaking, as it enables us to see the impact of the non-state (or quasi-state) actors on how policies are made.

Similarly, the role of civil society in influencing the public policy process, although growing, is still insignificant. Many scholars have noted the importance of the mobilization of women's groups and other social movements for the analysis of the politics of child care; however, in the Russian case, these movements do not have a strong influence over the policy process yet, as the civil consciousness of the Russian society is quite low. As noted by the deputy of the Russian State Duma "While there are more than 500 women's organizations in Russia, the women's movement in Russia is still gaining its strength." ${ }^{615}$ Some of the organizations, like All-Russia Union of Women, collaborate with the State Duma on a number of initiatives, including the gender equality concept, but the influence of such organizations is very limited. Perhaps, such weakness of civil society and women's organizations in particular can be seen as a legacy of the Soviet period, when most civic activities were banned and the only women's organization that existed during that period was Zhenotdel, a women's division of the Communist Party. The weakness or absence of feminist ideas and movements has been noted repeatedly in the post-1989 literature on Eastern Europe. In light of a relatively undeveloped civil society, it is hardly surprising that no significant feminist movement

${ }^{615}$ Rossiiskaia gazeta (August 21, 1998) - translated by the author 
has emerged on the Russian political scene. The state can be seen as quite autonomous from the civil society groups at this stage of development of the Russian Federation.

\section{Labour Code Debate}

The case study of the Labour Code debate demonstrates the internal dynamics and influence of external pressures on policymaking in the area of child care. It also underscores the importance of utilizing a combined state-centered and power resource approach to understanding how the policy is made. This case illustrates relative state autonomy; it also emphasized the importance of the non- and quasi- state forces, such as trade unions.

As shown earlier, the policymaking process in Russia, during the 1990s, was characterized by a number of policymaking gridlocks and stand offs between the executive and legislative branches of the states, as well as conflicts within those branches. Labor reform has also been a stumbling block among all players on the political arena, and a long-awaited initiative for the international financial community. In 1997, the Russian government committed to developing a new Labour code that would "bring the labor laws in compliance with the requirements of a market economy."616 The funding for the development of the Code was secured through the World Bank Social Protection Implementation Loan. This commitment was echoed in the joint memorandum of the government and central bank to the IMF. The Code gave rise to much more controversy among the internal players than the government and international community

${ }^{616} \mathrm{IMF}(1998)$ 
had anticipated. In February 1999, Yevgeniy Primakov's government submitted the draft Code to the State Duma, but encountered strong resistance from a number of "socialist conservative" parties in a number of areas, including women's protection.

Later in the process, seven different drafts of the Labour Code were submitted for consideration, including one originating from Yabloko, one hardline version of the government project supported by Unity and Zhirinovsky's Liberal Democratic Party, and one radical, labor-empowering draft, sponsored by an alternative post-Communist union, Zashchita Truda (Labour Protection). ${ }^{617}$

The strongest opposition, however, came from the Federation of Independent Unions of Russia (FNPR), which enlisted the support of the Fatherland-All Russia, the Communist Party with their Duma allies, the Agro-Industrial group and Regions of Russia. A number of women's organizations supported the FNPR's position as well. This bloc initiated its own alternative draft of the labor code, which, among other things, suggested preserving the majority of women's protections, contained in the previous labour code. ${ }^{618}$ This alliance was on the edge of depriving the government of a required majority, which led to extensive debates and negotiations. ${ }^{619}$ President Putin, in his Annual Address to the Federal Assembly, on April 2, 2001, urged the Duma to adopt the Code on the basis of the government draft "The corps of deputies, the government and trade unions have differing views of the labor code... I am counting on the parliament to

\footnotetext{
${ }^{617}$ Glinski-Vasiliev (2001): p. 2

${ }^{618}$ Stenogramma Zasedaniya Gosudarstvennoi Dumi (2001) [State Duma Hearings] - translation by the author; Glinski-Vasiliev (2001): p. 2

${ }^{619}$ Glinski-Vasiliev (2001): p. 2
} 
speed up the process of finalizing and adopting the labor code on the basis of the government's draft. I said on the basis of it, on the basis."

The draft codes differed on a number of principal issues. The first draft, sponsored by the government and international financial organizations, aimed at the fastest transition to liberal labour relations, and the establishment of a market economy. The second draft (FNPR's) was the complete opposite of the first, with the increase of existing benefits and protections not only to women, but other categories of workers as well. Finally, the third draft submitted by the working group headed by the deputy minister of Labour, aimed at providing a "golden mean." The existence of several versions of the draft code within the government points to internal disagreements, not only between the ministries, but also within the same Ministry of Labour. ${ }^{620}$ The protection of women's labour, including parental leave, became a contentious issue. The government draft cut the duration of benefits associated with parental leave, from 3 to $11 / 2$ years, while the FNPR insisted in keeping it at 3 years. ${ }^{621}$ Interestingly, policy changes were not discussed in the context of allowing women to maintain both career and family. The main focus was on women's functions as mothers, and giving them an opportunity to stay home if they wished. Another important point is that even the government's draft code, despite being "inspired" by IMF and World Bank, still allowed a woman to stay at home until her child reached the age of 18 months. The main consideration behind the reduction of the leave was to increase the employability of women, while reducing state expenditures. Another contentious issue was the old

${ }^{620}$ Rossiiskaia Gazeta (July 05, 2001) - translation by the author 621 Ibid.; Rossiiskaia Gazeta 12-20-2001: Stenogramma Zasedaniya Gosudarstvennoi Dumi (2001) [State Duma Hearings] - translation by the author 
provision banning night, weekend and overtime work for women with children aged up to 14 years old, or disabled children, etc. The government offered to reduce the age to 3 years-old. The opposition heatedly protested, by arguing that

First. The country is experiencing a demographic catastrophe, since, according to the official statistics, in the past three years the overall number of children in the country declined by 4 million. Second. We need a proactive demographic policy, and not a restrictive one. Women should not be punished for being brave to give birth to children in our times. Mikhail Kasyanov [Prime-Minister at that time] several times noted that the demographic problem is one of the most acute ones. ${ }^{622}$

The government representative, Minister of Labour and Social Development, Alexander Pochinok, counter-argued that "the salary is the only source of income of a single mother. By increasing the protection, we would drastically reduce her position in the labour market." This shows that a vision of a labour law also came from the internal, administrative perspective which the government had to develop in order to provide some acceptable rationale for the reduction in the duration of parental leave and its costs not only to the state, but also to women.

In order to balance different interests, the President created a working group headed by the new Minister of Labour, which considered three main drafts of the Code. After almost a year of additional debate and counterbalance, the Code was adopted in December 2001 and presented a number of compromises, including the preserved duration of maternity and parental leaves. Thus the "woman question" remained mostly untouched: under the new code, a woman still has a right to return to the same job after three years of parental leave, the "compensations" for leave until a child reaches the age author 
of three are still paid by the employer, etc. Only insignificant changes were made. For example, according to the old code, a woman could not be sent on a business trip if she had a child younger than 3 years old; under the new code, the organization has a right to send a woman with young children on the business trip, but only with her consent. ${ }^{623}$

Thus the opposition of the left-leaning bloc, supported by the FNPR, ILO and a number of women's groups was able to lever the necessary power to preserve most protective provisions for women. The main reasons for this "victory" included the deteriorating demographic situation in the country and remaining tensions in the Russian labour market. As discussed earlier in this chapter, the arguments used included a need to provide women with an opportunity to stay at home and care for children and adopt all possible measures to stimulate fertility. "Keeping women at home with children" thus became a compromise among various stakeholders, as in addition to potentially increasing the attractiveness of child birth, these measures could release some tension in the labour market. As such, this case shows both the significant influence of external actors on the shape of the debate (e.g., the IMF and the World Bank recommendations provided the basis for the original draft of the labour code; support of FNPR and other actors) and the fact that the ultimate debate took place between the state actors - the Government and the Duma. This highlights not only the importance of the internal state dynamics in the policymaking process and relative autonomy of the state in the area of child care but also the importance of non-state and quasi-state actors in the Russian policymaking process.

${ }^{623}$ Rossiiskaia Gazeta No.145 (August 1, 1998) - translation by the author 


\section{Discussion and Conclusions}

This chapter illustrated that a number of factors have contributed to the emergence of a mixed model of the Russian welfare state and paradigm shift in the area of child care. It accounted for how and why the change in the ideas about the role of women came about, as well as examined the process of policymaking in the area of child care, leading to the emergence of a new mixed welfare regime. As accounted for in chapter 3 , one of the main tenets of welfare state reconfiguration in the 1990s Russia was the contraction of the state responsibilities in the area of child care, and shifting of care from the public to the private domain (particularly in the absence and low affordability of the market solutions). We've seen that this process was highly political and involved a variety of factors, such as demographic crisis (dropping birth rates and increasing mortality), or the need for "flexible" labour markets, to reduce pressure of mass-unemployment in light of economic restructuring. These factors, as indicated, mediated shifts in the state and society's views of the role of women and social welfare and care. The magnitude of the shift in the framing of care was partly a reflection of the sense of urgency concerning the demographic and labour market crisis. It was also a reflection of the society's rejection of everything associated with the past, including full female employment. This also had an important impact on the scope of the shift.

This chapter also showed that state interaction with the non-state actors, particularly given the legacy of the party-state monopoly in both economy and politics, was very tight. As such, the changes in child care policies, along with the ideas governing these policies, are best understood through the use of a mixed approach, which analyzes 
the internal state dynamics (state-centered approach) as well as accounts for the influence of the external social and economic forces (power resource approach). Utilizing only one of these approaches would only account for half of the story. ${ }^{624}$ The state centered approach allowed us to see that, while the "interest group context is an important first step, a clear grasp of the state's internal dynamics and routines is critical for understanding the state's scope of action. ${ }^{\text {} 625}$ Following this approach, this chapter established the links between the state and non-state actors, and showed that the state was a source of independent goal formulation (like the extension of child benefits in 1994), despite pressures to the contrary. The power resource approach, in turn, helped to advance our understanding on the nature, process and impact of interaction among external and internal actors in the policymaking process.

Below I list the main conclusions with regard to the four hypotheses presented at the beginning of this chapter. First, this chapter demonstrated that, despite numerous attempts by external actors to influence the development of the Russian welfare state, the state remained relatively autonomous from the non-state actors in policymaking in the area of child care. It shows that non-state actors had only a limited impact on social and child care policies. The government, throughout the transformation years, was promoting the model of the "liberal" welfare regime, in which the state would play a minimal role through means-tested benefits, and most responsibilities for care and other welfare functions would be placed on markets and families. Such policy changes were inspired by the recommendations of the World Bank and IMF. At the same time, the complexity of

\footnotetext{
${ }^{624}$ Peng (2003)

${ }^{625} \mathrm{Pal}$ (1986): p.92
} 
the political process in Russia, and the scope of the legacies from the Soviet period stifled the liberal welfare reforms. This demonstrated that domestic political institutions, such as political parties, and the decentralization of decision-making determine the shape and design of social policies in Russia, and present a case for the relative autonomy of the state. Indeed, in many cases, the "changes/continuities" in the area of social care were driven by the state actors. Thus, the state's efforts in policymaking and social change need to be taken into account with full consideration, because they affect "political actions and make possible the raising of certain political issues (but not others)." At the same time, although the state has been the main driver in developing social and child care policies, the power of interest groups (industrial, left, and trade unions), which often found a political representation, cannot be underestimated. Thus domestic and international economic constraints were also important in shaping the welfare regime, even though the WB advice was only patchily implemented.

Second, the multiplicity of internal state actors often resulted in inconsistent policymaking. As shown, agencies of the state, including bureaucratic departments, political parties and regional/local governments and legislatures, often operate at crosspurposes and have divergent interests in reforms, including privatization of state preschool educational assets. ${ }^{626}$ In line with arguments of scholars such as Theda Skocpol and Les Pal, we can see that interactions between state actors can influence the capacities and degrees of state autonomy. Administrative arrangements, combined with policy legacies and the established ties to intellectuals, help understanding how the policy

${ }^{626}$ Skocpol (1985): p.21 
is made in the Russian state, and how this specific welfare model has emerged. The structure of the state, including executive and legislative powers at the federal, regional and local level, determine what kind of political issues can get on the agenda. Vertical and horizontal relationships within the state affect the final policy outcomes. Plekhanov notes

the reforms of the past decade have revealed a strong convergence between the neoliberal orthodoxy, with its insistence on the liberation of market forces, and authoritarian traditions of the Russian state. The orthodoxy could only be enforced in Russia by authoritarian means. And the Russian elites have benefited from the process so massively - at the expense of the masses of citizens - that one almost begins to suspect that the so-called "Washington consensus" was drafted in the Kremlin, not in Washington. ${ }^{627}$

Third, given the Soviet legacy of fusing the economic and the political, as well the decentralization of power, many actors (e.g. managers of the former state enterprises or members of communist party in the region/enterprise), who in other contexts would be considered to be outside of the state, keep maintaining the balance on the border of the state and economy, and often constitute a part of the state machinery inherited from the past. Some characterize Russia as a "chaotic social state," where "the capitalism as economic system which supports capital accumulation has not been established.... Personal networks, which have industrial, regional and bureaucratic basis determine economic activities to a greater degree than the market." ${ }^{, 628}$ These legacies have affected the autonomy of the state, by influencing policymaking from both within the state (regional / local governments) and outside of the formal state boundaries (former state enterprises).

${ }^{627}$ Plekhanov (2003)

${ }^{628}$ Lain as quoted in Shkaratan et al. (2003) 
Fourth, the chapter illustrates that the neoliberal changes "depended on the ability of societies to adapt to the changed environments by relying on their traditions and existing political culture - and sometimes by reviving and reinforcing them." ${ }^{\circ 29}$ As the Russian case indicates, neoliberalism was successful largely to the extent that the new ideas, such as reduction in social provisions and introduction of fee-system for public child care, were compatible with the inherited ones, including state commitment to provision of care and paid leave, resulting in a synthesis between the old and the new, which do not merely coexist with each other but are blended in a unique way.

It is evident that a complex set of ideas, historical and new interests, legacies and institutions, have shaped the emerging welfare regime in Russia. We can also see that the state remained an important actor in policymaking, despite many scholars arguing to the contrary. The next chapter will analyze the outcomes of the new welfare regime, while chapter 6 will assess the capacity of the state to implement its policies in the area of child care, and different strategies employed by various actors (e.g. women, families, enterprises), that influenced the policy outcomes and further contributed to the shape of the welfare regime.

${ }^{629}$ Dutkiewicz \& Plekhanov (2004): p.114 


\section{Chapter 5. Labour Market and Child Care Implications of the New Welfare Model}

\section{Introduction}

The previous chapters have shown that the paradigm shift in family/ child care policies was part of a more complex restructuring and repositioning of neofamilialist elements in the larger edifice of an emerging Russian welfare state. The shift towards neofamilialism, however, does not necessarily mean strong pro-family or gender equality policies. It rather implies a system in which public policy, while in principle accepting female participation in the labour force, assumes that families are the relevant locus of social aid and tends to enforce specific modes of child care provision strategies, such as homecare through extended leaves and in-home caregiving subsidies. ${ }^{630}$ As a result, neofamilialist policies tend to produce an identifiable set of outcomes, which would pull mothers out of the labour force, at least temporarily.

The focus of this chapter will be to examine whether neofamilialist policies achieved their outcomes in Russia. This chapter will show that the shift to neofamilialism was counterweighted by the impact of the transformation itself, through inflation and reduction in earnings, which altered the capacity of neofamilialist policies to achieve their goals. This chapter advances the dual sub-hypotheses that

${ }^{630}$ Ibid. 
- The shift to neofamilialism in child care policies had a selective and relatively limited impact on women's decisions about employment during child rearing and childbirth (e.g., withdrawal from the labour force); and

- The shift in child care policies resulted in the provision of the bulk of care at home.

This chapter advances the main hypothesis of the dissertation by analyzing some of the results of the shift towards neofamilialism, and showing that it had important but limited implications for the position of women in the labour market. In particular, this chapter focuses on the changes in female labour force participation, unemployment, and current working status. It also analyzes utilization of maternity and parental leave schemes, the changes in women's decisions to become full-time homemakers, as well as the changes in individual child care arrangements and assesses whether these changes are consistent with the original policy objectives. Finally, since in Russia neofamilialist policies were introduced not only to lower the pressure on the Russian welfare state, but also with often hidden but inherent objectives of increasing fertility rates, I will examine the effectiveness of policies to achieve these objectives. With these purposes, I analyze data drawn from the Russian Longitudinal Monitoring Survey, a household-based survey focused on the position of women in the labour market, as well as child care arrangements made by individual households. The data analysis was supplemented with personal observations and informal conversations with women in Russia. 
The chapter consists of three main sections. The first section focuses on the implications of the shift to neofamilialism for women's position in the labour market, parental leave utilization, as well as trends in women's choices of being a full-time homemaker. The second section analyzes the fertility rate trends in Russia during the transformation period. The third section will focus on the changes in the individual child care arrangements for children under seven years old.

\section{Labour Market Implications for Women}

\section{The Link between Child Care Policies and Mothers' Employment}

There is a well-developed literature about the social and economic effects of different child care regimes. One of the most obvious effects is the impact on the employment status of women. ${ }^{631}$ This relationship is due to the fact that the presence of children is likely to affect women's decision-making about employment, while the availability of child care options may either hinder or facilitate this employment. For instance, according to the standard labour -supply model,

having children in the home will influence women's employment decisions by changing the value that they place on their time outside paid work. The cost of alternative childcare arrangements will also lower women's effective market wages. The empirical literature confirms that women who care for a greater number of children... have a lower probability of being employed than similar women with fewer

${ }^{631}$ See Gornick et al (1997), Bettio \& Plantenga (2004) 
caregiving responsibilities; for mothers who are employed, greater childrearing responsibilities reduce hours in paid work ${ }^{632}$

Several other studies also support the link between employment-supporting policies for women, such as child care and parental leave, and women's employment continuity. Thus for instance Sainsbury argues that there are two approaches to understanding of impact of child care policies on female employment:

The first depicts childcare arrangements as affecting the value that a woman places on her time at home with better childcare alternatives reducing the attractiveness of full-time caregiving work at home. ${ }^{633}$ In the second approach, the cost of childcare is viewed as a 'tax' on mother's wages... Both approaches predict that improvements in women's childcare options will be associated with increases in employment... The relationship between maternal-employment and parental-leave policies is understood differently by economists. Generous maternity-leave provisions are generally believed to increase women's attachment to paid work in the short term... In the long term, there is more ambiguity about whether extended absences from the workplace will advantage or disadvantage women in the accumulation of experience and human capital. ${ }^{634}$

Thus in the context of welfare regime models, as explained by Mahon, one of the main effects of pure neofamilialist model is the mothers' withdrawal from the labour market for an extended period of time during child rearing. This leads us to anticipate that in broad terms neofamilialist policies could produce the following set of outcomes:

- Mothers of young children become more likely to be full-time homemakers than women without children;

- Overall decline in employment of mothers with young children;

- High utilization of maternity/parental leave;

\footnotetext{
${ }^{632}$ Sainsbury (1999): p.121; See also Connelly (1991); Leibowitz et al. (1992)

${ }^{633}$ Blau \& Ferber (1992)

${ }^{634}$ Sainsbury (1999): p.121
} 
- Increased part-time employment of mothers with young children; and

- Bulk of child care is provided at home.

In addition, in Russia, these policies were introduced not just to provide women with a "choice" of caring for children at home, but also to increase fertility rates and possibly reduce labour market pressures. Therefore, in assessing the impact of the policies, it is important to examine the labour market position of women, changes in the child care arrangements for young children (i.e., home-provided care, public care, private care), as well as changes in the fertility and childbirth rates during the transformation.

At the same time, the question of how and whether female employment was affected by the transformation to new economic conditions with elements of neofamilialism has no straightforward answers:

On the one hand, one would expect diminished access to childcare to reduce the extent of female participation. This would be compounded by the fact that the reduction in real wages... has reduced the attractiveness of market work outside the home. On the other hand, general reductions in labour earnings of men and women and the liberalisation of prices of basic goods and services would be expected to increase the incentive to find paid work to try and maintain, or at least protect, the living standards of the family. It might also be expected that relative wage adjustments associated with economic liberalisation would serve to benefit women, who traditionally entered the labour market with higher levels of education than men." Finally, it might be expected that greater flexibility in the labour market would allow women to take advantage of emerging private sector opportunities, and also engage in paid work on a part-time basis. ${ }^{635}$

These competing factors, as will be shown in this chapter, produced mixed results in the Russian welfare state. The next subsection will focus on the labour market indicators with

${ }^{635}$ Motivans and Klugman (2001): p.16 
specific attention being paid to the types and forms of female participation, particularly those mothers with children younger than seven years old. Changes in the child care arrangements and fertility rates will be analyzed in the subsequent sections.

\section{Unemployment and Labour Force Participation}

To illustrate the effects of family policies on women, this section studies changes in female employment from 1994 to $2001,{ }^{636}$ using the Russian Longitudinal Monitoring Survey (RLMS) ${ }^{637}$ The analysis in this section is focused on three main labour market indicators, such as unemployment, unemployment duration and labour force participation. As discussed in chapter 3, the Russian labour force has shrunk substantially since the beginning of the transformation. At the same time, the official unemployment

\footnotetext{
${ }^{636}$ This thesis is primarily focused on the first decade of the transformation (1991-2001). As discussed in chapter 3, this period was marked by high rates of inflation (1992 - 2,520\%; $1994-224 \%)$, declining wages and standard of living (in 1992, consumers' spending capacity had decreased by almost two thirds of its original capacity), as well as declining GDP (more than 50\%).

${ }^{637}$ This data set is based on individual records of the second RLMS panel. These records contain detailed information about gender, occupation, education levels and type, unpaid leave, wage arrears, and income from secondary jobs. The analysis in this thesis includes individuals from age 15 until retirement age (55 for females, 60 for males). The dataset also contains "information on the modes of child care arrangements made for each child in the household, the amount of time each child spent in formal and informal child care, and the amount of money paid for formal child care during the week of the survey. The part of the questionnaire that was administered to each individual household member yielded data on how much time each household member spent looking after children and was active at the labor market, as well as information on their monthly wages." Source: Lockshin (2001): p.11

The RLMS has some limitations however. Women are asked about leave in a combined way which includes both maternity and parental leaves. This combination does not allow us to separate the effect of these two, albeit very different, types of leave. Another limitation is that the data about the availability of leave and child care only became available in 2000 , while the main decline in employment took place in the middle of the 1990s. At the same time, the survey has a number of strengths. First of all, it is a longitudinal data set, which allows a comparison over time. There is a wealth of information not only on conventional income and employment variables, but on family composition, the presence or absence of extended family members, and variables such as attitudes. Moreover, the RLMS is collected independently from official government agencies, so it is not subject to state manipulation. Finally, it is simply the best publicly available data set on the issue of women's employment in Russia. Source: This paragraph draws significantly on the work of Teplova and Woolley (2005).
} 
rate in Russia has remained lower than in most developed countries, as shown in Table

30. As Grogan and van den Berg note, this has created puzzles for most western economists and transition specialists:

One of the great mysteries of economic transition in Russia has been the lack of an unemployment rise commensurate with the severity of output falls. Given that labour hoarding was generally agreed to be a cause of the very low unemployment rates in the late Soviet era, it might have been expected that the swift price deregulation would lead to a large one-off shedding of workers. Unemployment officially became legal in Russia in 1991, although it was always a small residual phenomenon in the Soviet times. Obsolescence of human capital, caused by the inappropriateness of Soviet-era skills in market economies was generally expected to lead many older workers into unemployment or nonparticipation. $^{638}$

It was also expected that women would be the first to be hit by unemployment. Indeed, at the beginning of the transformation " 60 per cent of those made redundant were women, rising to 80 per cent amongst managerial workers." ${ }^{\circ 39}$ Mezentzeva supported that "as a result of a drop in production and the closure of a whole range of technically obsolete and uncompetitive sectors, the trend toward shifting women from paid to unpaid domestic labour is likely to intensify." ${ }^{640}$ Nevertheless, these trends stabilized at a later stage of transformation (Table 30) and as acknowledged by a number of economists "unemployment does not seem to have afflicted women disproportionately." "641 For example, the official rate of unemployment -- the fraction of labour force not working

\footnotetext{
${ }^{638}$ Grogan and van den Berg (1999): p.2

${ }^{639}$ Rimashevskaya as quoted in Ashwin \& Bower (1997).

${ }^{640}$ Mezentzeva as quoted in Ashwin \& Bower (1997): p. 22.

${ }^{641}$ Ashwin \& Bower (1997): p. 23
} 
and looking for work - remained relatively low and stable over time (with a minor

decrease of 0.1 percentage points from 6.1 per cent to in 1994 to 6.0 per cent in 2001).

Table 30. Current Working Status, Unemployment and Labour Force Participation Rates among Working -Age Adults (Men 18-60; Women 18-55), 1994-2001, Russia

\begin{tabular}{|c|c|c|c|c|c|c|c|c|c|c|c|c|}
\hline \multirow{3}{*}{ Categories } & \multicolumn{6}{|c|}{1994} & \multicolumn{6}{|c|}{2001} \\
\hline & \multicolumn{2}{|c|}{ Total } & \multicolumn{2}{|c|}{ Men } & \multicolumn{2}{|c|}{ Women } & \multicolumn{2}{|c|}{ Total } & \multicolumn{2}{|c|}{ Men } & \multicolumn{2}{|c|}{ Women } \\
\hline & $\mathbf{N}$ & $\%$ & $\mathbf{N}$ & $\%$ & $\mathbf{N}$ & $\%$ & $\mathbf{N}$ & $\%$ & $\mathbf{N}$ & $\%$ & $\mathbf{N}$ & $\%$ \\
\hline $\begin{array}{l}\text { Current } \\
\text { Working } \\
\text { Status: }\end{array}$ & & & & & & & & & & & & \\
\hline Working $^{642}$ & 4289 & 70.9 & 2270 & 76.3 & 2019 & 65.7 & 4589 & 67.7 & 2243 & 70.9 & 2346 & 63.6 \\
\hline $\begin{array}{l}\text { On } \\
\text { maternity / } \\
\text { child care } \\
\text { leave }\end{array}$ & 174 & 2.9 & 0 & 0 & 174 & 5.7 & 136 & 2.0 & 1 & 0.0 & 135 & 3.7 \\
\hline $\begin{array}{l}\text { Other Paid } \\
\text { Leave }\end{array}$ & 52 & 0.9 & 32 & 1.1 & 20 & 0.7 & 58 & 0.8 & 34 & 1.1 & 24 & 0.7 \\
\hline $\begin{array}{l}\text { Unpaid } \\
\text { leave of } \\
\text { absence }\end{array}$ & 42 & 0.7 & 17 & 0.6 & 25 & 0.8 & 17 & 0.2 & 8 & 0.3 & 9. & 0.2 \\
\hline $\begin{array}{l}\text { Not } \\
\text { working } \\
643\end{array}$ & 1492 & 24.7 & 657 & 22.1 & 835 & 27.2 & 2049 & 29.9 & 276 & 27.7 & 1173 & 31.8 \\
\hline $\begin{array}{l}\text { Total } \\
\text { Current } \\
\text { Working } \\
\text { Status }\end{array}$ & 6049 & 100 & 2967 & 100 & 3073 & 100 & 6849 & 100 & 3162 & 100 & 3687 & 100 \\
\hline
\end{tabular}

642 "Working" category includes those who are currently working.

643 "Not working" category includes both registered unemployed and those who preferred to stay at home and are not registered as unemployed. 


\begin{tabular}{|c|c|c|c|c|c|c|c|c|c|c|c|c|}
\hline $\begin{array}{l}\text { Percentage } \\
\text { of labour } \\
\text { force } \\
\text { reporting } \\
\text { employment } \\
\text { and no } \\
\text { labour } \\
\text { earnings in } \\
\text { the last } 30 \\
\text { days }\end{array}$ & & 12.5 & & 15.3 & & 9.8 & & 7.5 & & 8.3 & & 6.8 \\
\hline $\begin{array}{l}\text { Unemploym } \\
\text { ent rate } \\
\text { (BLS/ILO } \\
\text { definition) }\end{array}$ & 353 & 6.1 & 161 & 5.6 & 192 & 6.6 & 386 & 6.0 & 186 & 6.1 & 200 & 5.9 \\
\hline \multicolumn{13}{|c|}{ Duration of unemployment (excluding hidden unemployment) } \\
\hline $\begin{array}{l}\text { Less than } 1 \\
\text { month }\end{array}$ & & 10.1 & & 15.6 & & 5.6 & & 9.8 & & 10.8 & & 8.9 \\
\hline 1-3 months & & 11.5 & & 12.6 & & 10.6 & & 18.6 & & 23.0 & & 14.4 \\
\hline $\begin{array}{l}\text { More than } \\
3 \text { months }\end{array}$ & & 78.4 & & 71.9 & & 83.9 & & 71.6 & & 66.2 & & 76.7 \\
\hline $\begin{array}{l}\text { Labour } \\
\text { force } \\
\text { participation } \\
\text { rate }^{644}\end{array}$ & 4930 & 85.2 & 2518 & 87.6 & 2412 & 82.7 & 5332 & 82.7 & 2631 & 86.7 & 2701 & 79.1 \\
\hline
\end{tabular}

Source: Calculated by the author using the Russian Longitudinal Monitoring Survey.

*Note: Sizes of various sub-samples used in this thesis are provided in Appendix 5.

**: Summary of questions

These results require a more detailed look at the interplay of what is understood by unemployment and dynamics of transformation. Table 30 contains both official unemployment and indicators of the so-called "hidden" unemployment, such as portion

\footnotetext{
${ }^{644}$ Labour force participation comprises those working, on maternity/ child care leave, other paid leave, unpaid leave of absence and those registered as unemployed.
} 
of those on unpaid leave and those who report no labour earning in the past days (while currently employed). The official ILO definition includes three criteria of unemployment: that an individual is without work, currently available for work, and seeking work at the time of interview. At the same time,

In situations where the conventional means of seeking work are of limited relevance, where the labour market is largely unorganized or of limited scope, where labour absorption is...inadequate, or where the labour force is largely self-employed, the standard definition of unemployed may be applied by relaxing the criteria of seeking work. $^{64}$

This means that, in interpreting the levels of unemployment in Russia, we need to pay attention to the conditions of the labour market, as well as broad socio-economic situations. For instance, in Russia, the job search intensity, availability of work, and unemployment are often affected by forced unpaid and partially paid leave, wage arrears, an ineffective Federal Employment Service, and the extensive scope of informal employment in Russia. For instance, unpaid leave schemes were widely utilized by enterprises across Russia to avoid laying off workers, and thus paying substantial amounts in unemployment insurance. The same is true for wage arrears. Wage arrears were used by enterprises to balance their financial obligations and again to avoid massive lay offs. Wage arrears, along with unpaid leaves, have the potential of altering the definition of unemployment in Russia, as workers while being employed, in many cases were not paid for as long as six months. According to the ILO employment criteria:

being "at work" explicitly involves remuneration in cash or kind during the reference period. Individuals experiencing spells of

${ }^{645}$ Rao \& Mehran (1995) as quoted in Grogan \& Van den Berg (1999): p. 7 
non-payment may not be considered ILO-employed. Thus, individuals who work but have not received wages during the reference period or for longer do not strictly comply with either the ILO-employment or the ILO-unemployment criteria. ${ }^{646}$

As such, in order to account for these factors, Table 30 presents information on those on unpaid leave or those without labour earnings. While the percentage of those on unpaid leave is very low (this practice started to decline by the mid-1990s), the percentage of those reporting no labour earnings is still rather significant (12.5 per cent in 1994 and 7.5 per cent in 2001). Furthermore, with regard to the distribution of men and women within the "unemployed" category, according to the National Statistical Agency of Russia

(Goskomstat) survey, women constituted a majority among the registered unemployed: in 1992, women represented 72.2 per cent. This trend, though reduced, is still true in the later transformation period (1995- 62.3 per cent; 1998 - 64 per cent ${ }^{647}$ ). Ashwin and Bowers help explain this evolution:

The fact that women appear more inclined to register as unemployed may be connected with the fact that men generally receive higher wages than women and see themselves as the primary breadwinners: the paltry levels of benefit on offer are therefore less likely to tempt them into what is still seen as the humiliation of registration, although the figures would suggest that this is gradually changing. It seems that unemployed men also earn significantly more than unemployed women from subsidiary economic activity, and so are less eligible [or inclined to - added by the author] to register for benefit. ${ }^{48}$

\footnotetext{
${ }^{646}$ Grogan \& Van den Berg (1999). As explained in Grogan et al (1999): p.9, according to the ILO, employed persons are those "above a specified age" who, during the reference period are either: i. At work, performed some work for wage or salary during the reference period.

ii. Generally work, but were ill or injured; on holiday; on strike; on training, maternity, or parental leave; iii. Persons who performed some work for profit or family gain (in cash or goods) during the reference period iv. Working with an enterprise but temporarily not at work during reference period for a specific reason.

${ }^{647}$ Center for Labour Market Studies. (2000).

${ }^{648}$ Ashwin \& Bowers (1997): p.23-24
} 
Figure 4. Duration of unemployment, by gender, 1994-2001, Russia

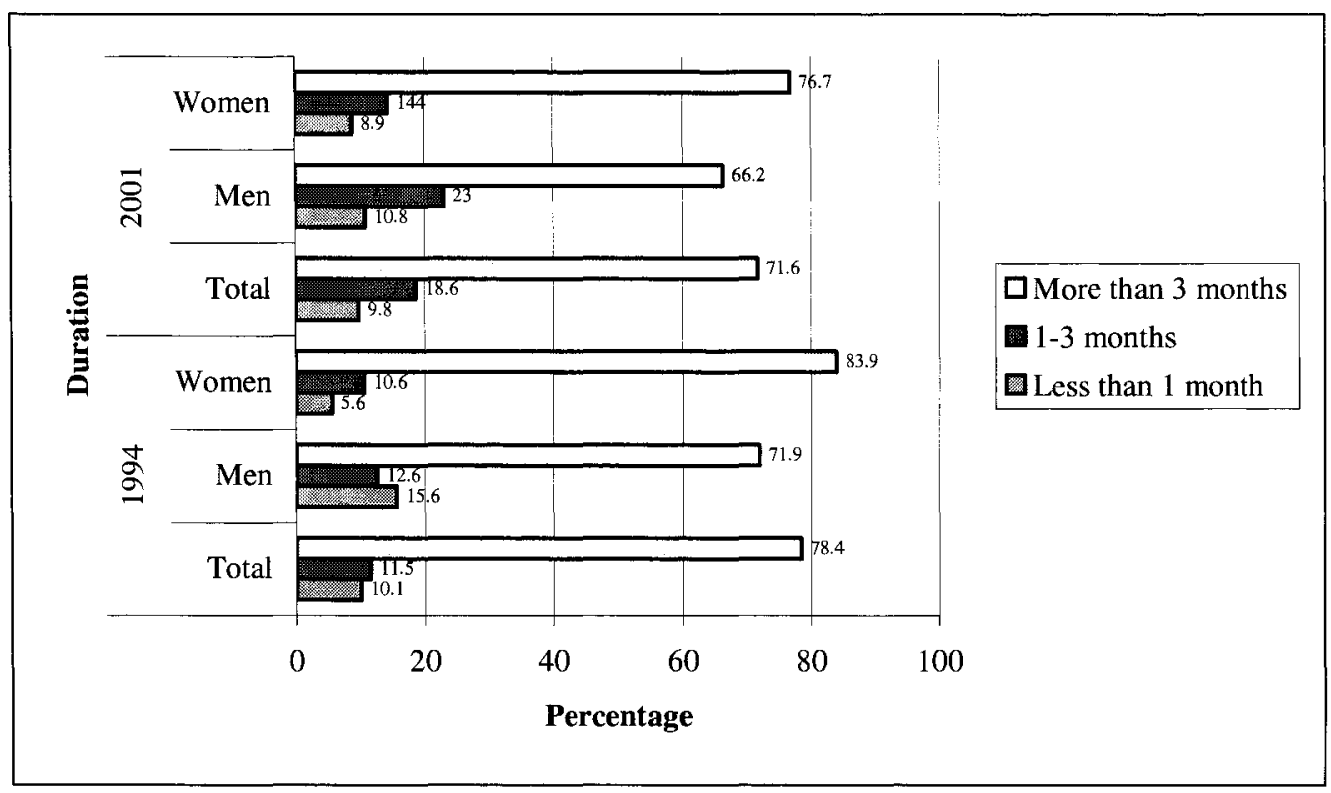

Source: Calculated by the author using the Russian Longitudinal Monitoring Survey.

Figure 4 indicates a general shift in the composition of unemployment, from short term and long-term unemployment, to unemployment in the one to three month range, for both men and women, but the trends are not similar for both sexes. For those women who reported being unemployed, short-term unemployment rate increased from 5.6 per cent (1994) to 8.9 per cent (2001); while 83.9 per cent of respondents indicated that they had been unemployed for more than three months in 1994, that figure dropped to 76.7 in 2001 , thus shifting the unemployment in the middle-term range, from 10.6 per cent in 1994 to 14.4 per cent in $2001 .^{649}$ For men, both short and long term unemployment rates had decreased, marking a significant increase in the middle-term.

\footnotetext{
${ }^{649}$ While it is acknowledged that it would be useful to look at those who were unemployed for longer than a year, due to the data constraints, this work is limited to the specified categories (i.e., less than 1 month; 1 3 months; more than 3 months).
} 
At the same time, despite the shift in the middle-term unemployment duration, the majority of the unemployed sought jobs longer than three months. This is particularly true for women. Mark Foley further notes that this effect is primarily visible among married women: "a married woman can expect to remain unemployed over 10 months longer before finding a job, compared to a married man." ${ }^{650}$ In addition, age can be seen as another factor determining duration of women's unemployment. For instance, our CLMS data indicate that women over 30 are more likely to be lengthily unemployed, and the chances to become unemployed for a prolonged period of time are in direct correlation with the woman's age. ${ }^{651}$ This is a reflection of a general labour market trend, when older workers are at a greater disadvantage in finding employment due to a range of factors, including a need to have retraining.

This points to gender, age and marriage status as determinants of the duration of unemployment. Foley notes that "having children has no effect on the duration of unemployment, however they do appear to motivate women to drop out of the labor force, significantly decreasing the time spent searching for work... women with children exit the labor force nearly 4 months sooner than those without children, suggesting that they have a higher shadow value of time in home production activities related to childrearing." ${ }^{52}$ This means that if women lost their jobs, it became harder for them to get hired again. This is also confirmed by the survey data conducted by the Moscow Centre

\footnotetext{
${ }^{650}$ Foley (1997)

${ }^{651}$ CLMS (2000)

${ }^{652}$ Foley (1997): p. 2-3
} 
for Labour Market Studies (CLMS) and Carleton University. ${ }^{653}$ The CLMS Survey revealed that, although the data did not show that unemployment was predominantly a women's problem, analysis of the structural characteristics of female unemployment allowed to see some negative tendencies:

- Increase in unemployment duration among women. Average duration of unemployment among women is higher than among men. The threat of lengthy unemployment becomes real for women over 30, and chances to become unemployed for a prolonged period of time are in direct correlation to the woman's age;

- Possibility of finding employment is decreasing for lengthily unemployed women. If 1993 the share of women belonging to the category of lengthily unemployed was $63 \%$, by 2000 it dropped to $55 \% .^{654}$

Figure 5. Labour Force Participation of Working-Aged Adults, by gender, 19942001, Russia

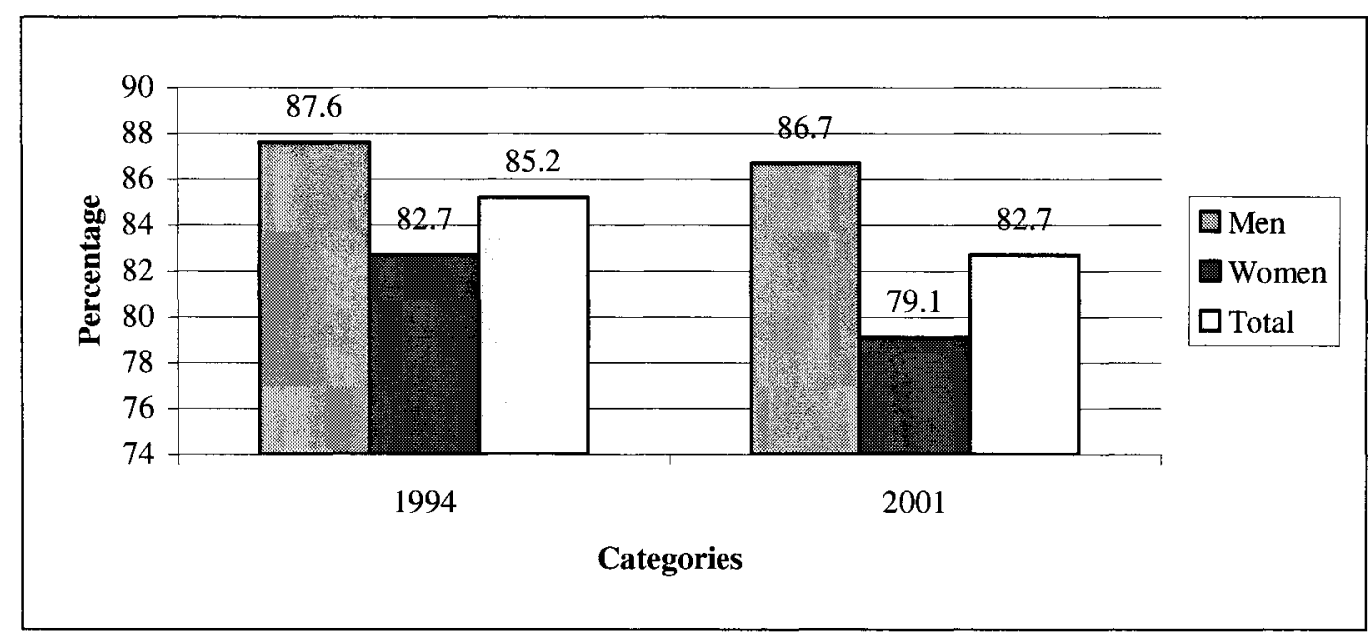

Source: Calculated by the author using the Russian Longitudinal Monitoring Survey

Finally, while the labour force participation rate of working-age women fell from 99.97 per cent, at the end of the Soviet era, to 82.7 per cent in 1994 , it has only declined

${ }^{653}$ Center for Labour Market Studies (2000)

${ }^{654}$ Ibid. 
by 3.6 per cent since then (Figure 5, Table 30). The truly wrenching period in the Russian labour market was 1989-1993/1994; after that there has been a remarkable stability in participation rates. While this confirms that fewer women of working age are in the labour force, what is striking is how relatively stable the participation rates were over this period, for both men and women.

In particular, the continuously high female labour force participation, despite the shift to neofamilialist ideology, poses a puzzle to Russian policymakers and transition specialists. While this thesis offers a number of potential explanations for this phenomenon, one of the plausible reasons for high participation rates includes the legacy of a provision of social services at the enterprise. As will be shown in the subsequent chapters, even during the transformation period, most former state enterprises continued to provide benefits to their employees, thereby compensating for low salaries, or their arrears, or the absence of services from other sources (state, families or markets). Such services include sick leaves, sanatoria and other health services, access to special goods for sale (in the conditions of scarcity of foodstuffs and other goods, at the beginning of the transformation) as well as sport and other facilities. For instance, Teplova and Woolley show that the availability of sanatoria was one of the main characteristics of an enterprise which tend to retain workers, thus demonstrating a strong link between the enterprise-level provision of various services and the employment of both men and women, including those with children. ${ }^{65}$

\footnotetext{
${ }^{655}$ Teplova \& Woolley (2005): p. 15 They further elaborate: “Availability of sanatoria refers to full or partial payment by the enterprise for sanatoria, children's camps, or tourist camps. Such payments are more
} 
Another explanation of why a much-predicted mass lay-off of women did not take place comes from the fact that enterprises attempted to avoid mass lay-offs of people. Enterprises attempted to preserve the "backbone" of their enterprises and labour collectives and used a range of strategies, including administrative paid, partially paid and unpaid leave, forced retirements of eligible groups, wage arrears and others. Yet another explanation is that women themselves are not eager to leave the labour market. As noted in chapter 3, many women prefer to keep working even if they could afford to stay at home. These factors will be examined in chapter 6 in greater detail. What is clear now is that irrespective of the various factors influencing the Russian labour market during the transformation period, female labour force participation remained relatively stable (after the original decline in 1992/94). This calls for further examination of the different components of the labour market position of women, such as actual employment and leave utilization. These, along with other indicators, will be analyzed in the next subsections of this chapter.

\section{Current Working Status of Women/Primary Occupation}

While the unemployment and labour force participation rates are important, they do not necessarily reflect the whole picture of employment decisions. The unemployment rate contains information with respect to people who are registered with employment services

common in public and large privatized enterprises, which have accumulated a large social infrastructure. More women than men had access to sanatoria; in general the benefit is available to just over one third of our sample. "Paid vacation" and "paid sick leave" are straightforward variables. However, as they are highly correlated with the availability of paid maternity/parental leave, they were not included in some of the regressions." 
(which is not the case with "hidden unemployment") and who are looking for jobs, while the labour force participation also includes women on maternity, parental, and any other types of leave (such as study leave and unpaid long-term care leave). In order to see the changes in the actual choices of women with respect to employment and motherhood, we need to go beyond labour force participation and unemployment rate categories. With this purpose in mind, I examined the current working status of women and their primary occupation, with specific attention to mothers with children under seven years of age (Table 31).656 This type of analysis has its limitations in overlooking the reasons for "working" or "not working," but it allows us to highlight whether women take the leave, stay at home without leave or other provisions, or actually go to work on a full or parttime basis. Of course, in the absence of work, or in the case of low leave payments and child benefits, the "choice" is often involuntary; however, this analysis is informative for understanding the conditions for certain decisions about employment and motherhood, within a certain set of constraints.

\section{Working/Not Working}

Overall, the data indicate a relative stability in the working/not working ratio for both men and women (Tables 30 and 31). At the same time, a more detailed analysis reveals some differences among different categories of respondents. For instance, it is safe to say that the rate of working for all women (with and without children - Table 30) is marginally decreasing, while that of not working is increasing. If we take a close look at

\footnotetext{
${ }^{656}$ The analysis indicators included 'working' and 'not working.' These indicators do not include those on maternity/parental, other paid/unpaid leave and refer only to those who are working or not in the labour force.
} 
women with children under seven, however, we can see an opposite trend. We can also see that overall, women with children under 7 tend to work less than all mothers. 
Table 31. Current Working Status of Working Age Adults, 1994-2001, Russia

\begin{tabular}{|c|c|c|c|c|c|c|c|c|c|c|c|c|c|c|c|c|}
\hline \multirow{3}{*}{ Category } & \multicolumn{8}{|c|}{1994} & \multicolumn{8}{|c|}{2001} \\
\hline & \multicolumn{2}{|c|}{$\begin{array}{l}\text { Working }^{657} \\
\text { a)full time } \\
\text { b)part-time }\end{array}$} & \multicolumn{2}{|c|}{$\begin{array}{c}\text { Not } \\
\text { working }\end{array}$} & \multicolumn{2}{|c|}{$\begin{array}{l}\text { Maternity/ } \\
\text { Child Care } \\
\text { Leave }\end{array}$} & \multicolumn{2}{|c|}{$\begin{array}{l}\text { Other } \\
\text { Paid or } \\
\text { Unpaid } \\
\text { Leave } \\
\end{array}$} & \multicolumn{2}{|c|}{$\begin{array}{l}\text { Working } \\
\text { a)full time } \\
\text { b)part-time }\end{array}$} & \multicolumn{2}{|c|}{$\begin{array}{l}\text { Not } \\
\text { working }\end{array}$} & \multicolumn{2}{|c|}{$\begin{array}{c}\text { Maternity/ } \\
\text { Child Care } \\
\text { Leave }\end{array}$} & \multicolumn{2}{|c|}{$\begin{array}{l}\text { Other } \\
\text { Paid or } \\
\text { Unpaid } \\
\text { Leave }\end{array}$} \\
\hline & $\mathrm{N}$ & $\%$ & $\mathbf{N}$ & $\%$ & $\mathbf{N}$ & $\%$ & $\mathrm{~N}$ & $\%$ & $\mathrm{~N}$ & $\%$ & $\mathbf{N}$ & $\%$ & $\mathbf{N}$ & $\%$ & $\mathrm{~N}$ & $\%$ \\
\hline All mothers, & $\begin{array}{l}1337 \\
\text { a) } 976 \\
\text { b) } 361\end{array}$ & $\begin{array}{l}54.3 \\
\text { a) } 39.6 \\
\text { b) } 14.7\end{array}$ & 945 & 38.4 & 156 & 6.3 & 26 & 1.0 & $\begin{array}{l}1370 \\
\text { a) } 1075 \\
\text { b) } 295\end{array}$ & $\begin{array}{l}58.8 \\
\text { a) } 46.1 \\
\text { b) } 12.7\end{array}$ & 826 & 35.5 & 116 & 5 & 18 & 1.1 \\
\hline $\begin{array}{l}\text { Mothers } \\
\text { with } \\
\text { children } \\
\text { younger } \\
\text { than seven, }\end{array}$ & $\begin{array}{l}493 \\
\text { a) } 338 \\
\text { b) } 155\end{array}$ & $\begin{array}{l}52.2 \\
\text { a) } 35.7 \\
\text { b) } 16.4\end{array}$ & 294 & 31.1 & 147 & 15.6 & 11 & 1.1 & $\begin{array}{l}459 \\
\text { a) } 350 \\
\text { b) } 109\end{array}$ & $\begin{array}{l}49.8 \\
\text { a) } 36.8 \\
\text { b) } 13\end{array}$ & 374 & 37.6 & 114 & 12.4 & 2 & .2 \\
\hline$\underset{659}{\text { Married, }}$ & $\begin{array}{l}393 \\
\text { a) } 254 \\
\text { b) } 139 \\
\end{array}$ & $\begin{array}{l}51.7 \\
\text { a) } 33.7 \\
\text { b) } 18 \\
\end{array}$ & 225 & 29.6 & 130 & 17.1 & 11 & 1.4 & $\begin{array}{l}356 \\
\text { a) } 257 \\
\text { b) } 99\end{array}$ & $\begin{array}{l}48.2 \\
\text { a) } 34.8 \\
\text { b) } 13.4\end{array}$ & 275 & 37.2 & 106 & 14.3 & 2 & .3 \\
\hline Lone, ${ }^{660}$ & $\begin{array}{l}94 \\
\text { a) } 61 \\
\text { b) } 33 \\
\end{array}$ & $\begin{array}{l}53.7 \\
\text { a) } 34.9 \\
\text { b) } 18.8\end{array}$ & 66 & 37.7 & 15 & 8.5 & 0 & 0 & $\begin{array}{l}103 \\
\text { a) } 76 \\
\text { b) } 27\end{array}$ & $\begin{array}{l}56.9 \\
\text { a) } 42 \\
\text { b) } 14.9\end{array}$ & 70 & 38.7 & 8 & 4.4 & 0 & 0 \\
\hline All fathers & $\begin{array}{l}\text { l446 } \\
\text { a) } 1258 \\
\text { b) } 188\end{array}$ & $\begin{array}{l}68.8 \\
\text { a) } 59.9 \\
\text { b) } 8.9\end{array}$ & 629 & 29.9 & 0 & 0 & 26 & 1.3 & $\begin{array}{l}1366 \\
\text { a) } 1217 \\
\text { b) } 149\end{array}$ & $\begin{array}{l}72.3 \\
\text { a) } 64.4 \\
\text { b) } 7.9\end{array}$ & 493 & 26.1 & 1 & .1 & 29 & .8 \\
\hline $\begin{array}{l}\text { Fathers with } \\
\text { children } \\
\text { younger } \\
\text { than seven }\end{array}$ & 674 & 81.4 & 145 & 17.5 & $\overline{0}$ & 0 & 9 & 1.1 & 596 & 78.6 & 149 & 19.7 & 1 & .1 & 12 & 1.6 \\
\hline
\end{tabular}

Source: Calculated by the author using the Russian Longitudinal Monitoring Survey

657 "Not working" and "Working" categories excludes those who are on maternity, child care or other form of paid or unpaid leave.

${ }^{658}$ While according to the Labour Code, a full time week consists of 40 hours in Russia, for the purposes of this thesis I will assume that those individuals who work less than 30 hours - work part-time, and those who work more than 30 hours are employed full-time.

659 "Married" category includes both married and cohabitating women

660 "Lone" category includes never married, divorced and not remarried and widowed women 
Additional research shows that not all mothers are alike, however, and neofamilialist policies have greater impact on some and less on others. For instance, as data show, married mothers with children younger than seven years old are more likely to drop out of the labour force than lone mothers. This is evident from the fact that the incidence of "working" for married mothers has declined from 51.7 per cent in 1994 to 48.2 per cent in 2001 (and "not working" increased by 7.98 percentage points, from 29.6 per cent to 37.2 per cent, respectively), while the number of working lone mothers had actually increased. ${ }^{661}$

The difference in employment rates between married and lone mothers highlights the greater need for work in the case of lone mothers. This is consistent with other studies, which suggested that "single mothers tend to have higher labour force participation rates and, for those employed, longer hours of work... [Since] about half of single parents live in an extended family context,... other family members may contribute to childcare. ${ }^{662}$ This was also a result of the fact that, while the transformation undermined the economic stability of many families, lone mothers' households were the ones which were hit the most. These women are often open to any kind of work, on a full- or parttime basis, with or without a contract, in order to make ends meet (as opposed to married women with husbands), because welfare provisions in Russia, while numerous, are not sufficient to provide even a minimum standard of living.

\footnotetext{
${ }^{661}$ Other scholars have shown that class matters too. For a detailed analysis of impact of neofamilialist policies on women from different class structures, see Mahon (2002); Heinen (2002).

${ }^{662}$ Klugman \& Kolev (2001): p.164
} 
For instance, as will be explained in detail in chapter 6, the in-home caregiving allowance was the equivalent of \$17 USD per month until the child reaches the age of 18 months. Figure 6 shows that poverty has become a real issue for the lone-parent household. Thus the poverty rate among these types of households "more than doubled from about 12 per cent to about 28 per cent." ${ }^{663}$

Figure 6. Poverty Status and Family Structure, RLMS 1994-1996 (percentages)

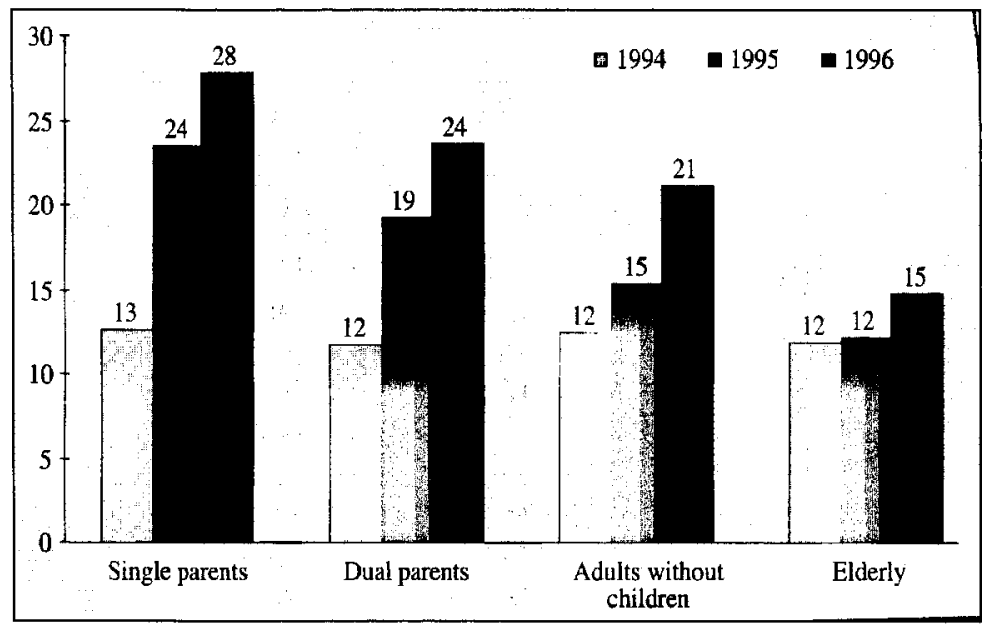

Source: Jeni Klugman and Alexander Kolev "The Welfare Repercussions of Single-Parenthood in Russia in Transition" in Jeni Klugman and Albert Motivans (eds.) (2001). Single Parents and Child Welfare in the New Russia. Unicef: Florence, Italy.

In addition, the analysis conducted by Teplova and Woolley (2005) suggest that education also has a strong effect on women's employment decisions. Thus, women with higher educational levels are more likely stay in the labour force then women with lower levels of education. ${ }^{664}$ Other factors, such as professional status and experience, perhaps surprisingly, tend not to have a strong impact on determining impact on women's employment decisions. It may be explained by the fact that a growing female workforce

\footnotetext{
${ }^{663}$ Ibid: p. 159

${ }^{664}$ Teplova \& Woolley (2005)
} 
is concentrated in the low paid spheres, such as light industry, healthcare, and education. $^{665}$

At the same time, all data related to "working / not working" should be carefully interpreted in the Russian conditions. This caution is needed because of the widespread informal entrepreneurship and household production, as well as other types of informal employment, which are in most cases not reported. Access to informal employment can also serve as a potential explanation for the difference between lone and married mothers. As Judith McKinney notes, lone mothers work more because they are unlikely to "moonlight in the unofficial economy...and may resist getting involved in potentially dangerous economic activities in order to protect their children, which would further reduce their income from unofficial sources. ${ }^{, 666}$ Low likelihood of accessing informal employment by lone mothers (for various reasons) was also highlighted during the conversations with women:

I am a lone mother, who works full-time as a teacher and has a threeyear-old son. I simply do not have the capacity to seek additional employment (e.g., private lessons) to complement my salary, as there is no one to take care for my son in the evening... This is why we often rely on the help of my parents... (Olga, 27 years old)

Working in the informal sector is very risky, as one would need to have enough money to engage in informal business (e.g., informal trade), but if something goes wrong, there is no insurance, no protection, no guarantees... this is why I am not seeking opportunities to engage in something as unstable and volatile... I know I could earn more money

${ }^{665}$ Ibid.: p. 20

${ }^{666}$ McKinney (2004): p.49 
there but it is more reliable and safe to simply have a stable even lowpaid job... (Elena, 24 years old)

First of all, one has to have certain social and adaptation skills as well as access to opportunities in order to be able to engage in informal employment ... I know that I would not be able to do it, particularly since I do not know that many people in this town who could help me to start earning money... (Natalia, 34 years old $)^{667}$

Thus lack of child care options, high risks often associated with informal employment as well as simple lack of access to opportunities for this type of employment often determined that lone mothers are less likely to be involved in those activities. In the Russian conditions, this meant that these women were more likely to find themselves under the poverty line. Chapter 6 will provide a more detailed account of the shadow economic sector and its influence on decisions about employment and childbirths.

Table 32. Current Working Status of Mothers with Children Younger than 7 Years Old, by age, 1994-2001, Russia

\begin{tabular}{|c|c|c|c|c|c|c|c|}
\hline \multirow{2}{*}{$\begin{array}{c}\text { Age } \\
\text { groups }\end{array}$} & \multicolumn{2}{|c|}{ Working } & \multicolumn{2}{c|}{$\begin{array}{c}\text { On Maternity/ } \\
\text { Child Care Leave }\end{array}$} & \multicolumn{2}{c|}{ Not Working } \\
\hline & & $\mathrm{N}$ & $\%$ & $\mathrm{~N}$ & $\%$ & $\mathrm{~N}$ & $\%$ \\
\hline & $18-29$ & 205 & 42.00 & 100 & 20.50 & 177 & 36.3 \\
\cline { 2 - 8 } & $30-39$ & 183 & 60.40 & 45 & 14.90 & 70 & 23.1 \\
\cline { 2 - 8 } & $40-49$ & 69 & 80.20 & 2 & 2.30 & 15 & 17.4 \\
\hline & $50-55$ & 36 & 52.90 & 0 & - & 32 & 47.1 \\
\cline { 2 - 8 } & Total & 493 & & $\mathbf{1 4 7}$ & & $\mathbf{2 9 4}$ & \\
\hline 2001 & $18-29$ & 227 & 43.20 & 87 & 16.60 & 211 & 40.2 \\
\hline & $30-39$ & 128 & 52.6 & 24 & 9.9 & 89 & 36.6 \\
\hline
\end{tabular}

${ }^{667}$ Conversations by the author 


\begin{tabular}{|c|c|c|c|c|c|c|c|}
\hline & $\begin{array}{c}\text { Age } \\
\text { groups }\end{array}$ & \multicolumn{2}{|c|}{ Working } & \multicolumn{2}{c|}{$\begin{array}{c}\text { On Maternity/ } \\
\text { Child Care Leave }\end{array}$} & \multicolumn{2}{c|}{ Not Working } \\
\hline $40-49$ & 78 & 65.00 & 3 & 2.50 & 39 & 32.5 \\
\hline $50-55$ & 26 & 42.60 & 0 & - & 35 & 57.4 \\
\hline & Total & $\mathbf{4 5 9}$ & & $\mathbf{1 1 4}$ & & $\mathbf{3 7 4}$ & \\
\hline
\end{tabular}

Source: Calculated by the author using the Russian Longitudinal Monitoring Survey

In addition to the marital status, age also seems to have an impact on whether and how mothers respond to neofamilialist policies. As shown in Table 32, there were noticeable declines in the rates of working for women of $30-39$ and 40 - 49 age groups. Such an age factor impact on the female employment may be related to the low prospects for women over 40 in the Russian labour market:

Where employers are actively seeking women to fill vacancies it is commonly stated that applicants should be under 30 or, at most, 35 . As this is precisely the age over which most redundancies have been occurring, the situation is extremely threatening for older women who lose their jobs. A willingness to employ women even up to the age of 40 is almost never expressed. ${ }^{668}$

The reluctance to hire women over 40 is consistent with other findings, which show that, in addition to the described earlier kind of prejudice against older women on the part of employers, women of this age category are likely to possess Soviet-type skills, which are obsolete in the market economy, and are not likely to be willing or have the resources to undergo retraining. These women are reluctant to retrain due to a number of factors. As explained by Olga (49-years-old),

All my life I knew what my job was - I was a teacher... I cannot imagine of changing my qualification now after 25 years of teaching... Earlier there was no tradition of changing career direction or profession in the

${ }^{668}$ Bridger \& Kay (1996): p. 23 
life time of employment. It used to be that career was something that you chose when you were young and were expected to stay on that path until retirement... Thus it is very difficult for me even imagine to undergo retraining at my age...669

In real terms, this means that once a woman over 40 loses her job, it is very difficult for her to find a new one. Overall, the findings with regard to "working" / "not working" categories show that the rates of "working" for both married and lone mothers remain relatively stable over the 1994-2001 period. This, once again, points to the fact that the most wrenching period in terms of female employment took place at the beginning of the transformation. With regard to the rates of "not working," however, there was a greater fluctuation among different categories of women. This calls for a more detailed look into other indicators, such as indicators "women on maternity/parental leave" and "homemakers as a primary occupation."

\section{Maternity / Parental Leave}

Another indicator of interest is the rate of women on maternity or parental leave (Figure 7). In the RLMS data set, the "provision of leave" variable refers to paid leave for pregnancy, giving birth and parental leave. ${ }^{670}$ It appears that in Russia, despite the extended paid leaves, the percentage of mothers with children under 7 on leave has in fact decreased by 3 percentage points, from 15.6 per cent in 1994 to 12.4 per cent in 2001

\footnotetext{
${ }^{669}$ Conversation by the author

${ }^{670}$ Teplova and Woolley (2005): p. 17 explain that "the limitation of this variable is that it does not distinguish between maternity (leave for pregnancy and giving birth) and parental leave. Eighty per cent of women reported that they did have a leave provision, which may be considered either high (most women can access leave) or low (given that leave is guaranteed by statute, the number of employed women reporting access to leave should be closer to 100 per cent than 80 per cent). It should be stressed that all employed women, including part-time, sessional and seasonal workers, are eligible for maternity leave benefits."
} 
(Table 31). This finding may seem odd, given the leave duration increase in the 1990s. It points to the potential influence of the contextual factors, which include employer-

financed structure of parental (child care) leaves and their long duration during the first years of the transformation period, in addition to the low level of actual leave payments. For instance, employer-financed "compensation" payments can significantly increase the costs of women's labour and, as such, lead to the employers' unwillingness to hire women. ${ }^{671}$ Parental leave costs are normally associated with women, since fathers are not required to take the leave, and our data (Table 31) show that nearly $100 \%$ of leaves are usually taken by women. ${ }^{672}$

Figure 7. Rate of Women on Maternity/Parental Leave, 1994-2001, Russia

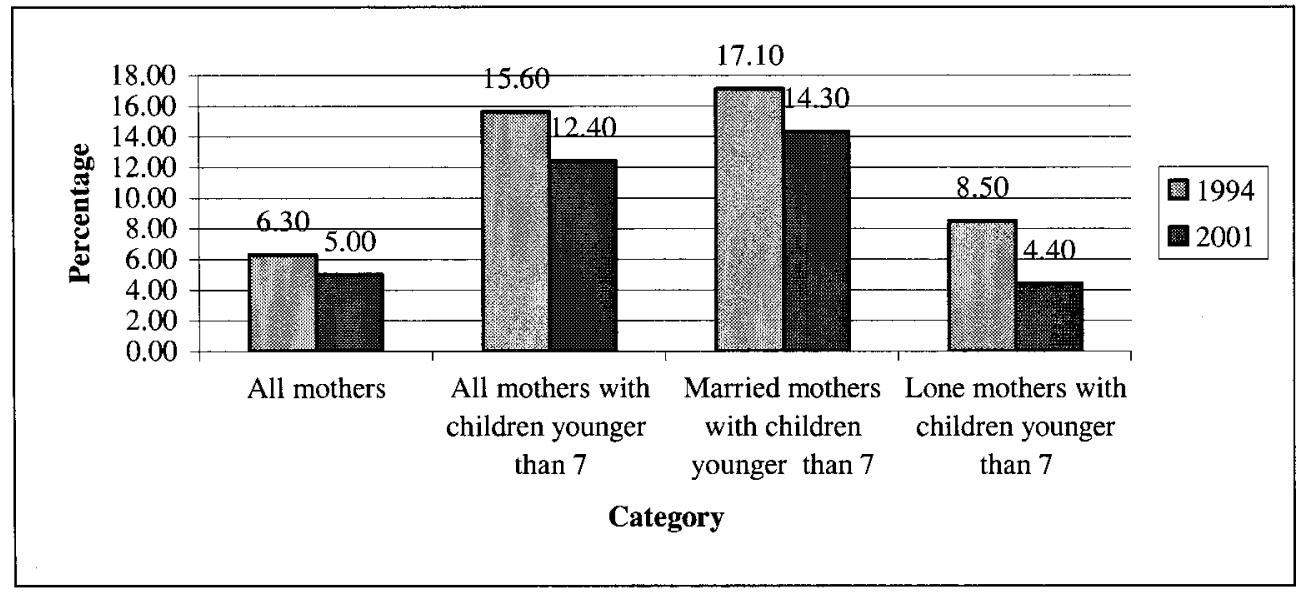

Source: Calculated by the author using the Russian Longitudinal Monitoring Survey

Some insight about what this means for employers can be gained from a survey conducted by the Centre for Labour Market Studies ${ }^{673}$ in Moscow, in 1999. This survey

\footnotetext{
${ }^{671}$ a)As discussed throughout this thesis, the so-called leave compensations until a child reaches three years of age are still paid by the employer from the organizational payroll fund, in addition to maternity benefits and in-home caregiving allowance, which are paid from the social insurance funds; b) The finding is based on the CLMS survey (2000).

${ }^{672}$ See Wilkinson, H. et. al. (1997); European Commission (1998); Waldfogel, (2001).

${ }^{673}$ Center for Labour Market Studies (2000).
} 
asked employers about gender preferences in their hiring practices and their reasons for having those preferences. When asked about their overall preferences, 88 per cent of employers preferred to hire men (however, when asked about specific positions, for example "receptionist," more employers had a preference for women). Of that 88 per cent, 11.4 per cent justified their preference on the grounds that fewer costs are associated with men's employment (Table 33). Interestingly, 38.6 per cent of employers, who indicated that they would prefer to hire women, would do so because women are more responsible than men (which could be explained by the high rates of alcoholism among male population in Russia).

Table 33. Employers' Reasons for Preferring to Hire Men or Women, Russia, 1999

\begin{tabular}{|l|l|l|}
\hline \multicolumn{2}{|c|}{ Percentage of employers with gender preference } \\
\hline $\begin{array}{c}\text { Reason given for } \\
\text { preference }\end{array}$ & \multicolumn{1}{|c|}{ Men preferred } & \multicolumn{1}{c|}{ Women preferred } \\
\hline Costs savings* & 11.4 & 4.1 \\
\hline Higher productivity & 24.3 & 3.5 \\
\hline Higher responsibility & 9.7 & 38.6 \\
\hline Less disposed to conflicts & 6.5 & $\mathrm{n} / \mathrm{a}$ \\
\hline
\end{tabular}

* For those preferring men, the answer was phrased as "women cost more," for those preferring women "women can be paid less"

Source: CLMS, 1999

Potential absences also may be viewed by employers as a disincentive to hiring women. Furthermore, it is often reported that such leaves fuel discriminatory practices in hiring, promotion and layoffs (UNICEF, 1999). Thus, according to other data from the CLMS survey, summarized in Table 34, when employers were asked to name all the benefits which decrease women's attractiveness as employees, 50.2 per cent of employers 
reported child care leave, among other benefits and privileges for mothers, as a factor among those most decreasing women's attractiveness as employees.

Table 34. Which Benefits Decrease Women's Attractiveness as Employees for Employers?

\begin{tabular}{|l|c|}
\hline \multicolumn{1}{|c|}{ Benefits } & $\begin{array}{c}\text { Percentage of } \\
\text { employers choosing } \\
\text { response }\end{array}$ \\
\hline Restriction on work during days off & 22.5 \\
\hline Restriction on overtime work and business trips & 21.2 \\
\hline $\begin{array}{l}\text { Prohibition on using pregnant women and women with } \\
\text { children under 3 years old for night and overtime jobs, as well } \\
\text { as for business trips }\end{array}$ & 27.7 \\
\hline Parental (child care) leave up to 3 years & 50.2 \\
\hline $\begin{array}{l}\text { Prohibition on firing pregnant women; women with children } \\
\text { under 3 and lone mothers with children under 14 }\end{array}$ & 23.4 \\
\hline
\end{tabular}

Source: CLMS (2000)

When asked whether leave is used by women at their enterprises, 82.3 per cent of employers believed that yes, such a benefit is available to women at their enterprises. Meanwhile, only 6.3 per cent of the female employees at these same enterprises reported that they "can use and have used" the leave provision. 37.1 per cent of women "can but do not use" leave benefits, 6.7 per cent "used it in the past" and a startling 49.9 per cent of female employees reported that they "will not be able to use and do not use" leave benefits.

The practice of informal contracts and shadow wages in the Russian labour market can offer another potential explanation. Informal contracts imply that individuals (most often women) are asked to decline the right to use legally stipulated benefits, in 
return for having a job or higher salaries. As will be explained in chapter 6 , this practice has become widespread in the Russian labour market. This, combined with the low generosity of leave allowances can perhaps help us explain this finding.

Although the direction of change appears to be consistent for both married and lone mothers (declining use of leave), the baseline difference between these types of mothers is, however, noticeable. For instance, in 2001, only 4.4 per cent of lone mothers were on maternity/parental leave, which is much lower than the respective number for married women (14.30 per cent). Again, caution is required in attributing this trend, but it appears that lone mothers are compelled to stay in the labour force due to the insufficiency of maternity/parental leave provisions for making ends meet.

At the same time, in their analysis of the relationship between female employment and leave provisions available at enterprises in Russia, Teplova and Woolley find that the results may have low significance for mothers of children under seven, but are highly significant for all women (with or without children). ${ }^{674}$ They argue that the high significance of results for all mothers is due to the fact that they experienced a pretransition maternity leave program. They hypothesize that "these mothers used leave provisions and then returned to their employers; hence leave provisions allowed them to keep, maintain, and build labor market attachment." ${ }^{675}$ They also note that the strong impact of leave on employment of all women (including mothers and childless women),

${ }^{674}$ Teplova and Woolley (2005)

${ }^{675}$ Ibid.: p. 20 
may be partially explained by the Soviet legacy to provide benefits, including maternity

leaves, through state enterprises. Specifically they argue that:

provision of leaves can be seen as a characteristic of workplaces/enterprises, which tend to retain workers. Hence there may be a positive effect of leave provision on employment of women without children as a result of their employment on such enterprises. As mentioned, these enterprises are most likely to be state or newly privatized enterprises. ${ }^{676}$

With regard to the low significance of results for mothers of children under 7 , Teplova and Woolley offer two explanations:

First, mothers who have made use of leave availability and are still on leave are counted as not employed. In our analysis, this translates to a negative coefficient on leave: people with access to leave being less likely to be employed. Second, mothers of young children, being themselves relatively young, are also more likely to be working in the private sector, and thus to have exchanged access to benefits for jobs and higher salaries. Lack of access to leave forces women to make one of two polar opposite choices: return to work immediately or quit. Other studies (Ruhm and Teague, 1995) have found that the absence of any leave provisions tends to lower female employment. In our analysis, this translates into a positive coefficient on leave. Given the various contradictory effects of leave on employment for women with young children, it is not surprising our results are of low significance. ${ }^{677}$

Surprisingly, they observed a similar effect for child care provision:

Childcare, perhaps somewhat surprisingly, has a strong positive effect for all women, but not for mothers or mothers of young children. It is likely that we are picking up an effect of provision being available historically at certain types of enterprises, that is, public enterprises or privatized enterprises. The enterprises that provide childcare may simply be different in ways that makes them more likely to retain workers. ${ }^{678}$

\footnotetext{
${ }^{676}$ Ibid: : p. 19

${ }^{677}$ Ibid.: p. 20

${ }^{678}$ The "Provision of child care" variable indicated whether or not the respondent had access to free child care in an enterprise's preschool, or full or partial payment for child care in another preschool institution. Child care is the least widely available of all of the various enterprise level benefits - only around 10 per cent of respondents had access to child care. Inherent limitations of the data set did not permit the inclusion
} 
These conclusions are supported by the finding that maternity/ parental leaves, as well as child care services, are most likely to be provided by public/former state enterprises. ${ }^{679} \mathrm{It}$ may be because most women are employed at these types of enterprises (Table 35). Or, alternatively, these women may be working at these enterprises precisely because they tend to provide benefits, including leaves. What is clear is that the public sector / former Soviet enterprises (with a significant share of state ownership) were and remain the major employers for mothers.

Table 35. Distribution of Mothers' Employment by Enterprise Type, 1994-2001

\begin{tabular}{|l|c|c|c|c|c|c|c|c|}
\hline & \multicolumn{2}{|c|}{1994} & \multicolumn{3}{c|}{2001} & \\
\hline $\begin{array}{l}\text { Categories } \\
\text { of } \\
\text { working*** } \\
\text { women/ } \\
\text { Sector }\end{array}$ & $\begin{array}{c}\text { Public } \\
\text { sector* }\end{array}$ & $\begin{array}{c}\text { Private } \\
\text { sector }\end{array}$ & $\begin{array}{c}\text { Self- } \\
\text { owned }\end{array}$ & $\begin{array}{c}\text { not } \\
\text { reported }\end{array}$ & $\begin{array}{c}\text { Public } \\
\text { sector* }\end{array}$ & $\begin{array}{c}\text { Private } \\
\text { sector }\end{array}$ & $\begin{array}{c}\text { Self- } \\
\text { owned }\end{array}$ & $\begin{array}{c}\text { not } \\
\text { reported }\end{array}$ \\
\hline $\begin{array}{l}\text { Mothers } \\
\text { with } \\
\text { children } \\
\text { younger } \\
\text { than 18 }\end{array}$ & 74.57 & 9.83 & 5.42 & 10.19 & 60.68 & 28.05 & 1 & 10.27 \\
\hline $\begin{array}{l}\text { Mothers } \\
\text { with } \\
\text { children } \\
\text { younger } \\
\text { than 7 }\end{array}$ & 74.25 & 10.5 & 4.25 & 11 & 64.17 & 21.95 & 1.39 & 12.5 \\
\hline $\begin{array}{l}\text { Married } \\
\text { mothers } \\
\text { with }\end{array}$ & 74.08 & 10.19 & 4.32 & 11.42 & 65.51 & 20.67 & 1.72 & 12.07 \\
\hline
\end{tabular}

of other variables pertaining to child care characteristics, such as care quality and proximity of child care centers, or allow us to distinguish between enterprise-provided workplace child care and enterprisesubsidized child care performed elsewhere.

${ }^{679}$ Teplova and Woolley (2005)

${ }^{680}$ The main reasons that the percentage of women employed at self-owned enterprises declined quite significantly include the unstable regulations (changing nearly every month), undeveloped market mechanisms, absence of reliable banking, credit and insurance system, low support for small and medium businesses, high extortion rates by organized crime groups as well as poor law enforcement mechanisms. Some of these factors will be discussed in chapter 6 in greater detail. 


\begin{tabular}{|l|l|l|l|l|l|l|l|l|}
\hline & \multicolumn{2}{|c|}{1994} & \multicolumn{3}{c|}{2001} & \\
\hline $\begin{array}{l}\text { children } \\
\text { younger } \\
\text { than 7 }\end{array}$ & & & & & & & & \\
\hline $\begin{array}{l}\text { Lone } \\
\text { mothers } \\
\text { with } \\
\text { children } \\
\text { younger } \\
\text { than 7 }\end{array}$ & 77.46 & 9.86 & 4.23 & 8.45 & 57.15 & 28.58 & 0 & 14.29 \\
\hline
\end{tabular}

*Public sector includes government and any other mixed form of ownership with government participation

** Private sector includes Russian, foreign enterprises, as well as enterprises of mixed form of ownership (Russian, foreign enterprises and own shares)

*** Only women who reported that they are working were selected for this analysis

Source: Calculated by the author using the Russian Longitudinal Monitoring Survey

In addition, Table 35 indicates that the general percentage of women employed in the private sector has increased by almost 20 percentage points. This also can shed a light on the decline in the number of women using maternity/parental leave provisions. Private enterprises are less likely to provide benefits, due to the high costs and taxes involved, and tend to utilize the system of so-called "informal contracts," where a woman would decline legally stipulated benefits for being able to work at the private enterprise. These factors will be elaborated upon in chapter 6 of this thesis.

\section{In-home Caregiving}

An additional indicator of interest is the increasing tendency of women to stay at home and care for their children as their primary occupation (Figure 8). This category of women was included in the category of "not working," but was not counted as "women on maternity/parental leave." The trend was established during the transformation period, and is increasing. In 1994, more than 11 per cent of women chose to stay at home as their 
primary occupation. The number further increased in 2001 (13.51 per cent). Notably, more married mothers tend to stay at home than those who are lone. In 1994, more than 17 per cent of married mothers with children younger than seven years old reported that their official status is a homemaker, while only 7 per cent of lone mothers reported a similar status. In 2001, the number of married mothers staying at home increased up to 23.08 per cent, while the number of lone mothers decreased to 5.81 per cent. While this balance highlights the general difference in the need for work for lone and married mothers, what is interesting here is that almost a quarter of those women who have partners and children prefer to stay at home. A low number of lone mothers caring for children at home can be explained by the very low generosity of the state's caregiving allowances and other benefits for children.

Figure 8. Rate of Women- In-home Caregivers as a Primary Occupation, 1994-2001, Russia

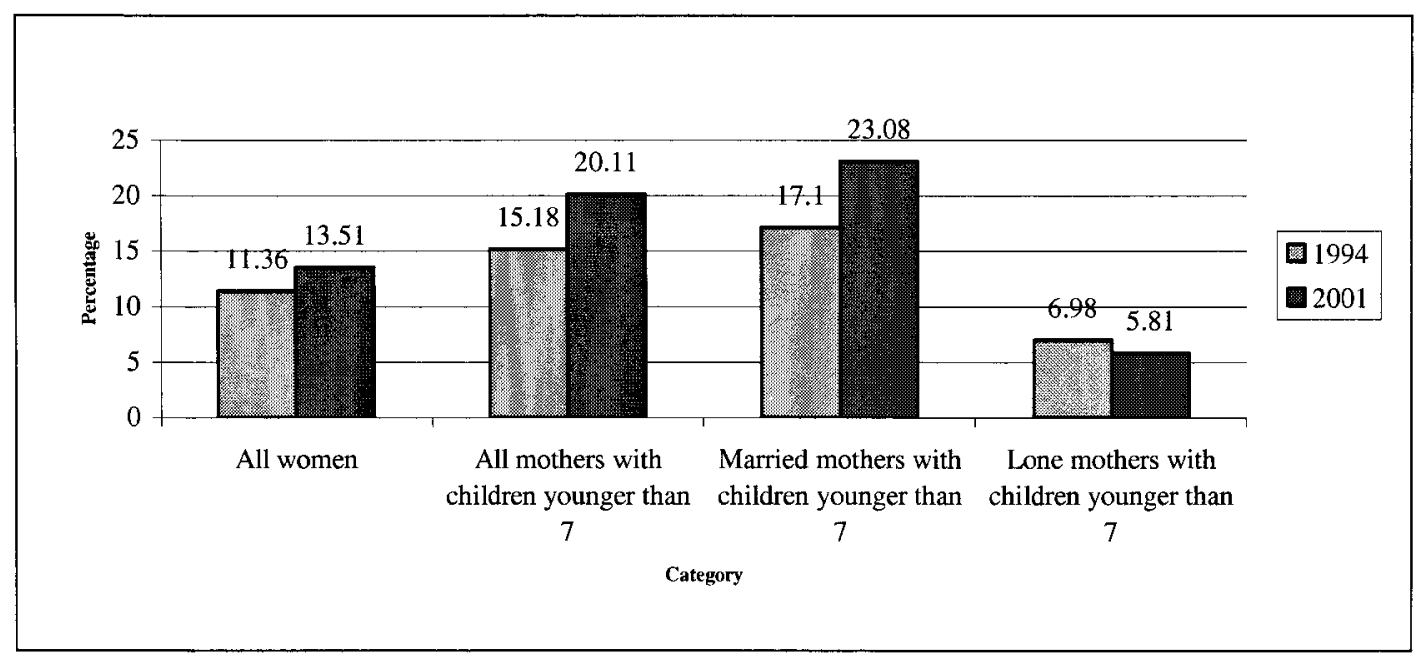

Source: Calculated by the author using the Russian Longitudinal Monitoring Survey

*Note: In-home caregivers defined as women who chose to stay at home and care for children and other family members 
Furthermore, it is not clear from the available data whether these women are registered at the enterprises (and are therefore receiving in-home caregiving allowance) or are supported through other sources. In general, however, the move towards in-home caregiving as a primary occupation can be seen as a result of the changing ideologies with regard to child care provision and role of women in society (for a detailed description, see chapter 3). These changes in ideologies are best expressed by Naina Yeltsina (the wife of Boris Yeltsin, the former Russian President), who declared in an interview, published in the newspaper My ("We") in August 1992, that "I am not the first lady, I am simply the wife of the Russian president... Everything is just as it was before for us. I've remained a housewife... I choose his ties, I take care of his shirts and suits..."681 Thus there appears to be a variety of potential explanations, which suggests the need for a cautious interpretation of data analysis results.

\section{Part-Time Employment}

The final employment indicator in this category is the emergence of part time employment. This indicator is important, particularly given the fact that during the Soviet period there was a legal requirement to work full-time (unless there is a well-documented reason to work on a part-time basis). A growth of part-time employment is a clear sign that "policies permitting the creation of more 'flexible' labour force, via changes to

${ }^{681}$ Attwood (1995) 
working time (such as part-time and flexi-hours or temporary and contingent labour contracts) have affected women's employment in significant ways." ${ }^{682}$

As we can see from Tables 30 and 36, "working" women generally work fewer hours per week than employed men. The trend towards variable working hours is very clear. Furthermore, the table suggests that working mothers with young children work fewer hours than all working women in general (with and without children). Our data show that, in 1994, 36 per cent of the mothers with young children had worked part-time (under 30 hours / week), while the corresponding number for all working women is 27.64. Table 36 also indicates that even though the difference between married and lone mothers is not significant, married mothers are slightly more likely to work part-time in the mid-1990s, while the rates became similar by 2001 (though with different distribution of the number of hours worked).

${ }^{682}$ Jenson and Sineau (2001a): p.29 
Table 36. Working Adults Hours of Work, by Presence of Children, 1994 - 2001, Russia

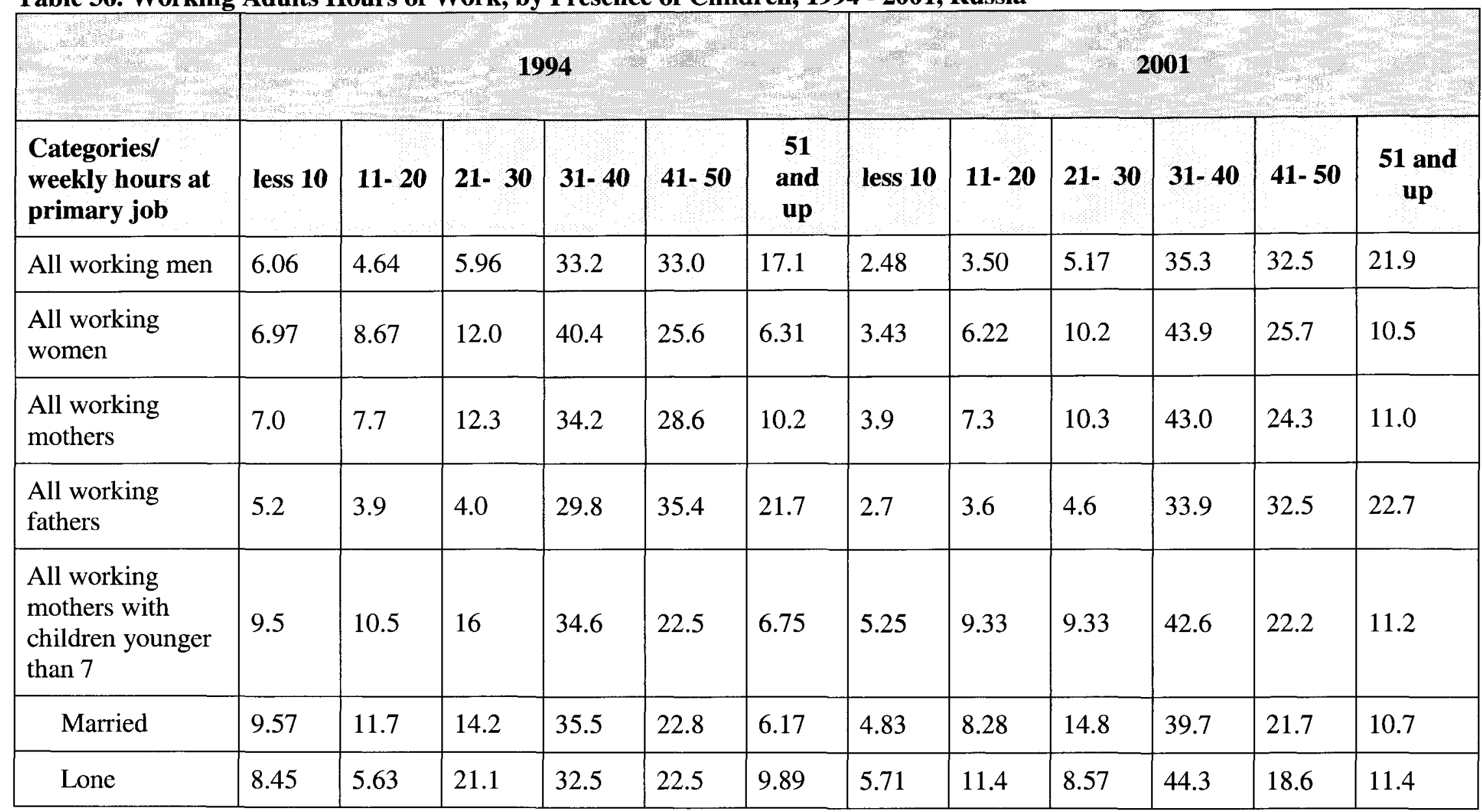

$* \mathrm{~N}$ is not significant

Source: Calculated by the author using the Russian Longitudinal Monitoring Survey 
The changes in the hours of work can partially serve as an explanation for the relative stability of employment rates. While, overall the part-time work trend is declining, the mere emergence of this type of employment during the transformation is notable and significant, particularly after the legally required Soviet legacy of full-time employment. This trend indicates the creation of "flexible" labour markets. There are a number of potential reasons for such a "popularity" of part-time employment. First, it can be seen as a response to the economic crisis, which was the deepest at the beginning to mid-1990s. In that period, nearly every fifth working woman was working part-time (every third mother with a child under 7 years old). Second, this may serve as a sign of the labour market's adaptation to the new economic conditions (e.g., involuntary part-time employment). Third, increased part-time employment can be seen as a reflection of changes in the nature of the economy in Russia towards greater service-orientation (more restaurants, bars, shops), that led to an increase in the demand for part-time work. For instance, more than $45 \%$ of all jobs in Russia in 1990 could be found in the service sector. As noted by Lukyanova, "the Russian service sector is currently employing at least as many workers as two other major sectors - industry and agriculture altogether." ${ }^{683}$ Such changing structure of the economy from industrial and agricultural sectors to mostly service-orientation allowed for creation of more "flexible" jobs, not requiring full-time presence.

Fourth, the emergence of part-time employment could mean that many men and women are able to find informal employment, or employment in informal economy, and

${ }^{683}$ Lukyanova (2003): p.4 
work part-time. ${ }^{64}$ As will be elaborated in chapter 6 , the proportion of informal jobs is quite significant in Russia. Some estimates show that in 2004 about 13 million jobs $(18 \%)$ in Russia we classified as informal. ${ }^{685}$ Given the unregulated character of this type of employment, there is a high incidence of both part-and over-time employment:

The structure of the hours worked under informal employment differs from the formal sector. It reflects under- and over-employment in the formal sector. In the formal sector, the majority of employed population ( $88 \%$ ) had one job and worked $31-40$ hours during the week of the survey... In the informal sector, $51 \%$ worked $31-40$ hours and $25 \%$ worked less than 30 hours. $24 \%$ of employed worked more than the normal work week of 40 hours, including $15 \%$ of those who worked over 48 hours a week. Underemployment [in the informal sector] is more common for women... $23 \%$ men and $28 \%$ of women worked less than 30 hours. ${ }^{686}$

As such, informal employment can explain some of the trends of increased incidence of part-time employment. The final possible reason considered here is that part-time employment could be seen as a response to family and child care policies, even in a patchy manner, since neofamilialist policies "favour the growth of labour market flexibility through the expansion of low wage, part time employment for women." ${ }^{687}$ As

${ }^{684}$ According to Guidelines adopted by ICLS in 2004, informally employed included:

- population involved in informal sector (the list of categories is mentioned in employment concept in informal sector description);

- employees who have informal jobs at formal sector enterprises; and

- family members who have informal jobs at formal sector enterprises and help their families (see the report at Federal State Statistics Service (2005)).

While the nature of informal employment will be described in chapter 6 , it is worth mentioning here that sectors in informal economy include: trade and maintenance (35\%), agriculture (42\%), industry (6\%), personal services (6\%), transport (4\%), construction (3.5\%). For more information, see Gimpelson (2003).

${ }^{685}$ The Russian Federal State Statistics Service (2005): p.2

${ }^{686}$ The Russian Federal State Statistics Service (2005): p.3 (minor changes of translation character in the quotation are made by the author)

${ }^{687}$ Mahon (2002): p. 352 
noted earlier, access to child care/parental leave and in-home caregiving allowance was possible while working part-time.

As cautioned by Jenson and Sineau however, the following questions still need to be answered with regard to the flexible labour markets and ("voluntary") part-time employment: Is it the women who are seeking this flexibility? Do they see it as a way to reconcile work and family life?.. Are women choosing flexible employment so they can care for their own children, or is this flexibility imposed by employers who provide a choice between working part time or being unemployed? ${ }^{688}$ The answers to these questions must be constructed with the great degree of care. In the Russian case, it is true that while those women who are forced to work part-time or combine multiple jobs wish to find regular stable employment, a number of women working full-time express a desire to find something more flexible. For instance, as noted by Svetlana (married, 29-yearsold):

It would be ideal for me to be able to work part-time. In that case, I would have a chance to work so that to feel important and, at the same time, devote due time to my family... I only wish part-time jobs were well-paid and well-respected...

This is also confirmed by the survey data which indicate that 81 per cent of the Russian women who mentioned that they would work irrespective of financial needs, would prefer to work part-time (a shorter day or a shorter week) ${ }^{689}$ At the same time, these statements could reflect constraints and difficulties in accessing child care services (either

\footnotetext{
${ }^{688}$ Jenson \& Sineau (2001a): p.32

${ }^{689}$ Mezentseva (1994): pp.119-121
} 
private or public). Perhaps, if these women had better child care options (access, quality and affordability), their need for flexibility could diminish.

Overall, it appears that the changes in the labour market status of mothers (particularly those with young children) -- the decline in paid work, a greater preference to stay at home, and the emergence of part time employment -- are similar to the common set of outcomes of neofamilialist policies, outlined at the beginning of the chapter. The effect is slightly more pronounced in the case of married women. At the same time, there is a uniqueness in the response given by the Russian women and labour markets so far: relative stability in female employment, almost no decline in the employment of lone mothers, and a decline in the number of women taking leaves. This calls for a cautious interpretation of the impacts of neofamilialist policies in Russia, particularly given the important differences of Russia from other countries building neofamilialist regimes. These differences, among others, include inherited high rates of female participation in the labour market, provision of services to women (as opposed to men as in many conservative models) through employment as well as high rates of education. These are elaborated upon in chapter 6. Furthermore, competing explanations for part-time employment (such as forced part-time employment or unpaid leave), which are particular to the Russian conditions, as well as the relatively weak links between employment of mothers with young children and leave and child care provision, requires us to be careful in directly attributing the changes in the female position on the labour market solely to neofamilialist policies. 


\section{Fertility Rates}

Since the beginning of transformation, fertility rates have declined dramatically in Russia and other countries of the former Soviet Union. For instance, as shown in Table 22 (chapter 3), the number of births fell from 2.3 million to 1.2 million, between 1989 and 2003, registering a drop of 1.1 million. The total fertility rate in Russia, over the same period of time, had fallen from 2.1 to 1.2 , and remains relatively stable since then. The decline occurred among women of all ages. This also included women younger than 20 , "the only age-group whose fertility rate had increased steadily since the mid-1960s.",690 This marks a dramatic decline of fertility rates from the Soviet period.

The trend is also depicted in Figure 9, which illustrates the overall decline in the total fertility rate across selected countries since the beginning of transformation. The high fertility rates at the end of the Soviet period were partly a result of the Soviet pronatalist policies. As described in chapter 2, although the Soviet Union had very high rates of female labor force participation, it also had policies promoting child bearing and rearing. These included public child care, maternity leaves, and a variety of protections available to mothers. No less important was the fact that the costs of food, education, and health care were low or nil, and there was no open unemployment, which provided stability and assurance in the future. As elaborated by Nina (50-years-old):

When we were young, life was completely different, it was predictable and stable. I knew what my path would be since I was very young: school, institute, guaranteed job with the secure income... The income for educated specialists was high enough so that not to worry about every day

\footnotetext{
${ }^{690}$ Hollander (1997)
} 
needs... Housing was also guaranteed... I agree at first housing is very small but it was guaranteed... I knew that I would not end up on the street... We simply had the assurance in the future... Also women had a lot of support with children... At work, health care system, everywhere... It was much easier to have children in those days... ${ }^{691}$

The experiences and statements of other women who had children during the Soviet period also confirmed that stability, security in the future and availability of "motherfriendly" policies facilitated early marriages and childbirths during the Soviet period.

\section{Figure 9. Total Fertility Rate in Selected CEE-CIS Countries, 1989-2003}

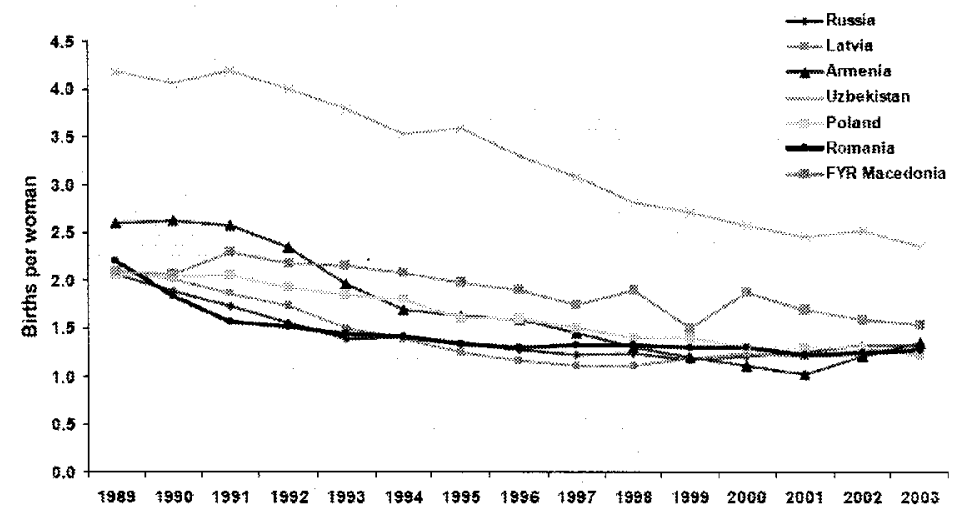

Source: UNICEF, TransMONEE Database, Heleniak (2005)

In the transformation period, in light of the social and economic changes, one could think of several explanations for the declining/low fertility and childbirth rates in the countries in transition, and in Russia in particular. Among others, they include overall rising ages for marriage and first childbirth, declining marriage rates and increased number of divorces (3.42 per 1,000 habitants). Other explanations include the rise of contraceptive usage and abortions. For instance, Figure 10 shows that

${ }^{691}$ Interview by the author 
there was an increase by about one-third of women of reproductive age who began using contraception during the period between surveys. This has to do with both supply and demand factors. With the transition to market economics and opening of these countries to the rest of the world, there has been increased production of domestic supply of modern contraception as well as increased imports. ${ }^{692}$

With regard to abortions, while the statistics on abortion are often heavily criticized, due to the imperfection of data collection systems in Russia, it still helps us to identify some general trends. For instance, "in 1992, 3.5 million Russian women obtained abortions, and the abortion rate was 98 per 1,000 women aged $15-49 \ldots$ The rate ranged widely among the country's 14 regions (from 75 per 1,000 to 123 per 1,000 ) and was relatively low in large cities (77-79 per 1,000 in St. Petersburg and Moscow). In all, 225 abortions occurred for every 100 births among Russian women." ${ }^{, 693}$ The number of abortions, while declining, has remained high during the transformation period: in 1996 - 69 abortion per 1,000 , in $2000-55 .^{694}$ In general, however, numbers in Figure 10 can be interpreted as representing a shift in the methods of contraception from abortion to pills, condoms and others.

\footnotetext{
${ }^{692}$ Heleniak (2005): p.13

${ }^{693}$ Hollander (1997)

${ }^{694}$ Wites (2004)
} 
Figure 10. Contraceptive Prevalence Rates in the CEE-CIS, 1990-2002

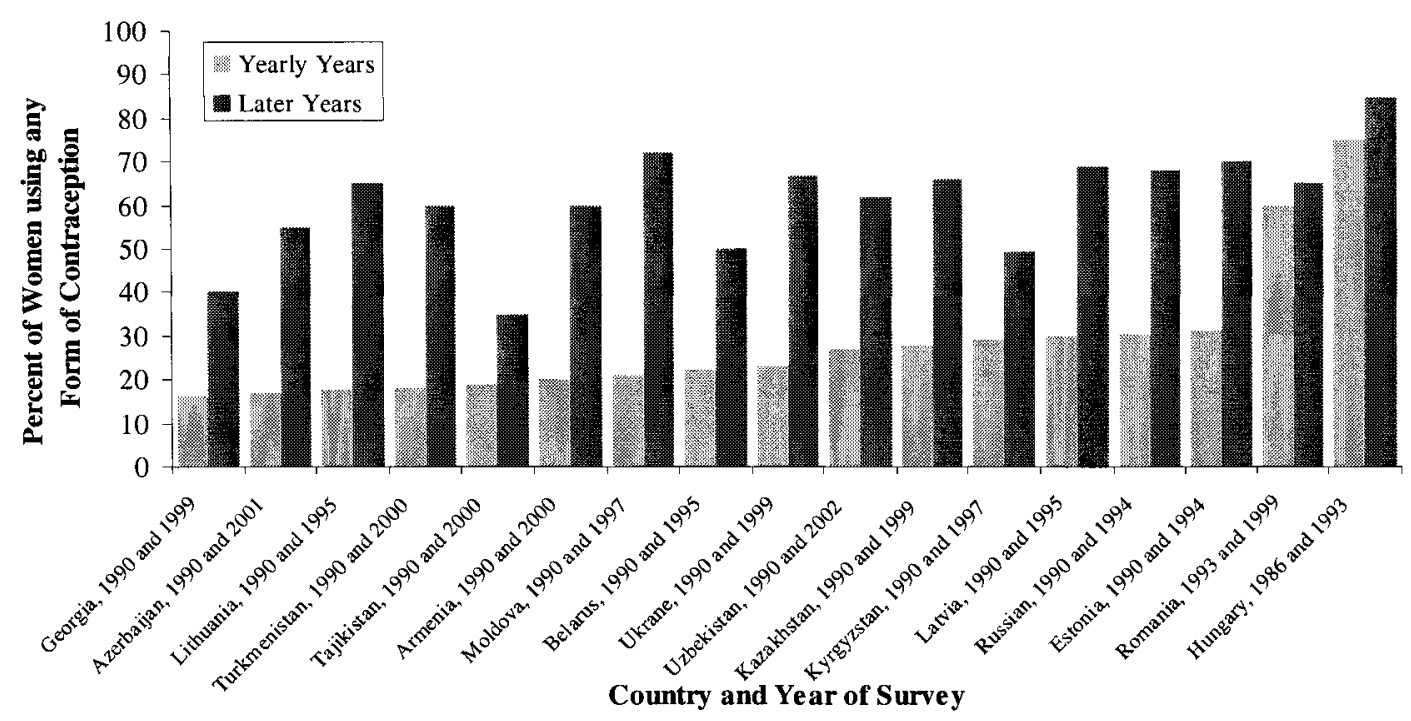

Source: Data are complied from various Demographic and Health, Reproductive Health, and Family and Fertility Surveys; Heleniak (2005)

Finally, pessimistic economic expectations and falling household incomes have also negatively affected the decisions about childbirth (or fertility). This trend has also been confirmed by the polling data: for instance, in 1992, three in four women mentioned insufficient income as a factor, which would discourage childbirth. ${ }^{695}$ In addition, when during informal conversations women mentioned that they could not "afford" to have children, the following reasons were named:

- High costs of giving birth ("Giving birth is very expensive in our days... I would not want to give birth in the public hospital as the conditions there deteriorated dramatically and I would simply be afraid for my life and a life of my child... At the same time, we simply cannot afford private hospitals yet..." Irina, 25-year old)

${ }^{695}$ Motivans (2001): p. 40 
- High costs of raising a child ("Prices are rising everyday... everything is very expensive, particularly for children good, as parents want to buy the best for them..."Vika, 25-years-old)

- Unstable economic situation ("I cannot predict what would happen with my job or the job of my husband tomorrow... I need to have some stability and security in order to make such an important decision as having a child" - Olga, 22-year-old) ${ }^{696}$

The mentioned factors once again illustrate that economic factors and expectations are important in making decisions about childbirth in Russia.

Overall, these results suggest that Russia's low fertility rates and high abortion rates are a sign of a continuous "demographic crisis" in the country. These patterns may be a response to the family and social changes which accompanied by economic and political reforms. As noted by Kulakov, a high-ranking Russian health official, "The collapse of the Soviet Union in 1991 and the ensuing hyperinflation and depression deprived millions of Russians of their incomes and savings and discouraged couples from having children." ${ }^{697}$ Thus, despite the seeming generosity of family policies in Russia, they had only a trivial impact on the childrearing decisions, due to economic conditions and broader socio-demographic changes. This situation, combined with low wages and the financial constraints of the Russian welfare state, points to the low capacity of the Russian welfare state to increase fertility and childbirth rates in the 1990s, which will be explored in greater detail in chapter 6. Other factors, similarly influencing the effectiveness of family/child care policies in Russia, are also described in chapter 6.

\footnotetext{
${ }^{696}$ Conversations by the author

${ }^{697}$ Mosnews (2005) - translated by the author
} 


\section{Child Care Arrangements}

The final indicator which will be considered in assessing the outcomes of the mix of child care policies is "child care arrangements," utilized by families to care for children of the pre-school age. The data shows (Table 37) that the bulk of child care is provided by families: in the middle of the 1990s, the official average rate of in- home care for children 4-6 years old was 47.32 per cent. This number is a little higher for children in the $1.5-3$ years old age group (about 60 per cent). While having slightly declined by 2001 , the bulk of child care is still provided by families. The data further reveals that there is a low reliance on private individual or group (non-relative provided) child care arrangements. Thus, for children in the 4-6 years old age group, less than 5 per cent of families relied on non-family provided, individual child care. The numbers are similar for the children of the 1.5-3 years old age group.

These findings are interesting, as they mark a significant decline from the Soviet period and point toward refamilialization of child care provision. While in the late Soviet period about 68 per cent of children attended child care institutions, child care attendance for all children (0-6 years old) plummeted to about 25 per cent in 2001. Such great preponderance of home care over the public/private child care can be seen as a response to the declining number of facilities and quality of public daycare, as well as the absence of market-provided child care services. The transfer in child care arrangements from the state to families can be attributed to the paradigm shift, changing care ideals (when preference is given to individual family-provided care) and accompanying policy changes, which had some impact on how child care arrangements are made. 
Table 37. Types of Child Care Arrangements, 1994 - 2001, Russia

\begin{tabular}{|c|c|c|c|c|c|c|c|}
\hline Categories & $\begin{array}{c}\text { All } \\
\text { children } \\
(0-6 \text { years } \\
\text { old })\end{array}$ & \multicolumn{2}{|c|}{$\begin{array}{l}\text { Younger than } \\
1.5 \text { years old }\end{array}$} & \multicolumn{2}{|c|}{$\begin{array}{c}1.6 \text { - } 3 \text { years } \\
\text { old }\end{array}$} & \multicolumn{2}{|c|}{$\begin{array}{l}4-6 \text { years } \\
\text { old }\end{array}$} \\
\hline $\begin{array}{l}\text { A child cared for } \\
\text { by: }\end{array}$ & $1985^{698}$ & 1994 & 2001 & 1994 & 2001 & 1994 & 2001 \\
\hline $\begin{array}{l}\text { only family } \\
\text { members }\end{array}$ & & 77.64 & 72.25 & 59.30 & 48.62 & 47.32 & 41.65 \\
\hline $\begin{array}{l}\text { relatives outside of } \\
\text { household }\end{array}$ & & 5.49 & 10.05 & 8.14 & 9.09 & 7.36 & 9.23 \\
\hline $\begin{array}{l}\text { child attended } \\
\text { kindergarten }\end{array}$ & 68.3 & 0.42 & 2.87 & 19.38 & $32.81^{699}$ & 35.59 & 39.40 \\
\hline non-relatives & & 1.69 & 1.91 & 3.88 & 5.53 & 4.77 & 4.74 \\
\hline Other & & 14.77 & 12.92 & 9.30 & 3.95 & 4.97 & 4.99 \\
\hline
\end{tabular}

Source: Calculated by the author using the Russian Longitudinal Monitoring Survey; Statistical Collection "Women of Russia." Goskomstat of Russia. Moscow, 1995.

An interesting question, then, inquires how Russian women manage to maintain high rates of female labour force participation and arrange for their children to be taken care of at home? The possible answers appear to be both simple and complex: first, most families primarily rely on extended family networks for child care provision. As will be elaborated in chapter 6 , grandparents head the list of the relatives caring for a child in most cases as they are seen as the second best solution after "full-time mother" care. Second is the usage of "living arrangements" (i.e., living together with the extended

\footnotetext{
${ }^{698}$ Late Soviet period

${ }^{699}$ The increase in child care attendance from 1994 to 2001 can partially be explained by the fact that the total number of live births and total fertility rate in Russia in the last decade steeply declined. In particular, as shown in Table 32, the number of live births declined from 1,793 thousand in 1991 to 1,259 thousand in 1997, thus resulting in a fewer number of children of 1.6-3 years of age in 1994 and 2000-2001 respectively. This in turn led to the relatively greater number of child care places per child.
} 
family) as a mechanism of coping with the changing economic conditions and decline in public child care. While several studies show that only 15 per cent of Russian families lived together with the grandparents during the Soviet period, the number appears to have increased during the transformation. ${ }^{700}$

In conclusion, this section shows that there were significant changes in the child care arrangements used by families, by moving from group to individual care, from public to home/ relative-provided. What is interesting here is that this move occurred in conditions of high female labour force participation (compared to other countries). Nearly absent private institutions/arrangements for care provision (both formal and informal) imply that families become the main factors responsible for provision of child care, thereby reinforcing the importance of family networks in the Russian economy and welfare state.

\section{Conclusion}

The analysis provided in this chapter indicates that the current configuration of family /child care policies produces mixed effects when combined with Russian realities. The evidence that neofamilialist policies (such as long parental leaves, payment of in-home caregiving, and lack of affordable child care services in Russia) have succeeded in achieving mothers' withdrawal from the labour market for an extended period of time is somewhat unclear. Indeed, women's increased tendencies to stay at home and attend to

${ }^{700}$ Motivans (2001) 
their children, families providing the bulk of carework, and the emergence of part time employment for women, point to some success in implementing these policies. ${ }^{701}$

At the same time, in many cases, it's the married women (who have an additional source of income) who can afford to take leave or stay at home and care for children as a primary occupation. The employment rate for lone mothers has remained relatively high over the period of transformation. The same is true in regard to maternity/parental leave utilization. This mixed evidence makes it very difficult to interpret the policy results unambiguously. The financial constraints of the Russian welfare state, manifested through low generosity of leave and in-home caregiving allowances, as well as low male wages, can partly account for such mixed results.

Moreover, the general rates of female labour force participation remain high even when compared to most developed countries. This can also be explained by the fact that Russia has inherited high levels of female labour force participation from the Soviet period. An additional explanation, which will be elaborated upon in chapter 6 , is that most benefits continued to be provided through enterprises, and that - in conditions of declining real wages and growing poverty - has become an important incentive to maintain one's connection to the enterprises, even if it is through unpaid leave or forced part-time employment.

Finally, although fertility rates have stabilized by 2000 , they still remain very low, compared to the Soviet period. Hence, while indeed affecting women's decisions about

${ }^{701}$ Mahon (2002) 
employment and childbearing, neofamilialist policies do so in a selective way. The women who maintain employment simply because they cannot afford to do otherwise will respond to changing child care policies by having very few children.

This points to the fact that, while the broad policy principles of child care policies are consistent with neofamilialism, the difference in policy emphasis and mechanisms (e.g., employer-financed leaves and low levels of allowances) as well as the capacity to implement policies affected the ultimate policy outcomes. This indicates the deeper need for a further investigation of the factors influencing decision-making, at both micro- and macro-level, such as institutional, political, social and economic constraints specific to Russia. Our next chapter will explore in greater detail why these policy provisions produced mixed and often contradictory set of outcomes, as described earlier. 


\section{Chapter 6. Explaining the Shift: State Capacities, Soviet Legacies and Adaptation Strategies}

The previous chapters examined the rationale behind the changes in child care policies in Russia during the transformation period, as well as their magnitude, nature and shape. Chapter 5 illustrated that, despite the neofamilialist goals of the child care policies in post-Soviet Russia (e.g., increasing fertility and "returning women back to homes," in order to release labour market pressures), these policies had a relatively limited impact on female decisions about employment and childbirth. This chapter looks at "why" and "how": Why did the neofamilialist policies have a limited impact on female decisions about employment in Russia? Why did majority of women chose not stay at home to have babies? How did women with small children manage to stay in the labour force, considering their limited options for child care? How did labour markets, and households in general, respond and adapt to these policies?

This chapter aims to show that complex interactions of policies with social, political and economic systems altered the ultimate policy outcomes (female employment and number of children), thus falling short of achieving their policy objectives to the full extent. For the purposes of this thesis, social, political and economic systems include: a) systems affecting the capacity of the state to achieve its objective (financial, administrative, law enforcement); b) Soviet legacies, such as full employment, traditional access to benefits through employment, high rates of education, traditional values and abolishment of the family wage; and c) formal and informal adaptation strategies used by institutions and individuals to cope with the changes in policies and socio-economic environments, such as informal employment contracts, part-time and multiple 
employment and use of family networks for child care. The chapter will advance a subhypothesis that:

- Limited state capacities ${ }^{702}$ to implement child care policies, Soviet legacies, and formal and informal adaptation strategies on the part of women, labour markets and households, contributed to the relatively low impact of neofamilialist child care policies in Russia.

This chapter will consist of two sections. The first section will assess the state's capacities to implement its policies, as well as the Soviet legacies. The second section will highlight the main strategies ușed by labour markets, households and women to adapt to the changing economic and social conditions.

\section{State Capacities and Soviet Legacies}

\section{State Capacities}

While the concept of state autonomy is a key factor in formulating policies (e.g., developing policy content and objectives), an extensive body of literature points to the importance of assessing state capacity for policy implementation, in order to understand the ultimate policy effects - or lack of thereof. ${ }^{703}$ This literature indicates that the state capacity for policy implementation, and the policy interaction with a set of socio-

\footnotetext{
${ }^{702}$ While it is recognized that state capacity, similarly to the policy feedback processes and other policy legacies, could be seen as an ultimate result of political processes in itself, this chapter attempts to analyze state capacity as an independent variable in policy-making process and asses its effects on the ultimate outcomes of child care policies.

${ }^{703}$ See Skocpol (1992), Pal $(1986,1988)$
} 
economic factors, ultimately determine the shape and form of policy effects and impacts and "deserve close analysis in their own right."704 The literature defines "state capacity" as the institutional capacity of the central state to penetrate territories and logistically implement decisions. ${ }^{705}$ Furthermore, "sheer sovereign integrity and the stable administrative-military control of a given territory are preconditions for any state's ability to implement its policies. Beyond this, loyal and skilled officials and plentiful financial resources are basic to state effectiveness in attaining all sorts of goals." 706

In general, the capacity of the state to achieve its goals is closely connected with the process of independent goal formation by the state. Sometimes, however, states pursue goals that are beyond their reach. ${ }^{707}$ In the Russian case, there is an extensive body of literature arguing that the post-socialist state has limited capacities to implement its policies, due to a number of factors, including oligarchy, corruption, underdevelopment of civil society, fusion of the state and economic interests, as well as weak economy. Indeed, as evidenced in chapter 5, a set of neofamilialist policies in Russia had a limited impact on female decisions around employment and childbirth. ${ }^{708}$ This is partly a result of ineffective policy implementation, which happens when "states attempt tasks they cannot complete and when the means they use produce unforeseen structural changes and sociopolitical reactions."709

\footnotetext{
${ }^{704}$ Skocpol (1992): p. 16

705 Mann (1993): p. 59.

${ }^{706}$ Skocpol (1992): p. 16

${ }^{707}$ Ibid.

${ }^{708}$ See Sperling (2000); Illarionov (1999); Malleret et al (1999); Robinson (1999); Sapir (1999); Hanson (1999); Bova (1999); Ma (2000); Peregrudov et al (1999); Roberts and Sherlock (1999); Robinson (2002); Smith (1999); Sperling (2000); Beissinger and Young (2002)

${ }^{709}$ Skocpol (1992):p.16
} 
It is also important to recognize that, while the main elements of the state capacities are important for analyzing policies, the degree of the state's capacity to implement its policies (similarly to autonomy) varies according to the policy area:

There is no reason to assume a priori that the pattern of strengths and weaknesses will be same for all policies. One state may be unable to alter the structure of its medical system but be able to construct an effective transportation network, while another can deal effectively with getting its citizens around but cannot get their illnesses cured. ${ }^{710}$

While, naturally, despite variations among issue areas, the overall capacity (or power) of the state has important effects on all policies, the uneven nature of the state's power makes a case for specific sectoral investigations. This chapter will look at the capacities of the state, in the area of social policies in general, and child care in particular. More specifically, this section will focus on three aspects of the state's capacity, identified as having the biggest impact on achieving the outcomes of the welfare model in Russia: financial, administrative and law enforcement capacities.

\section{Financial and Administrative Capacities of the State}

The financial capacity of the state is an important factor to consider, as it provides the foundation for welfare state policies. This capacity depends on the ability of the state to raise taxes and control the economy through financial and monetary levers. Skocpol notes that

factors determining state's financial resources may be somewhat more manipulable over time, though not always. The amounts and forms or

$\overline{{ }^{710} \text { Krasner (1978); Skocpol (1992) }}$ 
revenues and credit available to a state grow out of structurally conditioned, yet historically shifting political balances and bargains among states, and between a state and social classes. Basic sets of facts... involve the sources and amounts of state revenues and the degree of flexibility possible in their collection and deployment. ${ }^{711}$

Thus, in Russia, fiscal problems emerged during the transformation as a result of both a weak tax base and inability to collect revenue has significantly undermined the capacity of the state to implement its policies. As discussed in chapter 3, during the transformation, Russia's budgetary spending had fallen dramatically as a result of declines in GDP, the per cent of GDP spent by all levels of government and collapse of revenue from the state-owned enterprises combined with the lack of alternative taxing mechanisms. These trends are illustrated in Table 38. It is worth briefly mentioning here that due to the declining GDP, industrial subsidies to fund enterprise social services were substantially cut. While the explicit social expenditures were protected as a result of Duma's resistance to their cuts (at the average rate of average about $17 \%$ of GDP), their level remained significantly below other East European countries. ${ }^{712}$ In addition, the real value of social expenditures and thus mandated benefits, particularly in the poorest regions, declined with the fall in GDP.

Table 38. Government Social Expenditures in Russia (1987 - 1996); Roubles per year, deflated by cost of living index

\begin{tabular}{|l|c|c|c|c|c|c|c|c|c|c|}
\hline Programs & $\mathbf{1 9 8 7}$ & $\mathbf{1 9 8 8}$ & $\mathbf{1 9 8 9}$ & $\mathbf{1 9 9 0}$ & $\mathbf{1 9 9 1}$ & $\mathbf{1 9 9 2}$ & $\mathbf{1 9 9 3}$ & $\mathbf{1 9 9 4}$ & $\mathbf{1 9 9 5}$ & $\mathbf{1 9 9 6}$ \\
\hline $\begin{array}{l}\text { Pensions (gross) } \\
\text { As \% of GDP }\end{array}$ & 30.9 & 32.2 & 32.3 & 36.3 & 29.1 & 18.7 & 25.5 & 21.5 & 17.1 & 17.0 \\
& 6.2 & 6.1 & 6.0 & 6.4 & 4.8 & 3.9 & 6.0 & 5.8 & 5.1 & 5.6 \\
\hline $\begin{array}{l}\text { Family allowances } \\
\text { As \% of GDP }\end{array}$ & 8.4 & 9.2 & 10.7 & 10.8 & 5.0 & 1.3 & 2.5 & 2.6 & 0.2 & 2.6 \\
& 1.7 & 1.8 & 2.0 & 1.9 & 0.8 & 0.1 & 0.6 & 0.7 & 0.1 & 0.9 \\
\hline Child allowances & & & & & 1.3 & 0.1 & & & & \\
\hline
\end{tabular}

\footnotetext{
${ }^{711}$ Skocpol (1992): p. 16

${ }^{712}$ Cook \& Orenstein (1999)
} 


\begin{tabular}{|l|c|c|c|c|c|c|c|c|c|c|}
\hline As \% of GDP & & & & & 0.2 & 0.01 & & & & \\
\hline $\begin{array}{l}\text { Unemployment } \\
\text { benefits } \\
\text { As \% of GDP }\end{array}$ & & & & & 0.1 & 0.2 & 0.3 & 0.5 & 0.7 & 0.5 \\
\hline $\begin{array}{l}\text { Other: scholarships, } \\
\text { bread subsidies, } \\
\text { social assistance } \\
\text { As \% of GDP }\end{array}$ & & & & & 0.6 & 5.2 & 4.7 & 5.4 & & \\
\hline $\begin{array}{l}\text { TOTAL CASH } \\
\text { TRANSFERS } \\
\text { As \% of GDP }\end{array}$ & 39.3 & 41.4 & 43.0 & 47.1 & 36.2 & 25.5 & 37.1 & 33.9 & 21.6 & 22.6 \\
\hline Education & 16.8 & 7.9 & 8.0 & 8.3 & 6.0 & 5.4 & 8.7 & 9.2 & 6.5 & 7.4 \\
As \% of GDP & 3.4 & 3.5 & 3.4 & 3.5 & 3.6 & 3.5 & 4.0 & 4.4 & 3.4 & \\
\hline Health & 10.1 & 11.1 & 11.8 & 12.9 & 14.5 & 11.6 & 13.4 & 11.5 & 8.1 & \\
As \% of GDP & 2.0 & 2.1 & 2.2 & 2.3 & 2.4 & 2.4 & 3.2 & 3.1 & 2.4 & \\
\hline $\begin{array}{l}\text { TOTAL IN-KIND } \\
\text { TRANSFER } \\
\text { As \% of GDP }\end{array}$ & 26.9 & 29.3 & 30.2 & 32.5 & 36.0 & 28.3 & 30.5 & 27.5 & 19.5 & \\
\hline $\begin{array}{l}\text { TOTAL } \\
\text { TRANSFERS }\end{array}$ & 5.4 & 5.6 & 5.6 & 5.7 & 6.0 & 6.0 & 7.2 & 7.5 & 5.8 & \\
\begin{tabular}{l} 
As \% of GDP \\
\hline
\end{tabular} & 13.4 & 13.4 & 15.0 & 14.1 & 16.8 & 13.8 & 15.9 & 16.7 & 12.3 & \\
\hline
\end{tabular}

Source: The World Bank (1998), "Income Inequality, and Poverty during the Transition from Planned to Market Economy," Prepared by Branko Milanovic. Washington, D.C., pp.: 199-200.

Note: The expenditure data presented here is derived from actual survey data, and may differ from government budget data quoted elsewhere

The low capacity of the state to generate revenue resulted in its inability to maintain appropriate level of benefits and allowances - their generosity, in real terms, is almost negligible (Table 39). For example, the former Deputy-Prime Minister, Valentina Matvienko admitted that the average sum of child benefits is so small, that it is obvious these benefits would not stimulate fertility. ${ }^{713}$ The 1992 World Bank report noted that, in 1992, the child allowance was at about 13 per cent of the subsistence minimum, while in 1999, as a result of the 1998 financial crisis, it was only 6 per cent. The same is true for the maternity leave benefits:

\footnotetext{
${ }^{713}$ Stenogramma zasedanii (May 26, 2000)
} 
Maternity leaves provided in Russia are more extensive than in many Western countries, but since benefits are tied to the minimum wage rather than to the previous wage, they provide relatively less compensation. Although the benefits have been adjusted from time to time, it is widely felt that they are not adequate to meet the increased cost of living for families, particularly families headed by women. ${ }^{714}$

Table 39. Change in the Value of Child Allowances in Russia, 1991-1996 (Percentage of the Average Monthly Wages)

\begin{tabular}{|l|c|c|c|c|c|c|}
\hline \multirow{2}{*}{ Allowance for } & $\mathbf{1 9 9 1}$ & $\mathbf{1 9 9 2}$ & $\mathbf{1 9 9 3}$ & $\mathbf{1 9 9 4}$ & $\mathbf{1 9 9 5}$ & $\mathbf{1 9 9 6}$ \\
\cline { 2 - 7 } & Jan. & Dec. & June & year & year & Jan. \\
\hline Under 1 1/2 - years-old & & & & 5.5 & 4.5 & 6.8 \\
\hline 1 1/2-6 - years-old & & & & & & \\
\hline -base benefit & 10.7 & 2.5 & 4.0 & 5.5 & 4.5 & 6.8 \\
\hline -with compensation & 13.0 & 6.2 & 6.0 & & & \\
\hline 6-to-16-year-old & & & & & & \\
\hline -base benefit & 5.9 & 2.8 & 1.4 & 5.5 & 4.5 & 6.8 \\
\hline -with compensation & 8.8 & 3.7 & 4.0 & & & \\
\hline Children of lone parents & 11.9 & 5.6 & 3.2 & 8.5 & 7.7 & \\
\hline
\end{tabular}

Source: Fajth, 1994: UNICEF, 1997 as quoted in Klugman and McAuley (2001): p.141

Thus in general, mothers with at least one year of employment receive 100 per cent of their regular salary during their maternity leave, with a maximum total monthly payment of 85 times the minimum monthly wage (set at 450 roubles or about US\$14 per month in 2002). The in-home caregiving allowance (or parental leave benefit as it is often referred to) is substantially less generous, with a flat leave payment of 500 roubles (about US\$17) per month until the child reaches 1.5 years old. The comparison of the generosity of parental leave benefit (in the Russian case in-home caregiving allowance) with other countries is provided in Table 40.

Table 40. Parental Leave Benefit in Central and Eastern Europe (Percentage of the Average Wage)

\begin{tabular}{|r|c|c|c|c|c|c|c|}
\hline Country & 1989 & 1990 & 1991 & 1992 & 1993 & 1994 & 1995 \\
\hline
\end{tabular}

${ }^{714}$ World Bank. Report \# 117 48-RU. (1994c). 


\begin{tabular}{|l|c|c|c|c|c|c|c|}
\hline Czech Republic & 23.7 & 24.2 & 22.2 & 22.5 & 21.6 & & \\
\hline Bulgaria & 51.1 & 47.1 & 68.0 & 41.5 & 38.2 & 36.7 & 33.6 \\
\hline Lithuania & & 19.0 & 39.1 & 31.4 & 23.3 & 23.2 & 13.4 \\
\hline Russia & & & 25.6 & 7.4 & 4.3 & 8.1 & 9.0 \\
\hline
\end{tabular}

Source: Fajth, 1994: UNICEF, 1998 as quoted in Klugman and McAuley (2001): p.145

The research demonstrates that the financial generosity of in-home caregiving and child allowances, as well as parental leave provisions, are important for achieving the objectives of these policies. While studying the link between the generosity of parental leave and poverty levels in fifteen developed countries, Tommy Ferrarini found that the poverty rates are the highest in the countries with limited parental leave allowances. He argues that the amount of parental leave benefits "is not only likely to affect the behavioral patterns of parents but also the living conditions and agency of individuals in families with children. ${ }^{, 715}$ A number of other studies also assessed the impact of parental leave programs on outcomes such as female labor force participation or fertility. ${ }^{716}$ These studies also indicate a positive relationship between the generosity of the parental leave and fertility (e.g., the more generous the leave, the more likely women are to take it and have children).

In the Russian conditions, however, the low level of benefits in real terms often precluded women from using available programs. This is particularly important since very few women can be supported by their spouses. Thus as illustrated in chapter 5 , while policies are designed in principle to encourage women to stay at home (at least temporarily), the low capacity of the state to implement these policies resulted in mixed

\footnotetext{
${ }^{715}$ Ferrarini (2003): p.1

${ }^{716}$ See Ruhm \& Teague (1995); Ruhm (1996), Winegarden \& Bracy (1996), Hantrais (1997)
} 
policy effects, such as a limited use of the leave and continuing high participation of women in the labour force.

In addition to the low level of generosity of benefits, allowances and provisions, the transformation period was marked by widespread arrears in their payment. According to the Ministry of Labour, in 1998, 10 million people out of nearly 36 million did not receive child benefits, while being legally eligible. The delays sometime averaged to six months. As such, the government in Russia often simply failed to provide legally mandated benefits due to the low financial and administrative capacity. In order to cover at least the minimum provision, the Government set the payment priorities: the benefits were to be paid to the neediest families first (whose income is below the poverty line in Russia). The legal system in Russia is rather weak to enforce welfare provision obligations, and given the high distrust in the system, individuals rarely seek enforcement. In 1996, about $58 \%$ of the households with children did not receive monthly child support, while in some months of 1998 the numbers grew to $83 \% .^{717}$ Table 41 illustrates the amount of child allowance arrears by selected regions.

Table 41. Child Allowances Arrears by Selected Regions of Russia as of July 1, 2000 (million roubles)

\begin{tabular}{|l|r|}
\hline Russia Total & $\mathbf{2 7 , 9 4 0}$ \\
\hline Moscow & 0 \\
\hline Oryol & 18 \\
\hline Murmansk & 246 \\
\hline Irkutsk & 523 \\
\hline Voronezh & 615 \\
\hline Primorski Krai & 840 \\
\hline Rostov & 913 \\
\hline
\end{tabular}

717 Gruat et al. (2000) 


\begin{tabular}{|l|r|}
\hline Omsk & 1,006 \\
\hline Sverdlovsk & 2,260 \\
\hline
\end{tabular}

Source: Ministry of Labour and Social Development

While payment arrears can be seen as a result of a combination of factors, (including low financial capacity), it is also a sign of the limited administrative capacity of governments of all levels to administer payment of child allowances in the regions. Such limited administrative or institutional capacity of the state can be observed in a number of other areas as well, including the administration of municipal child care facilities centres. One of the main reasons for low capacity of municipalities to support child care facilities included downloading of the responsibilities for financing of these facilities to municipal budgets without appropriate subsidies and support from the federal level. For instance, during the local interviews stage of the study, the municipalities suggested that their limited capacity to maintain and administer the child care facilities was one of the main (official) factors for their closing or sale. These city officials also indicated an interest in delaying the social asset divestitures by the enterprises for as long as possible, due to their limited capacity to administer and maintain these assets. For instance, one interview participant mentioned that maintenance of child care facilities requires at least 3-4 per cent of the current municipal budget (compared to about 1 per cent in the middle of the 1990s).

An enterprise survey conducted by Freinkman and Starodubrovskaya revealed that municipalities attempted to delay or stop the process of transfer of social 
infrastructure from the enterprises in about $60 \%$ of cases. ${ }^{718}$ The interview participants also mentioned that municipal authorities often attempt to conclude agreements with enterprises for joint use and financing of child care facilities and other objects of social infrastructure in order to offset some costs. In many cases, however, such agreements implied that an enterprise would retain financial and administrative responsibility for the facilities, while the city would contribute funds sporadically. Thus the main reasons from the municipal point of view for the decline in child care facilities included, insufficient funding, lack of external funding as a result of low interest of external stakeholders in child care, inability to provide high quality of care due to the low wages of care providers (which in turn contributed to the declining demand in the 1990s). These factors "compelled" municipal authorities to either allow institutions to decay, dispose them for other use, seek agreements with former host enterprises or reject transfer of the institutions to the municipal administration.

Overall, the administrative capacity of the Russian welfare state during the first decade of transformation was characterized by institutional rigidities, obsolete institutions inherited from the Soviet period and not compatible with the new post-Soviet regime as well as lack of cooperation on the part of the regional elites. In general, new Russia lacked the institutional infrastructures in administrative, regulatory and law enforcement areas which in turn undermined the successful implementation of reforms in the 1990s. While these trends reflect changing economic and political realities, they also, as shown in the 2002 World Bank report, reflect systemic issues:

\footnotetext{
${ }^{718}$ Freinkman \& Starodubrovskaya (1996)
} 
- The lack of a comprehensive strategy to implement the new national policies;

- A much too rapid decentralization of policy implementations, in view of limited administrative capacities and resources, including financial resources at subnational levels;

- The ineffective implementation of national policies at the regional and local levels;

- The functional fragmentation of the system, with three ministries (Ministry of Health, Ministry of Education, and Ministry of Labor and Social Development) responsible for various segments of child welfare, resulting in inconsistent and uncoordinated approaches ${ }^{719}$

Inconsistent and uncoordinated policy making can also be seen as a result of elite

fragmentation. For example, as illustrated in the previous chapter,

elite fragmentation often undermines the capacity of state leaders to control their subordinates and consolidate autocratic rule. First, a proliferation of conflicting laws and decrees by the executive, ministries, and legislature undermines implementation by creating confusion among subordinates about which order is the "right" one. Division at the top may also create opportunities for subordinates to craft areas of autonomous action by playing one side off against the other. Finally, fragmentation and uncertainty about which elite faction will win may discourage subordinates from taking risks on behalf of a particular side. This is particularly important when it comes to implementation of relatively risky actions such as large-scale coercion or massive vote fraud. The possibility of victory by the other side is likely to encourage subordinates play it safe and do nothing rather than risk alienating a particular leadership faction. ${ }^{720}$

Way also showed that weak institutions may distort institutional objectives, or even generate negative incentives through undermining formal rules, such as restricting property rights. ${ }^{721}$ The relationship between formal and informal institutions hence forms some type of "institutional continuum: if the rule of law is weak... it is replaced by

\footnotetext{
719 The World Bank. Report \# 24450-RU (2002h)

720 Way (2002): p. 7-8

${ }^{721}$ Ibid.
} 
arbitrary rule." ${ }^{722}$ As such, it is important to recognize the strong potential of informal practices and rules to undermine reform attempts in order to appreciate all the challenges facing the countries in transition. The next sections of this chapter provide more examples of informal institutions and strategies.

These factors limited the ability of the Russian bureaucracy to effectively carry out administrative tasks in general, and child care policies in particular. Even though state institutions were relatively in place during the first decade of transformation, they seemed to preside over a growing political and economic vacuum. Due to the federal structure of the Russian state and empowerment of regional and local elites, administration of social policies in Russian regions was conducted differently, despite a unified legislative framework. A number of authors ${ }^{723}$ note that such a limited institutional capacity of the Russian government was due to the "specific design of the relationships between federal and local governments, where the relations of fiscal federalism created minimal incentives for local governments to cooperate and build institutions. Another potential explanation comes from Valerie Bunce, who argues that Russia did not inherit its own government institutions, such as Russian Ministry of Labour, as opposed to other FSU countries. ${ }^{724}$ The institutions inherited by Russia after the collapse of the Soviet Union, were mainly USSR-wide (e.g., USSR Ministry of Labour), as Russia during the Soviet period in most cases did not have its own Ministries or other "republican" institutions. This resulted in the need to restructure the USSR institutions, which often lost their

\footnotetext{
${ }^{722}$ Gel'man (2000)

${ }^{723}$ Zhuravskaya (1998), Yudaeva et al (2003)

${ }^{724}$ Bunce (1999)
} 
legitimacy in the new conditions and created additional administrative challenges for Russia during the transformation period.

Overall, there are several general reasons for such low financial and administrative capacities. First is the low ability of the post-Soviet state to impose and collect taxes, under conditions of high inflation rates, declining GDP and collapsing industrial production. The success and generosity of social welfare programs largely depends on the state's infrastructural power to tax and allocate resources. Russia's tax system, largely inherited from Soviet times, was characterized by a number of tax offsets, tax exemptions, and deductions granted by various levels of government. For example, by the end of 1996 , total tax concessions reached about $7 \%$ of the GDP. This contributed to the state's inability to raise sufficient tax revenue. In addition, the Soviet system generated revenue through state-owned enterprises, a feature lost during the transformation as a result of massive privatization of former state-enterprises. This also undermined the financial stability of the post-Soviet state, forcing it to print money in order to cope with high and increasing social expenditures.

Furthermore, the conditions of relative independence of the regions in Russia during the 1990s often resulted in the reluctance of Russian regions, enterprises and individuals to finance and "subsidize" the federal government. Tax evasion became a widespread phenomenon:

Evasion is a problem in every tax system, and it was exacerbated in Russia by the high level of social security taxes and the transitional economy. There emerged several distinct methods of evasion, with different implications for the state's penetration and autonomy. At one end of the state-society relationship workers and wages escaped into 
the informal economy, evading the state's reach. At the other end powerful economic actors colonized state institutions, negotiating tax avoidance. Much of the remaining formal sector relied on strategies of minimal or formal compliance. The federal nature of the state, the noncompliance of regional units with the federal tax regime, also complicated the picture. ${ }^{725}$

Such lawlessness was partly a result of the lack of a rule of law, which confronted Russia at the beginning of the transformation. The federal government's weakened ability to monitor and tax individuals and economic agents, slowly undermined its financing of social provisions.

The second reason is the decentralization of social expenditure programs in the regions, including the management and financing of health services, basic education and safety nets (family and child welfare). This, in many cases, left regions and municipalities struggling both financially and administratively with their new responsibilities in the social sphere: social protection, health, education, and provision of other social services. As mentioned, decentralization and downloading of financial responsibilities had an adverse effect on the capacity of local governments to maintain child care facilities since most of the funding was to come from local budgets. The Russian regions, however, like those in Canada and other federal states, differ in their financial, administrative and human resources, which led to significant differentiation in provision of services and payment of allowances.

Thus, while some regions have covered the entire population with social work and care services, many have barely started introducing them. A few regions pay a regular poverty benefit in cash, while most cannot afford even occasional assistance in

${ }^{725}$ Cook (2001): p.2 
kind. Inter- as well as intraregional inequities in access to education, health, and social assistance and services have become pronounced. Federal and regional transfer mechanisms have not been able to ensure equity in providing access for citizens throughout Russia to public services and minimum social guarantees. Hence, location is turning into one of the most important determinants of access to human capital formation. Mechanisms to ensure that national policies and strategies are correctly interpreted and implemented at subnational levels are lacking. Consequently, the policy and strategy intentions are diluted, the more so as one goes down administrative levels. ${ }^{726}$

In addition to the inability to pay benefits in some cases, the decentralization revealed a low administrative capacity of the regions to calculate and pay the benefits from the regional social assistance bodies and enterprises. In the absence of a mechanism set to ensure proper administration and control at all the stages of providing the benefits (from planning to paying), this resulted in numerous breaches in regulations, leading to significant arrears in paying the benefits.

The third reason for the low capacities is nature of the post-Soviet interbugetary relations between regions and the federal centre. ${ }^{727}$ The existing system of interbudgetary relations did not provide sufficient incentives for regions and municipalities to conduct a responsible and economically sound policy, and comply with the federal regulations. This resulted in a drastic differentiation of the regions, lack of incentives for paying their share of taxes to the federal budget, and the ineffective use of financial transfers received from the federal budget. Inter-budgetary relations are so complicated because historically - and increasingly so during the transformation - non-monetary instruments were more and more frequently used between the centre and the regions to

726 The World Bank. No 24450-RU. (2002h)

${ }^{727}$ Ministry of Social Protection of the Russian Federation (1996) - translation by the author 
settle fiscal relations. These instruments included promissory notes, barter and mutual reconciliation of debts. As such, in 1997, the mutual cancellation of debts amounted to $46 \%$ of the value of all payments, while the total share of non-monetary payments reached $70-80 \%$ of all payments. ${ }^{728}$ Despite the fact that this further decreased the financial capacity of both the federal and regional authorities to finance their social obligations, the regions were keen to widen the use of non-monetary payments. Edwards et al (2000) name the following reasons for this:

- Cancellation of debts was a hidden form of subsidies to enterprises allowing them to preserve work places;

- Allowing or disallowing former state enterprises to use non-monetary payments was a powerful lever in the hands of regional authorities over formally independent enterprises;

- Getting non-monetary payments from enterprises was much easier then trying to get them pay in monetary form;

- Non-monetary payments allowed regional and local authorities to redistribute budgetary payments, reserving a large share for themselves and transferring less to the federal budget. If enterprises were to pay with cash, most of it would first go to the Federal budget since the debt to the federal budget is normally larger than the one to the regional budgets (since according to the legislation, when paying taxes, enterprises have to clear previous debts first and then meet their current obligations). ${ }^{729}$

Such a system allowed some maneuvering, in the new economy, to enterprises which otherwise would have become bankrupt. This, in turn, explains the limited funding to implement the policies and maintain social infrastructure.

\footnotetext{
${ }^{728}$ Edwards \& Polonsky (2000): pp. 46-47

${ }^{729}$ Ibid.
} 


\section{Inability to Enforce the Law}

The third element of the state's capacity is the ability to enforce the law on its territory. Historically, Russia lacks the tradition of following the law. As noted by Alexander Radischev, a Russian Illuminist of the 18th century, "Russia's misfortune is that poor laws are being poorly enforced." ${ }^{, 730} \mathrm{~A}$ tradition of corruption and double morality in Russia also set limits to the development of law enforcement at the beginning of transformation. The legacy of "everything is possible if one really wants it" attitude, combined with the absence of many important democratic laws in the country, contributed to the extraordinary weakness of the Russian state to enforce its rules and regulations, collect taxes or prevent crime. This was exacerbated by the import of many foreign laws, a process done very quickly and poorly, which created what Berkowits, Pistor and Richard refer to as "unreceptive transplants.",731 They argue that "unreceptive transplantation," particularly when laws are poorly adapted to local conditions and institutions, involves little understanding and acceptance of the law by the public, leading to a poor familiarity with the law, and poor enforcement.

Furthermore, during the 1990 s, the capacity of the state to implement its policies was challenged by the growing independence, and in many cases outright noncompliance of the Russian regions. As discussed in the previous chapter, this noncompliance was expressed in passing legislation or adopting executive orders, in defiance of central state policy and the RF constitution. The central government lacked sufficient infrastructural power to ensure its authority extends across the country. The federal

\footnotetext{
${ }^{730}$ As quoted in Yudaeva et al (2003)

${ }^{731}$ Berkowits, Pistor \& Richard (2000) as quoted in Yudaeva et al (2003): p.35
} 
government also lacked strong coercive institutions capable of enforcing the rule of law. Kathryn Stoner-Weiss notes that the inability of the central state to ensure reliable regional government compliance to its policies and laws "is a result of both the constellation of political and economic forces that were created in the wake of the Soviet collapse, and the consolidation of these interests through Russia's early economic reform choices and compromises (in particular, the privatization program of 1992-1994 that included large and medium sized enterprises)., ${ }^{, 732}$ While these factors were discussed in detail in the previous chapter, it is worth mentioning here that the nexus of business and regional/local authorities seriously undermined the ability of the central state, not only to implement its policies, but also to enforce the law.

Inadequacies in the judicial system also contributed to a low enforcement of the law in the Russian regions. The Soviet legal practices and lack of new system experiences of the Russian lawyers resulted in their inability to prosecute defendants. The nexus between businesses, regional/local authorities and courts further prevented women from effectively protecting their legal rights in court, particularly when businesses were the defendants. Peter Solomon notes that despite the increased independence of courts in the 1990s, there have been a few obstacles to true independence, which include:

- dependence on the regional governments on judicial selection,

- regional governments' power of veto in the promotion of judges,

- failure of the federal government to deliver all the assigned funds to the courts and thus increased dependency on regional and local governments; and

${ }^{732}$ Stoner-Weiss (2003). 
- finally, a difficulty in assuring the implementation of judicial decisions. ${ }^{733}$

These factors significantly undermine the independence of courts in Russia, which

lack... both the power of the purse and the power of the sword...depend upon the cooperation of other government bodies... Patterns of this cooperation, or the lack thereof, depend in turn, less on the formal institutional arrangements, which are fragile in nascent post-authoritarian regimes. Rather, the structure of informal sanctions and incentives influences the extent to which bureaucrats are willing and capable of carrying out judicial decisions. ${ }^{734}$

Furthermore, these factors had important implications for the state's ability to enforce the everyday judgments of the courts. Yuri Chaika, a Russian Justice Minister, openly complained about the declining capacity to enforce judgments in the disputes between private litigants. ${ }^{735}$ This was also due to the fragmentation of resources devoted to law enforcement. As described by Stone-Weiss: "The infrastructural powers of the state were decentralized and, in some instances, privatized. In addition, some of the preexisting administrative mechanisms of implementation and enforcement were rendered irrelevant by the fundamental restructuring of the economic and political systems." ${ }^{736}$ The lack of resources resulted in a lack of basic equipment (e.g., computers, cars) in law enforcement structures, which in turn also created administrative inefficiencies. Similarly, the low pay of law enforcement officers made them vulnerable to bribes, in order to keep themselves above the poverty line. This was particularly prominent in the more remote regions, where the government had a lower capacity to closely monitor regional officials.

\footnotetext{
${ }^{733}$ Solomon (2002)

${ }^{734}$ Trochev (2005): p.5

${ }^{735}$ Chaika (2003) - translation by the author

${ }^{736}$ Stoner-Weiss (2003)
} 
The Russian state often lacked what Michael Mann called an infrastructural power of the state - the capacity to penetrate civil society and to implement policies throughout the realm. These factors contributed to the citizens' widely held perception that the courts are ineffective and corrupt, which in turn limited the desire to seek court decisions in cases such as illegal refusals to hire women, illegal firings etc. Public opinion surveys indicated a declining confidence in the court and law enforcement system. In 1994, two out of three Russians had very little or no confidence in courts (the New Russia Barometer). In 2000, the number had risen to $71.4 \%{ }^{737}$

Poor state capacity had important implications for both the implementation of family and child care policies, as well as female labour force participation. For instance, as seen in the next section of this chapter, poor law enforcement also compelled women to accept so-called "informal contracts" and not claim leave benefits, or avoid seeking legal protection in courts when illegally fired or refused benefits. The lack of financial resources to provide meaningful leave and child care benefits and allowances, combined with the incapacity to administer payments and maintain child care facilities, under conditions of poor law enforcement, had significantly undermined the intentions of neofamilialist policies. To be effective, the neofamilialist policies require a strong financial and tax system, powerful institutes of social insurance, and an ability of the system to provide a strong family (breadwinner) wage. Russia has a long way to go, in order to develop the conditions necessary to effectively implement such desired policies.

\footnotetext{
${ }^{737}$ Trochev (2005): p.11.
} 


\section{Soviet Legacies}

The individual decisions around employment, family and care were also shaped by a number of legacies from the Soviet period, such as the persistence of full employment and access to benefits through employment, a high rate of female education, along with traditional values and the absence of family wage. These factors can further help explain the mixed effects of the neofamilialist policies, such as the continually high rates of female labour force participation. These legacies also point to the fundamental difference of Russia from the conservative Western European countries that are the main ones developing a neo-familial model (with the exception of Finland, which began to develop a neofamilialist regime after the economic crisis of the 1990s and France, where again it was primarily as full employment came to an end that they began to experiment with neofamilial alternatives).

One of the most important differences is the legacy of full-time employment and entitlement to various social services and networks through work. This also reflects the fact that women had a great access to various supports and services in the Soviet welfare state. As illustrated in chapter 2, provision of employment enabling services for mothers is one of the highest among other countries, including the most developed ones. This has an important effect on how women think of working outside the home. Thus as previously noted, the Soviet legacies of nearly full employment (Table 42) continue to shape women's attitudes towards participation in the labour market.

Table 42. Female Labour Force Participation, 1970, 1979, 1989

\begin{tabular}{l|l|ll} 
Years & All & Age groups \\
\hline
\end{tabular}




\begin{tabular}{|l|l|l|l|l|l|l|l|l|}
\hline & women & $\mathbf{1 6 - 1 7}$ & $\mathbf{1 8 - 1 9}$ & $\mathbf{2 0 - 2 4}$ & $\mathbf{2 5 - 2 9}$ & $\mathbf{3 0 - 3 9}$ & $\mathbf{4 0 - 4 9}$ & $\mathbf{5 0 - 5 4}$ \\
\hline 1970 & 83.7 & 27.2 & 66.4 & 83.1 & 92.9 & 93.4 & 90.6 & 75.5 \\
\hline 1979 & 85.0 & 18.5 & 61.5 & 85.0 & 94.4 & 96.1 & 94.1 & 81.1 \\
\hline 1989 & 84.1 & 12.5 & 50.4 & 78.1 & 90.1 & 94.4 & 94.1 & 82.6 \\
\hline
\end{tabular}

Source: Working Women under the Conditions of Market Economy, Institute of Economics, Russian Academy of Science, Moscow 1993, Census materials

The importance of employment can also be explained by the legacy of entitlement to a number of programs through the workplace. Even though the state subsidies have been significantly scaled back and most enterprises were in the process of municipalisation of their social assets much of the Soviet legacy of workplaceentitlements remains. For instance,

[g]iven the low real monetary wages, and the fact that benefits are almost universal for all employees of an enterprise, a package of benefits can serve as an additional incentive for employees.

Despite the fact that during the transition period it became possible to obtain social benefit-type services in the market, low wages and general pauperization of the population kept the importance of benerits to employees high. ${ }^{738}$

These legacies contirye to influence individual decisions and policymaking in the regions by inertia, sunce in most cases the access to parental leave benefits and other services is

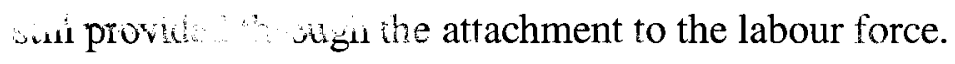

$$
\text { Th a next fact which helps explain Russian women's high commitment to paid }
$$

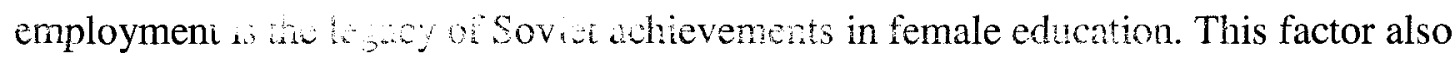
highlights the difference of the Russian case, compared to other countries that are in the process of building ncofamilialist regimes. Thus, according to the 1989 Census, $46.5 \%$ of working women had higher education or vocational training $(16.7 \%$ had higher education

${ }^{738}$ Teplova \& Woolley (2005) 
and $29.8 \%$ had vocational training). The proportion of men with higher education and vocational training constituted $34.2 \%$ (15.1\% and $19.1 \%$ respectively). This is an important factor, as studies indicate the positive relationship between the female educational level and attachment to the labour force. For instance, as revealed in the U.S. study "a mother's educational level is... associated with the probability that she will work during her first pregnancy... women with college degrees were much more likely to work during pregnancy (87 per cent) than were women with less than a high school diploma (29 per cent) or women who had just graduated high school (60 per cent).,"739

Furthermore, the legacy of traditional values defined Russia's particular response to the demographic and economic crisis and partly determined why Russia embarked on the neofamilialist path (at least ideologically and at the policy-level). Former Soviet leader Mikhail Gorbachev made headlines in 1987, when he said perestroika offered Soviet women what they really wanted - the chance to stay at home with their children. ${ }^{740}$ Yet, he was voicing sentiments shared by many Russian men. The 1994 World Values Survey data, cited by Heather Antecol, found that 76 per cent of Russian men agreed or strongly agreed that preschool children suffer if their mother is working, and 87 per cent agree that being a housewife is as fulfilling as working for pay. These were higher levels of agreement than in any other European country surveyed, or the U.S. and Canada. ${ }^{741}$ As discussed in chapter 3 , these various snapshots paint a consistent

\footnotetext{
${ }^{739}$ US Census Bureau (2001)

${ }^{740}$ UNICEF (1999)

${ }^{741}$ The sole exception is 77 per cent agreement in Hungary that preschool children suffer if their mother works for pay. By way of contrast, agreement for these statements in the US is less than 50 per cent for preschool children suffer and 45 per cent for being a housewife is as fulfilling. Source: Antecol (2003): p. 33
} 
picture of Russia being perhaps the most traditional of all of the developed European countries in terms of male attitudes towards gender roles. ${ }^{742}$ Traditional values shape the way in which both women and men make decisions about the distribution of labour in their households as well as some of the labour market responses (e.g., unwillingness to hire women).

Finally, the abolishing the family wage, as a means of stimulating female labour force participation by the Soviet government, also can be seen as a legacy, which influences individual decision-making around employment and care. In the transformation period this resulted in relatively low levels of individual/spousal incomes, which, combined with low (financial) levels of in-home caregiving allowances and leave provisions, limited women's (or men's) ability to care for their children at home. This explains the dominance of two-breadwinner families in the Russian demographic profiles. It also made the choice between "family" and "career" be practically very limited, due to the drastic fall in the standards of living and the necessity of basic survival. $^{743}$

Despite a decrease in employment and cuts in the public sector, one of the findings in this thesis has been that the women of Russia are used to working, and they continue working. Neofamilialist policy may attempt to push women into the homes, but a low generosity of neofamilialist policy provisions, the poor law enforcement, the hard reality of male unemployment, and low pay, mean that Russian women have to be able to

\footnotetext{
742 Teplova \& Woolley (2005)

${ }^{743}$ Gurgenko (2002)
} 
support both themselves and their family. These factors, combined with other legacies also contributed to the mixed effects of the neofamilialist policy package.

\section{Adaptation Strategies: Labour Markets, Households, Women}

There is a growing body of literature on Russia's non-traditional reaction to the transformation. ${ }^{744}$ These scholars note that most predictions made by the economists at the beginning of the transformation have failed, and most policies produced mixed outcomes. One of the explanations for such mixed outcomes is that Russian institutions used a variety of informal strategies, which allowed them to adapt to their new economic, social and political conditions, without formal restructuring. Similarly, this section argues that, in the area of social and child care policies, the actors on both "provision" and "receiving" sides employed a range of techniques and practices, which allowed them to adapt to the new conditions without significantly altering the existing social structures. Labour market practices included informal contracts, part-time and multiple employments; child care practices, in turn, included use of personal child care networks. This section hypothesizes that these strategies allowed women and labour markets to adapt to the new conditions in ways contradicting some of the predictions of the formal policy models.

\footnotetext{
${ }^{744}$ See Kapelushnikov (2001), Rimashevsakaya (2000)
} 


\section{Labour Market Adaptation Strategies}

\section{Informal Contracts ${ }^{745}$}

The Russian labour market has been characterized by a unique way of adapting to the economic and social changes. Kapelushnikov notes that this uniqueness was reflected in the flexibility of pay, as well as in labour duration and its intensiveness. ${ }^{746}$ This is reflected in the low level of official wages, high wage differentiation, widespread use of unpaid administrative leaves as well as part-time and multiple employments. These practices led to higher retention rates at the former state-owned enterprises, and low rates of official unemployment, particularly with high costs of releasing labour.

At the same time, the liberalized labour relations at the political and economic levels, and constraints by former regulations at the institutional level, led to the growth of unofficial relations in the labour market, through non-punishable violations of institutional norms and rules. As ILO noted,

presently we have a situation when practically all big companies and enterprises turned out to be involved in shadow relations. Thus, the main incentive for these unofficial relations is the drive of the decision-making managers, as well as bureaucrats, to provide and, if possible, to conceal their benefits and the ungrounded redistribution of resources, - independently on the efficiency of the decisions made. As a result, a growing inequality in resources distribution took place under economic decline, but not during growth. ${ }^{747}$

Such unofficial relations have a significant influence on women's position in the labour market. For example, in theory, pregnant women have iron-clad rights to keep their jobs

\footnotetext{
${ }^{745}$ Some part of this section are extensively based on the paper written jointly $(50 / 50)$ by Teplova \& Woolley (2005)

${ }^{746}$ Kapelushnikov (2001)

${ }^{747}$ ILO (2001)
} 
and to take leave if they wish. The Labour Code makes it very difficult to fire employees, particularly women. Article 261 of the 2002 Labour Code, entitled "Guarantees to pregnant women and women with children during the cancellation of a labour contract" provides the following:

Cancellation of the labor contract concluded with pregnant women by an employer is forbidden, except in the case of the liquidation of the enterprise. If the labor contract expires during a woman's pregnancy, the employer has to extend it until she is eligible for maternity leave. The cancellation of the labor contract of women with children younger than 3 years old, lone mothers with children younger than 14 years old (or, in case of disabled children - younger than 18 years old), other persons, [...] by an employer is forbidden. ${ }^{748}$

This job protection legislation is one of reasons why retention rates are rather high in public and privatized enterprises. While the reasons for a high retention rate of employees by the enterprises may vary, the high costs associated with releasing workers are a very important factor. A series of surveys done between 1996 and 1999 found that about 1/3 of all employers believed that it was cheaper to retain unnecessary workers rather than release them from the institution. ${ }^{749}$

Despite such rigid rules with respect to female employment, enterprises have found a number of ways to induce workers to quit, including forced unpaid leaves, wage arrears and deprivation of benefits. Often, newly recruited employees are offered fixedterm and short-term contracts, and even long-serving staff are transferred to a contract system for a limited duration, in order to avoid severance pay and legal obligations (e.g.,

\footnotetext{
${ }^{748}$ Labor Code (2002) - translation by the author

${ }^{749}$ Kapelushnikov (2001)
} 
protection for pregnant women, compulsory notice period) when the enterprises want to reduce their personnel. ${ }^{750}$

At the same time, institutions are reluctant to hire women. Almost one quarter of the employers with a declared preference for hiring men have listed the prohibitions on firing pregnant women as one factor that reduced women's attractiveness as employees (see Table 29). At the same time, once women become unemployed, it is harder for them to find new jobs. Among the women in the 2000 Russian Longitudinal Monitoring Survey who were unemployed at the time of the survey, over three quarters (76.7 per cent) had been unemployed for more than 3 months, compared to two-thirds (66.2 per cent) of men surveyed, suggesting that women have a harder time than men in finding work. The article by Nevinnaya in one of the central newspaper "I promise not to have children, in case of getting this job" also reported that, in some cases, women are asked to sign an informal agreement not to get married, much less have children.

To borrow a term from the taxation literature, the practice of newly privatized firms towards workers' rights has been more like "avoidance," that is, attempting to minimize provisions, while mostly staying within the law. The practice of the newly emerging private enterprises, however, is more like "evasion," using illegal means to get around providing benefits.

The most common evasion mechanism is the practice of "informal contracts," when employees (both men and women), in return for declining legally-stipulated social

${ }^{750}$ ILO (2001) 
benefits, are promised and paid "shadow" salaries much higher (numbers vary -from two to twenty times higher, depending on the enterprise) than the sums officially stated in the labor contract. The information about the wages and salaries is confidential, given its character when a person gets hired. However, quite often employees have only a very blurry idea of the amount of the compensation to be received evory month. ${ }^{751}$

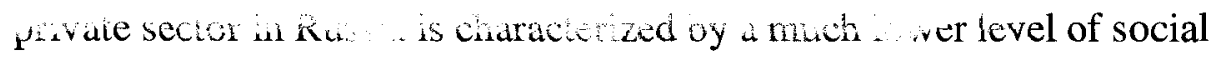
and gal protection for employos, particulaty women. Lacking the socid infrastructure Wh. 's in many cases available at public and privatized enterprises, private enterprises can provide benefits only through market channels, which leads to skyrocketing expenses. Thus, private enterprises are compelled either to offer a very high monetary compensation for labour, or provide social benefits comparable to the ones provided by the pubiic or (sometimes) privatized enterprises. In general, these enterprises tend not to offer social benefits, sometimes compensating employees through the form of higher wages, sometimes through informal cash payments or "shadow wages," as we will discuss further below. The research of the Institute of Economics RAS has revealed that $14.6 \%$ of the FSO enterprises and $32.4 \%$ of the private sector enterprises employed people without any formal agreements. Moreover, even with an official signing of a labour contract, about $50 \%$ of the private enterprises either did not specify the wage amount or declared an amount several times lower than the actual wage. ${ }^{752}$

\footnotetext{
${ }^{751}$ This discussion draws from an analytical report prepared by the Centre for Labour Market Studies (2000)

${ }^{752}$ Rimmashevskaya (2001)
} 
For newly-emerging firms without a ready-made social infrastructure (for example, an on-site child care facility) providing higher salaries is less costly than providing benefits. Yet one may ask why not pay high salaries legally, as part of the labour contract? The answer is twofold. First, the provisions of the labour contract cannot be less than those stipulated in the Labour Code (article 56 of the Labour Code of Russia, 2002) - this is why "informal contracts" emerged in the first place. A second explanation is the high level of payroll taxes, (that is, taxes on salaries paid by employers) which averaged 40 per cent prior to the reform of social benefit provisions in 2001 , and are still very high.

Although shadow wages and informal contracts are most common among new private enterprises, the scope of the shadow sector reaches 40 per cent of the Russian economy, according to a Ministry of Internal Affairs estimation. The official National Statistical Agency's estimates are much lower (25 per cent), but still significant. Kapelushnikov notes that even the largest private companies are engaged in this shadow economy. The CLMS data confirm that, in 1999, about 69 per cent of women admitted that they could not use their legal right for maternity leave. All this makes it rather difficult to estimate precisely the scope of the shadow economy and incidence of informal contracting, but we do know that it is substantial.

The significance of informal agreements and their impact on female employment cannot be underestimated. Within the general legislative framework around family created by the government, in conditions of poor law enforcement, the actual terms of 
employment were negotiated between employers and employees directly. ${ }^{753}$ Informal agreements often deprived employees of basic social guarantees (e.g., sick leaves, unemployment insurance), which result in a particularly poor bargaining position of working mothers, who remain the main users of maternity and child care leave provisions.

\section{Part-time and Multiple Employment}

The emergence of part-time and multiple employments can be seen as another labour market adaptation strategy. As illustrated in chapter 5, an increasing number of women engage in part-time employment during the transformation period. Part-time employment was seen by the state, enterprises, and workers as one way to overcome potential unemployment, when basically two employees could occupy one workplace. According to labour force surveys (LFS), part-time employment is not the choice of most workers, but a last resort for those who cannot find a full-time job. While women might prefer to work part-time for a certain period, in order to take care of small children, the present economic situation of their families does not allow many of them to do this, because they cannot afford the loss of income. A trend towards an increase in part-time employment is, however, clear. As already mentioned, administrative leave and shorttime work are widespread in many CIS countries.

This is significant, given the mandatory full-time employment inherited from the Soviet period. There are several factors to be emphasized here. The first is that part-time

${ }^{753}$ UNICEF (1999) 
employment was forced in many cases, particularly at the former-state owned enterprises in the manufacturing, light industry, construction, and chemical industries. Mandatory part-time employment was seen by enterprises as measure to retain workers and avoid massive lay-offs along with significant obligations for paying grievances (other similar strategies included unpaid and / or partially paid administrative leaves). Second, part-time employment can be seen as a hidden form of discrimination against women in Russia. Gurgenko argues that while part-time work gives women the flexibility to combine employment with family obligations, it was a forced choice for many women. Often, part-time employment, while seen as positive from the family perspective, hinders the professional growth of women. Those employed part-time become the first to go during the new dismissals and have the lowest levels of economic and social protection. As was illustrated in chapter 5 , women most often find themselves as victims of hidden unemployment.

The opposite side of the hidden unemployment is a growth of multiple employments, both formal and informal. Under the conditions of widespread economic and political instability, multiple employment becomes a way to maintain stable, (even low paid) jobs, with the hope for better times. It also allows avoiding the efforts for upgrading one's job qualifications. Most importantly, in case of forced unpaid leave, the loss of a salary is compensated through spare time for additional employment. Furthermore, as Gurgenko notes, women are often finding themselves working in the socalled "shadow" economic sector or finding informal jobs at formal sector enterprises, when these are "jobs obtained due to oral agreement, without registration of labour 
relations in written form and also work by independent contract and other civil law contracts." ${ }^{, 754}$ These are women in their $30-40$ s, who have secondary education or vocational training.

This form of employment, according to the official numbers, is becoming increasingly popular. Thus, according to the report Federal State Statistics Service, the official data suggest that

In 200412,7 million jobs (18\%) were classified as informal, including 11,9 million $(94 \%)$ referred to informal sector and 0.8 million informal jobs in the formal economy sector. In 2004 informal employment included $15 \%$ of main jobs and $87 \%$ of extra jobs. From 2001 until 2004 the number of informal jobs increased at 2,7 million or $27 \%$. This provided the general growth of employment in the Russian economy and reduction of formal jobs by 758 thousand people or $1,3 \%{ }^{755}$

The adjustment made by the additional survey demonstrated that "In 2003 the number of informal jobs reached 17,5 million, including 4,7 million main jobs and 0,9 million extra jobs. The adjusted data accounted 5.6 million (47\%) additional jobs in comparison with the results of employment survey."756

In light of this, the position of women becomes contradictory. On one hand, women's options for multiple employment are more limited than men's, due to family responsibilities, often narrow qualifications and limited access to some forms of activities (finances, banking etc). In addition, women tend to stay at the enterprises which continue offering social services and benefits. On the other hand, women effectively adapt to new conditions of employment, including less prestigious labour, by lowering expectations.

\footnotetext{
${ }^{754}$ Gurgenko (2002) - translation by the author

${ }^{755}$ Federal State Statistical Service of the Russian Federation (2005): p.2

${ }^{756}$ Ibid.
} 
This contradiction shows the interrelationships between the two trends in female employment: one is a drastic reduction of demand for female labour, shifting it from formal employment to either part time or informal, and self-employment, and the other, an increase of female economic activity, caused by a drastic fall in the incomes, economic situation and standard of living of many families in Russia. Female labour became an important reservoir of economic survival for families, but in order to realize their potential women face the necessity of working in unfavourable conditions, agreeing on various forms of inequality and discrimination. Furthermore, the somewhat limited success of the economic reforms led families to seek additional forms of economic activities:

While in Central and Eastern Europe though the role of wages and other incomes have increased, [in Russia and] Ukraine, it took form of naturalization of household economy, when a number of good and services started being produced/offered by the family. Such forced "decommodification" - a concept which under the new circumstances acquired a new negative meaning - means first of all change in the balance of paid and unpaid women's labour, drastic aggravation of economic and social status of women. ${ }^{757}$

The growth of underground, multiple and part-time employment illustrates the adaptation strategies utilized by both the Russian labour market and individuals, including women. For individuals, such strategies often were a matter of survival in the conditions of high inflation and minimal state guarantees. This can explain the slow restructuring of the Russian labour market and low official unemployment rates. It also adds additional clarity to how and why, despite the generous policy-level provisions of neofamilialist

${ }^{757}$ Gurgenko (2002): p. 211 - translation by the author 
policies, the shift in ideology towards female employment and the unwillingness of employers to hire women, women kept working in post-Soviet Russia.

\section{Child Care Adaptation Strategies}

Another set of factors which forms a part of the explanation for the mixed results of the neofamilialist policies is child care adaptation strategies, namely the use of family/ intergenerational networks for child care. The data analysis in chapter 5 indicated that nearly $50 \%$ of all children younger than 7 years of age were taken care of by the family members, either inside or outside of the household. In most cases, grandparents head the list of the relatives caring for a child. Even in the Soviet period, women in Russia and socialist countries often had close family ties with the older generation. This was due to a number of factors, including a historically high female labour force participation (which created the "double burden" faced by women, and made it convenient to have their parents reside in the same household), early eligibility for pension (55 and 60 years old for women and men respectively), and a housing shortage. ${ }^{758}$

The transformation period was marked by even increasing reliance on the older generation to care for their grandchildren. This apparently similar activity gained a completely different meaning: it increased the role of the family in providing care and added a factor of surviving in the new economic circumstances, considering low

\footnotetext{
${ }^{758}$ Swafford, Artamonova, and Gerassimova (2001): p.56. These authors elaborate on the housing shortage: "housing was administratively allocated by municipal governments and enterprises, rendered separate housing exceedingly rare for newly weds. Waits often to fifteen years were commonplace, as were situations in which one spouse was allocated housing by one employer, while the other was issued additional housing from another employer. Lack of housing per se tended to depress the number of households, while increasing their size and complexity markedly."
} 
provisions and allowances. In addition, the changing family structures in the transformation period, such as the increased rate of divorces and the increasing number of lone mothers, highlight the importance of intergenerational child care provision. For instance, there are a number of studies showing that divorced or otherwise unmarried mothers, in most circumstances turn to the help of the grandparents for child care. ${ }^{759}$

In addition to the challenges of obtaining a place in a public child care facility, other reasons for this increased reliance on family networks include increased distrust in the public care, due to the maternalist ideological framework, as well as no formal cost associated with using family members in the provision of care (which became a very important factor during the transformation period in the conditions of insufficient public child care spots and soaring prices for scarce private child care services). Finally, such increased reliance on intergenerational care also reflects the changing ideals of care in the society, when care provided by a family member (usually a grandmother) is seen as the second best to the one provided by the mother. For instance, given that many women have to go to work, the neofamilialist ideology and economic necessity (in the absence of viable market alternatives) made them to turn to family networks for child care as the one meeting the appropriate standards of quality, amount and form of care. In these cases, grandparental child care is seen as a form of intergenerational relation between grandparents and children, and grandparents and grandchildren, and often becomes a matter of personal preferences rather than economic reasons. Grandparental altruism here

\footnotetext{
${ }^{759}$ Balluseck, Hartmann et al. (1992); Cordon \& Soler (1998); Soler (1999)
} 
means that "children are not taken care of out of obligation, but for love." ${ }^{, 760}$ In these cases, even when public care is available, the decision is more about the choice of formal or informal child care provided by social or family networks. ${ }^{761}$

The cost factor also plays an important role in choosing child care. In Russia and other European countries, in contrast to the U.S., where it is common to pay relatives for child care because workfare laws allow for it, family network child care is far from being formalized and thus paid, which became an important factor in the condition of an impoverished population. This increasing reliance on families for provision of care, as well as other goods and services, illustrates that the state has shifted its responsibility to families. This also renders an explanation of how women with children of preschool age managed to combine motherhood and employment without the help of viable child care options in the post-Soviet Russia.

\section{Conclusion}

This chapter aimed to explore why the policies with neofamilialist goals had a relatively limited effect on female decisions about employment, care and children. It shows that the ultimate shape of the welfare state depends not only on the policy-making autonomy of the state, but also the capacity to implement those policies, as well as the responses provided by the actors in the civil society. The limited capacity of the Russian state to achieve its goals has influenced the actual effects of the neofamilialist policies. The low

\footnotetext{
${ }^{760}$ Roussel (1995): p.21

${ }^{761}$ See Larkin (1998); Puhn Pungello and Kurtz-Costes (2000); Brandon (2000); Hill (1989); Parish, Hao et al. (1991); Portugal (1995); Uttal (1999); Moss (2002); Wall (2003); Brandis (2003); Kivett (1991); Aldous (1995); Brandis (2003)
} 
ability to collect taxes, maintain effective control and ensure law enforcement in the regions, as well as the limited administrative infrastructure of the Russian state in the 1990s, has led in real terms to a decline in the welfare state provision, since these were the powers on which all welfare state models are founded.

This chapter contributes to the growing literature on comparative welfare states, and calls us to take into account not only policy-level provisions, but also to assess the interplay with socio-economic factors, such as dramatically declined standards of living and galloping inflation, along with the state's financial, administrative and law enforcement capacities. This chapter shows that an effective implementation of policies is impossible to achieve without cooperation at all the levels of bureaucracy, plus sufficient financial and law enforcement resources. The Soviet legacy of flexible institutions in Russia has negatively affected the local governments' and enterprises' willingness to cooperate, which, in the conditions of poor law enforcement and inability to create strong financial incentives, has led to the poor implementation of federal policies in the regions.

This chapter also showed that another set of factors, namely the adaptation strategies, has also affected the ultimate shape and nature of the welfare state in Russia. As discussed, one of the main features of the adaptation strategies in the Russian economy was the prevalence of informal rules - in the relations between the Centre and the regions, regional authorities and enterprises, employers and employees. The Russian economy is characterized by a variety of such informal rules, with previously formal institutions starting to function as informal, including labour markets and child care networks. Therefore, the informal side of the Russian economy has significantly 
influenced the ultimate shape of the welfare state model, since formal policies provide women with strong protection, while informal practices demonstrate a completely different reality. 


\section{Conclusion}

This thesis has sought to address the shift towards neofamilialism in the Russian welfare regime. With this purpose, it analyzed the elements of the Soviet and post-Soviet welfare states through the prism of child care arrangements in both regimes, such as child care services, maternity/parental leave provisions, as well as in-home caregiving, and other allowances. The specific objectives of this thesis were to understand the process and nature of changes in child care policies during the transformation period in Russia (1985 2000); to assess the scope and nature of the implications of this shift for the position of women in the labour market; to understand the factors influencing both changes and continuities in Russian child care policies, as well as picturing the ultimate policy effects.

The thesis also intended to advance a more nuanced account of social change in the region, and the dynamics of change within this particular social arena in two ways. First, this thesis aimed to challenge the rigid approaches of opposing "socialism" and "capitalism," and take into account the socialist institutional legacies inherited in the transformation period (such as the legacy of decentralization of authorities and enterprise-based service delivery), thus accounting for an element of path dependency in the process of transformation. Second, the multi-scale approach adopted in this thesis saw welfare states as layered institutions at the national, regional, local and enterprise levels, and analyzed their constant interaction and transformation over time. Utilization of this approach allowed us to obtain a deep understanding of the nature and scope of the process of change in child care policies during the transformation period in Russia; understand the dynamics of policy implementation and policy impacts at the local level, 
as well as account for specific institutional legacies, such as enterprise-based delivery of services and creation of local "power" centers.

In light of this, the unifying theme of this research concerned the need for a careful application of western theoretical frameworks to transition and developing countries, and highlighted the importance of institutions, ideas, historical legacies and various political and economic interests. The overall purpose was to illustrate a unique welfare system, which evolved as a result of complex interactions between deeply embedded patterns of traditional policymaking in Russia and neoliberal policies aimed at structural adjustment ${ }^{762}$ in the conditions of the demographic and perceived labour market crises.

\section{Paradigm Shift in Child Care}

In the past century, the Soviet/Russian welfare state took a journey with many twists and turns, exploring different paths in its policies to address the so-called "woman question," by balancing women's productive and reproductive functions. The subsequent policies were built on the preceding ones, and allowed women, in one way or the other, to combine employment and motherhood. These policy twists were supplemented with respective ideological shifts and various frames for child care policies, which placed an emphasis on the role of women as either workers or mothers, depending on the socioeconomic and political needs of the state.

${ }^{762}$ Dutkiewicz and Plekhanov (2004) 
Since the beginning of the transformation, child care and family policies in Russia have been marked by a variety of changes, from subtle to more dramatic ones. This thesis sought to develop a careful analysis of the process of change during the transformation period, since 'rupture' and 'continuity' are inadequate to the complexity of the situation at hand."763 This work illustrates that the process of change is taking place with "varying rates and temporalities." 764 While some phenomena are new to the regions, and represent a clear change (such as private child care and decline in public child care), most other phenomena represent some mixed forms of legacies and incremental changes (e.g., extension of maternity and parental leaves -at the policy level,- in-home care-giving allowances, or various other benefits and allowances for children and women). This type of change can be regarded more as continuities and serve as a clear sign of path dependency in certain areas in middle of drastic changes.

This thesis also illustrated that seemingly incremental policy changes may lead to a more transformative change. For instance, the first and the second-order changes (extension in leave schemes and in-home caregiving allowances) had a relatively incremental character, but served as a foundation of the broader change in the nature of welfare state, from the Soviet type to neofamilialist. These policy changes constituted not simply instrumental adjustments, they reflected a policy paradigm shift with regard to the role of women and thus child care. The paradigm shift involved led to the redefinition of the roles of the family, the state and the market, in the provision of care, and shifted responsibility for care provision from "the state" to "the family."

\footnotetext{
${ }^{763} \mathrm{Gal}$ and Kligman (2000): p.110

${ }^{764}$ Ibid.: p. 110
} 
Accordingly, the ideas about the "appropriate" role of women in society also changed, from those of being "mothers and/or workers" (depending on the needs of the state) to being predominantly seen as "mothers and wives." Chapter 3 specifically showed that the idea of offering women a "choice" to stay at home has become a critical concept in guiding the changes in child care policies. Women started being seen as a "reserve army" of part-time labour, but first of all as "producers" of children. This showed how ideas shape the new political factors, which in turn directly affect the development of welfare regimes. Thus, "the combination of pro-natalist and 'targeted' discourses of employment policies permitted the projection of an image of the mother at home who works only when she has time free from child care."765 While these changing ideas about the role of women in society were only partially accepted by women, whose majority remained in the labour force (for economic, ideological or professional reasons), they seemed to have contributed to the changing ideals of care among policymakers and society at-large, including women. The most popular and appropriate ideals of care included being 'full-time mother' and intergenerational care, which led to the actual process of refamilialization of care (despite high female labour force participation). Professional care ideal, which was relatively popular during the Soviet period, started quickly fading away at the beginning of the transformation period, partly as a result of dramatically declined quality of child care service in the early transformation period. Finally, the remaining two ideals of care were equally rare, but for different reasons. While the care ideal of a surrogate mother was considered as a viable option in terms of the quality and appropriateness of care (as the third best solution after full-time mother or

${ }^{765}$ Jenson and Sineau (2001a): p.112 
intergenerational care), the overall impoverishment of the population and underdeveloped market institutions/incentives for this form of care provision (e.g., there is no tax credit for child care expenses) made it relatively rare. The parental sharing of care ideal is the least popular in Russia due to the maternalist ideological framework and perception that care is predominantly a woman's business.

The paradigm shift was illustrated through Hall's three-level framework of institutional change. As such, the extension of parental leave and introduction of the inhome caregiving allowances represented incremental adjustments in the policy instruments inherited from the Soviet period (with nonetheless transformative potential) and thus served as the first- and second-order changes. Widespread and significant cutbacks in the provision of child care services, in turn, can be seen as a third-order change representing a drastic discontinuity with previous policies. The combination of these developments represents a significant ideological change in the Russian welfare state regime: from one, enabling employment of mothers, to another, promoting of a status of a temporary homemaker. Thus, while the state remained remotely committed to certain education standards for children, what has changed is the state's commitment to full-employment for all, particularly women.

Thus if the Soviet system was characterized by the relatively high degree of defamilialization in Esping-Andersen's terms, then the post-Soviet system is marked by the opposite process - refamilialization (expressed in a reduction of female economic independence, increase of the economic importance of men, and the re-emergence of families with one bread-winner). The changes in the broader political, and socio- 
economic needs of the state, led to the redefinition of the state goals with regard to women, which further were articulated in the changing instruments of the state - from those stimulating production and reproduction, to those mainly focused on reproduction. This points to the overall direction of the Russian welfare regime towards a unique form of 'neofamilialism.' The neofamilialist model emphasizes choice with a dual meaning: "choice between (temporary) homemaker status and paid employment; and choice among different forms of non-parental care. Each of these has significance for class, gender and racial-ethnic equality." ${ }^{, 766}$ The model reinforces the view that care-work is women's work, and consolidates the gender division of domestic labour.

What is unique about the emergence of the neofamilialist welfare regime in Russia is that it could embark on the path of becoming a US-type neoliberal regime under the pressures of external and internal forces, or pursue the path of deepening egalitarian norms, and become a version of "socio-democratic" regimes. Thus this shift represented a political compromise between new neoliberal forces and old institutions and interests. This thesis showed that the dominant political discourse in the 1990s, which aimed at adopting neoliberal ideas and structures, constructed new institutions such as free markets on top of old cultural norms and traditions associated with the socialist past, which cannot simply be wiped out and replaced by new ones. As Bunce notes,

Without a historically grounded and empirically detailed understanding of institutional context, we would be left with an empty argument that simply said that all of these leaders were pursuing their interests. And if we took institutions as simplistic behavior motivators, we would be unable to explain why pursuing interests in what appeared to be the

\footnotetext{
${ }^{766}$ Mahon (2000).
} 
same institutional context led to such different preferences and such different actions - and, significantly, with relatively similar payoffs. What constitutes rational behavior and what produces variations in payoffs, then, can only be determined by knowing a lot of less-thanobvious details - details that, of course, are subject to competing interpretations. $^{767}$

Thus, neoliberalism was successful largely to the extent that the new ideas were compatible with the inherited ones, resulting in a synthesis between the old and the new, which do not merely coexist with each other but blended in a unique way. Such a blend demonstrates a noticeable degree of path dependency, even during what appears to be a dramatic rupture in the welfare policies, leading to the emergence of the new welfare mix in contemporary Russia.

\section{Autonomy and Capacity of the State in Russia}

The Russian case allowed us to explore the dynamics of the welfare states in transition. Focusing on a single case provided a vehicle for fully contextualized problem definitions and allowed us to examine this particular national pattern in greater detail, with specific illustration of how and why the change took place. Specific attention paid to the policymaking process allowed obtaining an understanding of the processes and forces that influence the policy-making machinery in the Russian system.

This thesis illustrated the important distinction between the ability of the state to set independent goals (i.e., state autonomy) and its capacity to achieve them. ${ }^{768}$ The thesis showed that the policy logic which defined the nature of social provision and respective

\footnotetext{
${ }^{767}$ Bunce (1999)

${ }^{768}$ Skocpol (1985)
} 
roles of "the state" and "the family" has undergone a significant change, mainly as a result of complex interactions and debates within the Russian state. As illustrated in chapters 3 and 5, the transformation period was marked by increased advocacy of familial values, including opposition to female and especially maternal employment on the part of Russian policymakers. This in turn led to reduced support for public child care. We saw that the state actors were able to generate goals independently, not just in response to the demands of the World Bank, IMF and other external actors. These goals, in particular with regard to social and child care policies, were a result of complex interaction among various state institutions, such as the presidency, the insulation of Duma from the executive branch, Russian federalism, political parties, and prior policies and legacies, with interests and ideas supporting them:

The organizational arrangements of national states and political party systems influence the policy initiatives undertaken by politicians and officials. Acting in pursuit of their career interests, and engaged in conflicts or alliances with one another, political leaders try to use existing governmental or party organizations to devise and implement policies that will attract support from various social groups. Conforming to the needs and capacities of the organizations within which they must manoeuvre, officials and politicians often evolve distinctive policies that are not only responses to the demands of social groups. ${ }^{769}$

Hence, this thesis argued that, despite the growing number and influence of diverse interests, the domestic political institutions in practice determine the shape and design of social policies in Russia and presented a case for the relative autonomy of the state.

Relative autonomy in this case was considered as the ability of the state to set independent policy goals within the given economic, political and social constraints. A

${ }^{769}$ Skocpol (1992): p.527 
detailed analysis of interactions between the agencies of the state, including bureaucratic departments, political parties and regional governments and legislature helped increase our understanding of how policies are made.

In particular, it was noted that horizontally federal state agencies including bureaucratic departments, political parties and regional/local governments and legislatures, in many cases operate at cross-purposes and have divergent policy goals, objectives and instruments. For instance, the present thesis revealed the importance of historical interests within the state, including left-wing parties. As noted by Mark Cichkok,

The importance of the left as compared to the two other designations lies in its proximity to power. In contrast to the political right which stands no realistic chance of gaining either parliamentary or presidential power in the near future, or the centre where the so-called 'democrats' have not been certain what they wanted to do with the authority they held, the left has come close. A loose coalition of leftist parties holds a plurality of power in the Russian State Duma... it has achieved increasingly greater support in the federation Council... and finally it has managed to secure wins in presidential, gubernatorial and legislative elections in a number of Russia's republics and regions. ${ }^{770}$

Such proximity to power was also available to the so-called "socialist conservatives"/ economic networks at the beginning of the transformation; they shaped the privatization scheme, allowing the concentration of the most state assets in the hands of a few former state-enterprise managers, or members of the state networks. Chapter 4 showed that such proximity of the economic networks to power was a result of the blurred line between the state and economy inherited from the Soviet period. This lax boundary between the state and economic networks further led to what some scholars call a "chaotic social state,"

${ }^{770}$ Cichock (1999): p. 15 
where "the capitalism as economic system which supports capital accumulation has not been established. ... Personal networks, which have industrial, regional and bureaucratic basis determine economic activities to a greater degree that the market."771 These quasistate networks contributed to the shape of the welfare state, by resisting the restructuring of most social infrastructure.

Vertically, the cases of Novorossiysk and Sakha Yakutia illustrated that regional and municipal governments exercised significant autonomy from the federal level of government and played an important role in determining the shape of child care policies at the local level. As discussed in this thesis, such insulation of the local and regional governments from the federal centre was partly a result of the legacy of decentralization of authority, flexible institutions and the fusion between the state and economy. Increased empowerment of local and regional elites combined with apparent contradictions in the federal legislation regulating child care and imbalanced fiscal federalism defined the nature and degree of the involvement of local actors in shaping and administering child care policies in Russia.

Thus this thesis revealed that the Russian welfare mix has been a result of complex interactions among various players in the national political arena, guided by inertia and legacies from the previous periods, demographic crisis, new economic and labour market conditions, as well as traditional Russian values. We saw that reproduction and release of labour market tension were a priority and interest of the state players (even though for different reasons). Specifically, interest in reproduction of the Russian state

\footnotetext{
${ }^{771}$ Lain as quoted in Sharatan (2003)
} 
can be explained by the conditions of the "demographic crisis" in Russia, which stipulated the necessity to exercise relative autonomy of what is often referred to as a weak state. Thus, child care policies do not only reflect the power struggle among policy actors, but also the legacy of "statehood" and responsibility before nation.

At the same time, it was revealed that other non-state actors also had an effect on the nature of changes in child care policies. For instance, international organizations, such as the World Bank and the International Monetary Fund inspired the reform agenda of the Russian government, even though their advice was only patchily implemented. We learned that one of the main reasons of the limited success of international organizations was a lack of a coordinated assistance strategy and existence of the divergent policy orientations within the same institutions. Trade unions in turn, had a fluctuating impact on the development of child care policies in Russia. While labour activism has followed a downward curve over the 13 years since the beginning of the transformation, trade unions were nonetheless able to revamp themselves, and turned out to be one of the most powerful players on the Russian political arena during the development of the new Russian Labour Code, which contained important elements of child care policy. Finally, due to its limited history and development, the civil society in Russia had a low impact in this area. This was also due to the fact that most civil society activists focused their attention on human rights issues, as opposed to social policies.

Overall, while the limited impact of the external actors on the development of social/child care policies was mainly due to the lack of coordination as well as institutional arrangements, policy continuities and interests which protected them, these 
actors have made a contribution to how issues were framed and policies shaped. In this respect, a combination of both state-centred and power resource approaches allowed us to analyze the policymaking process with a significant degree of detail and depth, accounting for both intra-state interaction as well as interactions among other players on the Russian political arena. Such analysis provided a fuller understanding of how and why the changes in child care policies came into place in post-Soviet Russia.

Despite the ability of the Russian state to generate policy goals, its capacity to pursue these goals ultimately determines the shape and nature of child care provision in Russia. This thesis showed that complex interactions of policies with social, political and economic systems affected the ultimate policy outcomes, and fell short of achieving their policy objectives to the full extent. Thus the limitations of the state capacities in Russia were observed at all levels: financial restrictions, institutional and administrative vacuum, a lack of the rule of law, and poor law enforcement. These limitations resulted in low financial generosity of provisions, inability to defend basic rights in courts, along with often simple lacks of administrative systems of welfare provision. For instance, financial constraints of the Russian welfare state, resulted from the limited ability of the state to collect taxes and high inflation rates undermined the intent behind long parental leaves and in-home caregiving allowances, making level of provision very low. Low administrative and coercive capacity of the Russian state to enforce the rule of law in, under the conditions of widespread corruption, also contributed to the poor effectiveness of the neofamilialist policies in Russia. In other words, the specific shape of the Russian welfare mix can also be seen as unique product of the relative state autonomy to generate 
independent goals (e.g., in light of demographic and labour market pressures) and its limited capacity to achieve them (e.g., insufficient financial resources and poor law enforcement).

\section{Effects of Neofamilialist Policies}

In addition to the analysis of policymaking process, this thesis explored whether these policies were effective in achieving their outcomes, such as reduced female employment and increased number of childbirths. The quantitative analysis performed in chapter 5 revealed that, while there have been changes to the employment structure, most women were still attached to the labour force, the link between child care policies and female employment was weak, and the number of childbirths in the country was still low. While there has been a significant decline in the female employment in the post-Soviet Russia at the beginning of transformation, the female employment rate became relative stable in the later years of the 1990s.

This is not to say, however, that these policies had no impact. Quite the opposite, a number of married women did, in fact, stay home to care for their children. Moreover, many women indicated that they would stay home, if they had a chance. What was interesting and unexpected, though, is that a majority of women of childbearing age, even with small children, are still in the labour force, despite Russia's neofamilialist policies. This points to the fact that these child care policies had a relatively limited impact on female decisions concerning employment and childbirth. 
At the same time, data analysis revealed that there has indeed been a shift towards family provision of care. Thus the questions arose of why most women remained in the labour force despite policy incentives to the opposite with the simultaneous process of refamilialization of care. This research suggested that in addition to the limited state capacities and thus low monetary level of benefits, continuous employment of mothers could be explained by the difference of Russia from other countries which are building neofamilialist regimes. For instance, Russia inherited the legacy of nearly full female employment and access to benefits through employment, which became particularly important during the transformation period, under conditions of declining real wages and soaring prices for services and goods. Another factor is the utilization of various adaptation strategies by women, including part-time employment and informal contracts. Simultaneous familialization of care however could be explained by the increased reliance on intergenerational care, which was acceptable in terms of care ideals and economically expedient, due to low cost associated with this type of care. Thus these factors created limits and opportunities for child care policies to be devised and shaped in a way contributing to the uniqueness of the Russian welfare state. ${ }^{772}$

Nevertheless, it is difficult to evaluate policy changes and policy outcomes with respect to labour force participation, fertility growth and gender equality, because of several factors. First, some of the changes have a fluctuating and informal character (for example, the decline in the number of child care facilities) and therefore we may observe only some temporary effects. Second, the low generosity of benefits and allowances in

\footnotetext{
${ }^{772}$ The discussion on this page is along the lines with Theda Scokpol (1992): p 527
} 
real terms may be a temporary challenge, given the fact that the Russian state is no longer running a deficit. and has embarked on the path of economic growth. Finally, while some provisions generating gender inequalities were removed from the legislation, some new ones may arise (formal and informal - such as discrimination in the labour market through contracts).

As such, the real effects of these changes in child care policies and the direction and the precise model of the Russian welfare state are yet unclear and difficult to predict. It is hard to say whether this model will persevere or we are witnessing a temporary phenomenon which can be explained by the relatively short period elapsed since the beginning of the transformation. It is also unclear whether the Russian welfare state will crystallize into a full-fledged neofamilialist regime, or will more toward a more liberal/third way or egalitarian/social democratic model. Perhaps it will further evolve, maintaining a unique shape and a combination of welfare elements, specific to the context, history, tradition, socio-economic realities and Russian values.

What is clear, however, is that western theoretical frameworks need to be applied, when it comes to the countries in transition, with a great degree of caution and understanding of their realities. What is also clear to date is that the state policies with regard to women in post-Soviet Russia reinforce perception of women mainly as potential mothers and promote the image of a homemaker. Even though the impact of these policies on women's actual employment and childbearing choices is limited, the growing reliance on home-provided care not only exacerbates class differences among women, but 
also erodes support for public child care services. The displacement of "equality" by "choice" does not bode well for women's future status. ${ }^{773}$

\section{Contribution}

This work situates the Russian welfare state in the broader comparative welfare regime literature. While the existing typologies (Esping-Andersen; Mahon) of welfare state regimes serve as a solid foundation for the analysis of the Russian welfare state, this research demonstrated that a more nuanced approach is needed. This work contributed to our understanding of the process of welfare regime change. It helped to appreciate the complexities of the single-country case, pointing to the small-scale and large-scale variations in the values, ideas, discourse and representations embedded in the process of transportation of each welfare state. Child care has proved to be a useful lens to understand the scope and nature of welfare state transformation in Russia, as well as the impact of this transformation on families, and women in particular.

Overall, the analysis of the transformation of the Russian welfare state can offer several important lessons to other comparative welfare state research. In line with Lynne Haney's research on the Hungarian welfare state, this thesis has challenged the dichotomy between the "socialist past" and the "capitalist present," through providing a detailed account for the Soviet period as well as the changes and continuities in the postSoviet welfare regime. ${ }^{774}$ This work not only constructed a more accurate view of the

\footnotetext{
${ }^{773}$ Jenson and Sineau (2001b)

${ }^{774}$ Haney (2002)
} 
past, but aimed to develop a fuller understanding of the region's present and future, by accounting for some nuances in the development of the socialist institutions in different periods, as well as for the institutional legacies during the transformation period. This research advances the area of social politics and welfare state regimes, state theories, globalization and international relations, as well as comparative institutional analysis. The framework elaborated in this thesis creates a superior understanding of the challenges and opportunities faced by other countries in transition, during the process of welfare state transformation.

The present thesis further advances our understanding of the interaction between ideas, institutions and interests in the transition countries, adding to the literature on public policy-making in the transition context. It also makes a contribution to the larger transition literature, since it provides an analysis of various factors impeding the full transplantation of western policy frameworks, due to the specificity of the Russian context and needs. It enhances our comprehension of the process of policy transplantation, and advances the visibility of interplay between the various actors and institutional constraints influencing the process of such transplantation. By bringing such institutions in the analysis, we could see how they, even in the most rough sense, defined interests and shaped political powers in different locales of the Russian state, from the central to the regional and local levels.

Additionally, this work clarifies the manner in which paradigm shifts come about, and what factors influence such shifts. It contributes to the debate on the role of the state and non-state actors in bringing about the social change. While a number of studies of 
welfare regime transformation recognize the importance of various actors in affecting the regime change, the novelty of my approach lies in the investigation of the complex interaction among the state actors in the first place. It highlights the importance of a combination of the state-centred approach and power resource theory in providing the elements for analyzing the change in the societies with the legacies of the authoritarian statehood. This thesis provides insights on the autonomy of the state, and the factors challenging this autonomy. It also illustrates the difference between the state's autonomy to set independent policy goals and its capacity to achieve these goals.

Finally, this work contributes to the analysis of welfare states beyond the usual OECD countries. Many scholars have noted that the so-called countries in transition pose new challenges to welfare state research, including state autonomy, and other pre-existing models of social change. ${ }^{775}$ The changes taking place in the countries in transition create a number of controversies in the field of social sciences, pose puzzles and require further adaptations (or even modifications) of the pre-existing models of social change. This work allows us to address some of these challenges. Although the Russian case is unique in some senses, it helps us to increase our understanding of the challenges and opportunities faced by all the countries undergoing the transformation of their political, economic and ideological regimes. Moreover, since 1989, global trends are similarly affecting both East and West. This is why integrating the evidence from Russia as an example of the countries in transition with evidence from other regions adds complexity and nuance to the analysis of the factors influencing welfare state development. It also

${ }^{775} \mathrm{Gal}$ and Kligman (2000) 
broadens our understanding about the relationship of men and women to states and political processes.

\section{Generalizability}

The framework developed in this thesis can be useful for the analysis of the welfare state transformation in Russia, other countries in transition, as well as developed countries. The uniqueness of this framework is reflected in its comprehensive nature. It provides an opportunity not just to assess "how" and "why" policies are made (with specific attention to the role of ideas, interests and institutions), but also pays attention to the capacity of the state of implement these policies, and the tools for the assessment of the ultimate policy impact. In addition, this thesis adds another chapter to the history of child care and family policies in the former Soviet bloc by showing what happens in the post-Soviet period, using the example of one country.

Furthermore, this framework could be applied to a wide range of other policies, including education and healthcare; looking at the state as consisting of multiple actors can reveal the nuanced dynamics of internal interaction, both vertically and horizontally, and can shed a light on how policy choices are made within the state. Finally, applying the multiscale lens to the policy analysis allows us to trace the role of various policymaking actors on a global, national and local arena, which in turn will increase our understanding of the complex nature of policymaking in the "glocalized" world. 


\section{Future Research}

This thesis offers conclusions based on a single-country case-study. While offering important lessons and insights, these are still limited to the scope and confines of this study. There is a need for further comparative welfare state research, in order to develop wider generalizations. It would be interesting to compare the process of welfare regime transformation in Russia to other countries in the region, including former Soviet Union countries, along with other countries of the so-called former "Soviet bloc." In particular, it would be insightful to analyze the role of the state in the process of welfare regime transformation, as well as understand why some countries are more successful in adopting a neoliberal approach to social policies, while others, like Russia, embark on unique path of combining several approaches, and adopt neoliberal policies only to a certain extent. A comparative study of Russia, the Baltic States, Ukraine and other countries may shed some further light on this puzzle.

In addition, it would be interesting to further extend this work and apply the framework developed in this thesis to other policy areas in Russia, such as education, healthcare and pensions. It would also be insightful to compare how these policies evolved, and what factors influenced policy-development and implementation in other countries in transition. Finally, the extension of the analysis to the developed countries may further contribute to the development of comparative welfare state literature. 


\section{Bibliography}

Afontsev, S., Kessler, G., Markevich, A., Tyazhel'nikova, V. and Valetov, T. (2005), "Urban Households in Russia and the Soviet Union, 1900-2000. Size, Structure and Composition," Internationaal Instituut voor Sociale Geschiedenis. Available at www.iisg.nl/publications/respap44.pdf

Agarwal, B. (1997), "Bargaining and Gender Relations: Within and Beyond the Household," Feminist Economics 3(1).

Ahlander, A.S. (2001), Women and Women's Work in Transitional Russia. Impacts from the Soviet System. National Institute for Working Life, Ostersund, Sweden.

Aidukaite, J. (2004), The Emergence of the Post-Socialist Welfare State - the Case of the Baltic States: Estonia, Latvia and Lithuania. Stockholm: Sodertorns Hogskola University College.

All-Russia Scientific and Practical Conference (1999), "Family in Russia: Theory and Reality," Conference Materials, Tver', Moscow region, Russia, October 29-30.

Alshop, R. (2000), A Reversal of Fortunes? Women, Work and Change in East Germany. New York: Berghahn Books.

Amable, B., Barre R., and R. Boyer (1997), Les systèmes d'innovation à l'ère de la globalisation, Économica, Paris.

Anderson, C. (1978), “The Logic of Public Problems: Evaluation in Comparative Policy Research," in Ashford, D. ed., Comparing Public Policies. Beverly Hills: Sage.

Andreev, N. (1999), "Duma i Vlast'," [State Duma and Power] Rossiyskaya Gazeta. January 06, No 103

Antecol, H. (2003), "Why is there cross-country variation in female labor force participation rates? The role of male attitudes towards family and sex roles," Claremont College Working Paper number 2003-3.

Anttonen, A., Baldock, J. and J. Sipila (ed.), (2003), The Young, the Old and the State. Social Care Systems in five industrial Nations. Cheltenham, UK: Edward Elgar.

Appelbaum, E., Bailey, T., Berg, P., and A.L. Kalleberg (2002), "Shared Work, Valued Care: New Norms for Organizing Market Work and Unpaid Care Work," Paper prepared for Economic Policy Institute. Washington, D.C.

Archer, K., Gibbins, R. and L. Youngman (1998), Explorations: a navigator's guide to quantitative research in Canadian political science. Toronto: ITP Nelson.

Artyukhov, A. (2001), "Goals and priorities of the state family policies," Moscow State University. 
Ashwin, S. and E. Bower (1997), "Do Russian Women want to Work," in M. Buckley (ed.) Post-Soviet Women: from the Baltic to Central Asia. Cambridge: Cambridge University Press.

Aslanbeigui, N., Pressman, S. and G. Summerfield (1994), Women in the Age of Economic Transformation: Gender Impact of Reforms in Post-Socialist and Developing Countries. London \& New York: Routledge.

Aslund, A. (1995), Russian Economic Reform at Risk. London: Pinter Publishers.

Attwood, L. (1995), "The Post Soviet Women in the Move to the Market: a Return to Domesticity and Dependence?" in S. Bridger, K. Pinnick and R. Kay (eds.), No More Heroines? Russia, Women and the Market. Routledge.

Barry, D.D. (2002), Russian Politics. The Post-Soviet Phase. New York: Peter Lang Publishing, Inc.

Baskakova, M. (2004a), Gender Dynamics in the System of Education as a Factor in Decreasing Segregation in the Russian Labour Market. Moscow.

Baskakova, M.E. (ed.), (2004b), Gendernoe Neravenstvo v Sovremennoi Rossii skvoz, Prizmu Statistiki [Gender Inequality in Modern Russia through Statistics Prism translation]. Moscow: Editorial.

Benenson, H. (1991), "Patriarchal Constraints and Women Workers' Movements: The Lancashire Female Cotton Weavers, 1842-1919," Paper presented at the annual meeting of the American Sociological Association, 23 August, Cincinnati, OH.

Bergmann, B.R. (2000), "Subsidizing Childcare by Mothers at Home," Feminist Economics 6 (1).

Berkowitz, D., Pistor K., and J.-F. Richard (2000), "Economic Development, Legality, and the Transplant Effect," CID Working Paper No. 39.

Bernhardt, E. (2000), "Female Careers Between Employment and Children. Paper prepared for European Observatory on Family Matters," Sevilla, September 1516.

Bettio, F. and J. Plantenga (2004), "Comparing Care Regimes in Europe," Feminist Economics 10(1), pp. 85-113.

Blau, D. and L. Robins (1989), "Fertility, Employment and Child Care Cost," Demography 26(2).

Blau, F.D., and M.A. Ferber (1992), The Economics of Women, Men and Work. Englewood Cliffs, N.J: Prentice-Hall.

Blumstein, P. and P. Schwartz (1983), American Couples. New York: William Morrow. 
Bodrova, V. V. (1994), Economic Restructuring, New Social Policies and Working Women in Russia: Tendency and Behaviour. Moscow: Mimeo, VTsIOM.

Bodrova, V. V. (1995), "Work or Family: What is more Important for the Modern Woman?" Economic and Social Changes: Public Opinion Monitoring. Moscow: VTsIOM.

Brennan, D. (2003), “Balancing Work and Family: A Scandinavian Perspective," Review of Arnlaug Leira, Working Parents and the Welfare State: Family Change and Policy Reform in Scandinavia, Cambridge University Press, Cambridge, 2002. Available at www.australianreview.net/digest/2003/05/brennan.html

Bridger, S. and F. Pine (1998), Surviving Post-Socialism. Local Strategies and Regional Responses in Eastern Europe and the Former Soviet Union. London and New York: Routledge.

Bridger, S. and R. Kay (1996), "Gender/Generation in the New Labour Market," in H. Pilkington, (ed.), Gender, Generation and Identity in Contemporary Russia.

London, New York: Routledge.

Brown, D. (ed.), (1968), The Role and Status of Women in the Soviet Union. Columbia University, New York: Teachers College Press.

Brucan, S. (1998), Social Change in Russia and Eastern Europe. From Party Hacks to Nouveaux Riches. Westport, CT: Praeger Publishers.

Bruning, G., and J. Plantenga (1999), "Parental Leave and Equal Opportunities Experiences in Eight European Countries," Journal of European Social Policy 9, pp.195-209.

Bruno, M. (1998), "Playing the Co-operation Game: Strategies around International Aid in Post-Socialist Russia," in Bridger, S. and Surviving, F.P. (eds.) Post-Socialism: Local Strategies ad regional responses in Eastern Europe and the former Soviet Union. London: Routledge.

Buckley, M. (1992), Perestroika and Soviet Women. Cambridge: Cambridge University Press.

Bukowskiy, C. and R. Barnabas (1999), The Return of the Left in Post-communist States. Current Trends and Future Prospects. Cheltenham, UK: Edward Elgar Publishing Limited.

Bunce, V. (1981), Do New Leaders Make a Difference? Executive Succession and Public Policy under Capitalism and Socialism. Princeton: Princeton University Press.

Bunce, V. (1999a), “The Political Economy of Postsocialism," Slavic Review 4. 
Bunce, V. (1999b), Subversive Institutions: The Design and the Destruction of Socialism and the State. Cambridge: Cambridge University Press.

Campbell, J.L. (1998), "Institutional Analysis and the Role of Ideas in Political Economy," Theory and Society 27 (3).

Canales, P., Lo Manto, L.A. and S. Plekhanov (2004), "Russia: The Challenge of Change," Proceedings from the International Symposium held at Clendon College, York University, March 01, 2003 including essays written by members of the Russia Independent Study Committee.

Casper, S. (1999), "National Institutional Frameworks and High-Technology Innovation in Germany: The Case of Biotechnology," WZB Discussion Paper FS 199-306.

Castells, M. (1997), “The Power of Identity," The Information Age: Economy, Society and Culture. Vol.2. Oxford: Basil Blackwell.

Center for Labour Market Studies (2000), "Enhancing the Competitiveness of Women on the Russian Labour Market," Analytical report. Prepared with support of CIDA funded project Women and Labour Market Reform in Russia.

Center for Labour Market Studies. (2002), "Analysis of Implementation by the Russian Federation of UN Convention on Liquidation of all Forms of Discrimination against Women," Analytical report. Prepared with support of CIDA and Carleton University within the framework of the project Gender Strategies of Russia.

Central Committee of CPSU (1918), "Decree on Social Security."

Central Committee of CPSU (1931), "Decree on Social Insurance."

Central Committee of CPSU, The Council of the Ministers of USSR (1959), "O Merah po Dal'neishemu Razvitiu Detskih Doschkol'nih Uchregdenii, Uluchsheniu Vospitaniya i Medicinskogo Obslugivaniya Detei Doschkol'nogo Vozrasta," [Decree on Development of Preschool Institutions], No 558, 21/05.

Chaika, Y. (2003), Presentation on the Advisory Council for Minister of Russia, "Results for 2003 and Plans for 2004," December, 25.

Chandler, A. (2004), Shocking Mother Russia: Democratization, Social Rights and Pension Reform in Russia, 1991-2001. Toronto : University of Toronto Press.

Chandler, A. (2005), "Gender, Political Disclosure and Social Welfare in Russia: Three Case Studies," Paper prepared for the Annual Meeting of the Canadian Political Science Association.

Chinkin, C. (2001), "Gender and Globalization.” UN Chronicle. 
CIA World Factbook (2005), "Russia - Total Fertility Rate.” Available at www.indexmundi.com/g/g.aspx?c=rs\&v=31

Cichock, M.A. (1999), “The Russian Left in Transition,” in C. Bukowskiand and B. Racz (ed.), The Return of the Left in Post-Communist States. Cheltenham UK and Northampton, MA: Edward Edgar.

Clark, S.L. and D.R. Graham (1995), The Russian Federation's Fight for Survival. ORBIS 39 (3): p.337

Clements, B. E., Engel, B. A. and C. D. Worobec (1991), Russia's Women: Accommodation, Resistance, Transformation. Berkeley: University of California Press.

Collier, I., Roggemann, H., Scholz, O. and H.Tomann (1999), Welfare State in Transition. East and West. London: Macmillan Press 1td.

Commander, S. and M. Schankerman (1997), "Enterprise Restructuring and Social Benefits," European Bank for Reconstruction and Development, Working Paper No 22.

Connely, R. (1991), "The Importance of Child Care Costs to Women's Decision Making," in Blau, D. (ed.), The Economics of Child Care. New York.

Constitution of the USSR (1938).

Cook, L. (2002), "Institutional and Political Legacies of the Socialist Welfare State," in D. Lane (ed.), The Legacy of State Socialism and the Future of Transformation. Oxford: Rowman and Littlefield Publishers, Inc.

Cook, L. (2003), "State Capacity and Social Provision in the Russian Federation: The Case of Pensions," Research Paper Prepared for the Project: "Russian Governance: The Yeltsin Years," Institute of Law and Public Policy, Moscow.

Cook, L. J., Orenstein, M.A., and M. Rueschemeyer (1999), Left Parties and Social Policy in Postcommunist Europe. Boulder, Colo: Westview Press.

Corrigan, P.R. and D. Sayer (1991), The Great Arch: English State Formation as Cultural Revolution. Oxford and New York: Basil Blackwell.

Corrin, C. (1990), "The Situation of Women in Hungarian Society," in B. Deacon and J.Szalai (eds.), Social Policy in the New Eastern Europe: What Future for Socialist Welfare? Brookfield, Vt., USA : Avebury.

Council of Ministers of the USSR (1989), "Ob Uvelichenii Prodolgitelnosti Otpuskov Zhenzhinam Imeuschim Maloletnich Detey," ["Extension of Vacation for the Women with Children"], Resolution \# 677, 22/08 
Crouch, C and M. Keune (2005), "Rapid Change by Endogenous Actors: the Utility of Institutional Incongruence," in Streeck, W. and K. Thelen (eds), Continuity and Discontinuity in Institutional Analysis, Oxford University Press. Forthcoming.

Cuddy, M. and R. Gekker (2002), Institutional Change in Transition Economies. Hampshire, UK: Ashgate Publishing Limited.

Curry, J.L. and J.B.Urban (2003), The Left Transformed in Post-Communist Societies. The Cases of East-Central Europe, Russia, and Ukraine. Lanham: Rowman \& Littlefield Publishers, Inc.

Dale, K. (2000), "Gender and Economics: A European Perspective," Feminist Economics $6(2)$.

Daly, M. and J. Lewis (1998), Gender, Social Care and Welfare State Restructuring in Europe. Aldershot: Ashgate.

Daly, M. and J. Lewis (2000), "The Concept of Social Care and the Analysis of Contemporary Welfare States," British Journal of Sociology 51 (2), pp. 281-298.

Darmodekhin, (1998), "Concerning Condition and Perspectives of the State Family Policy," Moscow State University.

Davidova, N.M., Menning, N., Sidorina, T.U., Tikhonova, N.E., Shkaratan, O.I., and S.H. Smirnov (ed.), (2003), Gosudarstvennaya Social'naya Politika i Strategii Vigivaniya Domohoziastv [State Social Policy and Households' Survival Strategies - translation]. Gosudarstvennii Unversitet: Vishaya Schkola Economiki.

De La Porte, C. and B. Deacon (2004), "Social Policy Influence of EU and Other Global Actors: the Case of Lithuania," Policy Studies 25 (2).

Deacon, B. (1983), Social Policy and Socialism. The Struggle for Socialist Relations of Welfare. London: Pluto Press Limited.

Deacon, B. (2000), "Eastern European Welfare States: the Impact of the Politics of Globalization,” Journal of European Social Policy 10 (2).

Deacon, B., Hulse, M. and P. Stubbs (eds.), (1997), Global Social Politics: International Organizations and The Future of Welfare. London, Thousand Oaks, New Deli: Sage Publications.

Debardeleben, J. (1999), “Attitudes Towards Privatization in Russia," Europe-Asia Studies, 51(3): 447-465.

Demidenko, T.M. (1997), Changes of the Position of Women on the Labor Market in the 1980-90s. Moscow. 
Denisova, I., Kolenikov, S., and K. Yudaeva (2000), "Child Benefits and Child Poverty," Research Paper.

Derber, C., Ferroggiaro, K.M., Ortiz, J.A., Schwerner, C. and J.A. Vela-McConnel (1995), What's Left. Radical Politics in the Postcommunist Era. Amherst: University of Massachusetts Press.

Derluguian, G. M. (2001), "Recasting Russia," New Left Review (12), pp. 5-33.

Derluguian, G. M. and S. L. Greer (2000), "Questioning Geopolitics: Political Projects in a Changing World-System," Contributions in Economics and Economic History (216).

Diamond, L. and M.F. Plattner (1993), Capitalism, Socialism, and Democracy Revisited. London: The Johns Hopkins Press Ltd.

Dmitriev, M. (1998), "Social Reforms in Russia: Current Results and Future Perspectives", Obchestvennie Nauki i Sovremennost, pp.19-25.

Dobrowolsky, A and D. Saint-Martin (2002), "Agency, Actors and Change in a ChildFocused Future: Problematizing Path Dependency's Past and Statist Parameters," Working Paper No 3. Prepared for the Annual Meeting of the American Political Science Association, Boston, August.

Dodge, N.T. (1966), Women in the Soviet Economy. Their Role in Economic, Scientific, and Technical Development. Baltimore, Maryland, USA: The Johns Hopkins Press.

Doktorov, B. Z., Oslon, A. A., and E. S., Petrenko (2002), Epoha Eltcina: Mnenie Rossiyan. Sociologicheskie Otcherki [Yeltsin's Era: Opinions of Russians. Sociological Review], Moscow: Public Opinion Foundation's Institute.

Drum, R. E. (1977), "The Bolshevik Party and the Organization and Emancipation of Working Women, 1914 to 1921; or, A History of the Petrograd Experiment," Doctoral Dissertation. Columbia University.

Duki, A.V. (ed.), (2003), Vlast' i Eliti v Sovremennoi RossiilPower and Elites in Modern Russia]. Collection of Articles. St-Petersburg: Kovalevskiy's Sociological Society.

Dutkiewicz, P. and S. Plekhanov (2002), "The Politics of Mimicry: The Case of Eastern Europe," in A. Legault and J. Sokolosky (ed.). The Soldier and the State. December. Kingston, Queen's University: Quarterly Press. pp. 113-145.

Dutkiewicz, P. and V. Popov (2006), "Ahead or Behind: Lessons from Russia's Postcommunist Transformation," The Polish Association for the Club of Rome. Warsaw, Poland. 
Dutkiewicz, P., Geisler, M., and V. Suchan (2000), "Postcommunism and Globalization," in: Suchanek, K.I. (ed.), From Global Security to Transborder Initiative. Cambridge University, pp. 81-93.

Earle, J. (1999), "Privatization in Russia Offers Lessons for Others." Economic Reform Today: Privatization in the Digital Age. (2), Available at www.cipe.org/publications/fs/ert/e32/e32_08.htm

Edmonson, L. (ed.), (1992), Women and Society in Russia and Soviet Union. Cambridge: Cambridge University Press.

Edwards, V., Polonsky, G. and A. Polonsky (2000), The Russian Province after Communism: Enterprise Continuity and Change. New York: Mackmillan Press.

Einhorn, B. (1993), Cinderella Goes to Market: Citizenship, Gender and Women's Movement in East central Europe. London: Verso.

Eisenstadt, S. N. and S. Rokkan (eds.), (1973), Building States and Nations. Beverly Hills: Sage.

Elizarov, V. (2001), On Demographic Policy and Economic Family Support. Moscow State University.

Elizarov, V. Baskakova and Y. Neymatov (2002), Education in the $21^{\text {st }}$ Century: Trends and Forecast. Moscow: Algorithm.

Elizarov, V.V., Dganaeva, N.G, Zatonckih, N.A and E.H. Feoktistiva (1997), "Semeinaya Politika v SSSR i Rossii," ["Social Policies in USSR and Russina"], Domohozyastvo, Sem'ya i Semeinaya Politika. Moscow.

Ellman, M. (2000), "The Social Costs and Consequences of the Transformation Process," United Nations Economic Commission for Europe. Economic Analysis Division. Research Paper. Available at www.unece.org/ead/sem/sem2000/ellman.pdf

Engels, F. (1972), The Origin of the Family, Private Property and the Stale. New York: International.

England, P. and G. Farkas (1986), Households, Employment and Gender: A Social, Economic and Demographic View. New-York: Aldine.

England, P. and G. Farkas (1990), "Markets, Marriages and Other Mates: The Problem of Power," in R. Friedland and A. F. Robertson. (eds.), Beyond the Marketplace. Hawthorne, NY: Aldine de Gruyter.

Esping-Andersen, G. (1990), The Three Worlds of Welfare Capitalism. Princeton: Princeton University Press. 
Esping-Andersen, G. (1996), Welfare States in Transition. National Adaptations in Global Economies. London: Sage.

Esping-Andersen, G. (1999), Social Foundations of Post-industrial Economies. Oxford: Oxford University Press.

Esping-Andersen, G., Gallie, D., Hemerijck, A. and J. Myles (2001), “A New Welfare Architecture for Europe?" Report submitted to the Belgian presidency of the European Union.

European Commission (1998), "Care in Europe: Joint Report of the "Gender and Employment" and the Gender and Law," Group of Experts.

European Industrial Relations Observatory (2001), "Nordic Seminar Highlights Equal Opportunities from Men's Perspective," Available from Online article available at www.eiro.eurofound.eu.int

European Union (2001), Partnership and Cooperation Agreement. Russian Federation: Country Strategy Paper 2002-2006, National indicative program 2002-2003. Available at http://europa.eu.int/comm/external_relations/russia/csp/02-06_en.pdf

Evans, P., Rueschemeyer, D., and T. Skocpol (1985), Bringing the State Back In. Cambridge: Cambridge University Press.

Federal State Statistical Service of the Russian Federation (2005), "Informal Employment in Russia," Available at www.unece.org/stats/documents/2005/05/labour/wp.12.e.pdf

Federal State Statistics Service ${ }^{776}$ (1996), "The Main Demographic Characteristics of Families," Moscow.

Federal State Statistics Service (2000), "Men and Women in Russia in 2000," Moscow.

Federal State Statistics Service (2002), "The Demographic Yearbook of Russia," Statistical Handbook. Moscow.

Federal State Statistics Service of the Russian Federation (2005), “Informal Employment In Russia," prepared for UNECE/ILO/Eurostat Seminar on the Quality of Work, Geneva, May 11-13, Available at www.unece.org/stats/documents/2005/05/labour/wp.12.e.pdf

Fedorov, B. (1994), "Konets Vaucheram. Nachalo Privatizatsii," ["End of "Vauchers". Beginning of Privatization,”] Izvestiia, p. 123

Ferge, Z. (1979), A Society in the Making: Hungarian Social and Societal Policy 19451975. Baltimore: Penguin

\footnotetext{
${ }^{776}$ In 1996 Goskomstat of Russia was renamed to Federal State Statistics Service
} 
Ferge, Z. (2001), "Welfare and 'ill-fare' Systems in Central-Eastern Europe," in R. Sykes, B. Palier, and P. M. Prior (eds.), Globalization and European Welfare States: Challenges and Change. Basingstoke: Palgrave

Ferge, Z. and J.E. Kolberg (1992), Social Policy in a Changing Europe. Boulder: Wesview Press.

Ferrarini, T. (2003), "Paid Parental Leave and Poverty: Analyzing the Policy Outcome Link Among Families with Infants in Western Countries," Paper presented at RC 19 Annual Meetings, Toronto, August 21-24.

Foley, M. (1997), "Determinants of Unemployment Duration in Russia," Working Paper Number 81. Available at www.bus.umich.edu/KresgeLibrary/Collections/Workingpapers/wdi/wp81.pdf

Fraser, N. (1997), Justice Interruptus: Critical Reflections on the Post-Socialist Condition. Routledge.

Freeman, R. (1992), "Labour Market Institutions and Policies: Help or Hindrance to Economic Development?," Proceedings of the World Bank - Annual Conference on Development Economics.

Freinkamn, L.M., and I. Starodubrovskaya (1995), "Restructuring of Enterprise Social Assets in Russia: Trends, problems, Possible Solutions," World Bank. The initial draft of the paper was prepared for IIASA Conference, Vienna, February.

Gaidar, E.T. (1994), "Fashizm i Burocracy" ["Fascism and Bureaucracy"]. Segodnia 110 (15), p. 10

Gaidar, E.T. (1995), Besedi s Isbiratelyami [Conversations with Voters]. Moscow: Evraziya.

Gaidar, E. T. (1999), Dni Porazeniy I Pobed [Days of Defeats and Victories]. Moscow: Vagrius.

Gal, S. and G. Kligman (2000a), Reproducing Gender: Politics, Publics, and Everyday Life after Socialism. Princeton, New Jersey: Princeton University Press.

Gal, S. and G. Kligman (2000b), The Politics of Gender after Socialism. A Comparative -Historical Essay. Princeton: Princeton University Press.

Gauthier, A. (1996), The State and the Family: A Comparative Analysis of Family Policies in Industrialized Countries. Oxford: Clarendon.

Geiger, H. K. (1968), The Family in Soviet Russia. Harvard University Press.

Gel'man, V. (2000), "The Dictatorship of Law in Russia: Neither Dictatorship, Nor Rule of Law," ONARS Policy Memo No146. European University: St. Petersburg. 
Gel'man, V. and T. Hopf (ed.), (2003), Centr i Regional'nie Identichnosti v Rossii [Center and Regional Identities in Russia]. S-Peterburg: European University.

Gerard J. G. (2000), From Class to Commodity: Workers and Capitalist Industrialization in Vietnam, University of New South Wales.

Gill, G. (1998), Elites and leadership in Russian Politics. Selected Papers from the Fifth Congress on Central and east European Studies, Warsaw, 1995. London: Macmillan Press Ltd.

Glad, B. and E. Shiraev (1999), The Russian Transformation. Political, Sociological, and Psychological Aspects. New York: St. Martin's Press.

Gleb, A. and C. Greich (1995), Economical Transformation in Central and Eastern Europe. Moscow.

Glinski-Vasiliev, D. (2001), The Politics of Labour Code Reform in Putin's Russia. PONARS Policy Memo 197. IMEMO.

Goldman, W. (2002), Women at the Gates: Gender and Industry in Stalin's Russia. Cambridge, UK; New York, NY: Cambridge University Press.

Goldman, W. (1993), Women, the State, and Revolution: Soviet Family Policy and Social Life, 1917-1936. Cambridge; New York, New York, USA: Cambridge University Press.

Gornick, J., Meyers, M. and K. Ross (1997), "Supporting the Employment of Mothers: Policy Variation Across Fourteen Welfare States," Journal of European Social Policy (7)1.

Goskomstat of USSR. (1988), "Women in the USSR." Statistical Report. Moscow.

Goskomstat of Russia (1993), "Motherhood and Childhood in the Russian Federation in 1992," Moscow.

Goskomstat of Russia (1995), "Women of Russia", Statistical collection. Moscow

Goskomstat of Russia (2002), The Demographic Yearbook of Russia. Moscow

Gourevitch, P. (1986), Politics in Hard Times: Comparative Responses to International Economic Crises. Cornell University Press.

Goven, J. (2000), "New Parliament, Old Discourse? The Parental Leave Debate in Hungary," in S. Gal and G. Kligman (eds.), Reproducing Gender: Politics, Publics, and Everyday Life after Socialism. Princeton, New Jersey: Princeton University Press. 
Government of the Russian Federation (1992), "O Neotlognih Merah po Economicheskoi i Social'noi Zachite Sistemi Obrazovaniya," ["Regarding Urgent Measures in Economic and Social Protection of Education System"], Resolution No 312, May 13.

Government of the Russian Federation (1993), "On Financing of Objects of Social Infrastructure Transferred to Municipalities," Resolution of the Council of Ministers. Moscow.

Government of the Russian Federation (1994), Periodicheskii Doklad o Realisazii Rossiyskoi Federaciey Konvecii o Pravah Rebenka v 1993-1997 gg.

[Implementation in Russian Federation the Regulations of Convention for the Children Rights during 1993-1997. Status Report], Sem'ya v Rossii [Family in Russia]. Special Issue 4.97.

Government of the Russian Federation (1994), "Ob Utvergdenii Poryadka Naznacheniya

I Viplati Edinogo Egemecyachnogo Posobiya na Kagdogo Rebenka i

Egemesyachnogo Posobiya na Period Otpuska po Uhody za rebenkom do Dostigeniya im Vosrasta Polutora let," ["Rules for Monthly Child Benefits and In-home Caregiving Allownces until a Child Reaches 18 Months of Age"], Resolution No 133, February 20.

Government of the Russian Federation (1995), "Ob Utvrgdenii Tipovogo Pologeniya o Doshkol'nom Obrazovatel'nom Uchregdenii," ["Approval of Standard Bylaws for Preschool Insitutions"], Resolution No 677, 01/06.

Government of the Russian Federation (1995), "O Poryadke Naznacheniya i Viplati

Gosudarstvennih Posobii Gragdanam, Imeuchim Detei," [Decree on

Administartion of Child Benefits], Resolution No 883, September 04.

Government of the Russian Federation (1995), "Ob Untvergdeii Tipovogo Pologeniya o Doshkol'nom Obrazovatel'nom Uchregdenii," ["Approval of Standard Bylaw for the Preschool Educational Institution"], Resolution No 677, June 01, Moscow.

Government of the Russian Federation (1996), Osnovnie Napravleniya Gosudarstvennoi Social'noi Politiki po Uluchsheniu Pologeniya Detey v Rossiskoi Federacii do 2000 goda. Nacional'nii Plan Deistvii v Interesah Detei. [Main Directions of State Social Policy for Improvement of the Position of Children in the Russian Federation until 2000. National Action Plan]. Government Acts Collection. Moscow: Inergiya International Publishing House.

Government of the Russian Federation (1997), "Programma Social'nih Reform Rossiskoi Rederacii na 1996-2000 godi," ["Program of Social Reforms in the Russian Federation for 1996 - 2000"], No 222, February 26. 
Government of the USSR (1949a), "O Merah po Rasschireniu Seti Detskih Uchregdenii i Rodil'nih Domov" ["Measures to Expand the Development of Preschool Institutions and Maternity Houses"], Federal Law No 2004, 18/05.

Government of the USSR (1949b), Resolution No 2004, May 18, 1949.

Government of USSR (1956), "O dal'neishih Merah Pomochi Zhenchinam-Materiam, Rabotauchim na Predpriyatii i b Uchregdeniyah," ["Measures of Additional Support for Employed Mothers"], Federal Law No 1414, 13/10.

Government of USSR (1956). Resolution No 1414, October 13.

Government of the USSR (1973), "Ob Utvergdenii Osnov Zakonodatel'stva Souza SSR i Souznih Respublik o Narodnom Obrazovanii," ["Concerning the Approval of the Public Education Law"], Federal Law, 19/07.

Government of the USSR (1990), "O Vnesenii Izmenenii i Dopolneni v nekotorie Zakonodatel'nie Acti SSSR po Voprosam, Kasauchimsya Genchin, Sem'i I Detstva," ["Changes in the USSR Legislation Concerning Women and Children"], Federal Law No 1501-1, May 22, Moscow.

Gowan, P. (2002) "New Left Review," Available at www.newleftreview.net/NLR25801.shtml

Grachev, L. (1996), "Legal Guarantees and Social Benefits for Women with Children," Social Provision. 2/96.

Grishutina, I. N. (2002), “Ispol'zovanie Zhenskogo Truda v Sovremennoi Ekonomike Rossii", ["Labour of Women in Modern Economy of Russia"], PhD Thesis, Russian Academy of Science, Saratov.

Grogan, L. (2000), “Worker Flows in Russia. Tinbergen Institute,” Discussion Paper, TI $08 / 3$.

Grogan, L. (2002), "What Caused the Post-Transition Fertility Decline in Central and Easter Europe and the Former Soviet Union?" Department of Economics, University of Guelph.

Grogan, L. and G.J. Van den Berg (1999), “The Duration of Unemployment in Russia," Available at www.tinbergen.nl/discussionpapers/99011.pdf

Grogan, L. and J. Horrocks (2005), "Abortion and Contraceptive Use in Russia," Available at www.economics.uoguelph.ca/lgrogan/abocontr.JH.pdf

Grzymala-Busse, A. and P. J. Luong (2002), "Reconceptualizing the State: Lessons from Post-Communism," Politics \& Society, Vol. 30 No 4. December. 
Gurgenko, T. (2002), "Modern Ukraine: Family as a Resource of Social Transformation," in E. Mezentzeva. (ed.), Gender and Economics: International Experience and Analysis of Russian Practices. Moscow: Russian Panorama.

Gusov, K. (2003), Commentary to the 2002 Labour Code of the Russian Federation. Moscow: Prospect.

Hakim, C. (1987), "Trends in the Flexible Workforce," Employment Gazette. November, pp. 549-560.

Hakimian, H. and Z. Moshaver (2001), The State and Global Change. The Political Economy of Transition in the Middle East and North America. Richmond, Surrey: Curzon Press.

Hall, P.A. (1986), Governing the Economy. The Politics of State Intervention in Britain and France. Oxford, UK: Polity Press.

Hall, P.A. (ed.) (1989) The Political Power of Economic Ideas: Keynesianism Across Nations. Princeton, NJ: Princeton University Press.

Hall, P.A. (1993), "Policy Paradigms, Social Learning, and the State: the Case of Economic Policymaking in Britain," Comparative Politics 25 (3): pp. 275-296.

Hall, P.A., and D. Soskice (2001), Varieties of Capitalism. The Institutional Foundations of Comparative Advantage. Oxford: Oxford University Press.

Haney, L. (2002), Inventing the Needy: Gender and the Politics of Welfare in Hungary. London: University of California Press.

Hanf, K. and F.W. Scharpf (1978), Inter-organizational Policy Making. Limits to Coordination and Central Control. London: SAGE Publications.

Harwin, J. (1996), Children of the Russian State, 1917-95. Brookfield, USA: Avebury.

Hayden, C.E. (1973), "Feminism and Bolshevism: The Zhenodel and the Politics of Women's Emancipation in Russia, 1917-1930," Doctoral Dissertation, University of California, Berkley.

Heinen, J. (2002), "Ideology, Economics, and the Politics of Childcare in Poland before and after the Transition," in R. Mahon and S. Michel. (eds.), Child Care at the Crossroads: Gender and Welfare State Restructuring. Routledge.

Heinen, J. and H. M. De Koenigswarter (2001), "Framing Citizenship in France and Finland in the 1990s: Restructuring Motherhood, Work, and Care," Social Politics. Summer 2001. Oxford University Press.

Heitlinger, A. (1979), Women and State Socialism: Sex Inequality in the Soviet Union and Czechoslovakia. London: Macmillan. 
Heleniak, T. (2005), "The Causes and Consequences of Fertility Decline in the former Soviet Union and Central and Eastern Europe," Paper presented at the conference "Health and Demography in the States of the Former Soviet Union," Harvard University, April 29-30. Available at www.wcfia.harvard.edu/conferences/demography/papers/Heleniak.pdf

Heper, M., Kazancigil, A. and B.A. Rockman (1997), Institutions and Democratic Statecraft. Boulder, CO: Westview Press.

Hine, D. and H. Kassim (1998), Beyond the Market. The EU and National Policy. New York: Routledge.

Hobson, B. (1990), “No Exit, No Voice: Women's Economic Dependency and the Welfare State," Acta Sociologica (33), pp. 235-50.

Hollander, D. (1997), "In Post-Soviet Russia, Fertility Is on the Decline; Marriage and Childbearing Are Occurring Earlier," Family Planning Perspectives. March.

Holmes, L. (1997), Post-Communism. An Introduction. Durham, North Carolina, USA: Duke University Press.

Huber, E. and J. Stephens (2001), Development and Crisis of the Welfare State: Parties and Policies in Global Markets. Chicago and London: University of Chicago Press.

Huskey, E. (1999), Presidential Power in Russia. Armonk, N.Y.: M.E. Sharpe.

Ignatieva, U. (2003), "V Moskve Vozrozdaetsya Moda na Detey," ["The Popularity of Having Children is Growing in Moscow"] Izvestia. July 17.

International Labour Organization (1991), "Labour Market Transitions in Eastern Europeand the USSR," Special Issue of International Labour Review, 130 (2). Geneva.

International Labour Organization (1995), "World Employment Report 1995/96," Available at www.ilo.org/public/english/employment/strat/wer1995.htm

International Labour Organization (1999), "Employment and Labour Market Policies in Transition Economies," Geneva.

International Labour Organization (2001), "ILO Strategic Objectives," Available at: http://www.ilo.ru/other/acts2k01.htm\#sobj

International Labour Organization (2002), "Russian Federation: Unemployed, the working poor and social consequences," Paper Prepared by Moscow office of ILO, Gruat, J.V., Ivanova, E., Misikhina, S., Ovcharova, L., and Tchetvernina, T. Available at www.ilo.ru/publications/files/SPb0501E.pdf 
International Labour Organization (2002), "The Social Dimension of Globalization," ILO Roundtable Materials. Available at www.ilo.ru/publications/files/04_3EN.pdf

International Labour Organization (2003), "Social Protection. A Life Cycle Continuum Investment for Social Justice, Poverty Reduction and Sustainable Development," by Bonilla García, A., and J.V. Gruat, Geneva, November. Available at www.ilo.org/public/english/protection/download/lifecycl/lifecycle.pdf

International Labour Organization (2004a), "A National Roundtable Calls for a Fair Globalization for the Russian Federation," ILO News Release, September 13, Available at www.ilo.ru/news/200409/001.htm

International Labour Organization (2004b), "The Social Dimension of Globalization: a Review of the Literature," by Gunter, B.G., and R. Van der Hoeven., Working Paper No. 24, Geneva, June.

International Labour Organization (2005), "A Fair Globalization - Creating Opportunities for All," Report of the World Commission on the Social Dimension of Globalization, Available at www.ilo.org/public/english/fairglobalization/report/index.htm

International Monetary Fund (1993a), "Alternative Social Security Systems in CIS Countries," by Ahmad, S.A., and J. Schneider, Publication No WP/93/8-EA

International Monetary Fund (1993b), "Poverty, Demographic Characteristics, and Public Policy in CIS Countries," by Ahmad, S.A., Publication No WP/93/9-EA

International Monetary Fund (1995a), "Prospects and Challenges in our Globalized World Economy," by Camdessus, M., Presented at the Wharton School of the University of Pennsylvania, Philadelphia, April 04.

International Monetary Fund (1995b), "Russia's Transformation Efforts at a Turning Point," by Camdessus, M., Presented at a Conference of the U.S.-Russia Business Council, Washington, D.C., March 29.

International Monetary Fund (1995c), "Supporting Transition in Central and Eastern Europe. An Assessment and Lessons from the IMF's Five Years' Experience," by Camdessus, M., Presented at Second Annual Francisco Fernández Ordóñez, Madrid, December 21.

International Monetary Fund (1996a), "Health and Education Expenditures in Russia, the Baltic States, and the Other Countries of the Former Soviet Union," by Horton, M., Publication No WP/96/126-EA. 
International Monetary Fund (1996b), "Russia: Stabilization and Reform Address," by Camdessus, M., Presented at the U.S.-Russia Business Council, Washington, D.C., April 01.

International Monetary Fund (1996c), "The International Monetary Fund: Increasing Economic Opportunities and Meeting the Challenges in the Global Economy," by Camdessus, M., Presented at Mid-America Committee Chicago, Illinois, April 11.

International Monetary Fund (1997), "Legal and Institutional Obstacles to Growth and Business in Russia," by Buckberg, E., November 01.

International Monetary Fund (1998a), "Memorandum of the Government of the Russian Federation and the Central Bank of the Russian Federation on Economic and Financial Stabilization Policies to IMF," July 16.

International Monetary Fund (1998b), "Memorandum of the Government of the Russian Federation and the Central Bank of the Russian Federation on Economic and Financial Stabilization Policies," July 16.

International Monetary Fund (1998c), "On Russia," Press Briefing by Stanley Fischer, First Deputy Managing Director, IMF Headquarters, Washington, D.C., July 13

International Monetary Fund (1998d), "Russia and the IMF: Meeting the Challenges of an Emerging Market and Transition Economy," by Camdessus, M., Presented at the U.S.-Russia Business Council, Washington, D.C., April 01.

International Monetary Fund (1998e), "The IMF Responds on Russia," a Letter to the Editor by Odling-Smee, J., November 30.

International Monetary Fund (1999), "Achievements and Prospects after Ten Years of Transition," by Camdessus, M., Presented at the Warsaw School of Economics, Warsaw, Poland, December 10.

International Monetary Fund (1999), "Tax Reform in the Baltics, Russia, and Other Countries of the Former Soviet Union" by Ebrill, L., and O. Havrylshyn, August 30 .

International Monetary Fund (2000a), "Russian Economic Policy at the Start of the New Administration," by Stanley Fischer, Prepared for the conference on "Investment Climate and Russia's Economic Strategy", State University: Higher School of Economics, Moscow, April 06.

International Monetary Fund (2000b), “Transition Economies: An IMF Perspective on Progress and Prospects," Report, November 03.

Ispa, J. (1994), Child Care in Russia: In Transition. Bergin \& Garvey: Westport. 
Jalu iX, V. (1994), "Reasons for Anti-Feminist Views in Central and Eastern Europe and Ways of Changing Them," Keynote Speech. International Workshop on National Machinery to Promote Equality between Women and Men in central and East European Countries Establishing, Implementing, and Making Use of National Machinery to Promote Equality. Ljubljana.

Janos, A. C. (1986), Politics and Paradigms: Changing Theories of Change in Social Science. Stanford: Stanford University Press.

Jenson, J. (2003), “Child Care Policy Conference," Final Report, Canadian Policy Research Networks, Available at www.cprn.org/docs/family/ccp_e.pdf

Jenson, J. (2005), "From one Policy Paradigm to Another? The Place of Children in the Welfare State Reform in Canada and Britain," Paper presented at the Wellchi Network Conference 1 "Challenges and Opportunities Faced by European Welfare States: The Changing Context for Child Welfare," Oxford, August 7-8.

Jenson, J. and M. Sineau (2001a), "Comparing Childcare Programs: Commonalities Amid Variety and Citizenship in the Era of Welfare State Redesign," in J. Jenson and M. Sineau. (eds.), Who Cares? Women's Work, Childcare and Welfare State Redesign. University of Toronto Press.

Jenson, J. and M. Sineau (2001b), Who Cares? Women's Work, Childcare and Welfare State Redesign. University of Toronto Press.

Joukovskaya, N. (2001), “The Developmental State in Russia?,” Research essay submitted in partial fulfillment of the requirements for the degree of Master of Arts. Ottawa: Carleton University.

Kammerman, S. and A. J. Kahn (1991a), Child Care, Parental Leave and the Under 3s: Policy Innovation in Europe. New York: Auburn House.

Kammerman, S. and A.J. Kahn (1991b), "Government Expenditures for Children and Their Families in Advanced Industrialized Countries, 1960-1985," Innocenti Occasional Papers: Economic. Policy Series No. 20.

Kapelushnikov, R. I. (2001), Russian Labour Market: Adaptation without Restructuring. Moscow: Higher School of Economics.

Kapustin, B.G. (2001), "Postkommunism kak Postsovremennost', Rossiskiy Variant," [Postmodern Postcommunism. Russian Case] Polis - Politicheskie Issledovaniya. May.

Karelova, G.N. (1998), “Osnovnie Napravleniya i Tendencii Semeinoi Politiki v Rossii na Federal'nom, Regional'nom i Mestnom Urovne," ["Major Trends and Tendencies of Family Policy in Russia at the Federal, Regional and Municipal Levels"], Conference Materials, Family in the Process of Development. December, Moscow. 
Katz, K. (2002), Labour in Transition: Women and Men in Taganrog, Russia. Department of Economics. University of Stockholm.

Kharchev, A.G., and S.I. Golod (1968), "Molodezh i brak," ["Youth and Marriage"], Chelovek $i$ obshchestvo, No 6.

Khotkina, Z. (1994), "Women in the Labour Market: Yesterday, Today and Tomorrow," in Women in Russia. A New Era in Russian Feminism, ed. A.Posadskaya. Moscow: Verso.

Khoury, P. and J. Kostiner (1990), Tribes and State Formation in the Middle East. London: I. B. Tauris and Co.

Kligman, G. (1998), The Politics of Duplicity: Controlling Fertility in Ceausescu's Romania. Berkeley: University of California Press.

Klimenkova, T. (1994), "What Does Our New Democracy Offer Society?" in Posadskaya, A. (ed.), Women in Russia. A New Era in Russian Feminism. Moscow: Verso.

Klugman, J., and A. Kolev (2001), "The Welfare Repercussions of Single-Parenthood in Russia in Transition" in Klugman, J., and Motivans, A.(eds.), Single Parents and Child Welfare in the New Russia. Unicef: Florence, Italy.

Klugman, J., and A. McAuley (2001), "Social Policy for Single-Parent Families: Russia in Transition," in Klugman, J., and Motivans, A. (eds.), Single Parents and Child Welfare in the New Russia. Unicef: Florence, Italy.

Kochubei, Z.K. (2003), "Rol' Gosudarstva v Oblasti Demograficheskoi Politiki," [The Role of the State in Demographic Policies"], PhD Thesis. Moscow.

Kohli, A. (1986), The State and Development in the Third World. Princeton, NJ: Princeton University Press.

Kollontai, A. (1921), "Tezisy o Kommunisticheskoi Morali v Obtasti Brachnykh Otnoshenii," ["Communists' Morale in Marriage"], Kommunistka, 12-13.

Kollontai, A. (1922), "Position of Women in the Economic Evolution," Lectures for Sverdlov University. Moscow: State Publishing.

Kollontai, A. (1975), The Autobiography of a Sexually Emancipated Communist Woman. New York: Schocken Books.

Kollontai, A. (1980), Socialism, Feminism, and the Bolshevik Revolution. Stanford, CA, USA: Stanford University Press.

Kornai, J. (1996), "Paying the Bill for Goulash-Communism," Available at http://ideas.repec.org/p/fth/harver/1748.html 
Korpi, W. \& Palme, J. (2003), "New Politics and Class Politics in the Context of Austerity and Globalization: Welfare State Regress in 18 Countries, 1975-95." American Political Science Review, 97 (3), 425-446.

Kostelecky, T. (2002), Political Parties after Communism. Developments in East-Central Europe. Washington, D.C.: Woodrow Wilson Center Press.

Kozina, I. (2005), "The Development of the Former State Functions of the Trade Union," Paper Prepared for INTAS Workshop April 14-16.

KPMG. (2004), "Russia Tax Overview," Available at www.kpmg.ru/russian/supl/library/taxlegal/Tax\%200verview.pdf

Krasner, S. D. (1978), Defending the National Interest: Raw Materials Investments and U.S. Foreign Policy. Princeton: Princeton University Press.

Krasner, S. D. (1988), “Sovereignty - an Institutional Perspective," Comparative Political Studies 21 (1).

Krasnov, V.N. (1995), Sistema Mnogopartiinosti v Sovremennoi Rossii. [Multipartite System in the Modern Russia]. Moskva: AO RAU-Corporaciya.

Kremer, M. (2002), "The Illusion of Free Choice: Ideals of Care and Child Care Policy in the Flemish and Dutch Welfare States" in S. Michel and R. Mahon (eds.), Introduction to Child Care at the Crossroads: Gender and Welfare State Restructuring. Routledge.

Kremer, M. (2005), How Welfare States Care: Culture, Gender and Citizenship in Europe, Proefschrift Universiteit Utrecht. Available at http://igiturarchive.library.uu.nl/dissertations/2005-1116-200003/index.htm

Kuhn, T. (1970), The Structure of Scientific Revolutions. $2^{\text {nd }}$ ed. Chicago: University of Chicago Press.

Kurganov, I.A. (1967), Sem'ia v SSSR. New York.

Labour Code of RSFSR (1922).

Labour Code of the Russian Federation (1993).

Labour Code of the Russian Federation (2002).

Labour Code of USSR (1971).

Lane, D. and D. Cameron (1999), The Transition from Communism to Capitalism. Ruling Elites from Gorbachev to Yeltsin. New York: St. Martin's Press.

Lapidus, G. W. (1978), Women in Soviet Society: Equality, Development, and Social Change. Berkeley: University of California Press. 
Lapidus, G. W. (ed.) (1982), Women, Work and Family in the Soviet Union. New York: M.E. Sharpe, Inc.

Lapusta, M.G., and P.S. Nikolskiy (2002), Modern Financial and Credit Dictionary, M.:INFRA-M.

Leftwich, A. (1995), "Bringing Politics Back In: Towards a Model of Developmental State," Journal of Developmental Studies 31(3), pp. 400-427.

Legault, A. and J. Sokolsky (2002), "The Soldier and the State in the Post Cold War Era," Political issue of Queen's Quarterly.

Lehmann, H. and J. Wadsworth (2000), "Tenures That Shook the World: Worker Turnover in Russia, Poland, and Britain," Journal of Comparative Economics, 28 (4), pp. 639-664.

Leibowitz, A., Klerman, J., and L.Waithe (1992), "Employment of New Mothers and Child Care Choise: Difference by Children's Age", Journal of Human Resourses, 22(11), pp.112-33.

Leira, A. (1992), Welfare States and Working Mothers: The Scandinavian Experience. New York: Cambridge University Press.

Leira, A. (1998), "Caring as a Social Right: Cash for Child Care and Daddy Leave," Social Politics 5: 362-79.

Leira, A. (2002), Working Parents and the Welfare State: Family Change and Policy Reform in Scandinavia. Cambridge: Cambridge University Press.

Lenin, V. I. (1934), The Emancipation of Women. New York.

Lenin, V. I. (1970), The State and Revolution, Selected Works, Vol. 2. Moscow: Progress Publishing.

Levin, B.M. and M.V. Petrovich (1984), Economicheskaya Funkciya Sem'i. [Economic Function of the Family]. Moscow: Financi i Statistika.

Lewis, J. (1992), "Gender and the Development of Welfare Regimes.” Journal of European Social Policy 3, pp.159-73

Lewis, J. (1998), Gender, Social Care and Welfare State Restructuring in Europe. Aldershot: Ashgate.

Liberal Democratic Party of Russia (2000), “LDPR Program 2000,” Available at www.ldpr.ru/azbuka_women.html

Liborakina, M. (1999), "Zhenchini i Privatizaciya," ["Privatization and Women"], Moscow: "Institut Economiki Goroda" Foundation.

Lipsmeyer, C.S. (2000), "Reading Between the Lines: Politics and Policy Structure in Post-Communist Europe," Europe-Asia Studies 52 (7), pp. 1191-1211. 
Lissyutkina, L. (1993), "Soviet Women at the Crossroads of Perestroika," in Gender Politics and Post-communism: Reflections from Eastern Europe and the Frmer Soviet Union. N. Funk and M. Mueller (eds.). Routledge.

Lo Manto, L.A. and S. Plekhanov (2004), "Russia: The Challenge of Changes," Proceedings from the International Symposium held at Glendon College, York University, March 01, 2003 including essays written by members of the Russia Independent Study Committee. Toronto: University of Toronto Press.

Lobodzinska, B. (1995), Family, Women and Employment in Central Eastern Europe. Westport, CT/London: Greenwood Press.

Lopes, A. (2003), "Social Protection Systems in South Europe, Familialism and Care for the Elderly: a Discussion on Concepts and Methods Using some Evidence from the ECHP," Available at www.eiss.be/workshop2003/WYR2003paperLopes.htm

Lukyanova, A. (2003), "Transition to PostIndustrial Society?: A Study of the Service Sector Employment in Russia" Economics Education and Research Consortium Working Paper No 03/09.

Luong, P.J. (2002), Institutional Change and Political Continuity in Post-Soviet Central Asia. Power, Perceptions, and Pacts. Cambridge: Cambridge University Press.

Mace, D. and V. Mace (1963), The Soviet Family. London, UK: Hutchinson \& Co.

Madison, B. (1968), Social Welfare in the Soviet Union. Stanford: Stanford University Press.

Mahon, R. (2002a), “Child Care: Toward What Kind of Social Europe?" Social Politics: International Studies in Gender, State, and Society 9 (3).

Mahon, R. (2002b), "Gender and Welfare State Restructuring: Through the Lens of Child Care," in S. Michel and R. Mahon (eds.), Introduction to Child Care at the Crossroads: Gender and Welfare State Restructuring. Routledge.

Mahon. R. (2003), "Yet Another R? The Redesign and Rescaling of Welfare Regimes", Paper Prepared for 2003 Workshop of the ISA Research Committee 19, University of Toronto, August 21-24.

Mahon. R. (2005a), "Rescaling Social Reproduction: Childcare in Toronto/Canada and Stockholm/Sweden," International Journal of Urban and Regional Research, 29(2).

Mahon, R. (2005b), "The OECD and the Reconciliation Agenda: Competing Blueprints." The paper was presented at the conference Challenges and Opportunities Faced by European Welfare States: The Changing Context for Child Welfare, St. Anne's College, University of Oxford, Oxford, UK. 
Mahon, R., and R. Johnson (2003), "NAFTA, the Redesign and Rescaling of Canada's Welfare State," Research Paper, School of Public Policy and Administration, Carleton University.

Mahoney, J. (2000), "Path Dependency in Historical Sociology," Theory and Society 29 (4).

Malinova, O.Y. (1998), "Liberalizm v Politicheskom Spectre Rossii. Na Priemere Partii "Demokraticheskii vibor Rossii" i obchestvcennogo Ob'edeneniya "Yabloko". ["Liberalism in Russia. Using the Example of the Party "Democratic Choice of Russia" and Public Movement"Yabloko"]. Online Research Paper Accessible at www.yabloko.ru/koi/Publ/Liber/olga.html

Malisheva, M.M. (ed.) (2002), "Economics and Social Politics: Gender Measurement," Lectures Materials. Moscow: Academia.

Malloy, M. (2003), “Avoiding Problems in Russia: Some Legal Pointers for a Tough Market" Gowlings, Available at: http://www.gowlings.com/resources/publications.asp?pubid=933

Mandel, D. (2001), Why is there No Revolt? The Russian Working Class and Labour Movement, in L. Panitch and C. Leys (eds), Socialist Register Socialist Register 2001: Working Classes, Global Relaities. London: Merlin.

Mandel, W. M. (1975), Soviet Women. New York: Anchor Press.

Mann, M. (1988), States, War and Capitalism. New York: Basil Blackwell.

Mann, M. (1993), The Sources of Social of Social Power: vol. 11: The rise of classes and nation-states, New York: Cambridge University Press, p. 59.

Manning, P. (2000), "Gender and social policy: Comparing Welfare States in central and Easter Europe and Post Soviet Union," Journal of European Social Policy.

March, L. (2003), “The Pragmatic Radicalism of Russia's Communists,” in Leftwich J.C. and Urban J.B. (ed.), The Left Transformed in Post-Communist Societies. Rowman and Littlefield Publishers, Inc.

Marshall, T.H. (1963), “Citizenship and Social Class,” in Heinemann. (ed.),_Sociology at the Crossroads. London: Heinemann.

Mashika, T.A. (1989), Zaniatost' Zhenshin I Materinstvo. [Women' Employment and Motherhood]. Moscow: Misl' Publishing.

Matthews, M. (1986), Poverty in Soviet Union. Cambridge: Cambridge University Press.

Mayntz, R. and F.W. Scharpf (1975), Policy-Making in the German Federal Bureaucracy. New York: Elsevier. 
McFoul, M. (1999), "The Political Economy of Social Policy Reform in Russia," in Cook, L., Ornstein, M. and Rueschemeyer, M. (eds), Left Parties and Social Policy in Post-Communist Europe. Boulder Colorado: Westview Press. p. 211.

McKinney, J. R. (2004), “Lone Mothers in Russia: Soviet and Post-Soviet Policy," Feminist Economics 10 (2), pp.37-60.

Mezentseva, E. (1993), “Gosudarstvennoe Regulirovanie Zanyatosti Genchin v Usloviyah Perehoda k Rinochnoi Economike," ["State Regulation of Women' Employment in Transition to Market Economy"]. PhD Thesis. Russian Academy of Science. Moscow.

Mezentseva, E. (1994), "Equal Opportunities or Protectionist Measures? The Choice Facing Women," in Women in Russia. A New Era in Russian Feminism, Posadskaya, A. (ed.) Moscow: Verso.

Michel, S. (1999), Children's Interests/Mothers'Rights: The Shaping of America's Child Care Policy. Yale University Press.

Michel, S. and R. Mahon (2002), Introduction to Child Care at the Crossroads: Gender and Welfare State Restructuring. Routledge.

Ministry of Education of the Russian Federation (1993), "O Federal'nom Expertnom Sovete po Obchemu obrazovaniy Ministerstva Rossiiskoi Federacii," ["On Federal Expert Council on Public Education”], Order No 444, October 22.

Ministry of Education of the Russian Federation (1996), "Pologenie o Poryadke Attestacii I Gosudarstvennoi Akkreditacii Obrazovatel'nih Uchregdenii," ["Attestation and Accreditation of Educational Institutions"], Order No 27, January 25, Moscow.

Ministry of Education of the Russian Federation (1998), "O Statuse Obrazovatel'nih Uchregdenii," ["Status of Educational Institutions"], Information Letter No 30, June 08, Moscow.

Ministry of Education of the Russian Federation (1999), "O Raz'yasnenii inspekcionnoContral'noi Deyatel'nosti v Sisteme Obrazovaniya," ["On Clarifying Inspectioncontrolling Activities it the System of Education"], Federal Template of Bylaws on Controlling Inspections in the Subject of the Russian Federation", Order No 473, October, Moscow.

Ministry of Education of the Russian Federation (2000), "O Razrabotke Federal'noi Programmi po Orazovaniu," ["Development of Federal Program of Education"], Order No 51, April 10. Moscow.

Ministry of Labor and Social Development of the Russian Federation (2000), "Regional'nii Opit Naznacheniya i Viplati Gosudarstvennih Posobii Gragdanam 
Imeuchim Detei," ["Regional Practice of Administration of Child Benefits"], Documents Developed by the Experts of Child Benefits Pilot Project. Moscow: Prosvechenie.

Ministry of Labor and Social Development of the Russian Federation (2001), "Doklad o Sostoyanii i Tendenciyah Demograficheskogo Razvitiya Rossiyskoi Federacii," ["Status and Trends in Demographic Development of the Russian Federation"]. Report. Moscow: Human Rights Publishing.

Ministry of Labor and Social Development of the Russian Federation (2003a), "Pologenii Detei v Rossiyskoi Federacii," ["Children in the Russian Federation"], The State Report. Moscow.

Ministry of Labor and Social Development of the Russian Federation (2003b), "Novaya Model' Naznacheniya i Viplati Gosudarstvennih Posobii Gragdanam, Imeuchim Detei" ["A New Model for Administering of Child Benefits"]. Documents Developed by the Experts of Child Benefits Pilot Project. Moscow.

Ministry of Social Protection of the Russian Federation (1996), "Osnovnie Napravleniya Stanovleniya i Razvitiya Uchregdenii Social'nogo Obslugivaniya Sem'i i Detei," ["Main Trends in Development of Services for Families and Children"], Social'naya Pomosch' Sem'e i Detyam [Social Assistance for Families and Children]. Collection of the Document. Issue No 2.

Ministry of Social Protection of the Russian Federation (1996), "Osnovnie Social'nie Garantii Sem' yam, Imeuchim Detey." ["Main Social Guaranties to Families with Children"]. Social'naya Pomosch'Sem'e i Detyam. [Social Assistance for Families and Children]. Collection of the Document. Issue No 3.

Ministry of Social Protection of the Russian Federation (1996), "Social Assistance to Families and Children," Release 3: "Main Guarantees to Families with Children".

Mishra, R. (1999), Globalization and the Welfare State. Cheltenham, UK: Edward Elgar Publishing.

Moore, B. (1965), Soviet Politics - The Dilemma of Power. The Role of Ideas in Social Change. New York: Harper \& Rowe Publishers.

Morgan, K. (2002), "Does Anyone Have a "Libre Choix"? Subversive Liberalism and the Politics of French Child Care Policy" in Michel S. and R. Mahon (eds.), Introduction to Child Care at the Crossroads: Gender and Welfare State Restructuring. Routledge.

Moscow News (2005), "More Abortions than Births in Russia", August 23. Article available at www.mosnews.com/news/2005/08/23/abortionproblems.shtml

Moss, P. and Deven, F.F. (1999), Parental Leave: Progress or Pitfall? The Hague/Brussels: NIDI: CBGS Publications. 
Motivans, A. and Klugman, J. (2001), Single Parents and Child Welfare in the New Russia. Palgrave: London.

Mroz, T., Henderson, L., Bontch-Osmolovsii, M. and B.M. Popkin (2003), "Monitoring Economic Conditions in the Russian Federation: The Russia Longitudinal Monitoring Survey 1992-2002," Report Submitted to the U.S. Agency for International Development. Carolina Population Center, University of North Carolina at Chapel Hill, North Carolina.

Myles, J. and P. Pierson (1997), "Friedman's Revenge: The Reform of Liberal Welfare States in Canada and the United States," Politics and Society 25(4): pp. 443-472.

Myles, J. and P. Pierson (2001), "The Comparative Political Economy of Pension Reform," in Pierson, P. (ed.), The New Politics of the Welfare State. Oxford: Oxford University Press.

Myrdal, G. (1957), Economic Theory and Under-Developed Regions. London: Gerald Duckworth \& Co. Ltd.

Nelson, L.D. and I.Y. Kuzes (1995), "Privatization and the New Business Class," in Lane, D. (ed.) Russia in Transition: Politics, privatization and inequality. London and New York: Longman.

Nevinnaya, I. (1998), "Postupaya na Rabotu Obyazaus' ne Rogat"” [Promise not to Give a Birth in Case of Employment"]. Rossiiskaia gazeta.

Nordlinger, E. (1981), On the_Autonomy of the Democratic State. Cambridge, Massachusetts: Harvard University Press.

Norsworthy, L.A. (2002), “Assisting Russia's Transition: an Unprecedented Challenge,” Publication of World Bank Operation Evaluation Department: Presis, Summer 2002, No 225.

North, D.C. and B. Weingast (1979), "Constitutions and Commitment: The Evolution of Institutions Governing Public Choice in Seventeenth-Century England," The Journal of Economic History 49: pp. 803-33.

Nosyk, T. (2004), "Conflicting Elite Interests Hamper Reform Progress in Ukraine." Research Essay, Carleton University, Institute of European and Russian Studies.

Novorossiysk City Administration (2006), Pasport Municipal'nogo Obrazovaniya g. Novorossiysk [Passport of Novorossiysk Municipality], Available at www.nvis.ru/adm/modules.php? name=Content $\&$ pa $=$ showpage $\&$ pid=3

O'Connor, J. \& Prym, R. (1988), "Public Welfare Expenditure in OECD Countries: Towards Reconciliation of Inconsistent Findings," British Journal of Sociology 39 (1), pp. 47-69. 
O'Connor, J., Shaver, S., and A.S. Orloff (1999), States, Market, Families: Gender, Liberalism and Social Policy in Australia, Canada, Great Britain and the United States. Cambridge: Cambridge University Press.

OECD (1990), "Child Care in OECD Countries,” Employment Outlook.

OECD (2001), "Starting Strong: Early Childhood Education and Care," Paris, OECD.

Offe, C. (1984), "Contradiction of the Welfare State," in Keane, J. (ed.), Cambridge, Massachusetts, USA: The MIT Press.

Orloff, A.S. (1993a), "Gender and the Social Rights of Citizenship: The Comparative Analysis of Gender Relations and Welfare States," American Sociological Review $58(3)$.

Orloff, A.S. (1993b), The Politics of Pensions: A Comparative Analysis of Britain, Canada and the United States, 1880s-1930s. Madison, Wisconsin: University of Wisconsin Press.

Osborn, R. (1970), Soviet Social Policies, Illinois: Dorsey Press.

Pal, L.A. (1986), "Relative Autonomy Revisited: The Origins of Canadian Unemployment Insurance," Canadian Journal of Political Science. XIX:1. March.

Pal, L. A. (1988), State, Class, and Bureaucracy: Canadian Unemployment Insurance and Public Policy. Kingston and Montreal: McGill-Queen's University Press.

Pal, L.A. (1993), Interests of State. The Politics of Language, Multiculturalism, and Feminism in Canada. McGill-Queen's University Press.

Pal, L. A. (2005a), Beyond Policy Analysis: Public Issue Management in Turbulent Times. Canada: Nelson.

Pal, L. A. (2005b), "Case Study Method and Policy Analysis," in Iris Geva-May (ed), Thinking Like a Policy Analyst: A Clinical Approach to Policy Analysis. New York: Palgrave Macmillian.

Pal, L.A. and R. K. Weaver (2003), The Government Taken Away. The Politics of Pain in the United States and Canada. Washington, D.C.: Georgetown University Press.

Palier, B. (2003), "Analysing the Relationships Between Globalization, European Integration and Welfare State Changes." Global Social Policy 3.

Palier, B. (2005), “Ambiguous Agreement, Cumulative Change: French Social Policy in the 1990s" in W. Streeck and K. Thelen (ed.), Beyond Continuity: Institutional Change in Advanced Political Economies. Oxford, UK: Oxford University Press. 
Panitch, L. and D. Swartz (1994), The Assault on Trade Union Freedoms: From Wage Controls to Social Contract, 3rd ed. Aurora, Ontario: Garamond Press.

Pascal, G. and M. Manning. (2000), "Gender and Social Policy: Comparing Welfare States in Central and Easter Europe and Post Soviet Union," Journal of European Social Policy 10 (3).

Peck, J. (2002), "Political Economies of Scale: Fast Policy, Interscalar Relations, and Neoliberal Workfare," Economic Geography, July, Available at www.findarticles.com/p/articles/mi_qa3660/is_200207/ai_n9121445 38

Peng, I. (2002), "Social Care in Crisis: Gender, Demography, and Welfare State Restructuring in Japan," Social Politics: International Studies in Gender, State, and Society 9 (3).

Peng, I. (2003), "Explaining the 1990 Social Care Expansion in Japan: The New Politics of Welfare State," unpublished manuscript for ISA RC19 Conference, University of Toronto, Canada, August 21-24.

Peoples' Commissar Council of the RSFSR (1918), "Pologenie o Social'nom Obespechenii Trudyachihsya," [Concerning Provision of Social Assistance to the Workers"], Decree 31/10.

Peters, B.G., and B.A. Rockman (1996), Agenda for Excellence 2. Administering the State. Chatham, NJ: Chatham House Publishers, Inc.

Pierre, J. (ed.), (2000), Debating Governance: Authenticity, Steering and Democracy. Oxford: Oxford University Press.

Pierson, P. (1993), “When Effect Becomes Cause.” World Politics 45: 595-628.

Pierson, P. (1994), Dismantling the Welfare State? Reagan, Thatcher and the Politics of Retrenchment. New York: Cambridge.

Pierson, P. (1998), "Irresistible Forces, Immovable Objects: Post-industrial Welfare States Confront Permanent Austerity," Journal of European Public Policy_4(4): pp. 539-560.

Pierson, P. and S. Leibfried (1995), European Social Policy: Between Fragmentation and Integration. Washington, D.C.: Brookings Institution Press.

Popov, V. (2000), "Shock Therapy versus Gradualism: The End of the Debate (Explaining the Magnitude of the Transformational Recession)," Comparative Economic Studies, 42(1).

Popov, V. (2005), "Successes and Failures of Economic Transition of North and Central Asian Countries in the Era of Globalization," Paper presented to the International 
Conference on Strengthening Regional Cooperation for Managing Globalization Moscow, September 28-30.

Popova, N. (2001), "Change in reproductive views in the modern Russian family," Moscow State University.

Porter, C. (1980), Alexandra Kollontai. A Biography. London: Virago Limited.

Posadskaya, A. (ed.), (1994), Women in Russia. A New Era in Russian Feminism. Moscow: Verso.

Posadskaya, A. (ed.), (1996), Facing Women. Women in Russia. A New Era in Russian Feminism. Moscow: Verso.

Posadskaya, A. and N. Zakharova (1990), "To Be a Manager: Changes for Women in the USSR." Geneva: International Labour Office.

Preobrazhenskii, E. (1920), "Put' k Raskreposhcheniiu Zhenshchiny," ["Towards Liberation of Women"], Kommunistka, 7: p.19.

President of the Russian Federation (1993), “ O Neotlognih Merah po Stabilizacii Urovirya Zhizni Maseleniya," ["On Urgent Measures to Stabilize Standard of Living of the Population”], Decree No. 405, March, Moscow

Te of the Russian Federation (1993), “Ob Ispol'zovanii Ob'ektov Social'nogois $\quad$ mm: "no-Bitovoga Naznacheniya Prevatiziruemih

- upr yatii," [" 4 _....ung the Use of Social Assets of Privatized Enterprises"],

Decree ivo 8, January 10, Moscow.

President oi tae Russiar Federation (1994), "O Povishenii Razmera Kompensacionnih Vipiat Otdel' num: Kategoriyam Gragdan," ["Increasing Compensation Allowances for S̈pecific Categories of Citizens”], Decree No 1110, May 30, Moscow

Rees, T. (2000), "Mainstreaming Gender Equality in Science in the European Union: the "ETAN Report." Paper prepared for the Mainstreaming Gender in European Public Policy Workshop, University of Wisconsin-Madison, October 14-15.

Rimashevskaya, N. (1992), Perestroika and the Status of Women in the Soviet Union. Rai, S., Pilkington, H. and A. Phizacklea (eds), Women in the Face of Change: The Soviet Union, Easter Europe and China. London: Routledge.

Rimashevskaya, N. (2000), Issledovanie Narodonaseleniya v Perehodnii Period. Rabota Zhenchini v Usloviyah Perehoda Rossii k Rinku, [Population Research during the Transition Period. Woman's Labor in the Conditions of Transition to Market Economy].

Rimashevskaya, N. (2002), Social Protection of Population. Moscow: Institute for SocioEconomic Studies of Population RAS. 
Rimaschevskaya N. and C. Lundy (2001), Social Protection in Russia Under Conditions of Crisis. Final Report. Project of the University of Calgary Gorbachev Foundation. Moscow.

Ringen, S. (1997), Citizens, Families, and Reforms. Oxford, UK: Clarendon Press.

Ringold, D. (1999), "Social Policy in Postcommunist Europe: Legacies and Transition," in Cook, L.J. and Orenstein, M.A., and Rueschmeyer, M. (ed.), Left Parties and Social Policy in Postcommunist Europe. Boulder, CO: Westview Press.

Rjanitsina, L. (2002), "Macroeconomic Problems through Prism of Gender Approach: Analysis of Russian Practice," in Elena Mezentseva. (ed.), Gender and Economics: World Experience and Analysis of Russian Practice. Moscow: Russian Panorama.

Robinson, N. (2004), The State in Transition: the Russian State in Comparative Perspective. Paper for section on Rethinking the State in Developing and Transitional Countries, ECPR Standing Group on International Relations Conference, The Hague, September.

Rossiiskaia Gazeta (1997), "President Predlogil Dume Odumat'sya. Moskva, Kreml,," ["The president Offered to State Dume to Change their Minds"], No.193, November 02.

Rossiiskaia Gazeta (1998) Article by Nevinnaya, I., No.145 08/01

Rossiiskaia Gazeta. (1998), “Federal'nomu Sobraniu Obchimi Silami - k Pod'emu v Rossii. O Pologenii v Strane i Osnovnih Napravleniyah Politiki Rossiiskoi Federacii". ["Federal Assembly Report. Main Trends of Policies in Russian Federation"], No.036, February 24.

Rossiiskaia Gazeta (2001), "Hoziain i Rabotnik: Vmeste ili Porozn'," [“Employer and Employee: Together or Separated"], June 05.

Rossiiskaia Gazeta (2001), “Kodeks na Virost," [“Code for Growing”], December 20.

Ruhm, C. J. (1998), "The Economic Consequences of Parental Leave Mandates: Lessons from Europe," Quarterly Journal of Economics, p. 112.

Ruhm, C.J. and J.L Teague. (1995), Parental Leave Policies in Europe and North America. National Bureau of Economic Research Working Paper 5065.

Russian Economic Trends (June 2001), RECEP, Moscow.

Russian Fund of Social Reforms. (2001), "Development of Social Reforms in Russia. Social Insurance Fund of the Russia Federation". 
Sachs, J. (1995), Why Russia has Failed to Stabilize in Russian Economic Reform at Risk. London and New York: Pinter.

Sachs, J.D. and K. Pistor (1997a), The Rule of Law and Economic Reform in Russia. Westview Press.

Sachs, J.D., and K. Pistor (ed.) (1997b), Introduction: Progress, Pitfalls, Scenarios, and Lost Opportunities. Boulder, CO: Westview Press.

Sachs J.D., and A.M. Warner (1995), "Natural Resource Abundance and Economic Growth," Harvard Institute for International Development, Development Discussion Paper No. 517a.

Sachs, J., Woo, W.T., and X. Yang (2000), "Economic Reforms and Constitutional Transition," CID Working Paper No. 43.

Sacks, M. (1976), Women's Work in Soviet Russia, Continuity in the Midst of Change. New York: Praeger.

Sacks, M.P., and J.G. Pankhurst (eds.) (1988), Understanding Soviet Society. Allen and Unwin, London.

Sainsbury, D. (ed.), (1994), Gendering Welfare States. London: Sage Publications.

Sainsbury, D. (1999), Gender and Welfare State Regimes. Oxford University Press: Oxford.

Sakwa, R. (1999), Postcommunism. Cambridge, UK: Open University Press.

Savelyev, A. (2001), Higher Education: Status and Problems of Development, Moscow, p. 40.

Scharpf, F. (2000), "Globalization and the Welfare State: Constraints, Challenges and Vulnerabilities," Presented at the conference European Welfare States: Domestic and International Challenges.

Scharpf, F. W. (1997), Games Real Actors Play. Actor-Centered Institutionalism in Policy Research. Boulder, Colorado, USA: Westview Press.

Schlesinger, R. (1949), Changing Attitudes in Soviet Russia: Documents and Readings. London: Routledge and Paul.

Scott, J. (1998), Seeing Like a State: How Certain Schemes to Improve the Human Condition have Failed. New Haven and London: Yale University Press.

Sengenberger, W. (1999), "Employment and Labour Market Policies in Transition Economies," ILO Employment and Labour Market Policies Branch, Geneva. Available at www.ilo.org/public/english/employment/strat/publ/nesporov.htm 
Shapiro, J. (1992), "The Industrial Labor Force," in Buckley, M. (ed.), Perestroika and Soviet Women. Cambridge: Cambridge University Press.

Shiraev, E. and B. Glad (1999), "Gender Roles and Political Transformations," in B. Glad and Shiraev, E. (eds.), The Russian Transformation: Political, Sociological and Psychological Aspects. St. Martin's Press: New York.

Shkaratan, O., Davydova, N., Menning N., Sidoryna, T., and N. Tikhonava (2003), State Social Policy and the Strategy of Households Survival. Moscow: Higher School of Economics.

Sinelnikov, A. (2001), "What Kind of a Demographic Policy Should We Have?," (Translation of the Author), Moscow State University.

Skocpol, T. (1985), "Bringing the State Back In: Strategies of Analysis in Current Research," in P. Evans, D. Rueschemeyer and T. Skocpol. (eds.), Bringing the State Back In. Cambridge: Cambridge University Press.

Skocpol, T. (1992), Protecting Soldiers and Mothers. The Political Origins of Social Policy in the United States. Cambridge, MA, USA: The Belknap Press of Harvard University Press.

Slater, W. (1995), "Women of Russia and Women's Representation in Russian Politics," in Lane, D. (ed.) Russia in Transition: Politics, Privatization and Inequality. Longman Publishing: New York.: p.78.

Slavic Research Center, Hokkaido University (2006), "Soviet Economic Statistical Series," Available at http://src-h.slav.hokudai.ac.jp/database/SESS.html

Smirnova, N. (2004), "Job Search Behavior of the Unemployed in Russia," Available at http://ideas.repec.org/p/wpa/wuwpma/0401012.html

Smith, M.J. (1993), Pressure, Power, and Policy: State Autonomy and Policy Networks in Britain and the United States. Pittsburgh: University of Pittsburgh Press.

Smith, G. (1995), "The Ethno-Politics of Federation without Federalism," in Lane, D. (ed.), Russia in Transition: Politics, Privatization and Inequality. Longman Publishing: New York.

Smith, K.E. (2003), Mythmaking in the New Russia. Politics and Memory During the Yeltsin Era. Cornell University: Cornell University Press.

Smyth, R. (2002), "Building State Capacity from the Inside Out: Parties of Power and the Success of the President's Reform Agenda in Russia," In Politics and Society, Vol. 30 No. 4. 
Sokolin, V.L. and I.A. Zbarskaya (2002), The Demographic Yearbook of Russia 2002. Statistical Handbook/Goskomstat of Russia. State Committee of the Russian Federation on Statistics.

Sorenson, A. and S. McLanahan (1987), "Married Women's Economic Dependency, 1940-1980," American Journal of Sociology 93: pp. 659-687.

Soviet Union Information Bureau (1929), "The Soviet Union: Facts, Descriptions, Statistics," available at www.marxists.org/history/ussr/government/1928/sufds/index.htm

Standing, G. (1997), "Structural Adjustment and Labour Market Policies: Toward Social Adjustment?" in G. Standing and V. Tokman (eds.), Towards Social Adjustment. Geneva: International Labour Office.

State Duma of the Russian Federation (1991), "O Privatizacii Gosudrastvennih i Municipal'nih Predpriyatii v Rossiskoi Federacii," ["Regarding Privatization of State and Municipal Enterprises in Russian Federation”], Federal Law No 1531-1, June 03, Moscow.

State Duma of the Russian Federation (1992), “O Dopolnitel'nih Merah po Ohrane Materinstva i Detstva," ["Improving the Protection of Motherhood and Childhood"], Federal Law No 2660-1, April 04, Moscow.

State Duma of the Russian Federation (1995), "O Gosudarstvennih Posoboyah Gragdanam, Imeuchim Detei," ["Concerning State Allowances to Individuals with Children"], Federal Law No 81-FZ, May 19, Moscow.

State Duma of the Russian Federation (1995), "O Sohranenii Statusa Gosudarstvennih i Municipal'nih Uchregdenii i Maratorii na ih Privatizaciu," ["Regarding Preservation of the Status of State and Municipal Educational Institutions and Moratorium on their Privatization"], Federal Law No 74-FZ, May 16, Moscow.

State Duma of the Russian Federation (1996), "Zhenchini and TrudovoePravo" ["Woman and Labour Law,"], May 05. Hearings. Approved by the State Duma Council Meeting on February 08, Protocol No 7.

State Duma of the Russian Federation (1996), "O proekte Federalnogo Zakona: O Reproductivnih pravah gragdan I garantiyah ih osychestvleniya" ["Draft Federal Law: Reproductive Rights of Citizens' and Guaranties for their Realization,'], October 22. Hearings. Approved by the State Duma Council Meeting on October 08, Protocol No 14.

State Duma of the Russian Federation (1997), "O perspektivah coverschenstvovaniya zakonodatelstva o socialnoi poddergke semei c det'mi i uluchsheniya situacii c viplatoi gosudarstvennih posobii gragdanam, imeuchim detei" ["About Prospects of Development of Legislation for Social Support of Families with Children and 
Improvement of Situation with Welfare Payments for the Families with Children"]. Hearings. Approved by the State Duma Council Meeting on February 06, Protocol No. 68.

State Duma of the Russian Federation (1999), "O Reforme Trudovogo Zakonodatelstva I Proektah Truduvogo kodeksa" ["Reform of Labour Law and New Draft Labour Code"]. Hearings. Approved by the State Duma Council Meeting on January 21, Protocol No 184.

State Duma of the Russian Federation (2001), December 19, Moscow. Hearings. Labour Code Debates.

State Property Agency of the Russian Federation (1993), "O Merah po Sohraneniu Osnovnih Fondov Sistemi Obrazovaniya," ["On Protection of Property of Education System”], Letter No A-6/1389, March 01.

State Property Agency of the Russian Federation (1993), “Ob Uporyadochenii Processa Razgranicheniya Prav Sobstvennosti na Ob'ekti Social'no Culturnogo Naznacheniya," ["Improving the Process of Determining Ownership Rights on Social Assets"], Resolution No 135-P, January 27.

Steen, A and V.Gel'man (2003), Elites and Democratic Development in Russia. London and New York: Routledge.

Stepan, A. (1978), The State and Society: Peru in Comparative Perspective. Princeton, NJ: Princeton University Press.

Stepanova, V., (2004), “Moya Professiya Domohoziaika," [My Occupation is Housekeeper"], Mama \& Malish, August 10.

Stiglitz, J. (1999), "Whither Reform? Ten Years of the Transition," Voproci Econimici, v.7.

Stoner-Weiss, K. (2003), "The Sources of Resistance to Russian Central State Capacity in the Periphery," Available at www.ilpp.ru/projects/govern/ pdf/2003/StonerWeiss_eng.pdf

Streeck, W. and K. Thelen (eds.), (2005), Beyond Continuity: Institutional Change in Advanced Political Economies. Oxford, UK: Oxford University Press.

Strela, G.I., (2001), "Implementation of Gender's Approach in the Process of Collective Agreement," Analytical Materials. CIDA Funded Pilot Project, Moscow.

Stryker, R., Eliason, S., and E. Tranby (2004), “The Welfare State, Family Policies and Women's Labor Market Participation: A Fuzzy-Set Analysis," Paper Proposed for RC-19 Annual Meeting, Paris, September 3-7. 
Supreme Council of the RSFSR (1990), "O Neotlognih Merah po Uluchsheniy Pologeniya Genchin, Sem'i ohrani Materinstva i Detstva na Sele," ["On Urgent Measures on Improving the Position of Women, Protection of Motherhood and Childhood in Villages", Resolution No. 298/3-1, November 01, Moscow.

Supreme Council of the RSFSR. (1990), "O Neotlognih Merah po Uluchsheniy Pologeniya Genchin, Sem'I, Ohrani Materinstva i Detstva I Uluchsheniy Sem'i," ["On Urgent Measures on Improving the Position of Women, Protection of Motherhood and Childhood and Strengthening Family"], Resolution No. 1420-1, April 10, Moscow.

Supreme Council of the Russian Federation (1991), "O Razgranichenii Gosudarstvennoi Sobstvennosti v Rossiskoi Federacii na Federal'nuy Sobstvennost', Gosudarstvennuy Sobstvennost' Respublic v Sostave Rossiskoi Federacii, Kraev, Oblastei, Avtonomnoi Oblasti, Avtonomnih Okrugov, Gorodov moskva I Snktpeterburga I Municipal'nuy Sobstvennost'," ["On the Division of State Property in the Russian Federation"], Resolution No 3020-1, December 27.

Supreme Council of the Russian Federation. (1993), "On Payments for Attending Municipal/ Enterprise-based Child Care Facilities and Financial Support of the System of these Facilities," Resolution No. 112, Moscow.

Supreme Council of the Russian Federation (1994), "Ob Uvelichenii Gosudarstvennoi Pomochi Beremennim Genchinam, Mnogodetnim i Odinikim Materiam, Usilenii ohrani Materinstva i Detstva, Ob Ustanovlenn i Uchregdenii Ordena Materinskaya Slava i Medali Medal' Materinstva," ["About Improvement of State Help to Pregnant Women, Single Mothers and Mothers with many Children; Improvement of Protection of Motherhood and Childhood; and Inroduction of Government Award for Motherhood"], Resolution, July 08, Moscow.

Supreme Council of USSR (1947), "O Razmere Gosudarstvennogo Posibiya Mnogodetnim i Odinokim Materiam," ["Welfare Compensations for the Single Mothers and Mothers with Many Children"]. Resolution, November 25, Moscow.

Supreme Council of USSR (1949), "Ob Uluchshenii dela Gosudarstvennoi Pomochi Mnogodentim i Odinokim Materiam i Uluchshenii Uslovii Truda i Bita Zhenchin", ["Concerning Improvement of the Social Assistance to Lone Mothers and Mothers with Many Children and Improvement of Labor and Living Conditions"], Resolution, May 19, Moscow.

Supreme Council of USSR (1973), "Ob Izmenenii Stat'i 240 Kodeksa Zakonov o Trude,"

["Concerning the Amendments of the Article 240 of the Labour Code"],

Resolution, September 20, Moscow. 
Supreme Council of USSR (1982), "O Vnesenii Izmenenii v Kodeks Zakonov O Trude," ["Concerning the Amendments in the Labour Code"], Resolution, November 19, Moscow.

Supreme Council of USSR (1989), "Ob Uvelichenii prodolgitel'nosti otpuskov Genchinam, Imeuchim Maloletnih detei," ["Regarding Extension of Child Care Leave"], Resolution No 677, August 22, Moscow.

Svejnar, J. (1992), "Labour Market Adjustment in Transition Economies," Proceedings of the World Bank - Annual Conference on Development Economics.

Swafford, M., Artamonova, E., and S. Gerassimova (2001), "The Living Arrangements of Russian Children" in Klugman, J., and A. Motivans (eds.), Single Parents and Child Welfare in the New Russia. Unicef: Florence, Italy.

TACIS (1998a), "Municipalisation of Privatised Enterprise Social Assets: Essence, Problems, Solutions. Addressing the Social Impact of Economic Restructuring and Privatisation in the Russian Federation," Report No EDRUS 9410, November, Moscow.

TACIS (1998b), "Social Sector: Child Care and Preschool Institutions. Addressing the Social Impact of Economic Restructuring and Privatisation in the Russian Federation," Report No EDRUS 9410, October, Moscow.

TACIS (1999), "Concerning the Provision of Assistance to the Partner States in Eastern Europe and Central Asia," Council Regulations, December 29, Available at http://europa.eu.int/comm/external_relations/ceeca/tacis/reg99_00.pdf.

Tchekorina, N. (2002), "Women and Social Policy under the Conditions of Market Reforms," in Mezentseva, E. (ed.), Gender and Economics: World Experience and Analysis of Russian Practice. Moscow: Russian Panorama.

Teplova, T. and F. Woolley (2005), "Balancing Work and Care in the Post-Soviet Russian Labour Market," Carleton Economic Papers 05-04, Carleton University, Department of Economics, revised Apr 2005. Available at: http://ideas.repec.org/p/car/carecp/05-04.html

The Europian Union Online (1999), “The 1999 TACIS Agreement with Russia,” Official Journal of the European Communities. Available at http://europa.eu.int/comm/external_relations/ceeca/tacis/reg99_00.pdf

The Marriage Laws of Soviet Russia: The Complete Text of the First Code of the RSFSR (New York, 1921),

Tilly, C (ed.), (1975), The Formation of National States in Western Europe. Princeton, NJ: Princeton University Press. 
Tisheva, G. (2000), "Indicators for the Impact of Privatization on Women' s Labour Force in Bulgaria," Research project.

Tolkunova, V., Sergeeva, G., Eemel'yanova, Y., Zuikova, Y. and M. Gordeyeva (1985), Sovetskoe Gosudarstvo - Zhenchine. [The Russian State - to a Woman], Moscow: Progress Publishing.

Trochev, A. (2005), "Distrusted Courts: The Impact of State (In)capacity on Judicial Power in Post-Communist Countries." Paper prepared for the annual meeting of the Canadian Political Science Association, London, Ontario. Available at www.cpsa-acsp.ca/papers-2005/Trochev.pdf

UNDP (1995a), "International Cooperation at a Crossroads: Aid, Trade and Security in an Unequal World," Human Development Report, Available at http://hdr.undp.org/statistics/data/cty/cty f RUS.html

UNDP (1995b), "Status of Women in the Russian Federation," Human Development Report, UNDP Publications.

UNDP (1999), "Central and Eastern Europe”, Human Development Report, UNDP Publications.

UNDP (2005), "International Cooperation at a Crossroads: Aid, Trade and Security in an Unequal World," Human Development Report, UNDP Publications. Available at http:/hdr.undp.org/statistics/data/cty/cty f RUS.html

UNICEF (1999), "Women in Transition,” The MONEE Project. Regional Monitoring Report No 6. Available at www.unicef-icdc.org/publications/pdf/monee6.

United States General Accounting Office (2000), "Foreign Assistance International Efforts: to Aid Russia's Transition Have Had Mixed Results," Report to the Chairman and to the Ranking Minority Member, Committee on Banking and Financial Services, House of Representatives, November.

US Census Bureau (2001), "Maternity Leave and Employment Patterns: 1961-1995," Issue November 2001 No 70-79. Available at www.census.gov/prod/2001pubs/p70-79.pdf

Vasil'eva, E.K. (1975), Sem'ya i ee Funkcii [Families and their Functions]. Moscow: Statistika Publishing.

Vinokurova, O. (2005), "Passport of the Russian Trade-union Movement," Federation of Independent Trade unions of Russia (FNPR), Available at www.warwick.ac.uk/russia/Intas/Russianreport.doc

Walby, S. (2004), "The European Union and Gender Equality: Emergent Varieties of Gender Regime," Social Politics 11(1): pp. 4-29. 
Waldfogel, J. (2001), "Family and Medical Leave: Evidence from 2000 Surveys," Monthly Labor Review. www.childpolicyintl.org/issuebrief/issuebrief5.htm

Waterbury, J. (1992), "The Heart of the Matter? Public Enterprise and the Adjustment Process," in Haggard, S. and R. Kauffman (eds.), The Politics of Economic Adjustment: International Constraints, Distributive Conflict, and The State. Princeton: Princeton University Press.

Way, L. (2003), "Pluralism by Default and the Sources of Political Liberalization in Weak States: The Case of the Former Soviet Union," Available at www.yale.edu/leitner/pdf/PEW-Way.pdf

Weir, M., Orloff, S. and T. Skocpol (1988), The Politics of Social Policy in the United States. Princeton: Princeton University Press.

Wennemo, I. (1994), Sharing the Cost of Children. Doctoral Dissertation Series No 25. Swedish Institute for Social Research. Stockholm: Stockholm University.

Wilkinson, H. (1997), Time out: The costs and benefits of paid parental leave. London: Demos.

Wilson, C.A. (2000), "Policy Regimes and Policy Change," Journal of Public Policy 20: pp. 247-274. Cambridge University Press.

Wites, T. (2004), "Abortions in Russia Before and After the Fall of the Soviet Union," Miscellanea Geographica. Warzawa 2004, vol 11.

World Bank (1992), "Russian Federation - Income Transfers and Social Safety Net in Russia," Prepared by Barr, N. No 11168.

World Bank (1993a), "Integrating Housing Wealth into the Social Safety Net: the Elderly in Moscow," Prepared by Buckley, R., Cartwright, K., Struyk, R., and E. Szymanoski, Policy Research Working Paper No WPS3115.

World Bank (1993b), "Local Self-government and Civic Engagement in Rural Russia", Collection of Articles No 28377.

World Bank (1993c), "Providing Social Benefits in Russia: Redefining the Roles of Firms and Government," Policy Research Working Paper, Available at wwwwds.worldbank.org.

World Bank (1993d), "Russian Economic Reform: Crossing the Threshold of Structural Change," Publication, Available at www-wds.worldbank.org.

World Bank (1993e), "The Behavior of Russian Firms in 1992: Evidence from a Survey," Policy Research Working Paper, Available at www-wds.worldbank.org. 
World Bank (1993f), "The Role of Women in Rebuilding the Russian Economy," Prepared by Fong, M.S. No 12305.

World Bank (1993g), "The Russian Labor Market: Moving from Crisis to Recovery," Prepared by Andrews, E., Betcherman, G., Broadman, H., Earle, J., Kuddo, A., Rashid, M., Rescanitini, F., Sabirianova, N., Tchetvernina, T., and E. Zotova, Report No 29018.

World Bank (1993h), The East Asian Miracle: Economic Growth and Public Policy. New York: Oxford University Press.

World Bank (1994a), "Creating Private Enterprises and Efficient Markets," Working Paper, Available at www-wds.worldbank.org.

World Bank (1994b), "Poland and the Russian Federation: a Comparative Study of Growth and Poverty", Prepared by Dabrowski, M., Rohozynsky, A., and I. Sinitsina, Working Paper No 30795.

World Bank (1994c), "Russia. Social Protection During Transition and Beyond". Report No 11748-RU.

World Bank (1994d), "Russian Federation - Russia and the Challenge of Fiscal Federalism," Publication, Available at www-wds.worldbank.org.

World Bank (1994e), "Russian Federation - Social Protection During Transition and Beyond," Sector Report, Available at www-wds.worldbank.org.

World Bank (1994f), "Russia's Newly Privatized Firms: Heading in the Right Direction but Uncertainty Hampers Restructuring Efforts," Viewpoint, Available at wwwwds.worldbank.org.

World Bank (1994g), "Unemployment, Restructuring, and the Labor Market in Eastern Europe and Russia," Publication, Available at www-wds.worldbank.org.

World Bank (1995a), "Russian Federation - Creating Private Enterprises and Efficient Markets," Publication, Available at www-wds.worldbank.org.

World Bank (1995b), "Russian Federation - Poverty in Russia: an Assessment," Sector Report, Available at www-wds.worldbank.org.

World Bank (1995c), "Russia's Struggle with Stabilization: Conceptual Issues and Evidence," Comment Publication, Available at www-wds.worldbank.org.

World Bank (1996a), "Enterprise Restructuring and Economic Policy in Russia," Working Paper, Available at www-wds.worldbank.org.

World Bank (1996b), "Public Spending and the Poor: Theory and Evidence," Publication, Available at www-wds.worldbank.org. 
World Bank (1996c), "Restructuring of Enterprise Social Assets in Russia. Trends, Problems, Possible Solutions," Policy Research Working Paper No 1635 prepared by Freinkman, L.M. and I. Starodubrovskaya.

World Bank (1996d), "Restructuring of Enterprise Social Assets in Russia: Trends, Problems, Possible Solutions," Policy Research Working Paper, Available at www-wds.worldbank.org.

World Bank (1996e), "Why is Unemployment Low in the Former Soviet Union?: Enterprises Restructuring and the Structure of Compensation," Policy Research Working Paper, Available at www-wds.worldbank.org.

World Bank (1998), "Income, Inequality, and Poverty during the Transition from Planned to Market Economy," Publication Available at www-wds.worldbank.org.

World Bank (1999), "Household Child Care Choices and Women's Work Behaviour in Russia," Prepared by Lokshin, M., Development Research Group.

World Bank (2002a), “Assisting Russia's Transition: an Unprecedented Challenge,” OED Evaluation Report, Available at www-wds.worldbank.org.

World Bank (2002b), "Dismantling Russia's Non-payments System - Creating Conditions for Growth," Publication, Available at www-wds.worldbank.org.

World Bank (2002c), "Making the Transition Work for Women in Europe and Central Asia," Publication, Available at www-wds.worldbank.org.

World Bank (2002d), "Pension Reform in Russia: Design and Implementation," Prepared by Mansoora, R., Thompson, L., Von Gersdorff, H., and E. Zotova, Sector Report No 29017.

World Bank (2002e), "Rich and Powerful? Subjective Power and Welfare in Russia," Policy Research Working Paper, Available at www-wds.worldbank.org.

World Bank (2002f), "Russia: Bank Assistance for Social Protection," Prepared by Kolosnitsyna, M. and I. Topinska, Operations Evaluation Department (OED), Report No 27970.

World Bank (2002g), "Russian Federation - Country Assistance Evaluation," Operations Evaluation Study, Available at www-wds.worldbank.org.

World Bank (2002h), "Russian Federation. Child Welfare Outcomes During the 1990s: The Case of Russia", Report No 24450-RU.

World Bank (2002k), "Single Mothers in Russia - Household Strategies for Coping with Poverty," Policy Research Working Paper, Available at www-wds.worldbank.org. 
World Bank (20021), "Sub-national Budgeting in Russia: Preempting a Potential Crisis," Publication, Available at www-wds.worldbank.org.

World Bank (2002m), "Ten Years of Transformation - Macroeconomic Lessons," Policy Research Working Paper, Available at www-wds.worldbank.org.

World Bank (2005a), "Russia - Reducing Poverty through Growth and Social Policy Reform”, Report No 28923-RU.

World Bank (2005b), "Russia: Country Assistance Strategy", Progress Report No 31579RU

Yankova, Z.A. (1979), Gorodskaya Sem'ya [Urban Family]. Moscow: Nauka Publishing.

Yershova, E. (2002), "Implementation by the Russian Federation of UN Convention on Liquidation of all Forms of Discrimination against Women," Shadow Report prepared with support of Consortium of Women's Nongovernmental Associations.

Yin, R. (1989), Case Study Research: Design and Methods. Newbury Park, California: Sage Publications.

Yudaeva, K., Gorban, M., Popov, V. and N. Volchkova (2003), "Down and Up the Stairs: Paradoxes of Russian Economic Growth," Paper written for the GDN project "Explaining Growth". Forthcoming in a book volume at Oxford Press.

Yudkin, S. and A. Holme (1963), Working Mothers and Their Children: A Study for the Council for Children's Welfare. London: Michael Joseph Ltd.

Zhenshchina v SSSR. (1936).

Zdravomyslova, O. (2003), Family and Society: Gender Dimension of Russian Transformation. Moscow: Editorial.

Zhuravskaya, E. (1998), "Incentives to Provide Local Public Goods: Fiscal Federalism, Russian Style," Journal of Public Economics, 76(3), pp. 337-68.

Zolotova, N.P. (2001), "Draft of the Labour Code of the Russian Federation and Equal Opportunities in the Labour Market," Analytical bulletin of the Federation Council Labour Code of the Russian Federation. 22 (153). 


\section{Appendixes}

\section{Appendix 1. Administration of Social Services by Ministries of Welfare, Soviet Union, 1963}

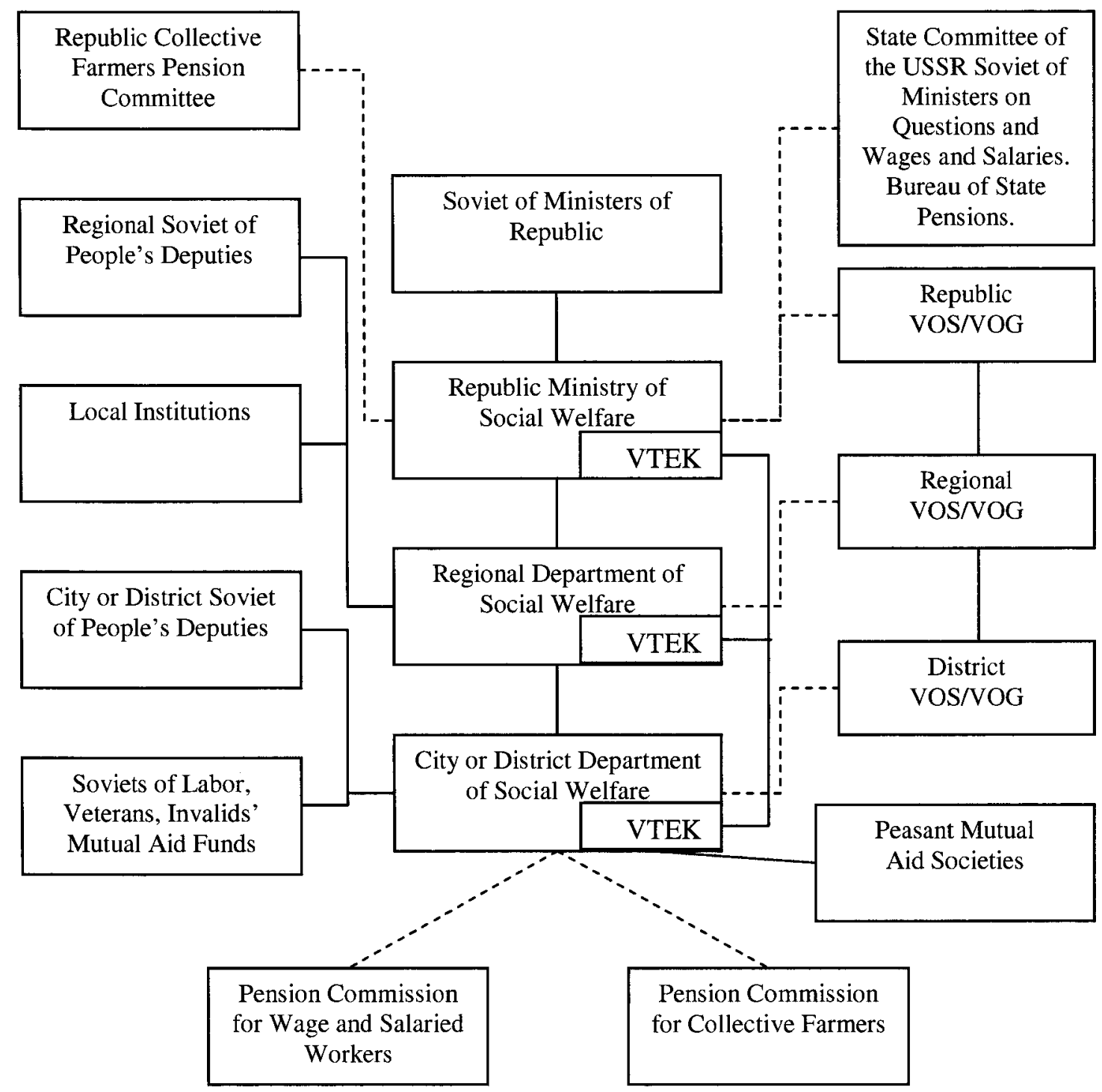

Source: Madison, B.Q. (1968). Social Welfare in the Soviet Union. Stanford, California: Stanford University Press. p. 85 


\section{Appendix 2. System of Education in the Soviet Union, 1968}
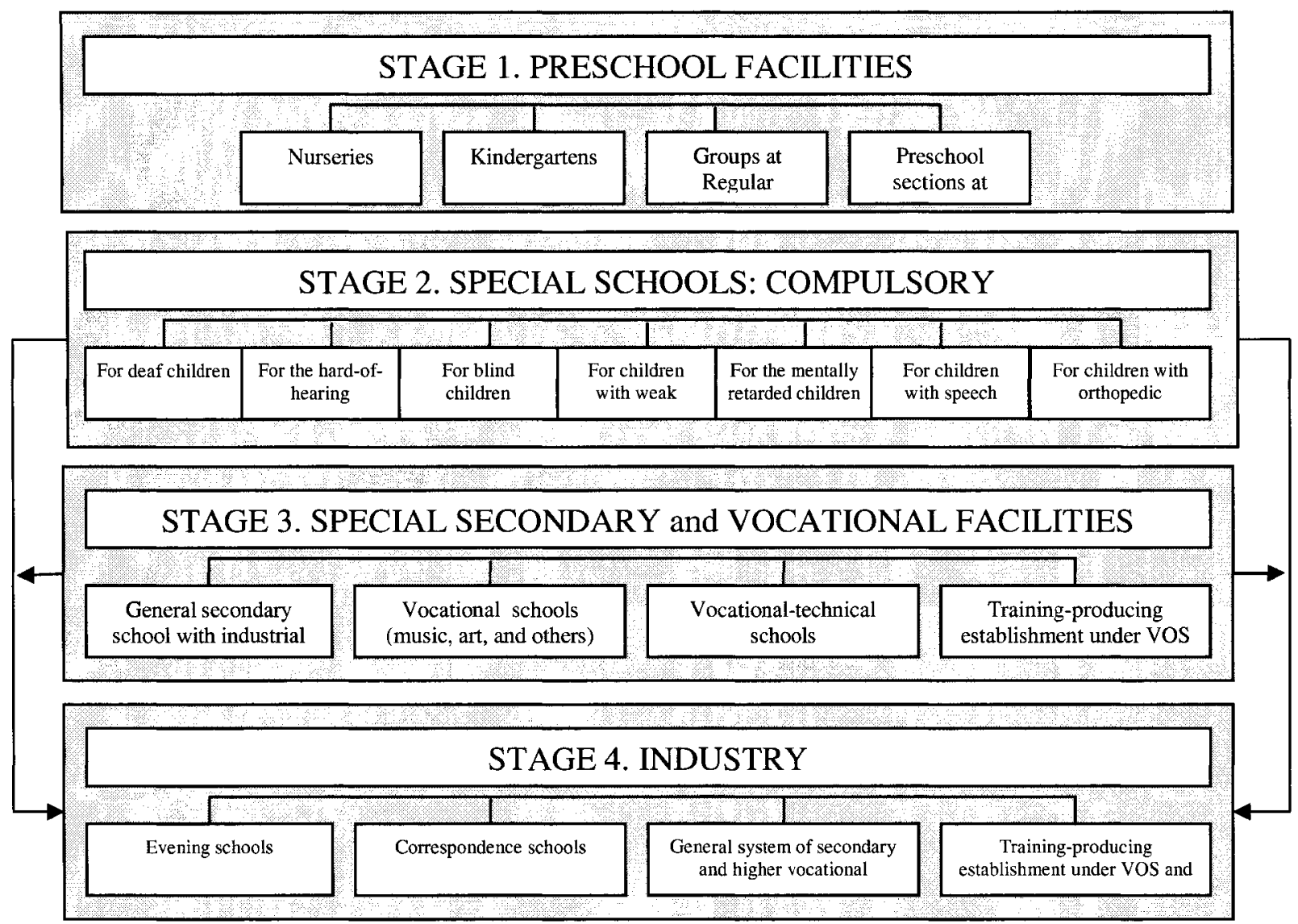

Source: Madison, B.Q. (1968). Social Welfare in the Soviet Union. Stanford, California: Stanford University Press. p. 164. 


\section{Appendix 3. Main legislation and policies with regard to the position of women in the Soviet period (1940-1988).}

\begin{tabular}{|c|c|c|c|}
\hline $\begin{array}{l}\# \\
\text { p.p }\end{array}$ & Date & Title & Source \\
\hline 1 & 2 & 3 & 4 \\
\hline \multicolumn{4}{|c|}{ 1. Obchie pologeniya o pravax genchin } \\
\hline 1 & 1936 & $\begin{array}{l}\text { Konstititciya (Osnovnoy Zakon) Soyza Sovetskih } \\
\text { Socialisticheskih Respublic }\end{array}$ & $\begin{array}{l}\text { Konstititciya } \\
\text { (Osnovnoy Zakon) } \\
\text { SSSR, M., } 1937 \\
\end{array}$ \\
\hline 2 & 1968 & $\begin{array}{l}\text { Osnovi zakonodateksva Soyza SSR i soyznih respublic o } \\
\text { brake i sem'e. }\end{array}$ & $\begin{array}{l}\text { Vedomosti Verhovnogo } \\
\text { Soveta SSSR. } 1968 \# \\
\text { 27. S. } 241\end{array}$ \\
\hline 3 & 1969 & $\begin{array}{l}\text { Osnovi zakonodateksva Soyza SSR i soyznih respublic o } \\
\text { zdravoohranenii }\end{array}$ & $\begin{array}{l}\text { Vedomosti Verhovnogo } \\
\text { Soveta SSSR. } 1969 . \# \\
\text { 52. Ct. } 466 .\end{array}$ \\
\hline 4 & 1976 & $\begin{array}{l}\text { Osnovnie napravleniya razvitiya narodnogo hoziaystva na } \\
197-1980 \mathrm{~g} .\end{array}$ & $\begin{array}{l}\text { Materiali XXV s'ezda } \\
\text { KPSS. M., 1976. S. } \\
\text { 217-218. }\end{array}$ \\
\hline 5 & 1997 & $\begin{array}{l}\text { Konstititciya (Osnovnoy Zakon) Soyza Sovetskih } \\
\text { Socialisticheskih Respublic }\end{array}$ & $\begin{array}{l}\text { Konstititciya } \\
\text { (Osnovnoy Zakon) } \\
\text { SSSR, M., } 1977 \\
\end{array}$ \\
\hline 6 & 1981 & $\begin{array}{l}\text { Osnovnie napravleniya economicheskogo I socialnogo } \\
\text { razvitiya SSSR na 1981-1985 godi I na period do } 1990 \\
\text { goda. }\end{array}$ & $\begin{array}{l}\text { Materiali XXVI s'ezda } \\
\text { KPSS. M., 1986. S. } 178\end{array}$ \\
\hline 7 & 1986 & $\begin{array}{l}\text { Osnovnie napravleniya economicheskogo I socialnogo } \\
\text { razvitiya SSSR na 1986-1990 godi I na period do } 2000 \\
\text { goda. }\end{array}$ & $\begin{array}{l}\text { Materiali XXVII s'ezda } \\
\text { KPSS. M., 1986. S. } 51\end{array}$ \\
\hline \multicolumn{4}{|c|}{ 2. Ohrana truda i zdorov'ya } \\
\hline 8 & 1940 & $\begin{array}{l}\text { O primenenii truda genchin na rabotah i v sisteme hozyaistva } \\
\text { rechnogo flota. } \\
\text { Postanovlenie Secretariata VCSPS ot } 13 / 06 / 1940 \text { goda. }\end{array}$ & $\begin{array}{l}\text { Bulleten VCSPS. } \\
\text { 1940. \#6. }\end{array}$ \\
\hline 9 & 1940 & $\begin{array}{l}\text { O primenenii truda genchin na podzemnich rabotax v } \\
\text { gornodobivaychey promishlennosti. } \\
\text { Postanovlenie SNK SSSR ot } 25 / 10 / 1940 \text { g. \# } 2128\end{array}$ & $\begin{array}{l}\text { SP SSSR. } 1940 . \# 30 . \\
\text { ST. } 730 .\end{array}$ \\
\hline 10 & 1942 & $\begin{array}{l}\text { Ob organizacii i rabote komnat lichnoy gigieni genchin na } \\
\text { predpriyatiyh. } \\
\text { Instrukciya, utvergdennaya Narkomzdravom SSSR, } \\
\text { 04/12/1942 g. }\end{array}$ & $\begin{array}{l}\text { Ohrana zdorovya i } \\
\text { prava genchin v } \\
\text { SSSR: Sb. } \\
\text { Vedomstvennih i } \\
\text { zakokodatelnih } \\
\text { aktov. M./ 1947. S. } \\
204\end{array}$ \\
\hline 11 & 1942 & $\begin{array}{l}\text { O komnatah dlya kormleniya detey na predpriyatiyah. } \\
\text { Postanovlenie SNK SSSR ot 10/11/1944 g. \# } 1571\end{array}$ & $\begin{array}{l}\text { Ohrana zdorovya i } \\
\text { prava genchin v } \\
\text { SSSR. S. } 205 \text {. }\end{array}$ \\
\hline 12 & 1957 & $\begin{array}{l}\text { O meroproyatiyax po zamene genskogo truda na podzemnih } \\
\text { rabotah v gornodobivaychey promischlennosti i na stroitelstve } \\
\text { podzemnih soorugeniy. } \\
\text { Postanovlenie SM SSSR ot } 13 / 06 / 1957 \text { g. \# } 839\end{array}$ & $\begin{array}{l}\text { SP SSSR. } 1957 \# 8 . \\
\text { St..81 }\end{array}$ \\
\hline
\end{tabular}




\begin{tabular}{|c|c|c|c|}
\hline 13 & 1960 & $\begin{array}{l}\text { O merah po dalneyschemu uluchscheniu torgovli. } \\
\text { Postanovlenie CK KPSS i SM SSSR ot 8/08/1960 g. \# } 851\end{array}$ & $\begin{array}{l}\text { SP SSSR. } 1960 \text { \# } 14 . \\
\text { St..114 }\end{array}$ \\
\hline 14 & 1962 & $\begin{array}{l}\text { O dalneyschem uluchschenii bitovogo obslugivaniya } \\
\text { naseleniya. } \\
\text { Postanovlenie CK KPSS i SM SSSR ot 08/08/1962 g. \# } 847 .\end{array}$ & $\begin{array}{l}\text { SP SSSR. 1962. \# } 16 . \\
\text { St. } 126 .\end{array}$ \\
\hline 15 & 1964 & $\begin{array}{l}\text { Recomendacii po ispolzovaniu truda beremennih genchin na } \\
\text { predpriyatiyah legkoy promischlennosti. } \\
\text { Pismo Ministerstva zdravoohraneniya SSSR i CK profsoyza } \\
\text { rabochih tekstilnoy promischlennosti ot 20/05/1964 g. \# 06- } \\
\text { 14/11-a. }\end{array}$ & $\begin{array}{l}\text { Zakonodatelstvo o } \\
\text { pravax genchin v } \\
\text { SSSR. M. 1975. S. } \\
\text { 105. }\end{array}$ \\
\hline 16 & 1967 & $\begin{array}{l}\text { O dalneyschem rasschirenii rpav ministrov SSSR } \\
\text { Postanovlenie SM SSSR ot 10/06/1962 g. \# 641. }\end{array}$ & $\begin{array}{l}\text { SP SSSR. 1967. \# } 17 . \\
\text { St. } 117 .\end{array}$ \\
\hline 17 & 1969 & $\begin{array}{l}\text { Perechen rabot i mehanizmov, na kotorih rekomenduetsya } \\
\text { preimuchestvenni genskiy trud. Utvergdeno GK SM SSSR po } \\
\text { voprosam truda i zarabotnoy plati, Ministerstvom } \\
\text { zdravoohraneniya SSSR i VCSPS ot } 29 / 12 / 1969 \mathrm{~g} \text {. }\end{array}$ & $\begin{array}{l}\text { Sbornik } \\
\text { zakonodatelnih aktov } \\
\text { po ohrane truda v } \\
\text { kolhozax. M., } 1971 . \\
\text { S. } 25-26 \\
\end{array}$ \\
\hline 18 & 1970 & $\begin{array}{l}\text { Osnovi zakonodatelstva Soyza SSR i soyznih respublic o } \\
\text { trude }\end{array}$ & $\begin{array}{l}\text { Vedomosti } \\
\text { verhovnogo soveta } \\
\text { SSSR. 1971. \# 29. St. } \\
265 \text {. }\end{array}$ \\
\hline 19 & 1971 & $\begin{array}{l}\text { Pologenie o pravah fabrichnogo, zavodskogo, mestnogo } \\
\text { komiteta professionalnogo soyza. } \\
\text { Utvergdeno Ukazom Prezidiuma Verhovnogo Soveta SSSR } \\
\text { on } 27 / 09 / 1971 \mathrm{~g} \text {. }\end{array}$ & $\begin{array}{l}\text { Vedomosti } \\
\text { verhovnogo soveta } \\
\text { SSSR. 1971. \# 39. St. } \\
\text { 382. }\end{array}$ \\
\hline 20 & 1975 & $\begin{array}{l}\text { O snigenii vozrasta dlya naznachenii pensii po starosti } \\
\text { genchinam-mehanizatoram. } \\
\text { Ukaz Presidiuma Verhovnogo Soveta SSSR ot 07/03/1975 }\end{array}$ & $\begin{array}{l}\text { Vedomosti } \\
\text { verhovnogo soveta } \\
\text { SSSR. 1975. \# 11. St. } \\
182 . \\
\end{array}$ \\
\hline 21 & 1978 & $\begin{array}{l}\text { Ob utvergdenii spiska proizvodstv, professiy i rabot s tygelimi } \\
\text { i vrednimi usloviyami truda, na kotorih zaprechetsya } \\
\text { primenenie truda genchin. } \\
\text { Postanovlenie GK Soveta Ministrov SSSR po trudu i } \\
\text { socialnim voprosam i Presidiuma VCSPS ot } 25 / 06 / 1978 \text { g. \# } \\
240 / 1110-3\end{array}$ & $\begin{array}{l}\text { Bulleten GK Soveta } \\
\text { Ministrov SSSR po } \\
\text { trudu i socialnim } \\
\text { voprosam. 1978. \# } \\
12 .\end{array}$ \\
\hline 22 & 1979 & $\begin{array}{l}\text { O merah po dalneyschemu soverschenstvovaniy podgotovki i } \\
\text { povischeniu kvalifikacii rabochix na proizvodstve. } \\
\text { Postanovlenie CK KPSS i SM SSSR ot } 21 / 06 / 1979 \mathrm{~g} \text {. \# } 568 \text {. } \\
\end{array}$ & $\begin{array}{l}\text { SP SSSR. 1979. \# } 17 . \\
\text { St. } 113 .\end{array}$ \\
\hline 23 & 1980 & $\begin{array}{l}\text { Ob uvelichenii nadbavki k pensii po starosti za neprerivniy } \\
\text { stag raboti na odnom predpriyatii, uchregdeii, organizacii. } \\
\text { Ukaz Prezidiuma Verhovnogo Soveta SSSR on } 07 / 01 / 1980 \\
\text { g. \# 1368-X }\end{array}$ & $\begin{array}{l}\text { Vedomosti } \\
\text { verhovnogo soveta } \\
\text { SSSR. 1980. \# 3. St. } \\
40 . \\
\end{array}$ \\
\hline 24 & 1980 & $\begin{array}{l}\text { O vnesenii nekotorich izmeneniy i dopolneniy b Primerniy } \\
\text { Ustav kolhozov. }\end{array}$ & $\begin{array}{l}\text { SP SSSR. 1980. \# } 21 . \\
\text { St. } 122 .\end{array}$ \\
\hline 25 & 1983 & $\begin{array}{l}\text { O vnesenii izmeneniy v nekotorie zakonodatelnie akti SSSR } \\
\text { po voprosam gragdanskih pravonaruscheniy, braka i sem'i, } \\
\text { truda i socialnogo obespecheniya. } \\
\text { Ukaz Prezidiuma Verhovnogo Soveta SSSR on } 02 / 02 / 1983 \mathrm{~g} \text {. }\end{array}$ & $\begin{array}{l}\text { Vedomosti } \\
\text { verhovnogo soveta } \\
\text { SSSR. 1983. \# 5. St. } \\
74 . \\
\end{array}$ \\
\hline
\end{tabular}




\begin{tabular}{|c|c|c|c|}
\hline 26 & 1987 & $\begin{array}{l}\text { O dopolnitelnih l'gotah po nalogu na holostyakov, odinokih i } \\
\text { malosemeynih gragdan. } \\
\text { Ukaz Prezidiuma Verhovnogo Soveta SSSR ot 13/01/1987 g. }\end{array}$ & $\begin{array}{l}\text { Vedomosti } \\
\text { verhovnogo soveta } \\
\text { SSSR. 1987. \# 2. St. } \\
\text { 34. }\end{array}$ \\
\hline 27 & 1944 & $\begin{array}{l}\text { Ob utvergdenii postanovleniya VCSPS "O poryadke vidachi } \\
\text { v voennoe vremya posobiy po beremennosti i rodam". } \\
\text { Postanovlenie SNK SSSR on } 11 / 03 / 1944 \mathrm{~g} \text {. \# } 262\end{array}$ & $\begin{array}{l}\text { SP SSSR. 1944. \# } 4 . \\
\text { St. } 62 .\end{array}$ \\
\hline 28 & 1944 & $\begin{array}{l}\text { Ob uvelichenii gosudarstvennoi pomochi beremennim } \\
\text { genchinam, mnogodetnim i odinokim materyam, usilenii } \\
\text { ohrani materinstva i detstva, ob ustanovlenii pochetnogo } \\
\text { zvaniya "Mat' - geroinya" i ucheregdenii ordena } \\
\text { "Materinskaya slava" i medali "Medal' materinstva". } \\
\text { Ukaz Prezidiuma Verhovnogo Soveta SSSR ot 08/07/1944 g. }\end{array}$ & \\
\hline 29 & 1945 & $\begin{array}{l}\text { Ob uvelichenii razmera posobiya na kormlenie rebenka. } \\
\text { Postanovlenie SNK SSSR ot 10/08/1945 g. \# } 1954 .\end{array}$ & $\begin{array}{l}\text { SP SSSR. 1945. \# } 7 . \\
\text { St. } 88 .\end{array}$ \\
\hline 30 & 1949 & $\begin{array}{l}\text { Ob uluchshenii dela gosudarstvennoy pomochi mnogodetnim } \\
\text { i odinokim materyam i uluchschenii usloviy truda i bita } \\
\text { genchin. } \\
\text { Ukaz Prezidiuma Verhovnogo Soveta SSSR ot } 19 / 05 / 1949 \mathrm{~g} \text {. }\end{array}$ & $\begin{array}{l}\text { Vedomosti } \\
\text { verhovnogo soveta } \\
\text { SSSR. 1949. \# } 26 \text {. }\end{array}$ \\
\hline 31 & 1955 & $\begin{array}{l}\text { Ob otmene zaprecheniya abortov. } \\
\text { Ukaz Prezidiuma Verchovnogo Soveta SSSR ot 23/11/1955 g. }\end{array}$ & $\begin{array}{l}\text { Vedomosti } \\
\text { verhovnogo soveta } \\
\text { SSSR. 1955\# 22. St. } \\
425\end{array}$ \\
\hline 32 & 1956 & $\begin{array}{l}\text { Ob uvelichenii prodolgitelnosti otpuska po beremennistri i } \\
\text { rodam. } \\
\text { Ukaz Prezidiuma Verhovnogo Soveta SSSR ot } 26 / 03 / 1956 \mathrm{~g} \text {. }\end{array}$ & $\begin{array}{l}\text { Tam ge. } 1956 . \# 6 . \\
\text { St. } 154 .\end{array}$ \\
\hline 33 & 1956 & $\begin{array}{l}\text { O poryadke naznacheniya genchinam rabotnitsam i slugachim } \\
\text { posobiy po beremennosti i rodam i viplati rabochim i } \\
\text { slugachim, zabolevschim vo vremya otpuska, posobiy po } \\
\text { vremennoy netrudosposobnosti. } \\
\text { Postanovlenie SM SSSR ot } 08 / 12 / 1956 \mathrm{~g} \text {. \# } 1586 \text {. }\end{array}$ & $\begin{array}{l}\text { SP SSSR. 1957. \# } 2 . \\
\text { St. } 9 .\end{array}$ \\
\hline 34 & 1957 & $\begin{array}{l}\text { Ob uluchschenii obespecheniya rabochi i slugashix } \\
\text { posobiyami po gosudarstvennomu socialnomu strahovaniu. } \\
\text { Postanovlenie SM SSSR ot } 28 / 01 / 1957 \text { g. \# } 79 \text {. }\end{array}$ & $\begin{array}{l}\text { SP SSSR. 1957. \# } 3 . \\
\text { St. } 22 .\end{array}$ \\
\hline 35 & 1959 & $\begin{array}{l}\text { O merah po dalneischemu razvitiu detskih doschkolnih } \\
\text { uchregdeniy, uluchscheniu vospitaniya i medicinskogo } \\
\text { obslugivaniya detey doschkolnogo vozrasta. } \\
\text { Postanovlenie CK KPSS i SM SSSR ot } 21 / 05 / 1959 \text { g. \# } 558 \text {. }\end{array}$ & $\begin{array}{l}\text { SP SSSR. 1959. \# } 12 . \\
\text { St. } 70 .\end{array}$ \\
\hline 36 & 1963 & $\begin{array}{l}\text { O viplate posobiy na deteyvoennoslugachih srochnoy slugbi. } \\
\text { Postanovlenie SM SSSR ot } 25 / 10 / 1963 \mathrm{~g} \text {. \# } 1108\end{array}$ & $\begin{array}{l}\text { SP SSSR. 1963. \# } 20 . \\
\text { St. } 198 .\end{array}$ \\
\hline 37 & 1964 & $\begin{array}{l}\text { Ob utvergdenii Pologeniya o poryadke naznacheniya i viplate } \\
\text { posobiy po beremennosti i rodam genchinam - chlenam } \\
\text { kolhozov. } \\
\text { Postanovlenie SM SSSR ot } 04 / 11 / 1964 \text { g. \# } 915\end{array}$ & $\begin{array}{l}\text { SP SSSR. 1964. \# } 22 . \\
\text { St. } 136 .\end{array}$ \\
\hline 38 & 1966 & $\begin{array}{l}\text { O vidache bolnichnih listov i viplate posobiy genchinam, } \\
\text { usinovivschm novorogdennix detey. } \\
\text { Postanovlenie SM SSSR ot 18/02/1966 g. \# } 127\end{array}$ & $\begin{array}{l}\text { SP SSSR. 1966. \# } 4 . \\
\text { St. } 41 .\end{array}$ \\
\hline 39 & 1969 & $\begin{array}{l}\text { Primerniy Ustav kolhoza. Prinyat III s'ezdom kolhoznikov i } \\
\text { utvergden postanovleniem CK KPSS i SM SSSR on } \\
28 / 11 / 1969 \text { g. \# 910. }\end{array}$ & $\begin{array}{l}\text { SP SSSR. } 1969 . \# 26 . \\
\text { St. } 150 .\end{array}$ \\
\hline
\end{tabular}




\begin{tabular}{|c|c|c|c|}
\hline 40 & 1970 & $\begin{array}{l}\text { Pologenie o poryadke naznacheniya i viplate posobiya po } \\
\text { socialnomu strahovanu chlenam kolhozov. } \\
\text { Postanovlenie Souznogo Soveta kolhozov i } \\
\text { PrezidiumaVCSPS ot } 04 / 03-15 / 04 / 1970 \text { g. s izmeneniyami, } \\
\text { vnesennimi postanovleniem Prezidiuma VCSPS i Presidiuma } \\
\text { Souznogo Soveta kolhozov ot } 27 / 09 / 1973 \mathrm{~g} \text {. }\end{array}$ & $\begin{array}{l}\text { Zakonodatelstvo o } \\
\text { pravah genchin } \mathrm{v} \\
\text { SSSR S. 158-159. }\end{array}$ \\
\hline 41 & 1970 & $\begin{array}{l}\text { Pologenie o poryadke naznacheniya i viplati posobiy } \\
\text { beremennim genchinam, mnogodetnim i odinokim materyam } \\
\text { Utvergdeno postanovleniem SM SSSR ot } 12 / 08 / 1970 \text { g. \# } 659\end{array}$ & $\begin{array}{l}\text { SP SSSR. 1970. \# } 15 . \\
\text { St. } 123 .\end{array}$ \\
\hline 42 & 1973 & $\begin{array}{l}\text { O merah po dalneyschemu razvitiu seti detskih doschkolnih } \\
\text { uchregdenii v kolhozah. } \\
\text { Postanovlenie SM SSSR ot 17/03/1973 g. \# } 162\end{array}$ & $\begin{array}{l}\text { SP SSSR. 1973. \# } 8 . \\
\text { St. } 34 .\end{array}$ \\
\hline 43 & 1973 & $\begin{array}{l}\text { Ob utvergdenii Pravil ischisleniya neprerivnogo trudovogo } \\
\text { staga rabochix i slugachih pri naznachenii posobii po } \\
\text { gosudarstvennimu strahovaniu. } \\
\text { Postanovlenie SM SSSR ot 13/04/1973 g. \# } 252\end{array}$ & $\begin{array}{l}\text { SP SSSR. 1973. \# } 10 . \\
\text { St. } 51 .\end{array}$ \\
\hline 44 & 1973 & $\begin{array}{l}\text { Ob uluchscheii obespecheniya posobiy po beremennosti i } \\
\text { rodam i po uhodu za bol'nim rebenkom. } \\
\text { Postanovlenie SM SSSR ot } 26 / 07 / 1973 \mathrm{~g} \text {. \# } 530\end{array}$ & $\begin{array}{l}\text { SP SSSR. 1973. \# } 18 . \\
\text { St. } 102 .\end{array}$ \\
\hline 45 & 1974 & $\begin{array}{l}\text { O dalniyschem uvelichenii materialnoy pomochi } \\
\text { maloobespechennim sem'yam imeychim detey. } \\
\text { Postanovlenie CK KPSS i SM SSSR ot } 12 / 09 / 1974 \text { g. \# } 748\end{array}$ & $\begin{array}{l}\text { SP SSSR. 1974. \# } 21 . \\
\text { St. } 121 .\end{array}$ \\
\hline 46 & 1974 & $\begin{array}{l}\text { Ob uluchscheii obespecheniya rabochih i slugachih } \\
\text { posobiyami po vremennoy netrusposobnosti. } \\
\text { Postanovlenie SM SSSR ot } 13 / 12 / 1974 \text { g. \# } 748\end{array}$ & $\begin{array}{l}\text { SP SSSR. 1974. \# } 4 . \\
\text { St. } 1 .\end{array}$ \\
\hline 47 & 1975 & $\begin{array}{l}\text { Pologenie o poryadke naznacheniya i viplate gosudarstvennih } \\
\text { pensiy. } \\
\text { Utvergdeno postanovleniem SM SSSR ot 03/08/1972 g. \# } 590 \\
\text { c izmeneniemi, vnesennimi postanovleniyami SM CCCR ot } \\
\text { 21/11/1973 g. i 07/03/1975 g. }\end{array}$ & $\begin{array}{l}\text { SP SSSR. 1972. \# } 17 \\
\text { St. } 186 . \\
\text { SP SSSR. 1973. \# } 25 \\
\text { St. 143. } \\
\text { SP SSSR. 1975. \# } 8 \\
\text { St. 43. }\end{array}$ \\
\hline 48 & 1981 & $\begin{array}{l}\text { O merah po usileniy gosudarstvennoy pomochi sem'yam } \\
\text { imeuchih detey. } \\
\text { Postanovlenie CK KPSS i SM SSSR ot 22/01/1981 g. \# } 235 \text {. }\end{array}$ & $\begin{array}{l}\text { SP SSSR. 1981. \# } 13 . \\
\text { St. } 75 .\end{array}$ \\
\hline 49 & 1985 & $\begin{array}{l}\text { O nekotorom primenenii poryadka vziskaniy alimentov na } \\
\text { nesovershennoletnih detey. } \\
\text { Ukaz Prezidiuma Verhovnogo Soveta SSSR ot 01/02/1985 g. }\end{array}$ & $\begin{array}{l}\text { Vedomosti } \\
\text { Verhovnogo Soveta } \\
\text { SSSR. } 1985 \text { \# 6. St. } \\
101 .\end{array}$ \\
\hline 50 & 1986 & $\begin{array}{l}\text { O nekotorom primenenii poryadka vziskaniy alimentov na } \\
\text { nesovershennoletnih detey. } \\
\text { Ukaz Prezidiuma Verhovnogo Soveta SSSR ot 14/10/1986 g. }\end{array}$ & $\begin{array}{l}\text { Vedomosti } \\
\text { Verhovnogo Soveta } \\
\text { SSSR. } 1986 \# \text { 43. St. } \\
895 . \\
\end{array}$ \\
\hline 51 & 1944 & $\begin{array}{l}\text { Ob uluchschenii gilichnih usloviy mnogodetnih materei s } \\
\text { grudnimi det'mi. } \\
\text { Postanovlenie SNK SSSR on 10/10/1944 g. }\end{array}$ & $\begin{array}{l}\text { Ohrana zdorov'ya i } \\
\text { prava genchin v } \\
\text { SSSR. M., 1947. S. } \\
99 .\end{array}$ \\
\hline 52 & 1959 & $\begin{array}{l}\text { O dalneischem razvitii i uluchschenii obchestvennogo } \\
\text { pitaniya. } \\
\text { Postanovlenie CK KPSS i SM SSSR on 20/02/1959 g. \# } 182 .\end{array}$ & $\begin{array}{l}\text { SP SSSR. 1959. \# } 4 . \\
\text { St. } 24 .\end{array}$ \\
\hline
\end{tabular}




\begin{tabular}{|c|c|c|c|}
\hline 53 & 1959 & $\begin{array}{l}\text { O merach po obslugivaniy bitivigo naseleniya } \\
\text { Postanovlenie CK KPSS i SM SSSR on 06/03/1959 g. \# } 245 \text {. }\end{array}$ & $\begin{array}{l}\text { SP SSSR. 1959. \# } 5 . \\
\text { St. } 30 .\end{array}$ \\
\hline 54 & 1965 & $\begin{array}{l}\text { Ob uluchschenii torgovli i obchestvennogo pitaniya v strane. } \\
\text { Postanovlenie SM SSSR on 13/03/1965 g. \# } 157 .\end{array}$ & $\begin{array}{l}\text { SP SSSR. 1965. \# } 6 . \\
\text { St. } 33 .\end{array}$ \\
\hline 55 & 1965 & $\begin{array}{l}\text { O merah po uluchscheniy raboti predpiyatii bitivigi } \\
\text { obslugivaniya naseleniya } \\
\text { Postanovlenie SM SSSR on } 15 / 05 / 1965 \mathrm{~g} \text {. \# } 384 \text {. }\end{array}$ & $\begin{array}{l}\text { SP SSSR. 1965. \# } 13 . \\
\text { St. } 94 .\end{array}$ \\
\hline 56 & 1965 & $\begin{array}{l}\text { Ob uporyadichenii raspredeleniya giloy plochdi i ucheta } \\
\text { gragdan, nugduchihsya v gil’e. } \\
\text { Postanolenie SM RSFSR ot 09/05/1963 g. \# 591 s } \\
\text { izmeneniyami, vnesennimi postanovleniem SM RSFSR ot } \\
\text { 19/10/1965 g. \# } 1176\end{array}$ & $\begin{array}{l}\text { SP RSFSR. 1963. \# } \\
\text { 10. St. 64: SP } \\
\text { RSFSR. 1965. \# } 24 . \\
\text { St. } 151 .\end{array}$ \\
\hline 57 & 1967 & $\begin{array}{l}\text { O merah po dalneischemu rasvitiu bitovogo obslugivaniya } \\
\text { naseleniya. } \\
\text { Postanovlenie CK KPSS i SM SSSR ot 26/08/1967 g. \# } 822 \text {. }\end{array}$ & $\begin{array}{l}\text { SP SSSR. 1967. \# } 23 . \\
\text { St. } 160 .\end{array}$ \\
\hline 58 & 1969 & $\begin{array}{l}\text { Pravila respredeleniya giloy plochadi i ucheta gragdan, } \\
\text { nugdauchichsya v gil'e. } \\
\text { Utvergdeno ob'edinennim rescheniem ispolnitelnogo } \\
\text { kommiteta Moscovscoko oblastnogo Soveta deputatov } \\
\text { trudyachihsya i presidiuma Moscovskogo oblastnogo Soveta } \\
\text { professionalnih soyzov ot } 28 / 03 / 1969 \mathrm{~g} \text {. \# 248-8-20 }\end{array}$ & $\begin{array}{l}\text { Bulleten } \\
\text { Mosoblispolkoma. } \\
\text { 1969. \# 1. S. 27-33. }\end{array}$ \\
\hline 59 & 1969 & $\begin{array}{l}\text { O merah po dalneischemu razvitiu materialno-technicheskoi } \\
\text { bazi i uluchscheniu bitovogo obslugivaniya naseleniya. } \\
\text { Postanovlenie SM SSSR ot 19/12/1969 g. }\end{array}$ & $\begin{array}{l}\text { SP SSSR. 1970. \# } 1 . \\
\text { St. } 5 .\end{array}$ \\
\hline 60 & 1977 & $\begin{array}{l}\text { O sostoyanii i merach po uluchscheniu demograficheskoi } \\
\text { obstanovki i stimulirovaniu estestvennogo prirosta naseleniya } \\
\text { g. Moskvi. } \\
\text { Postanovlenie Buro MGK KPSS ot } 21 / 09 / 1977 \text { g. \# } 2716 \\
\end{array}$ & \\
\hline 61 & 1981 & $\begin{array}{l}\text { Osnovi gilichnogo zakonodatelstva Soyza SSR i souznich } \\
\text { respublic. }\end{array}$ & $\begin{array}{l}\text { Osnovi gilichnogo } \\
\text { zakonodatelstva } \\
\text { Souza SSR i souznich } \\
\text { respublic. M., } 1981 . \\
\end{array}$ \\
\hline 62 & 1981 & $\begin{array}{l}\text { O sostoyanii raboti po uvelicheniy proizvodstva i povischeniu } \\
\text { kachestva tovarov, oblegchauschih trud genchin v } \\
\text { domaschnem hozyistve, v svete reschenii XXVI s'ezda KPSS } \\
\text { Postanovlenie Prezidiuma Verhovnogo Soveta SSSR on } \\
\text { 02/09/1981 g. }\end{array}$ & $\begin{array}{l}\text { Vedomosti } \\
\text { Verhovnogo Soveta } \\
\text { SSSR. 1981. \# 35. St. } \\
\text { 1016. }\end{array}$ \\
\hline 63 & 1983 & $\begin{array}{l}\text { O vnesenii posobiy na detei maloobespechennim detyam. } \\
\text { Ukaz Prezidiuma Verhovnogo Soveta SSSR ot 02/09/1983 g. }\end{array}$ & $\begin{array}{l}\text { Vedomosti } \\
\text { Verhovnogo Soveta } \\
\text { SSSR. 1983. \# 51. St. } \\
783 . \\
\end{array}$ \\
\hline 64 & 1984 & $\begin{array}{l}\text { O vnesenii izmenenii v st. } 13 \text { Osnov zakonodatelstva Souza } \\
\text { SSR i souznich respublic o brake i sem'e } \\
\text { Ukaz Presidiuma Verhovnogo Soveta SSSR on 19/01/1984 g. }\end{array}$ & $\begin{array}{l}\text { Vedomosti } \\
\text { Verhovnogo Soveta } \\
\text { SSSR. 1984. \# 4. St. } \\
77 . \\
\end{array}$ \\
\hline 65 & 1984 & $\begin{array}{l}\text { O povischenii minimalnih razmerov pensii i drugih merah po } \\
\text { uluchscheniy pensionnogo obespecheniya. } \\
\text { Ukaz presidiuma Verhovnogo Soveta SSSR ot } 02 / 09 / 1984 \mathrm{~g} \text {. }\end{array}$ & $\begin{array}{l}\text { Vedomosti } \\
\text { Verhovnogo Soveta } \\
\text { SSSR. 1984. \# 4. St. } \\
1033 . \\
\end{array}$ \\
\hline
\end{tabular}




\begin{tabular}{|l|l|l|l|}
\hline 66 & 1987 & $\begin{array}{l}\text { O raschirenii l'got rabotauchim beremennim genchinam i } \\
\text { genchinam, imeuchim malolenih detei. } \\
\text { Ukaz Presidiuma Verhovnogo Soveta SSSR ot 02/09/1987 g. }\end{array}$ & $\begin{array}{l}\text { Vedomosti } \\
\text { Verhovnogo Soveta } \\
\text { SSSR. 1987. \# 36. St. } \\
586 .\end{array}$ \\
\hline 67 & 1988 & $\begin{array}{l}\text { O vnesenii izmenenii i dopolnenii v Ukaz Presidiuma } \\
\text { Verhovnogo Soveta SSSR "Ob osnovnih obyazannostyah i } \\
\text { pravah inspekii po delam nesoverschnnoletnich, } \\
\text { priemnikovraspredelitelei dlya nesoverschennoletich i } \\
\text { specialnich uchebno-vospitatelnich uchregdeniy po } \\
\text { predupregdeniy beznadzornosti i pravonaruschenii } \\
\text { nesoverschennoletnich". } \\
\text { Ukaz Presidiuma Verhovnogo Soveta SSSR ot 05/01/1988 g. }\end{array}$ & $\begin{array}{l}\text { Vedomosti } \\
\text { SSSR. 1988. \# 2. St. } \\
\text { SSSRogo Soveta } \\
18 .\end{array}$ \\
\hline
\end{tabular}

Source: Mashika (1986); other acts 


\section{Appendix 4. Advice of International Organizations to Russia on Aspects of Social / Family/ Child Care Policies, 1991-} 2001

\begin{tabular}{|c|c|c|c|c|c|}
\hline $\begin{array}{l}\text { Elements of Child } \\
\text { Care Policies }\end{array}$ & World Bank & IMT & ILO & EU/TACIS & UNICEF \\
\hline $\begin{array}{l}\text { Enterprise Social } \\
\text { Infrastructure }\end{array}$ & $\begin{array}{l}\text { Privatization and } \\
\text { divesture to } \\
\text { municipalities }\end{array}$ & $\begin{array}{c}\text { Reduction of social } \\
\text { expenditures (including } \\
\text { but not explicit on the } \\
\text { part of enterprises and } \\
\text { municipalities) }\end{array}$ & $\begin{array}{l}\text { Enterprise restructuring } \\
\text { required but in a much } \\
\text { more gradual pace }\end{array}$ & $\begin{array}{l}\text { Socially-oriented } \\
\text { enterprise restructuring, } \\
\text { municipalization of } \\
\text { social infrastructure }\end{array}$ & 一 \\
\hline Child care services & $\begin{array}{l}\text { Development of private } \\
\text { system child care } \\
\text { provision } \\
\text { Restructuring of } \\
\text { municipal child care }\end{array}$ & - & $\begin{array}{l}\text { Emphasis on ensuring a } \\
\text { system of employment } \\
\text { enabling services, } \\
\text { including child care }\end{array}$ & $\begin{array}{c}\text { Fee-based (up to } 20 \% \text { ) } \\
\text { municipal provision } \\
\text { (with a number of } \\
\text { exemptions for fee } \\
\text { payment), state } \\
\text { standards } \\
\end{array}$ & $\begin{array}{c}\text { Development of home- } \\
\text { based private child are } \\
\text { system }\end{array}$ \\
\hline Leave provisions & $\begin{array}{l}\text { Downsizing, including } \\
\text { along with other } \\
\text { cutbacks }\end{array}$ & $\begin{array}{l}\text { Downsizing, along with } \\
\text { other cutbacks }\end{array}$ & $\begin{array}{l}\text { Extended maternity } \\
\text { provisions - ILO } \\
\text { Convention }\end{array}$ & $\begin{array}{c}\text { EU level - parental } \\
\text { leave }\end{array}$ & Parental leave \\
\hline $\begin{array}{l}\text { Child and family } \\
\text { benefits }\end{array}$ & $\begin{array}{c}\text { Streamlining, reducing } \\
\text { number and targeting } \\
\text { benefits } \\
1994 \text { - universal child } \\
\text { benefit provision } \\
\text { 1998- targeted benefit } \\
\text { provision }\end{array}$ & Means testing required & $\begin{array}{c}\text { Emphasis on protection } \\
\text { of women }\end{array}$ & $\begin{array}{l}\text { Proper targeting to the } \\
\text { needy; } \\
\text { Means test, a reduction } \\
\text { in the number of } \\
\text { benefits and subsidies } \\
\text { and an increase in their } \\
\text { cash value }\end{array}$ & $\begin{array}{l}\text { Need to streamline } \\
\text { benefits and modernize } \\
\text { the system to reduce } \\
\text { "benefit" - based } \\
\text { women's discrimination } \\
\text { in the labour market }\end{array}$ \\
\hline Social policy emphasis & $\begin{array}{c}\text { Poverty reduction } \\
\text { Ensuring social safety } \\
\text { net }\end{array}$ & $\begin{array}{l}\text { Economic growth } \\
\text { Social safety net }\end{array}$ & $\begin{array}{l}\text { Need for social } \\
\text { dialogue, social } \\
\text { protection and } \\
\text { tripartism }\end{array}$ & $\begin{array}{l}\text { Development of } \\
\text { acceptable regional } \\
\text { policy in the field of } \\
\text { social services } \\
\text { provision, based upon } \\
\text { regional socio- } \\
\text { economic realities }\end{array}$ & \\
\hline
\end{tabular}


Appendix 5. RLMS Sample Sizes, Working Age Adults

\begin{tabular}{|l|c|c|}
\hline \multicolumn{1}{|c|}{ Sub-sample } & $\mathbf{1 9 9 4 , \mathbf { n }}$ & $\mathbf{2 0 0 1 , \mathbf { n }}$ \\
\hline All adults & 6040 & 6849 \\
\hline All men & 2967 & 3162 \\
\hline All women & 3073 & 3687 \\
\hline All mothers & 2464 & 2330 \\
\hline $\begin{array}{l}\text { All mothers with children } \\
\text { under seven, including of } \\
\text { age groups: }\end{array}$ & 945 & 949 \\
\hline \multicolumn{1}{|c|}{$18-29$} & 488 & 525 \\
\hline 30-39 & 303 & 243 \\
\hline 50-49 & 86 & 120 \\
\hline \multicolumn{1}{|c|}{50} & 68 & 61 \\
\hline $\begin{array}{l}\text { Married mothers with } \\
\text { children under seven }\end{array}$ & 759 & 739 \\
\hline $\begin{array}{l}\text { Lone mothers with children } \\
\text { under seven }\end{array}$ & 175 & 181 \\
\hline All fathers & 2101 & 1889 \\
\hline $\begin{array}{l}\text { Fathers with children } \\
\text { younger than seven }\end{array}$ & 828 & 758 \\
\hline
\end{tabular}

Source: Complied by the author, using RLMS

Appendix 6. Former Communist Party Saturation, 1999

\begin{tabular}{|l|c|c|c|c|c|c|}
\hline $\begin{array}{l}\text { Present Elite } \\
\text { Constituency }\end{array}$ & High & $\begin{array}{c}\text { Medium } \\
(15+\text { Years })\end{array}$ & $\begin{array}{c}\text { Low } \\
(5-15 \\
\text { Years }\end{array}$ & $\begin{array}{c}\text { (0-5 } \\
\text { Years })\end{array}$ & $\begin{array}{c}\text { No } \\
\text { Participation }\end{array}$ & $\begin{array}{c}\text { Central } \\
\text { Average } \\
(\text { Years })^{*}\end{array}$ \\
\hline $\begin{array}{l}\text { Parliament Elite } \\
\text { RF (176) }\end{array}$ & 6 & 20 & 13 & 137 & 8.69 & 11 \\
\hline $\begin{array}{l}\text { Government } \\
\text { Elite RF(108) }\end{array}$ & 3 & 9 & 14 & 82 & 6.95 & 4 \\
\hline $\begin{array}{l}\text { Regional Elite } \\
\text { RF (195) }\end{array}$ & 33 & 43 & 26 & 93 & 11.25 & 10 \\
\hline Total (479) & 42 & 72 & 53 & 312 & & \\
\hline
\end{tabular}

* Average of persons participation

Source: Lane. D., Rass. C., The Transition form Gorbachev to Yeltsin. Ruling Elites from Gorbachev to Yeltsin. p. 151 (New York: St. Martin Press 1999)

777 "Married" category includes both married and cohabitating women

778 "Lone" category includes never married, divorced and not remarried and widowed women 
Appendix 7. Party Membership and Participation, by Sector Type of Economic Elite

\begin{tabular}{|c|c|c|c|c|c|c|}
\hline \multirow{2}{*}{ Sector } & \multicolumn{3}{|c|}{ PrtMembs } & \multirow{2}{*}{$P E N$} & \multirow{2}{*}{$\frac{P a K o E c}{\%}$} & \multirow{2}{*}{$\frac{\text { AvPerCap }}{\text { PrtSatInd }}$} \\
\hline & Total N & $N$ & PrtSat\% & & & \\
\hline Bank/Finance & 118 & 42 & 35 & 30 & 25 & 8 \\
\hline Executives & 27 & 14 & 51 & 10 & 37 & 20 \\
\hline Industry/Building & 53 & 22 & 41 & 9 & 16 & 2 \\
\hline Oil & 55 & 18 & 32 & 11 & 20 & 4 \\
\hline $\begin{array}{l}\text { Other } \\
\text { entrepreneurs }\end{array}$ & 50 & 27 & 54 & 6 & 12 & 1 \\
\hline Total & 303 & 123 & & 66 & & \\
\hline
\end{tabular}

Source: Lane. D., Rass. C., The Transition form Gorbachev to Yeltsin. Ruling Elites form Gorbachev to Yeltsin. p. 173 (New York: St. Martin Press 1999)

Appendix 8. Distribution of "Soviet" and New Business Elite between Sectors

\begin{tabular}{|l|c|c|c|c|c|}
\hline Sector & Total Sector & Soviet & New Comers & Soviet \% & $\begin{array}{c}\text { New Comers } \\
\text { \% }\end{array}$ \\
\hline Bank/Finance & 118 & 60 & 45 & 51 & 38 \\
\hline Executives & 27 & 15 & 10 & 56 & 37 \\
\hline Industry/Building & 53 & 9 & 38 & 17 & 52 \\
\hline Oil & 55 & 16 & 31 & 29 & 74 \\
\hline $\begin{array}{l}\text { Other } \\
\text { entrepreneurs }\end{array}$ & 50 & 41 & 37 & 8 & 53 \\
\hline Total & 303 & 104 & 161 & 34 & 5 \\
\hline
\end{tabular}

Source: Lane. D., Rass. C., The Transition form Gorbachev to Yeltsin. Ruling Elites form Gorbachev to Yeltsin. p. 179 (New York: St. Martin Press 1999) 